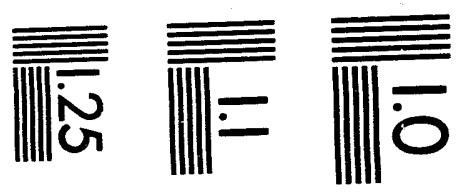

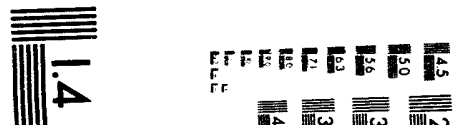

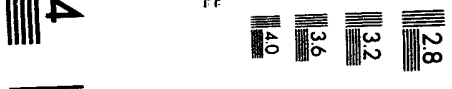

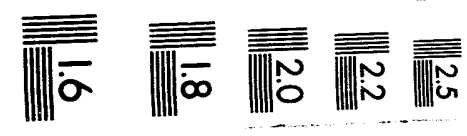



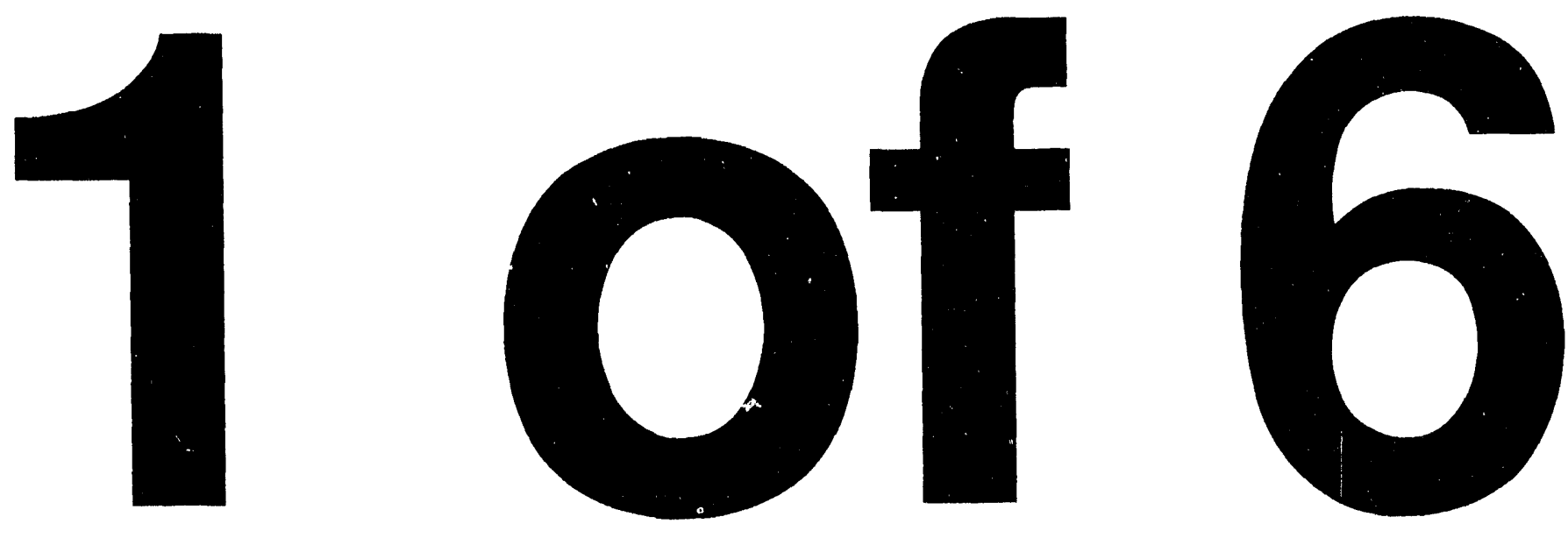


\section{DISCLAIMER}

This report was prepared as an account of work sponsored by an agency of the United States Government. Neither the United States Govemment nor any agency thereof, nor any of their employees, makes any warranty, express or implied, or assumes any legal liability or responsibility for the accuracy, completeness, or usefulness of any information, apparatus, product, or process disclosed, or represents that its use would not infringe privately owned rights. Reference herein to any specific commercial product, process, or service by trade name, trademark, manufacturer, or otherwise does not necessarily constitute or imply its endorsement, recommendation, or favoring by the United States Government or any agency thereof. The views and opinions of authors expressed herein do not necessarily state or reflect those of the United States Government or any agency thereof.

This report has been reproduced directly from the best available copy.

Available to DOE and DOE contractors from the Office of Scientific and Technical Information, 175 Oak Ridge Turnpike, Oak Ridge, TN 37831; prices available at (615) 576-8401.

Available to the public from the National Technical Information Service, U.S. Department of Commerce, 5285 Port Royal Road, Springfield, VA 22161; phone orders accepted at (703) 487-4650. 


\title{
The Extraction of Bitumen from Western Oil Sands
}

Annual Report

July 1991 - July 1992

A. G. Oblad

J. W. Bunger

D. A. Dahlstrom

M. D. Deo

F. V. Hanson

J. D. Miller

J. D. Seader

Work Performed Under Contract No.: DE-FC21- $\frac{89}{\pi} \mathrm{MC26268}$

For

U.S. Department of Energy

Office of Fossil Energy

Morgantown Energy Technology Center

P.O. Box 880

Morgantown, West Virginia 26507-0880

\author{
By \\ University of Utah \\ Departments of Fuels, Metallurgical, and Chemical Engineering \\ 1471 Federal Way \\ Salt Lake City, Utah $\mathbf{8 4 1 0 2}$
}

August 1992 
TABLE OF CONTENTS . . . . . . . . . . . . . . . . . . . . i

LIST OF TABLES . . . . . . . . . . . . . . . . . . . . ix

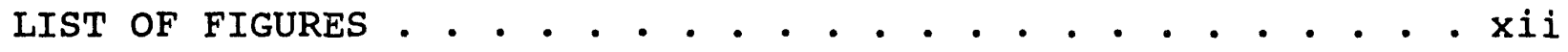

EXECUTIVE SUMMARY . • . • . . . • . . . . . . . . . . 1

INFORMATION REQUIRED FOR THE NATIONAL ENVIRONMENTAL POLICY

ACT . . . . . . . . . . . . . . . . . . . . 10

INTRODUCTION . . . . . . . . . . . . . . . . . . . 10

Thermal Recovery Methods . . . . . . . . . . . . 10

Water Assisted Recovery . . . . . . . . . . . . . 12

Solvent Extraction . . . . . . . . . . . . . . . . . 14

Upgrading of heavy oils to synthetic crude... . . . 15

Specialty products from Utah's oil sands..... . . 15

PROJECTS AND PRINCIPAL INVESTIGATORS . . . . . . . . . . 16

Laboratory locations . . . . . . . . . . . . . . 20

Environmental regulatory personnel . . . . . . . . . . 22

Department of Public Safety . . . . . . . . . . . . . 22

Program Environment Impact Potential . . . . . . . . 23

Air Quality.................... . 23

Water Resources . . . . . . . . . . . . . 24

Land Use . . . . . . . . . . . . . . . . . . . 24

Waste Management . . . . . . . . . . . . . 24

Ecological Impact . . . . . . . . . . . . . . 25

Archaeological, Cultural and Historical Resources . 25

Socioeconomic Impacts . . . . . . . . . . . . . .

Noise . . . . . . . . . . . . . . . . . . 26

Occupational Safety and Health . . . . . . . . . . . 26

Federal, state and local permits . . . . . . . . . . 27

Mining, sample procurement and characterization . . . 28

Mining and transportatjon . . . . . . . . . . . 28

Whiterocks deposit . . . . . . . . . . . . 28

Asphalt Ridge deposit . . . . . . . . . . . 29

Sample processing . . . . . . . . . . . . 32

PROJECT DESCRIPTIONS . . . . . . . . . . . . . . . 35

mask 1: Fluidized-bed coupled reactor-generator . . . . 35

Project description . . . . . . . . . . . . . . 35

Feedstocks, products and effluents . . . . . . . . . . 38

Environmental impact potential of the project. . . . . . 40

Task 2: Water assisted recovery of heavy oils. . . . . 41

Feedstocks, products and effluents . . . . . . . . . . 43

Environmental impact potential of the project. . . . . . 43 
Task 3: Thermal recovery of heavy oil using a rotary kiln reactor or a specially constructed fluidized-bed reactor . . . . . . . . . . . 45

Task 3a: Recovery of heavy oil by using the rotary kiln . . . . . . . . . . . . . . . . . 45 45 Project Description . . . . . . . . . . . . . . 45 Feedstocks, products and effluents . . . . . . . . . . . 46 Environmental impact potential of the project. . . . . 50

Task 3b: Recovery of heavy oil using a fluidized-bed . . 51 Project description . . . . . . . . . . . . . . 51 Feedstocks, products and effluents . . . . . . . . . 53 Environmental impact potential of the project. . . . . 54

Task 4: Recovery of heavy oil by solvent extraction . . 55 Project Description . . . . . . . . . . . . . . 55 Feedstocks, products and effluents . . . . . . . . 57 Environmental impact potential of the project. . . . . 58

Task 5: Heavy oil upgrading to synthetic fuels . . . . 59 Task 5a: Heavy oil upgrading to synthetic fuels . . . . 59 Project Description . . . . . . . . . . . . . . 59 Feedstocks, products and effluents . . . . . . . . . 61 Environmental impact potential of the project. . . . . 61

Task 5b: Heavy oil upgrading to synthetic crude Hydrotreating and hydrocracking . . . . . . . . 62 Project Description . . . . . . . . . . . . . . . 62 Feedstocks, products and effluents . . . . . . . . 63 Environmental impact potential of the project . . . . 65

Task 6: Production of specialty products from heavy oils such as asphalts and other products such as white oils, ink oils and jet fuels. . . . . . . . 66 Project Description .. . . . . . . . . . . . . 66 Feedstocks, products and effluents . . . . . . . . . 67 Environmental impact potential of the project. . . . . 68

Task 7: Rehabilitation of North Salt Lake pilot plant . 68

Task 8: Study of gravity separation of heavy oil concentrates from sand . . . . . . . . . . 69 Project Description . . . . . . . . . . . . . . . 69 Environmental impact potential of the project . . . . . 73

Task 9: Studies of disposal of sand concentrates by pumping . . . . . . . . . . . . . . . . 73 Project description . . . . . . . . . . . . . . 73 Environmental impact potential of the project . . . . 75

Task 10: Definition and remediation of the 
environmental problems associated with the operation of the North Salt Lake pilot plant . . 75

Task 11: Environmental issues associated with bitumen recovery from tar sand . . . . . . . . . . . 77

Project description . . . . . . . . . . . . . . 77

CHARACTERIZATION AND POTENTIAI, UTILIZATION OF THE

ASPHALT RIDGE OIL SAND BITUMEN . • . • . • . . . . . • . . . 79

INTRODUCTION . . . . . . . . . . . . . . . . . . . . 79

EXPERIMENTAL . . . . . . . . . . . . . . . . . . . . 80

Materials . . . . . . . . . . . . . . . . 80

Vacuum Distillation . . . . . . . . . . . . . . 80

Elemental Analysis and Physical Properties

Determinations . . . . . . . . . . . . . . . . . . 81

Fourier Transform Infrared Spectroscopic Analysis . . . 81

Gas Chromatography and Mass Spectrometry . . . . . . . . 82

Asphalt Specification Tests . . . . . . . . . . . 82

Simulated Distillation . . . . . . . . . . . . . . . 82

Curie-Point Low Voltage Mass Spectroscopic Analysis • • 83

RESULTS AND DISCUSSION . . . . . . . . . . . . . . . . . 83

Gas Chromatography-Mass Spectroscopic Analyses . . . . . 87

FTIR Analysis . . . . . . . . . . . . . . . . . . 105

Pyrolysis-Mass Spectroscopic Analysis . . . . . . . 106

SUMMARY AND CONCLUSIONS . . . . . . . . . . . . . . . 109

FUTURE ACTIVITIES . . . . . . . . . . . . . . . . . . 110

EFFECT OF SOLVENT AND INTRINSIC VOLATILE FRACTION OF BITUMEN

ON THE PRECIPITATION OF ASPHALTENES . . . . . . . . . . 111

INTRODUCTION . . . . . . . . . . . . . . . . . . . . 111

EXPERIMENTAL • . • . • . . . . . . . . . . . . . . . 113

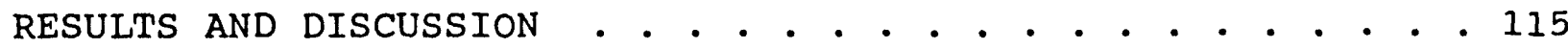

Fractionation . . . . . . . . . . . . . . . . 115

Elemental Analysis . . . . . . . . . . . . . . 118

Spectroscopic Analysis . . . . . . . . . . . . . . 121

SUMMARY AND CONCLUSIONS . • . • . . . . . . . . . . . . . 133

FUTURE ACTIVITIES . . . . . . . . . . . . . . . . . 135

WATER-BASED TAR SAND SEPARATION TECHNOLOGY . . . • • . . • . 136 
Natural Porosity of Tar Sands and its Impact on Water-Based Bitumen Recovery . . . . . . . . . . . . . . . . . . 136

INTRODUCTION . . . . . . . . . . . . . . . . . . . 136 Porosity Measurements . . . . . . . . . . . . 137

RESULTS AND DISCUSSION . . . . . . . . . . . . . . . . 139

CONCLUSIONS . . . . . . . . . . . . . . . . . . . . 147

FUTURE ACTIVITIES . . . . . . . . . . . . . . . . . . 148

FTIR ANALYSIS IN PROCESSING OF TAR SANDS . . . . . . . . . . 149

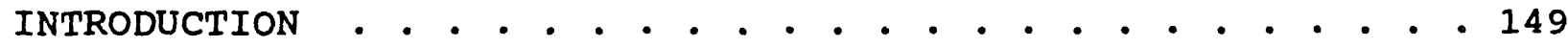

FTIR MICROSCOPE EXAMINATION OF THIN BITUMEN FILMS . . . . . . 150 Experimental Technique... . . . . . . . . . . . 150 Results and Discussion . . . . . . . . . . . . . 150

ADSORPTION/DESORPTION OF BITUMEN-DERIVED SURFACTANTS USING INTERNAL REFLECTION FTIR SPECTROSCOPY . . . . . . . . . 154 Experimental procedure. . . . . . . . . . . . . 154 Results and Discussion . . . . . . . . . . . . . 155

CONCLUSIONS • . • . . . . . . . . . . • . . . . • . . 157

FUTURE ACTIVITIES . . . . . . . . . . . . . . . 157

NEW SEPARATION CELL FOR BITUMEN RECOVERY FROM TAR SAND

SLURRY . . . . . . . . . . . . . . . . . . . . 159

INTRODUCTION . . . . . . . . . . . . . . . . . . 159

Basic Considerations . . . . . . . . . . . . . . 160

Experimental Verification of Gas Phase Content in the Bitumen Concentrate . . . . . . . . . . . . 161

FINAL COMMENTS . . . . . . . . . . . . . . . . 165

FUTURE ACTIVITIES • . . . . . . . . . . . . • . . 167

WATER RECYCLE IN MODERATE-TEMPERATURE BITUMEN RECOVERY

FROM WHITEROCKS TAR SANDS . . . . . . . . . . . . . . 168

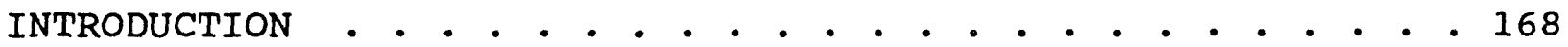

EXPERIMENTAL PROCEDURES . . . . . . . . . . . . . . . 170

RESULTS • • • • • • • • • • • . • • • • • • • • • • . . 173

Bitumen Recovery . . . . . . . . . . . . . . . 173 
Physicochemical Properties . . . . . . . . . . . 176

Bitumen Disengagement Mechanism ..$\cdot \bullet^{-} \cdot \bullet^{-} \cdot \bullet^{-} \cdot 183$

DISCUSSION . . . . . . . . . . . . . . . . . . . 183

Impact of Water Recycle . . . . . . . . . . . . 183

Bitumen Separation . . . . . . • • • • • . • • 187

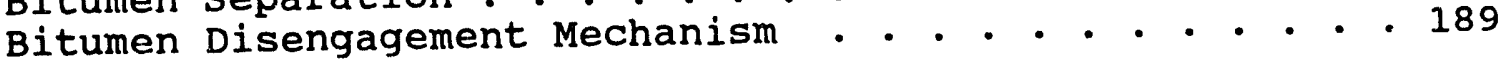

SUMMARY AND CONCLUSIONS . • . . • • • • • • • • • • • • 190

FUTURE ACTIVITIES . . . . . . . . . . . . . . . . . . 191

AIR-SPARGED HYDROCYCLONE FLOTATION OF OIL 192

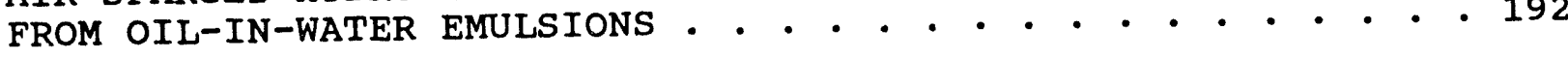

INTRODUCTION • • • • • • • • • • • • • • • • • • • • • • 192

Oil-Water Separation . • • . • • • • • • • • • • • 193

THE PRINCIPLES OF AIR-SPARGED HYDROCYCLONE FLOTATION • • • 194

EXPERIMENTAL PROCEDURE • . . . . . . . . . . . . . . 195

Surface Chemistry . . . . . . . . . . . . . . 195

ASH Oil Flotation . . • . . . . . . . . . . . • 197

RESULTS AND DISCUSSION . • . . . • . . • • . . . • • • • 199

Surface Chemistry . . . . . . . . . . . . . . . 199

Oil Separation by ASH Flotation . . . . . . . . . . 204

CONCLUSIONS . . . . . . . . . . . . . . . . . • • . 211

FUTURE ACTIVITIES . • • • • • • • • • • • • • • • • . 212

UNDERGROUND HOT WATER PROCESSING OF TAR SANDS • • • • • • • • 214

INTRODUCTION . . . . . . . . . . . . . . . . • • . . 214

BOREHOLE MINING OF TAR SANDS . . . . . . . . . . . . . . . 215

CONCEPT DEVELOPMENT FOR UNDERGROUND PROCESSING • • • • • • . 216

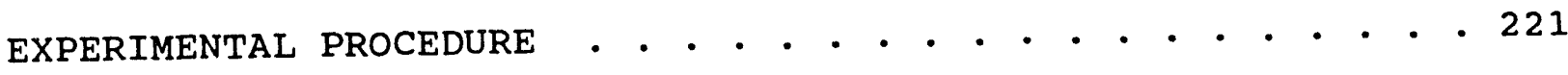

RESULTS AND DISCUSSION • • • • • • • • • • • • • • • • . 222

FUTURE ACTIVITIES . . . • . • • • • • • • • • • • • • 225

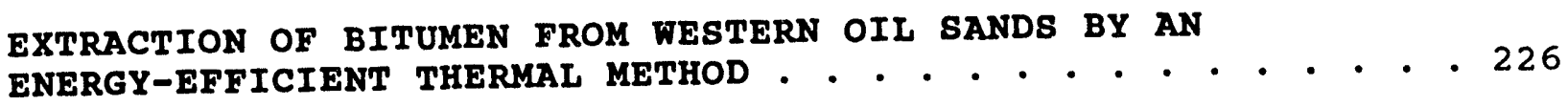

INTRODUCTION

Erosion and Corrosion . . . . . . . . . . . . . 229 
Minimum slugging Velocity . . . . . . . . . . . 231

EXPERIMENTAL . . . . . . . . . . . . . . . . . . . . 236

Erosion and corrosion ................ . 236

Minimum Slugging Velocity . . . . . . . . . . . . 241

RESULTS AND DISCUSSION . . . . . . . . . . . . . . . . . . . 246

Erosion and Corrosion . . . . . . . . . . . . . 246

Fluidizing velocity . . . . . . . . . . . . . . 249

Temperature .. . . . . . . . . . . . . . . 255

Rod orientation . . . . . . . . . . . . . . . . 267

Minimum Slugging Velocity . . . . . . . . . . . 272

FUTURE ACTIVITIES . . . . . . . . . . . . . . . . . . 288

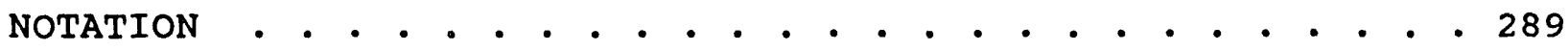

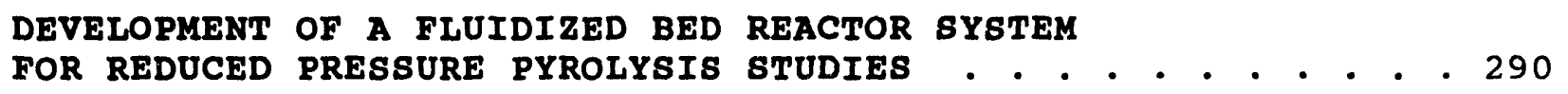

INTRODUCTION . . . . . . . . . . . . . . . . . . . . 290

Research Objectives . . . . . . . . . . . . . 294

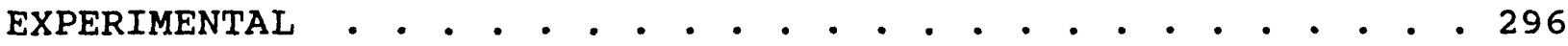

oil Sands Feeder and Controls . . . . . . . . . . . 296

Reactor Design and Construction . . . . . . . . . 298

Reactor Body . . . . . . . . . . . . . . 298

Key reactor specifications . . . . . . . . . 299

Heating and Fuel . . . . . . . . . . . . . . 300

Propane Burner . . . . . . . . . . . . . . . . 302

Fuel Control . . . . . . . . . . . . . . . . 302

Sand Removal System . . . . . . . . . . . . . . 304

Liquid Product Recovery System . . . . . . . . . . 307

Process Support Systems . . . . . . . . . . . . . 310

Process Monitoring . . . . . . . . . . . . . . 311

Feeder Calibration . . . . . . . . . . . . . . 313

Spent Sand Withdrawal System Operation . . . . . . . 316

Reactor Calibration and Startup . . . . . . . . . 320

Ambient Procedures and Air Fluidization . . . . . . 320

RESULTS AND DISCUSSION . . . . . . . . . . . . . . . . . . 324

Variables Effecting Feeder Calibration . . . . . . . 325

Control of Solids Flow with a Modified L-Valve . . . . 328

Air Fluidization with Push and Pull Gas Flows . . . . . 330

Relationship Between $U_{m f}$ and Temperature for spent Sand 331

SUMMARY AND CONCLUSIONS . . . . . . . . . . . . 333

FUTURE ACTIVITIES . . . . . . . . . . . . . . . . 336

NOTATION . . . . . . . . . . . . . . . . . 338 
PYROLYSIS OF OIL SANDS IN A ROTARY KILN REACTOR . . . . . • . 340 INTRODUCTION . . . . . . . . . . . . . . . . . . . 340 SUMMARY AND CONCLUSIONS . . . . . . . . . . . . . . . . . 341 FUTURE ACTIVITIES . . . . . . . . . . . . . . . . . . 341

HYDROTREATING THE BITUMEN FROM THE WHITEROCKS OIL SAND DEPOSIT . . . . . . . . . . . . . . . . . . . . 342

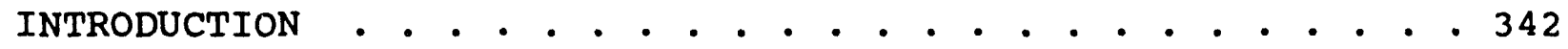

EXPERIMENTAL METHODS AND MEANS . . . . . . . . . . . . . . 343

Feedstock Preparation . . . . . . . . . . . . . 343

Hydrotreater Process Unit . . . . . . . . . . . . . . 343

Catalyst and Catalyst Activation . . . . . . . . . . 348

RESULTS AND DISCUSSION . • • . . . . . . . . . . . . . . 348

Process Variable Study . . . . . . . . . . . . . . . 348

Preliminary Process Kinetics . . . . . . . . . . . 352

Effect of WHSV . . . . . . . . . . . . . . . . 360

Effect of Reaction Temperature . . . . . . . . . . 363

Effect of Pressure . . . . . . . . . . . . . . . 365

Molecular Weight Reduction . . . . . . . . . . 367

SUMMARY AND CONCLUSIONS . . . . . . . . . . . . . . 369

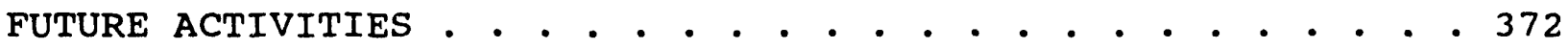

REACTION PATHWAYS IN THE OIL SAND PYROLYSIS-HYDROTREATING

SEQUENCE AS REVEALED BY HIGH RESOLUTION GC-MS ANALYZES • 373

INTRODUCTION . . . . . . . . . . . . . . . 373

EXPERIMENTAL METHODS AND MEANS . . . . . . . . . . . . . . 374

Fluidized Bed Pyrolysis system . . . . . . . . . . . . 374

Hydrotreater Process Unit . . . . . . . . . . . . . 374

Catalyst . . . . . . . . . . . . . . . . . 376

Analysis of Liquid Products . . . . . . . . . . 377

Simulated Distillation . . . . . . . . . . 377

Fourier Transform Infrared Spectroscopic Analysis . 377

Gas Chromatography-Mass Spectrometry Analysis . • 378

RESULTS AND DISCUSSION . . . . . . . . . . . . . . . . 378

GC-MS Analyses . . . . . . . . . . . . . . . . 380

Alkanes and A.lkenes . . . . . . . . . . . . . . . 399

Cycloalkanes . . . . . . . . . . . . . . . . . 399

Monocyclic Compounds . . . . . . . . . . . . 399

Bicyclic Compounds . . . . . . . . . . . . . 400

Tricyclic Compounds . . . . . . . . . . . 401

Tetracyclic Compounds... . . . . . . . . . 402

vii 
Pentacyclic Compounds and Tetraterpanes . . . . . 402

Carotenoid Alkanes . . . . . . . . . . . . 403

Unsaturated Compounds . . . . . . . . . . . . 403

Heteratom species . . . . . . . . . . . . . . . 404

Pyrolysis-Hydrotreating Reaction Pathways . . . . . . 404

SUMMARY AND CONCLUSIONS . . . . . . . . . . . . . . . . 4 409

FUTURE ACTIVITIES . . . . . . . . . . . . . . . . . . . 411

SUPERCRITICAL EXTRACTION OF WHITEROCKS BITUMEN ASPHALTENE

REJECTION . . . . . . . . . . . . . . . . . . . . . 4 42

INTRODUCTION . . . . . . . . . . . . . . . . . . 412

EXPERIMENTAL . . . . . . . . . . . . . . . . . . . . 413

RESULTS AND DISCUSSION . • . . . . . . . . . . . . . . . . 417

SUMMARY AND CONCLUSIONS . . . . . . . . . . . . . . . . 4 432

FUTURE ACTIVITIES • . . . . . . . . . . . . . . . . . 434

BITUMEN RECOVERY DURING TAILINGS DEWATERING . • . • • • . • . 435

INTRODUCTION . . . . . . . . . . . . . . . . . . 435

EXPERIMENTAL • . • . . . . . . . . . . . . . . . . . . 439

RESULTS AND DISCUSSION • • . . . . . . . . . . . . . . . . . 442

SUMMARY AND CONCLUSIONS . . . . . . . . . . . . . . . . . . 446

FUTURE ACTIVITIES . . . . . . . . . . . . . . . . . . 447 


\section{LIST OF TABLES}

Table 1. Bitumen content, porosity and air permeability of selected Canadian and Utah oil sands . . . . . 25

Table 2. Physical and chemical properties of native bitumens, Whiterocks oil sand.. . . . . . . 27

Table 3. Properties of the bitumen derived liquid product produced in the rotary kiln... . . . . . . . 32

Table 4. Properties of native bitumen and bitumen fractions frcm Asphalt Ridge tar sand (Utah) . . . . . . 84

Table 5. Comparison of physical properties of Asphalt Ridge bitumen light end fraction $(477-617 \mathrm{~K})$ with Russian thermally-stable jet fuel and tentative specification of high density-energy jet fuels . .

Table 6. Results of specification tests for Asphalt Ridge bitumen residual fraction . . . . . . . . . . .

Table 7. Cyclic alkanes identified in 477-711 $\mathrm{K}$ fraction of Asphalt Ridge bitumen from mass spectra of GC peaks . . . . . . . . . . . . . . . . .

Table 8. Aromatic species identified in the 477-711 $\mathrm{K}$

fraction of Asphalt Ridge bitumen from mass spectra of GC peaks . . . . . . . . . . . . . . .

Table 9. Variation in the asphaltene contents of the Athabasca bitumen and its residua with respect to solvent.......... . . . . . . . . . 116

Table 10. Elemental analyses of the Athabasca bitumen and its fractions.................. 119

Table 11. Summary of the hydrogen and carbon distributions among the bitumen and its fractions. Data is obtained from the proton and ${ }^{13} \mathrm{C}$ NMR spectroscopic analyses . . . . . . . . . . . . . . . . 129

Table 12. Bitumen density $\left(\rho_{b}\right)$, sand density $\left(\rho_{s}\right)$ and bitumen weight fraction $\left(X_{b}\right)$ for several Utah tar sands and Athabasca tar sand . . . . . . . . 140

Table 13. Natural porosity of Sunnyside tar sands (Utah) • . 141 Table 14. Natural porosity of P.R. Spring tar sands (Utah) . 142 Table 15. Natural porosity of Whiterocks tar sands (Utah) . 143 
Table 16. Natural porosity of Asphalt Ridge tar sands

(Utah) ..................... . 144

Table 17. Natural porosity of Achabasca tar sands (Utah) • . 145

Table 18. Volume percent of air necessary for bitumen concentrate separation in gravity cell . . . . . . 162

Table 19. $3 \mathrm{SH}$ flotation of hexadecane emulsion from a feed concentration of $240 \mathrm{mg} / \mathrm{dm}^{3}$, with $30 \mathrm{mg} / \mathrm{dm}^{3}$ SDS and $2 \mathrm{mg} / \mathrm{dm}^{3} \mathrm{PE}$ added to a feed pipe . . . . . 207

Table 20. ASH flotation of hexadecane emulsion in the revirculation conditions from a feed concentration of $86 \mathrm{mg} / \mathrm{dm}^{3}$, with $30 \mathrm{mg} / \mathrm{dm}^{3}$ SDS and $2 \mathrm{mg} / \mathrm{dm}^{3} \mathrm{PE}$ added to a storage tank . . . . 209

Table 21. ASH flotation of bitumen/kerosene emulsion from a feed concentration of $240 \mathrm{mg} / \mathrm{dm}^{3}$, with $9 \mathrm{mg} / \mathrm{dm}^{3}$ SDS

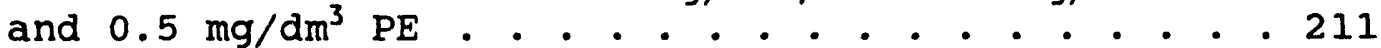

Table 22. Hot water digestion of diluent pretreated Asphalt Ridge $\operatorname{tar}$ sand . . . . . . . . . . . . . . 224

Table 23. Characteristics of the sand used in the fluidization studies . . . . . . . . . . . 242

Table 24. Physical properties of light hydrocarbons . . . . 301

Table 25. LPG energy content data . . . . . . . . . . . . 301

Table 26. Thermocouple numbers and locations . . . . . . . 312

Table 27. Sieve analysis of spent sand feed before $U_{m f}$ studies $(8 / 6 / 91$ data) . . . . . . . . . . . 321

Table 28. Mass of Whiterocks oil sand (WRWN) delivered in 8.0 minutes at $5 \%$ of maximum speed (Acrison BDF $1.5 / \mathrm{H} / 2$ feeder) . . . . . . . . . . . . 326

Table 29. Experimental $U_{m f}$ and $K_{f}$ at various temperatures . 332 Table 30. Analysis of the Whiterocks bitumen . . . . . . . 344

Table 31. Catalyst properties, base-case conditions and process variable ranges . . . . . . . . . . . 346

Table 32. Run conditions employed to hydrotreat the Whiterocks bitumen . . . . . . . . . . . . 349

Table 33. Effect of WHSV on the product properties of the hydrotreated bitumen from the Whiterocks oil sand 
formation .................. . 362

Table 34. Effect of temperature on the product properties of the hydrotreated bitumen from the whiterocks cii sand formation . . . . . . . . . . . . . 364

Table 35. Effect of pressure on the product properties of the hydrotreated bitumen from the whiterocks oil sand formation ............... . 366

Table 36. Values of rate constants, activation energies and preexponential factors derived for the Mosby model . . . . . . . . . . . . . . . 369

Table 37. Properties of bitumen and bitumen-derived liquids from the whiterocks oil sand deposit . . . . . 379

Table 38. Compounds detected in the volatile fraction (IBP$538^{\circ}$ C) of the Whiterocks bitumen . . . . . . . 381

Table 39. Compounds detected in the bitumen-derived liquid produced from the whiterocks oil sand in a large diameter fluidized-bed pyrolysis reactor . . . . 388

Table 40. Compounds detected in the hydrotreated total iiquid $(\mathrm{B}-13)$. . . . . . . . . . . . . . 391

Table 41. Selected properties of the Whiterocks bitumen . . 416

Table 42. Reduced density of propane at experimental conditions .. . . . . . . . . . . . . . 420

Table 43. Selected properties of the residual fractions after propane extractions of bitumen: pressure $=$ $10.3 \mathrm{MPA}$. . . . . . . . . . . . . . . 426

Table 44. Selected properties of the residual oils after propane extractions of bitumen: temperature $=380$ K . . . . . . . . . . . . . . . . . . 427 


\section{LIST OF FIGURES}

Figure 1.

Figure 2 .

Figure 3 .

Figure 4.

Figure 5 .

Figure 6.

Figure 7 .

Figure 8 .

Figure 9.

Figure 10.

Figure 11.

Figure 12 .

Figure 13.

Figure 14.

Figure 15.

Figure 16.

Figure 17 .

Figure 18 .
Campus map of the University of Utah . . . . 14

Whiterocks oil sand deposit sample locations . 23

Sample sites on Asphalt Ridge oil sand deposit 24

A schematic digram of the fluidized-bed

coupled reactor-regenerator . . . . . . 29

A schematic diagram of the water assisted recovery system . . . . . . . . . . . . 35

The rotary-kiln reactor for the recovery of heavy oil . . . . . . . . . . . . . . 40

The sand collection system for the rotary-kiln reactor . . . . . . . . . . . . . . 41

The hydrocarbon liquid collection system for

the rotary-kiln reactor . . . . . . . . . . 42

The process flow diagram of the fluidized-bed reactor for the recovery of heavy oil . . . . 45

A schematic diagram of the solvent extraction apparatus . . . . . . . . . . . . . 49

A schematic diagram of the hydropyrolysis system for the upgrading of bitumen . . . . 53

Process flow diagram of the fixed-bed hydrotreating-hydrocracking unit . . . . . 57

Cross-section of the gravity classifier . . . 64 Flow diagram of the gravity classifier . . . 65 Flow diagram of the spiral classifier . . . 67 Diagram of the special high torque thickener . 69 Mass spectra and proposed structures of the cycloalkanes in the low molecular weight fraction (477-711 K) of the Asphalt Ridge bitumen . . . . . . . . . . . . . . . 94

Mass spectra and proposed structures of the aromatic hydrocarbons in the low molecular weight fraction 477-711 $\mathrm{K}$ of the Asphalt Ridge bitumen .. . . . . . . . . . 102 
Figure 19.

Curie-point desorption mass spectra of the native Asphalt Ridge bitumen . . . . . . 107

Figure 20 .

Figure 21 .

FTIR spectra of (a) the bitumen, (b) maltene. fraction, and (c) asphaltene fraction . . . 122

FTIR spectra of the bitumen distillate fractions (a) distillate-I, and (b) distillate-II . . . . . . . . . . . 124

Figure 22. FTIR spectra of the pentane asphaltne fractions (a) from bitumen, (b) bitumen residue-I, and (c) bitumen residue-II . . . 125

Figure 23 .

${ }^{1} \mathrm{H}$ nmr spectra of (a) bitumen distillationII fraction, (b) bitumen, and (c) asphaltene fraction (from bitumen). . . . . . . . 127

Figure 24. ${ }^{13} \mathrm{C} \mathrm{nmr}$ spectra of (a) bitumen, (b) maltene fraction, and (c) asphaltene fraction . . . 130

Figure 25 .

${ }^{13} \mathrm{C}$ nmr spectra of bitumen distillate-II fraction................ 131

Figure 26. Experimental setup used for determination of tar sand natural porosity; (1) extraction vessel with cover; (2) hot plate; (3) funnel; (4) graduated pipette; (5) cell with flat walls; (6) tar sand sample; (7) solvent; (8) gas phase; (9) to vaccuum . . . . . . . 138

Figure 27.

Figure 28 .

FTIR spectra of Whiterocks oil sand sample. A - spectra received under FTIR microscope:

(a) an actual oil sand grain; (b) oil sand grain after extraction with toluene; (c) roasted oil sand grain, $550^{\circ} \mathrm{C}, 5$ hours; (d) beach quartz sand washed with deionized water $B$ - IR spectrum of bitumen extracted from oil sand with toluene and dissolved in $\mathrm{CCl}_{4}$. . . 152

FTIR microscope spectra of an organic film on a $150 \mu \mathrm{m}$ sand grain acquired from digested Whiterocks oil sand slurry; (a) $20 \mu \mathrm{m}$ sampling on a "rosty" spot; (b) $20 \mu \mathrm{m}$ sampling on "clean" surface . . . . . . . . . . . 153

Figure 29.

FTIR spectra of organic substances adsorbed on germanium IRE submerged in Asphalt Ridge oil sand process water. Equilibrium time: (a) 5 min; (b) $10 \mathrm{~min} ;$ (c) $20 \mathrm{~min} ;$ (d) $30 \mathrm{~min}$. . 156 
Figure 30 .

Figure 31.

Figure 32 .

Figure 33 .

Figure 34 .

Figure 35 .

Figure 36.

Figure 37.

Figure 38 .

Figure 39.

Figure 40 .

Figure 41 .
FTIR spectra of Asphalt Ridge bitumen film on germanium IRE digested in an alkaline solution at $\mathrm{pH}=10$. Digestion time: (a) $1 \mathrm{~h}$;

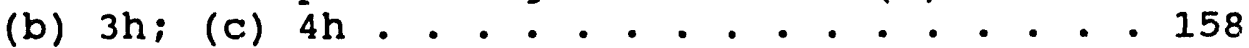

Schematic of a separation cell for bitumen recovery from digested tar sand slurry. 1steel/concrete casing; 2-shaft with paddles; 3-screw conveyor; 4-spiral classifier; 5-belt conveyor; 6-paddle skimmer; 7-adhesive skimmer . . . . . . . . . . . . . . 164

Microscopic photographs of digested oil sand slurry. A-Whiterocks oil sand slurry from under Zeiss stereo microscope. B-Whiterocks oil sand slurry from Zeiss fluorescent microscope; C-bitumen droplet entrapped in Asphalt Ridge tailings, as viewed under zeiss stereo microscope . . . . . . . . . . . 166

Schematic of moderate-temperature bitumen recovery process . . . . . . . . . . . . 171

Bitumen recovery as a function of cycle number . . . . . . . . . . . . • • . . 174

Solids in bitumen concentrate as a function of cycle number (weight of solids per unit weight of bitumen recovered, dry basis) • . 175

Process water $\mathrm{pH}$ as a function of cycle number 177

Specific conductivity of process water as a function of cycle number . . . . . . . 178

Surface tension of process water as a function of cycle number . . . . . . . . . 179

Zeta potential of fine particles as a function of cycle number . . . . . . . . . 181

Zeta potential of bitumen droplets as a function of cycle number . . . . . . . . . 182

Changes in structure of oil sand sample in alkaline solution $(\mathrm{pH}=9.0, \mathrm{~T}=323 \mathrm{~K}) ; t=1 \mathrm{~min}$ (A) - heated system, $t=3 \mathrm{~min}$ (B) - droplet formation resulting from bitumen layer disruption and formation of air bubbles at the capillary ends, $t=6 \mathrm{~min}(C)$ - bitumen spreading at bubble surface and air bubble size growth . . . . . . . . 184

$$
\text { xiv }
$$


Figure 42 .

Figure 43.

Figure 44 .

Figure 45.

Figure 46.

Figure 47 .

Figure 48 .

Figure 49.

Figure 50.

Figure 51.

Figure 52 .

Figure 53.

Figure 54.

Figure 55.

Figure 56.
Changes in structure of oil sand sample in alkaline solution ( $\mathrm{pH}=9.0, t=323 \mathrm{~K}) ; t=10 \mathrm{~min}$ (A) - detachment of bubble/bitumen aggregates, $t=15$ min (B) - sample disintegration due to decreased bonding forces . . . . . . . . 185

Schematic representation of the $\mathrm{ASH}$ and the experimental set-up . . . . . . . . . 196

spreading coefficient as a function of surfactant concentration . . . . . . . 200

Drainage time of water film for oil droplet at the air/water interface . . . . . . . 202

Zeta potential of oil droplets vs. flocculant addition . . . . . . . . . . . . . 203

ASH performance as a function of UF/OF split from hexadecane emulsion flotation at

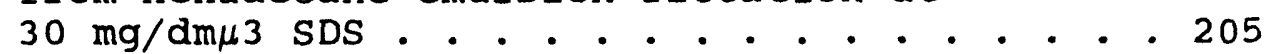

ASH performance as a function of UF/OF split from hexadecane emulsion flotation at $2 \mathrm{mg} / \mathrm{dm}_{3} \mathrm{PE}$. . . . . . . . . . . . 206

ASH performance as a function of UF/OF split from hexadecane emulsion flotation at $30 \mathrm{mg} / \mathrm{dm}_{3} \mathrm{SDS}$ and $2 \mathrm{mg} / \mathrm{dm}_{3} \mathrm{PE}$. . . . . . 208

ASH performance as a function of UF/OF split from bitumen/kerosene emulsion flotation . . 210

The Bureau of Mines borehole mining system . . 217

Conceptual steps for the underground processing of tar sand... . . . . . . 220

Advanced energy-efficient thermal process for the extraction of bitumen from Western tar sands .............. . . . . 227

A comparison of correlations for minimum slugging of a bed of sand particles fluidized by air at $25^{\circ} \mathrm{C},=165 \mathrm{~mm}, D_{8}=$

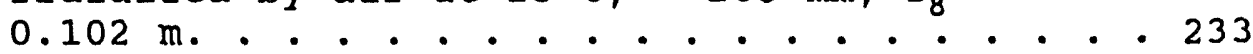

Schematic diagram of the fluidized bed used for wear tests... . . . . . . . . 237 Illustration of rod orientation . . . . . 239 xV 
Figure 57.

Experimental apparatus . . . . . . . . 243

Figure 58.

Cumulative weight loss of vertical 316 SS

rods as a function of time at $500^{\circ} \mathrm{C}$ for

two excess gas velocities . . . . . . . 247

Figure 59.

Effect of excess gas velocity on the wear rate of vertical SS 316 specimens at test

temperatures of $500^{\circ} \mathrm{C}$ and $25^{\circ} \mathrm{C} . . . . . .2251$

Figure 60.

Wear rate data ploted on a log-log scale

to investigate the velocity dependence. . . 253

Figure 61. Influence of test temperature on the wear rate of vertjcal 316 ss rods at constant excess gas velocity . . . . . . . . . . 256

Figure 62. Correlation of erosion rate of six metals with hardness at a test temperature of $25^{\circ} \mathrm{C} . \cdot 258$

Figure 63. Variation of wear rate of six metals with hardness at a test temperature of $500^{\circ} \mathrm{C}$. . 259

Figure 64 .

Analysis of the relative compositions in

the center and at the surface of a 316 SS

rod, after a high-temperature wear test,

by energy dispersive X-ray spectrometry . . . 262

Figure 65. Determination of the thickness of oxide

scale by dispersive microanalysis . . . . . 266

Figure 66. Effect of excess gas velocity on the wear rate of horizontal 316 ss rods at a test

temperature of $500^{\circ} \mathrm{C}$. . . . . . . . . . 268

FIgure 67. Increase in the wear rate of horizontal

316 ss rods with increasing distance between

the rods and the gas distributor plate. . . 271

Figure 68. Pressure-time records; $L_{m}=0.396 \mathrm{~m} ; u=0.236$

$\mathrm{m} / \mathrm{s}$ (slugging) and $\mathrm{u}=0.236 \mathrm{~m} / \mathrm{s}$ (bubbling) . . 273

Figure 69. Statistical properties of pressure

fluctuations as a function of fluidizing

gas velocity; $\mathrm{L}_{\mathrm{m}}=0.396 \mathrm{~m}$; the minimum,

maximum, mean, and standard deviation

are shown . . . . . . . . . . . . . 274

Figure 70. Power spectral density function of pressure fluctuations at several velocities; $\mathrm{L}_{\mathrm{m}}=0.396 \mathrm{~m} \cdot$. . . . . . . . . . . . . 276

$x v i$ 
Figure 71 .

Figure 72 .

Figure 73.

Figure 74 .

Figure 75.

Figure 76.

Figure 77.

Figure 78 .

Figure 79.

Figure 80.

Figure 81.

Figure 82 .

Figure 8.3.

Figure 84 .

Figure 85 .

Figure 86.

Figure 87.

Figure 88 .

Figure 89.
Dominant frequencies in the PSDF as a

function of gas velocity; $L_{m}=0.396 \mathrm{~m}$. . . . 278

Dominant frequencies in the PSDF as a function of gas velocity; $\mathrm{L}_{\mathrm{m}}=0.173 \mathrm{~m} . . . .279$

Dominant frequencies, $f_{d}$ as a function of gas velocity and settled bed height. . . . 281

Minimum slugging velocity as a function

of settled bed height . . . . . . . . . 282

Dominant frequency of a slugg.ng bed as a

function of settled bed height. . . . . . . 284

Dominant frequency, $f_{d}$, as a function of gas

velocity and settled bed height for a bed

fitted with three vertical rods . . . . . 285

Minimum slugging velocity as a function of

settled bed height for a bed fitted with

three vertical rods. An arrow pointing up

indicates that $u_{m s}$ is greater than the value.

at the base of the arrow. . . . . . . . 287

Typical fluidized bed oil sands pyrolysis

system . . . . . . . . . . . . . . . 292

Reduced pressure process flow diagram . . . 297

Propane burner schematic . . . . . . . 303

Fluidized bed gas distributor . . . . . 305

Diagram of spent sand removal system with

standpipe and modified L-valve. . . . . . 306

Reactor schematic . . . . . . . . 309

Rotameter calibration curves . . . . . . 314

E/2 auger spent sand calibration curves . . 315

E/2 auger oil sand calibration curves . . . 317

H/2 auguer oil sand calibration curves . . . 318

Oil sand mass delivered versus moisture

content for 8 minutes at 5\% speed . . . . . 319

Bed pressure drop versus mass of bed sand . . 322 xvii 
Figure 90 .

Figure 91 .

Figure 92 .

Figure 93.

Figure 94 .

Figure 95.

Figure 96.

Figure 97.

Figure 98.

Figure 99.

Figure 100.

Figure 101.

Figure 102.

Figure 103.

Figure 104.

Figure 105.

Figure 106.

Figure 107.
Bed pressure drop versus settled bed height . 323

Rotary kiln product recovery system . . . . 341

Flow diagram of the hydrotreating catalyst

testing unit... . . . . . . . . . . 345

Nitrogen concentration versus API gravity • . 347

API gravity time on-stream for base case

runs . . . . . . . . . . . . . . 351

Plot of -In (1-x) versus reciprocal WHSV for

nitrogen conversion . . . . . . . . . 353

Plot of -In (1-x) versus reciprocal WHSV for

sulphur conversion . . . . . . . . . . . 354

Plot of -In (1-x) versus reciprocal WHSV for

residuum conversion . . . . . . . . . 356

Arrhenius plot for desulfurization . . . . 358

Arrhenius plot for conversion of refractory

and whole residuum . . . . . . . . . 359

Arrhenius plot for denitrogenation . . . . 361

Diagram of reaction network used to model

residuum and gas oil conversion . . . . . 368

The effect of reciprocal WHSV on the

calculated and measured yields of residuum

and distillate fractions . . . . . . . 370

The effect of temperature on the calculated

and measured yields of distillate fractions . 371

Hydrotreater reactor schematic . . . . . 375

Schematic of the supercritical fluid

extraction system . . . . . . . . . . . . 414

Extraction yields for the bitumen with

propane at different pressures and a constant

temperature of $380 \mathrm{~K}$. . . . . . . . . . . 418

Extraction yields for the bitumen with

propane at different temperatures and a

constant pressure of $10.3 \mathrm{MPa}$. . . . . . . 419

xviii 
Figure 108. Comparison of the bitumen-propane extraction yields at two different pure propane reduced densities . . . . . . . . . . . . . . 421

Figure 109. Changing compositions as a function of time for bitumen-propane extracts at $380 \mathrm{~K}$ and

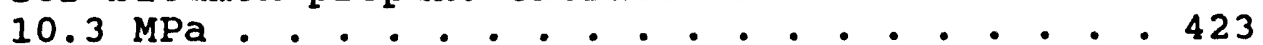

Figure 110. Compositional changes as a function of pressure for bitumen-propane extractions at $380 \mathrm{~K}$. . . . . . . . . . . . . . . . 424

Figure 111. Compositional changes as a function of temperature for the bitumen-propane extractions at $10.3 \mathrm{MPa}$. . . . . . . . . 425

Figure 112. Comparison of the high-temperature boiling point distributions of two of the residual fractions with the distribution for the bitumen .. . . . . . . . . . . . 429 
EXECUTIVE SUMMARY

Principal Investigator: A.G. Oblad

The oil Sand Research and Development Group at the University of Utah prepared, submitted and had approved a comprehensive environmental assessment of the impact of program related activities in accordance with the requirements of the National Environmental Policy Act.

The Asphalt Ridge bitumen was separated into several boiling range fractions for detailed analysis and characterization. The lighter fraction $(477-617 \mathrm{~K})$ was evaluated for use as an aviation turbine fuel and the residue $(>617 \mathrm{~K})$ was evaluated for use as an asphalt. The 477-617 $\mathrm{K}$ fraction appeared to meet most of the specifications for high density aviation turbine fuels. The $617 \mathrm{~K}$ plus residue from the Asphalt Ridge bitumen can be classified as a viscosity grade AC-30 asphalt. Several physical properties were also measured to evaluate the potential of the 477-617 $\mathrm{K}$ fraction as high density-energy aviation turbine fuel after mild rydrotreating. The detailed structure of the low molecular weight fractions of the Asphalt Ridge bitumen (477-617 $\mathrm{K}$ and $617-711 \mathrm{~K}$ ) was determined by combined gas chroma-ography and mass spectrometry. Additional insight regarding the chemical structure of the bitumen was also obtained by Fourier transform infrared analysis. The tentative identification of saturated and aromatic components in the 477-711 $\mathrm{K}$ fractions indicated that these can be related to bioiogically-derived compounds which are found in coal, petroleum, oil shale, and oil sand.

The effect of volatile hydrocarbons on the solubilization of intrinsic asphaltenes in the Athabasca bitumen was investigated. The bitumen was fractionated into maltenes and asphaltenes using two different solvents; hexane, and heptane. In addition, vacuum distillation was performed on two samples to remove portions of the volatile fraction. The distillation residue from each sample was collected and fractionated into maltenes and asphaltenes using the same set of solvents. The experimental results show that the 
volatile fractions of the bitumen do solubilize the asphaltenes, and when they are removed from the bitumen the asphaltene content increased slightly. However, it was noted that the influence of volatile fraction on the asphaltene content is smaller than the effect of the solvent used for fractionation of the bitumen.

similar to our previous reports on water-based separation technology for tar sands processing, the 91-92 Report provides an account on our activities both in basic and applied research. considerable progress has been made in the development of processing strategies which require less energy and which lead to higher grade bitumen concentrates. This water-based process development has been aided by fundamental research on the surface chemistry of bitumen-sand mixtures, the natural porosity of the oil sands accessible by various hydrocarbon diluents, the identification of natural surfactants released from the bitumen during processing and FTIR microscopic studies of tar sands.

Tar sand natural porosity data for samples from five different tar sand deposits have been determined. The previously used technique for porosity determination involving methanol penetration into the tar sand was supplemented by a new analytical technique based on extraction of the tar sand sample in an organic solvent and simultaneous volumetric determination of the gas phase released during extraction. These more reliable measurements allow for improved understanding of the variation in amenability of tar sand samples to hot water separation.

optical microscope examination of digested tar sand slurry revealed that some sand particles are still covered by bitumen. Further, air bubbles adhere firmly to sand grains which seem to be bitumen free. A newly acquired FTIR microscope was used for detailed examination of single tar sand grains for both digested and undigested tar sands. In the case of the whiterocks sample, the analysis revealed a noncontinuous bituminous film for some of the tar sand quartz particles $(60 \mu \mathrm{m}$ to $180 \mu \mathrm{m})$. A preliminary analysis of surfactant adsorption by in situ FTIR/IRE revealed the complex phenomenology of the process and the need for better 
identification of the role of surfactants in the wetting phenomena which control the hot water process.

Gravity separation has been incorporated in the tar sand processing strategy for domestic tar sands. In this regard, the design of a new gravity separation vessel has been proposed, based on our surface chemistry research. A more detailed analysis of the bitumen gravity concentrate has also been completed.

Additional experimental efforts were dedicated to the study of water recycle in hot water $\left(50-60^{\circ} \mathrm{C}\right)$ bitumen separation. supernatant tailings water was recycled six times and no deleterious effect on the amount of fine mineral particles reporting to the bitumen concentrate occurred during gravity separation.

In view of the water recycle results, fundamental surface chemistry studies have helped to define the mechanism of bitumen disengagement in a model system. The release of air bubbles from the oil sand at the onset of digestion was observed in a glass cell and found to precede the disruption of the bitumen-layer covering the surface of the mineral particles, and the formation of bitumen lenses. The subsequent bitumen spreading at the air bubble surface indicated a minimum in the surface Gibbs free energy.

It is expected that the high specific capacity of air-sparged hydrocyclone (ASH) flotation should have some distinct advantage in scavenging tar sand tailings. In this regard a better knowledge of the role of surfactants on oil filming of air bubbles has led to significant improvement in the performance of dispersed oil flotation from $O / W$ emulsions by $A S H$ flotation. The results of this phase of our research have been very promising. oil recovery of between 80 to $90 \%$ is possible, the exact value depending on the oil type and composition.

A new method for determining the onset of slugging in fluidized beds was explored. Pressure-drop fluctuations, measured from below the distributor to the gas exit line, are transformed to the frequency domain by the power spectral density function (PSDF). A fluidized bed is in the slugging regime when the dominant 
frequency of the PSDF, $f_{d}$, remains constant with changing gas velocity. This method was used to determine the gas velocity corresponding to the transition from the bubbling to the slugging regime for a $10-\mathrm{cm}$ diameter bed of sand fluidized with air and containing three $1.9-\mathrm{cm}$ diameter vertical rods on $5.2-\mathrm{cm}$ center-tocenter triangular spacing and extending the length of the bed, and to compare the results with those from the same bed without any internal rods. It was determined that the presence of the vertical rods inhibited the onset of the slugging regime, and significantly extended the bubbling regime into higher gas velocities.

A fluidized bed was operated in the bubbling regime with sand to determine the effects of process variables on in-bed metal wastage due to erosion and/or corrosion of immersed 316 ss rods. Weight loss as a result of erosion was determined by conducting experiments with air at room temperature and high fluidizing velocities. Weight loss due mainly to corrosion was determined by carrying out wear tests at $500 \mathrm{C}$ and relatively low gas velocity. By comparing the total weight loss obtained from the tests at high temperature and high gas velocity conditions with the sum of weight losses from erosion-dominated and corrosion-dominated studies, it was found that erosion and corrosion took place simultaneously and interacted in a way leading to accelerated wear of the 316 ss rods. The wear rates increased with increasing temperature and excess gas velocity and were also affected by rod orientation in that wear rates of vertical rods were less than those of horizontal rods under identical test conditions. In all cases, average wear rates were less than $3.0 \mathrm{~nm} / \mathrm{hr}$ in the radial direction

A new 6 inch ID fluidized bed reactor system has been designed, constructed and tested. A new process variable, reduced pressure, was identified and fluidization studies were initiated. Data for fluidization at less than ambient pressure is seldom reported in the open literature. A novel reactor design and configuration was tested which permits the use of propane combustion for heating and fluidizing gas supply at reduced pressure. 
The relevant variables for successful feeding of oil sands to the top of the fluidized bed and for withdrawal of spent sand from the bottom of the fluidized bed were identified. These two aspects of the reactor system have been problems for several years that are now considered solved. The solution represents a significant step forward in the materials handing aspect of our process engineering.

The operation of the fluidized bed at reduced pressure has been characterized and found to differ from conventional fluidized beds. One significant difference is the finding that deep beds can be fluidized without slugging when the gas flow is based on pulling gas from the top of the reactor.

A simple relationship between bed temperature and minimum fluidization gas velocity was found and reported based on previous studies. Work with the new fluidized bed reactor system this year has produced additional data to support the relationship.

The bitumen from the whiterocks oil sand deposit was hydrotreated in a fixed-bed reactor to determine the extent of upgrading as a function of process operating variables. The process variables investigated included pressure (11.2-16.7 MPa); temperature $(641-712 \mathrm{~K})$ and liquid hourly space velocity $(0.19-0.77$ $\mathrm{h}^{-1}$ ). The hydrogen/oil ratio, $890 \mathrm{~m}^{3} \mathrm{~m}^{-3}$, was fixed in all experiments. A sulfided $\mathrm{Ni}$-Mo on alumina hydrodenitrogenation catalyst was used in these studies.

The effect of temperature, weight hourly space velocity, and pressure on denitrogenation, desulfurization and residuum conversion were studied and apparent kinetic parameters determined. The effect of process variables on residuum conversion and conradson carbon residue reduction was also investigated.

Substantial molecular weight reduction occurred during hydrotreating which was the result of thermal and catalytic cracking. Catalyst activity remained stable for over 700 hours during normal hydrotreating conditions. The deactivation rate was $0.2^{\circ} \mathrm{C} \mathrm{day}{ }^{-1}$. The activity was substantially reduced after processing bitumen for short times temperatures above $700 \mathrm{~K}$. 
Denitrogenation was pseudo-first order, while desulfurization and residuum conversion were adequately represented by two paralle]. first order reactions. Sulfur conversion was linked to residuum conversion because sulfur contained in residuum moieties is unreactive until those moieties are cracked. The apparent activation energies for denitrogenation, refractory sulfur conversion, and refractory residuum conversion were $93 \mathrm{~kJ} \mathrm{~mol} \mathrm{k}^{-1}, 146$ $\mathrm{kJ} \mathrm{mol}^{-1}$ and $134 \mathrm{~kJ} \mathrm{~mol}^{-1}$, respectively.

The volatile fraction $\left(<1000^{\circ} \mathrm{F}\right)$ of the whiterocks bitumen; the bitumen-derived liquid produced from the pyrolysis of Whiterocks oil sand in a fluidized bed; and the total liquid products obtained from subsequent catalytic hydrotreating have been analyzed by high resolution gas chromatography-mass spectrometry. Major compound types found in the $1000^{\circ} \mathrm{F}$ minus fraction of the bitumen were substituted and unsubstituted cyclohexanes, benzenes, decalins, tetralins, naphthalenes, perhydrophenanthrene (tricyclic terpanes), octahydrophenanthrenes, tetrahydrophenanthrenes, phenanthrenes, phenyl(cyclohexyl) alkanes, indan (cyclohexyl) alkanes, perhydrochrysenes $\left(17,21\right.$-secohopanes), steranes $\left(C_{27}-C_{29}\right)$, hopanes $\left(\mathrm{C}_{27}-\mathrm{C}_{35}\right)$ and traces of paraffins. Several additional compound types were also identified in the bitumen-derived liquid: normal alkanes $\left(C_{7}-C_{30}\right)$ and $\alpha$-alkenes, branched alkanes $\left(C_{7}-C_{28}\right)$ and alkenes, cyclopentanes, styrenes, indenes, dihydronaphthalenes, dihydropenanthrenes, and the olefin related to perhydro- $\beta$-carotane. The hydrotreated bitumen-derived liquid consisted primarily of saturated compounds, such as alkanes (normal and branched) and cycloalkanes (1-5 rings). It also contained low concentrations of aromatic compounds which were predominantly monoaromatics. Several thermal reaction pathways have been proposed based on the structural analyses of these three samples. These reactions include cleavage of long side chains or bridges, dehydrogenation, polymerization and condensation, and decarboxylation. Hydrogenation, hydrogenolysis and heteroatom removal were the principal reactions which occurred in the hydrotreater. 
This work demonstrates that most of compound types in the volatile fraction of the bitumen, bitumen-derived liquid and hydrotreated products of the bitumen-derived liquid can be determined by GC-MS analyses. Two types of compounds present in the nonvolatile fraction of the whiterocks bitumen have been proposed: long alkyl chain attached to two- to five-ring terpenoids through $\mathrm{C}-\mathrm{C}$ bonds (alkyl groups linked to naphthenic, naphtheno-aromatic and aromatic moieties) and ester linkages formed during reactions between steroid and hopanoid acids and alkanoid alcohols and/or between fatty acids and condensed alcohols and phenols.

Several reaction pathways in the bitumen pyrolysishydrotreating sequence can be rationalized through the structural identification of various samples. In the thermal process, these reactions include cleavage of long side chains (or bridges), dehydrogenation, cracking, polymerization and condensation and decarboxylation. On the other hand, hydrogenation, hydrogenolysis, hydrodealkylation and heteroatom removal were the principal reactions which occurred in the hydrotreater. The processing sequence oil sand pyrolysis-hydrotreating over an HDN catalystic appeared to be a technically reasonable concept for the upgrading of the bitumen from mined oil sands to a hydrogen refining feedstock.

Continuous supercritical fluid extraction experiments were performed on a Uinta Basin bitumen using propane as the solvent at several temperatures and pressures and the asphaltene contents of the original material and residual fractions were determined.

The experimental data indicated that as the cosolubilizing lighter components of the oil are extracted, more of the heavier compounds precipitate in the pentane-insolubles test, thus showing an increase in the asphaltene content of the residual fractions. The polar to nonpolar compounds ratio also increased for the residual fractions relative to the original bitumen. This indicates that asphaltenes, defined as pentane-insolubles, are not a definite compound class and that their nature and quantity in a 
given mixture was determined by the overall composition of the mixture. The study also indicated that it may be inappropriate to perform asphaltene balances on different fractions of crude oils and bitumens since the solubility and precipitation characteristics of the mixtures change with composition. The asphaltene content of the original oil may not be an appropriate index in order to define the precipitation characteristics since this is not the only fraction susceptible to precipitation in a dense gas flooding process.

As the extraction pressure increased at a constant temperature of $380 \mathrm{~K}$, the asphaltene content of the residual fraction also increased. This was consistent with the observation that the extraction yields increased with pressure and that heavier compounds were extracted at higher pressures.

The $\mathrm{H} / \mathrm{C}$ ratio in the residual fractions was lower than the original oil establishing that saturated compounds were preferentially extracted leaving the residual fractions richer in unsaturated compounds (and thus more polar) than the original oil. The nitrogen and sulfur contents of the residual fractions were also higher which indicated that heteroatomic compounds concentrated in the heavier (unextracted) portion of the original oil.

This study indicated that care should be exercised when performing material balances on asphaltenes from fractionated oils and/or bitumens and that it may be inappropriate to presume that only the pentane-insoluble asphaltene fractions of the original materials are susceptible to precipitate in a given recovery (enhanced oil recovery) or refining process.

The three product cyclone exhibited a forced vortex and therefore a lower centrifugal force. It should recover $90+\frac{\%}{0}$ of solids coarser than a particle size between 150 to 250 microns. The unit was tested with polyelthylene pellets of 0.97 specific gravity and less than $1 \%$ was found in the underflow. As the pellets were around $1 / 4$ inch in size, these results cannot be considered as representing bitumen recovery. Furthermore, most of 
Utah bitumen has been indicated to lie between 0.99 and 1.0 specific gravity which will add to its separation difficulty. We hope to reduce its specific gravity by exposing it to very small bubbles of air.

The two product hydrocyclones must be tested on digested Utah tar sands to see if it will recover $90+\%$ of bitumen in the overflow. If it cannot, we would be unable to use it. This testing has to await the development of the pilot plant. We can size the pilot plant equipment from the literature.

The three product classifier-thickener can be designed for the pilot plant through Canadian operating data avajiable to us as it obtains $90+\%$ recovery of bitumen in the overflow stream. It would seem logical that it can be achieved on Utah tar sands, although the higher specific gravity of Utah bitumen should also increase the difficulty. It is also known that in Canada, bitumen grade of 6-8\% is much more difficult to achieve recovery in the overflow and flotation must also be employed on the middling stream.

The secondary classifier (spiral classifier) should be able to remove at least $80 \%$ of the remaining fine solids from the primary classifier underflow which should permit reduced coarse solids moisture content to 18 wt\% or less. This should be transportable by a belt conveyor. 


\author{
INFORMATION REQUIRED FOR THE \\ NATIONAL ENVIRONMENTAL POLICY ACT \\ Principal Investigator: \\ Co-Principal Investigators: \\ Alex G. Oblad \\ M.D. Deo \\ F.V. Hanson
}

\title{
INTRODUCTION
}

The University of Utah tar sand research and development program is concerned with research and development on Utah's extensive oil sands deposits. The program has beer intended to develop a scientific and technological base required for eventual commercial recovery of the heavy oils from oil sands and processing these oils to produce synthetic crude oil and other products such as asphalt. The overall program is based on mining the oil sand, processing the mined sand to recover the heavy oils and upgrading them to products. Multiple deposits are being investigated since it is believed that a large scale (approximately 20,000 bbl/day) plant would require the use of resources from more than one deposit.

The various oil sand recovery technologies can be classified as follows:

1. Thermal recovery methods

2. Water extraction methods

3. Solvent extraction methods

\section{Thermal Recovery Methods}

Thermal processes are used extensively to produce lighter products from heavy petroleum. These include thermal cracking, and coking with the latter still being an important process in modern 
petroleum refining. Since the heavy oils present in tar sands are similar in many respects to heavy petroleum residua, thermal methods are bein! explored for the recovery of the hydrocarbon values from utah oil sands. These include rotary kiln and fluidized bed methods both of which are continuous processes. Batch processing of oil sands by pyrolysis while technically possible is not feasible economically.

Extensive studies have been carried out investigating thermal processing of Utah's oil sands by rotary kiln and fluidized bed methods. On the basis of results obtained so far both methods appear to be technically feasible for the oil sands investigated (mainly whiterocks). Much more work including scaled-up operations are necessary before economic comparisons can be made regarding commercial feasibility of these two processes vis-a-vis each other and with other processes including water based extraction and solvent extraction methods.

The current program on thermal recovery is concerned with rebuilding and operation of the small diameter fluidized bed, determination of optimum conditions for fluidization of the various Utah oil sands, operation of the redesigned large fluidized bed reactor system at various conditions with different oil sands, comparison of yields with those previously obtained in fluid bed and rotary kiln studies, characterization of the liquid, gaseous and coke products and conducting combustion studies of the coked sand in a fluidized bed reactor system, continuation of process variable studies with the rotary kiln reactor and initiation of 
combustion studies of coked sand in the rotary kiln. Thase studies will help develop scale-up correlations and will generate process data for technical and economic process optimization and eventual commercialization.

A novel combination of two fluid bed reactors has been deviloped at the University for pyrolysis of oil sands. This combination involves two reactors one above the other. Pyrolysis occurs in the top reactor and combustion of the coked sand in the lower reactor with spent sand flowing from top to the lower. The heat from the combustion of coked sand with air is transferred to the top reactor by means of potassium loaded heat pipes. The feasibility of this system has been proven and mathematical models of the system have been developed. Currently, the reactor system is being enlarged and control systems are being added. When completed, the system will be run to confirm previous results from the hand-operated, smaller reactors and confirm the mathematical models. Also, the heat pipes are being run extensively to prove their operational stability and erosion resistance. Success in these studies will then advance the process development to pilot plant scale design, construction and operation.

\section{Water Assisted Recovery}

Two large plants in Canada producing $70,000 \mathrm{~b} /$ day and 160,000 b/day of heavy oil from Canadian oil sands utilizing water assisted recovery emphasize the importance of water based extraction technology. Hence water extraction process technology for Utah's oil sands has had priority in our program since inception of the 
program at the University. A moderate temperature process for recovery of the oil values from Utah's oil sands has been developed. A previous version of the process employing hot water and oil recovery by flotation was developed and tested on a pilot scale on several of Utah's oil sands. Work on the process since that has been concerned with simplifying the process using moderate temperatures and gravity separation techniques. This work has been successful and now the process is about ready for pilot plant testing. Final definition and optimization of the process are now underway. The continuing program to accomplish this is concerned with fundamental research on tar sand pretreatment with diluent, bitumen disengagement from sand, surface chemistry of oil disengagement and formation of oil and water particles. Applied research is continuing on the process design, the separation cell for pilot plant scale operation, bitumen concentrates clean-up, and underground slurry transport/oil separation exploratory studies. More detailed studies of the gravity separation of bitumen concentrate, middlings and clean sand are planned so that maximum efficiency in the separation and recovery can be obtained in pilot plant and commercial equipment. In addition, studies of dewatering of the tailings using chemical and mechanical means io maximize the recycling of water and the determination of the optimum means of transport of tailings are underway. From an economic perspective, the water extraction process appears to be the most $p$ omising. our initial calculations show that about $1.5 \mathrm{bbl}$ of water would be required to produce $1 \mathrm{bbl}$ of heavy oil. This is comparable to the 
water required to process 1 bbl of oil in a conventional petroleum refinery.

\section{Solvent Extraction}

Solvent extraction as a means of recovery of heavy oils from oil sands has been studied. on a very small scale solvent extraction works well and is used as an analytical procedure for estimating the amount of oil on a given oil sand. Use of this technique indicates that because of the large solvent to oil sand requirement to achieve high yields and recovery of the solvent coupled with dangers of fire from use of hydrocarbon solvents, costs and safety considerations are not comparable to the water extraction process. The feasibility of using solvent extraction as compared to thermal recovery processes is yet to be assessed.

In petroleum refineries, low molecular-weight hydrocarbons such as propane and butane are used at subcritical and supercritical conditions to remove the polycyclic aromatic constituents so that the remainder can be used as feedstock for other processes such as catalytic cracking. We have undertaken a study to determine what merit the refinery process techniques might have for full or partial recovery of heavy oils from oil sands and the potential that the use of the low molecular weight materials might have for upgrading of bitumens as a feedstock for further processing to synthetic crude oil or specialty products such as asphalt. Results thus far indicate that propane at supercritical conditions extracts about $60 \%$ of Whiterocks bitumen and that the 
extracted macerial is significantly upgraded compared to the original material.

\section{Upgrading of heavy oils to synthetic crude}

Conventional coking process for the upgrading of oil sand bitumens produces large amounts of coke which leads to serious environmental problems. There is a need for exploring new directions in the upgrading of heavy oils. We are now evaluating selected process schemes for upgrading Utah's oil sand bitumens obtained by water assisted extraction and those produced in the various thermal processes. The process concepts include hydrotreating and hydrocracking and hydropyrolysis which now appear as the most promising upgrading processes. We also plan to investigate in greater detail the value of appropriate fractions of syncrudes as feed stocks for catalytic cracking and reforming.

\section{Specialty products from Utah's oil sands}

We are systematically evaluating all of Utah's major oil sand deposits, making sure of obtaining fresh representative samples of the different sands. So far we have examined whiterocks and Asphalt Ridge and have plans to proceed this year with the evaluation of P.R. Springs and sunnyside deposits. The samples are examined with many different procedures to learn about the molecular composition of the various bitumens. This information along with physical properties information makes it possible to project possible uses for the bitumens in addition to making synthetic crude. Accordingly, we are investigating the use of 
bitumen as an asphalt, as a source material for the production of jet and diesel fuels, white oils, and lubricating oils. specialty products generally command a higher price than syncrude.

The tasks or projects in the program are organized according to the following classification.

1. Recovery technologies

a). Thermal recovery methods

b). Water extraction methods

c). Solvent extraction methods

2. Upgrading and processing technologies
a). Hydrotreating
b) Hydrocracking
c). Hydropyrolysis

3. Solvent extraction

4. Production of specialty products

5. Environmental aspects of the production and processing technologies

\section{Projects and Principal Investigators}

The Director of the overall program is Professor A. G. Oblad, Distinguished Professor of Fuels Engineering. The individual projects (tasks) are listed and described briefly along with the principal investigators in the following paragraphs.

1. Fluidized-bed coupled reactor-regenerator: Principal investigator - J. D. Seader, Department of Chemical Engineering. The concept of a dual fluid reactor system, for the pyrolysis of oil sands and the subsequent combustion of coked sand was developed 
at the University of Utah. The technical feasibility of this system using potassium loaded heat pipes for transfer of heat from the exothermic combustion unil to the endothermic pyrolysis unit has already been demonstrated. Currently an enlarged system with computer aided process control is being fabricated. Sophisticated mathematical models are being developed and heat tube stability tests are being conducted. Success in these studies will advance the process development to pilot plant scale design.

2. Water assisted recovery of heavy oils: Principal investigator -

J. D. Miller, Department of Metallurgical Engineering. A modified hot water process (from the original Canadian water extraction process) using moderate temperatures and gravity separation techniques was developed at the University of Utah. The technology is ready for pilot testing and final definition and optimization of the process is now underway. The studies include fundamental investigations about oil sand pretreatment with diluent, surface chemistry of oil disengagement, disengagement of bitumen from sand surface and formation of oil droplets as well as applied process and component design.

3. Recovery of heavy oils utilizing a rotary kiln and a specially-designed fluidized bed: Principal investigators - F. V. Hanson and M. D. Deo, Department of Fuels Engineering. The technical feasibility of using rotary kiln and fluidized-bed reactors for the pyrolysis of oil sands has been demonstrated at the University of Utah. The current focus is on obtaining process data in the rotary kiln and in a pilot-scale 6 in.-diameter 
fluidized bed so that larger-scale pilot plants and demonstration units can be designed.

4. Recovery of heavy oil by solvent extraction: Principal investigators - F. V. Hanson and M. D. Deo, Department of Fuels Engineering. Solvent recovery process, using both subcritical and supercritical solvents is being investigated at the University of Utah as recovery and upgrading option. Once the process studies are complete, a database for the comparison of all the recovery technologies would be available.

5. Heavy oil upgrading to synthetic crude: a). Hydropyrolysis: Principal investigator - J. W. Bunger, Department of Fuels Engineering. The concept of hydropyrolysis, a thermal upgrading process in the presence of hydrogen for the upgrading of oil sand bitumen was developed at the University of Utah. Preliminary experimental and modeling studies have provided data for the design and fabrication of a larger scale unit for the evaluation of this concept at a process level. Work is being completed on the smaller unit and the larger unit is being designed.

6. Hydrotreating and hydrocracking: Principal investigators - F. V. Hansch and M. D. Deo, Department of Fuels Engineering. Conventional hydrotreating and hydrocracking processes are being investigated at the University of Utah to provide a rational choice of a bitumen upgrading strategy. A continuous hydrotreating unit capable of operating both upflow and in the trickle-bed mode has been fabricated and process hydrotreating studies on pyrolyzed liquid product and Whiterocks native bitumen have been completed. 
Process studies using alternate catalysts are in progress. Design for a scaled-down ebullieted-bed hydrocracker with hydrodynamics similar to the commercial unit is complete. Future work will include fabrication of this unit and process hydrocracking studies. 7. Production of specialty products from heavy oils, such as asphalts and other specialty products: Principal investigators A. G. Oblad and F. V. Hanson, Department of Fuels Engineering. The potential of production of specialty products such as jet fuels, diesel fuels, white oils, lubricating oils and asphalt from Utah oil sand bitumens and bitumen-derived products is being systematically investigated at University of Utah. This work has demonstrated that high-quality jet fuels and asphalt can be made from the Utah bitumens and pyrolyzed liquid product.

8. Rehabilitation of North Salt Lake pilot plant: Principal investigators - A. G. Oblad and F. V. Hanson, Department of Fuels Engineering. State funds are being utilized to rehabilitate the North salt Lake pilot plant so that pilot-scale studies of the modified hot water process can be carried out.

9. Study of gravity separation of heavy oil concentrates from sand: Principal investigator - D. A. Dahlstrom, Department of Chemical Engineering. This task is essentially in support of task 2 on water extraction technology. The purpose of this task is the study, selection and design of appropriate units for the optimum separation of bitumen from sand. The preliminary laboratory studies and equipment design are in progress. 
10. Studies of disposal of sand concentrates by pumping: Principal investigator - D. A. Dahlstrom, Department of Chemical Engineering. Disposal of processed sands will be a major logistical and environmental concern. Process and equipment design to best accomplish this in the water extrusion technology is the purpose of this task. Initial laboratory rheology and pumping tests are in progress.

11. Definition and remediation of the environmental problems associated with the operation of the North Salt Lake pilot plant: Principal investigators - A. G. Oblad, F. V. Hanson and M. D. Deo, Department of Fuels Engineering. This task will identify the specific environmental concerns in the operation of the North Salt Lake pilot plant unit and will address remediation measures. Environmentally safe operation procedures will evolve out of this project.

12. Environmental issues associated with bitumen recovery from tar sand: Principal investigators - A. G. Oblad, F. V. Hanson and M. D. Deo, Department of Fuels Engineering. This task will address the overall environmental impact of the various production and processing technologies.

\section{Laboratory locations}

A campus map with the laboratory locations highlighted is shown in Figure 1. Project items $1-6,8$ and 9 will be conducted in the existing laboratories of the University of Utah. Project items 7 and 10 are concerned with the rehabilitation of the North salt Lake pilot plant. Project 11 is an environmental impact 


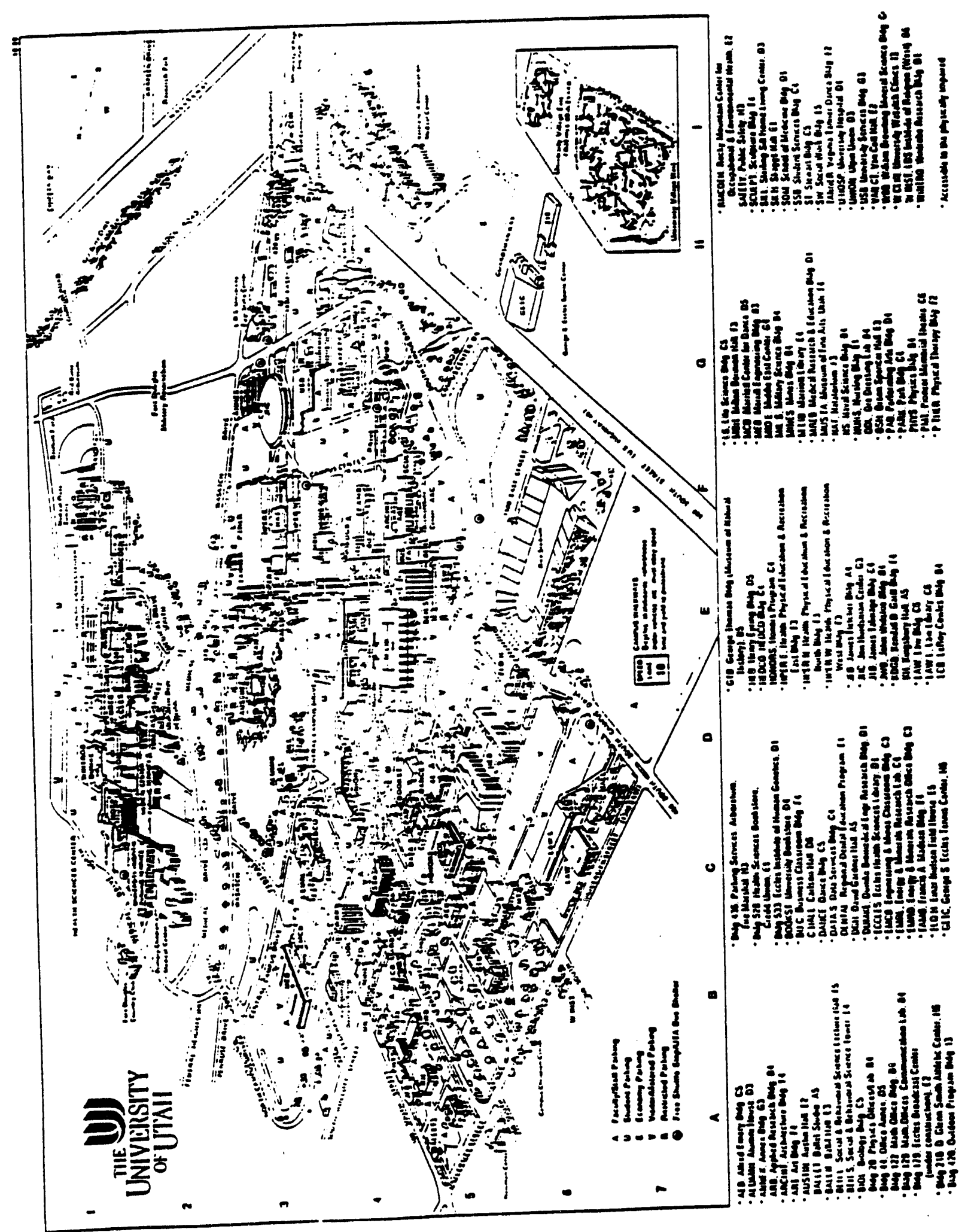

Figure 1. Campus map of the University of Utah 
assessment task which will be performed based on the information generated in our laboratories.

The existing project laboratories are located in the following buildings: Ore-dressing laboratory; Merrill engineering building (MEB) - 2509; Ivor Thomas laboratory; Hedco building, 110 \& 130; Browning building, 109 and Engineering and mines research laboratories (EMRL), 115.

These laboratories are used for storage, experimental and analytical work.

\section{Environmental regulatory personnel}

The research program has direct interactions with the University Department of Public Safety. This department in turn, ensures that the program conforms to the OSHA and to state and federal regulations. The address and telephone number for this office is listed below. The Department of Fuels Engineering interacts with this office through Mr. Rob Jackson, the environmental safety specialist and Ms. Miriam Vaughn, the industrial hygienist. The location of the public safety office is marked on the University of Utah map (Figure 1).

\section{Department of Public Safety}

Bldg. 301, University of Utah

Salt Lake City, Utah 84112 .

(801) 581-6590

(801) 581-7193 FAX

The University of Utah has contracts with APTUS ENVIRONMENTAL, for the disposal of its hazardous wastes. APTUS is a modern 
hazardous material incineration facility. The contact person at APTUS is Mr. Jerry Warner, (801) 973-9909.

The addresses and telephone numbers of the state safety and environmental offices are listed below. The Department of Public Safety interacts with these offices.

Utah Occupational Safety and Health

state of Utah : Industrial Commission of Utah

160 E $300 \mathrm{~S}$

P. O. Box 510870

Salt Lake City, Utah 84151-0870

(801) 530-6901

(801) 530-6804 FAX

Ken Alkema

Executive Director

Dept. of Environmental Quality

State of Utah

$288 \mathrm{~N} 1460 \mathrm{~W}$

SLC, UT, 84116 .

(801) $536-4000$

Program Environment Impact Potential

The overall environmental impact of the oil sands project at the University of Utah is summarized in the following paragraphs: Air ouality

The total program emissions per year are listed below

C1 - C6 hydrocarbon gases

Carbon dioxide

Carbon monoxide

Sulfur dioxide

Nitrogen oxides

Particulates

Hydrogen sulfide

Ammonia

Toluene
$58 \mathrm{~kg}$

$675 \mathrm{~kg}$

Trace amounts

$3.0 \mathrm{~kg}$

$6.3 \mathrm{~kg}$

Trace amounts

$3 \mathrm{~kg}$

$6 \mathrm{~kg}$

$4.5 \mathrm{~kg}$ 


\section{Water Resources}

Water used in this research program is obtained from University's connections to the salt Lake city Water system and from wells operated by the University. The project's water use does not affect the overall water resources. Water assisted recovery tasks are estimated to use a total of $5000 \mathrm{~kg}$ of water during the current year. All the other tasks use water only for cleaning and sanitary purposes.

\section{Land Use}

No additional land is required for this program. All the work is performed in existing laboratories.

\section{Waste Management}

Non-hazardous liquid wastes are discharged into the building sewer, which is eventually treated by the salt Lake sewage treatment facilities. Salt lake city periodically monitors University sewage to determine if it is within legal limits (100 $\mathrm{mg} / \mathrm{l}$ of oil and grease, a pH of 6-9, total suspended solids (TSS) level of $250 \mathrm{ppm}$ and a BOD of $200 \mathrm{ppm}$ ). The University discharge has never exceeded these limits.

Both bulk and liquid hazardous wastes are collected by the University Department of Safety Services along with other research wastes on campus and are disposed of according to state and federal guidelines. The waste sand is stored for further research and will eventually be hauled back to the mine for disposal. The guidelines specified by the University of Utah Hazardous material disposal procedures are followed. The document on the disposal of hazardous 
materials lists specific steps that must be followed by all the University personnel for the disposal of hazardous material. These are: 1. Identify the chemical name and its hazardous properties. 2 . Label the container. 3. Assign US EPA hazardous waste numbers to the material. 4. Fill out the Request for the Removal of Hazardous Materials form. 5. Package the material for transportation. 6. Mail the white copy of the request to the safety services. Place the yellow copy with the packaged material. Hazardous material is picked up when the form is received.

Thus a clear, concise flow-chart provides guidelines for dealing with hazardous materials from the point of identification to disposal.

\section{Ecological Impact}

The emissions resulting from this program are not large enough to cause local vegetation damage. The program does not contribute any chemicals to the water effluent streams. Hence, it is not expected to have any short or long term ecological impact. At this time, transporting spent sands back to the mines is considered the best alternative to disposing this material. Long term ecological impact of coked sand will be assessed as part of the environmental task of this program.

\section{Archaeological, Cultural and Historical Resources}

Not applicable for this project, since all the work is conducted in existing laboratories. 


\section{Socioeconomic Impacts}

The graduate students working on project tasks obtain advanced graduate degrees in the departments of Chemical Engineering, Fuels Engineering and Metallurgical Engineering. By providing an opportunity for quality higher education, the project has a greatly positive socioeconomic impact. By providing research opportunities on fundamental and applied issues related to the recovery of oil from tar sands, the program contributes to faculty development. A commercial process operating in the Uinta Basin will employ approximately 1500 people. This will be a tremendous boost to the local and state economy. The plant will result in the growth of a city which will have problems associated with large cities.

\section{Noise}

The noise levels in each of the laboratories is given under individual projects. In general, the background noise in most laboratories is 60-65 dBA. In some operations the noise level reaches 80-85 dBA. The minimum noise level with none of the equipment operating in most laboratories is $60 \mathrm{dBA}$. A maximum noise level of $85 \mathrm{dBA}$ was recorded in the operation of the 6-inch diameter fluidized-bed with the burner on. The personnel subjected to this noise level on a continuous basis are advised to wear ear protection such as ear muffs.

\section{occupational Safety and Health}

The guidelines for laboratory safety and health are presented in the Chemical Hygiene Plan of the University of Utah. All the 
laboratories are operated and maintained in accordance with these guidelines. The safety information is disseminated diligently. There are annual training sessions and inspections. The chemical hygiene plan of the University lays down the general principles for work with laboratory chemicals. It lists the engineering controls that the laboratories are subjected to prior to certification and authorization for use. According to these guidelines, MSDS for all the chemicals are filed in easily accessible locations in all the laboratories. Guidelines are provided for the ventilation, hoods, local ventilation devices, special ventilation areas, showers, eye-wash, extinguishers and alarms. The document also details the personal protective equipment such as eye protection, gloves, laboratory coats, respirators, shoes, disposable suits and ear protection. Quarterly inspection procedures, training and information dissemination methods are also explained.

\section{Federal, state and local permits}

All new constructions and operations at the University of Utah capable of generating about $1000 \mathrm{~kg}$ of criteria pollutants per year are required to have a state air quality permit. For example, the University of Utah hospital, power plant and the incinerator have state permits for their operation. Because of the small quantities of pollutants generated in laboratory, small-scale, operations, the state does not require the University of Utah laboratories to obtain air quality permits. This air quality waiver appears justified by surveying the total emissions from this program. The air quality at the University is monitored by the 
state, along with other locations in the salt Lake valley. In particular, the stacks and fume hoods at the University are inventoried on a regular basis.

As pointed out earlier, the program does not add chemicals to the University water effluents. The University discharges sewer water into the salt Lake city sewer system. The University has a Salt Lake sanitary sewer permit. The University of Utah is exempt from the NPDE permit through a special salt Lake city ordinance (Chapter 17 relating to sewer). The effluents from the University are screened periodically for pollutants by the city.

The University of Utah has an US EPA number for hazardous waste handling and disposal. US EPA monitors this phase of the University waste management.

General procedures regarding sample acquisition and treatment applicable to all the projects are described in the following paragraphs.

Mining, sample procurement and characterization

Mining and transportation

Whiterocks deposit

The Whiterocks oil sand deposit is located in sections 17 through 19, Township 2 North, Range 1 East, and section 24, Township 2, North, Range 1 West (United states Meridian), Uintah county, Utah. The mined ore from the whiterocks oil sand deposit was obtained from the Fausett pit on the outcrop on the Western flank of the Whiterocks River located in the NW $1 / 4$ of section 19 , Range 1 East Township 2 North. The mine site is on fee land and 
the leases and the mining permits are held by Mr. John Fausett of the Uintah county.

Two to three feet of oil sand on the surface of the floor of the pit were removed to expose fresh material in the three designated locations : West Central (WC), West North (WN) and West South (wS) regions of the pit (Figure 2). A backhoe was then used to mine barrel quantities (6-8 from each of the three sites) of the freshly exposed ore. The barrels were lined with polyethylene bags and sealed for transportation to the University of Utah. The drums are transported to salt lake city in trucks rented from U-HAUL or RYDER. The route is highway 40 and I-80 into salt Lake city. They are stored in Hedco 130, Chemical Engineering storage, MEB and the College of Mines Warehouse (Building 60).

\section{Asphalt Ridge deposit}

The Asphalt Ridge oil sand deposit is located in the north-central portion of the Uintah County, Utah. The deposit is accessible in several regions; the north-central region, along U.S. highway 40; the north region along state highway 121 ; and the south region along the Naples-Bonanza Road. Drum quantity samples were obtained from three distinct locations on Asphalt Ridge: a northern pit; the Uintah county pit and a southern pit (Figure 3). The northern pit is located in the NE/4 NE/4 of sections 25 , township 4 south, range 20 east and the NW/4 NW/4 of section 30 , township 4 south, range 21 east. The county pit is located in the $S / 2 S E / 4$ of section 30 and the $N / 2 N E / 4$ of section 31, township 4 south, range 21 east. The southern pit is located in NE/4 SW/4 of section 31 , 


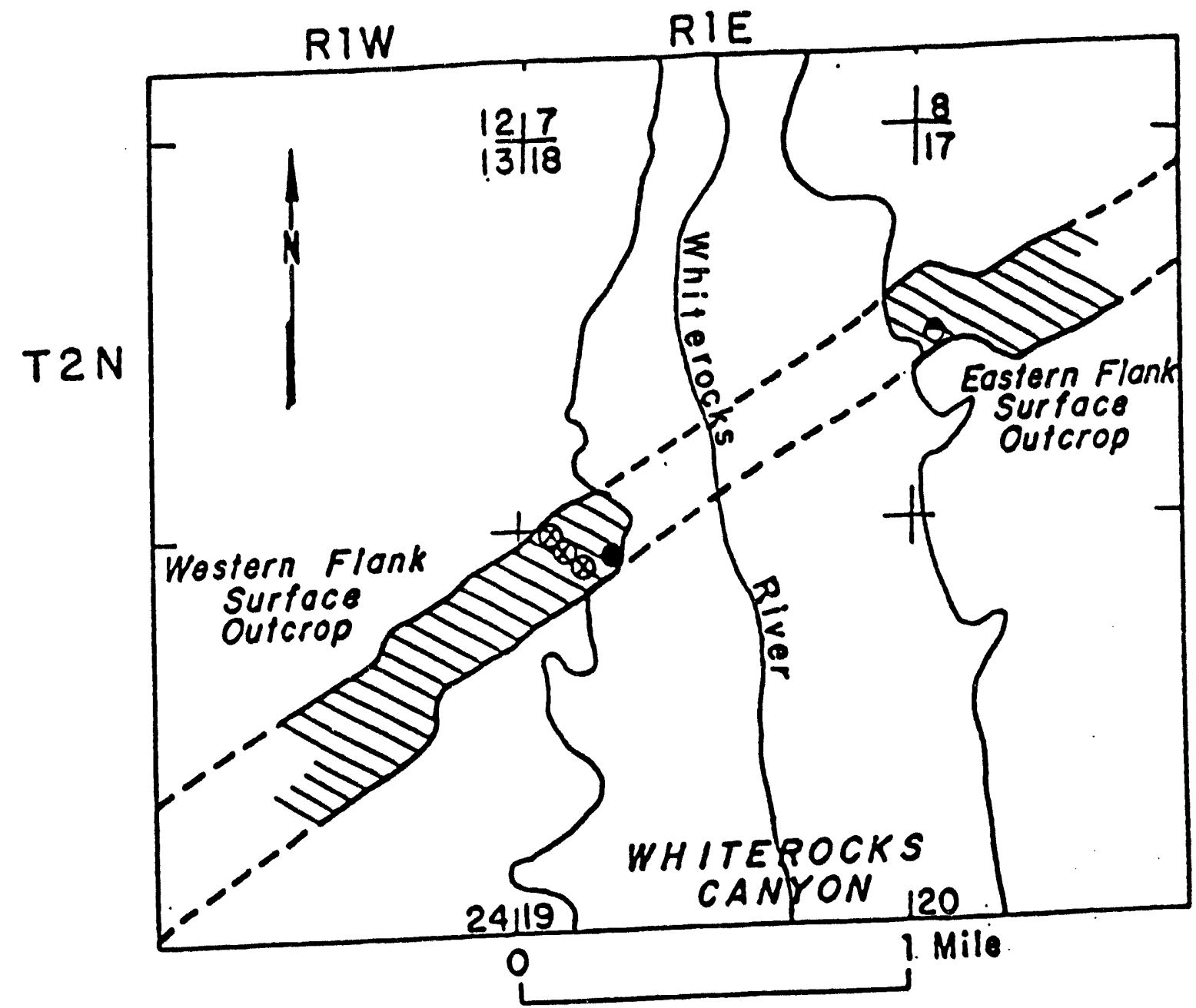

(- Somple Sites from Fouseft Pit (WS, WC, WN) $\$$ Exposed Surface Outcrop

- - Portion of Deposit Overlain by Overburden

Location of Core No. 1

- Location of Core No. 2

Figure 2. Whiterocks oil sand deposit sample locations 


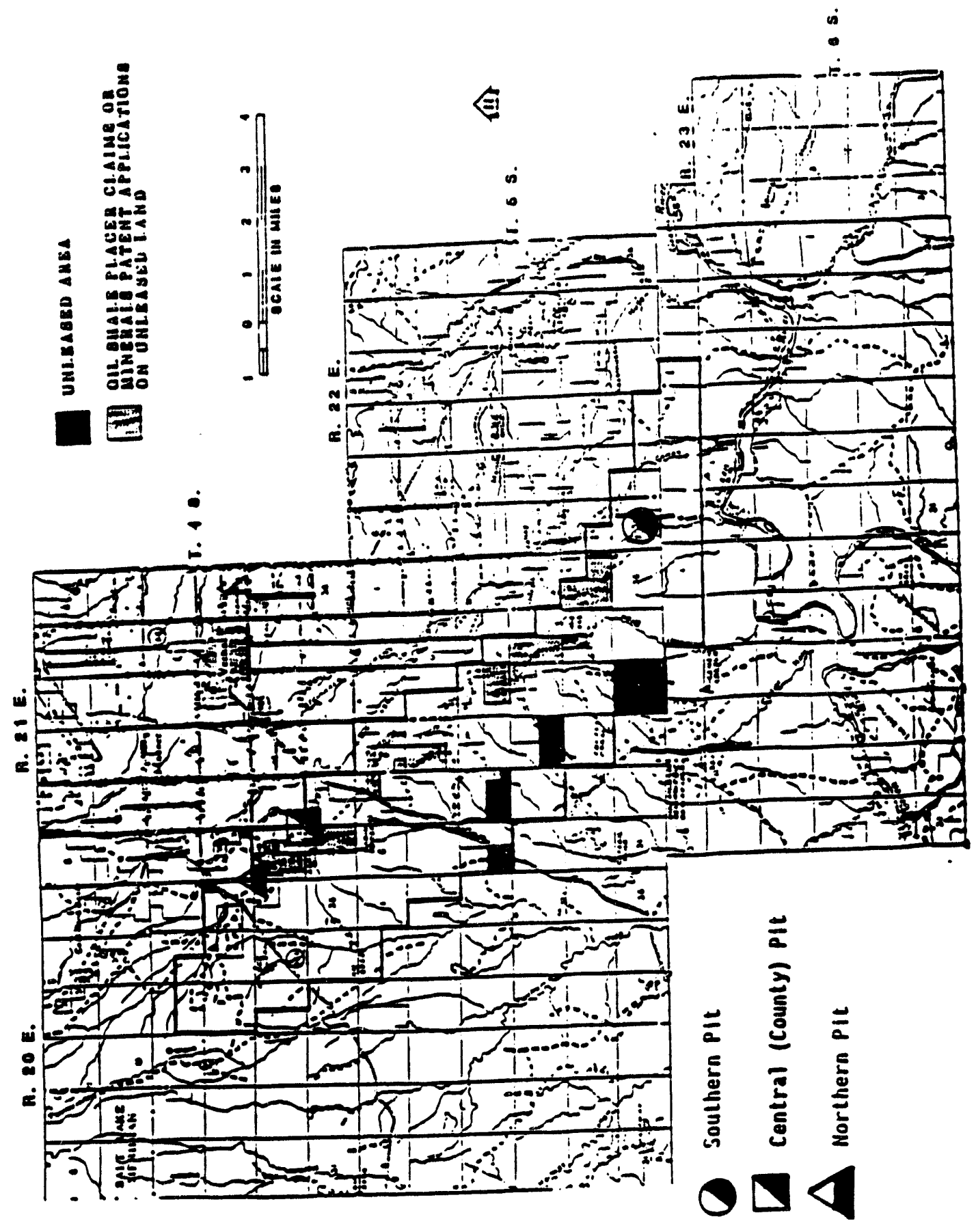

Figure 3. Sample sites on Asphalt Ridge Oil Sand Deposit 
township 5 south, range 22 east. A backhoe was used to mine the ore from these locations. A total of 36,55-galion drums were acquired during the Asphalt Ridge field trip.

\section{Sample processing}

The ore in the barrels was crushed to minus $1.25 \mathrm{~cm}$ after being transported to the University and the crushed ore from each specific location was mixed and blended in a cement mixer prior to storage in lined and sealed barrels. Typical properties of these oil sands are presented in Table 1

Table 1

TABLE 1: Bitumen content, porosity and air permeability of selected Canadian and Utah oil sands

\begin{tabular}{||cccc|}
\hline \multicolumn{1}{|c}{ Deposit } & $\begin{array}{c}\text { Bitumen } \\
\text { Content } \\
\text { (wt } 8)\end{array}$ & $\begin{array}{c}\text { Porosity } \\
\text { (vol } 8)\end{array}$ & $\begin{array}{c}\text { Permeability } \\
\text { (md) }\end{array}$ \\
\hline Athabasca & $12-14$ & 65 & $0-215$ \\
Asphalt Ridge & $8-17$ & $22-31$ & $5-745$ \\
Circle Cliffs & $3-7$ & $13-17$ & $1-3$ \\
Hill Creek & $8-11$ & $12-31$ & $2-1,355$ \\
PR Spring & $5-15$ & $7-37$ & $0-6,954$ \\
Sunnyside & $8-10$ & $25-30$ & $154-677$ \\
Tar Sand & $4-9$ & $20-35$ & $2-3,200$ \\
Triangle & $7-10$ & $14-32$ & $10-127$ \\
Whiterocks & & & \\
\hline
\end{tabular}

Twenty four drums (55 gallons each) (Approximately, $4000 \mathrm{~kg}$ ) of oil sand from the Whiterocks deposit and small amounts of samples from the Asphalt Ridge deposit, Utah will be used in the 
experimental program for the fiscal years 1991 and 1992. The bitumen saturation of this sand is between 7 and $8 \%$, the remaining 92-93 \& being silica sand. They are labeled according to University guidelines. The sand residues from various operations are stored in labeled, lined drums for future research. When sufficient quantities of these spent sands have been accumulated, they will be disposed of by transporting them back to the deposits. The bitumen used in several investigations is obtained by soxlet extraction using toluene as the solvent. Equal amounts of sand and toluene ( $1 \mathrm{~kg}$ each) are used. It is estimated that 25-30 extractions will be performed in the coming year. The solvent recovery on these extractions is 85-90\%. This amounts to toluene emissions of $0.1-0.15 \mathrm{~kg}$ for every extraction. These extractions are carried out in Hedco 110. The safety and health aspects of this laboratory are discussed under Task $5(b)$ in Project Descriptions. once the extraction is complete, the extracted sand is removed to a fume hood and is then transferred to a vacuum oven and heated at $100 \mathrm{C}$ for about $24 \mathrm{hrs}$ to remove residual toluene. The clean sand is stored in air-tight containers. The extracted solution is separated into toluene and bitumen using a Rotavapor. The recovered solvent is reused for further extractions. The unrecoverable bitumen portion is cleaned by toluene and is collected carefully into waste containers. These containers are collected regularly by the University Safety Service. Typical properties of the extracted bitumen are presented in Table 2 . 
Table 2

Physical and chemical properties of native bitumens, Whiterocks oil sand

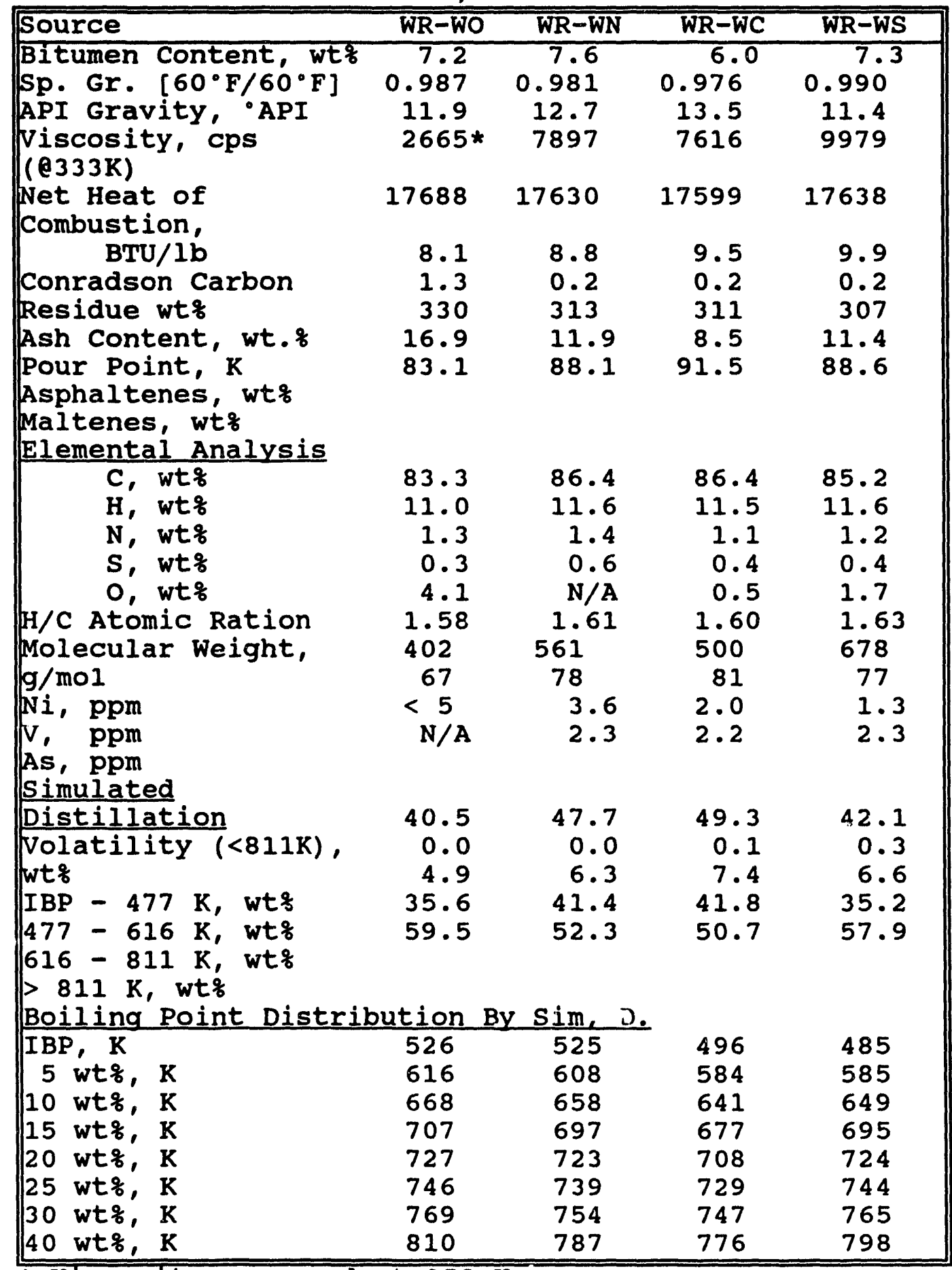

* Viscosity measured at $358 \mathrm{~K}$.

WR-WO: Whiterocks Western Outcrop WR-WN: Whiterocks West Flank North WR-WC: Whiterocks West Flank Central WR-WS: Whiterocks West Flank South $_{4}$ 
When bitumen fractions are required, the ASTM 2892 standard procedure is used. This is a simple distillation procedure to separate the bitumen into various boiling range fractions. The fractionation procedure does not yield any emissions.

\section{Project Descriptions}

\section{Task 1: Fluidized-bed coupled reactor-generator}

The objective of this project is the development of advanced technology for the production of an upgraded oil from oil sands by an integrated thermal process. For the current year the project goal is to determine optimum operating conditions with a mathematical model and demonstrate these conditions in a laboratory system.

\section{Project description}

A schematic of the process is shown in Figure 4. The process consists of three steps. First, mined and suitably sized oil sand fed to the reactor at a constant rate, is pyrolyzed at temperatures of $713 \mathrm{~K}$ to above $773 \mathrm{~K}$ in an inert atmosphere to volatilize and partially crack most of the contained bitumen. The vaporized products of the pyrolysis section are condensed to give a synthetic crude oil. Nitrogen is used as the fluidizing gas at a flow rate of $1.3 \mathrm{~m} 3$ a STP per hour. In the second step, coked sand formed as a by-product in the pyrolysis reactor, is combusted with air at temperatures between $823 \mathrm{~K}$ and $873 \mathrm{~K}$. In the third step, heat is recovered from the hot spent sand leaving the combustion bed by a fluidized-bed heat exchanger using vertical 


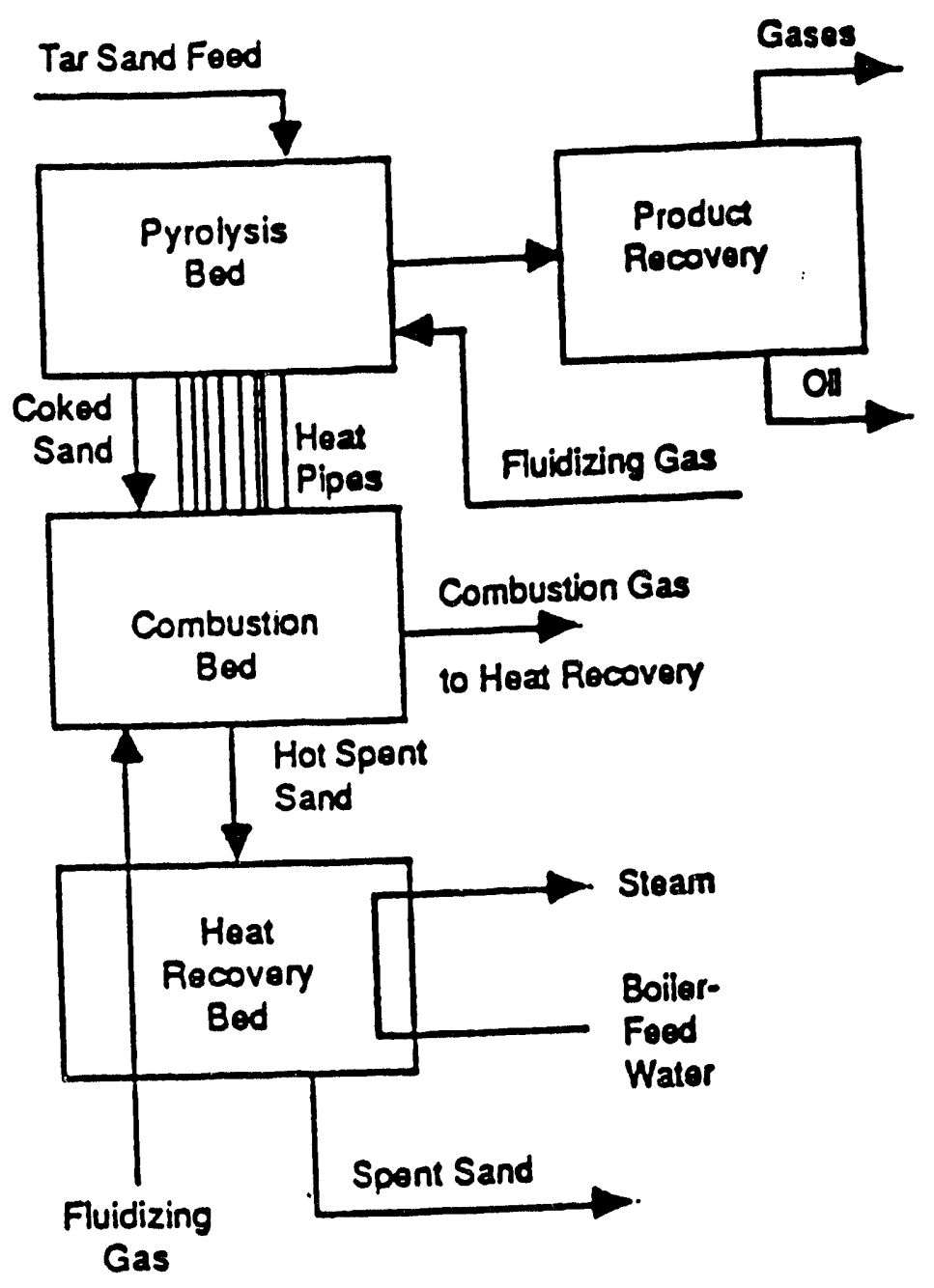

Figure 4. A schematic diagram of the fluidized-bed coupled reactorregenerator 
copper cooling tubes.

Three heat pipes are used to transfer $100 \%$ of the energy required to maintain the required temperature of pyrolysis in the upper bed from the lower combustion bed. Air is used to fluidize the combustion bed and the heat recovery bed while the pyrolysis bed is fluidized with nitrogen. The process is equipped with a digital control and a data acquisition system.

In addition to the main process studies, erosion tests are performed in a $1.52 \mathrm{~m}$ high reactor, which is able to operate at high temperature and hydrodynamic testing is performed in a 2.44 m high see-through glass reactor.

The laboratory for this project is located in room 2509 of the Merrill Engineering Building. The fluidized-bed reactor used to process the oil sands extends up to the next higher floor, in room 3520. The total height of the fluidized-bed unit is $4.57 \mathrm{~m}$. In room 2509, several 0.1 m ID fluidized-beds are housed. Erosion and hydrodynamic studies are conducted in room 2509.

The laboratory is well-lit by several fluorescent lights. Electric outlets at 110 volts carry a grounding connection requiring a 3-pronged plug. Several circuit breakers with manual override are employed to cut off electricity (110 V AC) to the laboratory in the event of an accident. Water is supplied and discharged to the house plumbing. Compressed air is supplied at 120 psi from the house compressor. Nitrogen gas is supplied to the processing unit from compressed gas cylinders. 


\section{Feedstocks, products and effluents}

The reactor is capable of processing $7 \mathrm{~kg}$ of oil sand per hour and is operated continuously for as long as 6 hours per run. It is estimated that about 70 runs will be conducted during the current year during which time about $3000 \mathrm{~kg}$ of oil sands will be processed.

At full operating capacity, the process produces $0.5 \mathrm{~kg}$ per hour of oil and $0.05 \mathrm{~kg}$ per hour of flue gas. About $0.15 \mathrm{~kg}$ of carbonaceous residue is deposited on $6.3 \mathrm{~kg}$ of clean silica sand. In the combustion unit, this carbonaceous residue combines with air to produce $0.528 \mathrm{~kg}$ of carbon dioxide per hour. Assuming that the sulfur and nitrogen compounds are deposited as coke on the sand, about $7 \times 10^{-3} \mathrm{~kg}$ per hour of sulfur dioxide and $15 \times 10^{-3}$ $\mathrm{kg}$ per hour of nitric oxide would be produced in the combustor. The flue gases contain C1 - C4 hydrocarbons. In actual practice, both clean silica sand and oil sand are fed to the fluidized-bed reactors. oil sands are prepared and handled by procedures explained in the previous section. General characteristics of the bitumen are given in Table 2 under Program Description. Selected properties of the bitumen derived liquids (oils) produced in the rotary kiln reactor are given in Table 3 . It was assumed that the properties of liquids to be produced in the coupled-fluidized bed reactor would be similar. These are general properties. They may vary depending on the thermal process employed, the process conditions and the type of oil sands used. However, this variation is not significant in terms of the environmental impact of this 
Table 3 .

Properties of the bitumen derived liquid product produced in the rotary kiln

\begin{tabular}{|c|c|}
\hline Properties & $\begin{array}{c}\text { Liquid Product } \\
\text { (RK-WR-18) }\end{array}$ \\
\hline $\begin{array}{l}\text { Gravity, 'API } \\
\text { Conradson Carbon Residue, wt } \% \\
\text { Ash Content, wt? } \\
\text { Viscosity, cp } \\
\text { Pour Point, K } \\
\text { Asphaltenes, wt? } \\
\text { Maltenes, wt }\end{array}$ & $\begin{array}{c}20.8 \\
2.6 \\
0.0 \\
57\left(\begin{array}{ll}298 & \mathrm{~K}\end{array}\right) \\
252 \\
2.6 \\
97.4\end{array}$ \\
\hline \multicolumn{2}{|l|}{ Elemental Analysis } \\
\hline $\begin{array}{l}\text { C, wt\% } \\
\text { H, wt\% } \\
\text { N, wt\% } \\
\text { S, wt\% }\end{array}$ & $\begin{array}{r}84.1 \\
11.7 \\
0.9 \\
0.2\end{array}$ \\
\hline $\begin{array}{l}\text { H/C atomic Ratio } \\
\text { Molecular weight, g/mol } \\
\text { Ni, ppm } \\
\text { V, ppm } \\
\text { As, ppm }\end{array}$ & $\begin{array}{l}1.67 \\
288 \\
9 \\
<1 \\
<1\end{array}$ \\
\hline \multicolumn{2}{|l|}{ Simulated Distillation } \\
\hline $\begin{array}{l}\text { Volatility, wt\% } \\
\text { IBP }-477 \mathrm{~K}, \text { Wt\% } \\
477 \mathrm{~K}-616 \mathrm{~K}, \mathrm{Wtq} \\
616 \mathrm{~K}-811 \mathrm{~K}, \mathrm{Wtq} \\
>811 \mathrm{~K}, \text { Wt\% }\end{array}$ & $\begin{array}{l}100 \\
6.7 \\
25.7 \\
67.5 \\
0.0 \\
\end{array}$ \\
\hline
\end{tabular}


product.

Spent sands from this process are virtually without coke and may be disposed of directly at land-fill sites. Oil produced by the oil sands extraction process is stored in plastic storage containers. It is used for upgrading research and the waste oil is collected according to the University hazardous materials handling procedure and disposed of accordingly. Exhaust gases from the oil sand processing unit first pass through a cyclone and filter to remove particles, then through a heat exchanger to reduce gas temperature and condense oil vapor, and finally through a mist collector to remove fine oil mist before entering the house exhaust system. All the discharge gases are fed to the house exhaust through a $0.94 \mathrm{~cm}$ tube.

Environmental impact potential of the project.

From an air emissions point of view, this project will generate about $21 \mathrm{~kg}$ of $\mathrm{Cl}$ - C4 gases, $222 \mathrm{~kg}$ of $\mathrm{CO}, 2.94 \mathrm{~kg}$ of 502 and $6.3 \mathrm{~kg}$ of No per year. These air emissions are not expected to cause any short or long term vegetation damage. Since no water effluents are involved, the project is not expected to have any other ecological impact. The wastes are handled according to the University of Utah Hazardous Waste Disposal Procedures Manual.

The noise levels in the project workplace do not exceed 75 dBA. The background noise in the laboratory is about 66 dBA. The laboratory is well-equipped in terms of occupational safety and health measures. Gloves and eye-protection goggles are available in 
the laboratory. Two fire sprinklers are located on the ceiling in room 2509. A fire extinguisher is located in the hallway $10 \mathrm{~m}$ outside room 2509. First aid equipment is available in room 2513 less than $10 \mathrm{~m}$ away. Please refer to the explanation in the Program Description on land use, archaeological and historic resources and the socio-economic impact of the project.

Task 2: Water assisted recovery of heavy oils.

The goal of this project to assist in the development of a commercial scale plant for the production of heavy oil from Utah's oil sands using hot water extraction technology. The objective for the current year is to understand the fundamental and process engineering aspects of bitumen disengagement from mineral particles, the development of advanced separation processes, tailings disposal and bitumen cleanup.

All experiments in this project are conducted in the University of Utah ore Dressing Laboratory. The experimental set-up occupies a total floor area of $50 \mathrm{~m} 2$. A schematic drawing of the process is shown in Figure 5. The oil sand is crushed to minus $i .88 \times 10^{-2} \mathrm{~m}$ followed by diluent (kerosene or naphtha) treatment for an appropriate period of time to insure complete penetration of bitumen by the diluent. This treatment is carried out at ambient temperature in a cement mixer for a few minutes and the oil sand is left in this state for several hours (under cover) for complete diluent penetration. The amount of diluent is 10 to $35 \%$ with respect to the bitumen content all of which ends up in the bitumen phase during processing. In the second step, the 


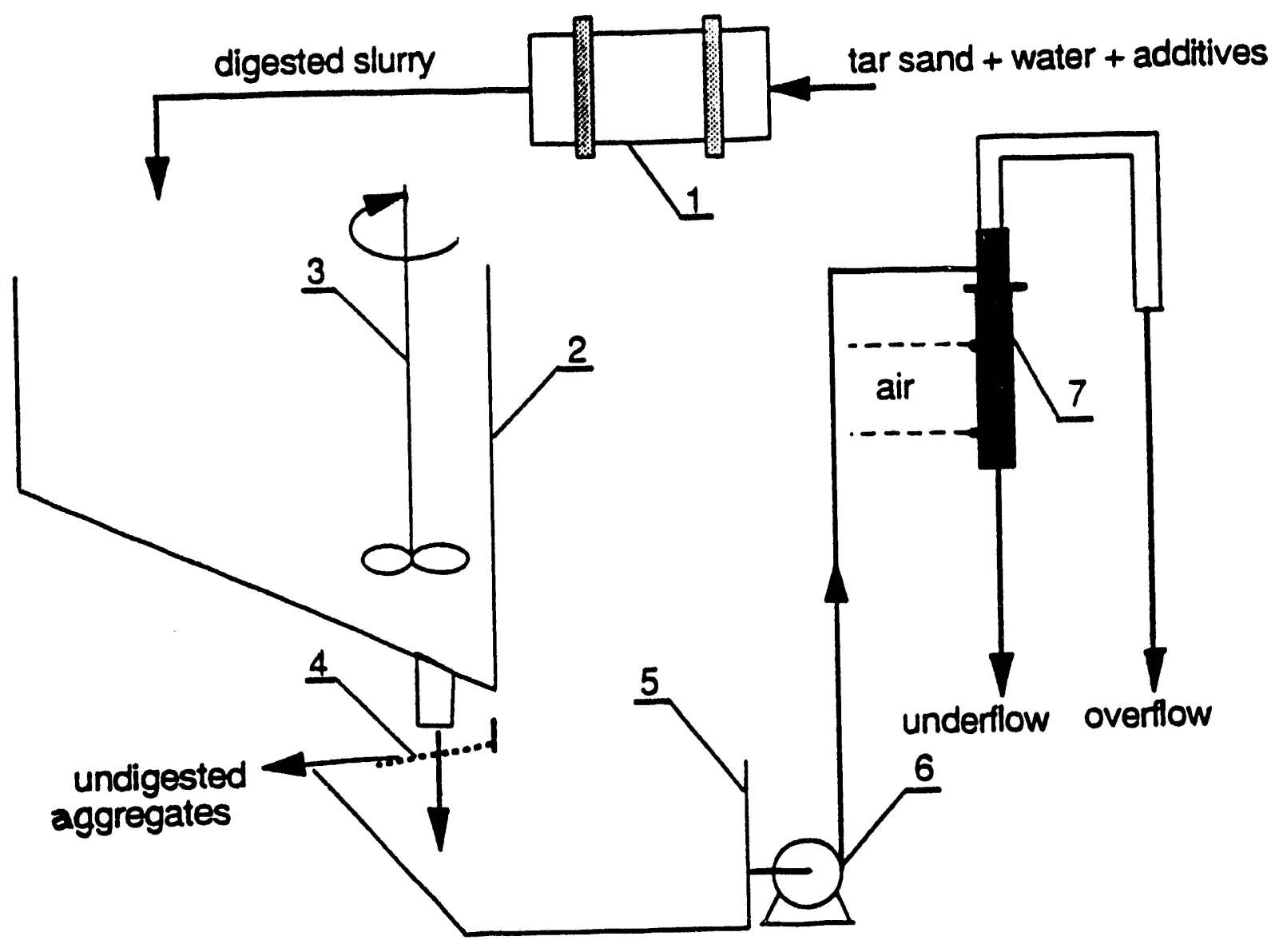

1. Digestion

2. Tank for gravity separation

3. Mixer

4. Screen

5. Storaze tank

6. Pump

7. Air-sparged hydrocyclone

Figure 5. A schematic diagram of the water assisted recovery system 
diluent treated oil sand is subject to digestion at 323 to $333 \mathrm{~K}$ in an alkaline solution to displace bitumen from the surface of the mineral matter. Four $20 \times 10^{-3} \mathrm{~m} 3$ stirred tank reactors and a small cement mixer serve for oil sand digestion. 95-100\% recovery of bitumen is achieved at the digestion stage. The bitumen recovery by gravity separation (in 20-200 X $10^{-3} \mathrm{~m} 3$ tanks) follows digestion. Flotation of digested oil sand slurry ( 20 wt $f$ solids) is accomplished in a $40 \times 10^{-3} \mathrm{~m} 3$ Denver type flotation cell and a concentrate containing about 55 wt\% bitumen (dry basis) is obtained in the first minute and subsequently lower grade concentrate products as the flotation continues. The tailings sand (containing about $5 \%$ bitumen) is subjected to sedimentation in a $60 \times 10^{-3} \mathrm{~m}_{3}$ container, dried, and collected in a barrel. The supernatant water is reused in subsequent experiments. The combined bitumen concentrate, i.e. from the gravity cell and from flotation, contains 20 to 60 wt $\&$ dispersed water and fine minerals. Cleaning of the bitumen concentrate is accomplished by dilution and subsequent sedimentation by gravity and centrifugation (bitumendiluent ratio $1: 2)$. Diluted bitumen is collected in $20 \times 10^{-3} \mathrm{~m} 3$ containers and is periodically picked up for disposal by University Safety Services.

\section{Feedstocks, products and effluents}

It is estimated that 60 batch experiments will be conducted in the current year. A single batch experiment would involve $5-40 \mathrm{~kg}$ of oil sand, $10-80 \mathrm{~kg}$ of water, 0-1 $\times 10^{-3} \mathrm{~kg}$ of sodium carbonate, $0-1 \cdot \times 10^{-3} \mathrm{~kg}$ of sodium tripolyphosphate and $0-10 \times 10^{-6}$ 
$\mathrm{m} 3$ of kerosene per $\mathrm{kg}$ of oll sand. The oll sands are prepared and handled according to the procedures outlined in the Program Description. In the same section, Tables 1 and 2 give the general characteristics of the feed and selected properties of the bitumen.

The only gaseous emission from these experiments is water vapor. 15-120 $\mathrm{kg}$ of bitumen are produced per year. The kerosene which is used as a diluent is present in the bitumen product. This bitumen-kerosene mixture is stored in plastic storage containers. It is collected according to the University hazardous materials handling procedure and disposed of accordingly. The salts added to the process distribute themselves between the aqueous and organic phases. In the aqueous phase, they undergo reactions that precipitate them, freeing the aqueous phase. The sands from this process also contain (for $40 \mathrm{kgs}$ of batch oil sand feed), about 160 gms of bitumen. These sands are stored in lined barrels for eventual disposal to the mine-site. The project uses $2-5 \mathrm{~kg}$ of steam per experiment for heating. Electricity is used for the generation of the steam. An estimated 20 of the 60 experiments will use $3 \mathrm{~m} 3$ each of compressed air which is supplied at $620 \mathrm{kPa}$.

\section{Environmental impact potential of the project.}

The only air emission from this project is water vapor which is innocuous from an environmental point of view. There are no water effluents either. Therefore, the project is not expected to have any ecological impact. The wistes, primarily bitumen and bitumen-containing sands, are handlea according to the University of Utah Hazardous Materials Disposal Manual. 
The noise levels in the laboratory in which the experiments are conducted do not exceed $65 \mathrm{dBA}$. The laboratory is adequately equipped with the means necessary for occupational safety and health. Goggles for eye-protection and gloves are available. There are three fire extinguishers at various points in the ore Dressing Laboratory, the nearest being next to the experimental set-up. There is, in addition an emergency station equipped with eye and skin neutralizers for acid and alkali burns. Please refer to the Program Description for an explanation of the land use, water resources, archaeologic and historic resources and the socio-economic impact of the project.

Task 3: Thermal recovery of heavy oil using a rotary kiln reactor or a specially constructed fluidized-bed reactor

The objective of this task is to develop semi-pilot scale technology for the production of bitumen from oil sands by thermal processing using either the fluidized-bed or the rotary kiln.

\section{Task 3a: Recovery of heavy oil by using the rotary kiln}

The goal of this project is to complete the process variable study for the pyrolysis of oil sands in the rotary kiln reactor.

\section{Project Description}

The University of Utah rotary kiln reactor, located in Hedco 130 is a semi-pilot scale, continuous flow thermal processing reactor. The reactor system consists of a rotary kiln reactor assembly, a spent sand receiver, a liquid product recovery system and a light gas flaring system. A detailed schematic of the 
apparatus is presented in Figure 6. Physically, the system is made of two distinct units, the kiln and the control system. The oil sands are introduced with a screw feeder from the feed hopper to the reactor. The sands are heated to the designated temperature in the kiln. Nitrogen, the sweep gas flows countercurrent to the sand stream. After pyrolysis, the processed sand or spent sand is withdrawn into the locked spent sand receiver (Figure 7). The collected spent sands are stored in polyethylene-lined sealed drums for future study. A hydrocarbon product vapor is produced in pyrolysis above $673 \mathrm{~K}$. During the continuous steady-state pyrolysis experiments, the hydrocarbon vapor enters the liquid product recovery system. The schematic of the liquid product recovery system is shown in Figure 8 .

Approximately 98-99\% of the liquid product is condensed and collected in the liquid product recovery system. The gases are burned in the flaring system along with some natural gas to yield carbon dioxide and water.

cooling water, directly from the tap, is used for the water-cooled condenser. This water does not contact any of the hydrocarbon products and is never contaminated. Utilities for this project include a $480 \mathrm{~V}, 60 \mathrm{~Hz}$ line for the furnace and about 0.1 $\mathrm{m}^{3} / \mathrm{hr}$ of cooling water.

\section{Feedstocks, products and effluents}

It is estimated that in the current year, 30 runs will be conducted using the rotary kiln. $15-20 \mathrm{~kg}$ of oil sand that have 


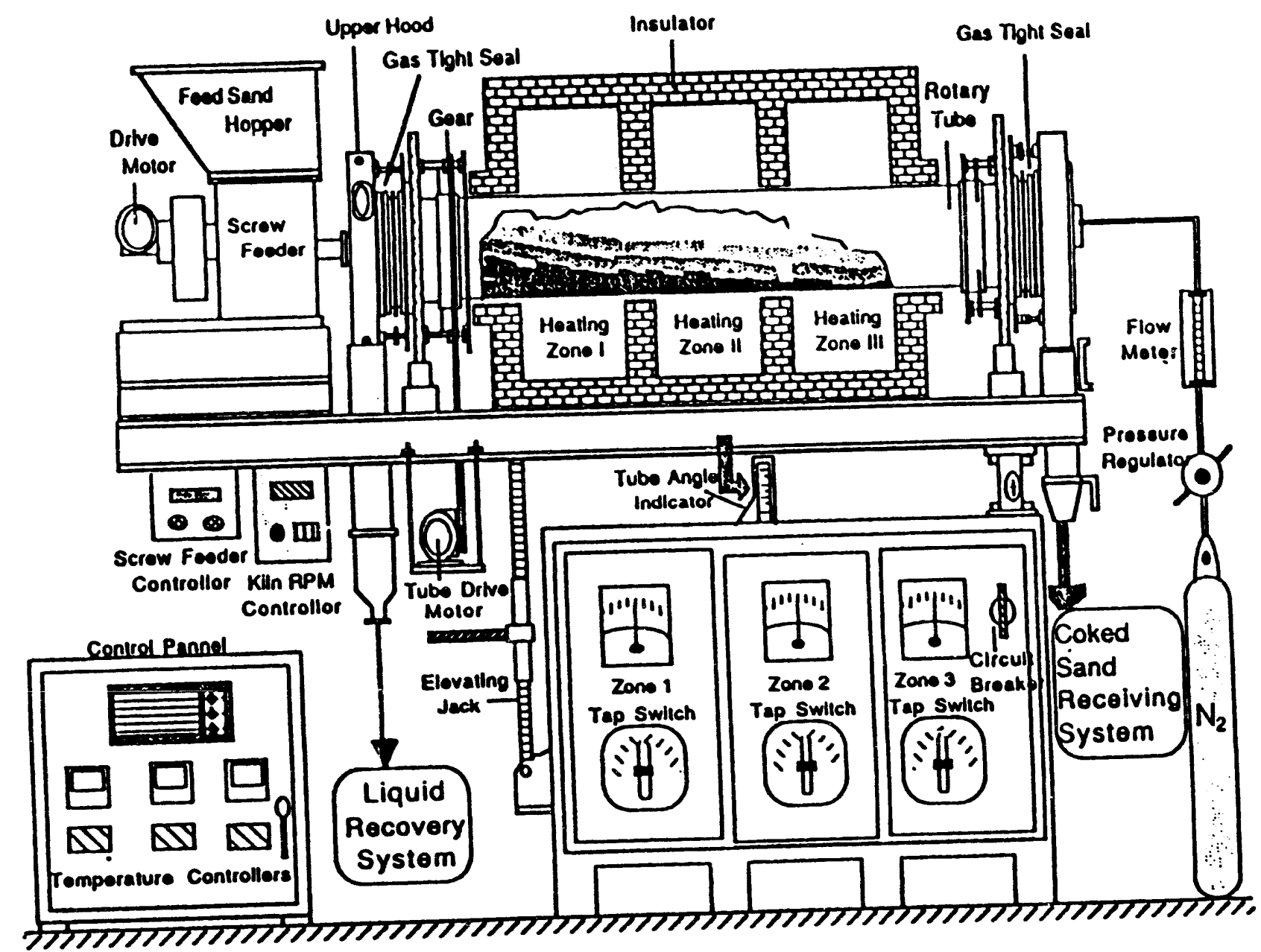

Figure 6. The rotary-kiln reactor for the recovery of heavy oil 


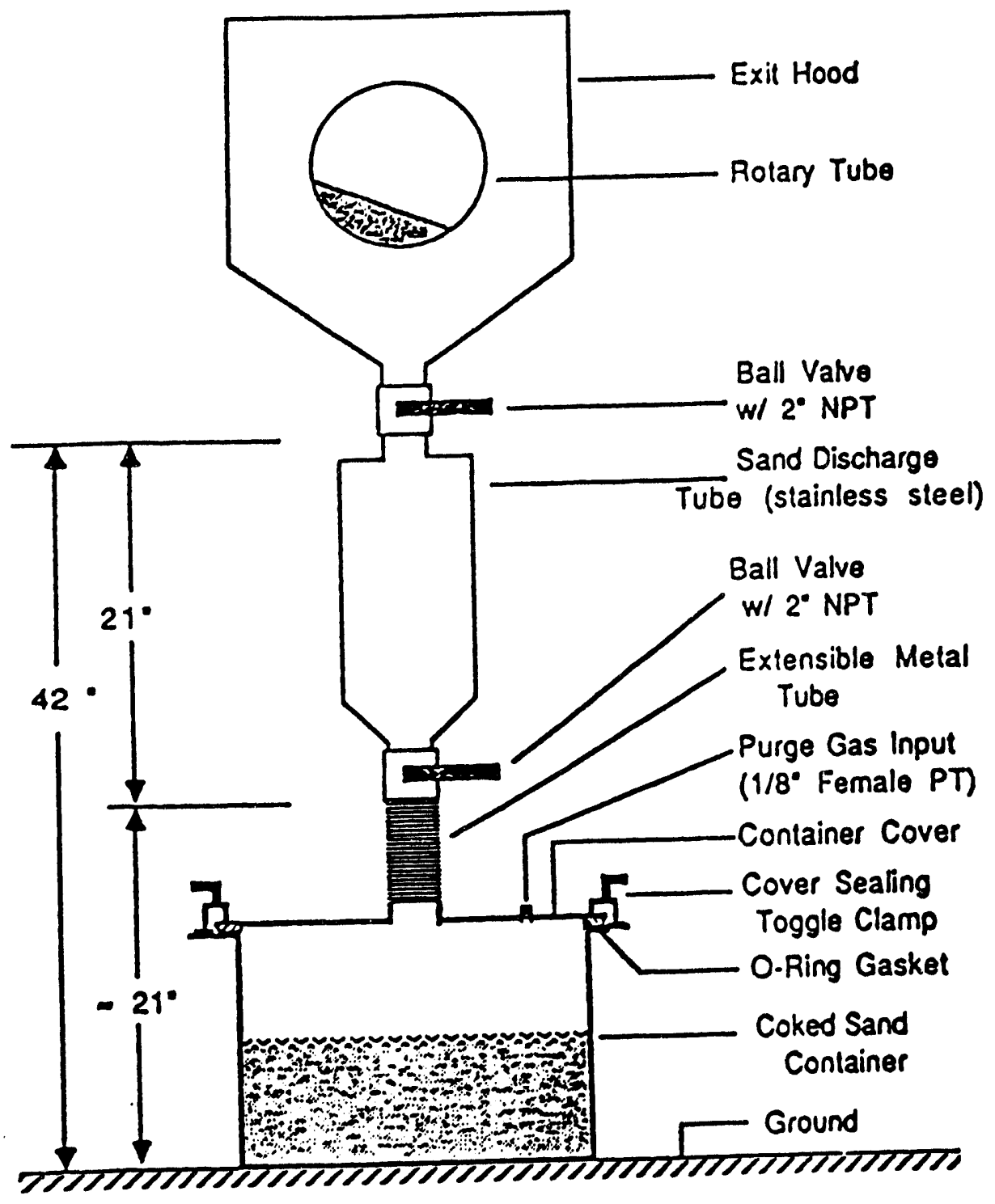

Figure 7. The sand collection system for the rotary-kiln reactor 


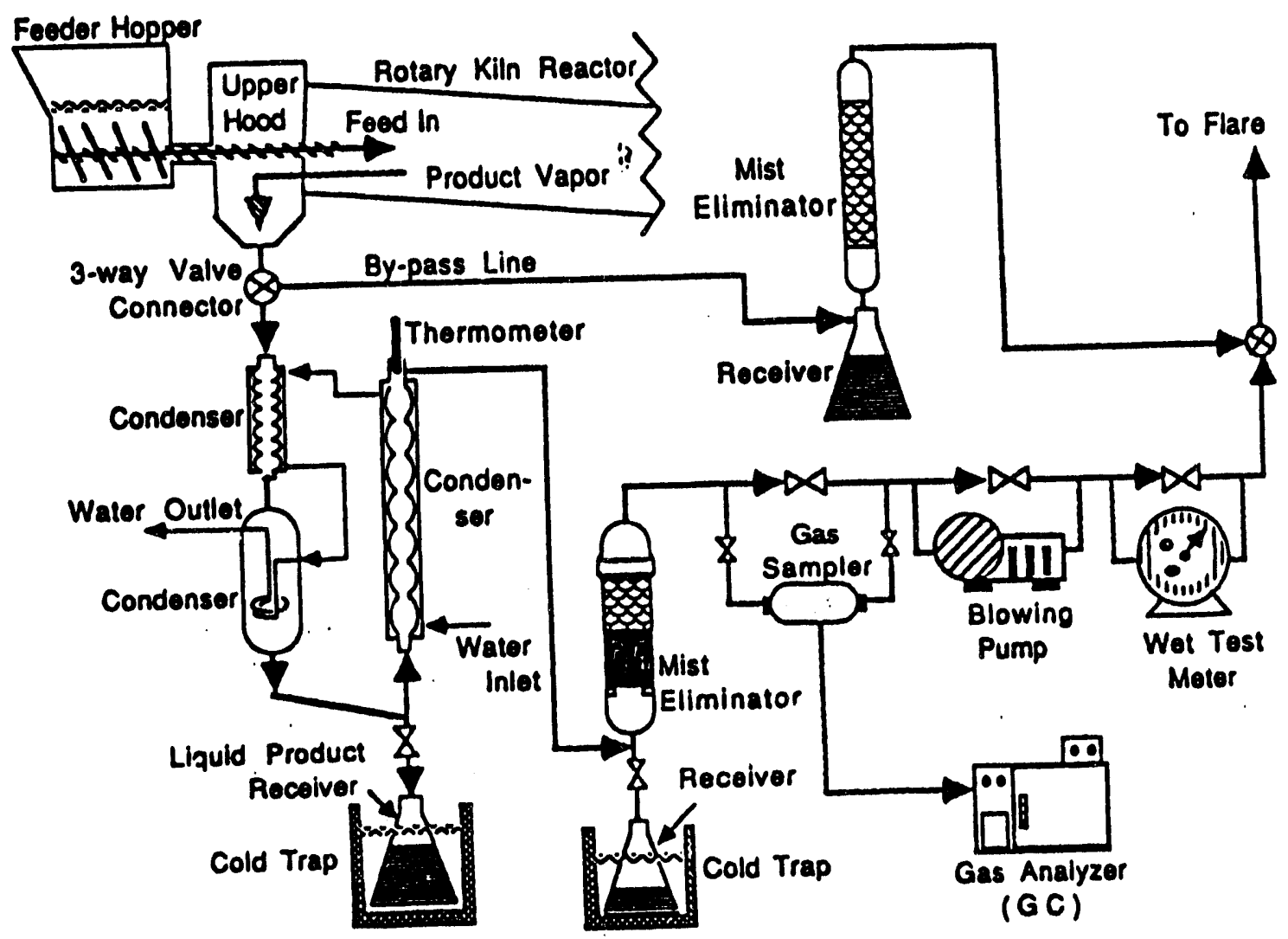

Figure 8. The hydrocarbon liquid collection system for the rotarykiln reactor 
been crushed and screened are fed to the reactor per run. The products are $1.3 \mathrm{~kg} /$ run of bitumen derived liquid, $0.3 \mathrm{~kg} / \mathrm{run}$ of hydrocarbon gases and $0.4 \mathrm{~kg} /$ run of carbonaceous residue distributed on $18 \mathrm{~kg} / \mathrm{run}$ of silica sand. Characteristics of the bitumen and bitumen derived liquid have been presented earlier (Tables 1 and 2). The hydrocarbon gases contain C1 - C4 compounds. Nitrogen is used as the sweep gas. Flaring of the hydrocarbon gases produces about $0.9 \mathrm{~kg} / \mathrm{run}$ of $\mathrm{CO}_{2}$ and $0.5 \mathrm{~kg} / \mathrm{run}$ of water vapor. The collected spent sands are stored in polyethylene-lined barrels for future study.

Environmental impact potential of the project.

The project will produce about $9 \mathrm{~kg}$ of hydrocarbon gases, 27 $\mathrm{kg}$ of $\mathrm{CO}_{2}$ and $15 \mathrm{~kg}$ of water vapor as air emissions. No chemicals will be discharged into the water effluents. The waste hydrocarbon liquids and miscellaneous chemicals will be stored in carefully labeled containers and will be disposed according to the University of Utah guidelines. With the aforementioned effluents and emissions the project will have no ecological or environmental impact.

The rotary kiln and the fluidized-bed reactors are both housed in Hedco 130. The noise level in this area with the propane burner fired is about $85 \mathrm{dBA}$. The background noise levels are in the range of 60-70 dBA. The students remaining in the area at the time of operation have access to ear protection. The laboratory is adequately equipped and is in compliance with the standards for occupational safety and health. Hedco 130 is equipped with a fire 
extinguisher. A first-aid kit, an eye-wash fountain and a safety-shower are located in Hedco 110, about $5 \mathrm{~m}$ away. Gloves are also available in the laboratory.

The Program Description provides a description of the land use, water resources, archaeological and historic resources and the socio-economic impact of the project.

Task 3b: Recovery of heavy oil using a fluidized-bed

The objective for the current year is to operate the 6 -inch diameter fluidized-bed reactor successfully and conduct preliminary process variable studies.

\section{Project description}

The University of Utah fluidized-bed process for the thermal processing of oil sands is shown schematically in Figure 9. The unit is housed in Hedco 130. The oil sands are fed to the reactor using an Acrison feeder and are pyrolyzed in a reactor tube that is $0.15 \mathrm{~m}$ in ID and $1.8 \mathrm{~m}$ long. The reactor tube is insulated over its entire length. The lower half is heated by propane, which is burned with the product gases $(\mathrm{Cl}-\mathrm{C} 4)$ in an outer jacket. The hydrocarbon product gases pass through two combination filter condensers. The iirst filter is 200 mesh and the second is 25 micron. Liquids (C5t) are collected in a closed and vented receiver. Noncondensibles are burned with propane as part of the reactor heater system. An alternate flare is provided. Exhaust from the propane heater and the flare are vented to a building chimney. The liquids are collected for analysis and further research and are 


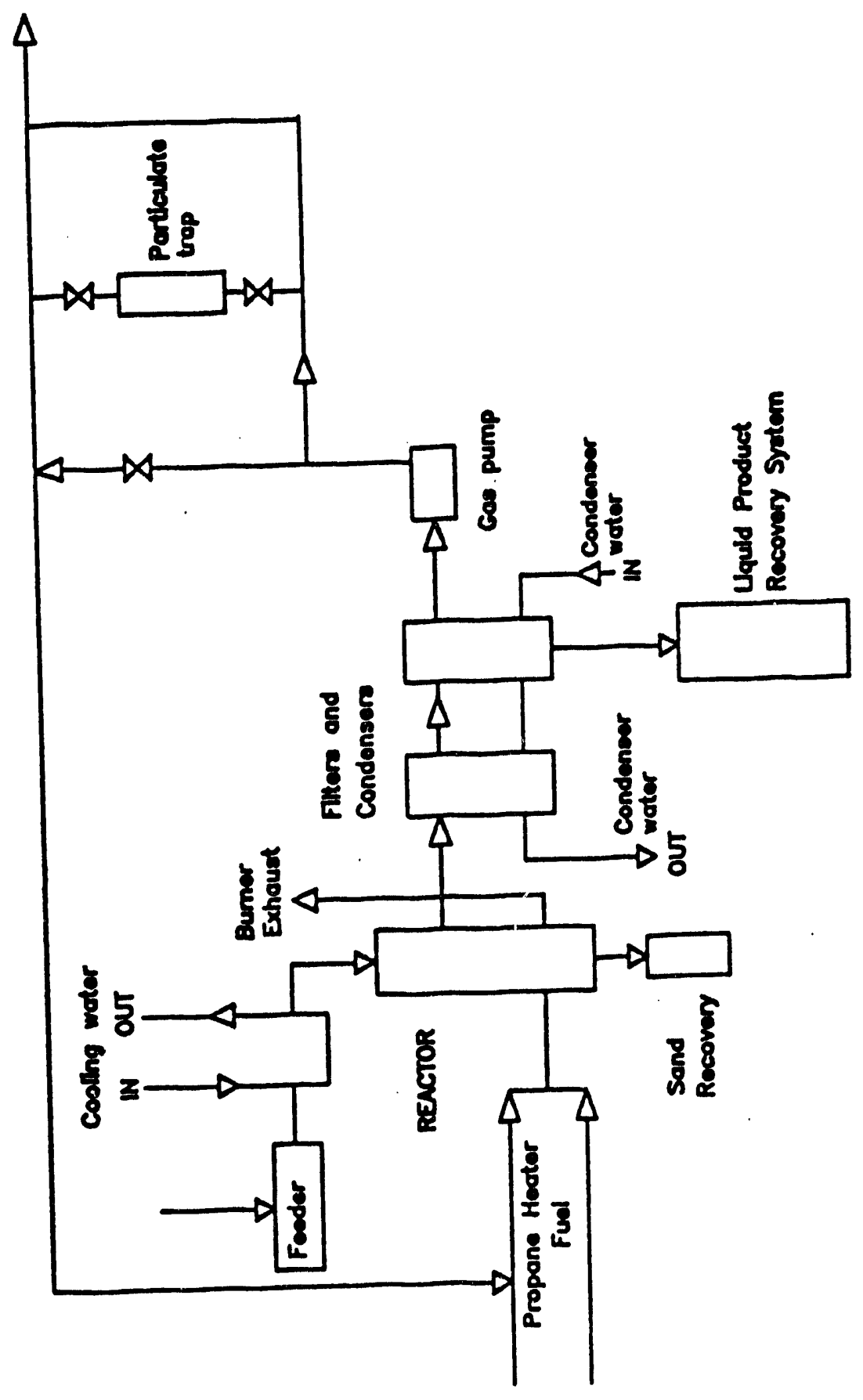

Figure 9. The process flow diagram of the fluidized-bed reactor for the recovery of heavy oil 
stored as per procedures previously outlined. Processed sand containing $1-2 \%$ coke is removed from the reactor so as to maintain a constant volume of fluidized material during processing. The hot sand is stored in an air-free receiver until cooled or can alternately, be removed to a coked sand combustor. Two water streams are used. One cools the oil sands to 283 to $293 \mathrm{~K}$ prior to processing. The second cools the liquid products in the filter/condensers. Neither stream contacts feed or product and the water is not contaminated.

\section{Feedstocks, products and effluents}

Between 20 and 25 runs (each about 10 hrs long) will be conducted in the current year. The feed will consist of whiterocks oil sand (7-8\% bitumen saturation), the feed rate being about $30 \mathrm{~kg}$ per hour. The feed will be prepared and handled according to the procedures described in the Program Description.

Under these conditions, the process produces $1.5 \mathrm{~kg}$ per hour of oil, $0.2 \mathrm{~kg}$ per hour of flue gas and $27.9 \mathrm{~kg}$ per hour of silica sand. $0.42 \mathrm{~kg}$ per hour of carbonaceous residue is deposited on the sand as the pyrolysis proceeds. Most of the sulfur and nitrogen in the feed material is deposited on the sand as part of the carbonaceous residue. The flue gases are flared. This process produces $0.6 \mathrm{~kg}$ per hour of carbon dioxide and $0.35 \mathrm{~kg}$ per hour of water vapor. Selected properties of the bitumen derived liquids (oils) are given in Table 3. The flue gases contain C1 to C4 hydrocarbons. Variations in process conditions, type of feed, etc. 
are likely to cause variations on these estimates which would not be significant from an environmental perspective.

The liquid product is stored in plastic storage containers and used for upgrading research. Any excess is treated as hazardous waste and collected and disposed of according to the University hazardous materials handling procedure. The spent sands from the process are stored in sealed polyethylene-lined barrels to be returned to the mine site eventually.

The pattern of electrical consumption is $120 \mathrm{~V}, 20 \mathrm{~A}$ max. cooling water is used at the rate of about $0.5 \mathrm{~m}^{3}$ per hour. Compressed air is supplied from the house compressor. The combustion of propane results in a stream of gaseous products that act as the fluidizing gases. Enough propane is burned to supply about $4.5 \mathrm{~kW}$.

Environmental impact potential of the project.

The air emissions generated by this project are approximately, $410 \mathrm{~kg}$ of carbon dioxide and $250 \mathrm{~kg}$ of water vapor per year. The Air Quality considerations of the University, as detailed in the Program Description show that these emissions are within the compliance limits. These low levels of emission would cause no damage to vegetation, either short or long term. The cooling water streams do not directly contact any of the product streams, thereby leaving the effluent water uncontaminated. The project is expected to have no ecological impact.

The hydrocarbon liquids produced in this project contain potential carcinogens. They are used as feed in upgrading projects. 
The excess liquids are collected and disposed of according to the University of Utah Hazardous Material Disposal Procedures Manual.

Aspects of land use, water resources, archaeological and historic sites and the socio-economic impact of the project are described under Program Description. The occupational safety considerations for this project are the same as those for the Rotary Kiln project.

\section{Task 4: Recovery of heavy oil by solvent extraction}

The objective of this task is to evaluate the solvent extraction process for the upgrading of the heavy oil and for the insitu recovery of oil from oil sands. For the current year, this task will focus on solvent extractions of different types of feedstocks using dense gas supercritical solvents such as carbon dioxide and propane.

\section{Project Description}

The system was custom-built for the University of Utah by Autoclave Engineers. The equipment is currently housed in 130 Hedco building. It occupies approximately $3 \mathrm{~m} \mathrm{X} 1.2 \mathrm{~m}$ X $1.8 \mathrm{~m}$ of floor space. Figure 10 shows a schematic drawing of the system. Central to the system is a temperature controlled extractor with a capacity of $300 \times 10^{-6} \mathrm{~m} 3$ and rated to a pressure of $41.5 \mathrm{MPa}$. The extractor is equipped with a magnetic-drive packerless stirring device. The solvent is charged into the extractor and the system is brought to the desired pressure by using a high-pressure liquid pump. Pressure control is achieved by incorporating a back pressure regulator in 
7
0
0
0
0
0
0
0

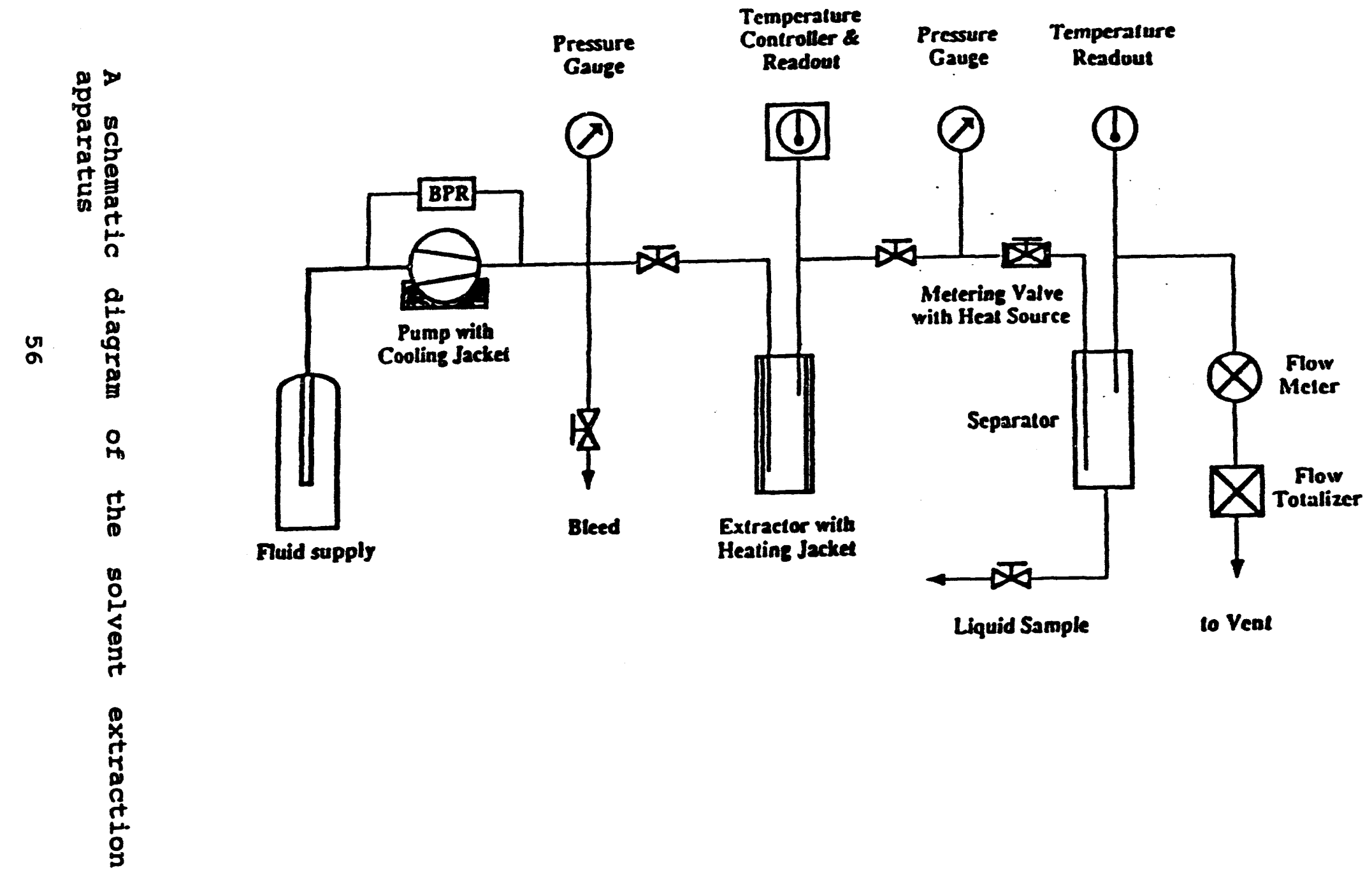


a loop with the pump. The pump head is cooled by a circulating cooling bath to ensure that the carbon dioxide is maintained in a liquid state at the pump head.

In all the experiments, a known amount of sample is charged into the extractor at the desired conditions and the dynamic extraction process begun. So far, pressures up to $34.48 \mathrm{MPa}$ and temperatures up to $422 \mathrm{~K}$ have been used in the process. The solvents currently in use are carbon dioxide and propane. The extracted phase flows through a heated metering valve into a separator, which is at room temperature and pressure. Under these conditions, carbon dioxide separates from the extracted oil and is vented through the hood system. The oil accumulated in the extractor is weighed and analyzed.

In each extraction, $150 \times 10^{-3} \mathrm{~m} 3$ of carbon dioxide at room temperature are vented to the atmosphere. The gas stream that is vented typically contains about $7 \mathrm{~g}$ of a mixture of $\mathrm{C5}-\mathrm{C7}$ gases per $150 \times 10^{-3} \mathrm{~m} 3$ of carbon dioxide at room temperature. When the system uses condensed propane as the extracting solvent instead of carbon dioxide, the effluent propane is flared and vented.

Any excess liquids or waste materials are deposited in liquid waste containers. These are collected periodically by the University Safety Service staff and are disposed of according to the University hazardous materials disposal procedures.

Feedstocks, products and effluents

Feed to the system consists of any one of pyrolyzed bitumen, native bitumen and crude oil. The bitumen feedstock is prepared 
according to the method outlined in the Program Description. Pyrolyzed bitumen could be from among the products of the rotary-kiln or fluidized bed pyrolysis reactors described earlier. Approximately, $0.1 \mathrm{~kg}$ of sample is charged into the extractor for each run. A single run uses $0.15 \mathrm{~m} 3$ of carbon dioxide at room temperature and pressure and $0.05 \mathrm{~m} 3$ of propane at the same conditions. Extractions of crude oils by $\mathrm{CO2}$ produce about 0.007 $\mathrm{kg}$ per run of $\mathrm{C3}$ - $\mathrm{C7}$ gases. Any compounds left inside the system and adhering to it, are cleaned using toluene, dichloromethane and acetone. These waste solutions are collected in labeled containers and periodically disposed of according to University safety procedures.

\section{Environmental impact potential of the project.}

The carbon dioxide extractions produce $13.5 \mathrm{~kg}$ of $\mathrm{CO} 2$ per year along with $0.35 \mathrm{~kg}$ of C3 - C7 hydrocarbon gases. Propane experiments emit $13.5 \mathrm{~kg}$ of $\mathrm{CO} 2$ and about $7.2 \mathrm{~kg}$ of water vapor. No chemicals enter water effluent streams due to this project. There are no solid wastes. These emissions are not expected to cause any impact on the vegetation or local ecology. Land use, archaeological and historical impact of the project on the site are explained in Program Description. The equipment is located in the same room as the fluidized bed and the rotary kiln and the occupational health and safety matters have been discussed as part of the rotary kiln pyrolysis project. 


\section{Task 5a: Heavy ofl uparading to synthetic fuels}

The objective of this task is to identify the best possible strategy for the upgrading of the heavy oils obtained from the oil sand deposits of Utah and to determine the catalyst types and process conditions for the strategy identified.

\section{Task 5a: Heavy oil upgrading to synthetic fuels}

Hydropyrolysis and hydrotreating The goal of this project is to develop a thermal hydrocracking process for upgrading heavy oils obtained from oil sand deposits and use subsequent hydrotreating to produce a refinery feedstock. For the current year this task will consist of conducting comparative analysis of upgrading options and selecting a technology sequence requiring piloting.

\section{Project Description}

The hydropyrolysis work is performed in the ore Dressing laboratory. Approximately $90 \mathrm{~m} 2$ of wet chemical and high-pressure equipment space is utilized by this system. Hydropyrolysis is a short residence time thermal hydrocracking process for heavy petroleum feedstocks. Hydrotreating is undertaken in a trickle-bed reactor. The schematic of the hydropyrolysis system is shown in Figure 11. The hydropyrolysis process produces lighter molecular weight compounds from heavier ones and minimizes the formation of coke and aromatics by limiting retrograde reactions. The process is carried out at temperatures of 500-600 C, pressures of 7-17 MPa and residence times of $1-50$ seconds. 

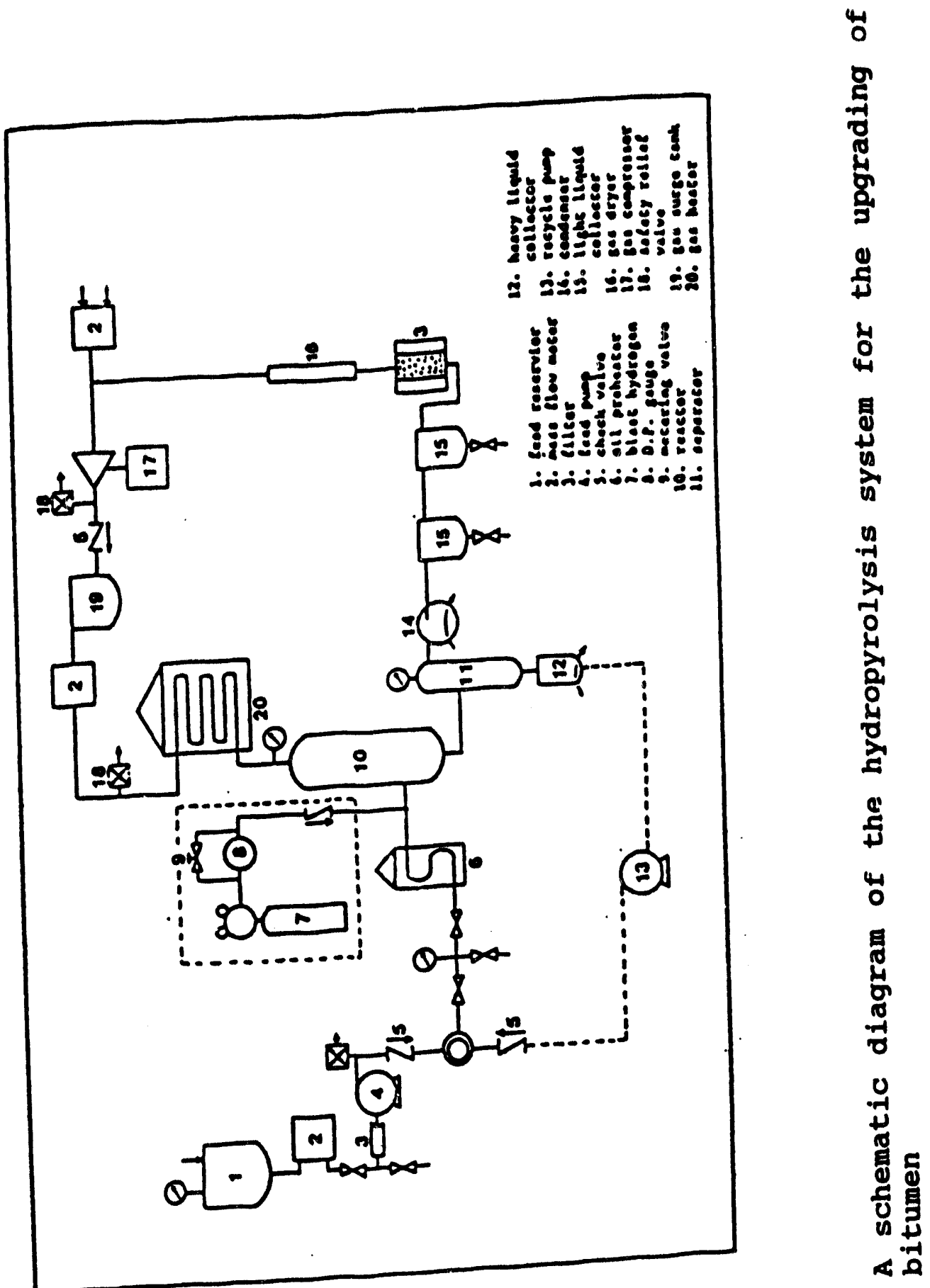

眪 
In general, the process equipment is pressure tested, heated components are brought to the desired temperature, feed and hydrogen are introduced in a continuous fashion and product liquid and gases are withdrawn until the run is complete. Processes are shut down by opening the heater circuits, gases are vented through scrubbers or flares. The process system is equipped with pressure relief valves and alarm systems. The chemicals stored in the laboratory include common hydrocarbon solvents, model compounds and catalysts. MSDS on all materials are available for quick review.

The laboratory is provided with all services including water, gas, vacuum, 2-phase and 3-phase power. The facility is modern, built to code and has adequate lighting and ventilation.

\section{Feedstocks, products and effluents}

About $20-40 \mathrm{~kg} r$ sar of bitumen are processed in about 10-20 experimental $I$ These produce synthetic crudes and distillates. It is estimated that approximately $0.1 \mathrm{~kg}$ of gaseous effluents per run are released into the hood system. These are predominantly $\mathrm{Cl}$ - $\mathrm{c6}$ normal alkanes with a few olefinic compounds. The liquid products are complex petroleum mixtures containing potentially carcinogenic materials. These are stored in air-tight plastic containers.

Environmental impact potential of the project. The project releases about $2 \mathrm{~kg}$ per year of gaseous effluents containing $\mathrm{Cl}$ - $\mathrm{C6}$ hydrocarbons. Water effluents are not contaminated by the project. No solid wastes are generated by the 
project. The project is not expected to have any impact on the local vegetation. The background noise level in this laboratory is about $65 \mathrm{dBA}$. During operation, it may reach $70 \mathrm{dBA}$. The hydropyrolysis work is carried out in the ore Dressing Laboratory and the hydrotreating work is performed in the high-pressure laboratory. Both these laboratories are equipped with safety equipment such as the fire-extinguishers, eye-wash fountains and safety showers. Occupational safety features prescribed in the Chemical Hygiene Plan of the University of Utah are strictly followed in the operation of this project. The remaining environmental considerations for this project are common with the program.

Task 5b: Heavy oil upgrading to synthetic crude - Hydrotreating and hydrocracking

The objective of this project is to demonstrate the viability of using conventional hydrotreating followed by hydrocracking to produce high-quality refinery feedstock. For the current year the workplan will consist of hydrotreating studies for the bitumen-derived liquid and the bitumen using conventional HDN catalysts and design of a laboratory scale hydrocracker.

- Project Description.

The hydrotreating/hydrocracking unit system is currently in operation in Hedco 110. The purpose of this catalytic reactor is the removal of $N, S$ and $O$ from liquid feed and the lowering of its molecular weight. The feed is either bitumen or liquid product(obtained from the pyrolysis of oil sand), and hydrogen. 
High temperatures $(773 \mathrm{~K})$ and high pressures $(20.69 \mathrm{MPa})$ are used to effect high conversions. Hydrogen from cylinders is compressed to reactor pressure by a compressor, then metered into the reactor. Liquid feed is fed through burets into a metering pump which boosts the liquid feed from atmospheric to reactor pressure at the desired feed rate. Gas and liquid enter the reactor where they are heated and contacted with the catalyst. The variables affecting conversion are temperature, pressure and feed rates. The desired liquid product is separated from the gas product in a vapor-liquid separator and is collected in a closed collector for use in further studies. The gas product consists of hydrogen sulfide, ammonia, water vapor and a mixture of light hydrocarbon gases (mainly methane, propane, $n$ - and iso-butane). This is bubbled through a basic solution of sodium and ammonium hydroxide. This removes most of the hydrogen sulfide and part of the ammonia. The gas stream is then vented into the atmosphere through a fume hood. It is estimated that about $10 \%$ of the hydrogen sulfide and 50\% of ammonia escape the trapping system and enter the fume hood. The emission calculations listed below are based on a conservative estimate that none of the effluent gases are trapped. Coke produced is deposited on the catalyst and the reactor packing material. Figure 12 , is a schematic drawing of the system.

\section{Feedstocks, products and effluents}

About $60 \mathrm{~kg}$ of bitumen or bitumen derived liquid is hydrotreated in each experimental sequence. About five experiments with an approximate on-stream time of 200 hours are planned for 

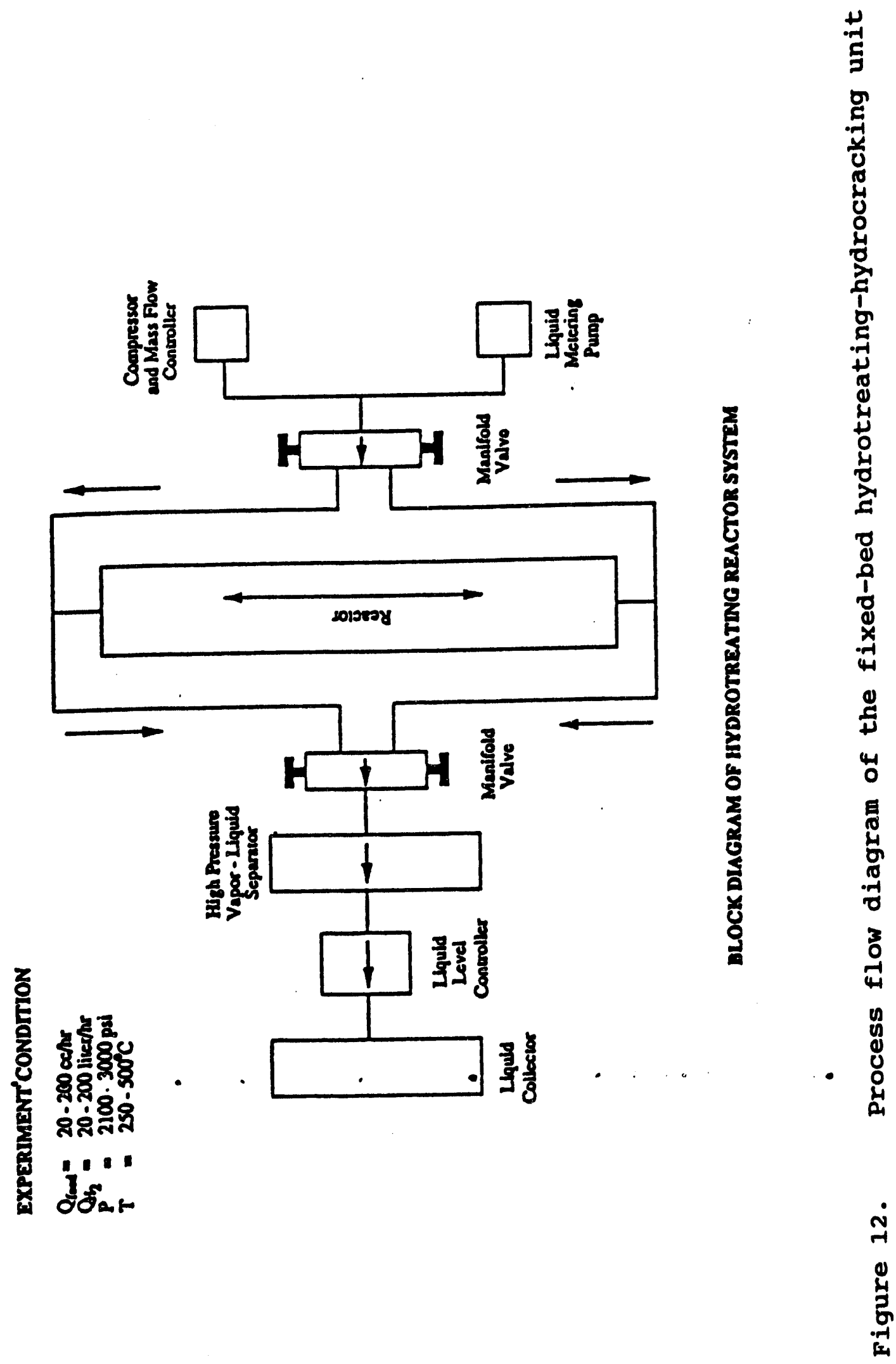
the coming year. During each of the runs about $5 \mathrm{~kg}$ of hydrogen are consumed. About $98 \%$ of the liquid feed is recovered as hydrotreated liquid. The process also produces $4 \mathrm{~kg}$ of hydrocarbon gases ( 11 - C4 alkanes and olefins), $0.3 \mathrm{~kg}$ of hydrogen sulfide, 1 $\mathrm{kg}$ of ammonia and $1 \mathrm{~kg}$ of water. The properties of bitumen and bitumen derived liquid have already been presented. The hydrotreated liquid is desulfurized and denitrogenated and is considerably lighter (higher API gravity) than the feed. The liquid products are stored in air-tight containers. The catalyst which has $15 \%$ nickel and molybdenum sulfides, alumina and traces of arsenic, vanadium and iron is sent to the catalyst supplier (UNOCAL) for further analysis.

\section{Environmental impact potential of the project}

The project generates about $15-20 \mathrm{~kg}$ of $\mathrm{Cl}-\mathrm{C4}$ hydrocarbon gases, $0.5-1.5 \mathrm{~kg}$ of hydrogen sulfide, 2-4 kg of ammonia and 4-6 kg of water per year. Most of the hydrogen sulfide and part of the ammonia is removed by bubbling through a basic solution of sodium and ammonium hydroxide. The rest of the gaseous effluents are vented through the hood system. These emissions are not expected to have any environmental and ecological impact. All the liquid products from the project are collected, stored and disposed if necessary. None of the operations in this project generates excessive noise. The noise level is below $65 \mathrm{dBA}$ at all times and this is the background noise level in this laboratory. Hedco 110 is equipped with a fire extinguisher and first-aid kit. An eye-wash fountain and a safety shower are also located in the lab. A 
high-pressure barrier will be erected to isolate the hydrotreating unit for high-pressure safety. Please refer to the program Description for an explanation on the land use, archaeological and historical resources and the socio-economic impact of the project.

Task 6: Production of specialty products from heavy oils such as asphalts and other products such as white oils, ink oils and jet fuels

The objective of this project is to identify the potential high-value products for the oil sand heavy oils and to develop technology for the production of these products. For the current year, based on the characterization of oil sand derived heavy oils, potential products will be identified and a small-scale research reactor to conduct selective processing will be designed.

\section{Project Description}

The heavy oils selected for study are those obtained from Whiterocks and Asphalt Ridge. Other oil sand deposits will be considered in the future. The oil sand samples will be subject to extraction using the soxhlet extraction method. The bitumen so obtained will be characterized through physical property determination and elemental analysis. The asphalt product will be subject to distillation using available apparatus to strip out the light front end components in order to meet the asphalt distillation standards set by ASTM for marketable asphalt. The light distillables would be similar to kerosene or \# 2 diesel in composition and would have to be handled accordingly. Experiments will be conducted on the light ends for physical property determination. Elemental analysis of the light ends will also be 
done. The product asphalt in proper amount will be submitted to the laboratories of the UDOT for testing. The upgrading of the heavy oils to jet fuels will utilize equipment and procedure described under the hydrotreating/hydrocracking project. The feed materials will be obtained by water extraction methods described under Tasks 2 and 4 respectively. The products will be recovered and distilled in a fractionation apparatus described in the Program Description. The products of distillation will be gasoline, jet fuel and heavy residue which can be sent to the upgrading apparatus or recovered as a gas oil for evaluation and disposal by methods outlined in the University of Utah hazardous material management manual. The schematic of a hydrotreating system is shown in Figure 12 . The hydrotreating operational procedures have been explained under Task 5. This part of the project would use $5 \mathrm{~kg}$ of the liquid product from the hydrotreater in Task 5b. Combination hydrotreating and hydrocracking at appropriate conditions will be used to produce specialty products such as lubricating oils, white oils, ink oils, etc. The hydrocracking reactor is expected to be $0.3 \mathrm{~m}$ long and $1.25 \times 10^{-2} \mathrm{~m}$ in diameter. All the experiments in this project will be conducted in Hedco 110. The proposed fixed bed reactor will be similar in deslgn and function to the reactor in Task 5b.

\section{Feedstocks, products and effluents}

About 20 experiments are planned for the coming year. Approximately $10 \mathrm{~kg}$ of feed material (bitumen, bitumen derived liquid) are expected to be processed in each of these experiments. It is estimated that $95 \%$ - $98 \%$ of this liquid product will be 
converted to the white oils or lube oils. The remaining feedstock will exit the reactor as $C 1$ - C6 hydrocarbons, hydrogen sulfide, ammonia and water. Catalysts will be handled according to the procedures explained in Task 5.

\section{Environmental impact potential of the project.}

The project will release a total of $10 \mathrm{~kg}$ of $\mathrm{Cl}$ - $\mathrm{C6}$ hydrocarbons, hydrogen sulfide, ammonia and water per year. It is difficult to estimate the relative amounts of these without direct experimental data. We estimate that about $5 \mathrm{~kg}$ of these emissions would be the hydrocarbon gases, $1 \mathrm{~kg}$ would be hydrogen sulfide, $2 \mathrm{~kg}$ would be ammonia and $2 \mathrm{~kg}$ would be water vapor. These emissions are not expected to cause any harm to the local environment. The equipment for this project will be located in Hedco 110 and the occupational safety aspects of the project will be as explained for Task 5 . other environmental aspects of the project are addressed in the Program Description.

\section{Task 7: Rehabilitation of North Salt Lake pilot plant}

The objective of this project is to bring the North Salt Lake pilot plant to an operational condition so that comprehensive pilot plant studies of the hot water extraction procass can be -conducted. These pilot plant studies are essential for the development of the any commercial process. The objective for this year is to refurbish the building and get the utilities hooked up. This project is funded by the state of Utah. 
Task 8: Study of gravity separation of heavy oil concentrates from sand

The goal of this project is to be able to maximize the recovery of bitumen from the bitumen beneficiation processes. The goal for the current year is to design a gravity classifier and conduct fundamental gravity separation studies involving bitumen-sand slurries.

\section{Project Description}

Tasks 8 and 9 involve the design of a separation system for the processing of oil sands. This equipment would take oil sands at a $1.9 \times 10^{-2} \mathrm{~m}$ top size and produce a clear bitumen product together with two fractions of tailings based on particle size. Principles of production of bitumen from oil sands by hot water extraction is discussed in Task 2 . The coarser fraction would be the sands product which would be primarily plus 100 to 200 mesh and should be around $15 \mathrm{wt} \%$ moisture. The -100 to 200 mesh solids would be produced from the underflow of a special very high torque thickener that would have a solids concentration up to $60 \mathrm{wt} \backslash \%$ solids. It is anticipated that these two tailings products would be combined and returned to the deposit from which it was mined. The major process equipment involved in dewatering the tailings would be a (1) gravity classifier, (2) a spiral classifier and (3) a special high torque thickener. The gravity classifier is discussed below.

The design of a gravity classifier would only involve bench scale tests in gravity separation. The technique will be used in 
the separation of bitumen from oil sands by flotation. Once the bench scale tests are clone, the process equipment will be designed and fabricated. The process equipment is a special form of gravity classifier. The three product streams from the classifier are expected to be: 1. An overhead of overflow stream which should contain bitumen and water (bitumen should be 35-50\%) with some fine solids (probably 2-5\%) and the rest water. 2. A secondary stream termed middlings coming off around half-way down the vertical height of the unit is expected to contain primarily water (around 70-80\%), fine sand (around 20\%), and bitumen (1-2\%). This would be sent to flotation for bitumen recovery. 3. An underflow product where withdrawal would be controlled by a variable speed pump of the progressive cavity type in order to maximize underflow solids concentration. Solids concentration should be around $65-70 \backslash \frac{1}{6}$ with the remainder being water and a very small amount of bitumen(less than $0.5 \%$ )

Figure 13 is a simple cross section of the gravity classifier. The unit will be around $1.2 \mathrm{~m}$ in diameter with a conical bottom and will have a vertical height of about $4.1 \mathrm{~m}$. The destinations of the three product streams are shown in Figure 14.

Laboratory bench-scale type tests will be performed to determine the probable operating performance to 'reach the objectives listed above. These would use various glassware, buckets, screens and drying ovens. These would be used to determine probable bitumen, solids and water content by weight $\%$ in each stream, solids size distribution in each stream, and upflow 


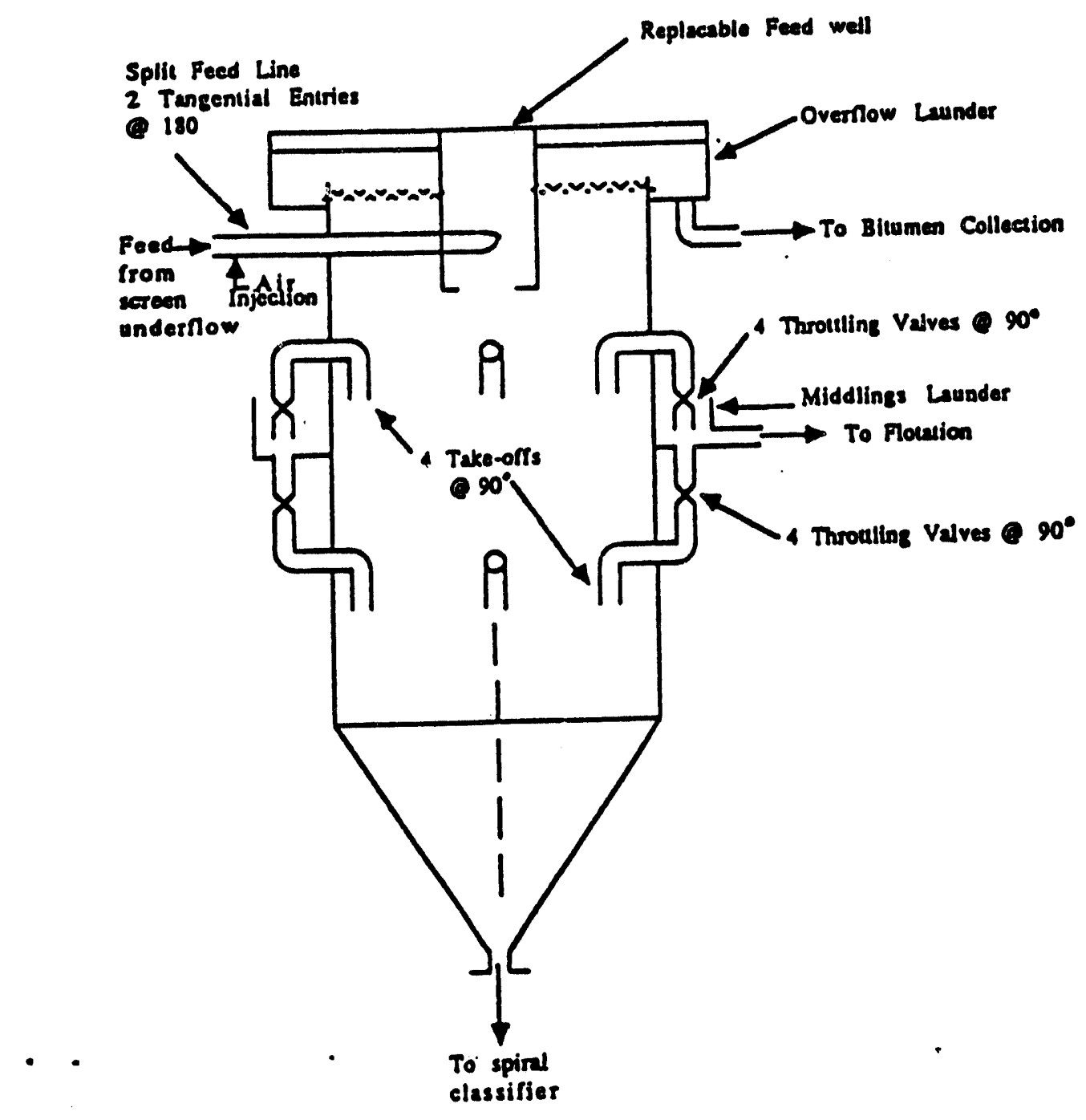

Figure 13. Cross-section of the grivity"classifier 


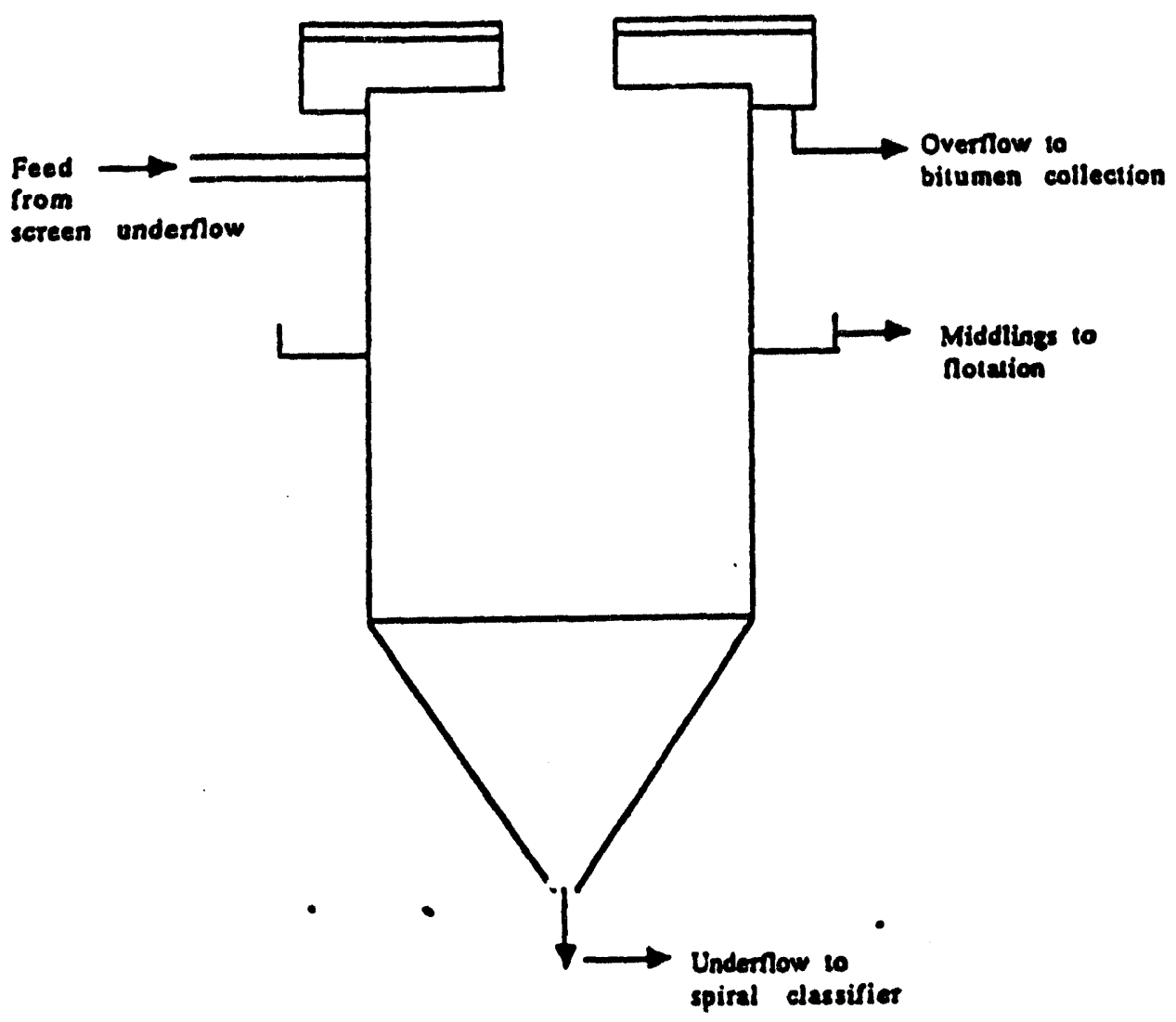

Figure 14. Flow diagram of the gravity classifier 
velocities required to achieve bitumen - solid - water separation as a function of maximum particle size in the middling stream. These residues, slurries, etc. resulting after the testing would be disposed to the various containers in the laboratory for final disposal. The solid wastes arising from this project consist of bitumen-sand mixtures from which the bitumen can be skimmed off and disposed of according to University regulations. The clays and fines remaining are innocuous in terms of environmental impact.

\section{Environmental impact potential of the project}

The environmental concerns of this project are similar to those of task 2 and have already been addressed.

Task 9: Studies of disposal of sand concentrates by pumping The idea of this project is to be able to pump the sand concentrates over long distances, thus avoiding the trucking costs. This will improve the economics of the hot water extraction process. The goal for the current year is to design the spiral classifier and the thickener required for dewatering the sand and to conduct pumping tests for sand-water mixtures.

\section{Project description}

- This task wilr investigate the feasibility of the dewatering. system by testing equipment such as a spiral classifier and a high-torque thickener. Figure 15 shows a diagram of the spiral classifier.

The special high torque thickener will be appropriately designed for this pilot plant. The principal is based on employing 


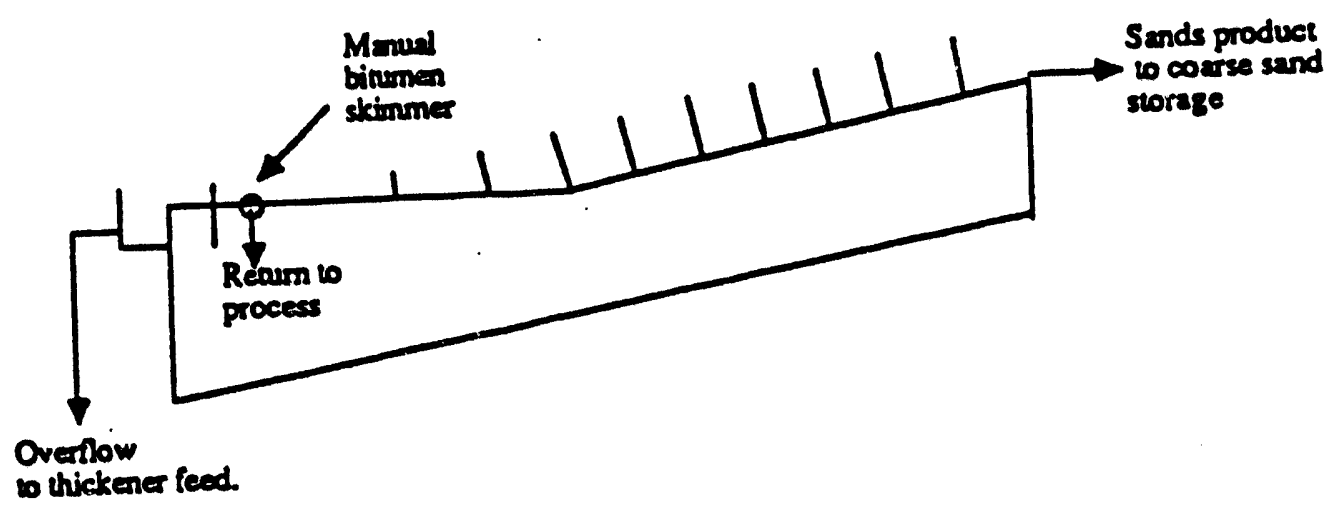

Figure 15. Flow diagram of the spiral classifier 


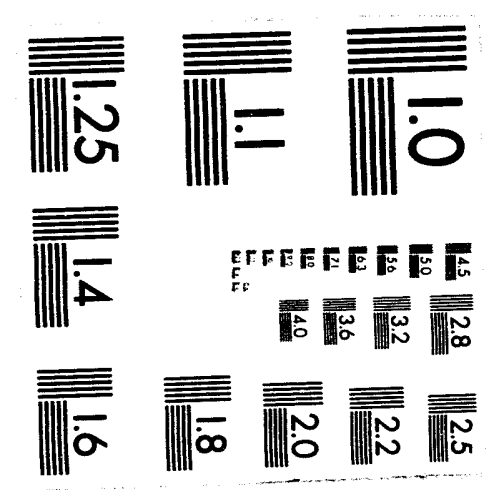



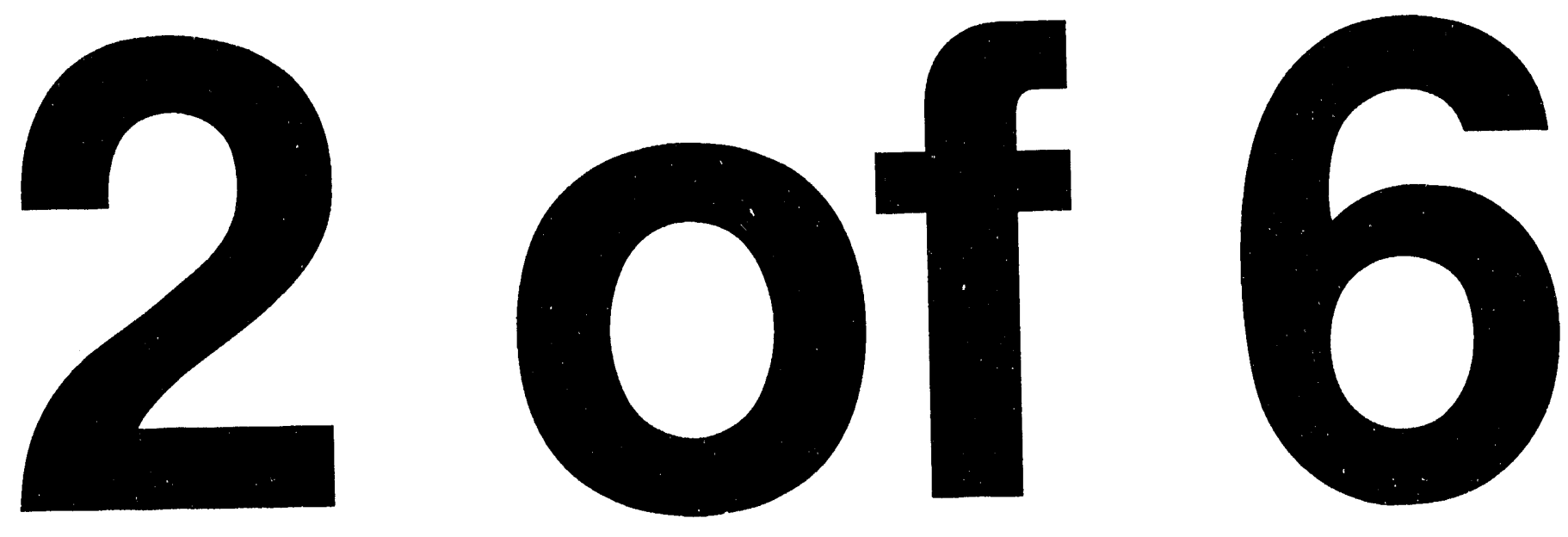
the hydrostatic pressure of the settling solids to significantly increase the underflow solids concentration. It also depends on using flocculating chemicals in order to form a proper floc structure. By this method, thickening of solids to around 52 wt? is achieved. This achieves the elimination of $73 \%$ of the water contained by previous thickening methods. The solids dry rapidly and heavy equipment can be driven on it after a few days. In so doing, a complete and difficult filter system is eliminated. A flow diagram for the thickener is presented in Figure 16.

In the current year, this project will only involve small units of special design for conducting fluid mechanics studies. The apparatus will consist of a pump and models constructed with transparent plastic. Use will be made of water and dyes for the study of flow patterns.

Environmental impact potential of the project

The experiments will have no environmental impact since there are no reactions taking place and no chemical compounds to be disposed of.

Task 10: Definition and remediation of the environmental problems associated with the operation of the North salt Lake pilot plant

The objective of this task is to outline steps required for the remediation of the existing environmental problems and development of environmentally sound procedures for the operation of the North salt Lake pilot plant. The objective for the current year is to identify the existing environmental problems and formulate a plan for cleanup. This will be a paper study and will 


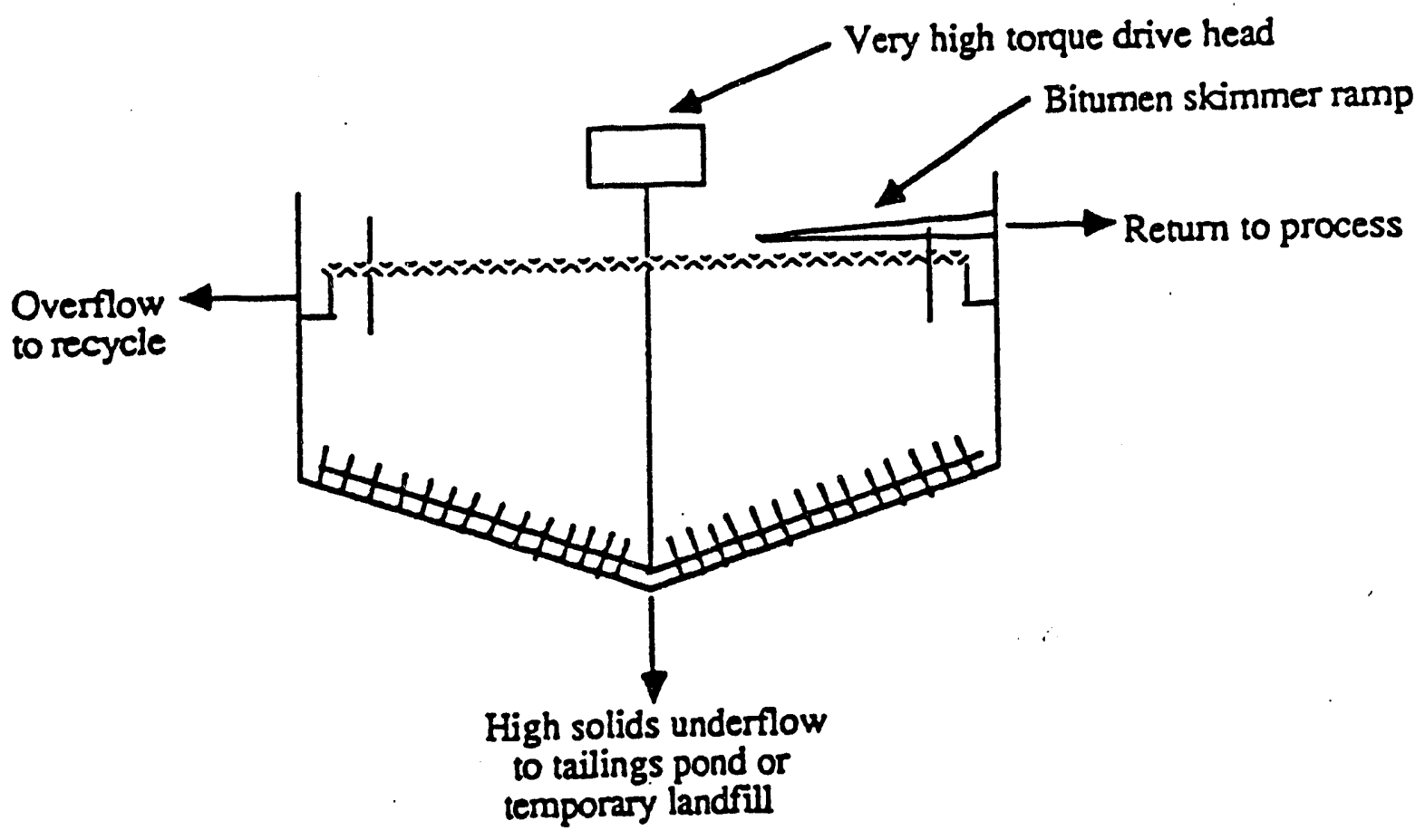

Figure 16. Diagram of the special high torque thickener 
not have any environmental impact.

Task 11: Environment -: issues associated with bitumen recovery from tar sand

This project will evaluate the overall environmental impact of various commercial oil sand development processes in the Uinta Basin. This study is essential before any commercial process is contemplated in the Basin. For the current year, this task will focus on developing material and energy balances for each of the processes and identifying the quality and quantities of potentially hazardous process streams.

\section{Project descriotion}

This project addresses the environmental concerns of the possible commercial exploitation of a Utah oil sands deposit. More specifically, the basis of study will be a 50,000 barrels per day plant in the Uinta basin.

A compilation of the oil sand deposits in the state of Utah indicates that the deposits in the Uinta Basin show great potential in terms of being tapped for this resource. The deposits include the Asphalt Ridge, Hill creek, PR Spring, Sunnyside and Whiterocks deposits.

The process of producing hydrocarbon liquids from oil sands generally involves four steps. The first is mining in which the surface overburden is removed and the oil sand mined and transported to the plant. The second step consists of the extraction of the bitumen from the sand. This could be done by pyrolysis, solvent extraction or water extraction of the oil sand. 
The third step involves the upgrading and refining of the bitumen. The final step consists of disposal of sand and other waste products.

Alternately, an in-situ extraction of bitumen from an oil sand deposit would replace the mining and extraction steps. This would be the method of choice if the overburden thickness is too large to facilitate surface mining.

The chief environmental constraints faced by an operation of this nature include regulations on air quality, water quality and solid waste disposal. The other concerns are mainly noise, and upsets in ecological balances resulting from disturbances to plant and animal life. This project will address these constraints in detail to evaluate the feasibility of an oil sands plant from an environmental perspective. The project will use as inputs, information from the other tasks in the oil sands program. This information would aid in an analysis of the effluent streams, both gas and liquid, and wastes generated by an oil sands plant.

The project does not use any resource samp? as or generate process products or wastes and it is purely a paper study. since the project is itself an environmental assessment, it will have no environmental impact potential of its own. 
CHARACTERIZATION AND POTENTIAL UTILIZATION OF THE ASPHALT RIDGE OIL SAND BITUMEN

$\begin{array}{ll}\text { Principal Investigator: } & \text { F.V. Hanson } \\ \text { Co-Principal Investigator: } & \text { M.D. Deo } \\ \text { Post Doctoral Fellow: } & \text { C.H. Tsai }\end{array}$

\section{INTRODUCTION}

The physical properties and elemental compositions of bitumens from the Uinta Basin (Utah) are quite similar to those reported for heavy asphaltic crude oils; that is, the $\mathrm{H} / \mathrm{C}$ atomic ratio is about 1.60, the nitrogen concentration is high $(>1.0 \mathrm{wt} \%)$ and the sulfur concentration is low (-0.4-0.5 wt:.$^{1,2}$ The decline in the supply of light, domestic crude oil, has made oil sand bitumens an important potential petroleum resource for the production of transportation fuels and/or asphalts. A variety of thermal and catalytic processes have been investigated for upgrading Utah oil sand bitumen. ${ }^{3}$ Direct catalytic cracking has been shown to produce higher yields of high-quality products as compared to coking. The highly naphthenic constituents render the bitumen responsive to catalytic cracking. ${ }^{3}$ Bunger et $a l^{4}$ concluded that the high molecular weight and high nitrogen content of Utah oil sand bitumens make the appropriateness of the catalytic cracking process questionable. However, their conclusions were based on the results from microactivity testing units which cannot simulate commercial resid cracking. This is due to the fact that resids contain nonvaporizable components. ${ }^{5}$ Recent process- and catalyst-related developments in fluid catalytic cracking (FCC) suggest that residFCC technology might be employed as a potential upgrading process 
for the production of transportation fuels from Utah oil sand bitumens. Selection of a bitumen upgrading process depends on the properties of bitumen and a knowledge of detailed chemical structure of bitumens. Although it is not possible to perform detailed characterization of the full-boiling range bitumen, the $711 \mathrm{~K}$ minus material is amenable to analysis by various chromatographic and spectroscopic techniques. Two low molecular weight boiling range fractions $(477-617 \mathrm{~K}$ and $617-711 \mathrm{~K})$ of the Asphalt Ridge bitumen were analyzed by a combination of gas chromatography and mass spectrometry. The results indicated that these two fractions contained mostly naphthenic and hydroaromatic constituents. The 477-617 $\mathrm{K}$ fraction appeared to be an excellent candidate for high density aviat_on turbine fuels and the $617 \mathrm{~K}$ plus residue can be classified as an AC-30 asphalt.

\section{EXPERIMENTAL}

\section{Materials}

The oil sand used in this study was a freshly mined sample from the county pit on the Asphalt Ridge oil sand deposit (Utah). The bitumen was obtained by conventional toluene Dean-stark extraction. The toluene was removed by rotary evaporation (Büchi Rotavapor RE 120) at $363 \mathrm{~K}$ and $20 \mathrm{~mm} \mathrm{Hg}$ vacuum for 5 hours.

\section{Vacuum Distillation}

A modified vacuum distillation assembly was used to recover the lower molecular weight fractions from the Asphalt Ridge bitumen. A Vigreux claisen type distillation column, packed with 
$5 \times 5 \mathrm{~mm}$ Raschig rings was used to achieve well-defined cuts. The 477-617 $\mathrm{K}$ and the 617-711 $\mathrm{K}$ boiling range fractions of the bitumen were collected for detailed analyses.

\section{Elemental Analysis and Physical Properties Determinations}

The elemental composition - carbon, hydrogen and nitrogen- of the native bitumen and the bitumen fractions was quantitatively determined using a Leco Carbon-Hydrogen-Nitrogen Determinator, Model CHN-600. Sulfur content was determined using a Leco sulfur Determinator, Model SC 132. A pyknometer (Mettler/Paar DMA 40 Digital Density Meter) was used to measure the specific gravities of the bitumen fractions and a bomb calorimeter (Paar 1241 Automatic Adiabatic Bomb Calorimeter) was used to determine the heats of combustion. Specific gravities of the bitumen residue fraction and the native bitumen were determined following the procedures described in the ASTM D70 test method.

\section{Fourier Transform Infrared Spectroscopic Analysis}

The Fourier transform infrared (FTIR) spectra were measured with a Perkin Elmer 1600 instrument in the absorbance mode. Absorbance spectra of the native bitumen and the bitumen residues were obtained by directly smearing the samples on $\mathrm{KBr}$ windows. Absorbance spectra of the low-molecular weight bitumen fraction (477-617 $\mathrm{K}$ and $617-711 \mathrm{~K})$ were obtained in a liquid absorbance cell with a path length of $0.015 \mathrm{~mm}$. 
Gas Chromatography and Mass spectrometry

The bitumen boiling range fractions were analyzed by gas chromatography/mass spectrometry. A Hewlett-Packard 5890-A analytical gas chromatograph equipped with capillary injector and linear temperature programmer, was used in this study. The chromatograph contained a $15 \mathrm{~m}$ x $0.25 \mathrm{~mm}$ tubular column coated with SE-54 (DB-5, J \& W Scientific). The helium carrier gas flow rate was $4 \mathrm{~cm}^{3} / \mathrm{min}$. The oven temperature was programmed to rise from $323 \mathrm{~K}$ to $523 \mathrm{~K}$ at a rate of $2^{\circ} \mathrm{C} / \mathrm{min}$ with a 5 -minute hold at $523 \mathrm{~K}$. An alternate program was also used: rise from $323 \mathrm{~K}$ to $573 \mathrm{~K}$ at $5^{\circ} \mathrm{C} / \mathrm{min}$ with a 5-minute hold at $573 \mathrm{~K}$. The injector temperature was $563 \mathrm{~K}$ and the detector temperature was $673 \mathrm{~K}$. The mass spectrometer had an ion trap detector (ITD - Finnegan MAT700) and was operated at a scan range of 40 to 450 amu at 1 scan/second. Mass spectra were determined at an ionizing voltage of $70 \mathrm{ev}$.

\section{Asphalt Specification Tests}

The determination of the physical properties of asphalt samples was conducted at the material and testing laboratory of the State of Utah Department of Transportation using recognized standard specification tests for asphalt cements. 6

\section{Simulated Distillation}

The boiling point distribution of the native bitumen was determined by simulated distillation. The native bitumen was dissolved in dichloromethane prior to injection. A programmed Hewlett-Packard model 5730A gas chromatograph was used for the 
analysis. The oven temperature was programmed to rise from 243 to $623 \mathrm{~K}$ at a rate of $11^{\circ} \mathrm{C} /$ minute with a 5-minute hold at $623 \mathrm{~K}$. The injector temperature was $623 \mathrm{~K}$ and the FID detector temperature was $673 \mathrm{~K}$. A U-shaped, stainless steel tube $(0.635 \mathrm{~cm}$ OD, 46-cm long) packed with $3 \%$ Dexsil 300 on Anakrom $Q$ was used for the bitumen analysis. The boiling point temperatures were calibrated with a standard mixture of normal paraffins $\left(C_{5}\right.$ to $\left.C_{44}\right)$.

\section{Curie-Point Low Voltage Mass Spectroscopic Analysis}

Curie-point, low voltage mass spectrometry experi-ments were carried out using an Extranuclear Model 5000-1 Curie-Point pyrolysis mass spectrometer system. Twenty-five microgram quantities of the bitumen were coated on a ferromagnetic wire in dichloromethane suspensions. The wires were placed in borosilicate glass reaction tubes and introduced into the vacuum system of the mass spectrometer. The ferromagnetic wires were inductively heated at approximately $100^{\circ} \mathrm{C} / \mathrm{s}$ to an equilibrium temperature of $883 \mathrm{~K}$. The total analysis time was 15 seconds. The low voltage-mass spectrometer conditions were as follows: the inlet temperature was held at $423 \mathrm{~K}$, the electron ionization voltage was $12 \mathrm{ev}$ (set value), the scanning rate was $1000 \mathrm{amu} / \mathrm{s}$, the total scan time was $24 \mathrm{sec}$. and the $\mathrm{m} / \mathrm{z}$ ratio scanned ranged from 40 to 340 .

\section{RESULTS AND DISCUSSION}

The elemental analyses, atomic $\mathrm{H} / \mathrm{C}$ ratios, specific gravities, heats of combustion, and simulated distilla-tion data for the native bitumen and the fractions are presented in Table 4 . The 
Table 4. Properties of Native Bitumen and Bitumen Fractions from Asphalt Ridge Tar Sand (Utah). ${ }^{\circ}$

\begin{tabular}{|c|c|c|c|c|}
\hline Property & $\begin{array}{l}\text { Native } \\
\text { Bitumen }\end{array}$ & $\begin{array}{l}477-617 \mathrm{~K} \\
\text { Bitumen } \\
\text { Fraction }\end{array}$ & $\begin{array}{l}617-711 \mathrm{~K} \\
\text { Bitumen } \\
\text { Fraction }\end{array}$ & $\begin{array}{l}>711 k \\
\text { Bitumen } \\
\text { Fraction }\end{array}$ \\
\hline$\overline{W t \%}$ & 100 & 7.8 & 12.3 & $79.4^{6}$ \\
\hline $\begin{array}{l}\text { Elemental analysis } \\
\text { C,wt\% } \\
H, w t \% \\
N \text {,wt\% } \\
\text { S,wt\% } \\
\text { 0,wt\% }\end{array}$ & $\begin{array}{r}85.7 \\
11.0 \\
1.0 \\
0.5 \\
1.8\end{array}$ & $\begin{array}{r}86.5 \\
12.4 \\
0.1 \\
0.2 \\
0.8\end{array}$ & $\begin{array}{r}86.1 \\
11.5 \\
0.3 \\
0.4 \\
1.7\end{array}$ & $\begin{array}{r}85.6 \\
10.7 \\
1.3 \\
0.5 \\
1.9\end{array}$ \\
\hline Atomic $\mathrm{H} / \mathrm{C}$ ratio & 1.53 & 1.72 & 1.61 & 1.49 \\
\hline $\begin{array}{r}\text { Specific gravity } \\
(289 \mathrm{~K} / 289 \mathrm{~K})\end{array}$ & 0.9871 & 0.8970 & 0.9473 & 1.0009 \\
\hline Gravity, ${ }^{\circ} A P I$ & 11.9 & 26.2 & 17.9 & 9.9 \\
\hline $\begin{array}{l}\text { Heat of combustion, } \\
\text { cal } / \mathrm{g} \text { (Gross) } \\
\text { cal } / \mathrm{g} \text { (Net) } \\
\text { cal } / \mathrm{cm}^{5} \text { (Net) }\end{array}$ & $\begin{array}{r}10,300 \\
9,790 \\
9,660\end{array}$ & $\begin{array}{r}10,650 \\
10,060 \\
9,020\end{array}$ & $\begin{array}{r}10,360 \\
9,850 \\
9,330\end{array}$ & $\begin{array}{l}\cdots \\
\cdots \\
\cdots\end{array}$ \\
\hline $\begin{array}{l}\text { Simulated distillation } \\
\text { IBP, K } \\
\text { Volatility } \\
(<811 \mathrm{~K}) \text {, wt } \% \\
\text { IBP-477 K, wt\% } \\
477-617 \mathrm{~K} \text {, wt\% } \\
617-811 \mathrm{~K} \text {, wt\% } \\
>811 \mathrm{~K} \text {, wt } \%\end{array}$ & $\begin{array}{r}506 \\
45.2 \\
0.0 \\
8.1 \\
37.2 \\
54.8\end{array}$ & $\begin{array}{c}-- \\
\cdots- \\
\cdots- \\
\cdots- \\
\cdots-\end{array}$ & $\begin{array}{l}\cdots \\
\cdots \\
\cdots \\
\cdots \\
\cdots \\
\cdots\end{array}$ & $\begin{array}{c}\cdots \\
\cdots \\
\cdots \\
-\cdots \\
-\cdots\end{array}$ \\
\hline $\begin{array}{l}\text { Overhead Fraction, } K \\
\text { (wt\%) } \\
5 \\
10 / 15 \\
20 / 25 \\
30 / 40\end{array}$ & $\begin{array}{c}580 \\
632 / 674 \\
711 / 731 \\
752 / 792\end{array}$ & $\begin{array}{l}\cdots \\
\cdots- \\
\cdots-\end{array}$ & $\begin{array}{c}\cdots \\
\cdots \\
\cdots \\
\cdots-\end{array}$ & $\ldots$ \\
\hline
\end{tabular}

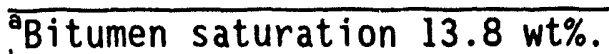

b. 0 wt\% of bitumen lost during distillation run.

'By difference. 
nitrogen, sulfur and oxygen contents increased as the boiling range of the fraction increased. The high content of nitrogen in the 711 $K$ plus residue suggests that severe hydrotreatment might be required to reduce the nitrogen content of the full boiling range native bitumens. The two low molecular weight fractions have similar properties to those of the low molecular weight fractions from the whiterocks bitumen (Utah).$^{7}$ However, the atomic H/C ratio of the $711 \mathrm{~K}$ plus residue is slightly lower than that of $728 \mathrm{~K}$ plus residue from the Whiterocks bitumen. This may be due to the higher concentration of asphaltenes in the Asphalt Ridge bitumen relative to the Whiterocks bitumen. 8

A comparison of physical properties of the $477-617 \mathrm{~K}$ fraction from the Asphalt Ridge bitumen with those of a thermally-stable jet fuel as well as with the proposed specifications for high densityenergy jet fuels are presented in Table 5. The physical properties of the 477-617 $\mathrm{K}$ fraction indicate that this fraction may be used as high density-energy advanced jet fuels. Although the heat of combustion per unit mass of this fraction is slightly lower than that of the advanced jet fuels, 9 the heat of combustion can be improved by mild hydrotreatment to remove heteroatoms and partially hydrogenate aromatic components. The heat of combustion per unit volume exceeds the specification for the JP-Il fuel and that determined for the thermally-stable jet fuel. The low molecular weight fraction of Uinta Basin oil sand bitumens appears to be particularly rich in naphthenic species and could serve as a source of high density jet fuels.? 
Table 5. Comparison of Physical Properties of Asphalt Ridge Bitumen Light End Fraction (477-617 K) with Russian Thermally-Stable Jet Fuel and Tentative Specification of High Density-Energy Jet Fuels.

\begin{tabular}{|c|c|c|c|c|}
\hline Property & $\begin{array}{l}477-617 \mathrm{~K} \\
\text { Fraction } \\
\text { Asphalt Ridge } \\
\text { Bitumen }\end{array}$ & $\begin{array}{l}\text { High Density- } \\
\text { Thermally Stable } \\
\text { Aviation Turbine } \\
\text { Fuel }\end{array}$ & $\begin{array}{l}\text { High De } \\
\text { Jet Fue } \\
\text { JP-8X }\end{array}$ & $\begin{array}{l}y \text {-Energy } \\
\text { Specs } \\
\text { JP-11 }\end{array}$ \\
\hline $\begin{array}{l}\text { Specific Gravity } \\
289 \mathrm{~K} / 289 \mathrm{~K}\end{array}$ & 0.8970 & 0.843 & $>0.840$ & $>0.900$ \\
\hline API Gravity, API & 26.2 & 36.3 & $<37.0$ & $<25.7$ \\
\hline Atomic H/C Ratio & 1.72 & 1.89 & $\cdots$ & $\cdots$ \\
\hline $\begin{array}{l}\text { Hydrogen content, } \\
\text { wt\% }\end{array}$ & 12.43 & 13.60 & 13.0 & 12.0 \\
\hline \multicolumn{5}{|c|}{ Heat of Combustion, } \\
\hline $\begin{array}{lc}\mathrm{cal} / \mathrm{g} & \text { (Gross) } \\
\mathrm{cal} / \mathrm{g} & \text { (Net) } \\
\mathrm{cal} / \mathrm{cm}^{3} & \text { (Net) }\end{array}$ & $\begin{array}{l}10,650 \\
10,060 \\
9,020\end{array}$ & $\begin{array}{l}10,930 \\
10,250 \\
8,640\end{array}$ & $\begin{array}{l}\cdots \\
\cdots, 650\end{array}$ & 8,990 \\
\hline
\end{tabular}

${ }^{a}$ This fuel sample was provided by the Wright Aeronautical Laboratories at WrightPatterson Air Force Base. 
The results of the asphalt certification tests performed on the bitumen residue $(>617 \mathrm{~K})$ are presented in Table 6 . The $>617 \mathrm{~K}$ bitumen fraction can be classified as an AC-30 viscosity graded asphalt cement based on its viscosity $(3,136$ poise at $333 \mathrm{~K})$. The analyses indicated that the kinematic viscosity and the penetration meet the specifications. A ductility of $100^{+} \mathrm{cm}$ for a 3,136 poise viscosity material is considerably higher than the $40 \mathrm{~cm}$ minimum specification.

\section{Gas Chromatography-Mass Spectroscopic Analyses}

The identification of individual compounds in the 477-617 $\mathrm{K}$ and 617-711 $\mathrm{K}$ fractions of Asphalt Ridge bitumen is based an a comparison of the spectra of the fractions to known spectra reported in the literature. ${ }^{10-26}$ GC/MS analysis of low molecular weight fractions of the whiterocks bitumen revealed that they contained mostly naphthenic compounds. ${ }^{7}$ The GC/MS analyses of the samples derived from the native Asphalt Ridge bitumen indicated that the chemical structures of the low molecular weight fractions of the Whiterocks and Asphalt Ridge bitumens are similar. Traces of alkylcyclohexanes and alkanes (i.e., pristane and phytane) were present in the volatile fractions $(477-711 \mathrm{~K})$ of the Asphalt Ridge bitumen. A similar observation was made for the volatile fractions $(477-711 \mathrm{~K})$ of the Whiterocks bitumen.

The molecular and tentative structural formulae of the major constituents, i.e., cyclic alkanes, identified in the two fractions are presented in Table 7. The mass spectra of $\mathrm{C}_{n} \mathrm{H}_{2 n-2}$ bicycloalkanes indicate a polyalkyl substituted (mainly methyl groups) decalin 
Table 6. Results of Specification Tests for Asphalt Ridge Bitumen Residual Fraction.

\begin{tabular}{|c|c|c|}
\hline Property & $\begin{array}{l}>617 \mathrm{~K} \\
\text { Bitumen } \\
\text { Fraction }\end{array}$ & $\begin{array}{l}\text { AC- } 30 \\
\text { Specification } \\
\text { Fraction }\end{array}$ \\
\hline \multicolumn{3}{|l|}{ viscosity } \\
\hline $\begin{array}{l}333 \mathrm{~K} \text { (poise) } \\
408 \mathrm{~K} \text { (centistokes) }\end{array}$ & $\begin{array}{r}3,136 \\
477\end{array}$ & $\begin{array}{l}3,000 \pm 600 \\
350 \text { (minimum) }\end{array}$ \\
\hline Ductility $277 \mathrm{k}$, cm & $100+$ & 40 (minimum) \\
\hline $\begin{array}{l}\text { Penetration } 298 \mathrm{~K} \\
100 \mathrm{~g}, 5 \mathrm{sec}(1 / 10 \mathrm{~mm})\end{array}$ & 59 & 50 (minimum) \\
\hline \multicolumn{3}{|l|}{$\begin{array}{l}\text { Test on Residue from } \\
\text { Rolling Thin-oven Test }\end{array}$} \\
\hline $\begin{array}{l}\text { Viscosity } 333 \mathrm{~K} \\
\text { (poise) }\end{array}$ & 7,426 & 12,000 (maximum) \\
\hline $\begin{array}{l}\text { wt. } \% \text { Loss Upon } \\
\text { Heating }\end{array}$ & 1.37 & 0.5 (maximum) \\
\hline
\end{tabular}


Table 7. Cyclic Alkanes Identified in 477-711 K Fraction of

Asphalt Ridge Bitumen from Mass Spectra of GC Peaks.

\begin{tabular}{llcc}
\hline Cycloalkane & Molecular & Tentative Molecular & Major and Molecular \\
Classification & Formula & Structure & Ion Fragments (m/z)
\end{tabular}

Bicjelies $\mathrm{C}_{\mathrm{H}} \mathrm{H}_{2 \mathrm{n}-2}$

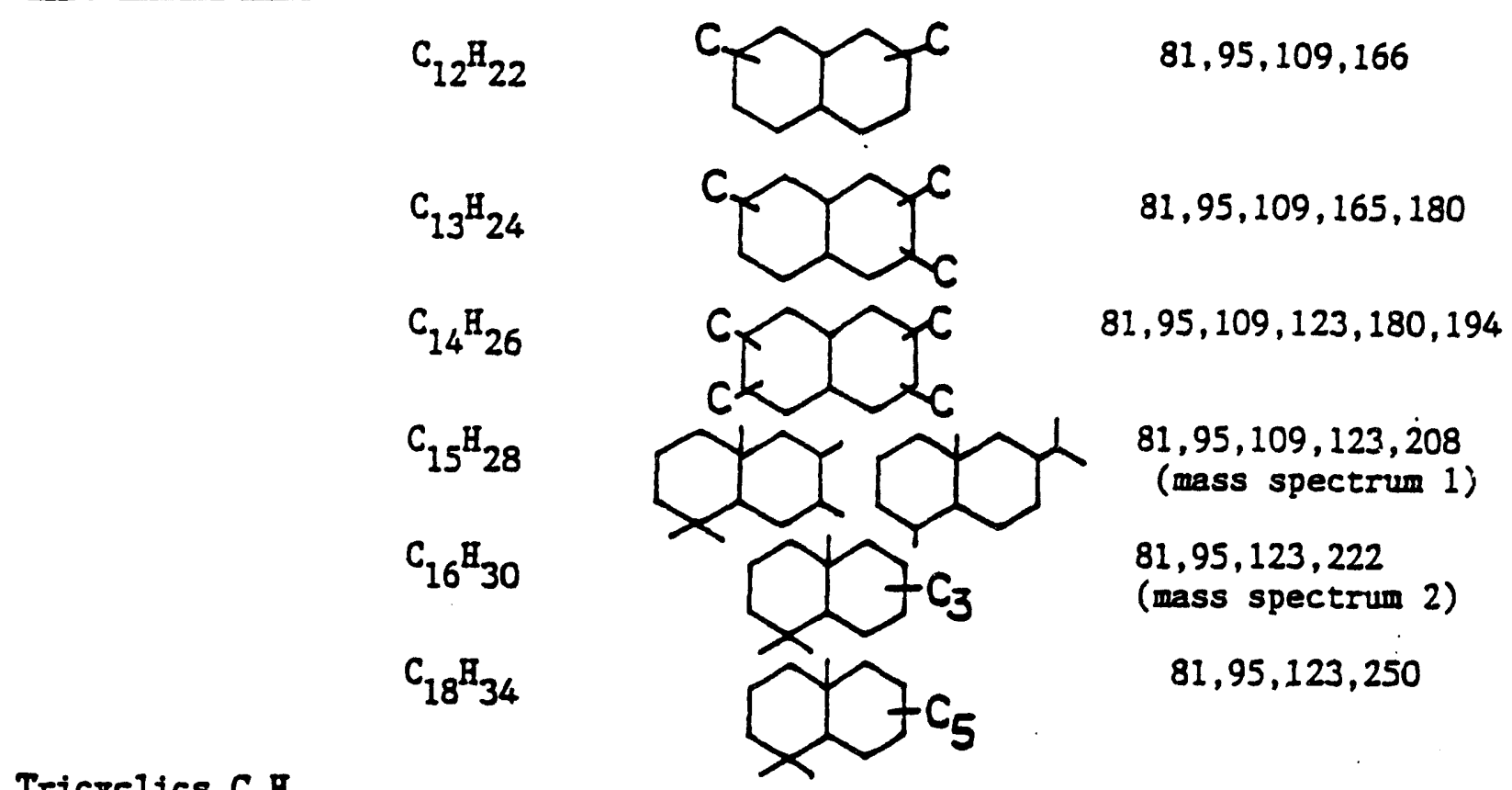

Tricjelies $\mathrm{C}_{\mathrm{n}} \mathrm{H}_{2 \mathrm{n}-4}$

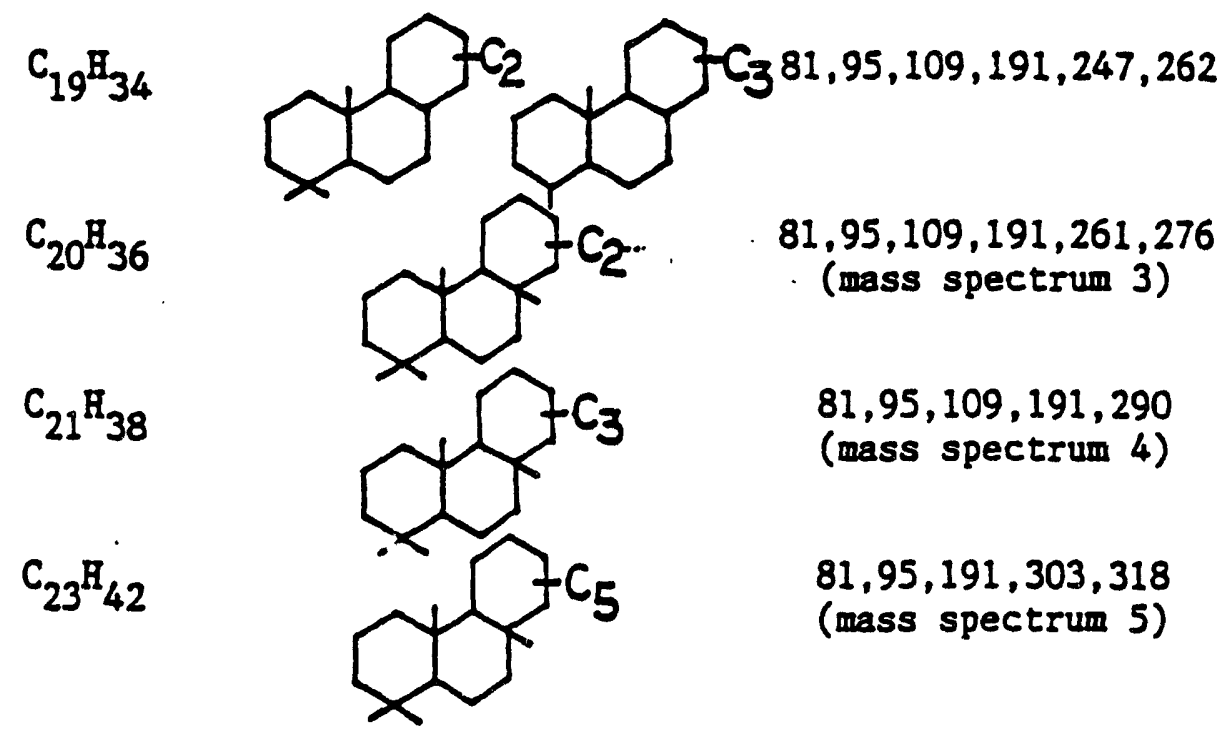


Table 7 Cyclic Alkanes Identified in 477-711 K Fraction of Asphalt Ridge Bitumen from Mass Spectra of GC peaks. (continued)

$\begin{array}{llcc}\text { Cycloalkane } & \text { Molecular } \\ \text { Classificatioli } & \text { Formula } & \begin{array}{c}\text { Tentative Molecular } \\ \text { Structure }\end{array} & \begin{array}{c}\text { Major and Molecular } \\ \text { Ion Fragments }(\mathrm{m} / \mathrm{z})\end{array}\end{array}$

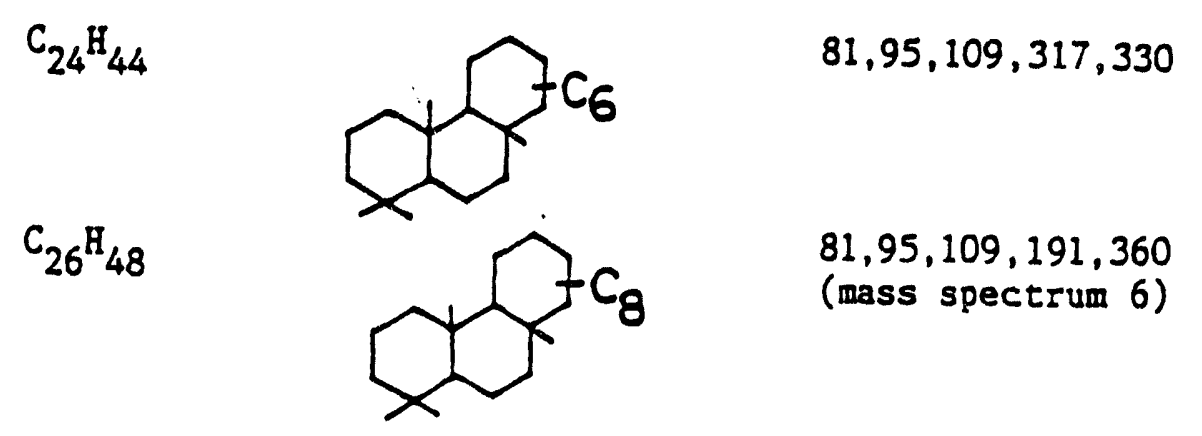

Tetracjelies $\mathrm{C}_{n} \mathrm{H}_{2 n-6}$

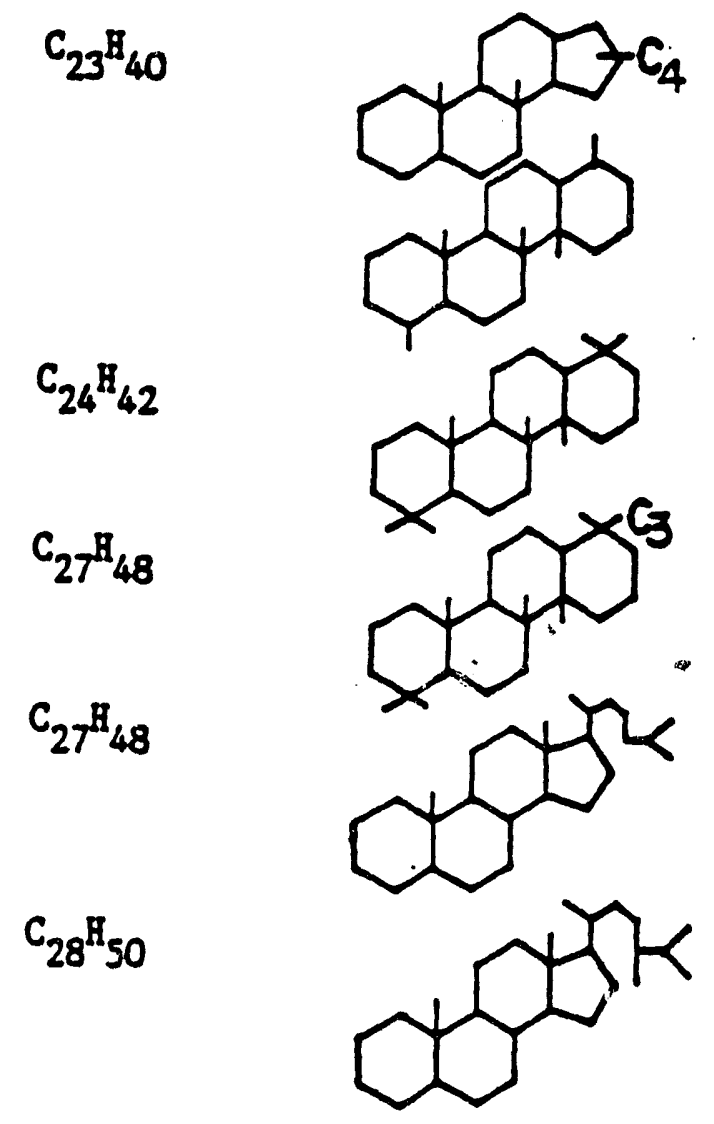

$69,81,95,109,177,316$

(mass spectrum 7)

$81,95,109,177,316$

(mass spectrum 8)

$81,95,109,191,330$

$81,95,109,123,191,372$

$81,95,109,123,149,217,372$

(mass spectrum 9)

$81,95,109,149,217,371,386$

(mass spectrum 10) 
Table 7 Cyclic Alkanes Identified in 477-711 K Fraction of Asphalt Ridge Bitumen from Mass Spectra of GC peaks. (continued)

\begin{tabular}{|c|c|c|c|}
\hline $\begin{array}{l}\text { Cycloalkane } \\
\text { Classification }\end{array}$ & $\begin{array}{l}\text { Molecular } \\
\text { Formula }\end{array}$ & $\begin{array}{c}\text { Tentative Molecular } \\
\text { Structure }\end{array}$ & $\begin{array}{l}\text { Major and Molecular } \\
\text { Ion Fragments }(\mathrm{m} / \mathrm{z})\end{array}$ \\
\hline
\end{tabular}

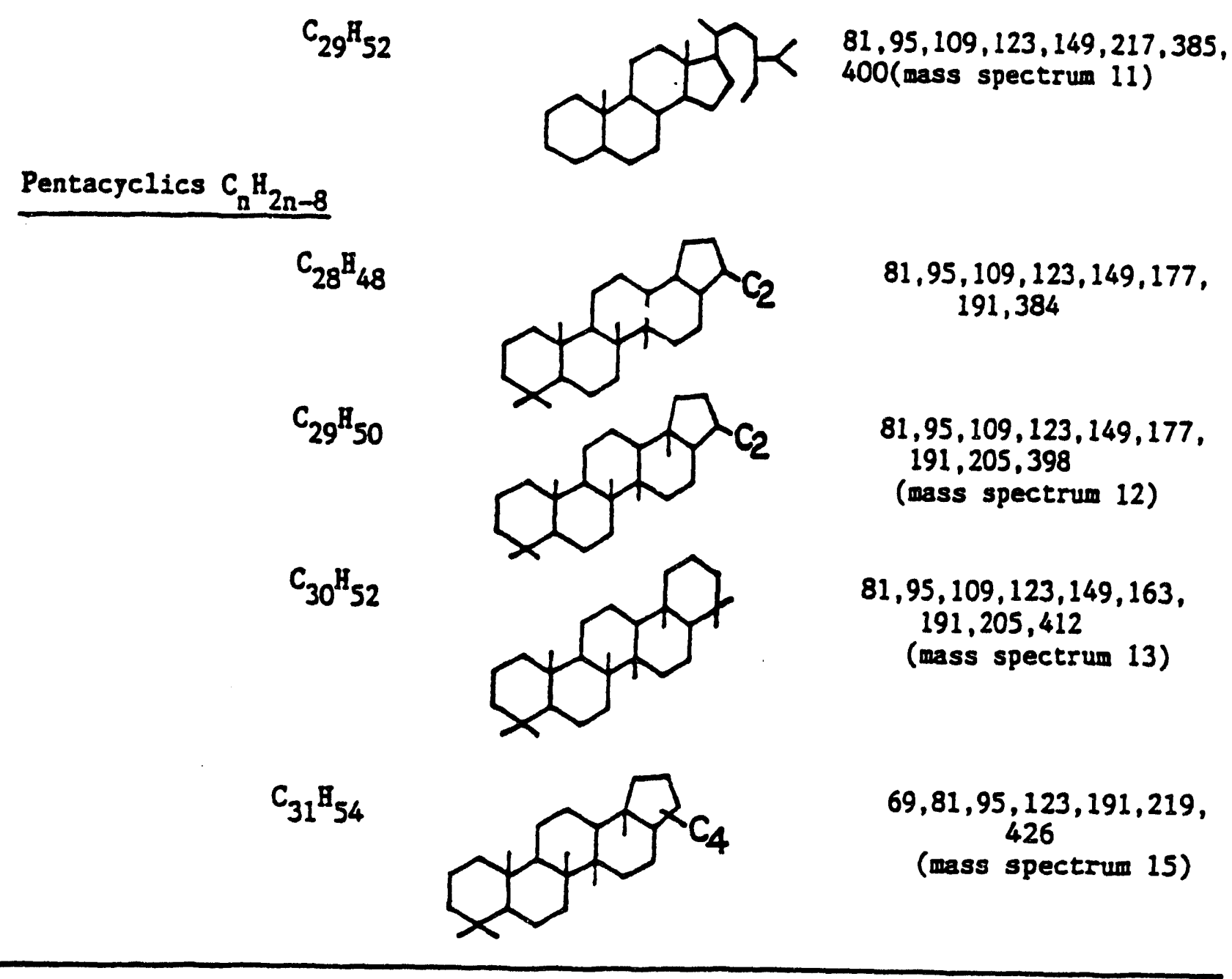


structure. Some gem-dimethyl-type substituted decalins were detected as evidenced by the relatively stronger intensity of the $(\mathrm{M}-15)^{+}$ion peak. Bicyclic alkanes can originate from the cyclization of terpanes or from the degration of pentacyclic triterpanes (typified by $\beta$-amyrin) 24,27

Several tricyclic $C_{n} H_{2 n-4}$ alkane homologs from $C_{21}$ to $C_{26}$ were detected in this study. Tricyclic terpanes may be derived from diterpenionds such as abietic or pimaric acids. ${ }^{28}$ They may also arise from cyclization of squalene to yield the tricyclic alkane (Structure I). After geochemical degradation involving the alkyl group, $R$ may contain 1 to 11 carbon atoms.

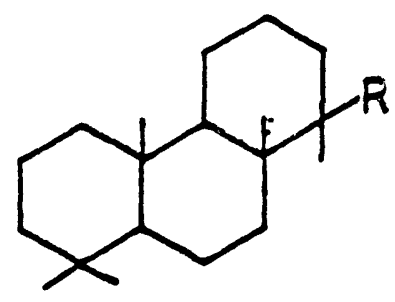

Two types of tetracyclic terpanes, i.e., 17,21-secohopanes $\left(C_{24}, C_{27}\right)$ and steranes $\left(C_{27}-C_{29}\right)$ were identified from the fragmentation pattern of the mass spectra. The tetracyclic terpanes and steranes were detected in the Asphalt Ridge bitumen sample using GC/MS of the characterization ion at $\mathrm{m} / \mathrm{z} 191$ and $\mathrm{m} / \mathrm{z}$ 217, respectively. Theories advanced for the origin of these tetracyclic terpanes (17, 21-secohopanes series) include thermocatalytic degradation of hopane precursors, microbial opening of ring $\mathbf{E}$ of hopanoids, or cyclization of the precursor squalene stopping at ring $D$ to produce tetracyclic precursors which could be 
further reduced by geochemical processes. ${ }^{26}$ steranes are derived from sterols that are widely dispersed in plants and microorganisms with the $c_{27}$ and $c_{28}$ streols most abundant in marine organisms and the $c_{29}$ streols most abundant in the higher plants, diatoms and various kinds of algae. ${ }^{29}$

Several hopanes $\left(C_{28}, C_{29}, C_{31}\right)$ and gammacerane were identified in the Asphalt Ridge bitumen. These hopane type com ounds probably arise by either microbiological degradation and alkylation reactions of a $c_{30}$ precursor (diplothene) or by degradation of a $c_{35}$ precursor (tetrahydroxyhopane). ${ }^{30}$ selected spectra of cycloalkanes and tentative assignments are listed in Figure 17.

The parent molecular ions identified as aromatic hydrocarbons and their tentative structure assignments are presented in Table 8 . The fragmentation patterns of these compounds resembled those found in Green River oil shale $e^{10,15}$ and the low molecular weight fraction $(477-711 \mathrm{~K})$ of the Whiterocks bitumen. ${ }^{7}$ Selected spectra of these aromatic hydrocarbons and their tentative structural assignments are depicted in Figure 18. It has been suggested that the phenyl(cyclohexyl) alkanes which are found in shale oil ${ }^{15}$ and in a Uinta Basin bitumen ${ }^{7}$ were probably formed from tricyclic and pentacyclic terpenoids or even from steroids by dehydrogenation of one of the rings ( $A$ or $C$ ) and cleavage of the center or B-ring bond during maturation. 15 

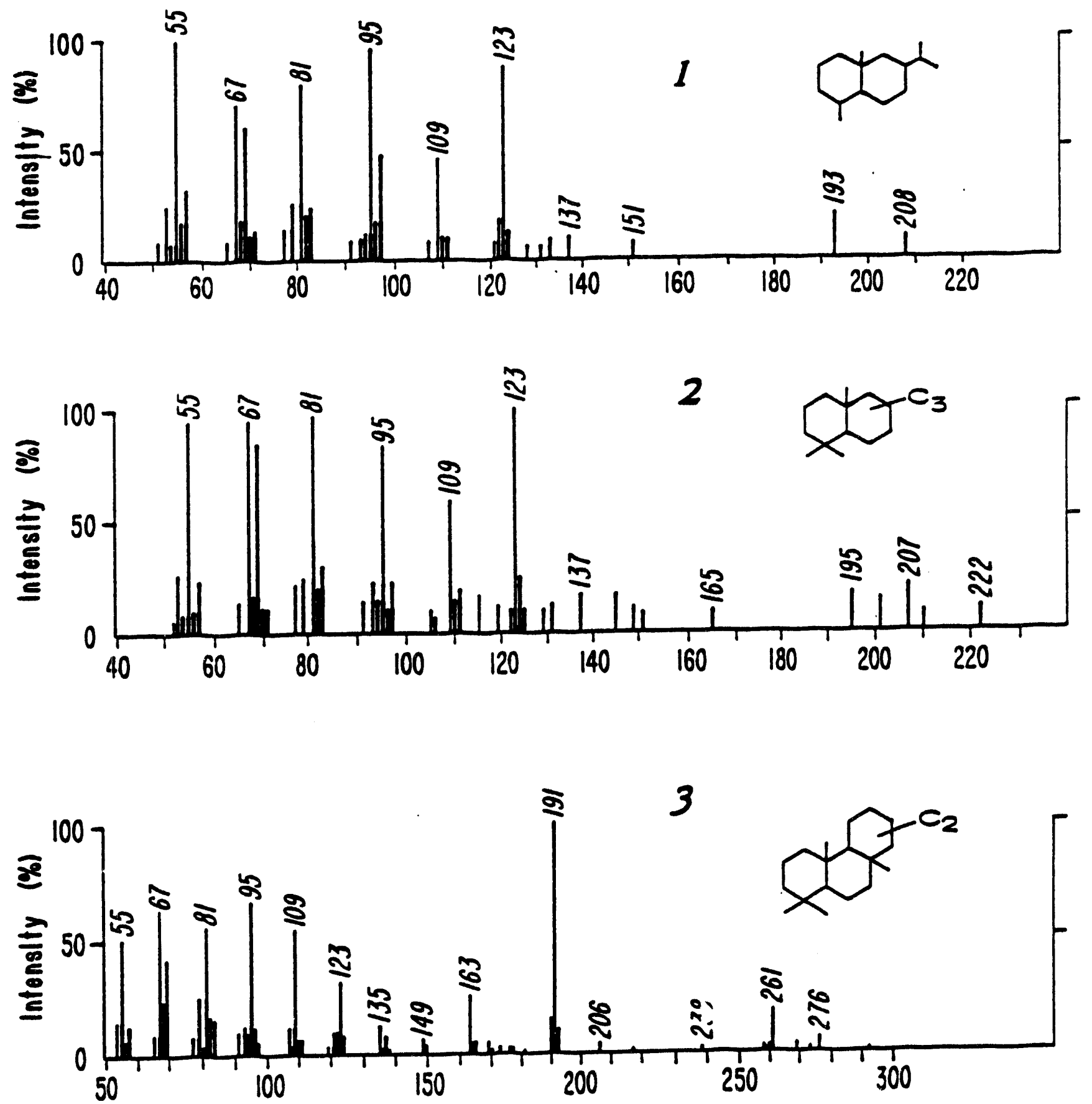

Figure 17. Mass spectra and Proposed structures of the
Cycloalkanes in the Low Molecular Weight Fraction
$(477-711 \mathrm{~K})$ of the Asphalt Ridge Bitumen 

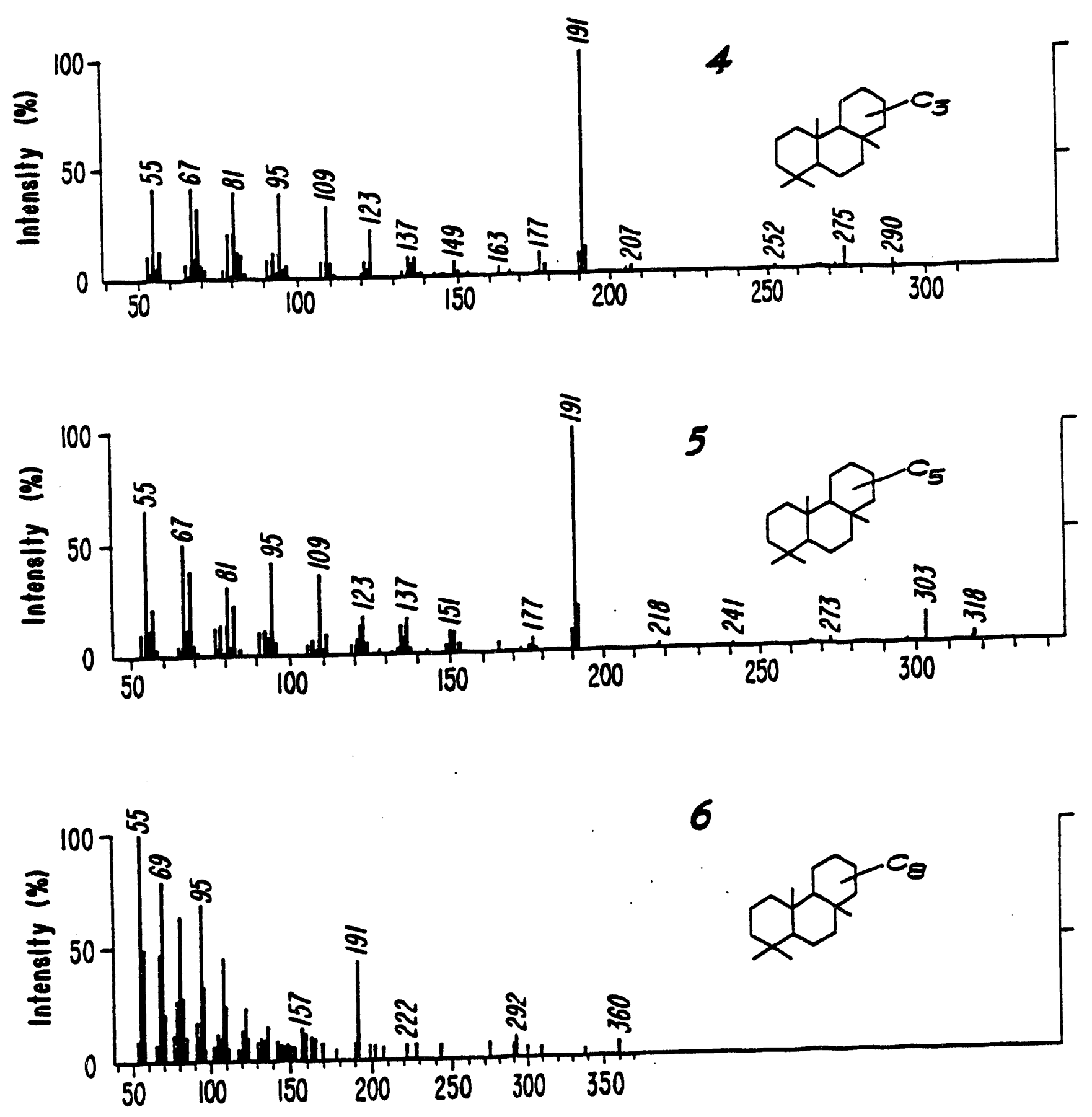

Figure 17. (continued) 

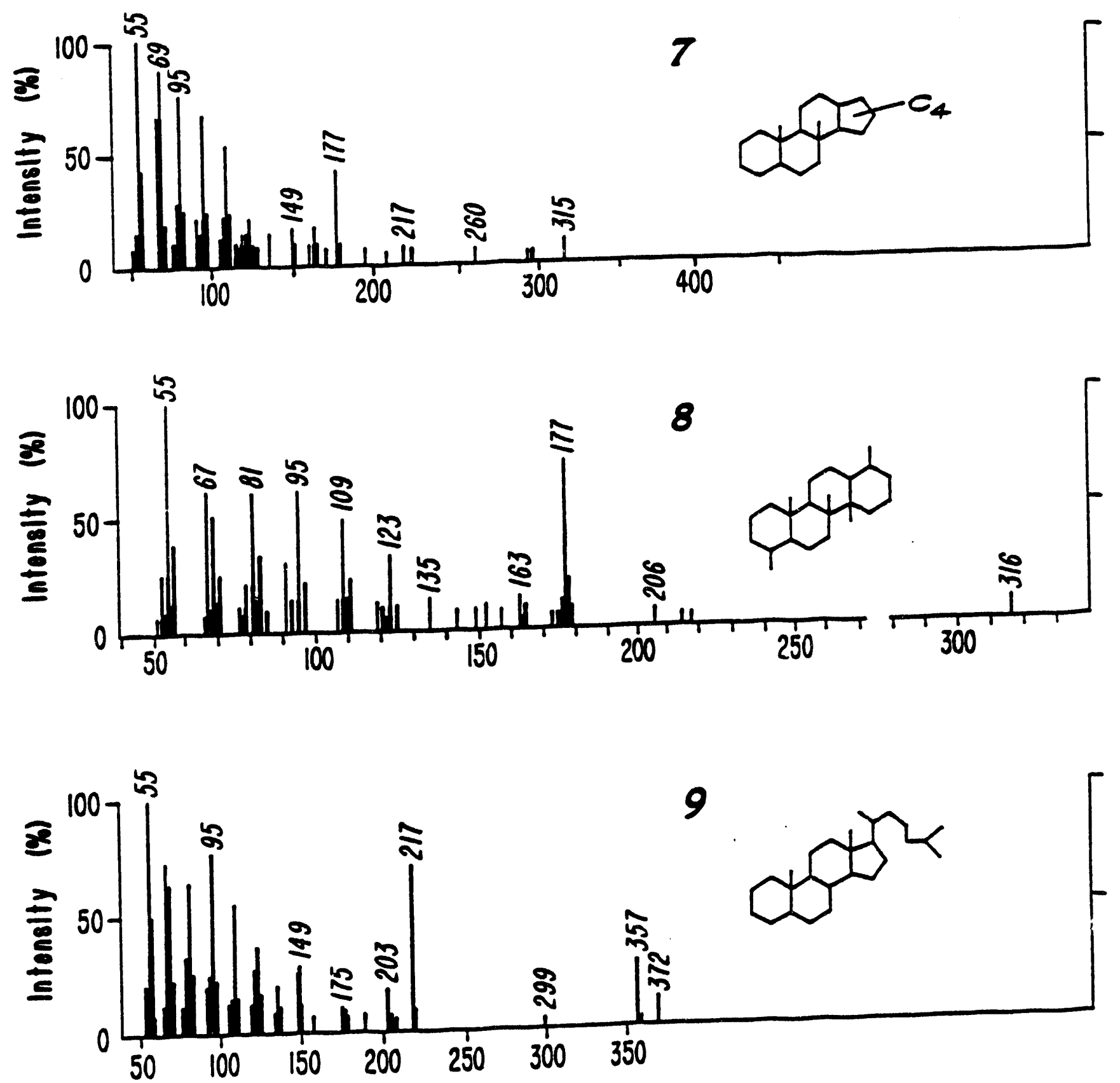

Figure 17. (continued) 

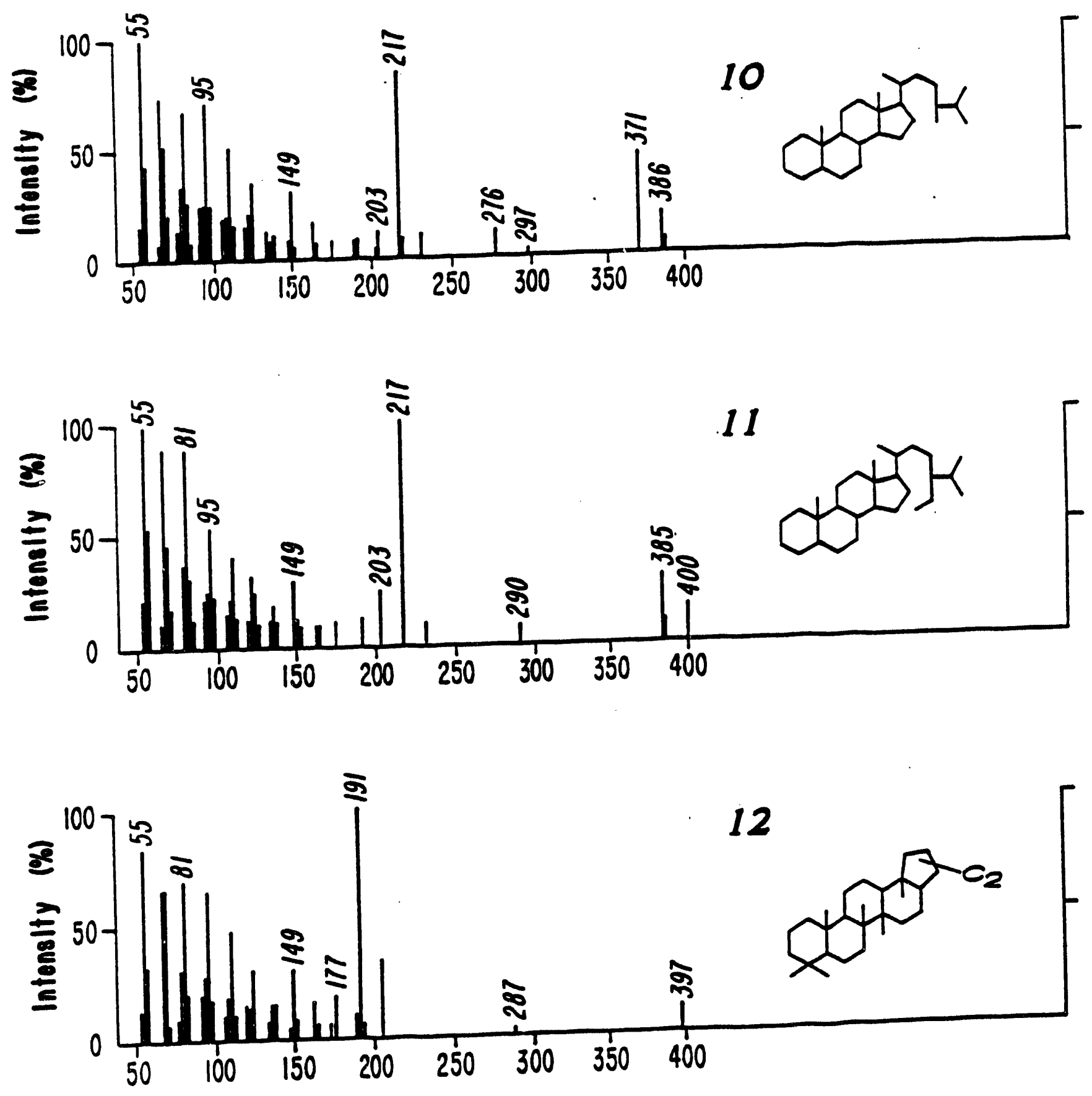

Figure 17. (continued) 

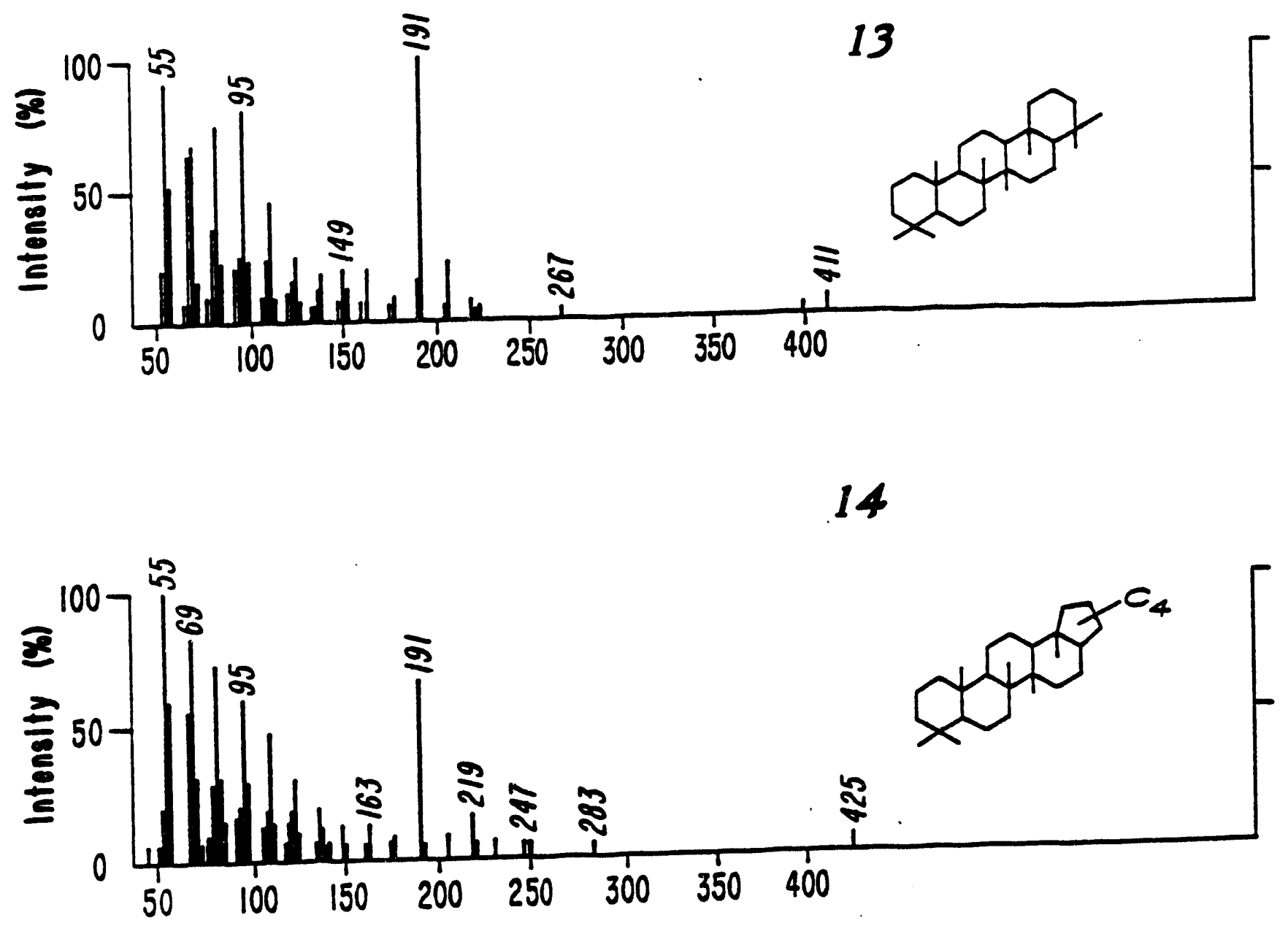

Figure $17 . \quad$ (continued) 
Table 8. Aromatic Species Identified in the 477-711 K Fraction of Asphalt Ridge Bitumen from Mass Spectra of GC Peaks.

Compound Molecular Tentative Molecular Classification Formula Structure

Major and Molecular Ion Fragment $(\mathrm{m} / \mathrm{z})$

$\mathrm{C}_{\mathrm{n}} \mathrm{H}_{2 \mathrm{n}-6}$

$\mathrm{C}_{15} \mathrm{H}_{24}$

$\mathrm{C}_{16} \mathrm{H}_{26}$

$\mathrm{C}_{18} \mathrm{H}_{30}$

$\mathrm{C}_{19} \mathrm{H}_{32}$

$\mathrm{C}_{21} \mathrm{H}_{36}$

$\mathrm{C}_{\mathrm{n}} \mathrm{H}_{2 n-8}$<smiles>Cc1cccc(C)c1CCC#[SH]</smiles>

$91,105,119,204$

$91,133,218$

(mass spectrum 15)

$105,119,133,246$

$105,120,133,260$

$105,120,133,223,288$

(mass spectrum 16)
$\mathrm{C}_{12}{ }^{\mathrm{B}}{ }_{16}$<smiles>Cc1ccc2c(c1)CC1CCCC2C1</smiles>

$\mathrm{C}_{13} \mathrm{H}_{18}$<smiles>Cc1cc2c3c(c1)C3C[C-]CC2</smiles>

$\mathrm{C}_{14^{1}} \mathrm{H}_{20}$

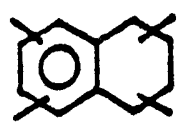<smiles>CC(C)C1CCc2c(I)cccc2C1</smiles>

$\mathrm{C}_{15^{\mathrm{H}}} \mathrm{H}_{22}$
$117,131,145,160$

$117,145,159,174$

$131,145,159,188$

$131,173,188$

$117,131,145,187.202$<smiles>Cc1cc(C)c2c(c1)CC(C(C)C)CC2</smiles> 
Table 8. Aromatic Species Identified in the 477-711 K Fraction of Asphalt Ridge Bitumen from Mass Spectra of Gr. Peaks. (continued).

Compound Molecular Tentative Molecular Classification

Formula

Structure

Major and Molecular

Ion Fragment $(\mathrm{m} / \mathrm{z})$

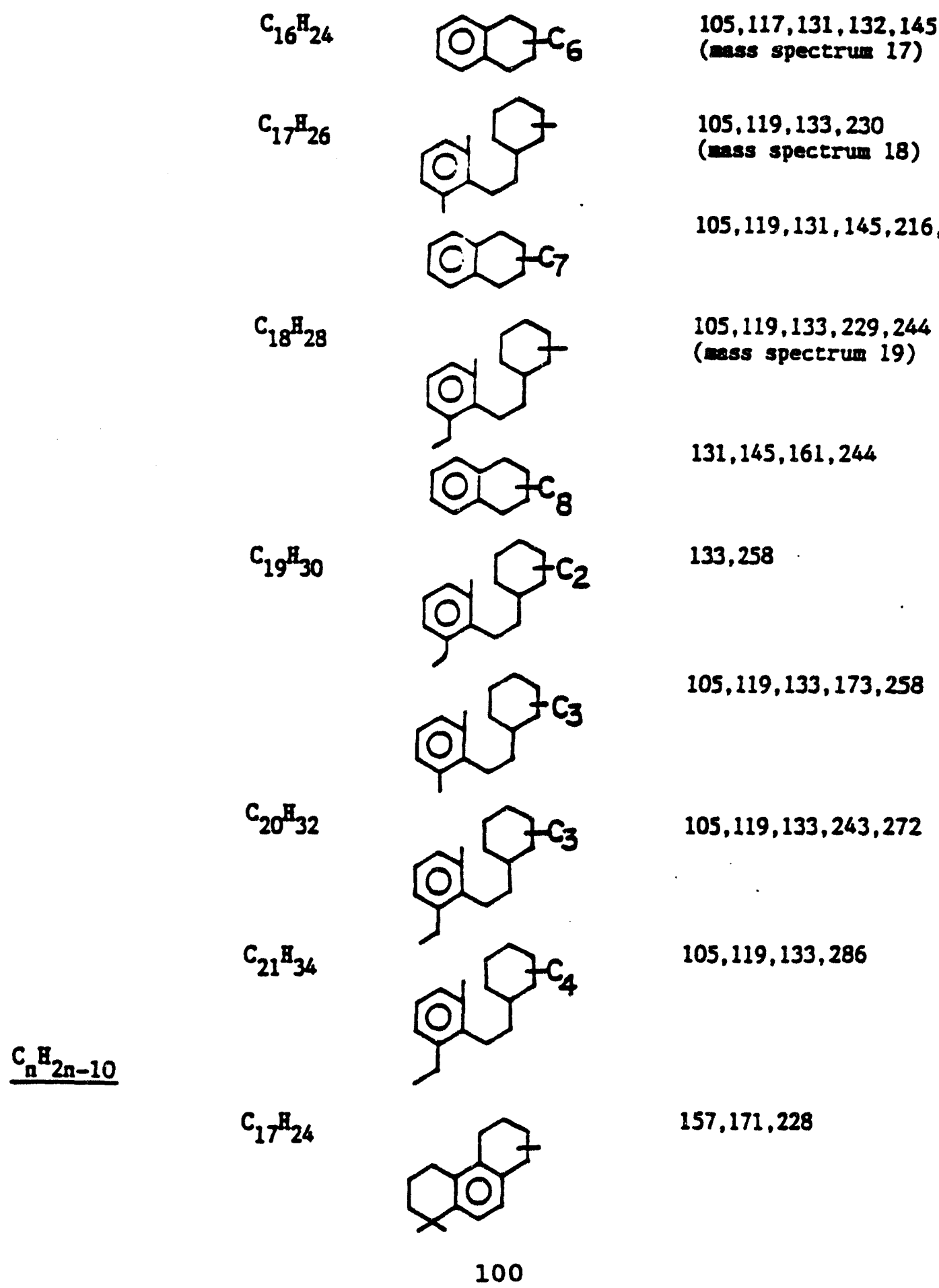


Table 8. Aromatic Species Identified in the 477-711 K Fraction of Asphalt Ridge Bitumen from Mass Spectra of GC Peaks. (continued).

Compound Molecular Tentative Molecular Classification Formula Structure

$\mathrm{C}_{18^{\mathrm{H}}} \mathrm{H}_{26}$<smiles>CC1CCc2c(ccc3c2CCC3)C1</smiles>

$\mathrm{C}_{19^{\mathrm{B}}}{ }^{28}$<smiles>CC1(C)CCCc2c1ccc1c2CCC1</smiles>

$C_{n}{ }^{12 n-12}$
Major and Molecular

Ion Fragment $(\mathrm{m} / \mathrm{z})$
$158,171,242$

(mass spectrum 20)

$157,171,256$

$128,169,184$

(mass spectrum 21)

$\underline{C_{n} B_{2 n-14}}$<smiles>Cc1cccc2cc(C(C)C)ccc12</smiles>

$128,141,181,196$<smiles>c1ccc2c3c(ccc2c1)CCCC3</smiles>

$\mathrm{C}_{16} \mathrm{H}_{18}$<smiles>CC1(C)CCc2ccc3ccccc3c2C1</smiles>

$128,141,155,183,195,210$

$\mathrm{C}_{21}{ }^{\mathrm{B}}{ }_{28}$<smiles>c1ccc2c3c(ccc2c1)CCCCC3</smiles> 

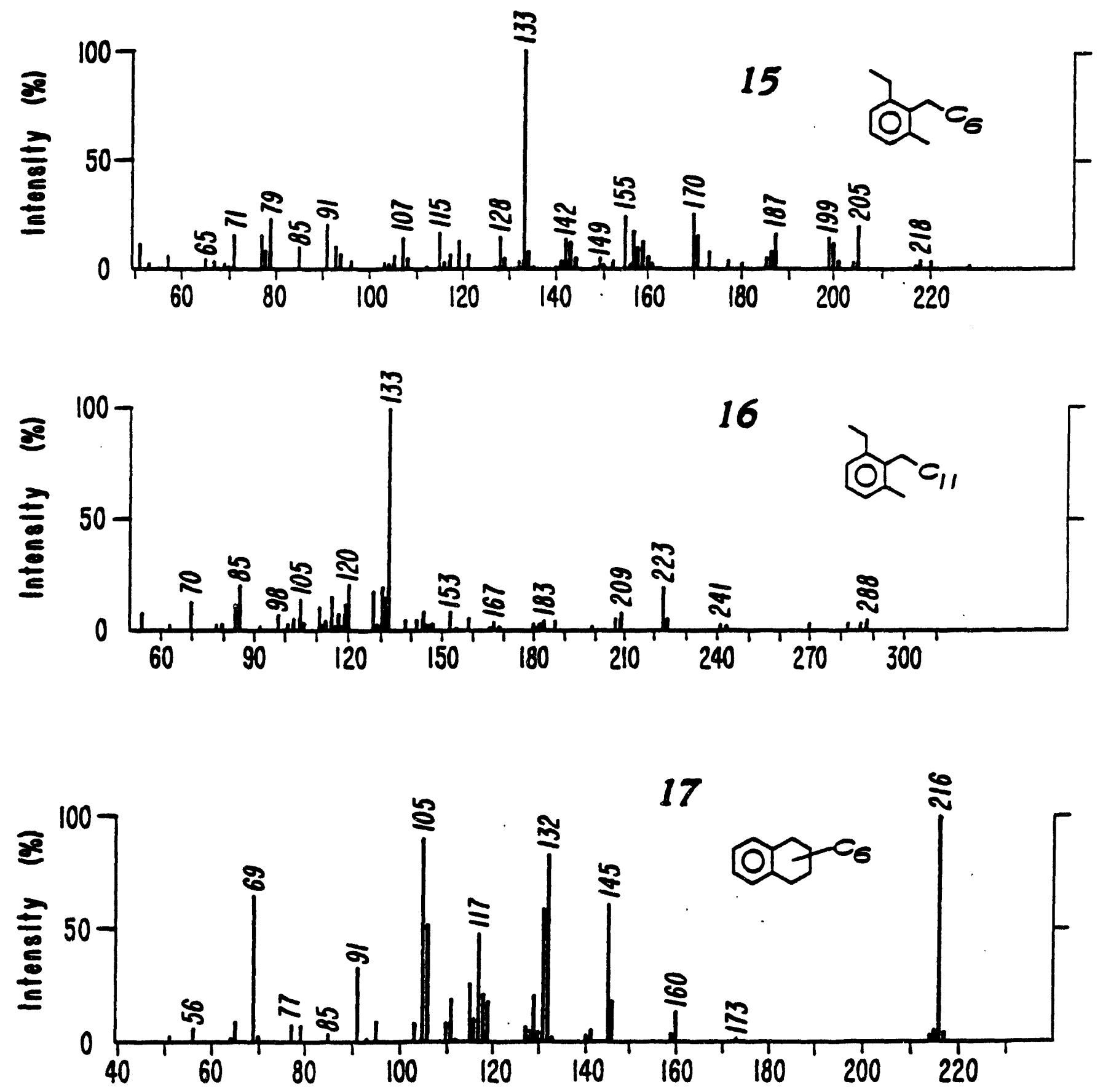

Figure 18. Mass spectra and Proposed structures of the Aromatic Hydrocarbons in the Low Molecular Weight Fraction 477-711 $\mathrm{K}$ of the Asphalt Ridge Bitumen 

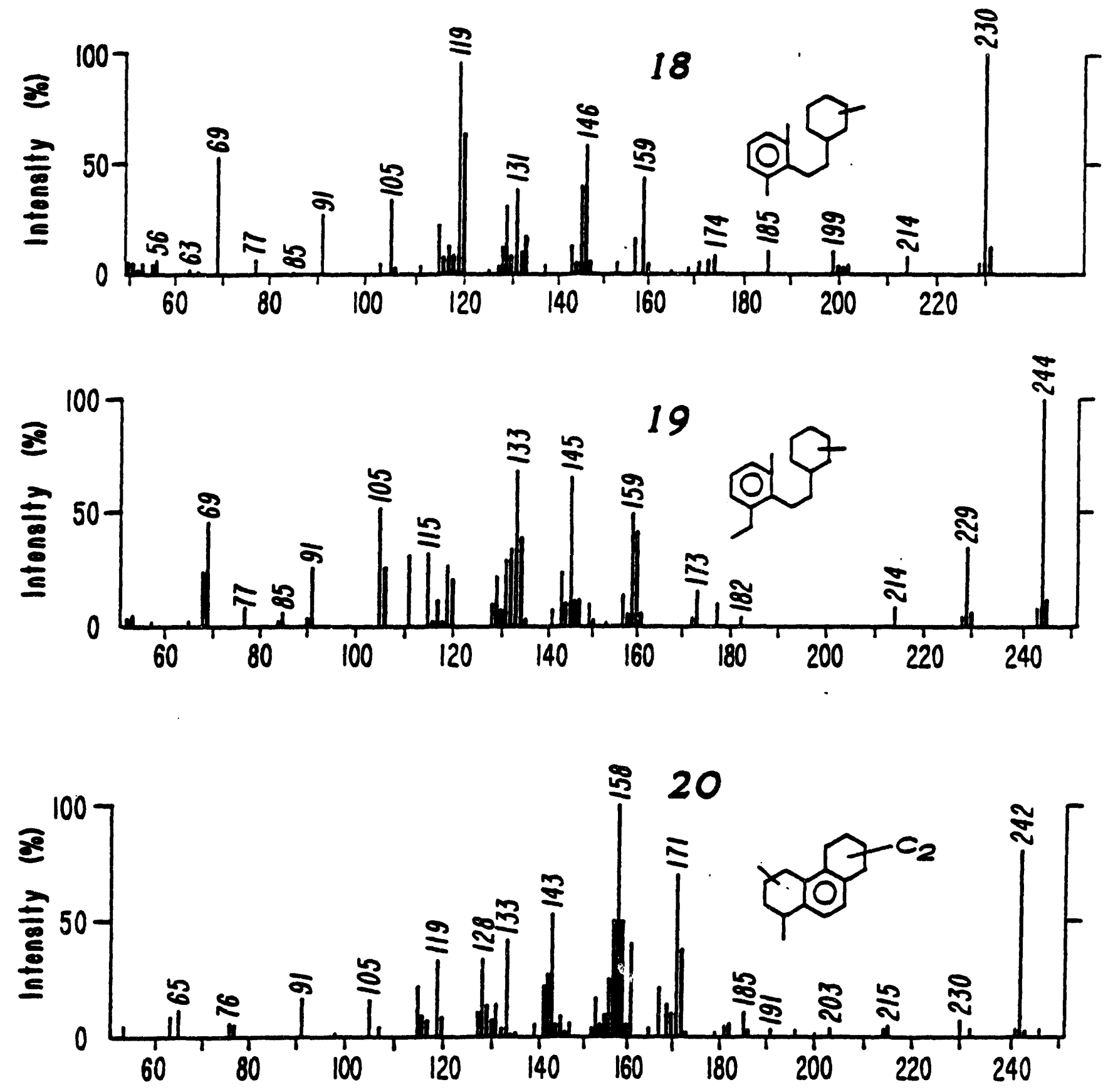

Figure 18. (continued) 

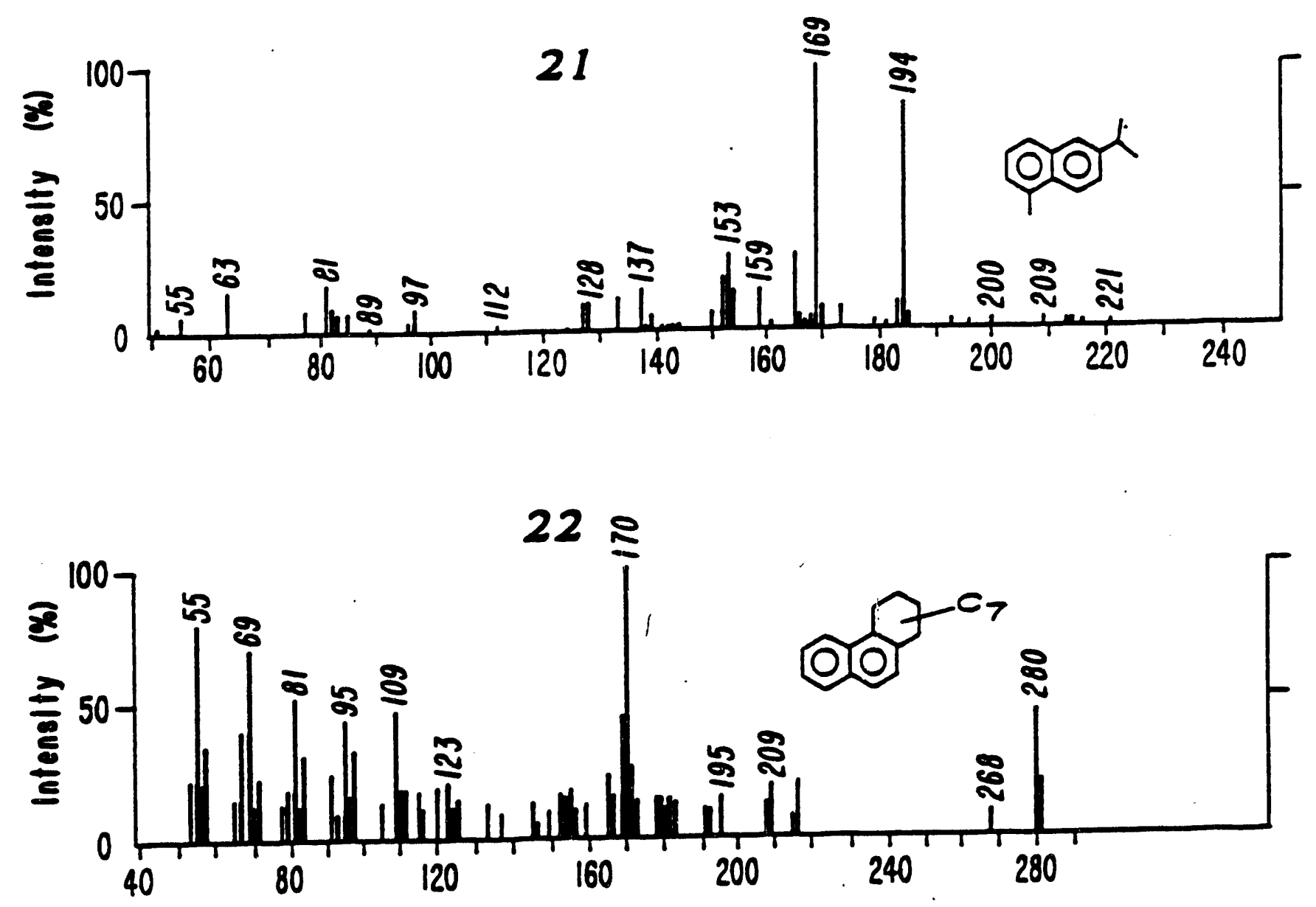

Figure 18. (continued) 


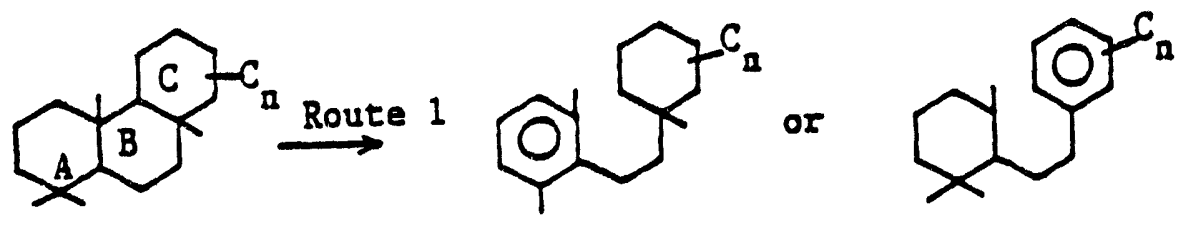

Route 2<smiles>CCC1(C)CC(C)CCC1c1cccc(C)c1</smiles><smiles>CCC1C(c2ccc(C)cc2)CCCC1(C)C</smiles>

The similarity of those tricyclic, tetracyclic and pentacyclic terpanes and their degradation products (aromatic hydrocarbons) in Uinta basin oil sand bitumens and Green River shale oils suggests that the crude oils, oil sand bitumens and the Green River oil shale kerogens may have been derived from the same sources.

\section{FTIR Analysis}

The infrared spectra of the Asphalt Ridge bitumen was similar to that of the Whiterocks bitumen. ${ }^{7}$ The spectra included a weak band at $3470 \mathrm{~cm}^{-1}$ (pyrollic $\mathrm{N}-\mathrm{H}$ stretch), as well as bands at 3400$3200 \mathrm{~cm}^{-1}(\mathrm{O}-\mathrm{H}$ and $\mathrm{N}-\mathrm{H}$ stretching modes of hydrogen bonded compounds), 2965,2930, 2860 and $2849 \mathrm{~cm}^{-1}$ (C-H vibration), $1703 \mathrm{~cm}^{-1}$ (carbonyl C=0 stretch, carboxylic acid), $1600 \mathrm{~cm}^{-1}$ (conjugated $C=C$ stretch), 1459, 1378, and $1366 \mathrm{~cm}^{-1}$ ( $\mathrm{C}-\mathrm{H}$ bending in $-\mathrm{CH}_{3}$ or -C$\left.\left(\mathrm{CH}_{3}\right)_{2}\right), 1169 \mathrm{~cm}^{-1}\left(\mathrm{C}-\left(\mathrm{CH}_{3}\right)_{2}\right.$ skeletal vibration or C-O-C vibration in esters), $1033 \mathrm{~cm}^{-1}$ (ether linkage or $\mathrm{C}-\mathrm{O}-\mathrm{H}$ deformation), and 870 , 800,735 , and $703 \mathrm{~cm}^{-1}$ (aromatic $\mathrm{C}-\mathrm{H}$ bending).

Evidence for the presence of gem-dialkyl sub-stituents on the naphthenic rings is found in the double skeletal vibration band near 1366 and $1376 \mathrm{~cm}^{-1}$ (approximately equal intensity) observed in the FTIR spectra of the 477-711 $\mathrm{K}$ and $617-711 \mathrm{~K}$ fractions. The 
strong intensities of the bands at 2965, 2860, 1459, 1378, and 1366 $\mathrm{Cm}^{-1}$ indicate that the Asphalt Ridge bitumen contains a large number of methyl groups. This agrees with the results from GC/MS analyses. When the bands at $1703 \mathrm{~cm}^{-1}$ for the three fractions (477$617 \mathrm{~K}, 667-711 \mathrm{~K}$, and $711 \mathrm{~K}$ plus) are compared, it is apparent that the 617-711 $\mathrm{K}$ fraction has the highest intensity whereas the $711 \mathrm{~K}$ plus fraction exhibited moderate intensity. This suggests that most of the carboxylic acids are found in the 617-711 $\mathrm{K}$ fraction. The $711 \mathrm{~K}$ plus fraction plus residue had the highest oxygen content, and the highest intensity for the $1033 \mathrm{~cm}^{-1}$ band among these three fractions. This leads to the speculation that the precursers of steranes and hopanes such as diplotene, tetrahydro:yhopane and sterols which contain hydroxyl groups reacted with hydrocarbons via dehydration reactions to form higher molecular weight species with ether linkages. In addition, the intensity of the $3400-3200 \mathrm{~cm}^{-1}$ band is indicative of a high concentration of hydroxyl groups in this fraction. The high aromatics content in the $711 \mathrm{~K}$ plus fraction was indicated by the strong intensity of the $1600 \mathrm{~cm}^{-1}$ band. This is consistent with the low H/C atomic rtio for this fraction.

\section{Pyrolysis-Mass Spectroscopic Analysis}

The results of curie-point low voltage mass spectroscopic analysis of the Asphalt Ridge bitumen are presented in Figure 19. The spectrum indicates that the primary pyrolysis products are alkenes (m/z:42,56,70, $84,98,112,126,140,196)$, condensed naphthenes (m/z:109, 123,137,151,165,179,193, 2 rings/molecule; m/z:149, 163, 


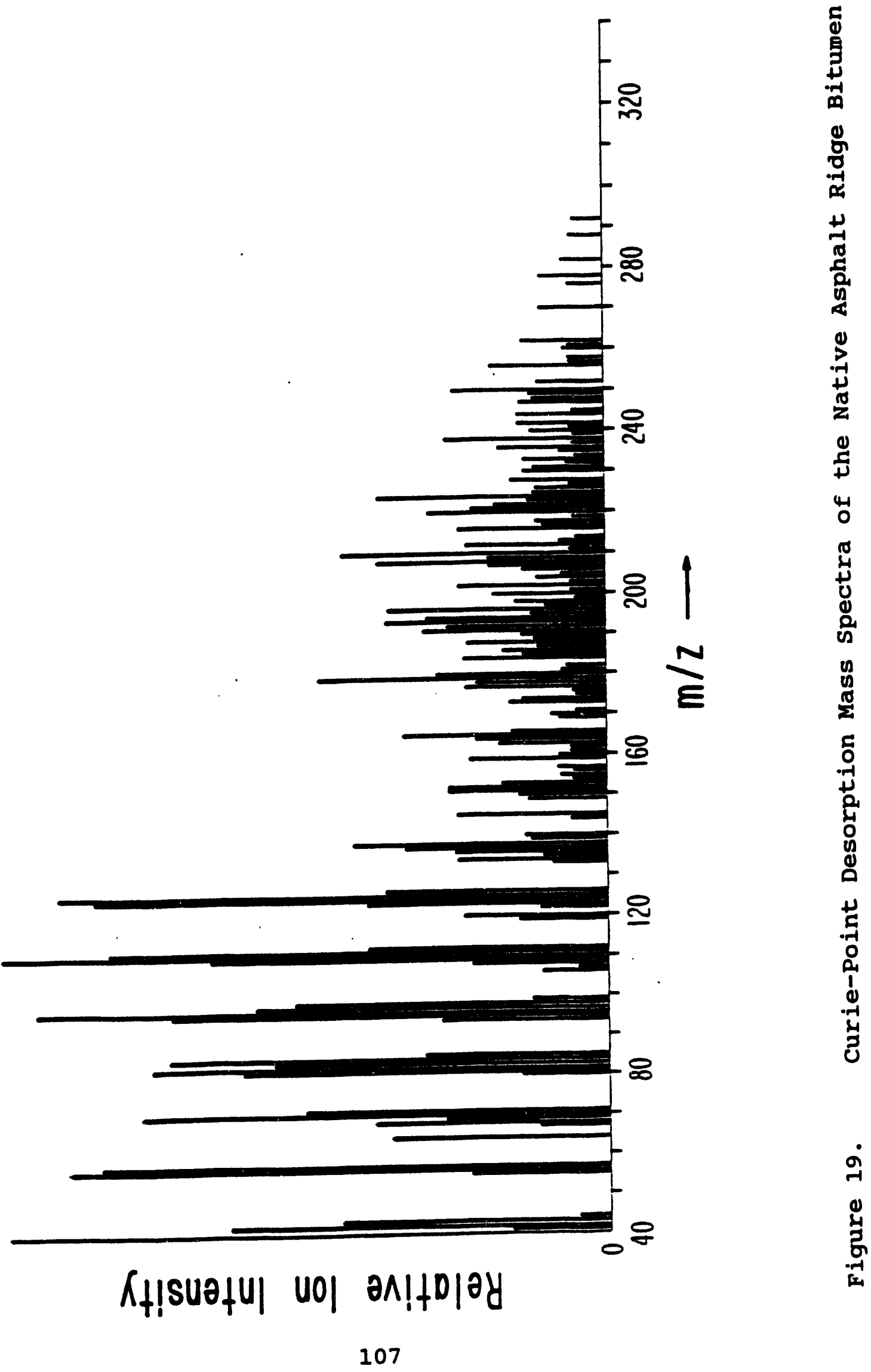


$177,191,205,3$ to 5 rings/molecule; and $\mathrm{m} / \mathrm{z}: 189,203,217,231$, $245,258,4$ rings/molecule), alkylbenzene (m/z:106, 120, 134), alkyltetralins (m/z:145,159, 173, 187,201), alkyl-naphthalene (m/z: $184,198,212,226)$, alkyloctha-hydrophenanthrenes, trinaphthenebezenes (m/z:155, 169, 197, 211), alkyltetrahydrophenanthrenes $(\mathrm{m} / \mathrm{z}: 182,196,210,224,238,252)$, alkylphenanthrenes (m/z: 178, 192, 206, 220), alkylchrysenes (m/z: 228, 242, 256, 270), alkylpicenes (m/z: 278, 292), phenols (m/z: 108, 122, 136, 150), and alkyl-hydroxytetralins (m/z: 162, 176, 190, 204, 218, 232). The tentative structure for molecular ion peaks at $\mathrm{m} / \mathrm{z}, 282$ is shown in structure II. The molecular ion peaks at $\mathrm{m} / \mathrm{z}, 208,222,236$, 250 may have a structure similar to that in structure III.

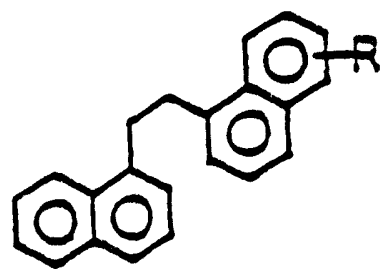

(II)

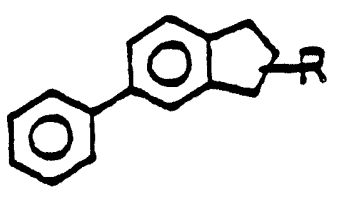

(III)

The $\mathrm{C}_{n} \mathrm{H}_{2 n}^{+}$series $(\mathrm{m} / \mathrm{z}: 42,56,70,84,98,112,126,140,196)$ in Figure 3 may be derived from the high molecular weight portion of the Asphalt Ridge bitumen because a low concentration of alkanes was observed in the 477-711 $\mathrm{K}$ fractions of this bitumen. The presence of an ion peak at $\mathrm{m} / 2,196$ suggests a long chain alkylsubstitutent which contains an isoprenoid sub-unit attached to a 
naphthenic, hydroaromatic, and/or aromatic ring structure.

SUMMARY AND CONCLUSIONS

The native Asphalt Ridge bitumen was separated into several boiling range fractions for detailed analysis and characterization. The lighter fraction $(477-617 \mathrm{~K})$ was evaluated for use as an aviation turbine fuel and the residue $(>617 \mathrm{~K}$ ) was evaluated for use as an asphalt. The 477-617 $\mathrm{K}$ fraction appeared to meet most of the specifications for high density aviation turbine fuels. The $617 \mathrm{~K}$ plus residue from the Asphalt Ridge bitumen can be classified as a viscosity grade $\mathrm{AC}-30$ asphalt. Several physical properties were also measured to evaluate the potential of the 477-617 K fraction as high density-energy aviation turbine fuel after mild hydrotreating. The detailed structure of the low molecular weight fractions of the Asphalt Ridge bitumen (477-617 $\mathrm{K}$ and 617-711 $\mathrm{K}$ ) was determined by combined gas chromatography and mass spectrometry. Additional insight regarding the chemical structure of the bitumen was also obtained by Fourier transform infrared analysis. The tentative identification of saturated and aromatic components in the 477-711 $\mathrm{K}$ fractions indicated that these can be related to biologically-derived compounds which are found in coal, petroleum, oil shale, and oil sand.

The major constituents of the low molecular weight portion (477-711 K) of Asphalt Ridge bitumen are condensed ring naphthenic hydrocarbons and hydroaromatic hydrocarbons. These compounds are related to biologically derived components. Traces of isoprenoid alkanes were also found. The $617 \mathrm{~K}$ plus residue was evaluated for 
potential asphalt applications. The results indicated that the 617 $K$ plus residue has excellent physical properties and passes the specifications for an AC-30 viscosity graded asphalt cement. The 477-617 $\mathrm{K}$ fraction appeared to be an excellent candidate for high density aviation turbine fuels following mild hydrogenation to reduce the nitrogen and sulfur contents.

FUTURE ACTIVITES

Continue detailed characterization of the whiterocks and Asphalt Ridge oil sand bitumens. Acquire barrel-quantity samples of the mined oil sand ore from the PR spring deposit. 
EFFECT OF SOLVENT AND INTRINSIC VOLATILE FRACTION OF BITUMEN ON THE PRECIPITATION OF ASPHALTENES

Principal Investigator

Post Doctorate Fellow
J.D. Miller

K. Bukka

\section{INTRODUCTION}

Precipitation and deposition of asphaltenes are costly impediments to the production of oil from a conventional reservoir. These problems are encountered not only in the secondary and tertiary recoveries of oil but also, in some instances, during the primary recovery. In a practical sense these problems result in partial plugging of the well $1^{31-33}$ and require frequent washing of the flow 1 ines $^{34}$. Since the world reserves of 1 ight crude oil are fast depleting, it is anticipated that in order to satisfy energy requirements attention will be increasingly focused on heavy oils and bitumen. In this regard, the problem of asphaltene precipitation will become more acute in the recovery operations from the heavy oil deposits. Thus, a better understanding of asphaltene precipitation is necessary to help eliminate or minimize the problems encountered in the production of oil.

Asphaltic substances such as bitumen and tar are considered to have internal structure and have been the subject of study since the $1930 \mathrm{~s} \cdot .^{35,36}$. These substances are believed to be colloidal suspensions of asphaltenes in oils and their stabilities were attributed to the constituent resin molecules which take positions at the interface between the solid asphaltenes and the oil. The internal structure for the bitumen like materials has been invoked 
to explain the differences in their rheological behavior. The principal component in this structural model is the asphaltene content of the bitumen. It has been well documented that asphaltene content of a given bitumen varies depending on the solvent used in its precipitation. ${ }^{37-39}$ Asphaltenes are precipitated from bitumen using saturated hydrocarbons of lower molecular weight, which are usually in the range $c_{3.8}$, with pentane being the most commonly used solvent. The asphaltene content of a given bitumen decreases with an increase in the carbon number of the solvent indicating that asphaltenes are not a distinct group of compounds and that precipitation is governed mainly by the prevailing solubility equilibrium, which apparently varies with the nature of solvent. ${ }^{40,41}$ The nature of asphaltenes in solution is not well understood. There are two schools of thought which describe state of asphaltenes. ${ }^{33}$ The first of them considers asphaltenes to be distinct solids that are soluble in oil (bitumen) resulting in a true solution and their precipitation is determined by thermodynamic conditions as described by the temperature, pressure, and composition. Accordingly, the precipitation of asphaltenes is a reversible process. 40,41 The second school of thought also believes that asphaltenes are solids but are suspended in colloidal form and that the suspension is stabilized by the polar molecules present in the oil (bitumen). Consequently, according to this model the precipitation of asphaltenes is an irreversible process. 32.42 However, there is no reason for these two models to be mutually exclusive. 
The fractional composition of bitumen indicates that a significant portion of it is in the form of saturate hydrocarbons both aliphatic and naphthenic in nature. If the solvent used in the precipitation of asphaltenes plays an important role in the determination of the asphaltene content, then it is conceivable that the saturate fraction may also have an equally important role in influencing the solubility equilibrium. In this study, in order to investigate the influence of the intrinsic saturate or volatile fraction (since the volatile fraction contains predominantly lighter hydrocarbons) of the bitumen on the determination of asphaltene content, Athabasca bitumen has been chosen. Three different solvents have been used to determine the asphaltene content of the bitumen. In addition, the bitumen was subjected to two separate vacuum distillations, and in each case a portion of the relatively volatile fraction was collected as a distillate. The residual material from both the distillations was recovered and analyzed for asphaltene contents using the same set of solvents. The asphaltenes recovered in each case were examined by FTIR and NMR spectroscopjc techniques.

\section{EXPERIMENTAL}

The Athabasca bitumen used in this study was kindly furnished by Syncrude Research (Edmonton, Alberta, Canada). It is a well characterized coker feed bitumen obtained from the commercial hot water extraction plant. Hydrocarbon solvents used in the fractionation of bitumen into maltenes and asphaltenes were n-pentane, $n$-hexane and n-heptane. All three solvents were of 
"Omnisolv" grade, and obtained from the EM Science corporation.

In order to separate the volatile fractions, the bitumen sample was subjected to two different vacuum distillations. In the first distillation the bitumen sample was heated to a temperature of $240^{\circ} \mathrm{C}$ under vacuum $(0.6 \mathrm{~mm}$ of $\mathrm{Hg}$,$) and 10.98$ of the original weight of bitumen was collected as a volatile fraction and labeled as Distillate-I. The residue from the distillation was recovered and labeled as Residue-I. In the second distillation the bitumen sample was heated to $270^{\circ} \mathrm{C}$ under vacuum $(0.25 \mathrm{~mm}$ of $\mathrm{Hg})$ and 19.08 of the original weight of bitumen sample was collected as a volatile fraction and labeled as Distillate-II and similarly the remaining material as Residue-II. In each case the residue as well the distillate samples were stored at $5^{\circ} \mathrm{C}$ for further analysis. In order to account for the losses incurred in these distillations the weights of bitumen and the volatile fractions were carefully determined. The mass balance indicated that the weight loss due to the volatile gasses given off during the distillation was no more than $0.2 \%$.

Bitumen and its distillation residua were fractionated into maltenes and asphaltenes using the earlier reported methods. ${ }^{13}$ Elemental analysis of all the samples were determined on LECO-600 and LECO-SC132 analyzers. On some seiected samples FTIR and NMR spectroscopic analyses were performed. Infrared spectra were obtained on a Digilab FTS-40 spectrometer equipped with liquid nitrogen cooled MCT (mercury cadmium telluride) detector and 3240-SPC data processing station. For the distillate fractions of the bitumen the spectra were obtained in the transmission mode. However, for asphaltenes and 
viscous samples such as bitumen and its distillation residua spectra were obtained using the specular reflectance accessory (Spectra Tech, Model No. 502). Sample preparation and details of the technique have been described el sewhere. ${ }^{44}$ The samples were scanned in the mid infrared region $\left(4000-700 \mathrm{~cm}^{-1}\right)$ with a nominal resolution of $4 \mathrm{~cm}^{-1}$.

${ }^{13} \mathrm{C}$ and proton NMR spectra of the bitumen fractions were obtained on a Varian, Unity 300 spectrometer. Spectra were obtained in the solution phase using deuterated dichloromethane (99.6\% $\mathrm{D}$ atom, Isotec Inc.) as the solvent. In the case of asphaltenes and bitumen residue the solute concentrations were limited by their solubilities and generally the solute concentrations were in the 7-63 weight percent range (distillates fractions being highly soluble and the asphaltenes were relatively less soluble). The operating conditions for ${ }^{13} \mathrm{C}$ and proton (in the parenthesis) NMR analyses were as follows: 8 (7) microseconds $60^{\circ}$ pulse width, $128 \mathrm{~K}$ data points, 25 (100) $-\mathrm{kHz}$ spectral width, $2.56 \mathrm{~s}(0.640 \mathrm{~s})$ acquisition time, $5 \mathrm{~mm} O D$ tubes, 16-bit digitizer resclution, and $5-\mathrm{Hz}$ line broadening at an ambient temperature of $25^{\circ} \mathrm{C}$, number of transients were 1024 (16), pulse repetition time was $4.56 \mathrm{~s}(5.64 \mathrm{~s})$. Proton decoupling was applied using the WALT2 modulation technique. All chemical shifts were referred to TMS via $\mathrm{CD}_{2} \mathrm{Cl}_{2}$ as a secondary reference.

\section{RESULTS AND DISCUSSION}

\section{Fractionation}

The asphaltene content of the Athabasca bitumen, which depends on the nature of solvent, is presented in Table 9. In agreement with earlier observations $37,39,45$ the asphaltene content of the bitumen was found to decrease with an increase in the number of carbon atoms in the solvent molecule. Also the decrease in asphaltene content by changing the solvent from pentane to hexane was 
Table 9. Variation in the asphaltene contents of the Athabasca bitumen and its residua with respect to solvent.

\begin{tabular}{|c|c|c|c|}
\hline & & $\begin{array}{l}\text { Asp } \\
(w t . \vartheta)\end{array}$ & \\
\hline & Pentane & Hexane & Heptane \\
\hline$\overline{\text { Bitumen }}$ & $\overline{16.8}$ & $\overline{14.4}$ & $\overline{13.8}$ \\
\hline Bitumen Residue-I" & $\begin{array}{r}19.5 \\
(17.4) \\
\end{array}$ & $\begin{array}{r}15.9 \\
(14.2) \\
\end{array}$ & $\begin{array}{l}15.4 \\
(13.7)\end{array}$ \\
\hline $\begin{array}{l}\text { Bitumen } \\
\text { Residue-II* }\end{array}$ & $\begin{array}{l}21.6 \\
(17.5)\end{array}$ & $\begin{array}{l}16.8 \\
(13.6)\end{array}$ & $\begin{array}{l}18.1 \\
(14.7)\end{array}$ \\
\hline
\end{tabular}

* Athabasca bitumen from which 10.9 weight percent of relatively volatile portion removed. * Athabasca bitumen from which 19.03 weight percent of relatively volatile portion removed.

The values in the parenthesis indicate the amounts of asphaltenes based on the composition of the pre-distilled bitumen. 
relatively larger than when changing the from hexane to heptane. The fractional analyses of the bitumen residua, obtained from the vacuum distillation, are also presented in Table 9. It was assumed that during the vacuum distillation the bitumen did not undergo decomposition or cracking reactions. The results presented in Table 1 indicate that the apparent asphaltene contents of both the residua, compared to the bitumen, have increased in every solvent (Table 9, first row), but when the values are pro-rated to the original bitumen composition, considering that $10.9 \%$ and $19 \%$ of the volatile portions were removed to obtain residue-I and residue-II respectively, the changes are very small. These pro-rated asphaltene contents are presented in parenthesis in Table 9, which were calculated by making allowance for the separated volatile fractions from the original bitumen. Using pentane as the solvent, it was observed that the asphaltene contents of the bitumen residua I and II have slightly increased by $0.6 \%$ and $0.7 \%$ respectively (the reproducibility of the fractionation was determined to be within $0.3 \%$ of the reported values). A somewhat similar observation was made with the solvent heptane, in which case there was no increase in the asphaltene content for bitumen residue 1 , but a $0.9 \%$ increase was observed for the bitumen residue II. By contrast, the results obtained by using hexane as the solvent were quite different. As shown in Table 9 the asphaltene contents of bitumen residue I and II have actually reduced, perhaps indicating the increased solubilizing effect of hexane on the asphaltenes. These results clearly indicate the anomalous behavior of hexane, particularly when compared to pentane and heptane, with regard to asphaltene solubilities. This difference in the behavior of hexane is assumed to be fundamentally rooted, and probably related to the properties of the hydrocabon molecules containing odd and even number of carbon atoms. ${ }^{46}$ It is important to emphasize here that perhaps in 
recognition of this anomalous behavior of hexane, the bitumen fractionation schemes often employ either pentane or heptane as solvent to the exclusion of hexane. In view of this it is deemed necessary to exclude the data obtained from hexane and focus on the results obtained from pentane and heptane. Thus, to summarize the results presented in Table 9, a comparison across the row indicates the effect of external solvent on the asphaltene determination, while the comparison down the column indicates the effect of intrinsic solvent (viz., the volatile fraction of the bitumen). It is evident that the asphaltene content is more influenced by the external solvent than by the intrinsic volatile fraction of the bitumen. If the volatile fraction was to soubilize the asphaltenes in the composite bitumen, then the fractionation results would have shown consistently increased amounts of asphaltenes in each case compared to that of the original bitumen (values in the top row of Table 9). In other words, the results imply that the volatile oil fraction of the bitumen does not help solubilize the asphaltene fraction in a significant manner.

\section{Elemental Analysis}

In order to examine the differences in the chemical composition of asphaltenes obtained from the fractionation of Athabasca bitumen and its distillation residua, elemental analyses were performed. The results are presented in Table 10, which show expected trends viz., reduced hydrogen contents in the residue-I and $I I$, and particularly in the atomic ratio of $H / C$. The amount of hetero atoms in both the residua was found to be similar except in the case of sulfur which was observed to have increased marginally in the residue-II. The elemental analysis of the distillates I \& II indicated that the $H / C$ ratio decreased from distillate-I to distillate-II. Their elemental composition indicates that these volatile fractions were not entirely composed of 
Table 10. Elemental analyses of the Athabasca bitumen and its fractions.

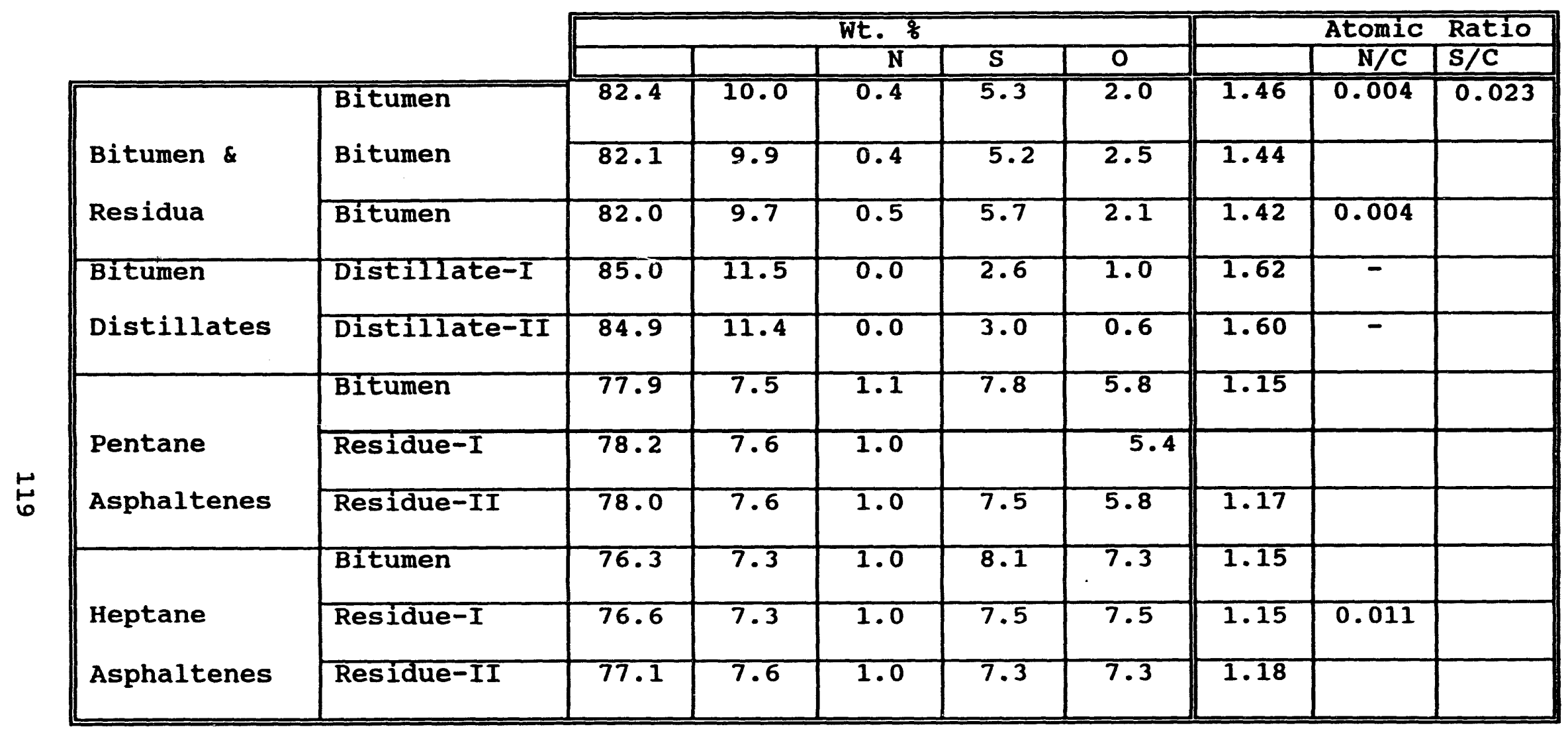


hydrocarbons but some amounts of oxygen and sulfur. The sulfur containing compounds appear to be slightly higher in the distillate-II fraction. On the other hand, the nitrogen containing compounds appear to have remained exclusively in the residual bitumen. Ratios of $H / C$ for the distillate fractions I \& II (1.62 and 1.60 respectively) indicated that these contained a significant amounts of unsaturated or aromatic compounds. This conclusion is based on the comparison of $\mathrm{H} / \mathrm{C}$ ratio of saturate fraction (1.72) obtained from the Athabasca bitumen using a modified SARA fractionation. ${ }^{47}$ This observation may indicate that the distillate fractions of bitumen are more polar than the saturate fraction obtained by the modified SARA fractionation. In view of this it is anticipated that a slightly more polar fraction of the bitumen (distillate I\&II) would have higher solubilizing effect on asphaltenes than a non-polar fraction (saturate fraction). Based on this argument it can be concluded that if the distilled portions of the bitumen have no significant solubilizing effect on the constituent asphaltenes, then the pure saturate fraction separated by the SARA fractionation, which is of higher $\mathrm{H} / \mathrm{C}$ ratio, would have even lesser solubilizing effect.

The elemental analysis of the asphaltenes presented in Table 10 provide some interesting information. $\mathrm{H} / \mathrm{C}$ ratios for asphaltenes obtained from the bitumen and its residua shows that it does not significantly vary with the precipitating solvent (heptane asphaltenes from residue-I seems to be an exception). But for a given solvent, the same ratio was observed to increase from bitumen to bitumen residue-II. Not surprisingly, all the hetero atoms appear to concentrate in the asphaltene fraction. The nitrogen contents of the asphaltenes derived from the bitumen and its residua, including those obtained from two different solvents, show consistently similar values. This clearly 
indicates that there is no preferential distribution of the nitrogen compounds among the asphaltenes precipitated by different solvents. Sulfur content of the asphaltenes on the other hand, show slight decrease from bitumen through residue-I and residue-II. However, the decreasing trend in sulfur is more pronounced in the case of heptane asphaltenes. Although oxygen content was not directly determined, it is noted that for a given asphaltene fraction the observed difference in the oxygen content for the two solvents was greater than the other two hetero atoms. However, for a given solvent the differences in the oxygen contents of the asphaltenes obtained from the bitumen, residue-I and residue-II are small.

\section{Spectroscopic Analysis}

The main purpose of employing the spectroscopic methods of analysis to bitumen and its various fractions was to see whether any useful information can be obtained with regard to the distribution of functional groups and changes in the aromaticity as a result of fractionation. The infrared analysis was conducted on the bitumen, bitumen distillates, bitumen residua, and finally on the maltene and asphaltene fractions thereof using pentane and heptane as solvents. Examination of the infrared spectra obtained from bitumen, its maltene and asphaltene fractions shows (Figure 20) that a group of compounds containing sulfur are selectively accumulated in the asphaltene fraction. The infrared band observed at $1032 \mathrm{~cm}^{-1}$ is generally attributed to the functional groups containing sulfur such as sulfoxides. ${ }^{48-50}$ Accumulation of these groups in asphaltenes was also observed in the fractionation of both the bitumen residua. In spite of this observation, a major portion of the sulfur originally present in the bitumen ends up in the maltene fraction. Sulfur content of the bitumen is believed to be distributed in several functional groups such as thionyls, thiols, thioethers, 


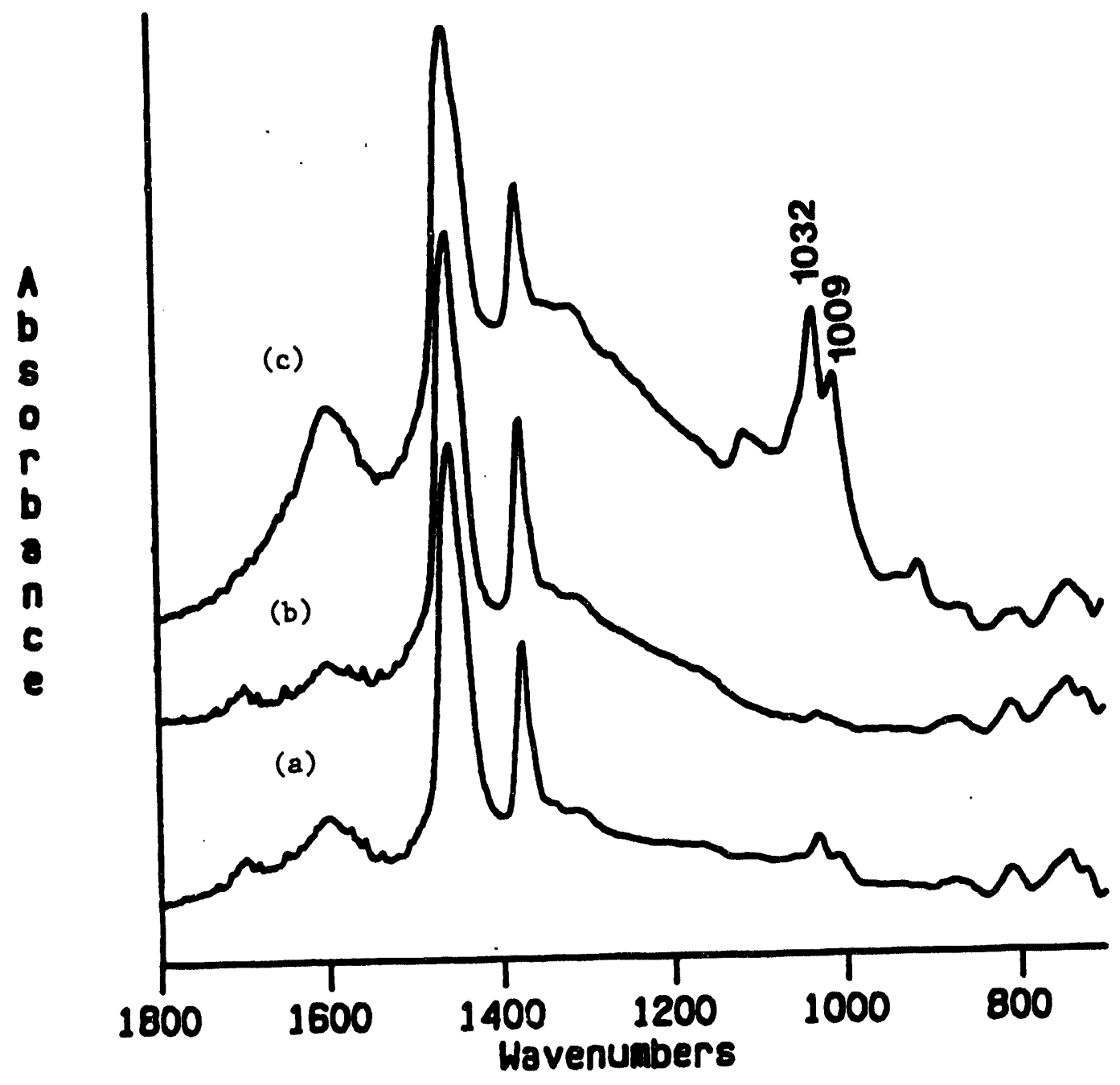

Figure 20. FTIR spectra of (a) the bitumen, (b) maltene
fraction, and (c) asphaltene fraction. 122 
sulfonic acids, thiophenes and benzothiophenes. However, identification of these functional groups by infrared spectroscopy remains uncertain due to the complexity of the sample, and also to their probable low absorptivities.

In agreement with the elemental analysis, the infrared spectra of the bitumen distillate fractions show (Figure 21) the presence of some aromatic compounds, as indicated by the absorbance band at $1600 \mathrm{~cm}^{-1}$. The spectra also indicate an additional band at $1703 \mathrm{~cm}^{-1}$ due to some polar compounds such as carboxylic acids. Although the elemental analyses of these fractions indicate a significant amount of sulfur $12.6 \%$ and $3.0 \%$ in distillates-I and II respectively), the absence of the absorbance band at $1032 \mathrm{~cm}^{-1}$ may indicate that the sulfur containing functional groups are other than $S=0$ and $C=S$.

Another significant piece of information obtained from the infrared spectra of the pentane asphaltenes derived from the bitumen and its residua involves the absorbance band at $1263 \mathrm{~cm}^{-1}$. The spectra of these fractions are presented in Figure 22. The assignment of the band at $1263 \mathrm{~cm}^{-1}$ is uncertain but is believed to be due either to the $-\underline{C-O}-\mathrm{C}-$ or $-\underline{C-S}-\mathrm{C}$ - bond present in acid anhydrides, esters, and ethers. The presence of esters, acid anhydrides, and other oxygen functionalities in Athabasca bitumen has been firmly established. ${ }^{51.53}$ As the relative intensity of this band increases from bitumen to bitumen residue-II, it is inferred that the compounds containing the above mentioned functional groups are progressively concentrated in the asphaltene fractions. A similar observation was made for the asphaltenes obtained from the same materials using heptane as solvent, though the differences in this case were less pronounced.

For complex mixtures like bitumens, proton and ${ }^{13} \mathrm{C}$ NMR data is of limited use in its interpretation, particularly in the elucidation of structural features. For this reason the analyses was confined to a few selected samples 


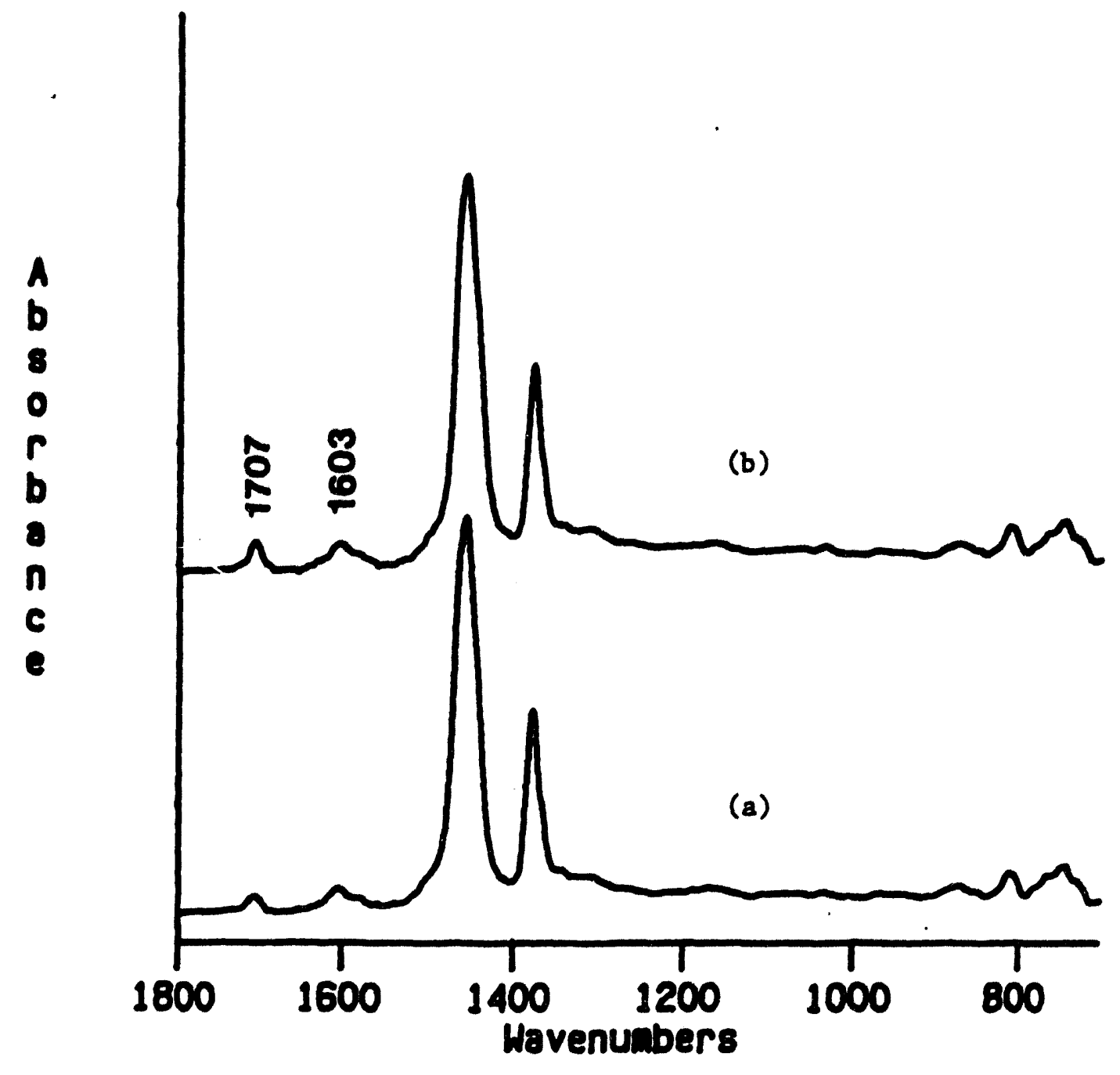

Figure 21. FTIR spectra of the bitumen distillate fractions. (a) Distillate-I, and (b) Distillate-II. 


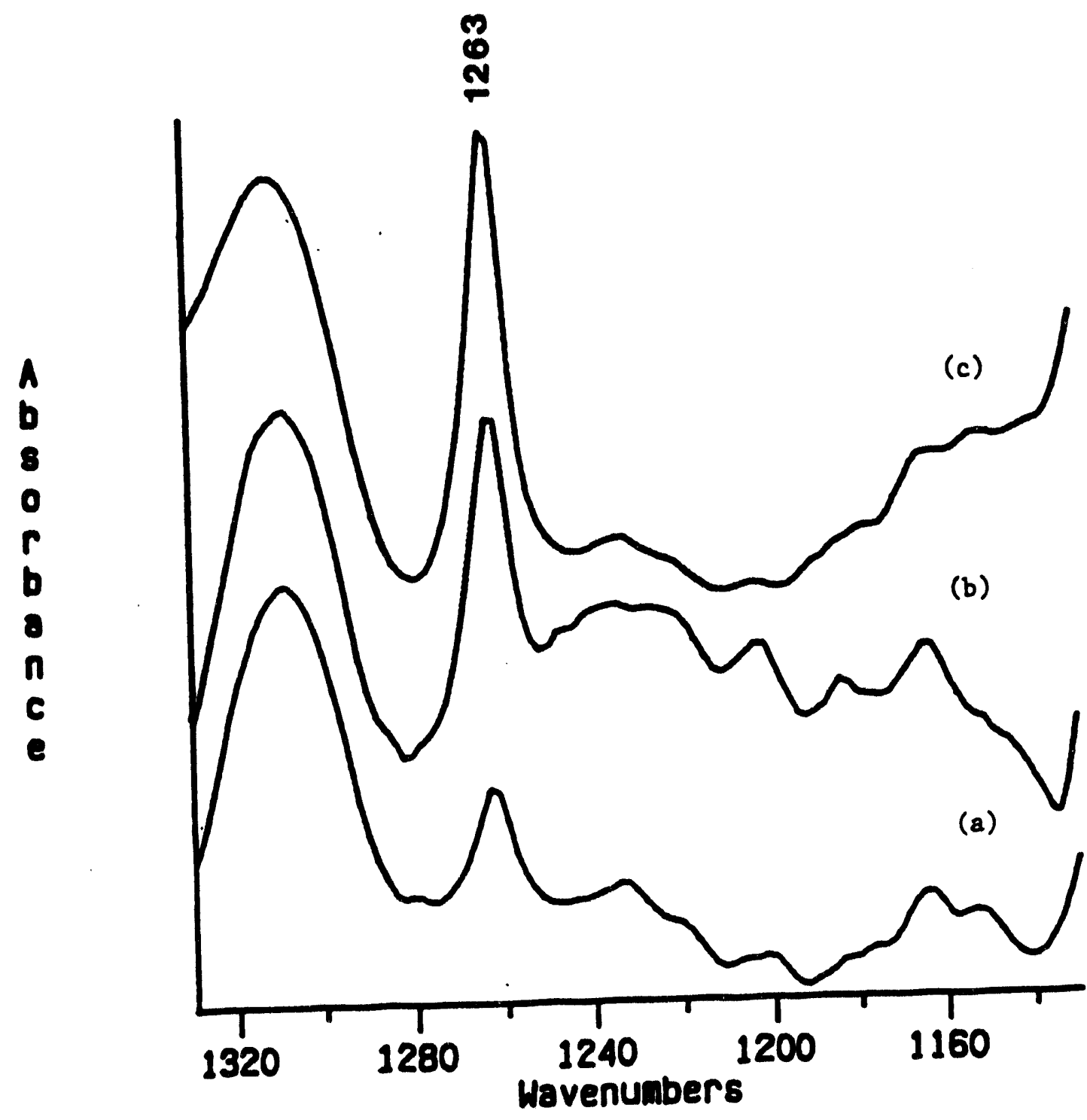
Figure 22. FTIR spectra of the pertane asphaltene fractions.
(a) From bitumen, (b) bitumen residue-I, and (c) bitumen residue-II. 
of the bitumen and its fractions. The samples chosen for these analyses are; (i) bitumen, (ii) bitumen distillate-II, (iii) pentane maltenes from bitumen, (iv) pentane asphaltenes from bitumen, (v) bitumen residue-II, (vi) pentane maltenes from (v), (vii) pentane asphaltenes from (v). The results from the NMR analysis were not expected to provide definitive structural features of the fractions, however, a quantitative estimation of the relative amounts of aromatic and non-aromatic carbon (including both aliphatic and naphthenic) and hydrogen atoms attached to such carbon atoms present in a given fraction was made possible.

Proton NMR spectra of the bitumen distillate-II, bitumen and the asphaltene fraction are presented in Figure 23. It is evident from Figure 23 that the vast majority of the hydrogen atoms $(>92 \%)$ are of non-aromatic nature. ${ }^{54}$ It was not possible to distinguish between the aliphatic and naphthenic hydrogen. However, the relative intensities for two of the chemical shifts observed in the spectrum of each sample at $d=1.22 \mathrm{ppm}$ and $d=1.60 \mathrm{ppm}$ provide some useful comparisons. The chemical shifts at $1.22 \mathrm{ppm}$ and $1.60 \mathrm{ppm}$ represent hydrogen atoms in the methyl and methylene groups respectively. The intensity of the chemical shift observed at $1.60 \mathrm{ppm}$ in the spectra of bitumen and its pentane asphaltene fraction is higher than that at 1.22 . Whereas in the spectrum of bitumen distillate-II the intensity of the chemical shift at $1.22 \mathrm{ppm}$ predominates that at $1.60 \mathrm{ppm}$. This indicates that there is a preponderance of methyl groups among the compounds present in the distillate-II fraction. The proton NMR spectrum of the maltene fractions obtained from both the bitumen and the bitumen residue-II appe:ared identical. In all these spectra the hydrogen atoms were broadly divided into two groups based on their attachment to either aromatic or non-aromatic carbon atoms. The aromatic hydrogens have characteristic shifts in the $d=7-8.5$ ppm. Although there are other hydrogen atoms bound to heteroatoms and other 


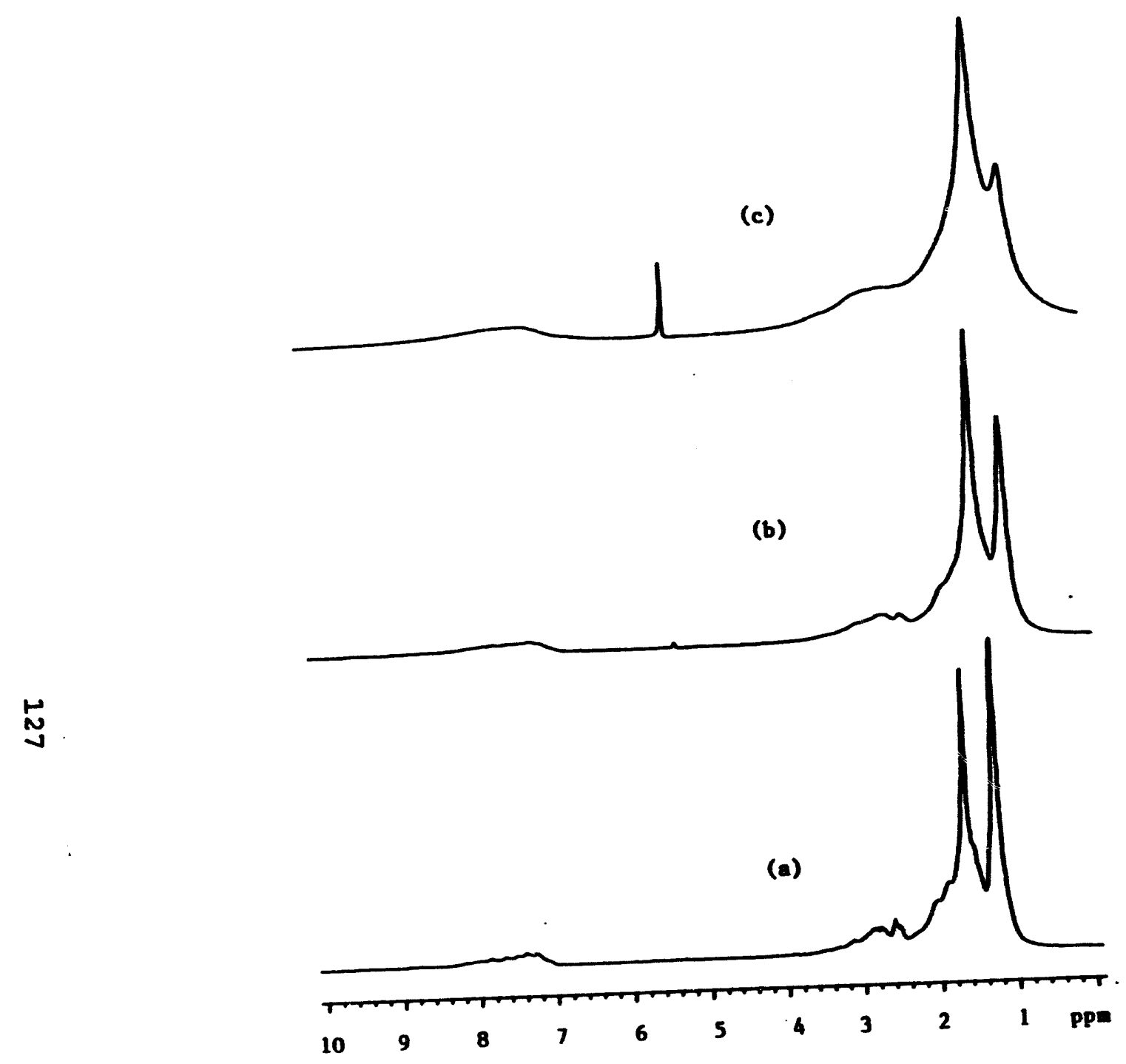

Figure 23. $1_{\mathrm{H}} \mathrm{nmr}$ spectra of (a) bitumen distillation-II fraction, (b) bitumen, and Figure 23.
(c) asphaltene fraction (from bitumen). 
functional groups, it is believed their proportion is too small to make any difference in the discussion. The proportional content of each type of hydrogen in a given fraction was determined by the integration of the proton NMR bands in the spectrum. The percentage ratio of these groups of hydrogens was determined for each bitumen fraction, and presented in Table 11. In all bitumen fractions the hydrogen atoms were inferred to attach themselves overwhelmingly to non-aromatic carbon atoms.

The ${ }^{13} \mathrm{C}$ NMR spectra of the bitumen and its fractions were complex and the assignment of their constituent bands are at best speculative. However, there are several references in the literature ${ }^{55-58}$ that are devoted to the assignment of the observed bands and determination of structural parameters of the compounds present in bitumen. In this study no attempt was made to correlate the observed chemical shifts to the structural features of the constituent compounds present in the bitumen fractions. However, the carbon content of the bitumen and its fractions was divided into aromatic and non-aromatic fractions based on their characteristic chemical shifts. ${ }^{13} \mathrm{C}$ NMR spectra of the bitumen, its maltene and asphaltene fractions, obtained from pentane solvent, are presented in Figure 24. Qualitatively, there appeared to be no differences in the spectra observed between the bitumen and its distillation residue-II. This similarity persisted even between their corresponding maltene and asphaltene fractions. The spectrum of the distillate-II fraction is presented in Figure 25. The only noticeable difference between the bitumen and the distillate-II was observed in the relative intensities of the peaks in the $d=25-50 \mathrm{ppm}$ region, which was attributed to the naphthenic carbon. 59 For the distillate-II fraction, the intensity of the peaks in the $d=25-50 \mathrm{ppm}$ region was observed to be small in comparison to those in the $d=10-25 \mathrm{ppm}$ region with the latter representing the branched aliphatic 
Table 11. Summary of the hydrogen and carbon distributions among the bitumen and its fractions. Data is obtained from the proton and ${ }^{13} \mathrm{C}$ NMR spectroscopic analyses.

\begin{tabular}{|c|c|c|c|c|}
\hline & Hydroge & $\begin{array}{l}\text { Distributi } \\
\text { on }\end{array}$ & $\overline{\mathbf{C a}}$ & $\begin{array}{l}\text { Distributi } \\
\text { on }\end{array}$ \\
\hline & $\begin{array}{l}\text { Non } \\
\text { Aromatic }\end{array}$ & Aromatic & $\begin{array}{l}\text { Non } \\
\text { Aromatic }\end{array}$ & Aromatic \\
\hline Bitumen Distillate-II & $\overline{93}$ & $\overline{\overline{7}}$ & 82 & $\overline{18}$ \\
\hline Bitumen & 94 & 6 & 78 & 22 \\
\hline Pentane Maltenes (From Bitumen) & $\overline{94}$ & 6 & 78 & 22 \\
\hline $\begin{array}{l}\text { Pentane Asphaltenes (From } \\
\text { Bitumen) }\end{array}$ & $\overline{92}$ & 8 & 66 & 34 \\
\hline Bitumen Residue-II & 93 & 7 & 77 & 23 \\
\hline $\begin{array}{l}\text { Pentane Maltenes ("rom Bitumen } \\
\text { Residue-II) }\end{array}$ & 93 & 7 & 79 & $\overline{21}$ \\
\hline $\begin{array}{l}\text { Pentane Asphaltenes (From } \\
\text { Bitumen Residue-(I) }\end{array}$ & 92 & 8 & 62 & 38 \\
\hline
\end{tabular}




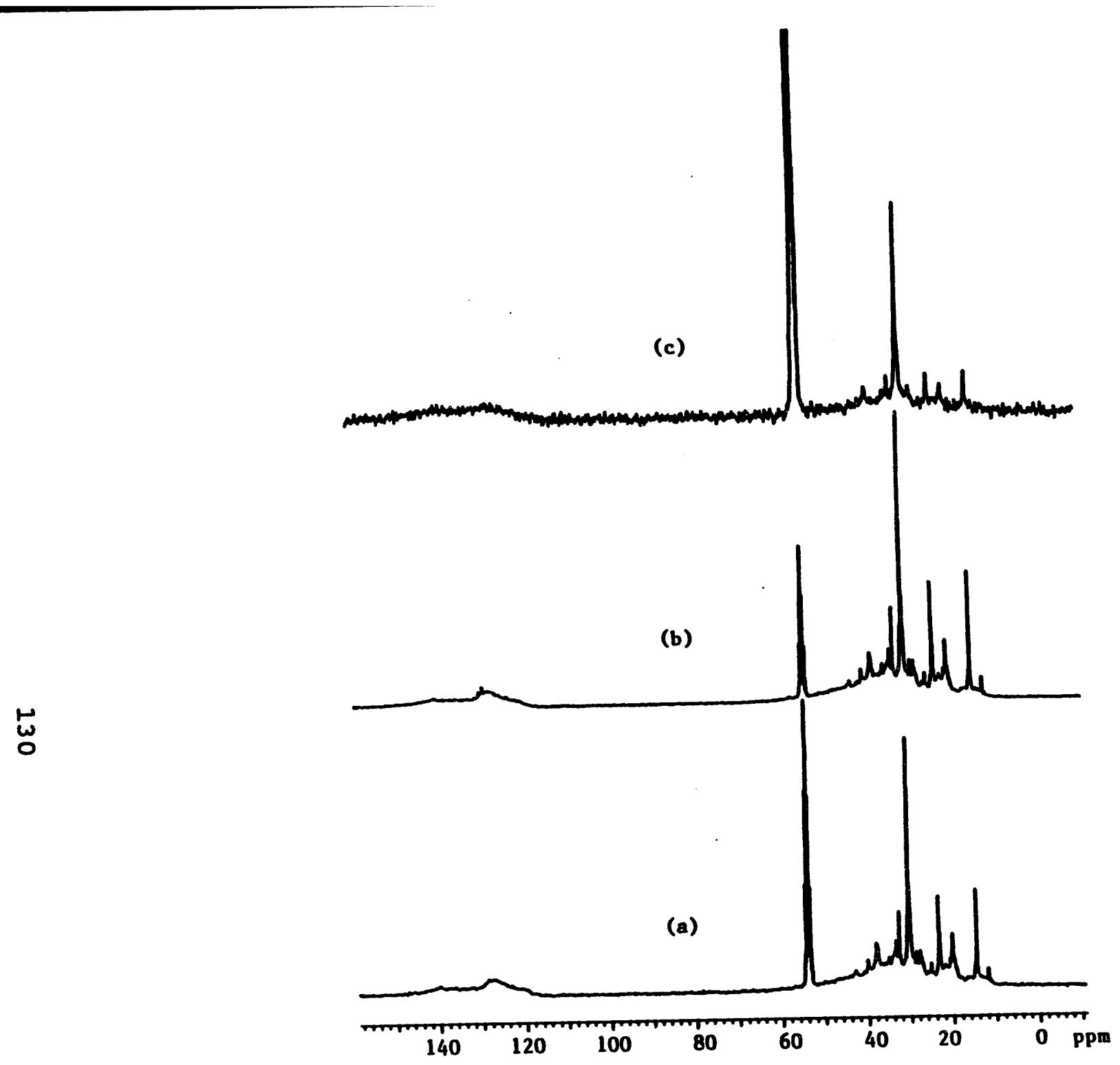

Figure 24. ${ }^{13} \mathrm{C}$ nmr spectra of (a) bitumen, (b) maltene fraction, and (c) asphaltene fraction. 


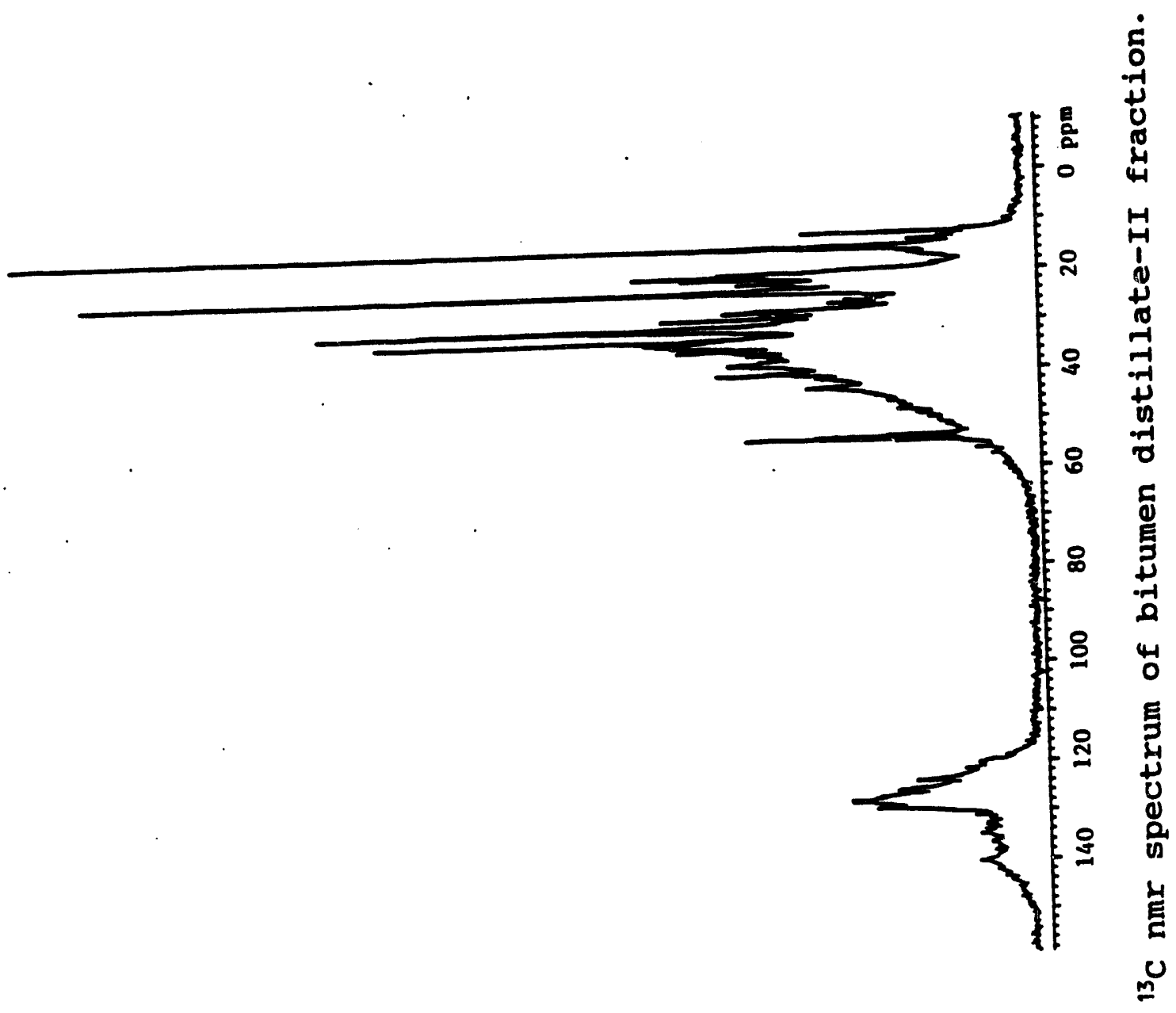

占 
carbon. Whereas in the spectra of bitumen and its maltene fraction, the naphthenic carbon contents appear comparable but higher than that of distillate-II fraction. A similar observation was made for the bitumen residue-II and its maltene fraction. In addition to this comparison, the ${ }^{13} \mathrm{C}$ NMR spectral data was used to determine the relative amount of the aromatic carbon content of the various bitumen fractions. From the spectral analysis, it was observed that in each case the proportion of carbon engaged in functional groups such as carbonyls and carboxylic acids was extremely small in comparison to the total carbon content. The carbon type distribution values for the bitumen, and its various fractions are summarized in Table 11.

The data presented in Table 11 provides some information about the nature of asphaltenes. As shown earlier the asphaltene content of the bitumen is greatly influenced by the solvent used in the fractionation. To a smaller extent, it was also shown to depend on the volatile fraction of the bitumen, which was interpreted to assist in the solubilization of the asphaltenes. Thus, when the volatile fraction is removed from the bitumen the asphaltene content was slightly increased. If the precipitation of asphaltenes is a result of the prevailing solubility equilibrium, then a change in the equilibrium condition would alter the amount of asphaltenes precipitated. The variables which would influence the solubility equilibrium include the temperature, composition of the bitumen, and the nature of the solvent. Removal of the volatile fraction from the bitumen brings about a change in the bitumen composition and thereby increases the amount of asphaltenes precipitated. Chemical and spectroscopic analysis of the asphaltenes precipitated under these two different equilibrium conditions sheds some light on the properties of the molecules that report to asphaltenes.

With respect to the earlier described models of asphaltenes, the results 
from this study tend to support the view that asphaltenes are colloidally suspended particles which are stabilized by the other polar molecules (resin) present in the bitumen. This is inferred by the small changes observed in the asphaltene content of the bitumen as a result of changing the bitumen composition. It may appear that there are subtle differences in the description of asphaltenes by both the models, but there is no reason for them to be mutually exclusive. Indeed the results from this study indicate that the true nature of asphaltenes embraces the features of both the asphaltene models.

In this study, it has been shown that varying the external solvent (from heptane to pentane) and partial removal of the volatile fraction from the bitumen, the asphaltene content was increased. The compounds which contribute to the increase in asphaltene fraction were mainly of aromatic nature (Table 3 ). The elemental analysis, as presented in Table 10, indicates that these compounds have high heteroatom contents. Finally, the infrared analysis indicates that these compounds have increased amounts of functional groups containing sulfur and oxygen.

It would be presumptuous to generalize the results noted here for all bitumens and heavy oils. It is quite possible that the solvent dependence of asphaltene precipitation may itself be a function of the bitumen composition. In order to explore this aspect a similar type of work is being carried out on a different bitumen

\section{SUMMARY AND CONCLUSIONS}

The asphaltene content of bitumen is known to depend on the nature of the solvent used in the fractionation. This dependence of asphaltene precipitation is often attributed to the prevailing solubility equilibrium. Since the bitumen contains a significant amount of volatile hydrocarbons, their effect on the 
solubilization of intrinsic asphaltenes was investigated. In order to accomplish this task Athabasca bitumen was selected for study, and was fractionated into maltenes and asphaltenes using three different solvents; hexane, and heptane. In addition, vacuum distillation was performed on two samples of Athabasca bitumen to remove portions of the volatile fraction. The distillation residue from each sample was collected and fractionated into maltenes and asphaltenes using the same set of solvents. The experimental results show that the volatile fractions of the bitumen do solubilize the asphaltenes, and when they are removed from the bitumen the asphaltene content was shown to increase slightly. However, it was noted that the influence of volatile fraction on the asphaltene content is smaller than the effect of the external solvent used for fractionation of the bitumen. Spectroscopic analysis of the bitumen and its fractions indicated the chemical characteristics of compounds found in the asphaitenes.

The asphaltene content of Athabasca bitumen was determined in three different hydrocarbon solvents viz., pentane, hexane and heptane, and was shown to decrease with an increase in the carbon number of the solvent. In order to investigate the solubilizing effect of the volatile fractions of the bitumen on the precipitation of asphaltenes, portions of the volatile fraction were separated by vacuum distillation. The fractionation of the bitumen residua was again performed by using the same three solvents. The asphaltene contents of the residua were found to have increased slightly in the case of pentane and heptane, whereas in the case of hexane they were found to have decreased. Thus hexane was anomalous in its behavior towards the bitumen residua. However, results from the other two solvents indicated that the volatile fraction does solubilize the asphaltenes in the composite bitumen, though to a very small extent. The chemical and spectroscopic analysis indicates that these solubilized asphaltenes 
contain sulfur and oxygen functionalities and are aromatic in nature.

\section{FUTURE ACTIVITIES}

The future research plan includes a detailed characterization of the bitumen and mineralogical composition of Circle Cliffs and PR Spring tar sand deposits of Utah. In addition, the effect of bitumen chemical composition or the nature of asphaltenes will be investigated for a Uinta Basin tar sand bitumen. 


\section{WATER-BASED TAR SAND SEPARATION TECHNOLOGY}

\section{Principal Investigator: Res. Assoc. Professor: Research Associate: Graduate Students:}

J. D. Miller

J. Hupka

M. Hupka

Y. Yang

J. Drelich

D. Lelinski

Natural Porosity of Tar Sands and its Impact on Water-Based Bitumen Recovery

\section{INTRODUCTION}

The natural porosity of tar sand accessible by diluent has a crucial impact on the reduction of bitumen viscosity, and influences the penetration time required for successful bitumen separation from tar sand. The actual tar sand porosity, i.e., the pore volume of the bitumen impregnated sandstone which is filled with gaseous hydrocarbons, air or water (i.e., the unoccupied-by-oil part of the pore volume) was termed the natural porosity of tar sand.60 If diluent is being used prior to digestion to reduce the bitumen viscosity, ${ }^{61}$ the tar sand natural porosity determines the lowest processing temperature applicable, unless size reduction to almost elemental grains is provided prior diluent pretreatment.

The natural porosity of tar sand will also determine the efficiency of digestion. It is expected that the alkaline aqueous phase must first migrate into the pores, wet the sand and then the sand grain can be detached from the tar sand fragment. on the other hand, a high volume of voids is conducive to chemical changes in the bitumen through oxidation and the loss of native gases present in the pores, which may change bitumen surface properties. Such a change of surface properties may lead to stronger bitumen 
adhesion to the minerals, the release of more surfactants to the aqueous phase, and a change in the air bubble filming ability.

\section{Porosity Measurements}

The natural porosity was previously determined by submersion of tar sand samples in two liquids of differing ability to wet, and thus penetrate, the capillaries.60 These liquids were water and methyl alcohol. The difference in volume for the same tar sand sample immersed in water, and then in methanol, allowed for the determination of the natural porosity. Volumetric measurements were supplemented by weighing the tar sand samples after each submersion or liquid removal by evaporation under vacuum.

The original technique for porosity determination using methanol was supplemented by the extraction of the tar sand sample in an organic solvent and simultaneous volumetric determination of the gas phase released during extraction. Three organic solvents were used; toluene, carbon tetrachloride and kerosene. The experimental set-up, shown in Figure 26, consisted of an extraction vessel with cover, a water bath or hot plate, and a funnel extended with a calibrated glass tube, a graduated pipette. Prior to the measurement the vessel and the funnel were filled with an organic solvent and heated to the desired temperature. Subsequently a sample of tar sand was placed under the funnel and left for complete bitumen dissolution. The gas phase released from tar sand was metered in the calibrated tube. The new procedure was more accurate than the methanol penetration test, and was particularly useful for unconsolidated tar sands. Each value of the natural 


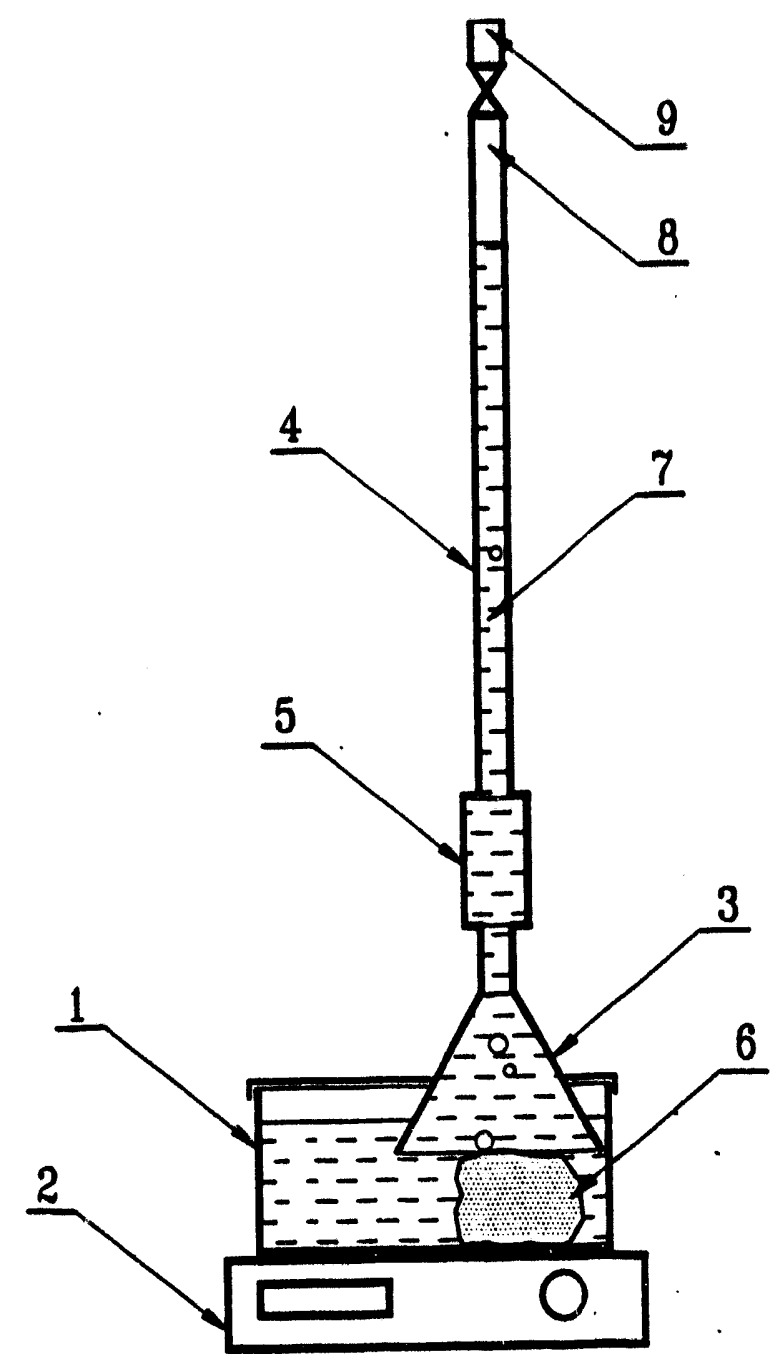

Figure 26.

Experimental setup used for determination of tar sand natural porosity; (1). extraction vessel with cover: (2) hot plate; (3) funnel; (4) graduated pipette; (5) cell with flat walls; (6) tar sand sample; (7) solvent; (8) gas phase; (9) to vacuum 
porosity for a given tar sand sample was obtained from at least five independent samples. The experimental error was \pm 5 percent. The greatest contribution to the experimental error arose from the determination of the tar sand sample volume. The data obtained also allowed for the calculation of the apparent density. Preliminary drying of each tar sand sample at $25^{\circ} \mathrm{C}$ and $3 \mathrm{kPa}$ vacuum for constant weight allowed to exclude free water present in the tar sand sample.

\section{RESULTS AND DISCUSSION}

The original porosity of the host sandstone and the degree of saturation with bitumen determine the natural porosity. Based on the literature, the porosity (including all fluid phases) of the tar sand host rock ranges from 15 to $408.62,63$ These values can be related to the nature of the host rock, varying in texture from a fine silt to a coarse grit. Oil saturation usually accounts for 20 to $75 \%$ of the free volume; thus the natural porosity should extend from a few percent to 30 percent. The natural porosity $(\epsilon)$ can be calculated from the tar sand apparent density $\left(\rho_{a}\right)$ if the bitumen density $\left(\rho_{b}\right)$, the sand density $\left(\rho_{s}\right)$, the bitumen weight fraction $\left(x_{b}\right)$, and the sand weight fraction $\left(x_{s}\right)$ are known:

$$
\epsilon=1-x_{s} \rho_{a} / \rho_{s}-x_{b} \rho_{a} / \rho_{b}
$$

If water is removed from the tar sand sample prior porosity measurements $x_{s}$ can be expressed in terms of $x_{b}$ :

$$
x_{s}=1-x_{b}
$$

The values of $\rho_{b}, x_{b}$, and $\rho_{s}$ are given in Table 12 . 
Table 12. Bitumen Density $\left(\rho_{b}\right)$, Sand Density $\left(\rho_{s}\right)$ and Bitumen Weight Fraction $\left(x_{p}\right)$ for Several Utah Tar Sands and Athabasca Tar Sand

\begin{tabular}{llll}
\hline Tar sand & $\rho_{\mathrm{b}}$ & $\mathrm{x}_{\mathrm{b}}$ & $\rho_{\mathrm{s}}$ \\
\hline Asphalt Ridge & 0.97 & 0.118 & 2.55 \\
P.R. Spring & 1.01 & 0.12 & 2.55 \\
Sunnyside & 1.03 & 0.095 & 2.55 \\
Whiterocks & 1.00 & 0.08 & 2.55 \\
Athabasca & 0.95 & 0.16 & 2.55 \\
\hline
\end{tabular}

The natural porosity data for several Utah tar sands and the Athabasca (Alberta, Canada) tar sand are presented in Tables 13-17. Each tar sand sample, before it was submitted to methanol penetration or to solvent extraction, was weighed and its volume was determined by submersion in water. Such a procedure allowed for the calculation of the natural porosity from the apparent density using equation (1). Unless unnoticed large air bubbles adhered to the tar sand surface, the apparent density provided quite accurate measure of natural porosity, to which the porosity obtained by the two other experimental techniques could be compared.

A general observation from tables $13-17$ is that for some tar sand samples very good agreement with the porosity determined by $\rho_{a}$ can be noticed, while in certain instances large discrepancies were found. Experimental errors may account for this, but closed pores (inaccessible by methanol or even by the organic solvent) may be another cause. Additionally, based on the porosity values determined by $\rho_{a}$, tar sand samples showed rather diverse porosity, 
Table 13. Natural Porosity of Sunnyside Tar Sands (Utah)

\begin{tabular}{|c|c|c|c|c|c|c|}
\hline $\begin{array}{c}\text { Sample } \\
\text { No. }\end{array}$ & {$\left[\mathrm{kg}^{\rho} \mathrm{m}^{-3}\right]$} & $\begin{array}{c}\text { Estimated } \\
\text { from } \rho_{0}\end{array}$ & $\begin{array}{l}\text { Kerosene } \\
\text { Extraction }\end{array}$ & $\begin{array}{c}\text { Toluene } \\
\text { Extraction }\end{array}$ & $\underset{\text { Extraction }}{\mathrm{CCl}_{4}}$ & $\begin{array}{c}\text { Methanol } \\
\text { Penetration }\end{array}$ \\
\hline $1 B$ & 2240 & 1 & 1.1 & - & - & - \\
\hline $1 F$ & 2200 & 2 & 2.1 & - & - & - \\
\hline $2 B$ & 2200 & 2 & 2.2 & - & - & - \\
\hline $2 F$ & 2250 & 1 & 0.9 & - & - & - \\
\hline $3 B$ & 2090 & 7 & - & - & 7.2 & - \\
\hline 4B & 2140 & 4 & - & - & 5.1 & - \\
\hline $5 B$ & 2150 & 5 & - & 9.2 & - & - \\
\hline $6 B$ & 2140 & 4 & - & - & - & $0.2^{(1)}$ \\
\hline $7 B$ & 2060 & 8 & - & - & - & $0.8^{(2)}$ \\
\hline 8B & 2210 & 1 & - & - & - & $1.9^{(3)}$ \\
\hline $9 \mathrm{~B}$ & 2150 & 4 & - & - & - & $1.2^{(3)}$ \\
\hline 10B & 2060 & 8 & - & - & - & $1.1^{(3)}$ \\
\hline $11 B$ & 2120 & 5 & - & - & - & $1.5^{(3)}$ \\
\hline $11 F$ & 2170 & 3 & - & - & - & $3.0^{(3)}$ \\
\hline $12 \mathrm{~B}$ & 2170 & 3 & - & - & - & $3.3^{(3)}$ \\
\hline $12 F$ & 2110 & 5 & - & - & - & $2 \cdot 5^{(3)}$ \\
\hline $13 \mathrm{~B}$ & 2230 & 4 & - & - & - & $1.1^{(3)}$ \\
\hline $14 \mathrm{~B}$ & 2250 & 1 & - & - & - & $2.2^{(3)}$ \\
\hline $15 B$ & 2240 & 1 & - & - & - & $2 \cdot 1^{(3)}$ \\
\hline
\end{tabular}

B - tar sand sample in one block; F - tar sand sample in several fragments

(1) -1 min: (2) -30 min; (3) 24 hours 
Table 14. Natural Porosity of P.R. Spring Tar Sands (Utah)

\begin{tabular}{|c|c|c|c|c|c|c|}
\hline \multirow[b]{2}{*}{$\begin{array}{l}\text { Sample } \\
\text { No. }\end{array}$} & \multirow[b]{2}{*}[\mathrm{kg}^{\rho}\mathrm{m}^{-3}]{} & \multirow[b]{2}{*}{$\begin{array}{c}\text { Estimated } \\
\text { from } \rho_{.}\end{array}$} & \multicolumn{4}{|c|}{ Natural Porosity $[\xi]$} \\
\hline & & & $\begin{array}{c}\text { Kerosene } \\
\text { Extraction }\end{array}$ & $\begin{array}{c}\text { Toluene } \\
\text { Extraction }\end{array}$ & $\underset{\text { Extraction }}{\mathrm{CCl}_{4}}$ & $\begin{array}{l}\text { Methanol } \\
\text { Penetration }\end{array}$ \\
\hline 1 & 1940 & 10.1 & - & - & - & $13.1^{(1)}$ \\
\hline 2 & 2030 & 5.9 & - & - & - & $3.0^{(1)}$ \\
\hline 3 & 2060 & 4.4 & - & - & - & $5 \cdot 5^{(1)}$ \\
\hline 4 & 1860 & 13.7 & - & - & - & $6.2^{(1)}$ \\
\hline 5 & 2010 & 6.8 & - & - & - & $2.8^{(2)}$ \\
\hline 6 & 2040 & 5.4 & - & - & - & $5.5^{(2)}$ \\
\hline 7 & 2040 & 5.4 & - & - & - & $4.1^{(1)}$ \\
\hline 8 & 1970 & 8.6 & - & - & - & $2.1^{(1)}$ \\
\hline 9 & 2200 & 2.7 & - & - & - & $4.2^{(1)}$ \\
\hline 10 & 2200 & 2.7 & - & - & - & $1.9^{(1)}$ \\
\hline 11 & 2010 & 6.8 & 6.8 & - & - & - \\
\hline 12 & 2000 & 7.3 & - & - & 17.6 & - \\
\hline 14 & 2030 & 5.9 & - & 6.0 & - & - \\
\hline & & & & & & \\
\hline
\end{tabular}

(1) -1 min; (2) -30 min; (3) 24 hours 
Table 15. Natural Porosity of Whiterocks Tar Sands (Utah)

\begin{tabular}{|c|c|c|c|c|c|c|}
\hline \multirow[b]{2}{*}{$\begin{array}{c}\text { Sample } \\
\text { No. }\end{array}$} & \multirow[b]{2}{*}[\mathrm{kg}^{\rho_{\mathrm{m}}^{-3}}]{} & \multirow[b]{2}{*}{$\begin{array}{l}\text { Estimated } \\
\text { from } \rho_{a}\end{array}$} & \multicolumn{3}{|c|}{ Natural Porosity $[z]$} & \multirow[b]{2}{*}{$\begin{array}{l}\text { Methanol } \\
\text { Penetration }\end{array}$} \\
\hline & & & $\begin{array}{c}\text { Kerosene } \\
\text { Extraction }\end{array}$ & $\begin{array}{c}\text { Toluene } \\
\text { Extraction }\end{array}$ & $\underset{\text { Extraction }}{\mathrm{CCl}_{4}}$ & \\
\hline 1 & 2190 & 3.5 & 2.5 & - & - & - \\
\hline 2 & 2160 & 4.8 & 3.9 & - & - & - \\
\hline 3 & 2090 & 7.9 & 7.9 & - & - & - \\
\hline 4 & 2160 & 4.8 & - & - & 9.2 & - \\
\hline 5 & 2100 & 7.4 & - & 3.8 & - & - \\
\hline 6 & 2190 & 3.5 & - & - & - & $4.0^{(1)}$ \\
\hline 7 & 2170 & 4.4 & - & - & - & $1.5^{(1)}$ \\
\hline 8 & 2170 & 4.4 & - & - & - & $2.9^{(3)}$ \\
\hline 9 & 2130 & 6.1 & - & - & - & $6.0^{(3)}$ \\
\hline 10 & 2160 & 4.8 & - & - & - & $4.6^{(3)}$ \\
\hline 11 & 2210 & 2.6 & - & - & - & $2.2^{(2)}$ \\
\hline 12 & 2230 & 1.8 & - & - & - & $1.8^{(2)}$ \\
\hline 13 & 2090 & 7.8 & - & - & - & $3.5^{(2)}$ \\
\hline 14 & 2160 & 4.8 & - & - & - & $2 \cdot 4^{(2)}$ \\
\hline
\end{tabular}
(1) -1 min:
(2) - 30 min;
(3) 24 hours 
Table 16. Natural Porosity of Asphalt Ridge Tar Sands (Utah)

\begin{tabular}{|c|c|c|c|c|c|c|}
\hline \multirow[b]{2}{*}{$\begin{array}{l}\text { Sample } \\
\text { No. }\end{array}$} & \multirow[b]{2}{*}[\mathrm{kg}^{\rho_{\mathrm{m}}-3}]{} & \multirow[b]{2}{*}{$\begin{array}{l}\text { Estimated } \\
\text { from } \rho_{0}\end{array}$} & \multicolumn{3}{|c|}{ Natural Porosity $[8]$} & \multirow[b]{2}{*}{$\begin{array}{c}\text { Methanol } \\
\text { Penetration }\end{array}$} \\
\hline & & & $\begin{array}{l}\text { Kerosene } \\
\text { Extraction }\end{array}$ & $\begin{array}{l}\text { Toluene } \\
\text { Extraction }\end{array}$ & $\stackrel{\mathrm{CCl}_{4}}{\text { Extraction }}$ & \\
\hline $1 N *$ & 2040 & 4.7 & - & - & - & $3 \cdot 3^{(1)}$ \\
\hline $2 N$ & 2000 & 6.7 & - & - & - & $4.6^{(1)}$ \\
\hline $3 N$ & 1970 & 8.0 & - & - & - & $3.2^{(1)}$ \\
\hline $4 N$ & 2030 & 5.4 & - & - & - & $5.8^{(3)}$ \\
\hline $5 N$ & 1930 & 9.7 & - & - & - & $5.7^{(2)}$ \\
\hline $6 \mathrm{~N}$ & 1925 & 10.0 & - & - & - & $5.8^{(2)}$ \\
\hline $7 C \star$ & 2000 & 6.6 & - & - & - & $6.3^{(2)}$ \\
\hline $8 C$ & 1990 & 7.0 & - & - & - & $8.0^{(2)}$ \\
\hline $9 \mathrm{C}$ & 1970 & 8.0 & - & - & 13.5 & - \\
\hline $10 \mathrm{C}$ & & & & & & \\
\hline
\end{tabular}

$N, C$ - sample originated from the North or Central part of the deposit. (1) -1 min; (2) -30 min; (3) 24 hours 
Table 17. Natural Porosity of Athabasca Tar Sands (Utah)

\begin{tabular}{|c|c|c|c|c|c|c|}
\hline \multirow[b]{2}{*}{$\begin{array}{c}\text { Sample } \\
\text { No. }\end{array}$} & \multirow[b]{2}{*}[\mathrm{kg}^{\rho_{\mathrm{m}}^{-3}}]{} & \multirow[b]{2}{*}{$\begin{array}{l}\text { Estimated } \\
\text { from } \rho_{a}\end{array}$} & \multicolumn{4}{|c|}{ Natural Porosity $[\xi]$} \\
\hline & & & $\begin{array}{l}\text { Kerosene } \\
\text { Extraction }\end{array}$ & $\begin{array}{l}\text { Toluene } \\
\text { Extraction }\end{array}$ & $\underset{\text { Extraction }}{\mathrm{CCl}_{4}}$ & $\begin{array}{l}\text { Methanol } \\
\text { Penetration }\end{array}$ \\
\hline 1 & 2060 & 1.0 & - & - & - & $14 \cdot 3^{(1)}$ \\
\hline 2 & 1820 & 9.5 & - & - & - & $21 \cdot 5^{(2)}$ \\
\hline 3 & 1840 & 8.5 & - & - & - & $18.1^{(2)}$ \\
\hline 4 & 1800 & 10.4 & - & - & - & $19 \cdot 9^{(2)}$ \\
\hline 5 & 1880 & 6.4 & - & - & - & $18 \cdot 6^{(2)}$ \\
\hline 6 & 1720 & 14.5 & 14.9 & - & - & - \\
\hline 7 & 1770 & 11.9 & - & - & 12.6 & - \\
\hline 8 & 1870 & 7.0 & - & 7.6 & - & - \\
\hline
\end{tabular}

(1) -1 min; (2) -30 min; (3) 24 hours 
even within the same large fragment, which was split into $25 \mathrm{~g}$ to $100 \mathrm{~g}$ pieces for measurements. The existence of closed pores seems to be more probable for well consolidated tar sand (e.g. Sunnyside), with the closed pores being stabilized by inorganic cementing material. During the stagnant solvent extraction, the rate of gas release was found to be strongly dependent on the tar sand origin and the microstructure. The porosity determined from several smaller pieces of tar sand was greater than the porosity determined from one larger tar sand fragment, supporting the existence of inaccessible void space within the tar sand.

Considering solvents used for extraction, kerosene provided the best outcome, while carbon tetrachloride gave the most deviating results (always to high) compared to the $\rho_{a}$ porosity Blank tests with each solvent, conducted without the tar sand sample, proved the lack of the air "pumping" effect into the pipette for at least 24 hours. The volume of the collected gas depends clearly on the experimental temperature. There is also possibility of the release of dissolved gases from the bitumen and solvent which will result in porosity larger than the actual one. On the other hand, some gases may rather dissolve in the organic solvent thus lowering the porosity value. The stagnant extraction technique was found particularly practical for unconsolidated tar sands, for which other conventional methods probably would fail. For example, attempts to measure methanol penetration for the Athabasca tar sand lead to sample fragmentation (and loss of some part of the sample) which accounts for the discrepancy with the 
rest of the porosity results, see Table 17. However, very consitent data were obtained with methanol penetration for the Whiterocks tar sand (consolidated).

The data from Tables 13-17 indicate that only for certain tar sands is the pore volume sufficient to contain all the kerosene necessary for bitumen dilution for hot water processing at $50^{\circ} \mathrm{C}$. As discussed earlier, ${ }^{60}$ by limiting the amount of diluent available to the bitumen, the natural tar sand porosity can be a decisive factor in determining the lower limit of the processing temperature. Undigested particles will report to the concentrate or will be found in the tailings, depending on their residual bitumen content, the degree of bitumen dilution, and the bitumen surface characteristics.

\section{CONCLUSIONS}

The natural porosity measurements for consolidated and unconsolidated tar sands can be reliable, assuming that sufficient time is allowed for either methanol penetration or solvent extraction during the measurement. The porosity data determined in such a manner can be used to characterize tar sand with respect to its amenability to hot-water separation. of course, higher natural porosity may also mean greater sensitivity of the mined tar sand to oxidation, which can alter processing efficiency. Rather higher boiling solvents are recommended for the solvent extraction technique. 
FUTURE ACTIVITIES

In the future the tar sand natural porosity will be correlated with the sand particie size distribution and with the rate of bitumen release from tar sand. Considering different methodology, the $x$-ray computer Tomography represents a great opportunity for a detailed study of the tar sand porosity, the distribution of bitumen, water, cementing inorganics and the gas phase in the pores, and may be an excellent tool for tracing migration of the diluent during the pretreatment step of the $U / U$ hot water process. 
FTIR ANALYSIS IN PROCESSING OF TAR SANDS

INTRODUCTION

IR spectroscopy has been used extensively for the characterization of feed and products from the hot water processing of tar sands. In particular, near-infrared diffuse reflectance (NIR-DR) analysis was found to be useful for estimating the amount of bitumen in the Athabasca oil sand, 64 and for optimization of the bitumen hot water extraction process. 65 FTIR analysis, combined with different analytical techniques, allowed for the determination of mineral matter distribution during hot water processing of Utah $\operatorname{tar}$ sands.66 other investigations on Utah tar sands, using FTIR spectroscopy, allowed for the determination of bitumen chemical composition ${ }^{67,68}$ and led to elucidation of the role of chemical composition on the bitumen viscosity. ${ }^{69}$

In our earlier paper 70 it was reported that sand with the intrinsic water left on its surface (dried at $60^{\circ} \mathrm{C}$ for 4 hours) could be easily separated from oil by digestion in an alkaline aqueous phase, while practically no separation occurred when the calcined sand-oil mixture was used. The water layer firmly adsorbed at the silica surface significantly attenuates oil bonding to sand, while considerable surface forces are established under direct silica-oil contact. FTIR spectroscopy may reveal if these strong forces result predominantly from the interaction between oxygen and nitrogen containing functional groups present in the oil phase, and what the role of adsorbed water at mineral particle surfaces may be. 
In this section we are presenting a brief account of our FTIR preliminary work involving microscopic examination of thin bitumen films and the adsorption of bitumen-derived surfactants on a germanium internal reflection element from actual process water.

\section{FTIR MICROSCOPE EXAMINATION OF THIN BITUMEN FILMS}

\section{Experimental Technique}

Recent advances in FTIR microscopy allowed us to focus on single tar sand grains, and, therefore, to alleviate the shortcomings of the diffuse reflectance analysis, strongly influenced by sample preparation. The analysis of single tar sand grains for different tar sand samples was carried out. The samples were examined using Bio-Rad Digilab FTS-40 FTIR spectrometer, equipped with MCT liquid nitrogen cooled detector and coupled with UMA300A Universal Microsampling Accessory (incorporating a diffraction limited $36 \mathrm{X}$ Cassegrainian IR/Visible objective, a turret-mounted $4 \mathrm{X}$ viewing-only objective and 10x eyepieces). Typical samples were single mineral grains $50 \mu \mathrm{m}$ to $500 \mu \mathrm{m}$ in size. Reflection and transmission spectra were recorded at $8 \mathrm{~cm}^{-1}$ resolution using up to 512 scans for both the sample and background. Loose grains, preselected under a Carl zeiss stereo microscope, were placed on a gold plated microscope slide or on a calcium fluorite crystal. Sampling size could be changed from a maximum $250 \mu \mathrm{m}$ down to less than $20 \mu \mathrm{m}$.

Results and Discussion

optical microscope examinations of digested tar sand slurry revealed that some sand particles were still covered completely or 
in part by bitumen. Mechanical entrapment of bitumen in microcracs on the sand surface might be responsible for that. However, bitumen site-specific adsorption seems to be more likely explanation for the observation. Additionally, some air bubbles adhered firmly to sand grains which seemed to be bitumen free.

A newly acquired FTIR microscope has allowed for detalled examination of single tar sand grains for both digested and undigested tar sands. With respect to the digested tar sand slurry, hydrophobic sand particles would report to the bitumen concentrate and diminish the grade, thus lowering the process efficiency. Even when all the bitumen seemed to be removed from these sand grains under an optical microscope, IR microscopic analysis allowed for the identification of certain spots at the sand surface exhibiting organic film and an indication of the chemical nature of the remaining, invisible bitumen residue on the sand grain. Interestingly, the analysis also revealed a noncontinuous bituminous film for some $60 \mu \mathrm{m}$ to $150 \mu \mathrm{m}$ Whiterocks tar sand quartz grains. The observations provide for better understanding of he phenomenon of bitumen displacement from sand, and can be related to the different separation efficiency for tar sand samples acquired from different locations of the Whiterocks deposit.

Several transmission IR spectra of the Whiterocks tar sand single grains are compared in Figure 27 and 28. Please note, that silica is transparent to only $2200 \mathrm{~cm}^{-1}$. In Figure $27 \mathrm{~A}$ spectrum (a) characterizes an actual oil sand grain; spectrum (b) represents the tar sand grain after extraction with toluene, spectrum (c) was 

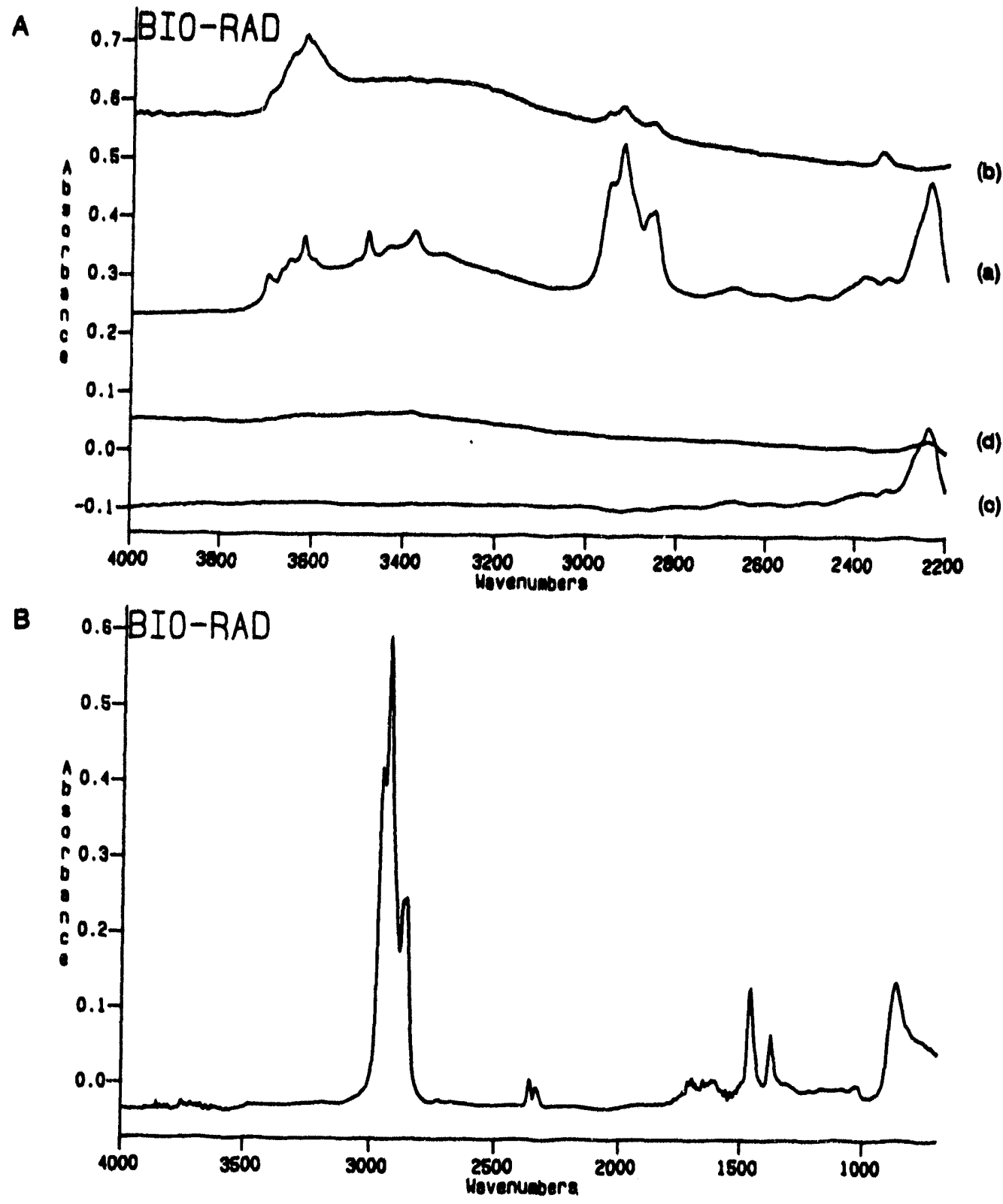

Figure 27. FTIR spectra of Whiterocks oil sand sample. A spectra received under FTIR microscope: (a) an actual oil sand grain; (b) oil sand grain after extraction with toluene; (c) roasted oil sand grain, $550^{\circ} \mathrm{C}, 5$ hours; (d) beach quartz sand washed with deionized water. B - IR spectrum of bitumen extracted from oil sand with toluene and dissolved in $\mathrm{CCl}_{4}$ 


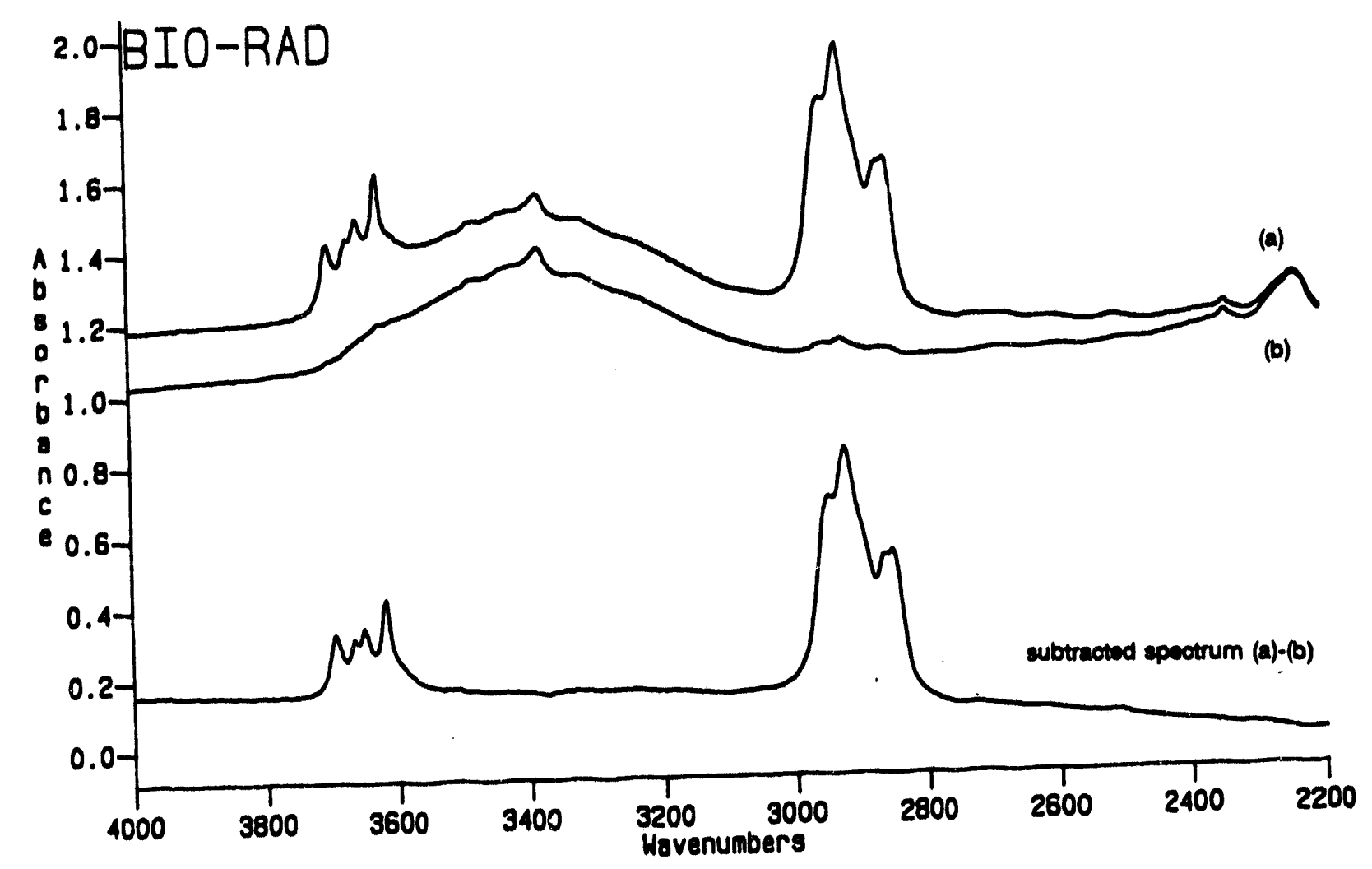

Figure 28. FTIR microscope spectra of an organic film on a 150 $\mu \mathrm{m}$ sand grain acquired from digested Whiterocks oil sand slurry: (a) $20 \mu \mathrm{m}$ sampling on a
(b) $20 \mu \mathrm{m}$ sampling on "clean" surface 
taken for roasted grain at $550^{\circ} \mathrm{C}$ for 5 hours, while spectrum (d) was taken for a beach quartz sand washed thoroughly with deionized water. spectrum in Figure $27 \mathrm{~B}$ is of bitumen extracted from the tar sand by toluene. Toluene was evaporated and the residue was dissolved in $\mathrm{CCl}_{4}$ and subsequently submitted to IR analysis. Another spectra of a single tar sand grain after hot water digestion are presented in Figure 28 . In this case, two locations of different appearance were sampled on a single grain: a brown ("rusty") spot and a clear surface. Hot water digestion was as effective in removal bitumen from sand surface as the toluene extraction, with exception of the "rusty" spot which appeared to be bitumen associated with clay minerals.

ADSORPTION/DESORPTION OF BITUMEN-DERIVED SURFACTANTS USING INTERNAL REFLECTION FTIR SPECTROSCOPY

Experimental Procedure

Internal Reflection Spectroscopy was utilized in two kinds of cells (Harrick scientific Corporation): the ILC-soo flow-through cell with a $10 \mathrm{~mm}$ dia. cylindrical germaniurn element, $60 \mathrm{~mm}$ in length, and the MEC-000 liquid cell with a germanium $50 \mathrm{~mm} \times 10 \mathrm{~mm}$ $x 1 \mathrm{~mm}$ plate element. Proper design of these cells eliminates spurious bands caused by optical sampling of the gaskets. The ILCsoo cell was used to monitor natural surfactant adsorption from an actual process water. In this regard, $50 \mathrm{~g}$ sample of the Asphalt Ridge or the Athabasca tar sand was placed in $500 \mathrm{~mL}$ of $1.3 \cdot 10^{-3} \mathrm{M}$ $\mathrm{Na}_{2} \mathrm{CO}_{3}$ solution $(\mathrm{pH}=10)$ at $50^{\circ} \mathrm{C}$ and submitted to stagnant digestion for 24 hours. The aqueous phase was periodically pumped 
through the IRS cell and after certain equilibration time IR spectra were recorded. The scanning was repeated throughout the entire digestion time in one to six hour intervals.

In another approach the germanium plate was covered with approximately $0.3 \mu \mathrm{m}$ thick bitumen film by immersion in 0.85 wt. 8 bitumen solution in toluene and subsequent toluene removal in the air and/or vacuum. Next, only the bitumen film in the central part on each side of the plate was left, i.e., $5 \mathrm{~mm} \times 42 \mathrm{~mm}$ bitumen strips to be in contact with the aqueous phase, while the rest of the bitumen was thoroughly removed. The germanium crystal was then placed in the cell, the cell was filled with $1.3 \cdot 10^{-3} \mathrm{M} \mathrm{Na}_{2} \mathrm{CO}_{3}$ solution $(\mathrm{pH}=10)$ and the bitumen was submitted to stagnant digestion for several days at $50^{\circ} \mathrm{C}$. The IR spectra were recorded in one hour intervals.

\section{Results and Discussion}

We were very disappointed to find that no surfactant was adsorbed on the germanium rod, even when the equilibration time was extended well over 30 minutes. Later it was discovered that surfactants initially adsorbed on the IRE, however, with progressing of the equilibration time competitive adsorption of other species (apparently inorganic) displaced the surfactants, which is evident from the weakening of the $\mathrm{C}-\mathrm{H}$ stretching peaks. These peaks disappeared almost entirely after 30 minutes. See Figure 29. This phenomenon seems to be independent of the $\mathrm{pH}$ in the range $\mathrm{pH} ?-10$. 


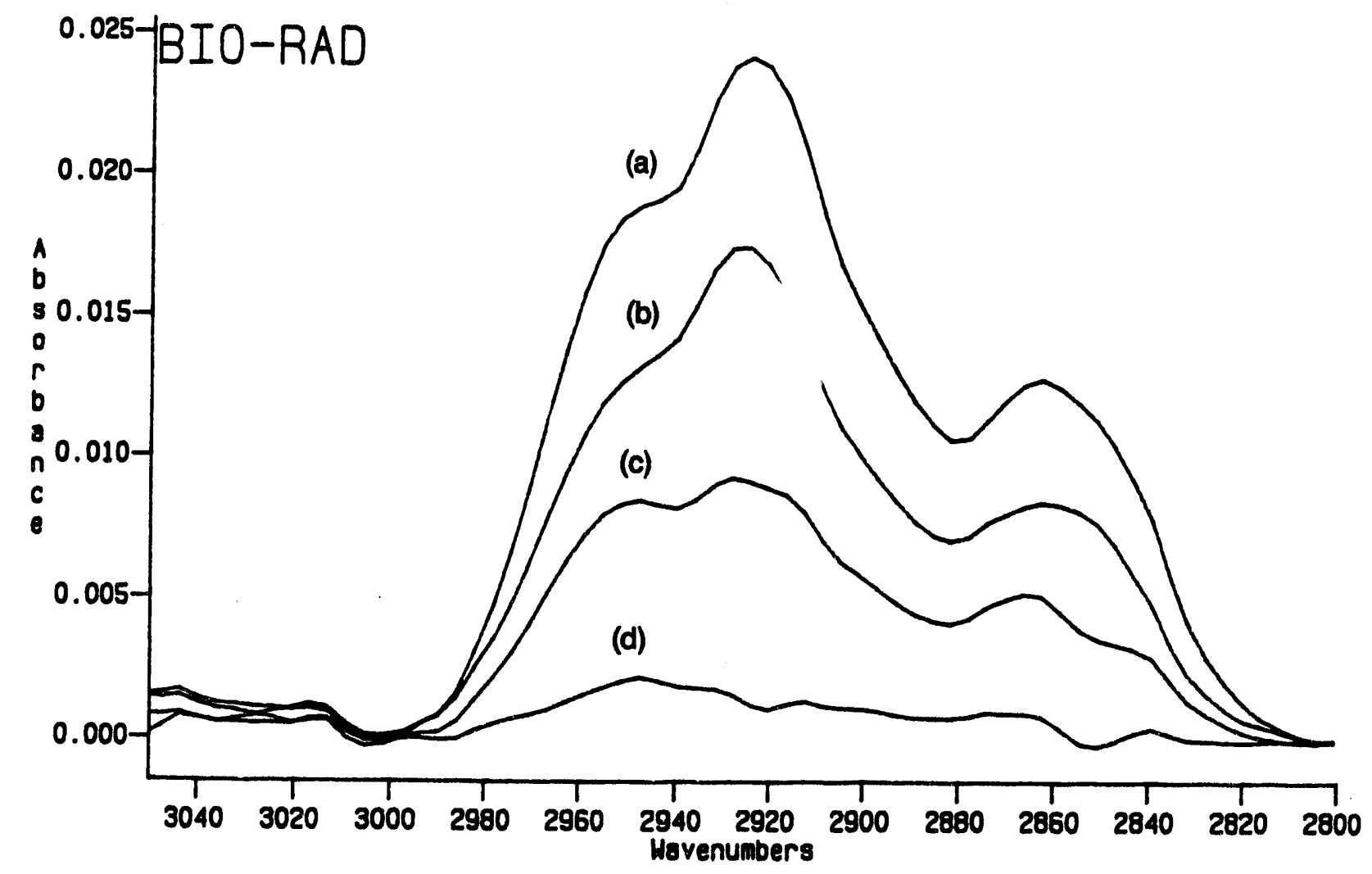

Figure 29. FTIR spectra of organic substances adsorbed on germanium IRE submerged in Asphalt Ridge oil sand process water. Equilibration time: (a) 5 min; (b) $10 \mathrm{~min}$; (c) $20 \mathrm{~min} ;$ (d) $30 \mathrm{~min}$ 
Other experiments involving surfactants were performed with the flat germanium crystal covered by a bitumen film. The spectra after a several hour sequence are presented in Figure 30. Judging from the peak intensity for water and that for the $\mathrm{C}-\mathrm{H}$ stretching frequency, the bitumen was displaced from the crystal exposing more surface to the aqueous phase. Future experiments will involve bitumen displacement rate studies using different digestion conditions and different tar sand samples.

\section{CONCLUSIONS}

The FTIR spectroscopy was successfully used for the examination of single tar sand grains allowing better understand the sand-bitumen-bubble interactions, which finally decide about the hot water processing efficiency. A preliminary investigation of the in situ surfactant adsorption on a germanium IRE using tar sand process water revealed the complexity of the process and the need for better understanding of the role of surfactants in wetting phenomena controlling the hot water process.

\section{FUTURE ACTIVITIES}

The FTIR spectroscopy will be used, in combination with other analytical techniques, such as the contact angle measurements at the surface of bitumen and quartz, electrophoretic mobility, microcalorimetry, and the atomic force microscopy to correlate the degree of hydration of the sand surface at the time of contact with oil with the efficiency of the oil-sand separation process. 


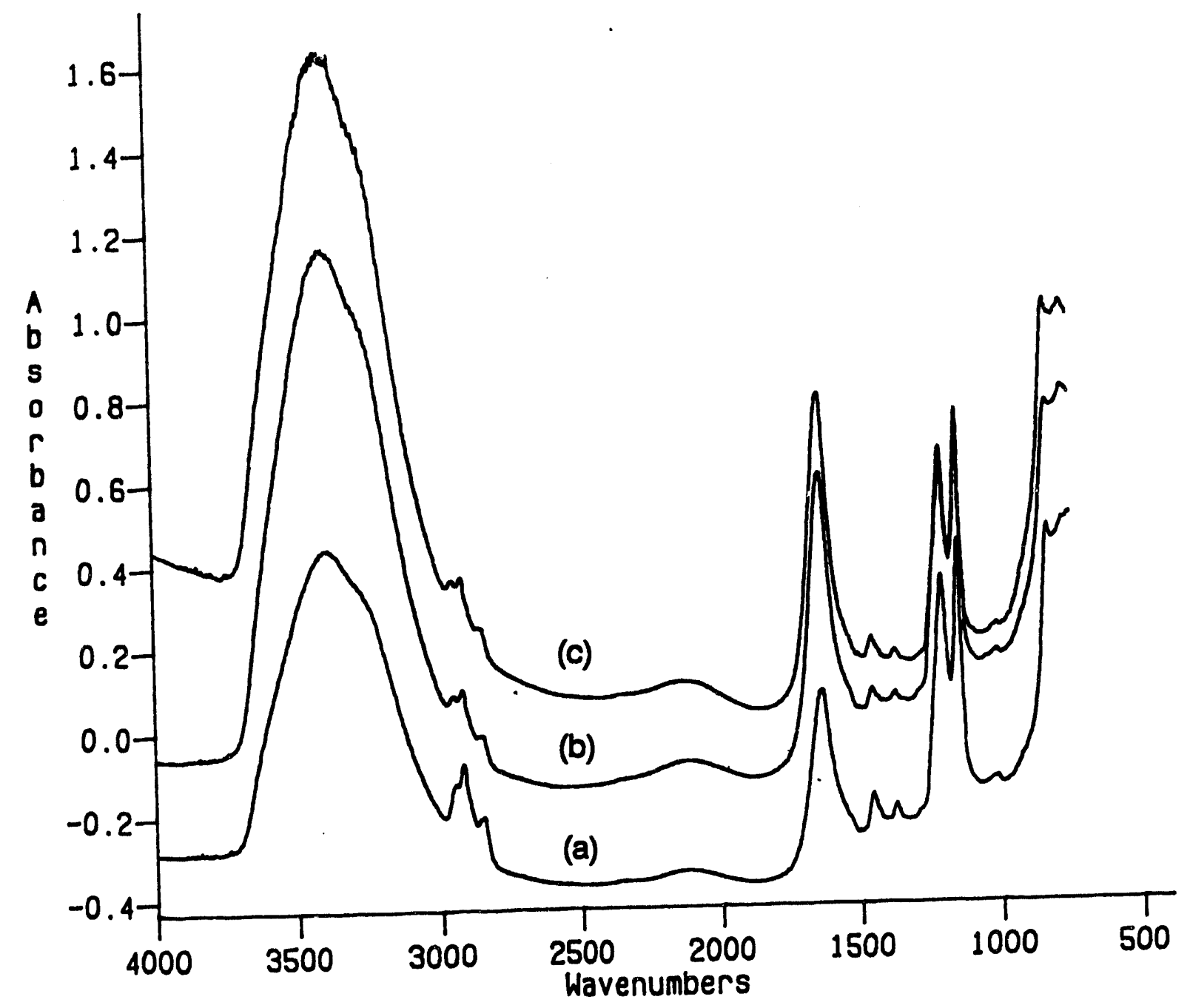

Figure 30. FTIR spectra of Asphalt Ridge bitumen film on germanium IRE digested in an alkaline solution 
NEW SEPARATION CELL FOR BITUMEN RECOVERY FROM TAR SAND SLURRY

\section{INTRODUCTION}

Bitumen recovery from tar sands by water-based surface processing is accomplished in two main stages: digestion and separation of phases. In the last three years conditions have been identified which allow for low shear digestion and for gravity separation of the bitumen concentrate. Up until this most recent effort bitumen recovery had been limited to traditional flotation technology. Now by controlled surface chemistry it is possible to produce high grade bitumen concentrates (up to $90 \%$ bitumen at $>90 \%$ recovery from Asphalt Ridge tar sand) by gravity separation. Such bitumen concentrate quality is not possible by traditional flotation technology. Thus gravity separation has been incorporated in the tar sand processing strategy for domestic tar sands.

Two approaches have been adopted for bitumen separation from digested tar sand slurry:

1. bitumen concentrate separation in a gravity cell followed by flotation of middlings and rejection of coarse sand to the tailings pond, as practiced in both commercial plants in Alberta, Canada. This strategy allows for a significant reduction in the volume of the process stream right after gravity separation.

2. bitumen concentrate separation in a gravity cell followed by flotation of the entire tar sand slurry, as proposed for processing of Utah tar sands, in order to maximize bitumen 
recovery to the concentrate and minimize bitumen (and diluent, if applied) loss with the spent sand.

While digestion requires only 25-30 wt. $\%$ of the aqueous phase, the separation stage is carried out in diluted tar sand suspension in order to enhance bitumen liberation from the slurry. Thus, with a reduced amount of solids (e.g., $50 \mathrm{wt}$. for gravity separation and 20 wt. \& for flotation), the volume of the tar sand slurry increases several times with respect to that during digestion which weighs heavily on the economy of the process.

In this regard, the design of a new gravity separation vessel has been proposed, but first a more detailed analysis of the bitumen gravity concentrate is presented.

\section{Basic Considerations}

Gravity separation is the simplest technique to separate the bitumen from digested tar sand slurry. In order to make the gravity separation successful one has to assume that bitumen is displaced from sand, forms relatively large droplets, and has a density sufficiently lower than that of the aqueous phase. The beneficial influence of sodium tripolyphosphate on the process has to be stressed here as discussed in last year's report. ${ }^{71}$ sodium tripolyphosphate as a chelating agent for polyvalent ions present during tar sand digestion not only facilitates bitumen displacement from sand but also enables much better aeration of the bitumen. Gravity separation has been applied in laboratory experiments, and in both commercial operations in Alberta for processing Athabasca tar sands with recoveries exceeding $80 \% .{ }^{72}$ Flotation of 
middlinrs, following the gravity separation, accounts for only 108 of the bitumen recovered in the hot water separation process.

Even high-grade bitumen concentrates still contain from 5 to 20 wt. $q$ of fine minerals, and additionally various amounts of process water. The necessary buoyancy in the gravity cell has to be provided by the gas phase - in part by the intrinsic gas from the tar sand pores, but predominantly air intercepted during digestion. Assuming the bitumen concentrate composition 50 wt. $\%$ oil (of density close to that of the aqueous phase), 25 wt. \& mineral particles (density $2500 \mathrm{~kg} / \mathrm{m}^{3}$ ) and $25 \mathrm{wt}$. \% water, the required volume of air is $30 \mathrm{vol}$. \& to provide $80 \mathrm{~kg} / \mathrm{m}^{3}$ density difference between the bitumen concentrate and the aqueous phase. It should be noted that density differences of $80 \mathrm{~kg} / \mathrm{m}^{3}$ is recommended as a minimum density difference required for effective phase separation in a gravitational field. ${ }^{73}$ As the solids content in the bitumen concentrate increases, the amount of required air should also increase, compare Table 18.

\section{Experimental Verification of Gas Phase Content in the Bitumen Concentrate}

Several hot water experiments, using Asphalt Ridge and Whiterocks tar sands, were carried out to correlate bitumen recovery in the gravity cell with the air/gas content in the bitumen phase. The bitumen concentrate was skimmed from the gravity cell and placed in graduated cylinders. The cylinders were kept in a water bath at $80^{\circ} \mathrm{C}$ for the separation of air bubbles until the volume did not change. The difference between the 
Table 18. Volume Percent of Air Necessary for Bitumen Concentrate Separation in Gravity Cell

Assumptions :

Density of bitumen with 15 wt. $\%$ kerosene:

Density of aqueous phase during digestion

and gravity separation:

Density of fine mineral components

$950 \mathrm{~kg} / \mathrm{m}^{3}$

$1000 \mathrm{~kg} / \mathrm{m}^{3}$

$2500 \mathrm{~kg} / \mathrm{m}^{3}$

Percent Minerals Density of Concentrate Volume of Air in in Concentrate * without Air wt. \& $\mathrm{kg} / \mathrm{m}^{3}$

\&

\begin{tabular}{rll}
5 & 1028 & 11 \\
1.0 & 1105 & 17 \\
15 & 1183 & 22 \\
20 & 1260 & 27 \\
30 & 1415 & 35 \\
40 & 1570 & 41 \\
50 & 1725 & 47 \\
\hline
\end{tabular}

** ary basis

** resulting in bitumen concentrate density $920 \mathrm{~kg} / \mathrm{m}^{3}$

original and the final volume of the bitumen concentrate makes the gas phase volume. It was found, that the gravity cell operated successfully only when the bitumen concentrate contained an adequate volume of entrapped air, as has been suggested from the calculations presented in Table 18. The results from this study very clearly showed the importance of gas phase entrapment for efficient bitumen separation in a gravity cell.

\section{llew Cell}

Based on our surface chemistry research, a new cell design, combining gravity separation and flotation, for bitumen recovery from digested tar sand slurry has been proposed. The cell comprises an inclined U-shaped tank, divided into three sections, 
and a shaft at the bottom for stirring and transport of the sand, as shown in Figure 31. In sections one and two the shaft is furnished with a ribbon screw or paddles which provide turbulence to prevent settling of the tailings. In section three the shaft serves as a screw conveyer moving tailings toward the spiral classifier dump - for final removal of the settled sand. Steam, containing $0.1 \%$ air, may be injected in section one. The second section serves as a dissolved/dispersed air flotation cell, with an flowrate $0.1 \mathrm{~L} / \mathrm{min} \cdot \mathrm{L}$.

For certain processing schemes, e.g., when the residual bitumen is scavenged in an air-sparged hydrocyclone, 74 the section serving for flotation can be excluded; therefore, the separation cell will consist only of two sections. The bitumen can be removed from each section by a paddle skimmer, however, steel belt adhesive skimmers are preferable in section one and two. Adhesive skimmers will provide bitumen of superior quality to that obtained with other skimmers. The bitumen viscosity of $0.1-1.5 \mathrm{~Pa} \cdot \mathrm{s}$, maintained during tar sand digestion and separation of phases in the University of Utah modified, diluent-assisted hot water process, provides maximum efficiency for the adhesive skimmer.

The average solids concentration throughout the cell is equal to 25-30 wt. $\%$, however, two zones of different solids content may be distinguished. The bottom zone directly adjacent to the shaft will have solids concentration of 50-55 wt. $\%$, while a much lower solids content will be found in the subsurface layer. The residence time of the tar sand slurry in the separation cell is 


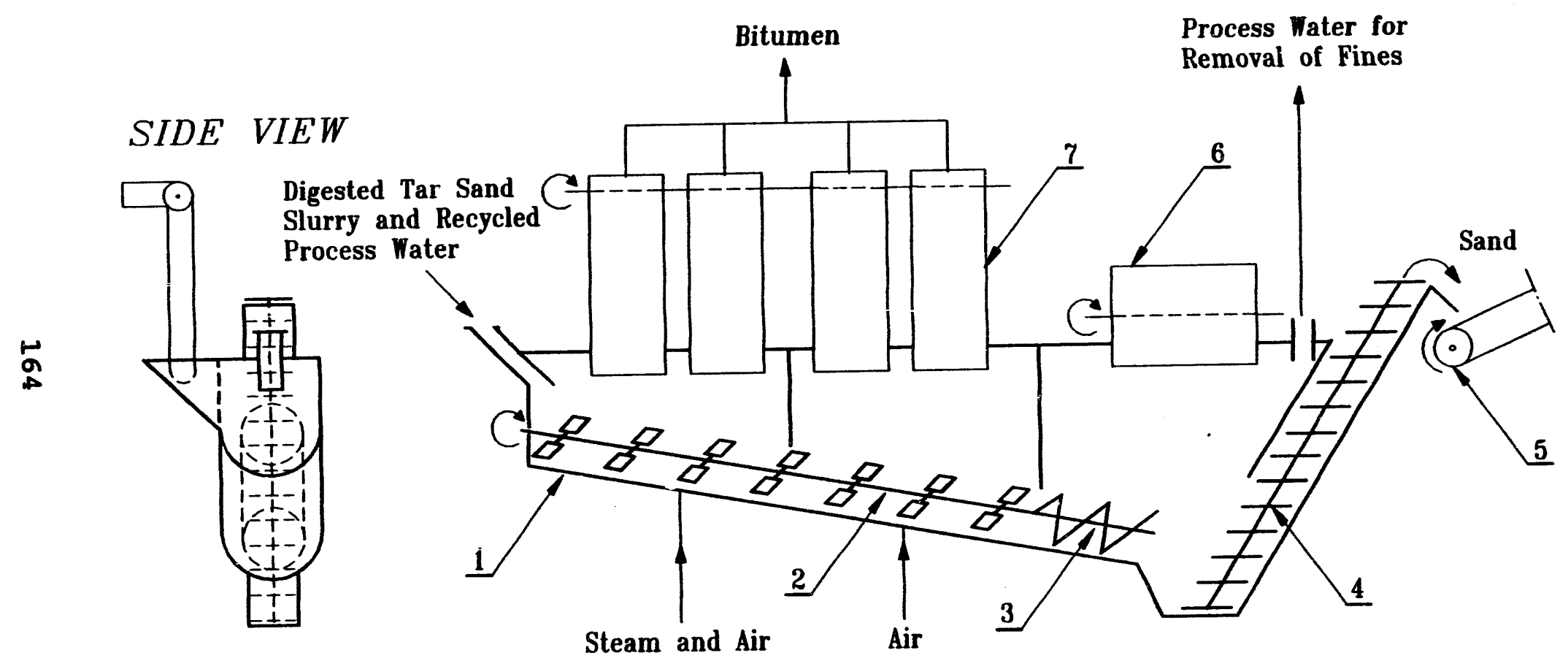

Figure 31. Schematic of a separation cell for bitumen recovery from digested tar sand slurry. 1-steel/concrete casing; 2-shaft with paddles; 3-screw conveyor: 4-spiral classifier; 5-belt conveyor; 6-paddle skimmer; 7-adhesive skimmer 
expected to be 3 to 5 minutes, and the processing temperature $55-60^{\circ} \mathrm{C}$.

The cell is designed for total removal of bitumen which has undergone successful separation from sand particles during digestion and exists in the tar sand slurry as discrete droplets, see photographs in Figure 32 .

The digested tar sand slurry is fed, together with recycled process water, to the first section of the cell. sufficiently aerated bitumen separates rapidly and smaller droplets, which might get entrapped in the sand, report also to the concentrate. Very fine droplets, less than $100 \mu \mathrm{m}$ and without entrapped air, can be floated to the surface in the second section. Dispersed-air flotation, resulting in small air bubbles and low air flowrates, is preferable in order to limit the flotation of fine mineral particles. ${ }^{71}$

\section{FINAL COMMENTS}

In the last three years conditions have been identified which allow for low shear digestion and for gravity separation of the bitumen concentrate. Up until this most recent effort bitumen recovery had been limited to traditional flotation technology. Thus gravity separation has been incorporated in the tar sand processing strategy for domestic tar sands. In this regard, the design of a new gravity separation vessel has been proposed, based on our surface chemistry research. A more detailed analysis of the bitumen gravity concentrate is also presented. The cell 
A

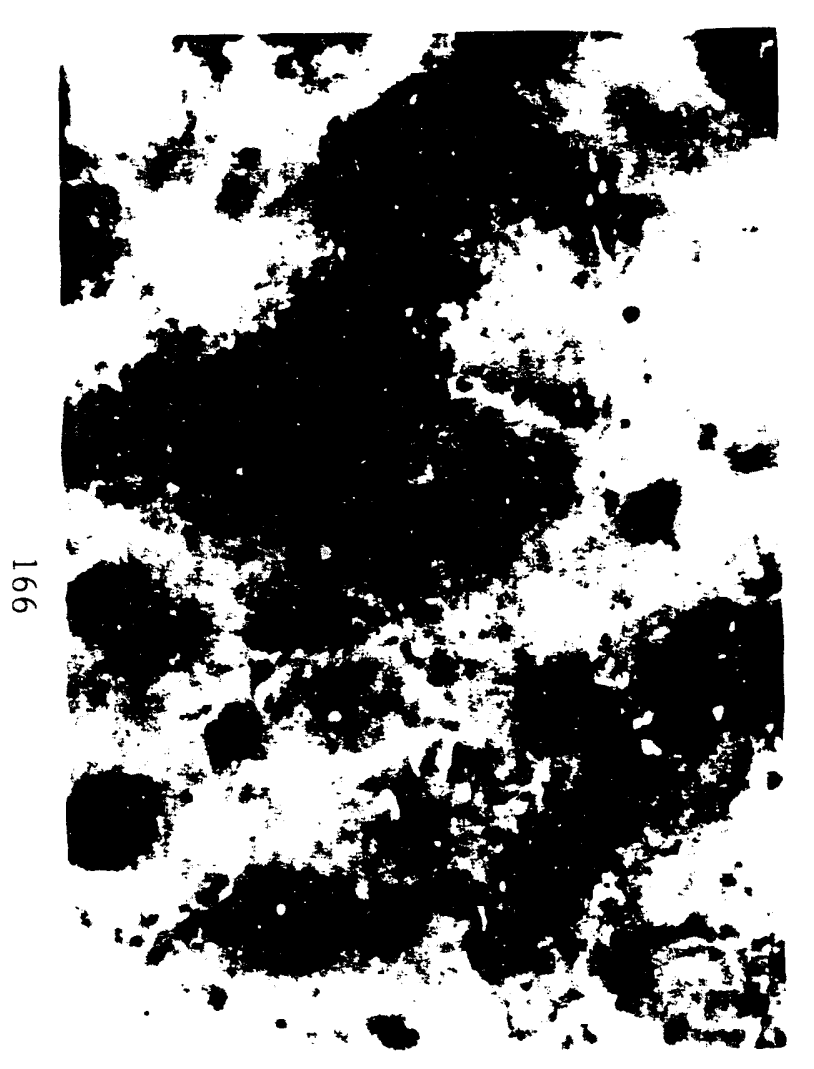

B
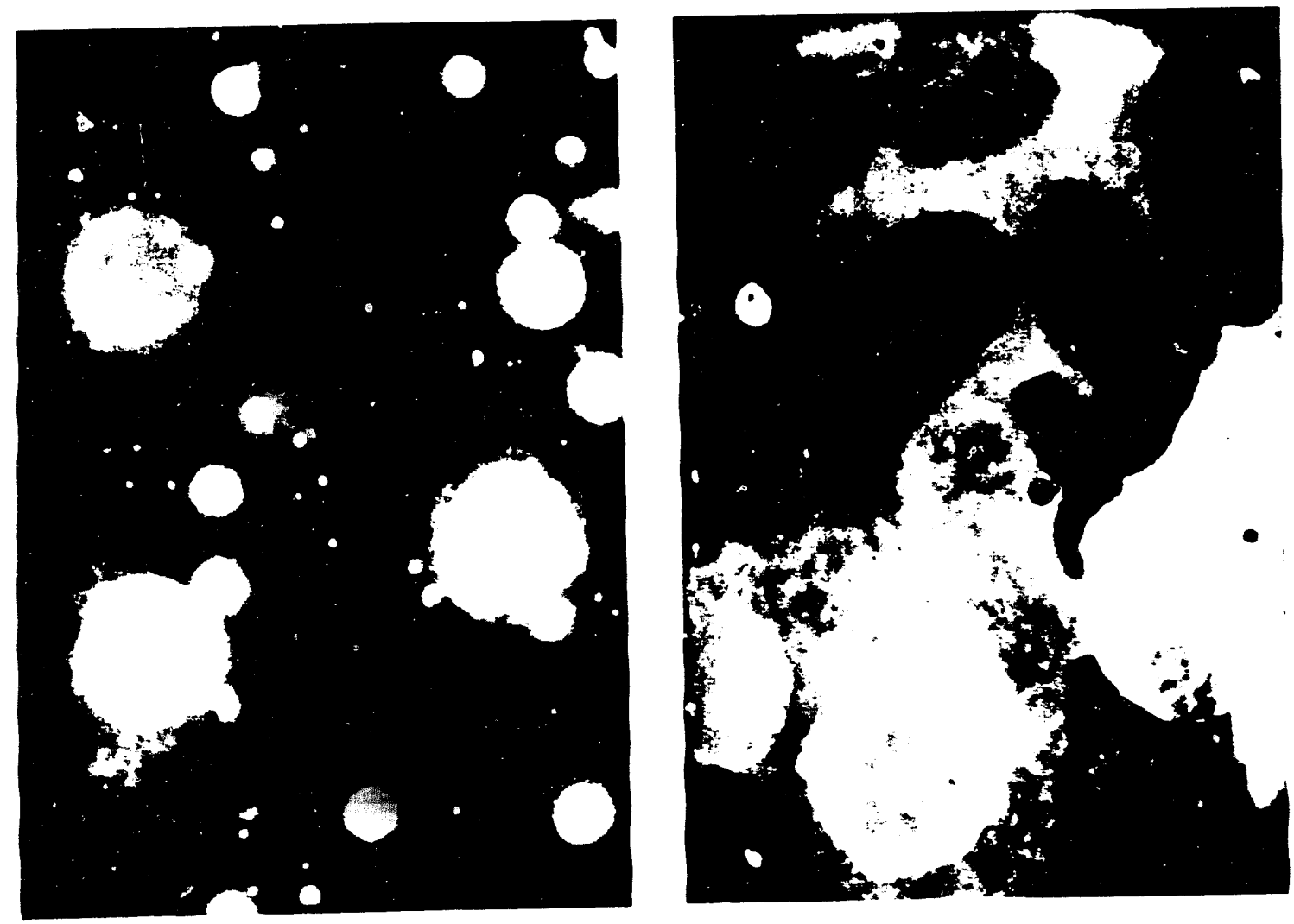

Figure 32 .

Microscopic photographs of digested oil sand slurry. A-Whiterocks oil sand slurry from under zeiss stereo microscope. B-Whiterocks oil sand slurry from zeiss fluorescent microscope; C-Bitumen droplet entrapped in Asphalt Ridge tailings, as viewed under Zeiss stereo microscope 
construction and amenability tests will require operation of a 50 bpd pilot plant in which case performance characteristics will be established.

FUTURE ACTIVITIES

Future research will incorporate both the construction and the experimental evaluation of the new cell design including performance of the adhesive, stainless steel belt skimmer. However, a continuous supply of tar sand tailings must be available, which can be provided either after refurnishing the 50 bbl/day North Salt Lake Tar Sand Pilot Plant or after acquiring a mobile tar sand processing unit capable of handling 100 to 2001 bs of tar sand per hour. 
WATER RECYCLE IN MODERATE-TEMPERATURE BITUMEN RECOVERY FROM WHITEROCKS TAR SANDS

\section{INTRODUCTION}

Surface-mining and recovery methods and/or in-situ technology can be used to recover hydrocarbon values from oil sand deposits. Although in-situ technology has been successfully applied to low viscosity bitumens in Alberta, Canada, ${ }^{76}$ such an application to Utah's tar sands has not been successful. 77 This means that surface-mining recovery processes may be the only viable methods for the high viscosity Uinta Basin oil sands, at the present time. The Canadian hot-water process is based on the pioneering studies of clark. ${ }^{78}$ The extraction of bitumen from Athabasca oil sands is accomplished by a hot water, $358 \mathrm{~K}$, separation process in rotating drums. Caustic soda is added to adjust the alkalinity in digestion step.

The modified water-based process developed for Utah's oil sands requires a moderate digestion temperature $\left(323\right.$ to $333 \mathrm{~K}$ ). ${ }^{79}$ However, a pretreatment step which involves kerosene addition to the oil sand is necessary to reduce the bitumen viscosity below 1.5 $\mathrm{Pa} \cdot 5$. The alkalinity of the aqueous phase is adjusted ( $\mathrm{pH}=8.0$ to $9: ;$ with sodium carbonate $\left(\mathrm{Na}_{2} \mathrm{CO}_{3}\right)$ and sodium tripolyphosphate $\left(\mathrm{N}{ }_{5} \mathrm{P}_{3} \mathrm{O}_{10}\right)$ is added to facilitate bitumen disengagement. The digestion temperature is maintained in the range of 323 to $333 \mathrm{~K}$. After several minutes of digestion, the slurry is discharged into a gravity separation cell and diluted with water. The bitumen concentrate is skimmed and the slurry is transferred to a flotation 
cell to recover the residual bitumen. The coarse solid particles are screened, and the tailings are subjected to sedimentation for 20 minutes. Finally, the tailings water is recycled to the digestion reactor. The bitumen concentrate requires fines and water cleanup before utilization and/or upgrading.

The disposal of the tailings, produced in the hot water process, has been a major problem affecting the cost of bitumen recovery. In the Canadian plants, tailings water is recycled when the fine particles content does not exceed 2 wt. 8.80 Laboratory experiments demonstrated that a recycled aqueous phase containing 4 to 5 wt. \& suspended matter had no deleterious effect on the separation efficiency of the process, with the whiterocks oil sand. 81

The objective of the present work was to continue the previous investigation ${ }^{81}$ on the impact of water recycle on the separation efficiency of the moderate-temperature water-based recovery process when $\mathrm{Na}_{5} \mathrm{P}_{3} \mathrm{O}_{10}$ is used to facilitate bitumen disengagement. The purpose of $\mathrm{Na}_{5} \mathrm{P}_{3} \mathrm{O}_{10}$ addition was to counter the eventual detrimental effects of polyvalent cations on bitumen separation and to increase the effectiveness of surface-active compounds at the bitumen-water interface. The recycle stream consisted of tailings water from the flotation cell. The fine particles were allowed to settle for 20 minutes in a sedimentation tank before the decanted water was recycled. The process water from the bitumen concentrate cleanup, which comprised less than $5 \%$ of the total recoverable water, was 


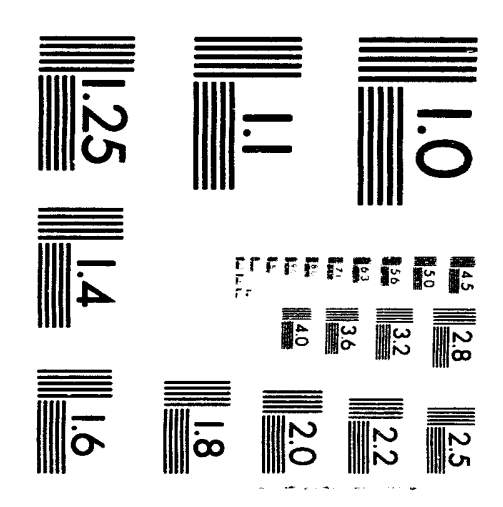



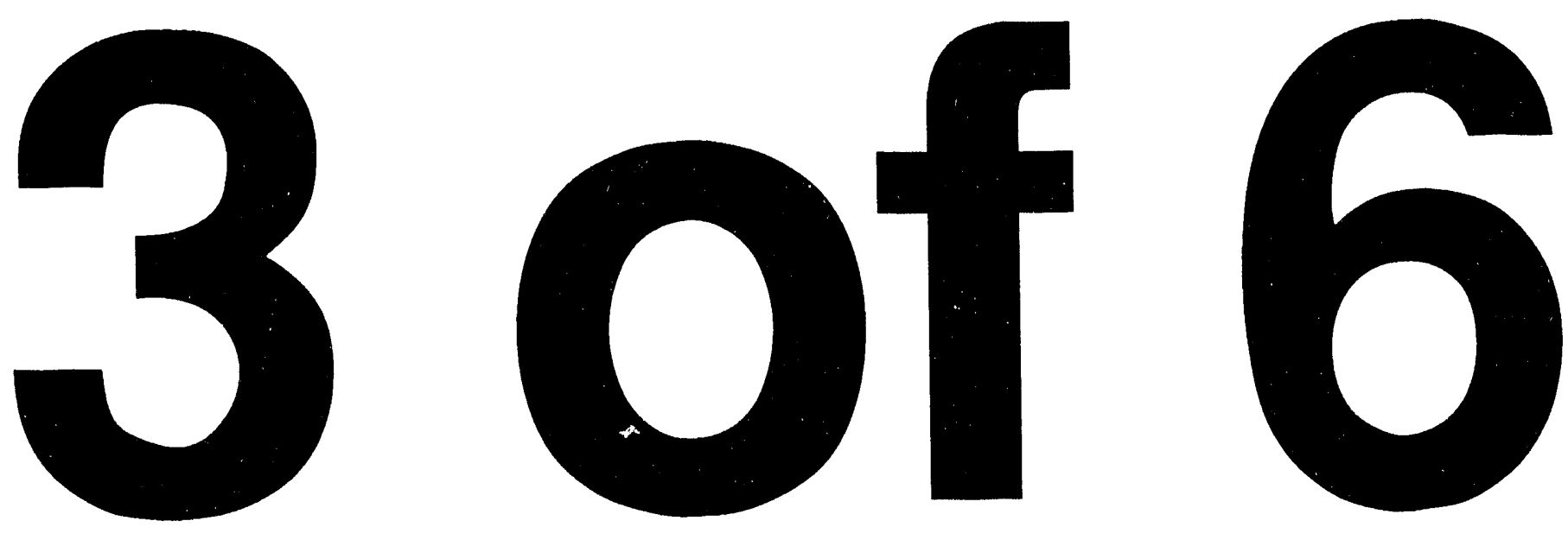
discarded. The mined and crushed material from the whiterocks oil sand deposit was used in all experiments.

\section{EXPERIMENTAL PROCEDURES}

oil sand samples from the West-Central location of the Whiterocks oil sands deposit (5.8 wt. \& bitumen) were crushed, screened, and pretreated with kerosene according to a procedure described previously. ${ }^{79}$ Mineralogical analyses of solids from the Whiterocks oil sand have been reported by Bukka et al. ${ }^{82}$ Also, the analyses and composition of the Whiterocks bitumen have also been reported by Bukka et al. ${ }^{83}$ A schematic of the moderate-temperature water-based process for bitumen recovery is presented in Figure 33 . The major steps of the process include: diluent pretreatment, digestion (A), gravity separation (B), flotation (C), and sedimentation (D).

Batch aqueous digestion experiments $(328-333 \mathrm{~K})$ were conducted in a baffled stirred-tank reactor ( $A, 3.8$ liters) equipped with a double blade turbine impeller. The concentration of oil sand ore in the digester was 75 wt. $\%$. The aqueous phase alkalinity was adjusted with $\mathrm{Na}_{2} \mathrm{CO}_{3}\left(1 \mathrm{~g} / \mathrm{kg}\right.$ oil sand ore); and $\mathrm{Na}_{5} \mathrm{P}_{3} \mathrm{O}_{10}(\mathrm{lg} / \mathrm{kg}$ oil sand ore) was added to improve the bitumen disengagement. After 5 minutes the digested slurry was discharged into a gravity separation cell (B) and diluted with water (323 K, $40 \mathrm{wt}$. \% solids) for gravity separation of the solids. The system was gently stirred and 2 to 3 minutes were allowed for sedimentation. The bitumen concentrate was then skimmed from the surface of water. Batch 


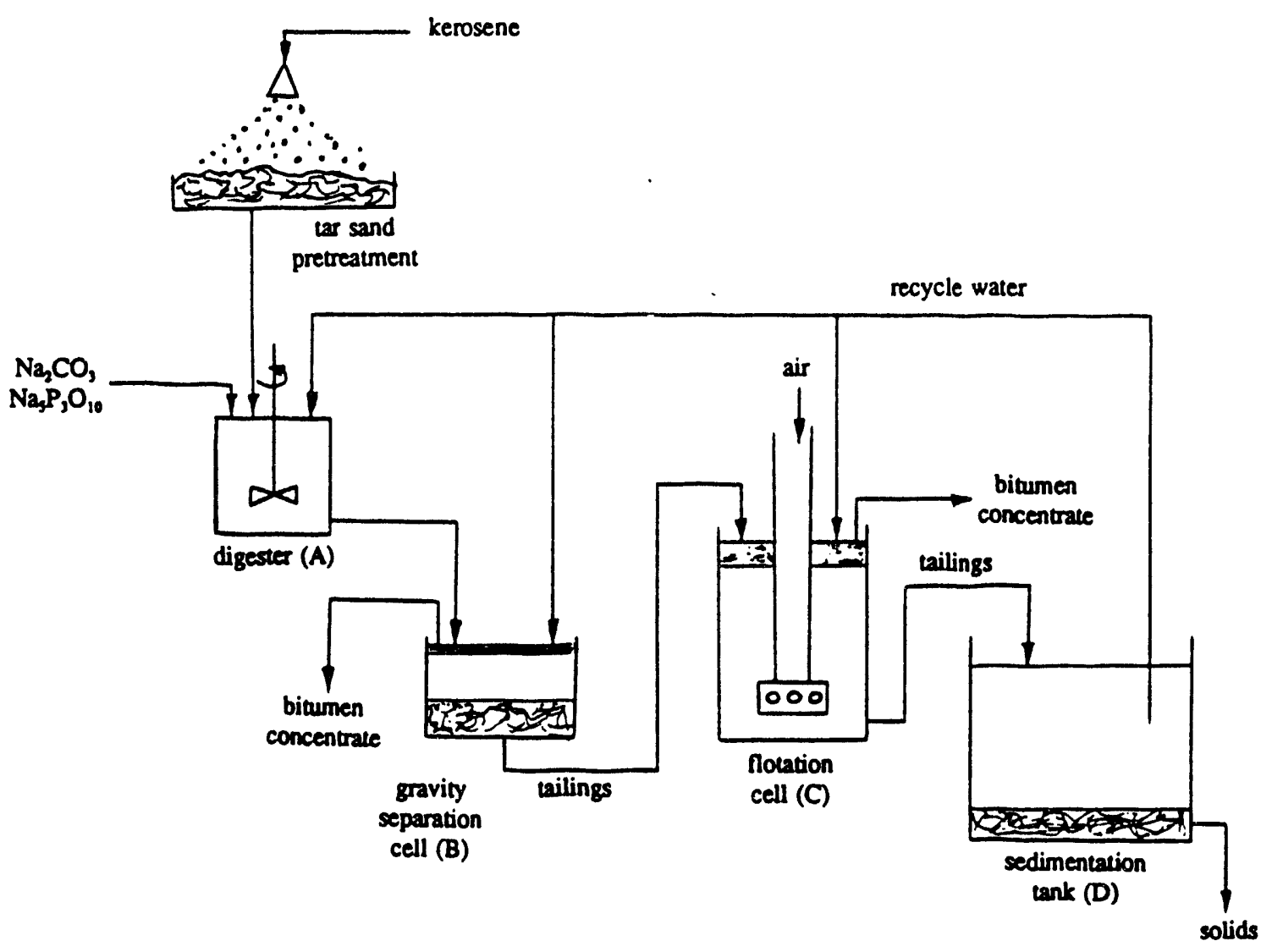

Figure 33. Schematic of moderate-temperature bitumen recovery process 
flotation (15 wt. $\%$ solids) in a Denver-type air sparged flotation cell (C, 38 liters) followed gravity separation. The air flow rate was 5 liters per minute. The bitumen concentrate was skimmed and collected at 2-minute intervals and the concentrate and aqueous phase were retained for analysis. The tailings were placed in a 40-liter sedimentation tank (D) where the entrained solids were allowed to settle-out after each run. The supernatant liquid was syphoned after 20 minutes and recycled to the digestion reactor (A), the gravity separation cell (B), and the flotation cell (C). The same amounts of the two reagents, $\mathrm{Na}_{2} \mathrm{CO}_{3}$ and $\mathrm{Na}_{5} \mathrm{P}_{3} \mathrm{O}_{10}$, were added in each of the seven cycles. Tap water was used in the first experiment whereas recycled water was used in each subsequent experiment. Eight percent makeup tap water was added to the flotation cell (C) in the second and third cycles to compensate for losses. In each run the aqueous phase was sampled for subsequent analysis.

The composite bitumen concentrate samples were subjected to Dean-Stark toluene extraction for the determination of solids and bitumen content. The analyses of the aqueous phase included electrophoretic mobility (Zetasizer 3, Zeta Meter Inc., New York), $\mathrm{pH}$ and specific conductivity (pH/conductivity meter; ICM, Hillsboro, U.S.A.), and surface tension (Digital-Tensiometer K1OT; KRUSS GmbH, Germany) measurements. Fine particles were removed from aqueous phase samples by centrifugation before $\mathrm{pH}$, specific conductivity, and surface tension measurements. A zeiss stereo 
microscope was used to investigate the mechanism of bitumen disengagement from the sand particles.

RESULTS

Bitumen Recovery

Bitumen recovery increased in each subsequent experiment with the recycled water, Figure 34 , and attained a maximum value of 99.8 wt. $\%$ in the fifth cycle. A slight decrease in the separation efficiency was noticed in the sixth and seventh cycles; nevertheless, the bitumen recovery was still satisfactory (92-93\%). Fifty to $70 \%$ of the recovered bitumen concentrate was obtained in the gravity separation cell (B).

The bitumen concentrate from the gravity separation cell (B) contained 19-25 wt. \& solids and 23-39 wt. \& water, as well as air bubbles, which provided the necessary buoyancy to float the concentrate. The froth from the flotation cell contained 29-50 wt. $\%$ solids and 24-50 wt. \& water. Water and solids can be removed from a kerosene-diluted concentrate by sedimentation and/or centrifuging to produce a bitumen co centrate containing 5 wt. $\%$ water and 0.1 wt. $\%$ solids. ${ }^{84}$

A constant weight percent of solids was observed in the gravity separation cell concentrate (Figure 35). The concentration of solids in the flotation cell froth decreased monotonically after the second cycle (Figure 35). The water content of the batch flotation concentrates depended upon the concentrate handing procedures; therefore, the data may not be representative for process design applications. 


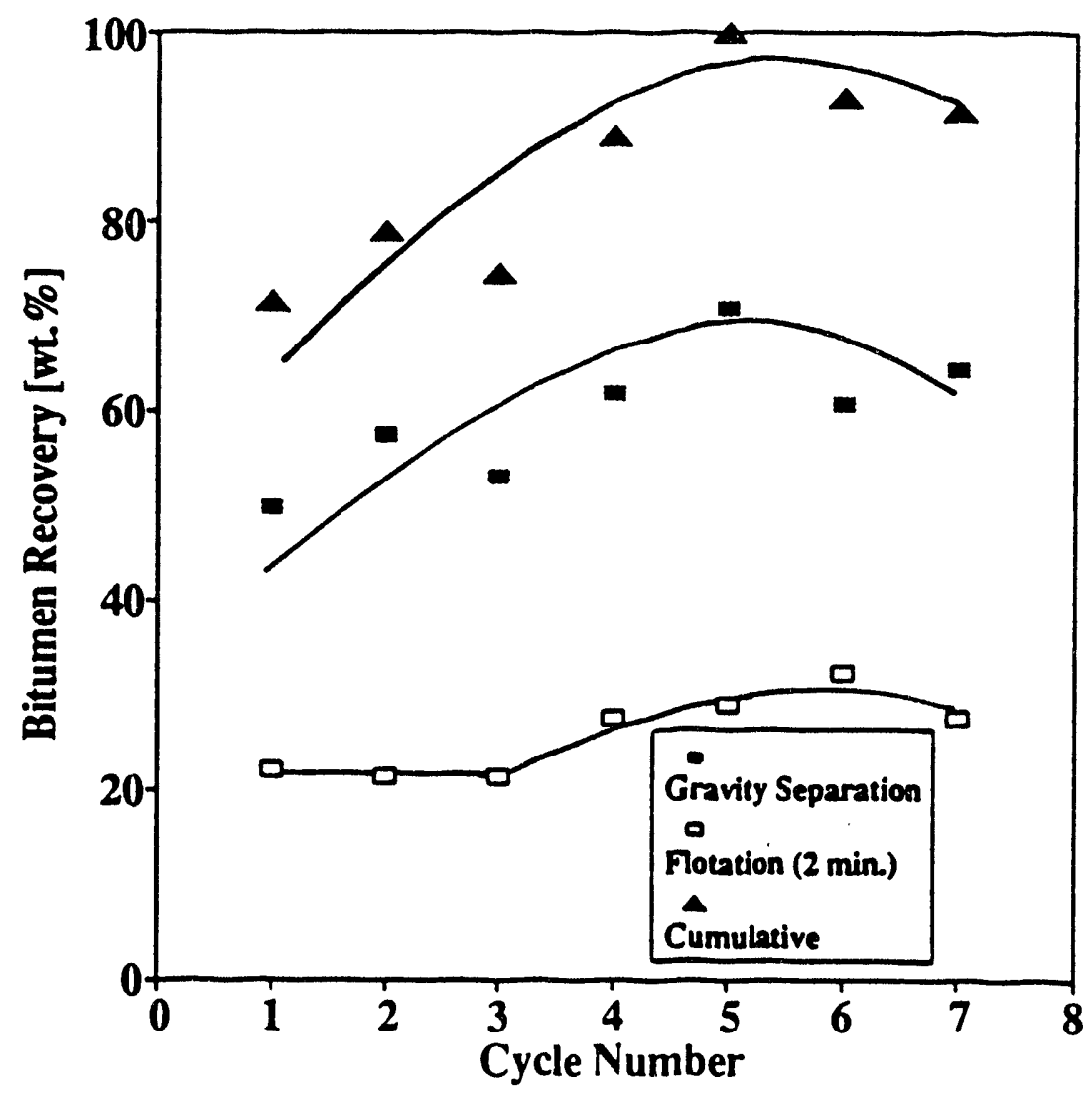

Figure 34. Bitumen recovery as a function of cycle number 174 


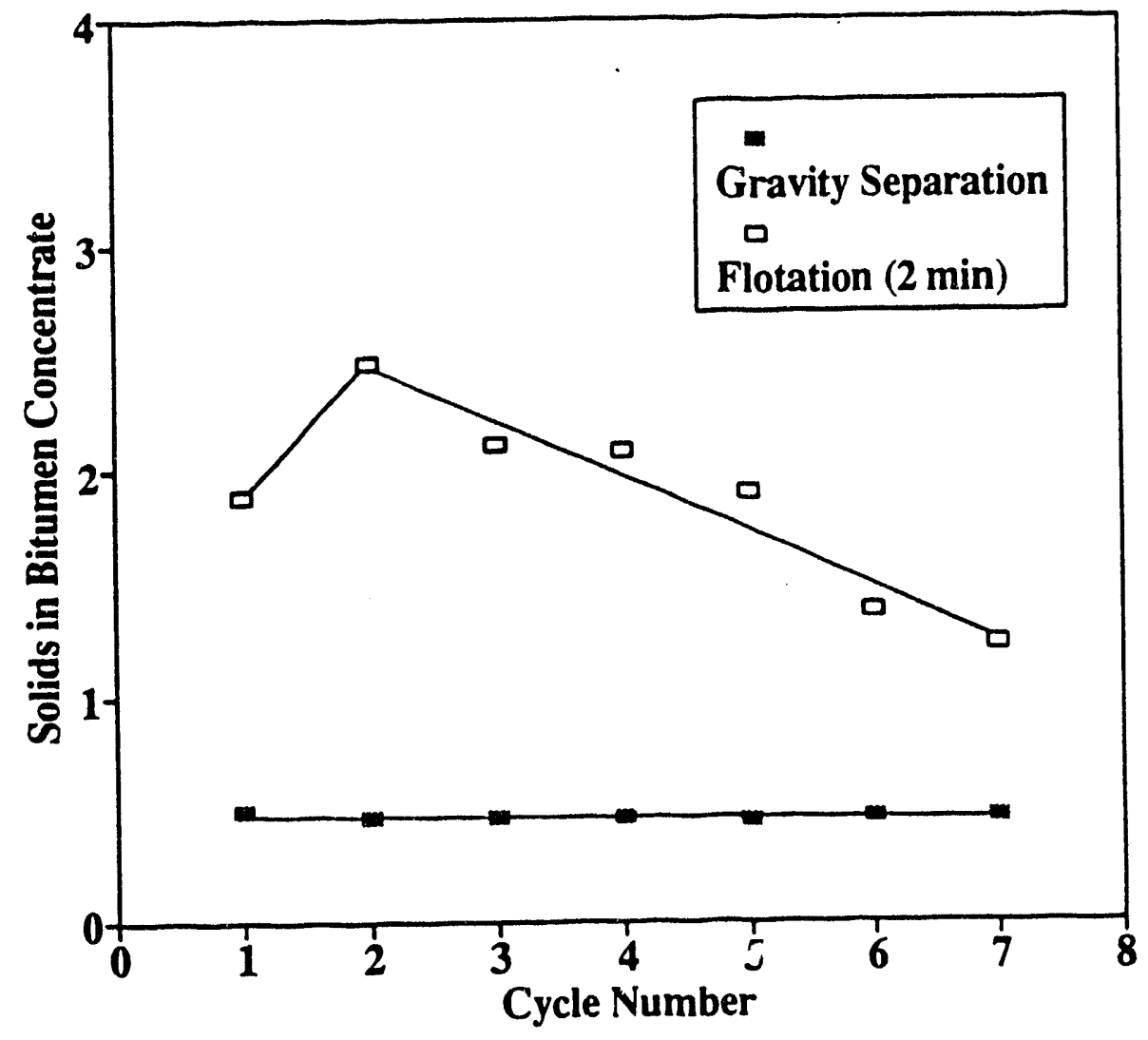

Figure 35. Solids in bitumen concentrate as a function of cycle number (weight of solids per unit weight of bitumen recovered, dry basis) 


\section{Physicochemical Properties}

Process water samples were taken from the gravity separation cell (B) (process water denoted as G) and the flotation cell (C) (process water denoted as $\mathrm{F}$ ). The $\mathrm{pH}$, specific conductivity, and surface tension of the process water samples, and zeta potential of fine particles suspended in aqueous phase samples were measured at ambient temperature $(295 \mathrm{~K})$. The zeta potential of tolueneextracted bitumen dispersed in clarified tailings water was also measured.

An increase in $\mathrm{pH}$ of the process waters, $\mathrm{G}$ and F, (Figure 36) was observed in each cycle as a result of $\mathrm{Na}_{2} \mathrm{CO}_{3}$ and $\mathrm{Na}_{5} \mathrm{P}_{3} \mathrm{O}_{10}$ addition. A constant $\mathrm{pH}$ value of 9.0 to 9.2 was attained in the fourth cycle for the gravity separation cell process water (G); whereas, it required seven cycles for the flotation cell process water (F) to attain a $\mathrm{pH}$ of 8.9 to 9.0 .

A steady increase in the specific conductivity (Figure 37) was observed without reaching a plateau. The initial net difference in the soluble salts concentration between the aqueous phases, $G$ and F, apparently did not change with the cycle number.

The presence of surface-active compounds in the aqueous phases ( $G$ and F) was monitored by surface tension measurements. Two measurements were made for the aqueous phase from the flotation cell (C): before ( $\mathrm{Fb}$ ) and after a 2-minute purge with air (Fa). The surface tension decreased from about 60 to $55 \mathrm{mN} / \mathrm{m}$ (G), from 68 to $59 \mathrm{mN} / \mathrm{m}(\mathrm{Fb})$, and from 70 to $61 \mathrm{mN} / \mathrm{m}$ (Fa) after seven cycles (Figure 38 ). These results indicate that a portion of the surface- 


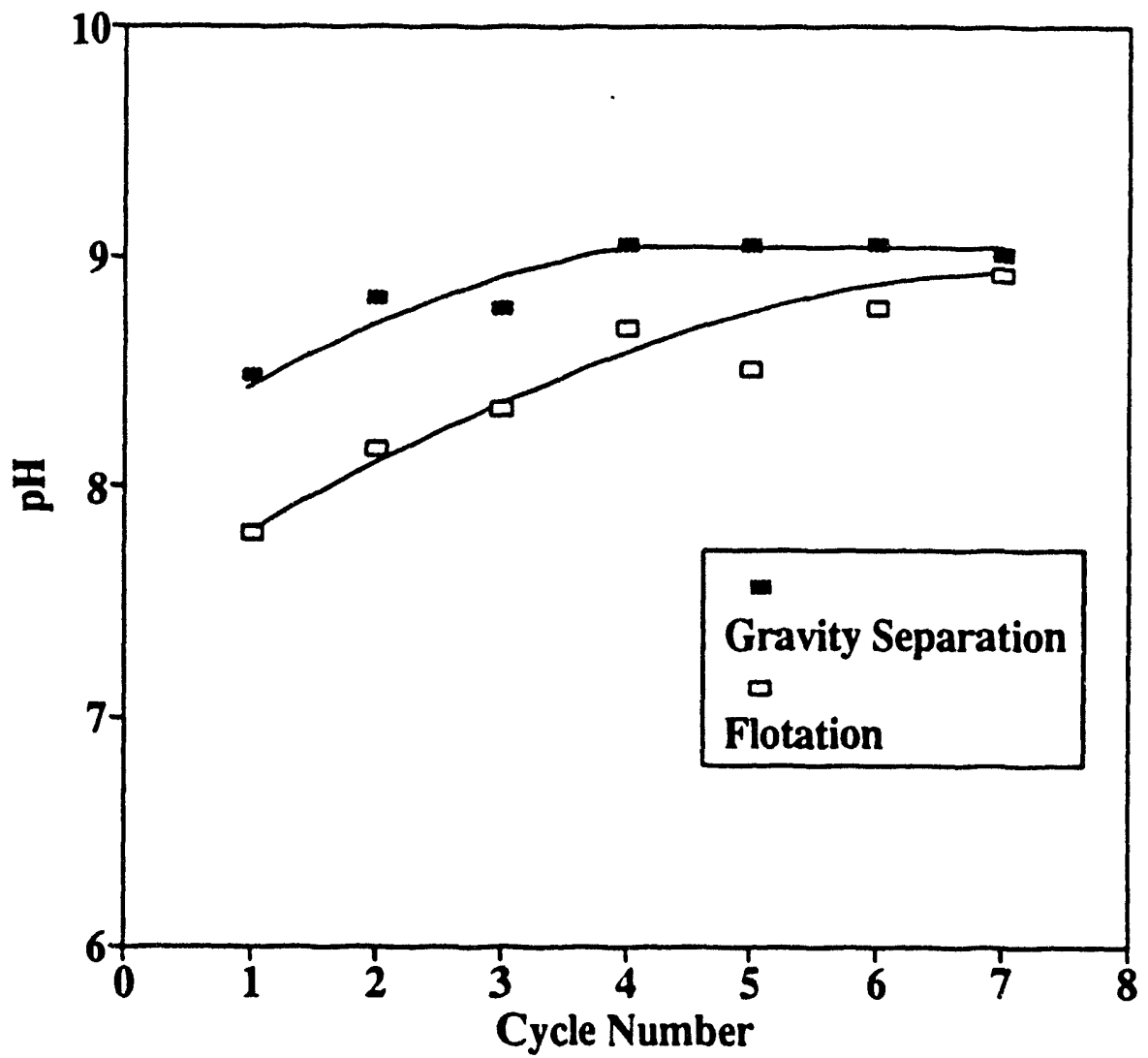

Figure 36. Process water $\mathrm{pH}$ as a function of cycle number 


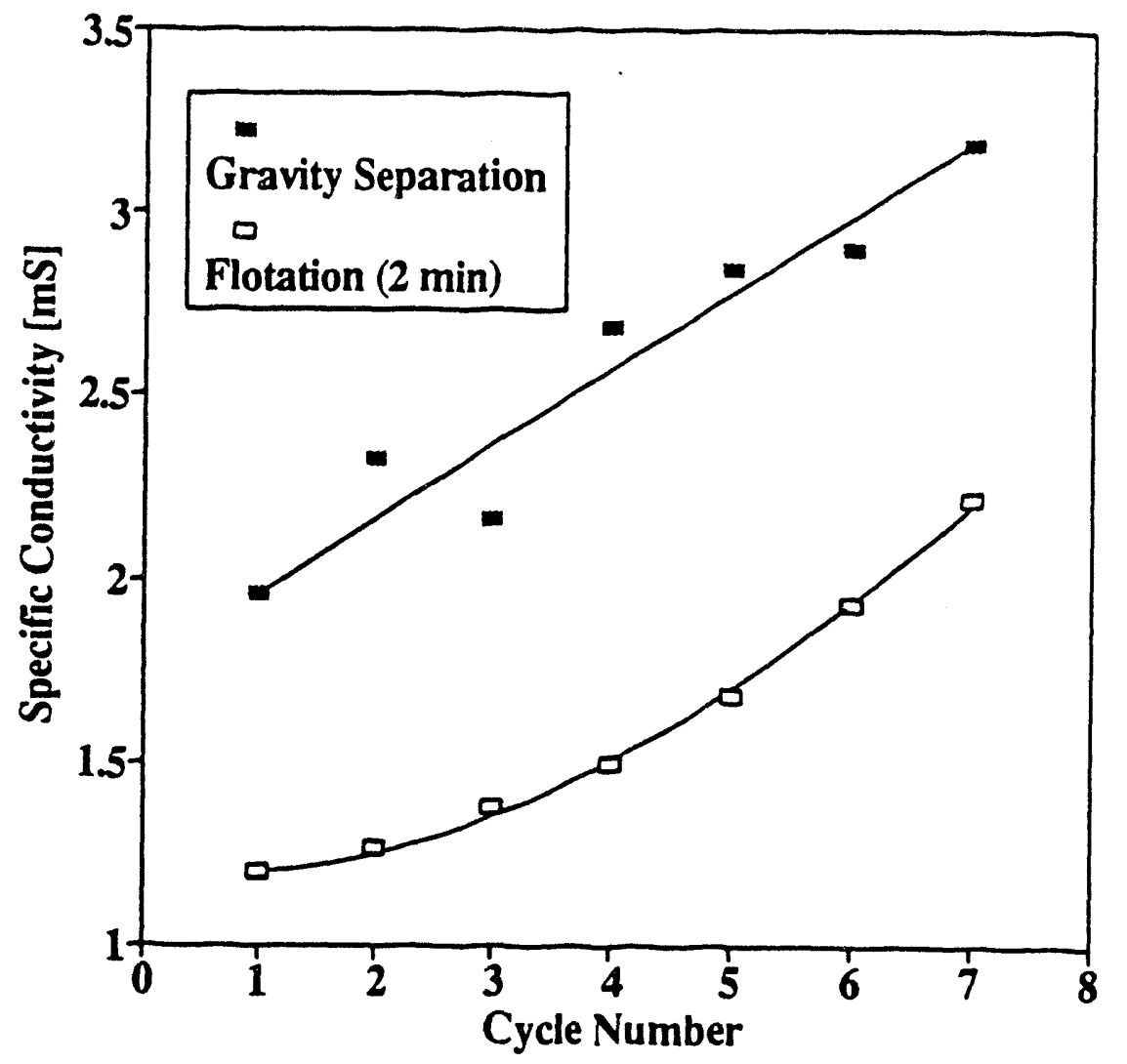

Figure 37. Specific conductivity of process water as a function of cycle number 


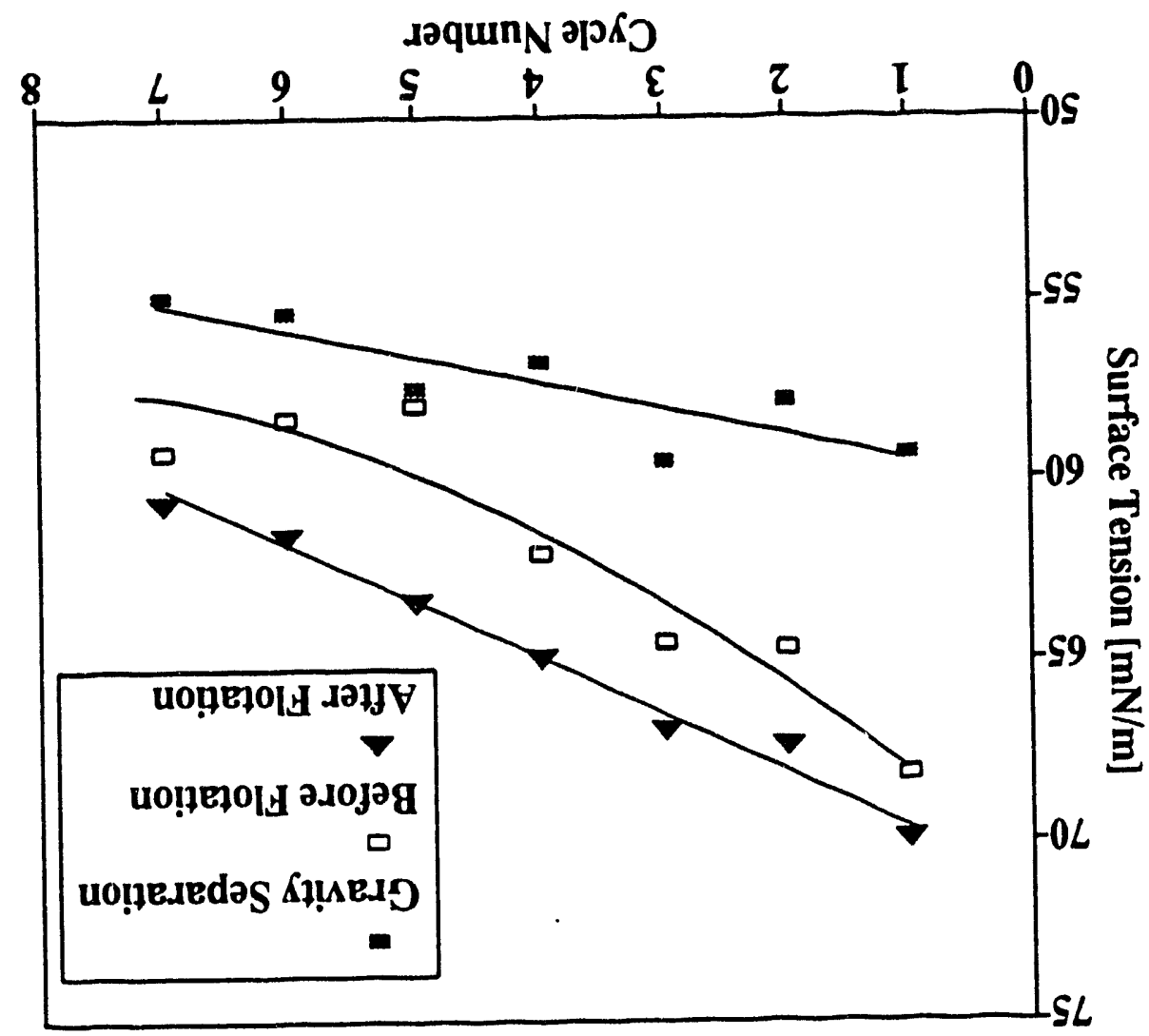


active compounds in the tailings were transferred to the bitumen froth in the flotation cell (C). This means that flotation or foaming could be a successful step in removal of natural surfactants from recycle water.

Negative zeta potential values were calculated from the electrophoretic mobilities for both fine particles (Figure 39) and bitumen droplets (Figure 40 ). The zeta potential of fine particles changed from $-26 \mathrm{mV}$ to $-35 \mathrm{mV}$ for the process water $\mathrm{G}$ and from -12 $\mathrm{mV}$ to $-33 \mathrm{mV}$ for the process water $\mathrm{F}$. The bitumen droplets were eventually more negatively charged and thus more stable (Figure 40), and an increase in the zeta potential was observed except for the process water G. The zeta potential of bitumen droplets, dispersed in the aqueous phase (G) from the gravity separation cell (B), decreased monotonically through the fourth cycle reaching an extreme of $-19 \mathrm{mV}$, and increased in the subsequent cycles to -43 $\mathrm{mV}$.

The surface tension of bitumen was $21.5 \mathrm{mN} / \mathrm{m}$ at $323 \mathrm{~K}$. The interfacial tension for the bitumen-process water interface was difficult to determine precisely due to the high bitumen viscosity and low interfacial tension values. Nevertheless, the interfacial tension measurements showed that this value is less than $7 \mathrm{mN} / \mathrm{m}$ when the aqueous phase withdrawn from the gravity separation cell (B) in the first cycle was analyzed. Also, it was found that the bitumen-process water interfacial tension decreased in each subsequent experiment to a value of less than $3 \mathrm{mN} / \mathrm{m}$. 


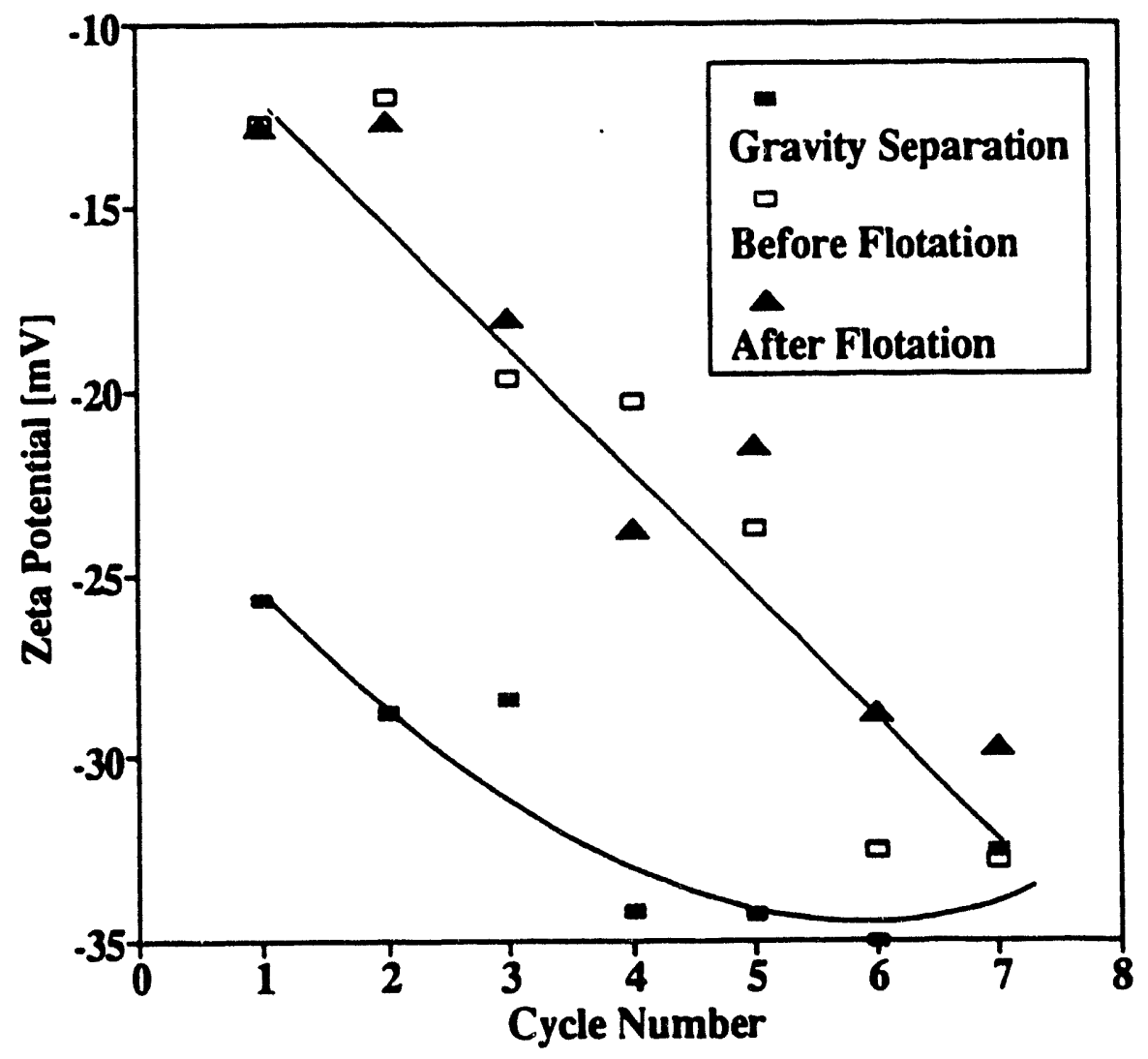

Figure 39. zeta potential of fine particles as a function of cycle number 


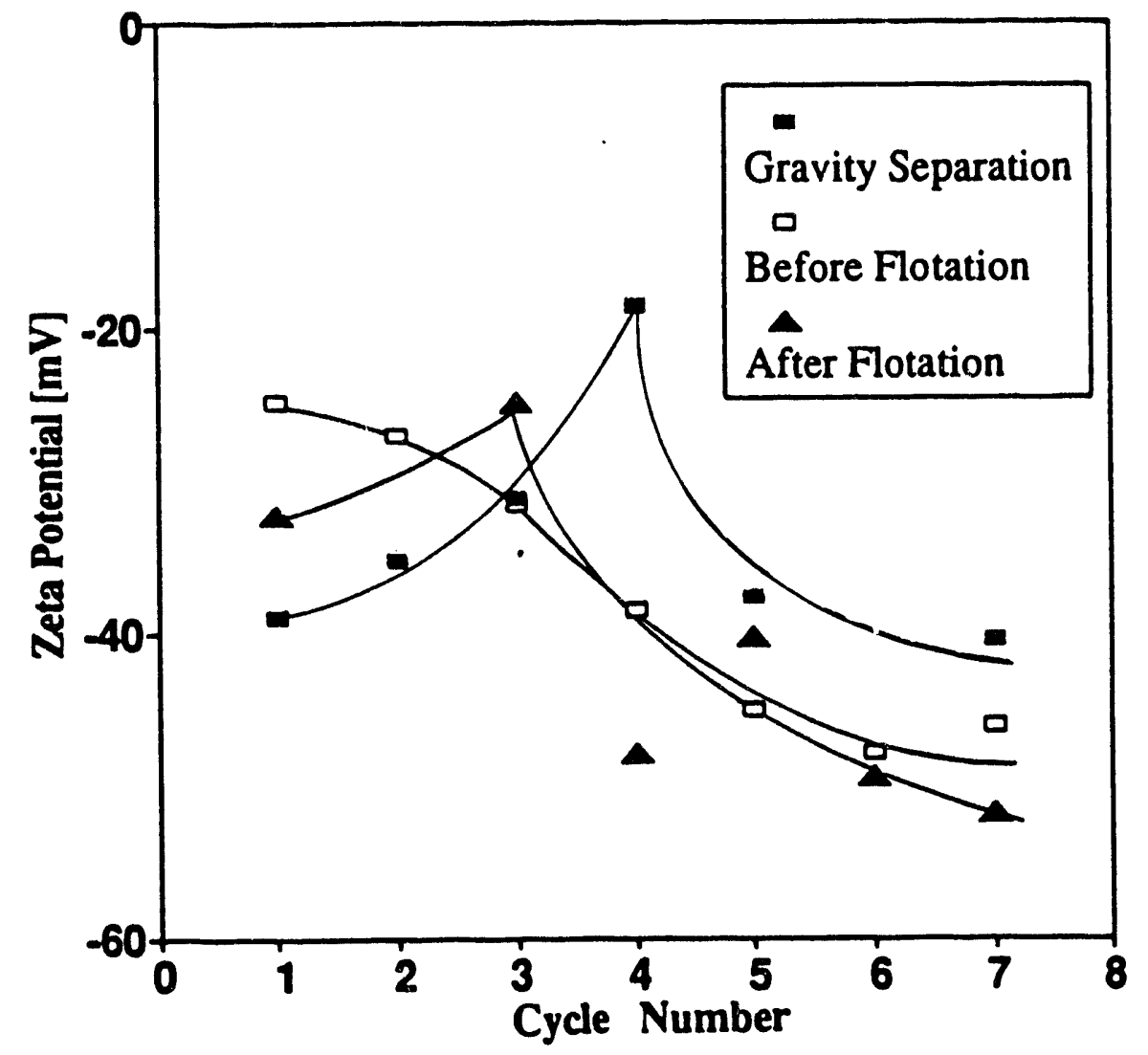

Figure 40. Zeta potential of bitumen droplets as a function of cycle number 


\section{Bitumen Disengagement Mechanism}

Samples of the Whiterocks oil sand were submerged in an alkaline solution $\left(\mathrm{Na}_{2} \mathrm{CO}_{3}, \mathrm{pH}=9.0, \mathrm{~T}=323 \mathrm{~K}\right)$ in a glass cell and the changes in sample structure were observed with a stereoscopic microscope for 30 minutes. Initially, air bubbles, displaced from the pores by the aqueous phase, adhered to the surface of the bitumen-sand agglomerate (Figure 41 ). The layer of bitumen was ruptured and small droplets formed at the surface of the sand grains in the first minute. A portion of the bitumen spread over the air bubbles. Next, bitumen-sand aggregates collapsed (Figure 42) and air bubbles covered with bitumen and hydrophobic fine particles rose to the surface of the water.

\section{DISCUSSION}

\section{Impact of water Recycle}

Soluble inorganic salts and surface-active organic compounds appeared to exert a major influence on bitumen recovery and the bitumen-concentrate grade. The concentration of dissolved species increased with the cycle number as indicated by the pH (Figure 36), the specific conductivity (Figure 37) and the surface tension (Figure 38).

The bitumen recovery by gravity separation steadily increased from $50 \%$ to approximately $70 \%$ through the five cycles. A similar trend was observed for the flotation step (Figure 34). The constant concentration of fine particles in the bitumen concentrate from the gravity separation cell (Figure 35) suggested that the recycled water had a minimal impact on the separation of bitumen 

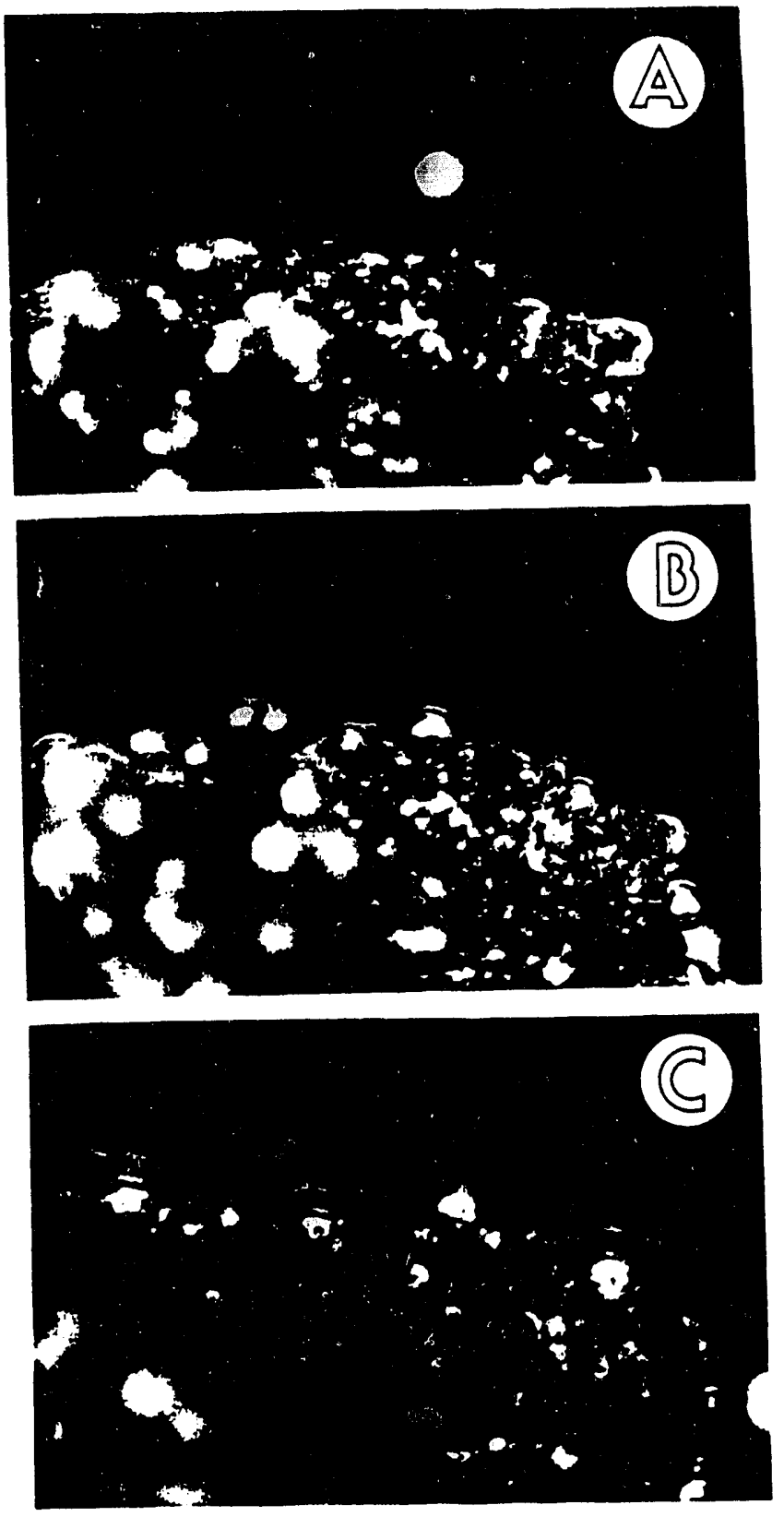

Figure 41 .

Changes in structure of oil sand sample in alkaline solution $(\mathrm{pH}=9.0, \mathrm{~T}=323 \mathrm{~K}) ; t=1 \mathrm{~min}(\mathrm{~A})$ heated system, $t=3 \mathrm{~min}$ (B) - dropl.et formation resulting from bitumen layer disruption and formation of air bubbles at the capillary ends, $t=$ 6 min (C) - bitumen spreading at bubble surface cand air bubble size growth 

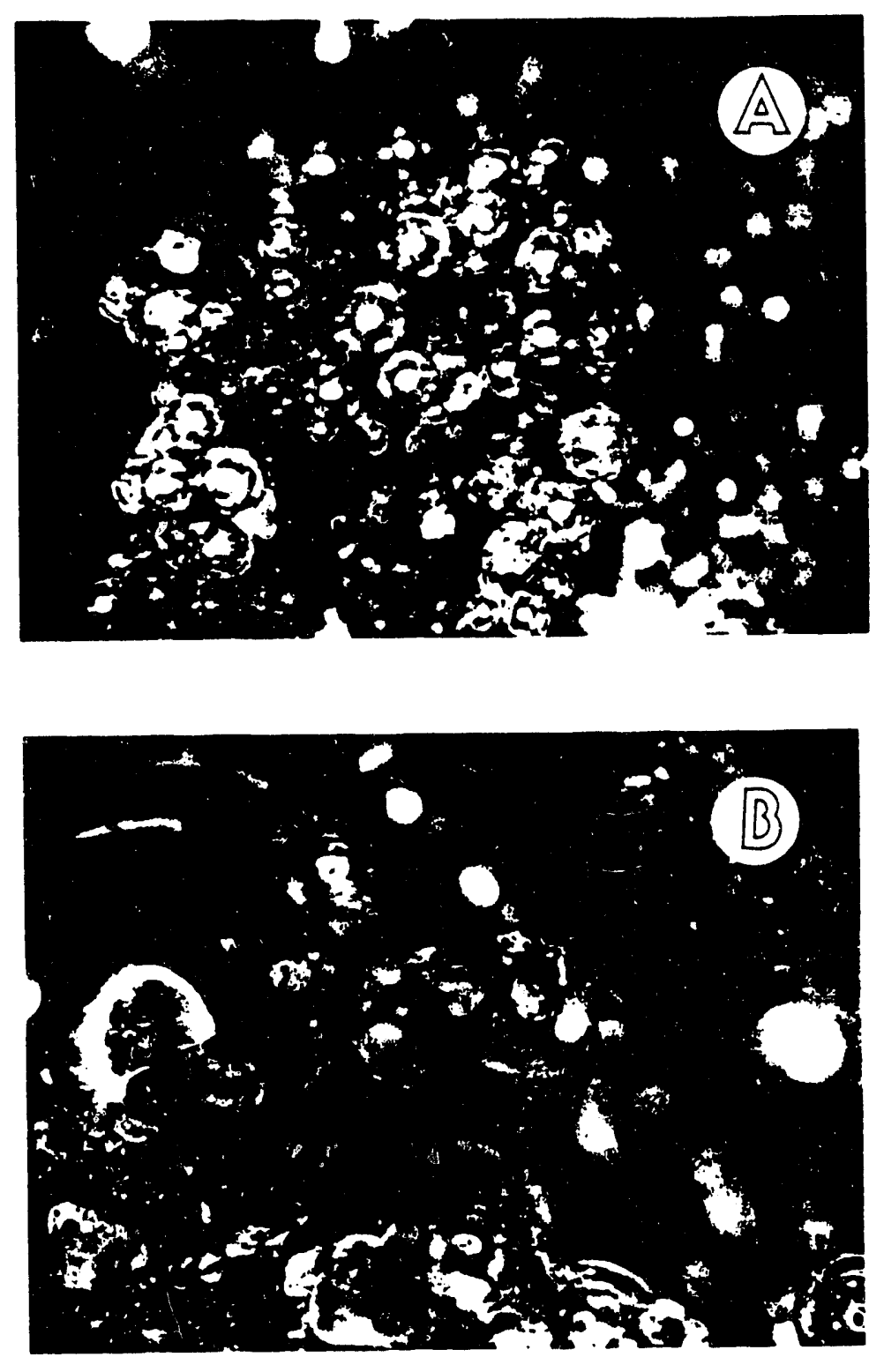
Figure 42. Changes in structure of oil sand sample in alkaline
solution $(\mathrm{pH}=9.0, \mathrm{~T}=323 \mathrm{~K}) ; t=10 \mathrm{~min}(\mathrm{~A})-$ detachment of bubble/bitumen aggregates, $t=15 \mathrm{~min}$ (B) - sample disintegration due to decreased bonding forces 
from the fine particles.

The increased flotation efficiency, despite a more negative bitumen zeta potential in subsequent runs (compare Figure 34 with Figure 40), was to some extent consistent with the observations of Schramm and Smith. ${ }^{85}$ Schramm and co-workers ${ }^{85,86}$ reported a maximum in bitumen recovery which corresponded to a maximum in the electrophoretic mobility of bitumen droplets in the hot-water process. The maximum was attributed to the formation of a monolayer on the droplet surface by surface-active compounds which released from the bitumen. Schramm and $\operatorname{smith}^{85}$ proposed the existence of a critical concentration of surface-active compounds which was responsible for high bitumen recoveries (>90\%) in the hot-water process. If this critical concentration really existed in examined systems with the Whiterocks oil sand then the concentration of the surface-active compounds could correspond to the surface tension of the recycle water of $55-60 \mathrm{mN} / \mathrm{m}$. However, it was observed that a maximum in bitumen recovery (Figure 34) does not have to correspond to a maximum in electrophoretic mobility of bitumen droplets (Figure 39), in examined systems. It seems that concept of Schramm and Smith does not have to be applicable for bitumen separation from the whiterocks oil sand.

Further, Schramm and Smith $^{85}$ reported that charging of both surfaces; bitumen-water and solid-water, facilitates bitumen separation from mineral matter. This concept is especially useful for oil sands with wetting water films separating bitumen from 
mineral surface, such as reported for Athabasca oil sand, ${ }^{87}$ and does not have particular significance for "dry" Utah's oil sands.

A decrease in flotation efficiency could be expected due to the increasing repulsive electrostatic forces as indicated by zeta potential measurements (Figure 40). However, a slight increase in flotation efficiency was observed in the fourth, fifth, and sixth cycles (see Figure 34). Some increase may have been related to an increase in the residual bitumen concentration in the recycled water but general increase in the recovery of bitumen cannot be fully explained based on the increasing concentration of residual bitumen in the tailings water.

The increased negative zeta potential (Figure 39) was presumed to have resulted from the adsorption of surface-active compounds on fine particle surfaces. This led to a decrease in the flotation effectiveness with respect to fine mineral particles (Figure 35). The difference in the size of the fine mineral particles and the bitumen droplets, which were similarly charged (Figures 39 and 40), may have promoted preferential bitumen flotation.

\section{Bitumen Separation}

The disengaged bitumen was recovered from the oil sand slurry after digestion by gravity separation and flotation. A rapid separation in the gravity separation cell (B) was desirable ${ }^{88}$; however, it depended upon the degree of bitumen displacement from the sand and upon the extent of bitumen concentrate aeration. Bubble entrapment in the bitumen may have involved air contained in pores, as was observed in our experiments. Atmospheric air 
incorporated into the slurry during digestion was another source of air bubbles.

The bitumen concentrates collected in both the gravity and flotation cells were four-phase mixtures of bitumen, fine solid particles, water and air bubbles. Air bubbles were encapsulated in the bitumen during oil sand digestion. The release of air bubbles from the organic phase was slow due to the viscous nature of the bitumen, however, the presence of air bubbles did not complicate the concentrate cleanup step.

The water content of the bitumen concentrates varied from 24 to 50 wt. $\%$, and the "free" water (not dispersed as droplets), in the concentrate, 10-30 wt. $\%$, was drained on filter paper for 20-40 minutes. The residual water ( 5 wt. $\%$ ) existed as fine water droplets with diameters below $5 \mu \mathrm{m}$ was difficult to remove.

The content of fine solid particles; 45-50 wt. $\%$ based on the weight of the recovered bitumen, released from the oil sand ore in the digestion step, was invariant in all experiments even after the soluble species concentration increased in the recycled process water (Figure 35). Also, fine particles attached to air bubbles during flotation. The bitumen recovery in the 2 -minute flotation reached 20-30 wt. $\%$ (Figure 34). The concentrate from the flotation cell (C) contained 18-30 wt. $\%$ bitumen, 30-50 wt. \% solids and 24-50 wt. $\%$ water, depending upon the cycle. The flotation cell concentrate had a higher concentration of fine sand particles than the concentrate skimmed from the gravity separation 
cell (B); however, the solids flotation efficiency decreased monotonically after the second cycle (Figure 35).

\section{Bitumen Disengagement Mechanism}

In the case of the Athabasca oil sand it has been proposed that a thin water film separates mineral surfaces from the bitumen 87 ; however, the existence or absence of a water film has not been firmly established for Utah oil sands. The hydrophobic nature of the Uinta Basin bitumen ${ }^{89}$ may hinder water penetration into the pores. The elevated temperature, used in oil sand processing, reduces bitumen viscosity and contributes to the rupture of the bitumen layer. It had been previously determined that bitumen viscosity should not exceed $1.5 \mathrm{~Pa} \cdot \mathrm{s}$ during digestion. ${ }^{79}$ It was observed in a glass cell that when the unconsolidated oil sand was contacted with the aqueous phase small bitumen lenses where formed; the sand-bitumen contact area was reduced and the force of adhesion was weakened.

Observations made in a glass cell indicated that roll-up of the bitumen film was accompanied by the release of air bubbles from the oil sand. These bubbles adhered to mineral surfaces via bitumen bridges and were eventually covered by the spreading bitumen. The thermodynamic conditions for the spreading phenomenon have been reported in literature ${ }^{90}$ ar.i nave also been described for bitumen filming on air bubbles by Leja and Bowman. ${ }^{91}$ The criterion was reported as follows:

$$
\gamma_{\text {aw }}>\gamma_{\text {ow }}+\gamma_{\text {ao }}
$$


where $\gamma_{\text {aw }}, \gamma_{\text {ow }}, \gamma_{\text {ao }}$ are the interfacial tensions and the subscripts $a, w$, and o correspond to air, water, and oil phases, respectively. The buoyancy force and the shear force field in the digester stimulate the detachment of aerated bitumen from the mineral particle surface. It was reported ${ }^{92}$ that hydrophobic fine particles remained associated with the bitumen which had been separated from sand. Hydrophobicity of the fine particles was caused by residual organic matter bound to mineral surfaces. These organic species were presumed to be too polar to be soluble in toluene. 92

\section{SUMMARY AND CONCLUSIONS}

Water recycle influenced bitumen recovery in the two bitumen separation steps: the 2- to 3-minute gravity separation step and the 2-minute flotation step. The $\mathrm{pH}$ of the recycled water stabilized at 9.0 to 9.2 . The recovery of bitumen from low-grade Whiterocks oil sand using recycled water in the gravity separation and flotation cells exceeded $90 \%$ in fourth to seventh cycles, and a maximum in bitumen recovery was obtained between the fifth and sixth cycles. This observation may be related to the amount of $\mathrm{Na}_{2} \mathrm{CO}_{3}$ and $\mathrm{Na}_{5} \mathrm{P}_{3} \mathrm{O}_{10}$ used and to the amount of free natural surfactants released to the aqueous phase and activated at the bitumen-water interface.

Recycled process water had no deleterious effect on the amount of fine mineral particles reporting to the concentrate during gravity separation.

The release of air bubbles from the oil sand at the onset of digestion was observed in a glass cell and preceded the disruption 
of the bitumen-layer covering the surface of the mineral particles, and the formation of bitumen lenses. The subsequent bitumen spreading at the air bubble surface indicated a minimum in the surface Gibbs free energy.

\section{FUTURE ACTIVITIES}

The hot-water processing technology for the Whiterocks tar sand has been well described in our previous contributions but our understanding of the mechanisms of bitumen separation from tar sand is incomplete. Future research activities will be focused on the fundamentals of wetting phenomena in three-phase systems including the study of the surface/interfacial properties of bitumen and analysis of thermodynamics of tar sand systems in alkaline solutions. Three physico-chemical properties of bitumen, viscosi$t y$, surface tension and interfacial tension, are expected to be of great importance in the bitumen release + rom tar sand. The effect of bitumen viscosity on the hot water process has been studied extensively in eighties but no study has been performed regarding the significance of surface/interfacial tension on the recovery of bitumen from tar sands. It is intended to examine and find a correlation between the bitumen separation from mineral matter and bitumen-water interfacial tension. Based on these fundamental studies it is intended to establish the most appropriate conditions for effective bitumen recovery from tar sand by water-based processes. 


\section{AIR-SPARGED HYDROCYCLONE FLOTATION OF OIL FROM OIL-IN-WATER EMULSIONS}

\section{INTRODUCTION}

Tar sand processing using water-based separation techniques is one example in which separation of heavy oil droplets from a rather composed dispersed system is required. Bitumen recovery by waterbased above-ground processing is accomplished in two main stages: digestion and subsequent phase separation. While digestion requires only 25-30 wt. \& of the aqueous phase, the separation stage is carried out in a diluted tar sand suspension in order to enhance bitumen removal from the slurry. Thus, with a reduced amount of solids (e.g., 20 wt. $\left.\frac{8}{6}\right)$, the volume of the tar sand slurry increases several times with respect to that during digestion which causes processing and equipment costs to increase.

Laboratory experimental results pertaining to the U.S. tar sands, 93 and to the canadian tar sands show that tailings from the gravity cell usually contain more than $1 \%$ of bitumen. If this bitumen is disposed with the spent sand, the bitumen recovery to the concentrate can exceed $90 \%$ for a high grade feed (above 10\% bitumen), but will remain well below $90 \%$ for a lean tar sand (less than $8 \%$ bitumen). Water-based processing of tar sands at a moderate temperature $\left(50^{\circ} \mathrm{C}\right)$ requires addition of diluent prior to digestion. 94 The diluent present in bitumen which is from 5 to 30 wt. $\%$ of the contained bitumen may also be lost with bitumen in the tailings.

Flotation of the digested tar sand slurry, directly following digestion or preceded by a gravity separation, can reduce the 
bitumen content in the tailings sand to as little as $0.2 \%$ bitumen.94,95 However, high investment and operating costs can be expected, due to the immense amount of tar sand slurry being processed to recover the bitumen in conventional flotation machines. In this regard, the high specific capacity of airsparged hydrocyclone (ASH) flotation should have some distinct advantage in scavenging tar sand tailings. Aeration under turbulent shearing conditions, as is developed in the ASH, should benefit the separation process by disrupting relatively weak mineral-bitumen interactions, according to the model and experimental data of Hall and Tollefson. ${ }^{96,97}$ processing tar sands with a high fines content should therefore be less demanding.

\section{Oil-Water Separation}

Advanced oil-water separation techniques are gaining increasing attention due to more stringent requirements for the treatment of oil polluted water streams. Oil-water emulsions/dispersions are found in waters from many sources (including petroleum refineries, washrack and hangar waste waters, rolling mills, and chemical processing and manufacturing plants). In some situations the treatment of large amounts of oily water at a high flowrate is required (e.g., ballast and bilge water on ships, washing in shipyards, cooling water from power plants or steel works). In situations of an accidental oil spill, large amounts of water containing bulk and/or dispersed oil must be processed. Many commercial techniques and devices are being developed and marketed for removal of oil from water, but a simple, economical, and 
efficient method to treat oil-in-water dispersion in a wide range of droplet size is not yet available. Although methods involving bed separators (coalescers, filters) can be used to produce a clean effluent, their capacity per unit volume limits their usefulness. Gravity settlers and plate separators are usually the most suitable for handling voluminous streams, but because of their size and weight they are not always easily moved on site. Hydrocyclones have been considered as a possible alternative to gravity and plate separators. ${ }^{98}$ In the last decade, the air-sparged hydrocyclone has been found to be effective for fast flotation of solid particles. 99 In the present report the application of the ASH has been extended to the processing of oil-in-water emulsions. The de-oiling possibility in the ASH was already examined in two papers ${ }^{100,101}$ and the results were encouraging. Therefore it was concluded that further investigation of the ASH design, the flow conditions, and the surface chemistry is necessary to in order improve the efficiency of oil separation.

THE PRINCIPLES OF AIR-SPARGED HYDROCYCLONE FLOTATION

Limited fine particle recovery and relatively slow rates of conventional flotation led to the concept of air-sparged hydrocyclone flotation.99,102,103 A controlled high centrifugal force field is developed by the swirl flow in the ASH. In this way the inertia of fine particles is increased and a high concentration of fine air bubbles with directed motion is produced by sparging of the air through a porous tube. The net result is effective fine particle flotation with a flotation rate requiring retention times which 
approach the intrinsic bubble attachment time. This corresponds to a capacity exceeding 100 times the capacity of a conventional mechanical or column flotation cell.

A simplified schematic of the ASH is shown in Figure 43. Air is sparged through the jacketed porous tube wall and is sheared into numerous small bubbles by the high-velocity swirl flow of the aqueous phase. Hydrophobic particles are transported into the froth phase which forms on the cylindrical axis. The froth phase moves towards the vortex finder of the cyclone header, being discharged as an overflow product. Most of the aqueous phase with hydrophilic particles - if present - is discharged as the underflow product.

\section{EXPERIMENTAL PROCEDURE}

Two fundamental aspects of the ASH oil flotation were examined before the flotation experiments were initiated. First, the necessary conditions for oil filming at the air-bubble surface ${ }^{104,105}$ were established. Second, the conditions under which the electrophoretic mobility of oil droplets in the emulsion was significantly reduced, were established as described below.

\section{Surface Chemistry}

In order to find the most favorable conditions for air bubble filming by oil, three interfacial tensions (air/water, air/oil, and water/oil) were determined at different surfactant concentrations, ranging from $0.3 \mathrm{mg} / \mathrm{dm}^{3}\left(10^{-6} \mathrm{M}\right)$ to $3 \mathrm{~g} / \mathrm{dm}^{3}\left(10^{-2} \mathrm{M}\right)$. Several pure hydrocarbons (n-heptane, n-decane, n-dodecane, n-tetradecane, and n-hexadecane) and a bitumen-kerosene blend (different bitumen/ 


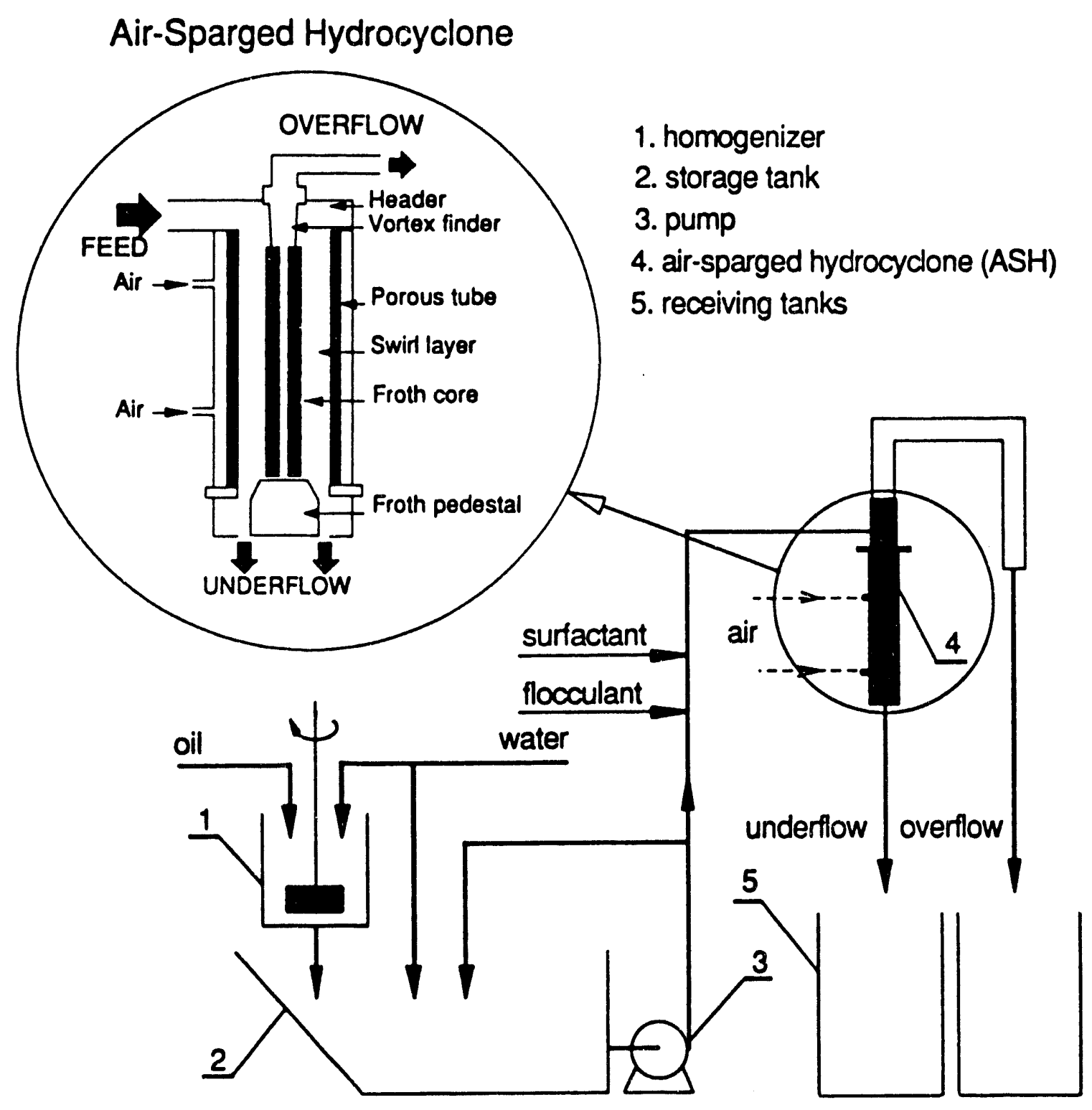

Figure 43. $\begin{aligned} & \text { Schematic representation of the ASH and the } \\ & \text { experimental set-up }\end{aligned}$ 
kerosene weight ratios) were used in these experiments. The measurements were carried out using the du Noüy ring method, with a Krüss semiautomatic tensiometer type K10T.

The bubble filming conditions were verified experimentally using a syringe to form oil droplets in sodium dodecyl sulfate solution and the drainage time of the oil droplet residing at the air/surfactant solution surface was measured.

Two oils were used in the ASH flotation experiments, namely hexadecane and a $20 \%$ bitumen in kerosene blend. For both oils the zeta potential and the droplet size distribution were determined using the Zetasizer 3, Malvern Instruments Ltd. The same emulsion was used for the surface chemistry measurements and the ASH flotation experiments. The zeta potential measurements were performed after $15 \mathrm{~min}$. conditioning time.

\section{ASH Oil Flotation}

The two oils used for flotation in the ASH represent two different spreading coefficient vs. surfactant concentration functions. For each oil the susceptibility to filming occurs at distinct surfactant concentrations.

The oil samples were emulsified in $5 \mathrm{~L}$ of water using the SILVERSON L4R homogenizer ( $5 \mathrm{~min} ., 7200 \mathrm{rpm}$ ) and then diluted to 200 L. The bitumen/kerosene blend emulsion was equalized in a storage tank by recirculating for $1 \mathrm{hr}$. with a pump. The concentration of oil after dilution was approximately $200 \mathrm{mg} / \mathrm{dm}^{3}$ in most experiments, unless stated differently. The temperature was maintained at $25^{\circ} \mathrm{C}$ (note that the solidification of hexadecane 
occurs at $18^{\circ} \mathrm{C}$ ). The average droplet size changed with chemical additions and varied between 2 and $10 \mu \mathrm{m}$. The measurements of oil concentration were performed using the HORIBA OCMA-220 Oil-in-water analyzer. For concentrations which were expected to be higher than $200 \mathrm{mg} / \mathrm{dm}^{3}$ the extraction was performed in a separatory funnel with $1: 1 \mathrm{CCl}_{4} / \mathrm{H}_{2} \mathrm{O} \mathrm{vol}$. ratio and subsequently the oil concentration in $\mathrm{CCL}_{4}$ was measured with the HORIBA analyzer. Such a method of oil content determination has been shown to be sufficiently accurate for these experiments. ${ }^{106}$

A $5 \mathrm{~cm}$ dia. and $47 \mathrm{~cm}$ long (two sections: 16 and $31 \mathrm{~cm}$ ) ASH unit (the ASH-2C) with separate, adjustable air supply to both sections was used in all experiments. The operating variables were: the flowrates of emulsion and air (expressed as the $Q^{*}-$ dimensionless flowrate ratio $Q_{\text {air }} / Q_{\text {water }}$ ) and the underflow and the overflow opening areas (expressed as the $A^{*}$-dimensionless OF/UF area ratio). The chemical additives were: an anionic surfactant - sodium dodecyl sulfate (SDS) - at concentrations of 0, 9, 15, 30 and $50 \mathrm{mg} / \mathrm{dm}^{3}$ as established from surface chemistry measurements and a high molecular weight cationic polyelectrolyte (PE) copolymer of a quaternary acrylate salt and acrylamide produced by Allied colloids - at concentrations of $0,0.5,1.0,2.0$ and 5.0 $\mathrm{mg} / \mathrm{dm},{ }^{3}$ as established fron zeta potential measurements. 
RESULTS AND DISCUSSION

Surface Chemistry

Based on the concept of surface tension, the necessary condition for oil spreading at the air-water interface is given in Equation $1^{107}$ :

$$
\gamma_{a / w}>\gamma_{0 / w}+\gamma_{a / 0}
$$

where $\gamma$ - interfacial tension, $\mathrm{mN} / \mathrm{m}$, at air-water $(\mathrm{a} / \mathrm{w})$, oil-water $(0 / w)$, and air-oil $(a / 0)$ interfaces.

our experimental data are presented in terms of the spreading coefficient ${ }^{108}$ :

$$
S_{o / a}=\gamma_{a / w}-\left(\gamma_{o / w}+\gamma_{a / o}\right)
$$

It is understood here that a positive spreading coefficient will result in an enhanced separation of oil droplets from the emulsion due to filming which may occur during flotation.

The spreading coefficient, calculated from Equation (2), vs. surfactant concentration is presented in Figure 44 . In the case of pure hydrocarbons and kerosene the spreading coefficient reaches a maximum between $15 \mathrm{mg} / \mathrm{dm}^{3}\left(5 * 10^{-5} \mathrm{M}\right)$ and $30 \mathrm{mg} / \mathrm{dm}^{3}\left(10^{-4} \mathrm{M}\right)$ surfactant concentration, with more negative values at $0.3 \mathrm{mg} / \mathrm{dm}^{3}\left(10^{-6}\right.$ $\mathrm{M})$, and even more negative values at $300 \mathrm{mg} / \mathrm{dm}^{3}\left(10^{-3} \mathrm{M}\right)$. For the bitumen-kerosene blend the spreading coefficient was positive for low concentrations of surfactant, and started to decrease at 3 $\mathrm{mg} / \mathrm{dm}^{3}\left(10^{-5} \mathrm{M}\right)$, finally reaching negative values for $300 \mathrm{mg} / \mathrm{dm}^{3}$ $\left(10^{-3} \mathrm{M}\right)$. In summary, the tendency of the kerosene-bitumen blends to spread at the water surface is most pronounced. The different impact of the surfactant concentration on the spreading coefficient 


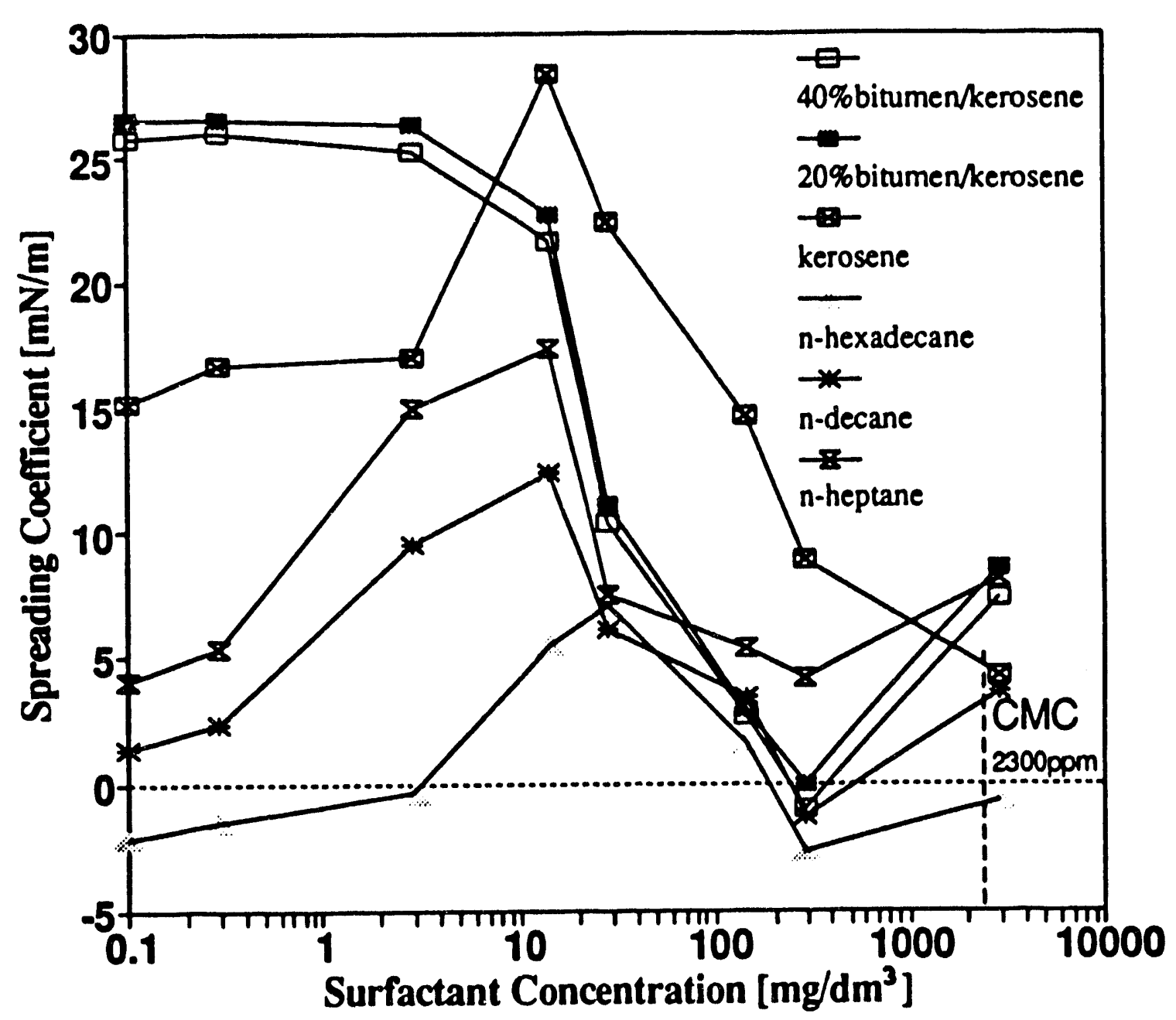

Figure 44. Spreading coefficient as a function of surfactant concentration 
for pure hydrocarbons and for the bitumen in kerosene blends is believed to result from the contribution of natural surfactants present in the tar sand bitumen. ${ }^{109}$

The oil filming experiments show that the time which elapsed from the moment of oil placement at the oil/water surface to oil spreading (i.e., the time of water film drainage), increases with an increase of the molecular weight of the oil phase. The shortest filming time was found, as expected, for the largest spreading coefficient. The data presented in Figure 45 indicate that the static drainage time remains in excellent correlation with the spreading coefficient.

In addition to the filming characteristics of the system the influence of the flocculant concentration on the zeta potential of oil droplets was determir:ed (Figure 46). The Allied colloids polyelectrolyte (PE) Percol 592, which previously proved to be effective ${ }^{110,111}$ was selected to control the zeta potential. The required concentration of the $\mathrm{PE}$ to reach the isoelectric point is different for different oils and surfactant concentrations. The zeta potential approached zero at $1.5 \mathrm{mg} / \mathrm{dm}^{3}$ and $1.0 \mathrm{mg} / \mathrm{dm}^{3}$ of $\mathrm{PE}$ concentration for hexadecane emulsion with and without surfactant, respectively. For the bitumen in kerosene blend emulsion the i.e.p. was achieved at $0.1 \mathrm{mg} / \mathrm{dm}^{3}$ without SDS addition - and at 0.3 $\mathrm{mg} / \mathrm{dm}^{3}$ with surfactant addition. In this regard polyelectrolyte concentrations were varied accordingly depending on surfactant concentration for ASH testing of the hexadecane and bitumen/kerosene emulsions. 


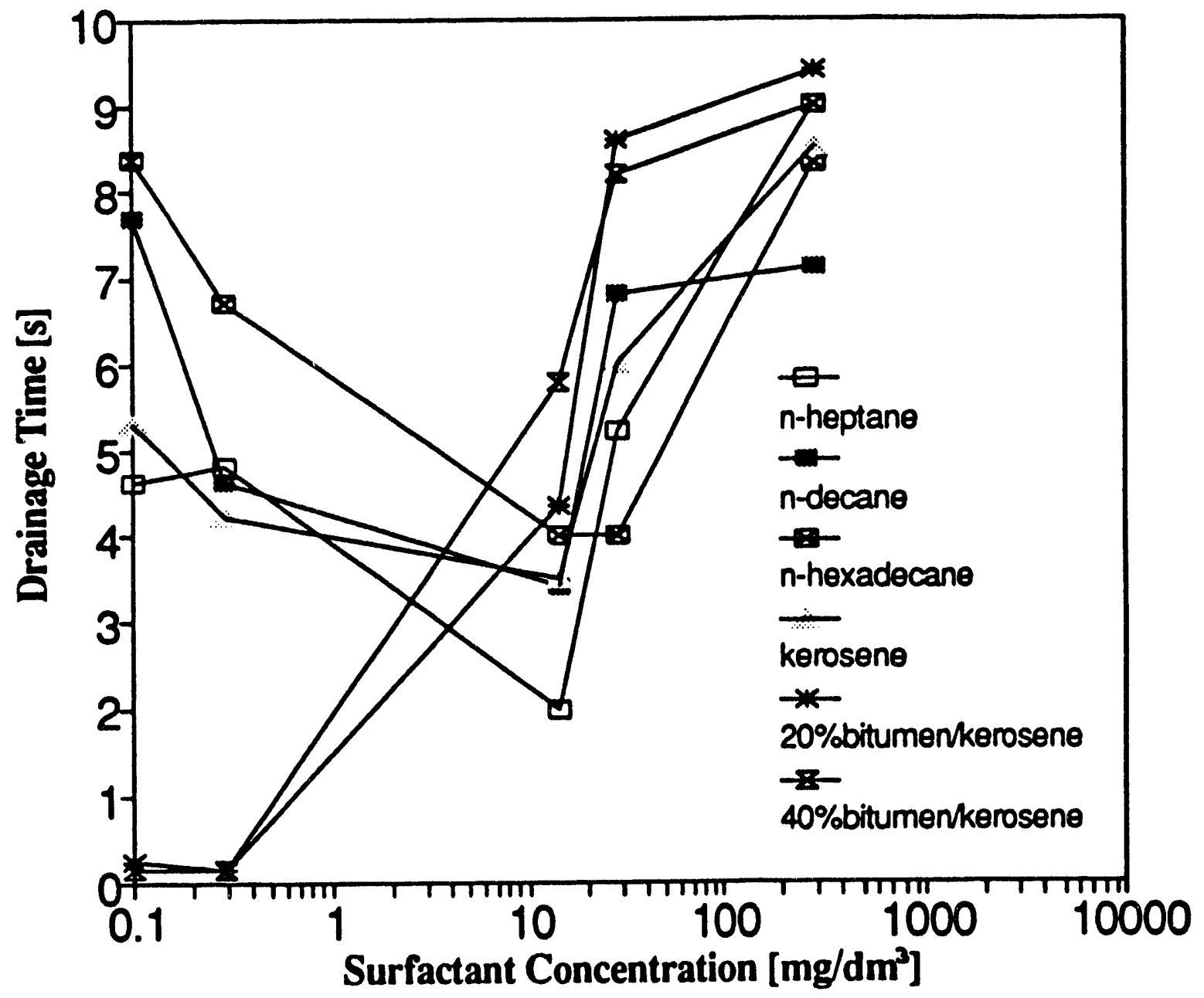

Figure 45. Drainage time of water film for oil droplet at the air/water interface 


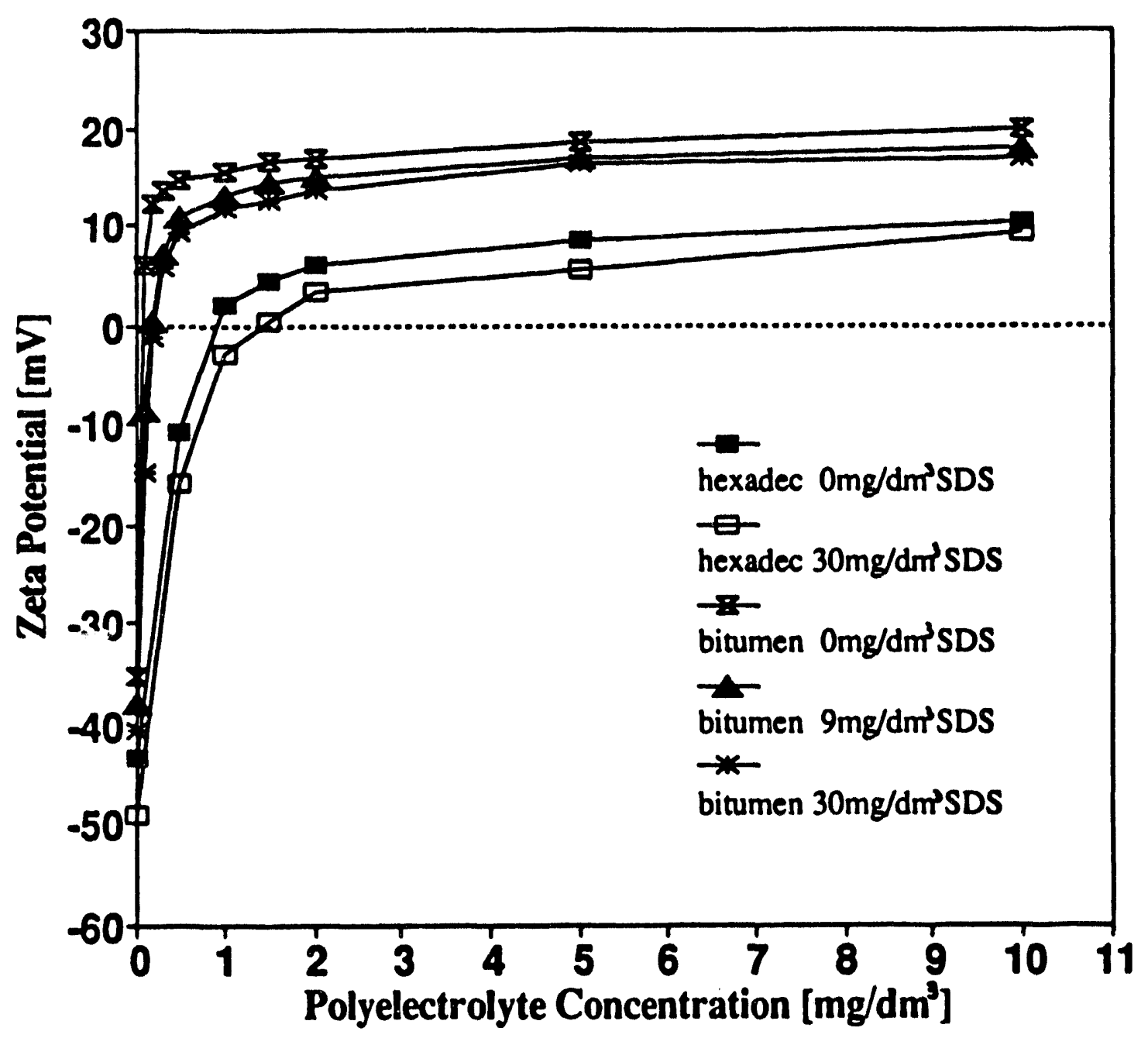

Figure 46. Zeta potential of oil droplets vs. flocculant addition 


\section{Oil Separation by ASH Flotation.}

The technological part of this research involved oil separation by $\mathrm{ASH}$ flotation. The emulsion flowrate was changed from 30 to $80 \mathrm{dm}^{3} / \mathrm{min}$, and the air flowrate - from 30 to $280 \mathrm{~cm}^{3} / \mathrm{min}$ (which corresponds to a range for $Q^{*}$ from 0.5 to 5). The ASH flotation results for hexadecane emulsion are presented in Figures 47 and 48 . All data reported in this paper were evaluated for emulsion flowrate $55 \mathrm{dm}^{3} / \mathrm{min}$ and air flowrate $200 \mathrm{dm}^{3} / \mathrm{min}\left(Q^{*}=3.5\right)$. Generally oil recovery increases with an increase in the water split to the overflow which is controlled by variation in the underflow opening and thus $A^{*}$. As was expected, the highest oil recovery to the overflow was obtained for $30 \mathrm{mg} / \mathrm{dm}^{3}$ of SDS and 2 $\mathrm{mg} / \mathrm{dm}^{3}$ of $\mathrm{PE}$, regardless of the overflow/underflow split. The worst result was obtained without addition of flocculant, the presence of which is necessary to neutralize the charge on the oil droplets and provide bubble attachment. The effect of polyelectrolyte addition on hexadecane recovery is shown in Figure 47 for a constant surfactant concentration of $30 \mathrm{mg} / \mathrm{dm}^{3}$. The surfactant addition on hexadecane recovery is shown in Figure 48 for a constant polyelectrolyte concentration of $2 \mathrm{mg} / \mathrm{dm}^{3}$. It is evident that the recovery goes through a maximum at approximately $30 \mathrm{mg} / \mathrm{dm}^{3}$ SDS and $2 \mathrm{mg} / \mathrm{dm}^{3} \mathrm{PE}$, which corresponds to the best conditions for filming (see Figures 4.4 and 45 ) and to the i.e.p. for the system (see Figure 46).

Another series of experiments were performed with both chemicals ( $30 \mathrm{mg} / \mathrm{dm}^{3} \mathrm{SDS}$ and $2 \mathrm{mg} / \mathrm{dm}^{3} \mathrm{PE}$ ) added directly to the feed 


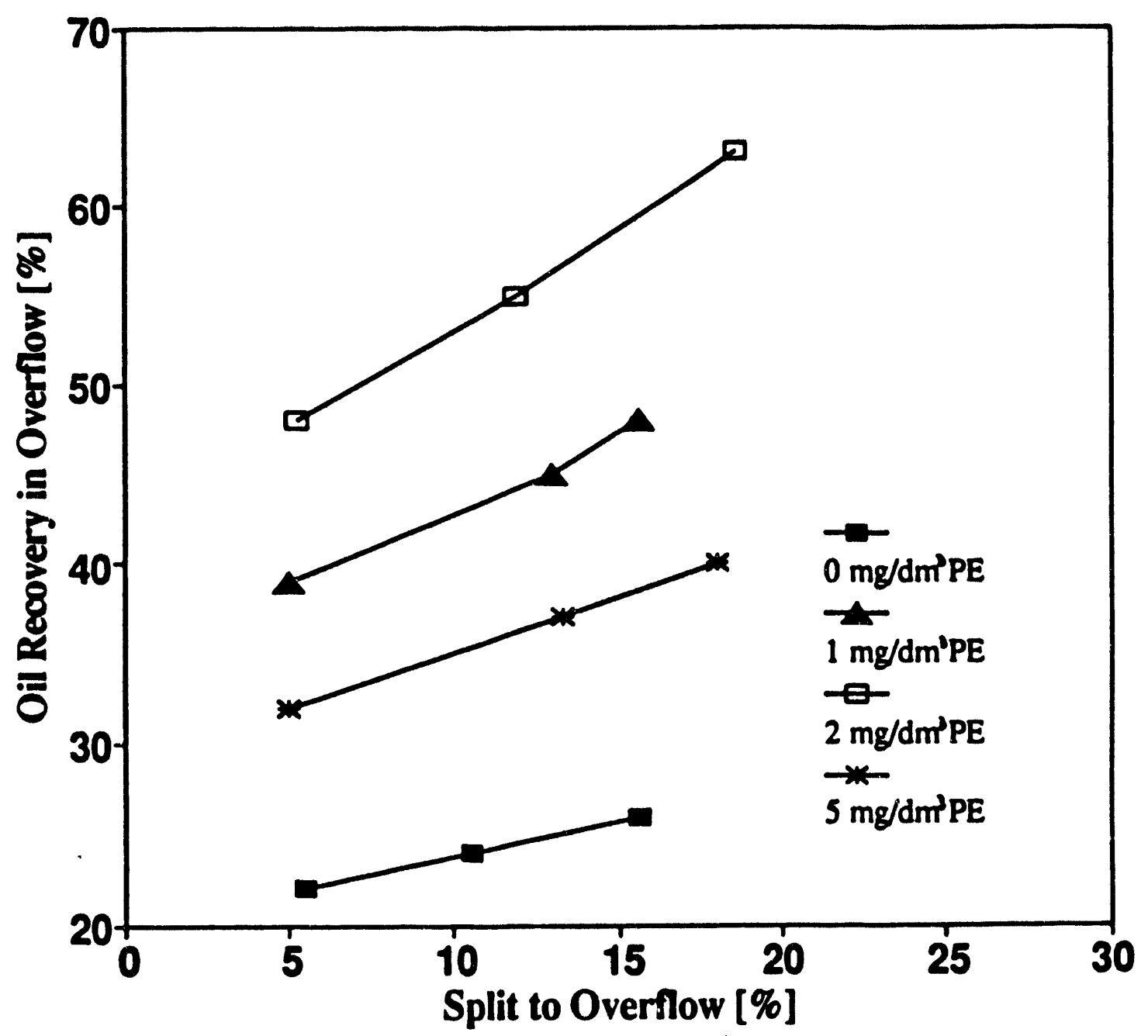
Figure 47. ASH performance as a function of UF/OF split from
hexadecane emulsion flotation at $30 \mathrm{mg} / \mathrm{dm} \mu 3 \mathrm{sDS}$

205 


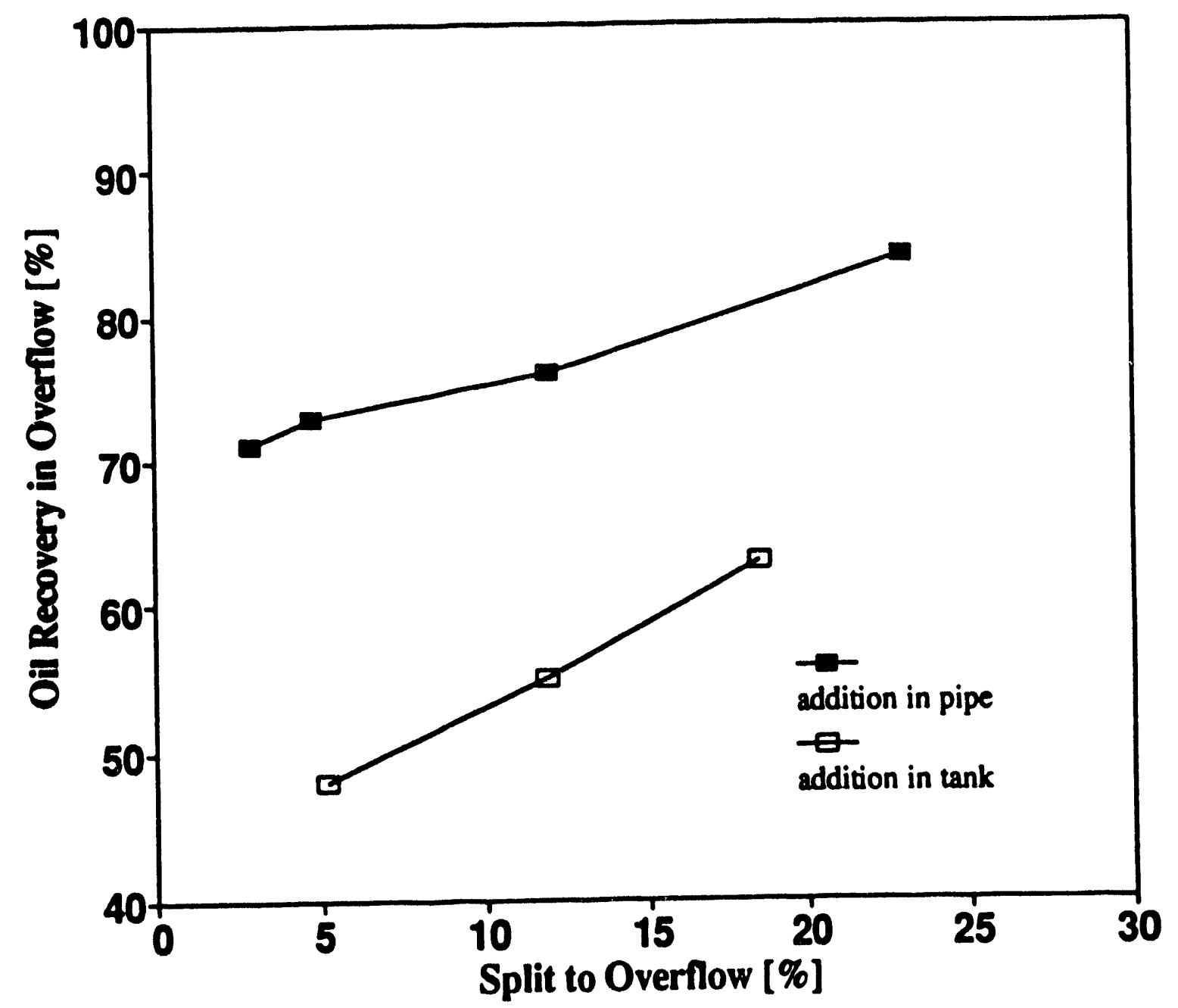

Figure 48. ASH performance as a function of UF/OF split from hexadecane emultion flotation at $2 \mathrm{mg} / \mathrm{dm}_{3} \mathrm{PE}$ 206 
line, using a peristaltic pump, see schematic in Figure 43 . This change in experimental set-up arose from the difficulty encountered in maintaining the required oil concentration in the feed due to gravity separation of oil in the storage tank after addition of chemicals. The results of these experiments show improvement in hexadecane recovery to the overflow by $20 \%$ (Figure 49). The concentration of hexadecane in the feed was $240 \mathrm{mg} / \mathrm{dm}^{3}$ and after a single pass through the $\mathrm{ASH}-2 \mathrm{C}$ was lowered to about $60 \mathrm{mg} / \mathrm{dm}^{3}$ as presented in Table 19 (each result is the average of from three to five runs).

Table 19. ASH flotation of hexadecane emulsion from a feed concentration of $240 \mathrm{mg} / \mathrm{dm}^{3}$, with $30 \mathrm{mg} / \mathrm{dm}^{3} \mathrm{SDS}$ and $2 \mathrm{mg} / \mathrm{dm}^{3} \mathrm{PE}$ added to a feed pipe.

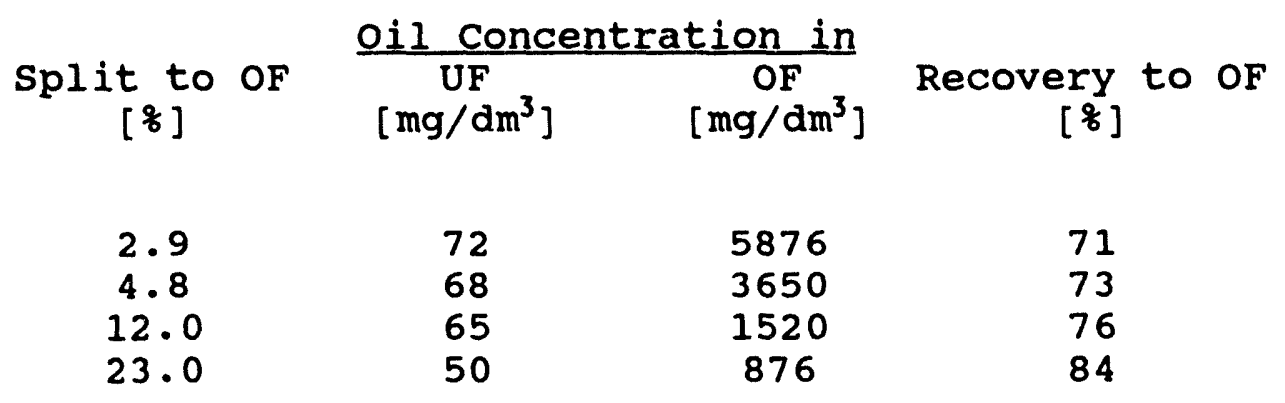

The ASH flotation of hexadecane was also tested in the recirculation condition after addition of chemicals to the storage tank. Because of difficulties with maintaining the oil concentration at higher level due to the gravity separation, this experiment was performed at starting concentration of $86 \mathrm{mg} / \mathrm{dm}^{3}$ of hexadecane. The flowrate conditions were identical with once-through experiments; the split to overflow was $6 \%$ all the time. The results are presented in Table 20. 


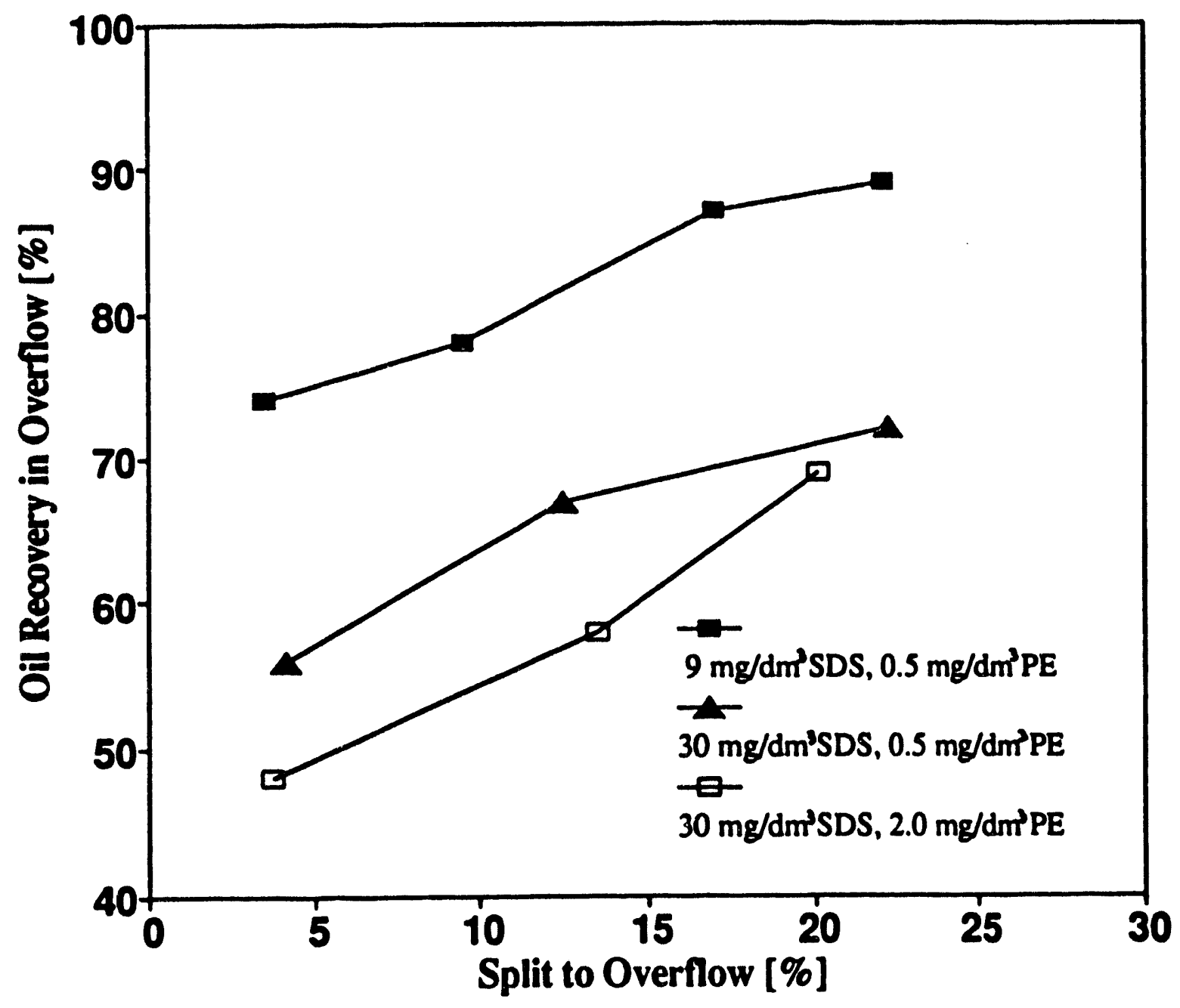

Figure 49. ASH performance as a function of UF/OF split from hexadecane emulsion flotation at $30 \mathrm{mg} / \mathrm{dm}_{3} \mathrm{SDS}$ and $2 \mathrm{mg} / \mathrm{dm}_{3} \mathrm{PE}$ 
Table 20. ASH flotation of hexadecane emulsion in the recirculation conditions from a feed concentration of $86 \mathrm{mg} / \mathrm{dm}^{3}$, with $30 \mathrm{mg} / \mathrm{dm}^{3}$ SDS and 2 $\mathrm{mg} / \mathrm{dm}^{3} \mathrm{PE}$ added to a storage tank.

\begin{tabular}{|c|c|c|c|c|c|c|c|c|}
\hline Time & [sec] & 0 & 5 & 30 & 60 & 180 & 420 & 900 \\
\hline $\begin{array}{l}\text { Feed } \\
\text { OF }\end{array}$ & $\begin{array}{l}{\left[\mathrm{mg} / \mathrm{dm}^{3}\right]} \\
{\left[\mathrm{mg} / \mathrm{dm}^{3}\right]}\end{array}$ & 86 & $22 \overline{5}$ & $\begin{array}{r}65 \\
139\end{array}$ & $\begin{array}{r}38 \\
-\end{array}$ & $\begin{array}{l}14 \\
66\end{array}$ & $\begin{array}{l}13 \\
52\end{array}$ & $\begin{array}{r}9 \\
73\end{array}$ \\
\hline
\end{tabular}

A satisfactory result (concentration in the UF of $14 \mathrm{mg} / \mathrm{dm}^{3}$ ) was reached after $3 \mathrm{~min}$. of recirculation. In the case of recirculation with the emulsions of higher oil concentrations, the process should be performed in three stages. First, addition of chemicals and equilibration of the system. Second, the collection of the top layer of oil after gravity separation. Third, ASH flotation with underflow recirculation.

Finally, the ASH flotation results for emulsion of the bitumen in kerosene blend are presented. For this oil-in-water type emulsion, the oil phase containing 208 bitumen in kerosene is less stable than the hexadecane in water emulsion. Experiments with the bitumen emulsion were performed by continuous addition of chemicals to the ASH feed pipe. The results are given in Figure 50. A higher oil phase recovery to the overflow was achieved for surfactant doses established from surface chemistry experiments, namely $9 \mathrm{mg} / \mathrm{dm}^{3} \mathrm{SDS}$ and $0.5 \mathrm{mg} / \mathrm{dm}^{3} \mathrm{PE}$. The initial concentration for the feed was $240 \mathrm{mg} / \mathrm{dm}^{3}$ and after a single pass through the ASH the oil content was reduced to as $10 \mathrm{w}$ as $34 \mathrm{mg} / \mathrm{dm}^{3}$. See Table 21 (each result is the average from three to five runs). 


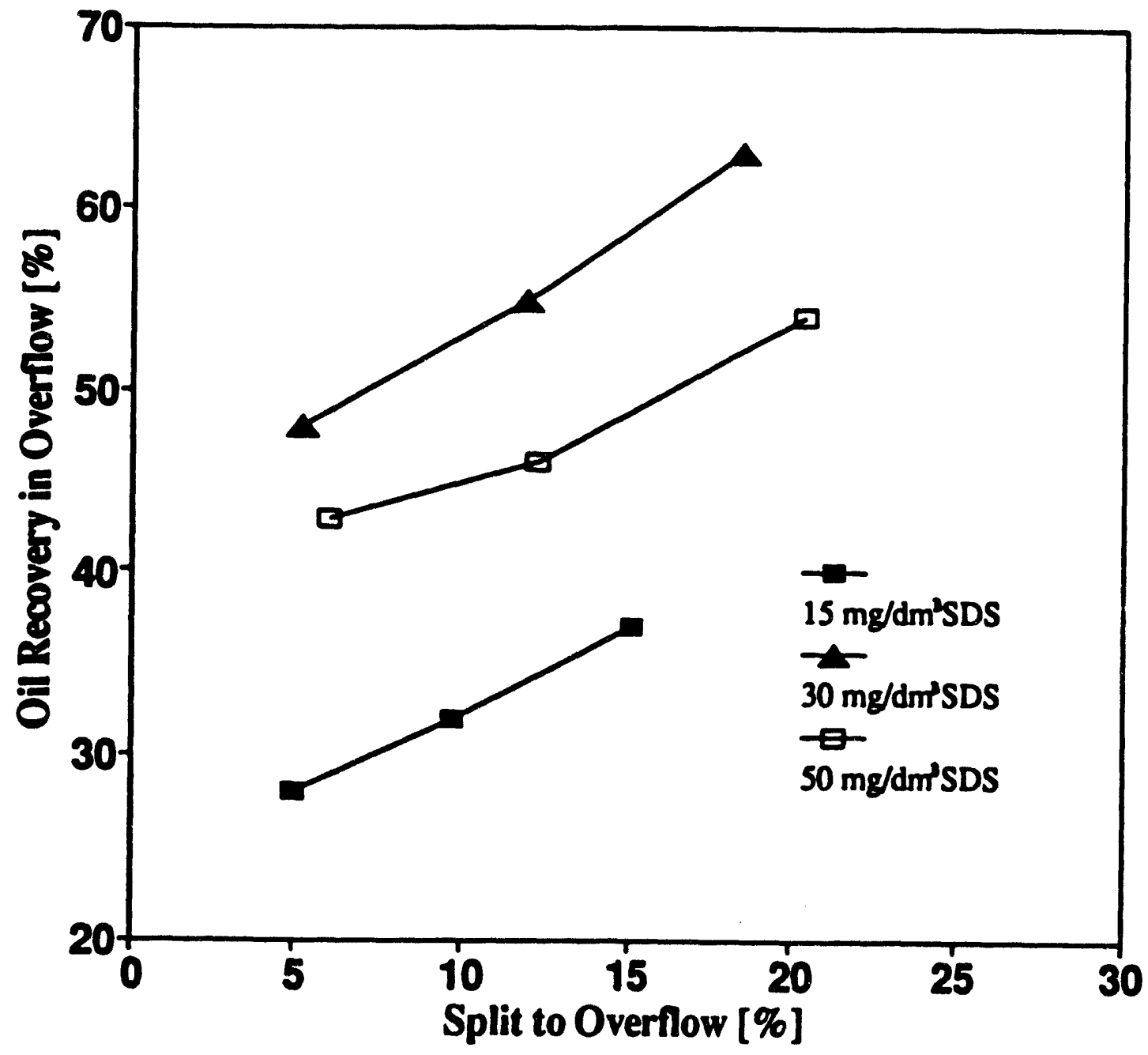

Figure 50. ASH performance as a function of UF/OF split from bitumen/kerosene emulsinn flotation 
Table 21. ASH flotation of bitumen/kerosene emulsion from a feed concentration of $240 \mathrm{mg} / \mathrm{dm}^{3}$, with $9 \mathrm{mg} / \mathrm{dm}^{3} \mathrm{SDS}$ and $0.5 \mathrm{mg} / \mathrm{dm}^{3} \mathrm{PE}$.

\begin{tabular}{cccc}
$\begin{array}{c}\text { Split to of } \\
{[\%]}\end{array}$ & \multicolumn{3}{c}{ Oil Concentration in } \\
{$\left[\mathrm{mg} / \mathrm{dm}^{3}\right]$} & $\begin{array}{c}\text { OF } \\
{\left[\mathrm{mg} / \mathrm{dm}^{3}\right]}\end{array}$ & $\begin{array}{c}\text { Recovery to oF } \\
{[\%]}\end{array}$ \\
3.5 & & & \\
9.5 & 65 & 5074 & 74 \\
17.0 & 58 & 1970 & 78 \\
22.0 & 38 & 1228 & 87 \\
& 34 & 971 & 89
\end{tabular}

An increase in surfactant and polyelectrolyte concentration lowers the recovery of oil to the overflow, because, similar to hexadecane flotation, the conditions at the oil/water and air/water interfaces apparently deviated from the required values. The spreading coefficient indicates (Figure 44) that the best condition for filming is the absence of surfactant. However, a certain amount of frother $\left(\mathrm{e} . \mathrm{g} ., 9 \mathrm{mg} / \mathrm{dm}^{3}\right)$ is required to produce smaller bubbles and a suitable froth phase with sufficient stability to carry the oil droplets.

\section{CONCLUSIONS}

Dispersed oil flotation from emulsions in an air-sparged hydrocyclone requires the control of several processing parameters. These parameters include: the ASH operating conditions (air and water flowrates as well as the size of overflow and underflow openings) and the surface chemistry conditions at the oil/water and the air/water interfaces as controlled by the addition of surfactant and polyelectrolyte. Due to the complexity of the emulsion- 
surfactant system, optimum conditions must be determined experimentally. The amount of surfactant should be established based on the evaluation of the spreading coefficient bearing in mind the requirements for ASH flotation. The appropriate concentration of polyelectrolyte can be established by zeta potential measurements. After these surface chemistry experiments the best conditions for ASH flotation can be estimated. It was shown, that the performance of the ASH system for dispersed oil flotation is significantly dependent on the tendency of oil to film at the air bubble surface. The results of this phase of our research have been very promising. Separation efficiency between 80 to $90 \%$ is possible, the exact value depends on the oil type and composition. The manner in which the ASH flotation system is operated depends on the quality of the underflow water desired. Given the present design considerations, in order to achieve an underflow product containing less than $10 \mathrm{mg} / \mathrm{dm}^{3}$ of oil from a feed of about $200 \mathrm{mg} / \mathrm{dm}^{3}$, two to four-stages of ASH flotation or the equivalent in underflow recycle will be required.

\section{FUTURE ACTIVITIES}

The promising results of the presented research encourage us to investigate the ASH oil flotation in more details. Especially the properties such as the stability and susceptibility to chemical change of the oil/water interface shall be examined in detail. For all those experiments the influence of those emulsion properties on oil separation from oil-in-water emulsion should be the main objective. 
Further attention will be given to the influence of chemicals on the air/water interface properties and on the size distribution of gas bubbles generated in the hydrocyclone. Other variables influencing the bubble size distribution which need to be studied are: the emulsion and the air flowrates, and the dimensions of the ASH (diameter, length, froth pedestal and vortex finder cross section area). 


\section{UNDERGROUND HOT WATER PROCESSING OF TAR SANDS}

\section{INTRODUCTION}

Only a small fraction of known tar sand reserves is amenable for open pit mining. In this regard, there is a continuing search for new bitumen recovery techniques which would allow exploitation of these vast Utah tar sand deposits. Up till now, conventional in-situ recovery methods (fire flood, steam injection or microemulsion injection) have proved to be inefficient or impractical, mainly due to the high bitumen viscosity of Utah tar sands. ${ }^{112}$ Some success has been reported for the lower viscosity tar sands of Canada. For example, an in-situ method for the Athabasca tar sands, the steam-assisted gravity drainage (SAGD) method, has shown great potential at the AOSTRA-operated Underground Test Facility. ${ }^{112,113}$ This method may not be suitable for major us tar sands due to the bitumen viscosity, which is several orders of magnitude greater than that of the Alberta bitumen. Another factor which would limit the application of SAGD is the much lower porosity of the Utah tar sand, and usually much smaller thickness of the tar sand seam. See reference ${ }^{114}$ and the section on tar sand porosity in this Report.

Hydraulic mining may be another method for bitumen recovery from these U.S. deposits. The outstanding potential of hydraulic extraction and transport, and the characteristic features such as: virtual tool wear elimination, flexibility in the size, shape, and orientation of the deposit that can be mined, remote control, simplicity and reliability, have been indicated in the litera- 
ture. ${ }^{115}$ A manless mining technique, known as the hydraulic borehole mining, may be of particular interest for tar sand underground mining. In fact, the feasibility of underground slurrying carried out by a single borehole drilled from the surface to the deposit was also demonstrated for California tar sand. 116

The objective of our new initiative on the underground bitumen separation from tar sand is the development of a novel technology which would allow successful underground bitumen displacement from sand and pumping to the surface only the bitumen concentrate for further processing and recycle of the aqueous phase. In the upcoming research effort, the $U / U$ water-based process for bitumen recovery from tar sands will be evaluated with regard to the possibility of underground slurrying and subsequent bitumen recovery by gravity separation. The recovery technique proposed in this section differs from conventional in-situ techniques and therefore will be termed underground processing.

BOREHOLE MINING OF TAR SANDS

Borehole mining was proposed over half a century ago, but its application to tar sands was considered much later, in the seventies and eighties. ${ }^{117.118}$ The method involves fragmentation of the ore by the water jet, formed by a tool lowered through a single borehole drilled from the surface to the deposit, and subsequent lifting of the slurry to the surface. The nozzles of the mining tool operate at $6 \cdot 10^{6} \mathrm{~Pa}$ and more than $400 \mathrm{gpm}$ to create the water jets. The resulting slurry contains 30 to 45 percent solids. One thousand short tons of oil sands were mined in Kern county, 
California, from two holes at the average rate of $14 \mathrm{st} / \mathrm{h}$ from a depth of 110 to $150 \mathrm{ft}$ in 1979.116 what is worth mentioning, in contrast to conventional mining methods, preparations preceding production are limited to a minimum for borehole mining.

Borehole mining causes minimal disruption to the environment. No overburden removal or permanent tailings stockpiling takes place, because the tailings can be backfilled to the borehole cavity.

The Bureau of Mines borehole mining system is presented on the self-explanatory schematic in Figure 51. More details are available in reference. ${ }^{116}$ The borehole mining field tests demonstrated the technic 1 feasibility of the remote extraction of oil sands through boreholes, but the rates at which the ore was produced was too low for commercial viability. The test demonstrated the need for developing borehole mining equipment that would allow higher productivity. Backfilling of the borehole-mined cavities by horizontal, underwater jetting of slurry into the cavities was proven to be feasible. Environmental monitoring for groundwater pollution and subsidence conducted during mining tests indicated the virtual absence of both phenomena. Unfortunately, no attention was given to processing the slurry and to the recovery of a bitumen concentrate. In this regard, our current initiative has been undertaken.

CONCEPT DEVELOPMENT FOR UNDERGROUND PROCESSING

originally, the underground processing was considered in terms of underground diluent pretreatment and digestion followed by 


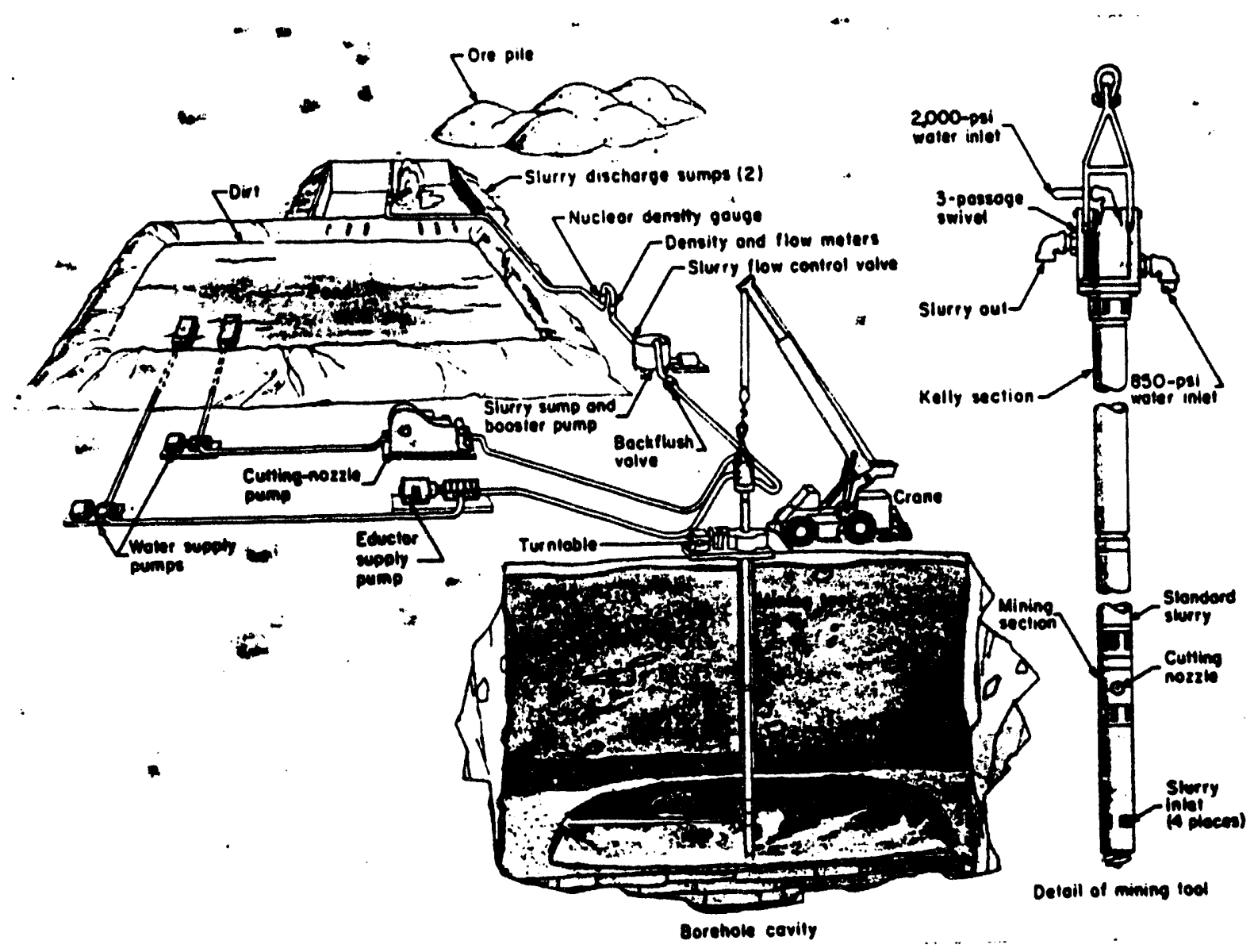

Figure 51. The Bureau of Mines borehole mining system ${ }^{116}$ 
lifting and further processing digested tar sand slurry at the surface. Later it was decided that only the bitumen concentrate and the process water need to be pumped to the surface, while the tailings advantageously may remain underground. Our approach is based on the following postulates, in view of previous experience in the surface processing of tar sands:

1) In order to save energy, the processing temperature should not exceed $50^{\circ} \mathrm{C}$, unless the inherent temperature of the deposit is greater than $50^{\circ} \mathrm{C}$. It has already been demonstrated that the processing temperature can be lowered if diluent is added to the tar sand prior tar sand contact with the aqueous phase. 119

2) Bitumen separation from sand should be accomplished at a low shear which can be obtained by the action of the water jet, and subsequent suspension transport and injection of steam and air. Any kind of agitation should aid the release of bitumen drops entrapped in tailings. Ideally, the air (or gas) should be intercepted by bitumen resulting in an increase in the buoyancy of the bitumen concentrate. Bitumen disengagement and displacement from sand may be enhanced if the tar sand is conditioned in an alkaline solution. ${ }^{120}$

3) The bitumen concentrate will be recovered from the digested tar sand slurry by gravity separation. At favorable conditions more than $70 \%$ of bitumen is expected to be recovered by gravity separation and a $90 \%$ grade bitumen concentrate (dry basis) can be expected. See the section of this Report on the new separation cell. 
4) A significant part of the water with dissolved alkalis will be recovered and reused. Process water recycle benefits bitumen separation from sand. ${ }^{121}$

The concept and the sequence of the processing steps are presented in Figure 52. The first step involves drilling, exploration, sampling and characterization for tar sand porosity, bitumen content and bitumen viscosity. Diluent alone, or saturated under pressure with $\mathrm{CO}_{2}$, is forced into the deposit in order to achieve as favorable a bitumen-diluent ratio as possible. ${ }^{114}$ In order to avoid diluent loss the penetration zone should correspond to the limits of the cavity. See Figure 52 B and C. Borehole mining of the first cavity will require lifting part or all of the slurry to the surface. In such a case the separation cell, described in a preceding section of this report, can be applied to continuously treat the slurry as it is removed from the cavity. The tailings will have to be stored temporarily in a PE lined pond. If an empty cavity is available the mined slurry can be directed to it for the separation of phases and for the recycle of the process water, see Figure 52 D. Stagnant conditioning of the tar sand slurry may enhance the bitumen separation. The final agitation can be provided by a circulating pump or by steam/air injection. The bitumen concentrate and the process water are recovered in the next step. The mined-out cavity will be backfilled with tailings to alleviate environmental problems and minimize ground subsidence, as shown in Figure $52 \mathrm{E}$. 
A

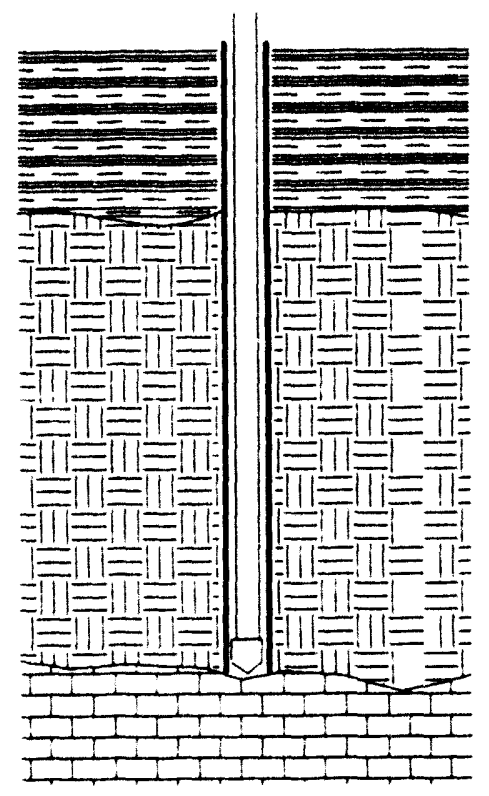

$\mathrm{B}$

$\mathrm{D}$

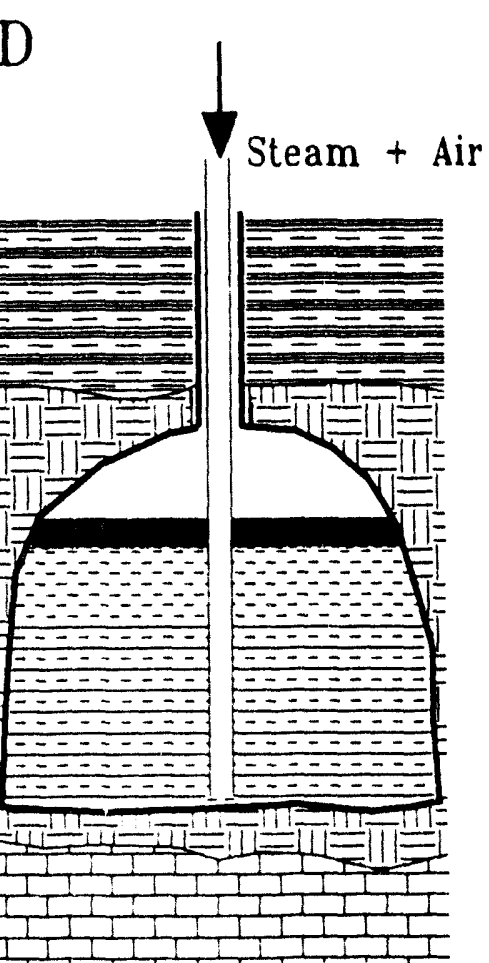

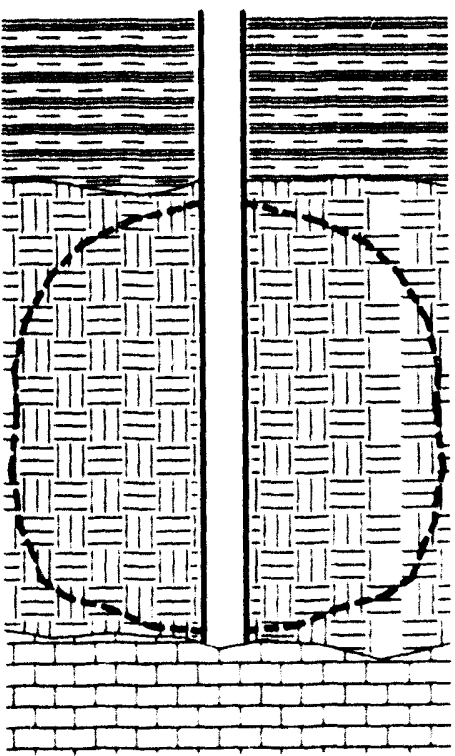
$+\mathrm{CO}_{2}$

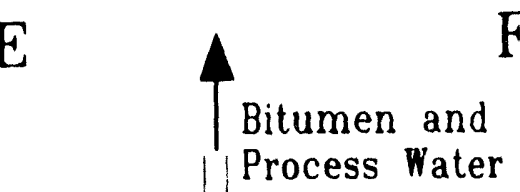

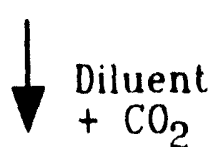
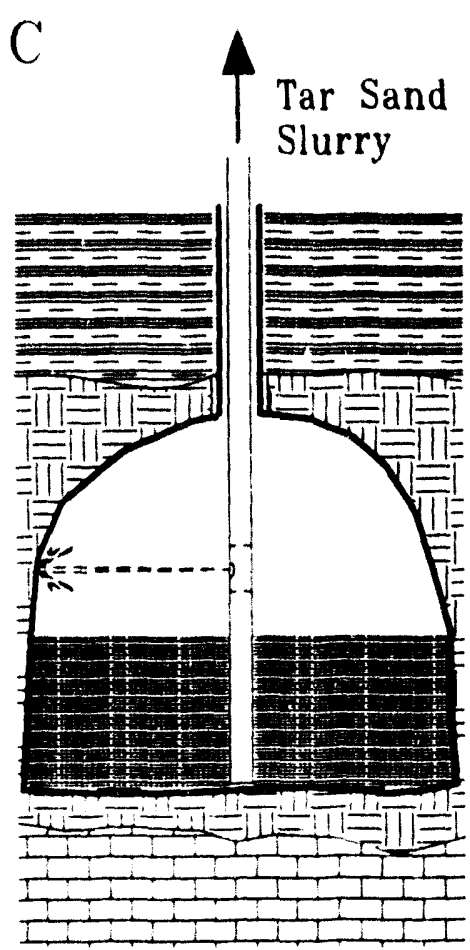

F

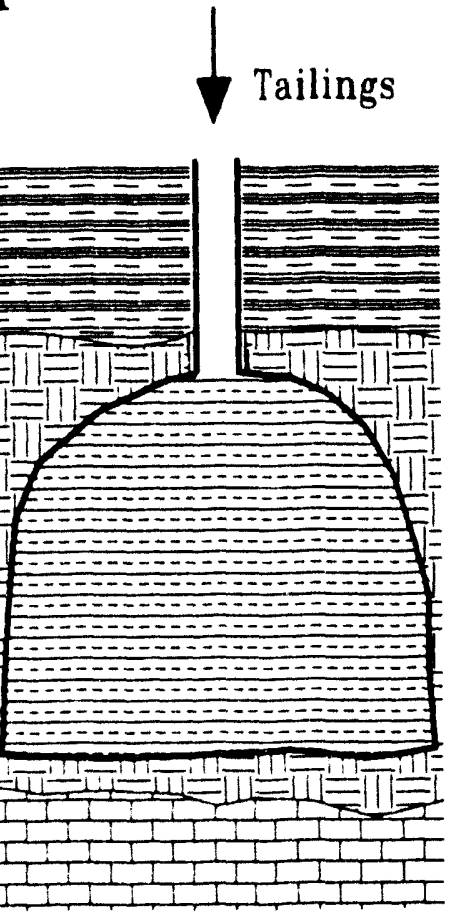

Figure 52.

Conceptual steps for the underground processing of tar sand 
The technical feasibility of these steps will have to examined in the forthcoming research effort. Tar sands composed of sharpedged mineral grains (sharp sands) may exhibit higher resistance to ablation with the water stream than the round sands. Sand characterization with respect to its shape and sphericity will be another parameter to be determined beside the tar sand tensile strength. The impact of microstructure, composition, and origin on the efficiency of ablation of oil sand samples under the influence of water jets should be studied using the successful experimental technique used for the Athabasca tar sands. ${ }^{122}$ The influence of bitumen saturation with $\mathrm{CO}_{2}$ and subsequent gas release with the formation of a separate phase (i.e., bubbles) during digestion and gravity separation needs extensive study. In the current year, the influence of tar sand conditioning in an alkaline solution on the efficiency of the hot water process was examined and is described in the following paragraphs.

\section{EXPERIMENTAL PROCEDURE}

The influence of tar sand conditioning in an alkaline solution was examined in large-scale experiments. In the standard case 20 $\mathrm{kg}$ tar sand (5 cm max. size) samples were sprayed with $400 \mathrm{cc}$ kerosene (15 wt.\% kerosene with respect to bitumen content) and 24 hours pretreatment time was provided for the diluent to penetrate the $\operatorname{tar}$ sand. In some cases $6.7 \mathrm{~L}$ of water with $20 \mathrm{~g}$ of sodium carbonate and $10 \mathrm{~g}$ of sodium tripolyphosphate was added to the pretreated tar sand (75 wt. 8 tar sand during digestion), and the mixture was left stagnant for one week in a water bath at $53 \pm 2^{\circ} \mathrm{C}$. 
These procedures for sample preparation are referred to as one week preconditioning and standard condition.

In one set of experiments a small cement mixer (32" max. dia., $33 \mathrm{rpm}$ ) was used for digestion in the rotating drum. The tar sand preconditioned in the alkaline solution for one week was simply transferred to the cement mixer and conditioned for $5 \mathrm{~min}$. In the case of the tar sand sample which was only pretreated with kerosene, water with alkalies was put directly into the cement mixer. In both cases after digestion the slurry was discharged to a container with $10 \mathrm{~L}$ of warm water (resulting in 55 weight percent tar sand for gravity separation) and the bitumen concentrate was skimmed from the surface. The tailings were then shortly agitated with steam in order to liberate residual bitumen trapped in sand, which increased the tailings temperature from $50^{\circ} \mathrm{C}$ to $72-74^{\circ} \mathrm{C}$. Bitumen skimmed after steam agitation was collected in a separate container.

Another set of experiments was carried out in a baffled stirred tank as the digester (double blade stirrer, $900 \mathrm{rpm}$ ) using identically prepared feed and the same experimental conditions as before. The maximum shear force attained in the stirred tank reactor was estimated to be 10 dynes $/ \mathrm{cm}^{2}$ while the shear force in the cement mixer was estimated to be an order of magnitude smaller. All bitumen concentrates were analyzed with respect to their composition in the Dean-stark apparatus after three days of tar sand processing to allow coarse water droplets to separate from the bitumen concentrate. The remaining water was highly emulsified. 


\section{RESULTS AND DISCUSSION}

The tar sand digestion/separation experiments were performed for both feeds (i.e., for the one week preconditioned sample and for the standard sample) at two different digestion temperatures. One temperature was below the critical temperature as dictated by bitumen viscosity. The other temperature was at the desired level. Additionally, it should be noted that each digester provides a different amount of mechanical energy which is dissipated into the slurry during digestion.

The processing results are presented in Table 22 . Very high bitumen recoveries and grades were obtained in all experiments when the critical temperature was met, i.e. the bitumen viscosity during processing was below $1.5 \mathrm{~Pa} \cdot \mathrm{s}$. For the Asphalt Ridge tar sand sample one week conditioning in the alkaline solution improved the process efficiency. Higher sand content in the first gravity concentrate probably resulted from the transfer of the digested slurry through the forming bitumen concentrate layer in the receiving container. Unlike the stirred tank reactor allowing fast bottom discharge of a well mixed digested tar sand slurry, the discharge from the cement mixer allowed for sand entrapment during formation of the bitumen layer in the receiving tank.

The experiments confirmed that the cement mixer supplying less turbulence during digestion, which means cost effectiveness due to energy saving, provided equal separation yield and a bitumen concentrate containing much less finely dispersed water. 
Table 18. Hot Water Digestion of Diluent Pretreated Asphalt Ridge Tar Sand

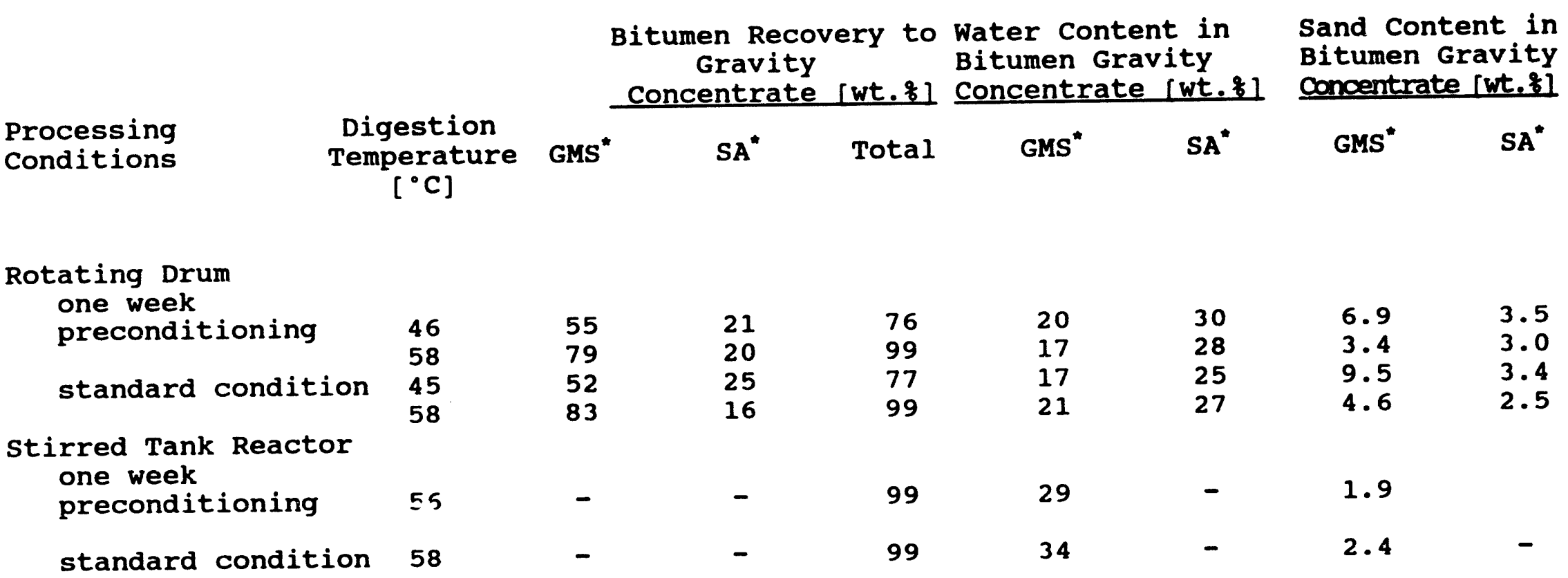

- GMS - first gravity concentrate obtained with only gentle manual stirring of the digested slurry, SA - second gravity concentrate obtained with steam agitation 
CONCLUSIONS

Considering surface chemistry principles and hydrodynamic features, successful bitumen recovery from diluent-treated Utah tar sands provides the possibility for underground processing if an adequate tar sand rubbling technique can be developed. Conceptual processing steps have been presented, and a laboratory experimental program has been initiated. At this point it has been concluded that the underground processing concept has merit and further study is justified. If successful, such a process could be less expensive and would greatly lessen the environmental problems of land reclamation. Appropriate bitumen dilution prior slurrying will have a crucial impact on bitumen recovery.

\section{FUTURE ACTIVITIES}

The technical feasibility of the proposed steps for the underground processing will be evaluated using laboratory techniques. Tar sand composition and microstructure should be correlated with the ablation efficiency using water jet streams. Tar sand characterization with respect to tensile strength and sand grains shape and sphericity will be determined. Finally, the influence of bitumen saturation with $\mathrm{CO}_{2}$ and subsequent gas release with the formation of a separate phase (i.e., bubbles) during digestion and gravity separation will be studied. 
EXTRACTION OF BITUMEN FROM WESTERN OIL SANDS BY AN
ENERGY-EFFICIENT THERMAL METHOD

Principal Investigator: Post-doctoral student: Graduate student:
J. D. Seader

S.Y. Lee

C. J. Coronella

\section{INTRODUCTION}

During the year ending July 1992, significant progress was accomplished in the development of an energy-efficient process for the extraction of cracked bitumen from tar sands by a thermal method. The process and apparatus described below involves advanced technology based on the use of thermally coupled fluidized beds. The cracked bitumen, following hydrotreating for removal of nitrogen and sulfur, is a high-grade synthetic crude oil. The process is characterized by the absence of a need to provide process water or solvents and does not require the recycle of large amounts of sand.

The extraction equipment, shown in Figure 53, consists of a vessel segregated into a pyrolysis reaction zone, a first-stage combustion zone, and a second-stage combustion zone. Each zone operates as a fluidized-bed reactor. Tar sand feed at ambient temperature and pressure is fed by a conveyor from a hopper down into the pyrolysis reactor, which operates at $450-525^{\circ} \mathrm{C}$ and where bitumen is thermally cracked to about 80 weight percent vapor and 20 weight percent coke that remains deposited on the sand particles. The vapor is sent to a condensing system, where almost 90 weight percent of the vapor is condensed to oil. The coked sand flows downward to the first-stage combustion reactor, where 


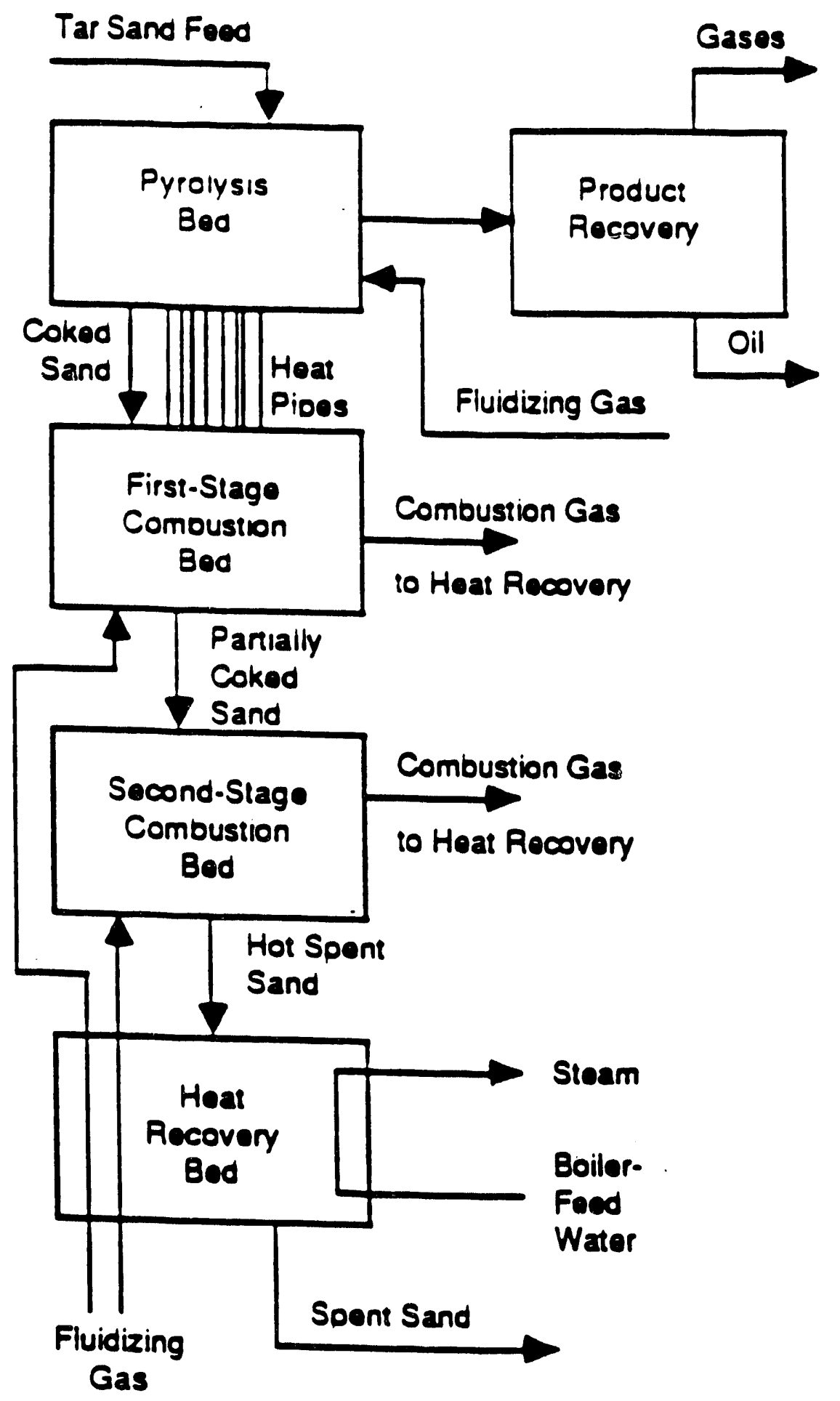

Figure 53. Advanced Energy-Efficient Thermal Process for the
Extraction of Bitumen from Western Tar Sands. 
approximately $90 \%$ of the coke is combusted with air or oxygenenriched air at $550-600^{\circ} \mathrm{C}$. The heat of combustion is transferred to the pyrolysis zone by heat pipes. The remaining coke is combusted adiabatically with air in the second-stage combustion zone. Energy remaining in the sand is used to preheat the combustion air and produce steam from boiler feed water. The clean sand can be returned to the environment or used for other purposes, such as for drilling or for making glass.

In other fluidized-bed thermal processes for extraction of bitumen from tar sands, energy requirements in the pyrolysis zone, including preheating of tar sands and heat of pyrolysis, are provided by recycling large amounts of hot sand from the combustion zone to the pyrolysis zone, with recycle ratios of 4 -to-1 being typical. In the process being developed here, sand recycle is eliminated by transferring the heat between the two zones with heat pipes, which are closed tubes that contain a heat transfer medium that boils at the lower end and condenses at the upper end. Heat pipes can transfer heat at extremely high rates so that the pipes operate almost isothermally.

In large-scale applications of the process, a large number of heat pipes would be provided for transferring the thermal energy from the first-stage combustion zone to the pyrolysis zone. The equipment may also include additional heat exchangers for heating the incoming combustion air for the combustion zone and cooling the sand. The combustion air serves as the fluidizing medium for the fluidized bed reactors of the combustion zones while flue gases 
from the combustion zone can serve as the fluidizing medium for the fluidized bed reactor of the pyrolysis zone. Alternatively, recycled light hydrocarbon gases produced from the bitumen and/or steam may be used to fluidize the pyrolysis zone.

Two experimental studies were completed during the year ending July, 1992. The first study was directed at the determination of the extent and mechanism of erosion and corrosion of the vertical heat pipes in the fluidized beds. The second study involved the determination of the effect of the vertical heat pipes on the minimum slugging velocity in the fluidized beds, since it is important to operate the beds in the bubbling regime.

\section{Erosion and corrosion}

Metal wastage of heat transfer tubes in fluidized-bed combustors (FBC) has recently emerged as a potentially serious problem that affects the commercialization of FBC technology for various applications, as discussed by Anderson et al. ${ }^{123}$. Since most combustors are operated at high temperatures and the combustion gases are oxidizing agents, the wastage process might involve two mechanisms: (1) erosion - metal loss caused by mechanical action resulting from impingement of solid particles and (2) corrosion - tube surface deterioration caused by chemical action due to oxidation at high temperature. Even though metal wastage in fluidized-bed combustors could be caused by erosion and corrosion, previous studies have concentrated mainly on erosion of metals. For example, Dennis, zhu et al. ${ }^{125}$, MacAdam and stringer ${ }^{126}$, and $\mathrm{zhu}$ et al. ${ }^{127}$ studied erosion of metals in fluidized beds by conducting 
experiments at room temperature to minimize the influence of corrosion. Only the studies by wright et al. ${ }^{128}$, Levy et al. ${ }^{129}$, and stott et al. ${ }^{130}$ have involved the combined erosion-corrosion behavior of metals at elevated temperatures. Questions regarding whether wear in fluidized bed combustors is caused by an erosion or corrosion mechanism or a combination of the two mechanisms still exist, as discussed by Gansley and O'Brien ${ }^{131}$.

The effect of increasing temperature in conjunction with corrosion on wear of metals in fluidized beds has been studied in the last few years. Levy et al. ${ }^{129}$, who investigated the wear of 1018 steel by particles in circulating fluidized-bed combustors, observed a large increase in the metal wastage for temperatures from 450 to $650 \mathrm{c}$. On the other hand, smeltzer et al. ${ }^{132}$ reported a decrease in the wear rate of type 410 ss (stainless steel) with increasing temperature in the range of 25 to $370 \mathrm{C}$. In addition to the above two trends, other researchers, including Young and Ruff $\mathrm{f}^{133}$ and stott et al. ${ }^{130}$, observed that the oxide scales formed by corrosion of steels at high temperatures could either enhance or inhibit erosion leading to higher or lower wear rate, respectively, depending on the operating conditions. In view of all these studies, it is evident that the erosion-corrosion behavior of metals in FBC is so complex that generalization on the basis of any particular research results could lead to erroneous conclusions.

Extensive research has been conducted at the University of Utah to develop a two-stage, thermally coupled fluidized-bed 
processing system for energy-efficient conversion of tar sands to synthetic crude oil, as discussed by oblad et al, ${ }^{134}$ and coronella and seader ${ }^{135}$. In an experimental laboratory model of the system, three vertical immersed heat pipes, with liquid potassium as the working fluid, are used to transfer excess heat from a lower fluidized-bed combustion reactor to the upper fluidized-bed pyrolysis reactor. A primary concern is the wear of the heat pipes under continuously operating conditions. Because small changes in operating conditions can produce extremely large variations of wastage behavior and because most previous studies, e.g. Levy et al. ${ }^{129}$ and stott et al. ${ }^{130}$, used relatively high gas velocities typical of circulating fluidized beds, the wear-test results reported in the literature may not be applicable to our system, which typically operates in the bubbling regime. Therefore, the objective of this study was to investigate the influences of operating parameters on in-bed metal wastage, especially for fluidized beds operated in the bubbling regime as expected for commercial operation. Although the heat pipes in our system are installed vertically, some tests were also performed with a horizontal orientation.

\section{Minimum Slugging Velocity}

In order to properly scale-up a fluidized-bed reactor, it is necessary to identify the regime in which it operates. Certainly, all hope of successful scale-up must be abandoned if no attempt is made to operate both large and small reactors in the same regime. At the operating conditions under consideration in the research 
reported here, only the bubbling and slugging regimes need to be considered.

Briefly, the bubbling regime is characterized by the passage of small bubbles, growing by coalescence, throughout the height of the bed. In a slugging bed, the bubble size has grown to some maximum size, directly proportional to the bed diameter, with different values for this constant of proportionality being given by different authors. The rate at which the bubbles pass through a slugging bed is significantly reduced, compared to that in a bubbling bed. Since the bubbles (slugs) have grown to a maximum and relatively uniform size, they pass through the bed essentially at a single, characteristic frequency. More detailed descriptions of these and other regimes possible in a fluidized bed are given by Clift ${ }^{136}$ and Wen $^{137}$.

There is widespread disagreement in the literature in predicting $u_{m s}$, the superficial gas velocity above which a bubbling bed becomes a slugging bed. Let us consider as an example a 10-cm diameter bed of sand, with an average particle size of $165 \mathrm{~mm}$ diameter, fluidized by air at $25 \mathrm{C}$ and 1 atm. Four correlations from the literature predicting the onset of the slugging regime in an open bed, i.e., one without internal solid parts, as a function of $L_{m f}$, the bed height at minimum fluidization, are shown in Figure 54. For the sake of illustrative comparison, $u_{m f}$ is also shown. The correlation given by Broadhurst and Becker ${ }^{138}$ predicts a lower value for $u_{m s}$ than the others. Stewart and Davidson ${ }^{139}$ did not consider the effect of bed depth in their work. However, for a bed 


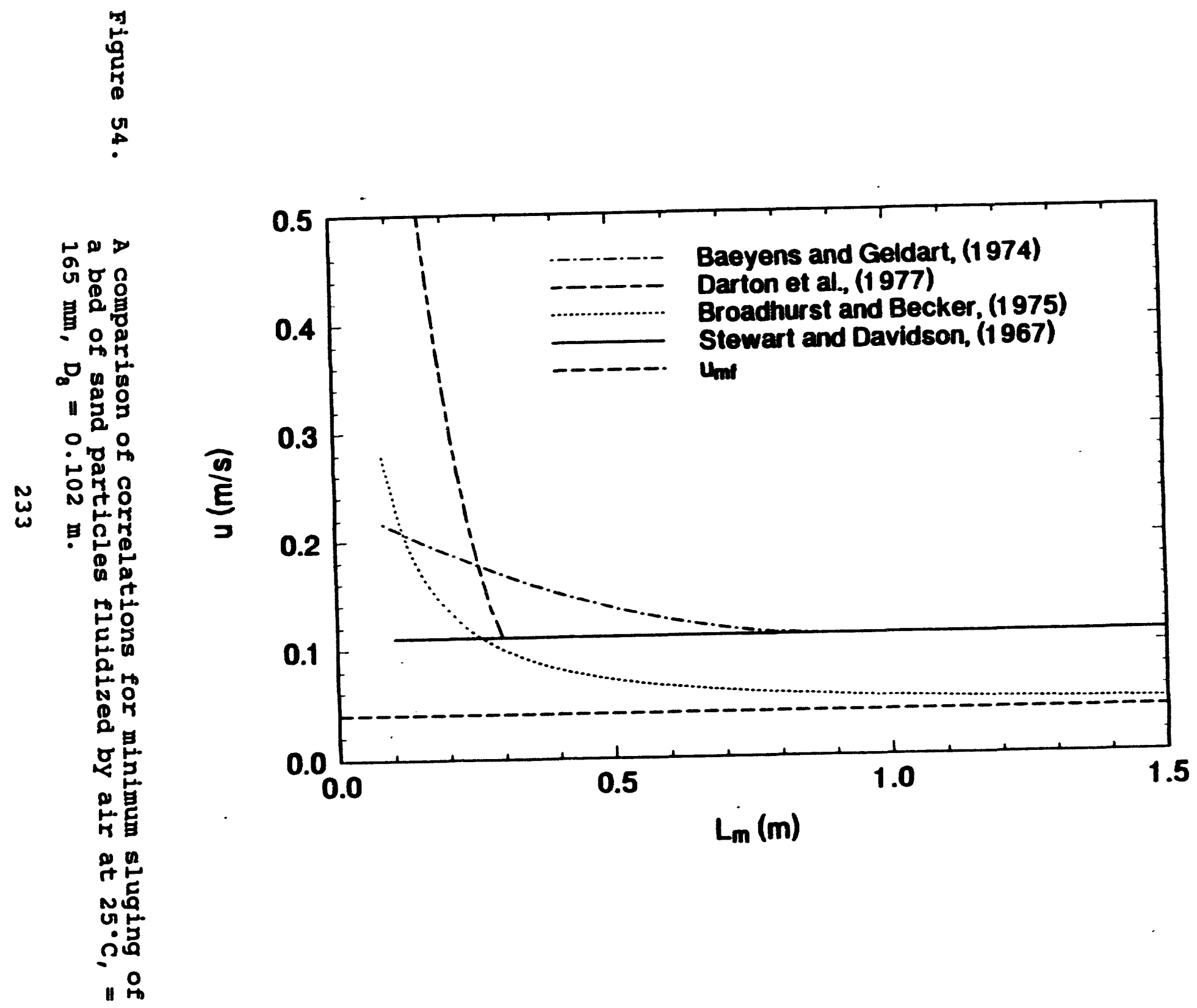


deeper than about $0.7 \mathrm{~m}$, Darton et al. ${ }^{140}$ and Baeyens and Geldart ${ }^{141}$ confirm the following correlation given by stewart and Davidson ${ }^{139}$ :

$$
u_{m s}=u_{m f}+0.07\left(g D_{b}\right)^{0.5}
$$

Thus, except for Broadhurst and Becker, there is accord in predicting $u_{m}$ for deep beds (with a height-to-diameter ratio greater than 7) among the different groups of workers. However, there is little consensus regarding $u_{m s}$ in shallow beds. Apparently, one cause of the disagreement in the curves of Figure 54 lies in the definition of the bubbling and slugging regimes. Thus, the issue of slugging is perplexing, since each investigator has chosen different experimental criteria to differentiate between the two regimes.

Many studies have been presented regarding the effects on fluidization of fixed internal objects, typically horizontal heatexchanger tubes. It is widely acknowledged that fluidization and, hence, fluidization regime can be affected by the presence of internal objects within a bed ${ }^{142-146}$. It is usually said that a network of horizontal tubes within a bed either inhibits bubble growth or breaks up large bubbles. Thus, the transition from the bubbling to the slugging regime is shifted to a higher gas velocity. However, no investigation has quantitatively described the effect of vertical tubes, as used in fluidized beds for bitumen recovery from tar sands. Conseq ently, the goal of this study was to quantitatively determine the influence of vertical tubes upon the regime of fluidization within a bed. 
Several experimental methods have been employed to identify the regime of fluidization. A pressure probe offers the simplest. nonintrusive device for studying properties of fluidized beds in an objective fashion. To prevent the probe from interfering with the fluid dynamics, most researchers prefer to place the probe flush against the reactor wall $1^{147}$. However, it has been shown recently that meaningful pressure-fluctuation data may be obtained from a probe placed below the distributor in the plenum chamber ${ }^{148,149}$.

The phenomenon of pressure fluctuations induced by bubble eruptions can be described as follows ${ }^{141}$. A gas bubble erupting at the surface of a fluidized bed projects particles into the freeboard region, resulting in a reduction of pressure drop. This can be attributed to the reduced height of dense bed which the fluidizing gas must pass through. Thus, pressure below the surface of the bed is reduced for the period of time that particles are in the freeboard. As the particles subsequently fall back into the bed, pressure in the bed is increased by the larger pressure drop across the dense region. Thus, each bubble or slug erupting at the surface causes a pressure fluctuation. These fluctuations may be masked by other pressure-related phenomena, including overlapping bubble eruptions, bubble coalescence within a bed, and bubble formation at the gas distributor.

Broadhurst and Becker ${ }^{150}$ proposed the method of studying the power spectral density function (PSDF) of the pressure fluctuations for describing the fluidization quality. Spectral analysis is a powerful tool used to study data taken in the time domain for the 
purpose of examining a specific phenomenon of interest, when it might not otherwise be easily isolated, due to the presence of noise or other signals. The PSDF identifies the frequencies present in a signal, and assigns to each a power, which is indicative of the relative strength of that frequency in the signal. In other words, the PSDF of a true periodic function has a peak at the frequency of periodicity, and has zero power at all other frequencies. Individual physical phenomena can be studied by identifying distinct frequencies dominant in a particular signal and attributing each to the relevant mechanisms. Hence, a spectral analysis of the pressure fluctuations is useful for the purpose of studying the bubble eruption phenomenon.

\section{EXPERIMENTAL}

\section{Erosion and Corrosion}

Wear experiments were performed in a 309 SS fluidized-bed test unit having a diameter of $10.8 \mathrm{~cm}$ and a height of $140 \mathrm{~cm}$, as shown in Figure 55. Silica sand ( $99 \%$ quartz) was chosen as the bed material in this study because it is typical of the major constituent of tar sands and is believed to be primarily responsible for any metal wear. The average sand-particle size, computed from a geometric average, was 153 microns, and more than $90 \%$ by weight of the sand fell into the range 124 to 297 microns. The sand-particle shape factor was found to be 0.7 by the method of Casal et al. ${ }^{151}$. A differential pressure gauge was used to monitor bed level, which was maintained constant by adding suitable amounts of sand as required during a run to replace any losses due to 


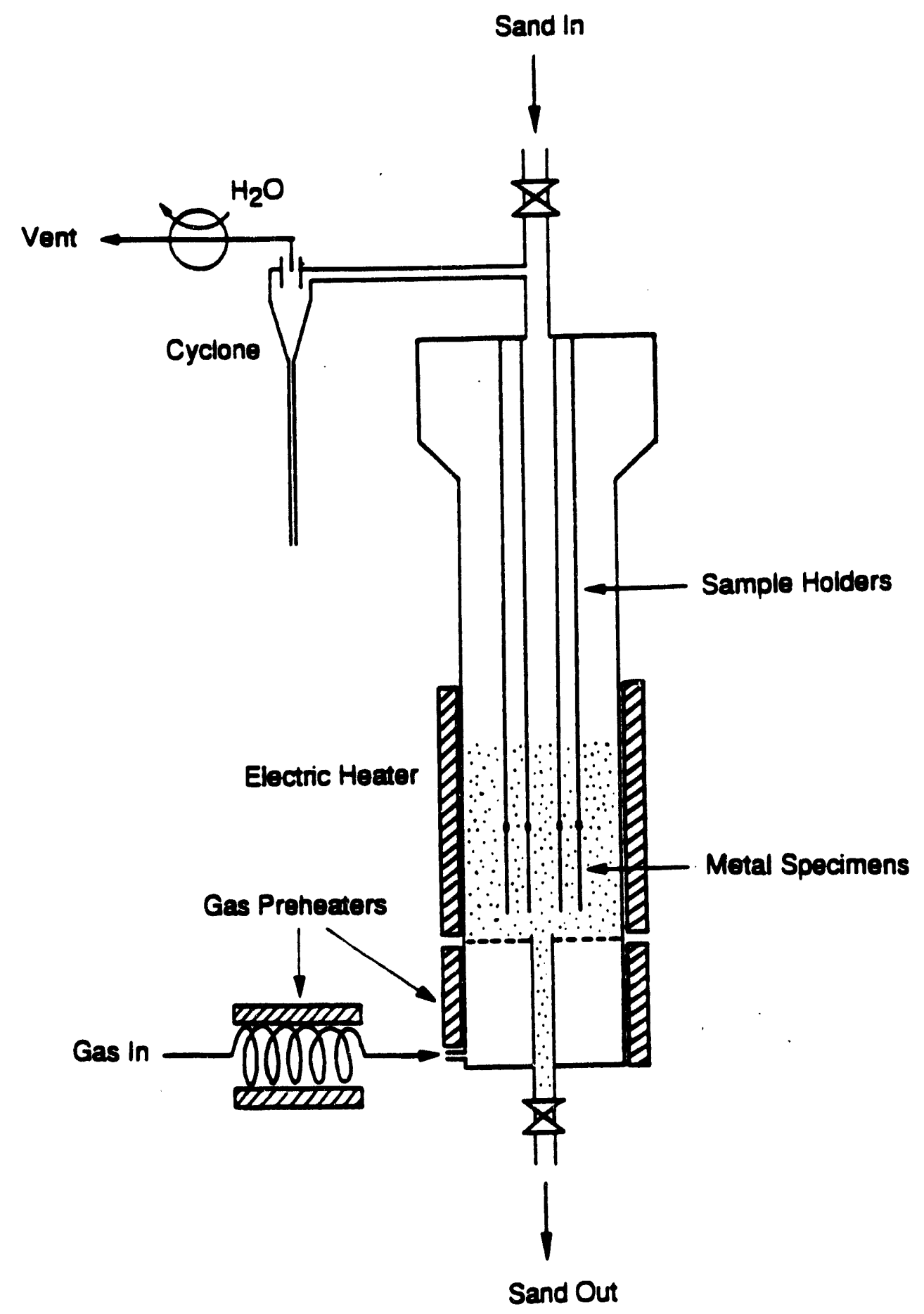

Figure 55. Schematic diagram of the fluidized bed used for
wear tests. 
entrainment.

Most tests were conducted with air as the fluidizing agent at superficial velocities of $0.07-0.37 \mathrm{~m} / \mathrm{s}$. The air was fed to a gas distributor consisting of a perforated steel plate of $0.16-\mathrm{cm}$ thickness with $0.1-\mathrm{cm}$-diameter holes at a center-to-center hole spacing of $1 \mathrm{~cm}$. When in operation, air first passed through a preheater and then entered the bed via the distributor, flowing upward through the bed towards the exhaust at the top, where it passed through a cyclone that collected fines elutriated from the bed. A relatively high rate of formation of fines was observed during the first 24 hours of fluidization (i.e., nearly $5 \%$ of the initial weight), due probably to the loss of sharp corners and edges of the silica sand by particle attrition. After a period of two weeks of operation, the overall weight loss of the silica sand was less than $8 \%$ corresponding to less than a $4 \%$ decrease in average particle size. A $1.5 \mathrm{~kW}$ external furnace was used to accurately control the temperature of the test unit. Wear tests were conducted under different conditions of gas velocity, temperature, rod orientation, and rod metal. To test the effect of gas composition, tests were conducted on beds fluidized by air and by nitrogen of $99.95 \%$ purity.

Solid metal rods of $0.64-\mathrm{cm}$ diameter were used to simulate the heat pipes. The rods tested were mounted on six equally spaced sample holders, $3.6 \mathrm{~cm}$ center-to-center, hanging from the top head of the fluidized bed. As shown in Figure 56, the metal rods were mounted in either a vertical or horizontal configuration with 
(i) Vertical Orientation

(ii) Horizontal Orientation

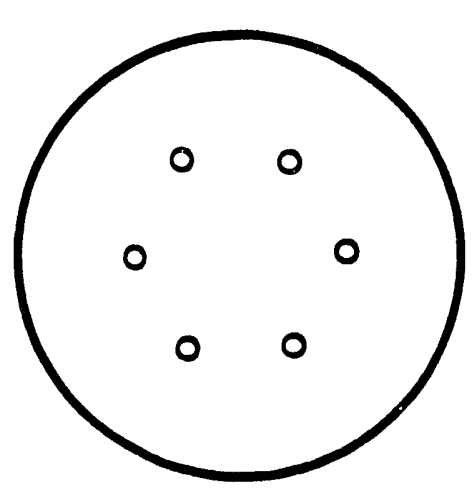

Top View

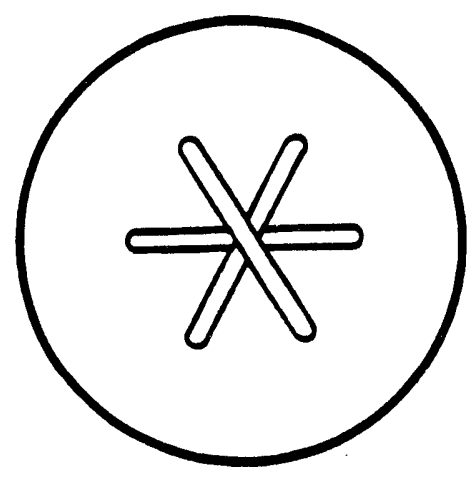

Side View

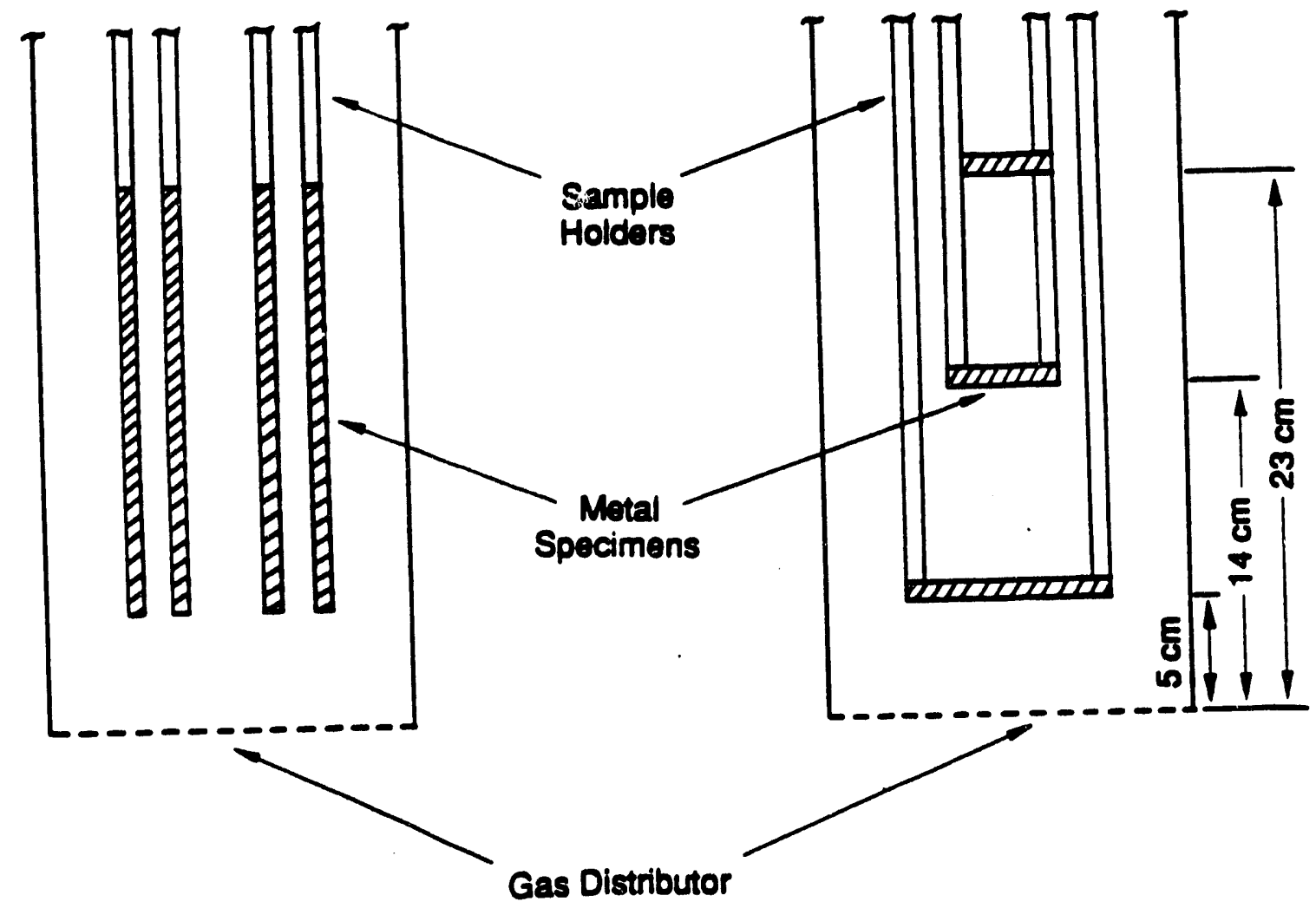

Figure 56. Illustration of rod orientation. 
lengths of 18 and $6 \mathrm{~cm}$, respectivaly. For the vertical orientation, six metal rods were tested simultaneously with the bottoms of the rods located approximately $5 \mathrm{~cm}$ above the distributor plate. Three metal rods, located about 5, 14, and 23 cm, respectively, above the distributor plate, were used for the horizontal-orientation tests. For all test runs, the metal rods were fully immersed in a bed of silica sand of a $35-\mathrm{cm}$ depth under static conditions. Most wear rates were determined based on the weight loss occurring during an approximately 336-hour (2-week) continuous operation. Following each test run, the weight loss of each rod was measured with a Denver Instruments scale accurate to $0.1 \mathrm{mg}$ and its wear rate was then determined based on the average weight loss of all the metal rods tested. The average weight loss was typically in the range of 3 to $20 \mathrm{mg}$ relative to the initial weight of approximately $44.5 \mathrm{gram}$.

It was observed that the vertical rods in the fluidized bed did not wear uniformly and their wear rates were affected by the rod location. Large variations were obtained when using low gas velocities whereas relatively uniform wear was observed under high gas velocity. It is believed that the hydrodynamics of the fluidized bed is more prone to stable flow patterns with minimum friction resistance under the condition of low gas flow rate, as opposed to a random, well-mixed bed under the condition of high gas flow rate. The relative standard deviations of the measured wear rates varied from 6 to 14 percent. Duplicated wear tests with identical materials and under identical conditions showed wear 
rates to be consistent within $\pm 12 \%$. The average results used in this study actually reduced uncertainty associated with preferential bubble paths and uneven fluidization and eventually improved statistical accuracy.

\section{Minimum slugaing Velocity}

Table 23 shows the experimentally determined physical parameters of the sand used in minimum slugging velocity study. Particle diameter was taken as the harmonic average. Particle shape factor was foind by a standard method ${ }^{151}$, and minimum fluidization velocity was found by the usual method of plotting fluidizing gas velocity vs. pressure drop, and fitting two lines, the intersection of which gives $u_{m f}$.

As shown in Figure 57, the study was conducted using a cylindrical glass reactor, with an inside diameter of $10.2 \mathrm{~cm}$ and height of $170 \mathrm{~cm}$. The distributor was made of sintered steel 0.32 cm thick. Three $1.9-\mathrm{cm}$ aluminum rods, mounted on a triangular pitch, were inserted in the bed to simulate the presence of the vertical heat pipes. The center-to-center spacing was $5.2 \mathrm{~cm}$ and the rods extended down to $1.3 \mathrm{~cm}$ above the distributor. The rods hung from the top lid, and were supported by a triangular brace welded to each at about the midsection of their length to prevent horizontal motion during the experiments. Pressure taps were located at the top of the column by the gas exit line and in the plenum chamber, below the distributor. The volume of the plenum chamber was $3350 \mathrm{~cm}^{3}$.

The data-acquisition system that recorded the pressure-drop 
Table 23

Characteristics of the sand used in the fluidization studies

$\begin{array}{ll}\text { Mean dp } & 165 \mathrm{~mm} \\ u_{m f} & 0.0404 \mathrm{~m} / \mathrm{s} \\ r_{s} & 2580 \mathrm{~kg} / \mathrm{m3} \\ e_{m f} & 0.49 \\ f_{s} & 0.90\end{array}$




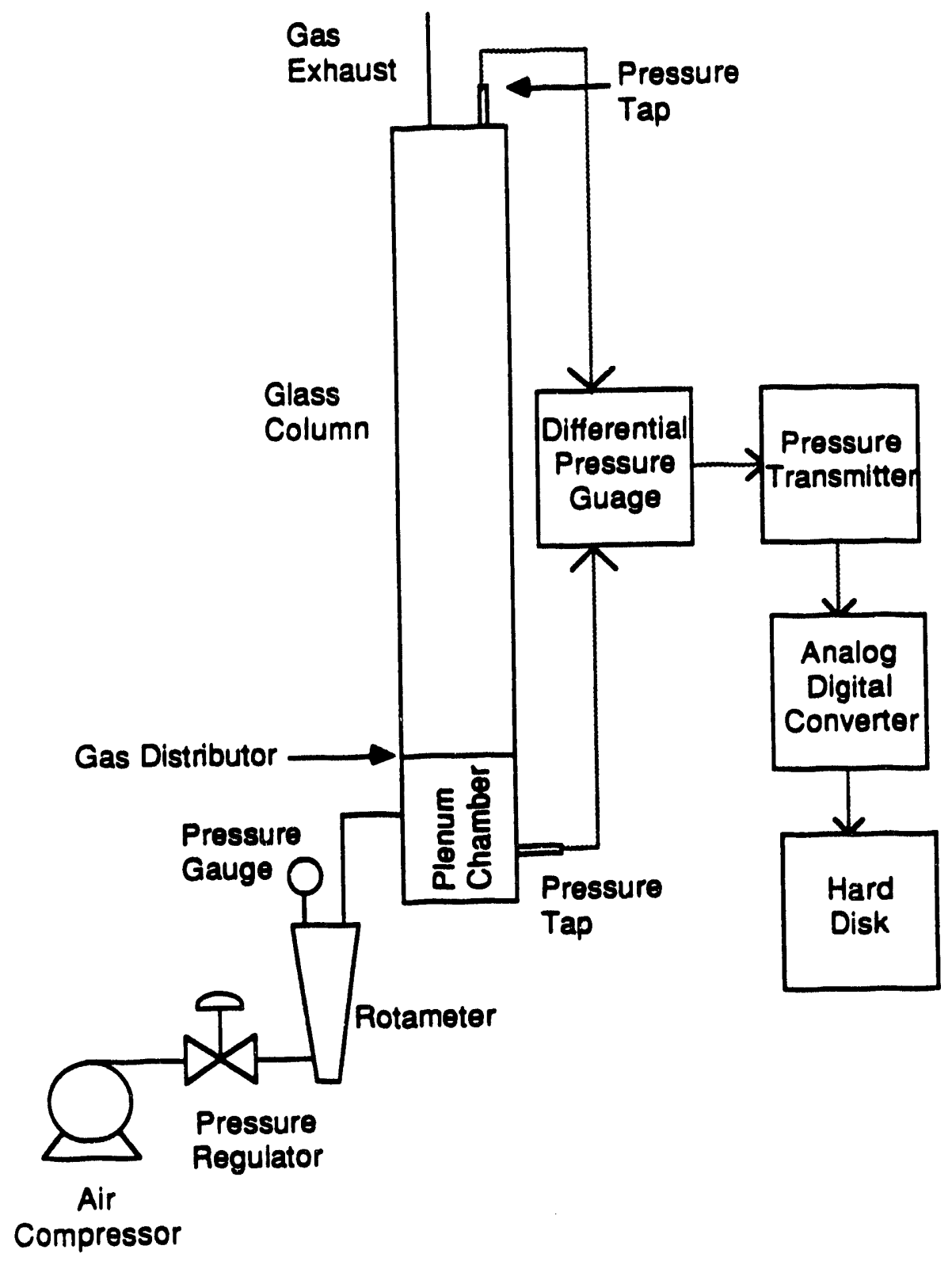

Figure 57. Experimental apparatus. 
data is capable of measuring pressures between 0 and $21 \mathrm{kPa}$ at a rate of $19 \mathrm{~Hz}$. Although this rate of data sampling is apparently slow compared to the rate previous investigators have used (as high as $100 \mathrm{~Hz}$ ), several research groups have shown this rate to be adequate $^{147,149}$. The only limitation to this slower sampling rate is that no information can be gleaned about frequencies greater than the Nyquist frequency, $9.5 \mathrm{~Hz}$ in this system. It has been shown ${ }^{152}$ that all meaningful frequencies in the bubbling system are well within the range that can be measured accurately by our system.

The procedure used for a given amount of sand in the bed was straight forward. A predetermined amount of sand was put in the bed and the bed was fluidized at a gas rate high enough to ensure vigorous bubbling. Then the air flow was slowly reduced, over the period of about a minute, to zero, after which the settled bed height was measured. This was done to ensure consistency in the height measurement. For each of several gas flow rates, starting with the largest, and finishing with the smallest, the pressuredrop data were recorded 500 times, the gas flow rate was recorded, and visual observations of the bed were made, as described below. This procedure was repeated several times with different amounts of sand in the bed. Then the apparatus made of three aluminum rods was inserted into the bed, and the entire procedure was repeated. Visual observations of the fluidization regime were classified as follows: If bubbles were visible along the length of the column, and the diameter of the bubbles erupting on the surface was obviously less than the bed diameter, and the height of the bed was 
relatively constant, then the bed was said to be in the bubbling regime. The bed was said to be in the slugging regime when bubbles were visible along the entire length of the column, and when at some point along the column bubbles appeared to span the width of the column or when the level of the bed fluctuated widely. If the bed was not clearly operating in either regime, then this also was recorded. Thus, a crude estimate of $u_{m s}$ was established by bracketing the value between a lower and an upper estimate, based on visual observation alone.

Power spectra of the data were computed offline in order to study the frequency of bubble or slug eruption. To prevent the signal from being dominated by a peak at a frequency of zero, the mean value was subtracted from each collection of 500 data points before processing. The versatile algorithm for computing the PSDF by the fast Fourier transform algorithm (FFT) ${ }^{153}$ was used for the computations. The power spectra were computed at $\mathrm{N}_{r}=32$ different frequencies. Detail about the theory and applications of spectral functions is available in textbooks ${ }^{154}$.

It is widely recognized that beds of large particles (Group D) slug at a single dominant frequency. This is reflected in the PSDF by one, or at most, two peak frequencies. This is typical of socalled square-nose slugging ${ }^{155}$, which is characterized by nearly square slugs of gas rising through the bed. slugging beds of smaller Group B particles, however, are characterized by less orderly slugs. Although it is recognized that slugging in largeparticle systems (Group D particles) is more likely to have a PSDF 
with an easily identifled dominant frequency ${ }^{155}$, it will be shown below that this method can indeed be used to extract useful information from smaller-particle systems (Group B particles).

RESULTS AND DISCUSSION

Erosion and corrosion

Duration of run. As many as three successive runs of approximately two-weeks duration each were made with the same rods to better determine the characteristics of the wear process as a function of time. The experimental results of two 1000-hour-total wear tests using six 316 ss rods mounted vertically are given in Figure 58 for superficial gas velocities, $U$, of 0.133 and $0.266 \mathrm{~m} / \mathrm{s}$ and an operating temperature of 500C. As shown in Figure 58, the cumulative weight loss increases with time of exposure. A higher superficial gas velocity causes a larger weight loss, implying that metal wear as a result of erosion may be significant.

The wear rate can be calculated based on the weight loss per unit time, i.e., from the slopes of the cumulative-weight-loss curves. Figure 58 shows that at first the wear rate (or slope) decreases with time, but then seems to tend towards a constant value after about 400 hours of operation. Therefore, it was assumed that a steady wear rate is achieved after about two weeks of operation. Initial wear rate is herein defined as wear rate calculated on the basis of weight loss in the first two-week period. The initial wear rates calculated from Figure 58 are 1.27 and $1.99 \mathrm{~nm}$ of rod depth (in the radial direction) per hour for gas superficial velocities of 0.133 and $0.266 \mathrm{~m} / \mathrm{s}$, respectively, while 


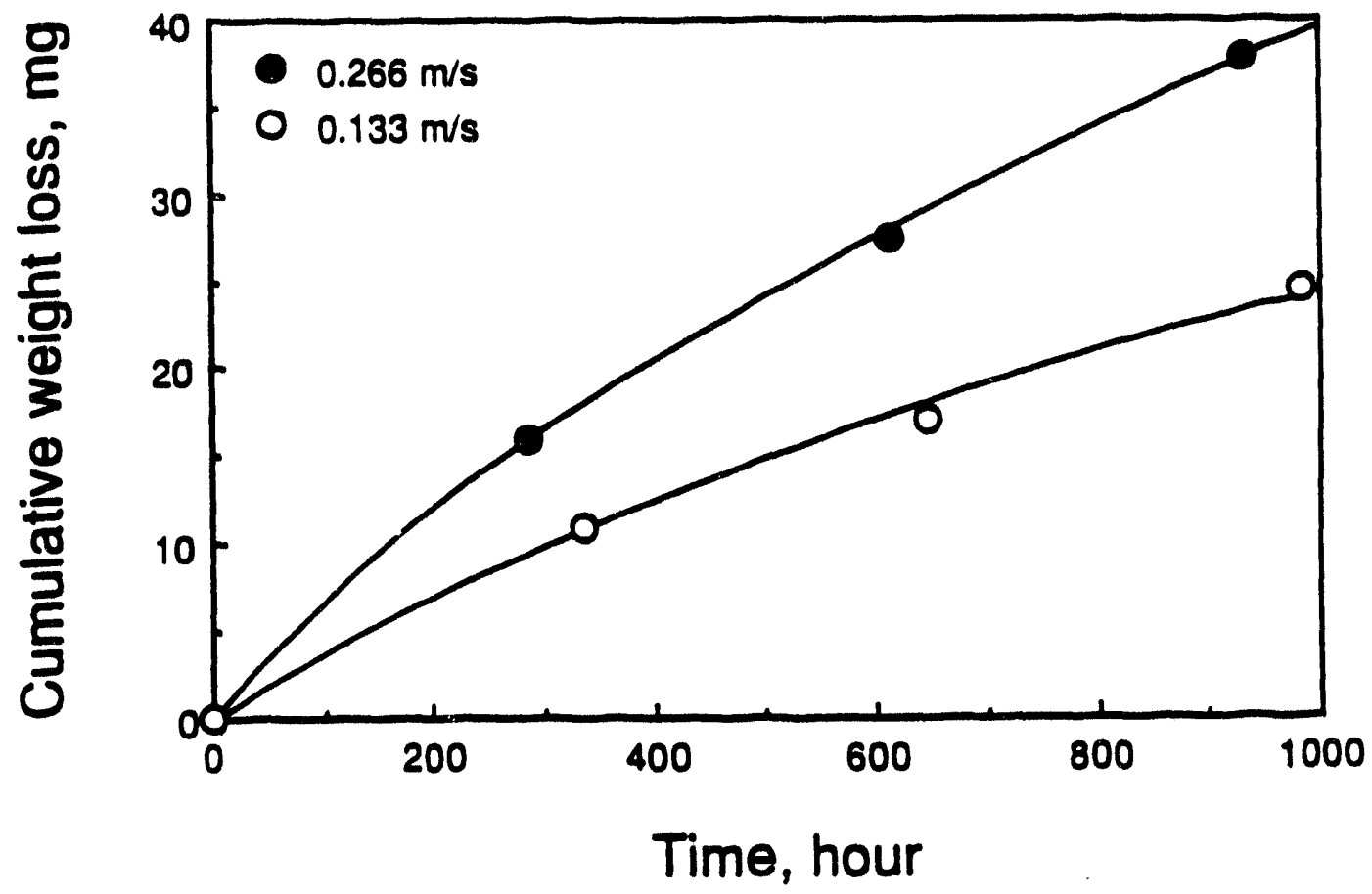

Figure 58. Cumulative weight loss of vertical 316 ss rods as a function of time at $500^{\circ} \mathrm{C}$ for two excess gas velocities. 
the corresponding steady wear rates are 0.73 and $1.16 \mathrm{~nm} / \mathrm{hr}$, respectively.

Even though the more angular particles tend to cause higher wear rate, as found by $\mathrm{zhu}$ et $\mathrm{al} .{ }^{125}$, and particles in fluidized beds gradually becomes rounded with operation time, the differences in the initial and the corresponding steady-state wear rates observed herein can not be attributed to the different erosive properties of angular and rounded silica sands. This is because the silica sand was replaced by fresh sand every two weeks in the 1000-hour tests. It is likely that the wear process of the $316 \mathrm{sS}$ rods is dominated by abrasive erosion as a result of low drag forces of the slowly-moving particles sliding along the metal surface, as shown by Tucker ${ }^{156}$ and Hutchings ${ }^{157}$. Accordingly, the wear of the 316 ss rods in the fluidized bed is caused mainly by low-energy stresses, which is very similar to particle attrition, as discussed by shamlou et al. ${ }^{158}$. Thus, the differences in the initial and steady-state wear rates could be due to the changes in the abrasive properties of the metal rods. It is postulated that the higher initial wear rate is caused by preferential abrasion of the edges at the bottom of the vertical rods, because this region is more susceptible to low-energy stresses. As the edges became less angular with operation time, the wear rate gradually decreased and then eventually reached a constant value. Levy et al. ${ }^{129}$ found that less than 5 hours of operation was long enough to achieve steady state conditions at a particle velocity of $20 \mathrm{~m} / \mathrm{s}$ and the period required to achieve a steady-state loss rate increased with 
decreasing particle velocity. Since our wear tests were conducted at lower gas velocities and the removal rate of the edges and corners of the metal rods was slower, a longer period of operation was required to achieve the steady-state. Consequently, it is believed that the time required to achieve a steady-state wear rate is strongly dependent on the severity of test conditions.

For commercial applications, steady wear rate is of more concern than initial wear rate. Based on the steady wear rate at $500 \mathrm{C}$ and a superficial gas velocity of $0.266 \mathrm{~m} / \mathrm{s}$, a heat pipe with an $0.165-\mathrm{cm}$ wall thickness would require more than 150 years to wear through provided that wear is evenly distributed around all surface area. Regardless of the significance of the steady-state wear rate, it is very time-consuming to obtain a steady-state wear rate datum (i.e., 45 days). Instead, the initial 14-day wear rate was used to investigate the influence of process variables on wear. Even though these two wear rates are not the same, the ratios of initial wear rate to steady wear rate were found to be approximately the same, based on the data shown in Figure 58 . Thus, it was presumed that conclusions based on initial wear rate are indicative of the steady-state wear rate.

\section{Fluidizing velocity}

Metal wastage in a fluidized bed operated at room temperature is mainly caused by the impact forces of particles, which are carried upwards in the wake region behind rising bubbles, as shown by Yates ${ }^{159}$. Thus, wear rate might be correlated to the excess energy of fluidizing gas above its minimum fluidization value, $U_{m f}$. 
Accordingly, the effect of fluidizing-gas velocity on the wear rate is illustrated by plotting initial wear rate vs. excess gas velocity $\left(U-U_{m f}\right)$, as shown in Figure 59 for temperatures of 25 and 500C. In these tests, the 316 ss rods were mounted in a vertical orientation and the minimum fluidization velocities, $U_{m f}$, were calculated by the relationship between the Archimedes number and Reynolds number, as discussed by Geldart ${ }^{160}$, which showed agreement with those determined by experiments within $\pm 8 \%$. As might be expected, the wear rate increases with increasing excess gas velocity due to deeper plowing and gouging of the metal surface by the silica sand on the 316 ss rods. The wear rate at $500 \mathrm{C}$ is much higher than that at $25 \mathrm{C}$ for all excess gas velocities, signifying that temperature has a large effect on the wear rate. As the temperature is increased the effect of gas velocity is much more pronounced.

As can be seen in Figure 59, there is essentially no wear when excess gas velocity $\left(U-U_{m f}\right)$ approaches zero. Thus, the threshold gas velocity, below which no wear can be detected, of the system investigated here can be assumed to be minimum fluidization velocity. When the fluidizing gas velocity is lower than the minimum fluidization velocity, the test urit would be operated in the fixed-bed mode without particle movement and then there would be negligible wear of the metal rods. At gas velocities above this threshold, the wear rate $(R)$ of the metal rods may be described by an equation of the form

$$
R \text { a }\left(U-U_{m f}\right)^{n}
$$




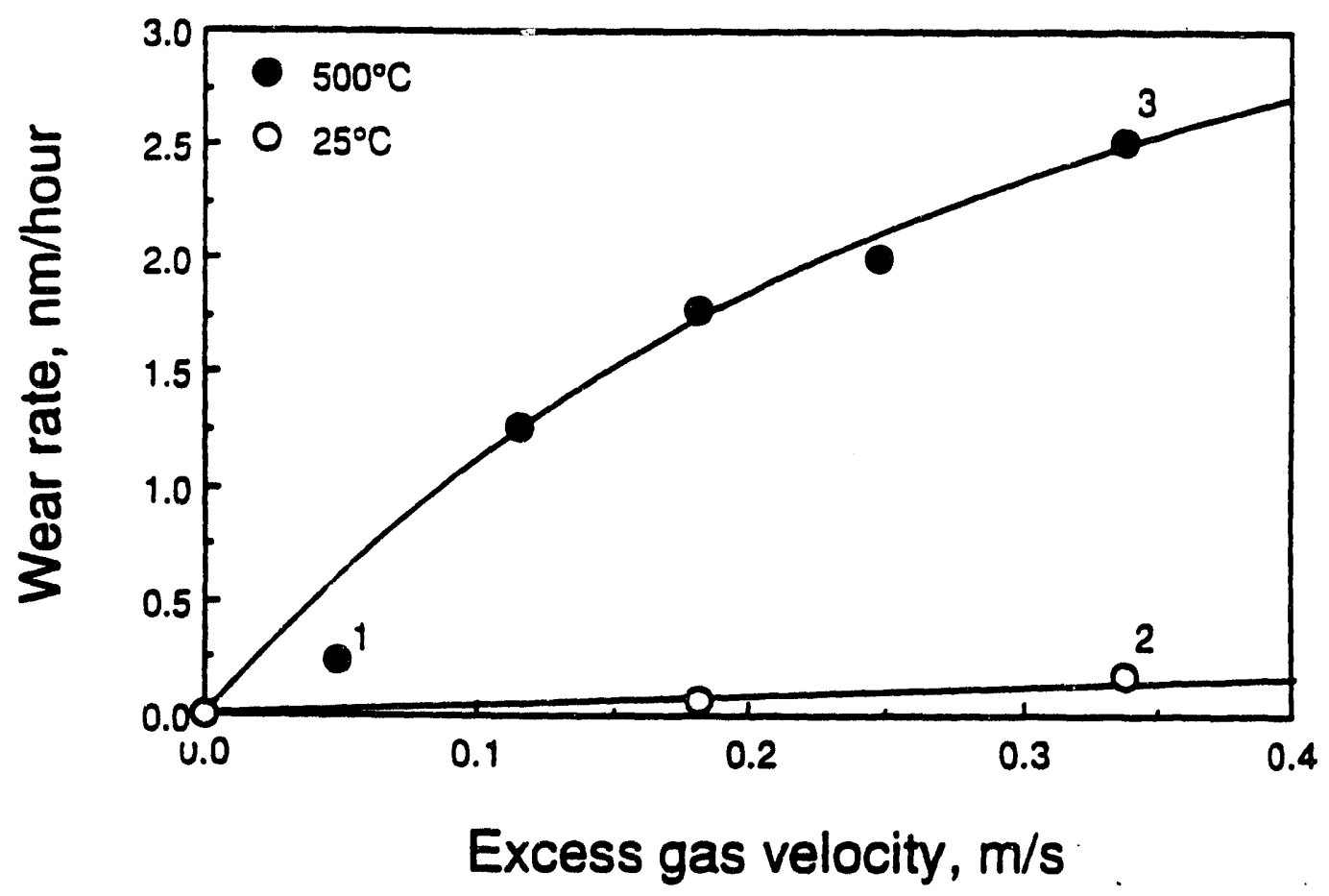

Figure 59. Effect of excess gas velocity on the wear rate of vertical ss 316 specimens at test temperatures of $500^{\circ} \mathrm{C}$ and $25^{\circ} \mathrm{C}$. 
The wear rate at $500 \mathrm{C}$, shown in Figure 59 is proportional to excess gas velocity but is less sensitive at relatively high velocities. This result is not in agreement with that reported by $\mathrm{Zhu}$ et $\mathrm{al} .{ }^{125}$, who found that wear rate of metals at room temperature increased rapidly with superficial gas velocity and was more pronounced at high velocities. This discrepancy could be due to different test temperatures, because their wear tests were conducted at room temperature and only erosion of metals was of concern, whereas the wear process investigated in this study might involve erosion combined with corrosion under high-temperature test conditions. In our tests, we found essentially negligible wear of the metal rods at $25 \mathrm{C}$, but, as shown in Figure 59 , the wear rate does appear to be increasing fister at the higher excess gas velocity.

Most theoretical studies for erosion of metals in fluidized beds, e.g. Gansley and O'Brien ${ }^{161}$, are based on the erosion model of Finnie 162 , which predicts erosion due to particle motion combined with an appropriate hydrodynamic model describing the particle motion induced by bubbles. Finnie and McFadden ${ }^{163}$ predict that the erosion rate increases with particle impact velocity raised to the power 2.0 to 2.5. Based on Eq. (2), a logarithmic plot of wear rate vs. excess gas velocity should yield a straight line with slope equal to $n$, as given in Figure 60. Accordingly, the velocity exponent, $n$, was determined to be 1.2 , which shows less dependence of wear rate on the excess gas velocity at 500C compared to the prediction of the model. 


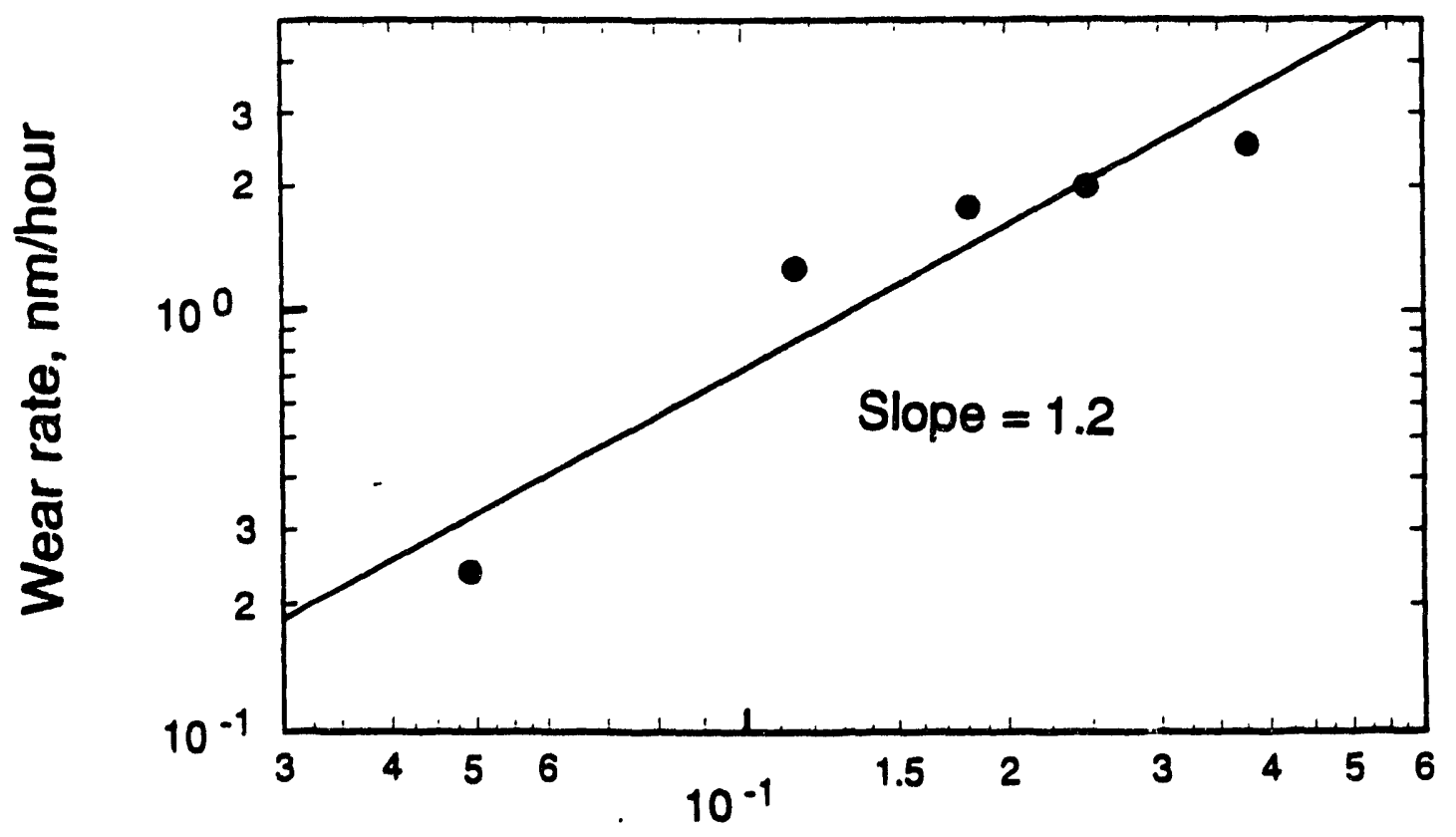

Excess gas velocity, $\mathrm{m} / \mathrm{s}$

Figure 60. Wear rate data plotted on a log-log scale to investigate the velocity dependence. 
Levy et al. ${ }^{164}$ conducted a study to investigate the dependence of the velocity exponent on temperature. They found, as we did, a lower velocity dependence of erosion on 310 ss at a higher temperature, i.e., the slope of the line at high temperature was lower than the corresponding slope at room temperature. The slope of 1.23 was reported for erosion tests at $800 \mathrm{C}$, while an average slope of 2.5 was determined from room temperature tests. This difference was attributed to the higher test temperature causing a change in the kinetic energy distribution of the impacting particles in the target material. Thus, the low $\mathrm{n}$ value obtained in this study might be due to the temperature effect alone. It is also noted that Levy et al. ${ }^{164}$ conducted their tests in a nitrogen atmosphere to avoid the complexity of erosion combined with corrosion. The work presented here was carried out in air. Thus, a good fit to their data was obtained, with a straight line through all data points in a logarithmic plot similar to Figure 60 . The fit of our data is as satisfactory, as can be seen in Figure 60. It is believed that in addition to the above-mentioned temperature effect, corrosion of the metal rods occurred during the wear tests, as discussed below, resulting in the less satisfactory correlation. Nevertheless, the result of a lower velocity exponent value at higher temperature obtained in the study reported here is consistent with the finding of Levy et al. ${ }^{164}$.

Finnie's erosion model was developed for estimating wear due to airborne particles cutting an eroding surface at relatively high speeds (e.g., 75-140 m/s). Because our experiments were conducted 
in the bubbling regime, the velocity dependence of Finnie's model may not be appropriate for the relatively low-speed particle motion expected in the bubbling fluidized bed. Additionally, it is believed that most wear found in our tests with the vertical 316 Ss rods is due to abrasive erosion by particles sliding against the rods, typical at low flow velocities. This abrasive erosion mechanism is not considered in Finnie's model and, thus, the use of that model to justify the wear behavior reported in this study is questionable.

\section{Temperature}

The effect of temperature on the wear behavior of vertical 316 ss rods was studied over a range of temperatures while keeping constant the excess gas velocity and exposure time. As can be seen in Figure 61, there is a marked difference in the amount of wear at different temperatures. The wear rate only slightly increases until a test temperature near $350 \mathrm{C}$ is reached, above which the wear rate begins to increase rapidly. The result obtained here is in agreement with that reported in the literature. For example, stott et al. ${ }^{130}$ observed, in wear tests using coarse particles at a speed of $5 \mathrm{~m} / \mathrm{s}$, that the extent of wear of $310 \mathrm{ss}$ increased considerably on increasing the temperature from 300 to 500C. Levy et al. ${ }^{129}$ found that the wear rate of 1018 steel significantly increased when test temperature changed from 450 to $650 \mathrm{C}$, while only a slight increase in the wear rate was observed when the test temperature was changed from 25 to $450 \mathrm{C}$.

The drastic increase in the weight loss of metals at some 


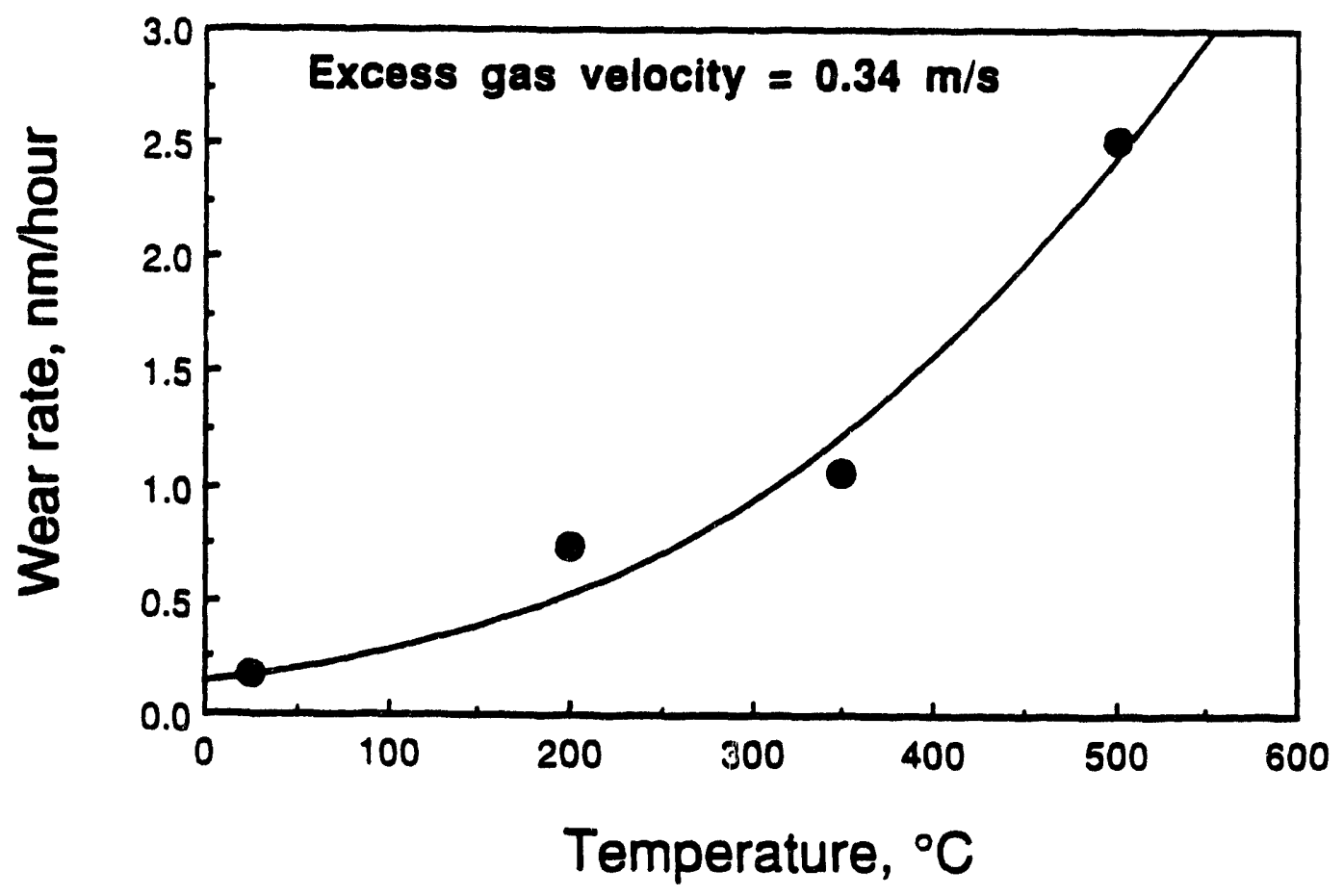

Figure 61. Influence of test temperature on the wear rate of vertical 316 ss rods at constant excess gas velocity. 
elevated temperatures has been rationalized in two ways: (1) metal surface deterioration due to corrosion at high temperature, as discussed by stott et $a .^{130}$ and (2) a rapid decrease in the mechanical properties of metals, such as short-time tensile strength, as discussed by Levy et al. ${ }^{164}$. Among the mechanical properties, hardness of test specimens is normally a good indicator of wear resistance (i.e., 1/wear rate), as discussed by Kruschov ${ }^{165}$. To determine the effect of hardness on wear resistance, wear rates of various metals with a range of hardness were measured at 25 and 5000. The results are shown in Figures 62 and 63 for test temperatures of 25 and 500C, respectively. The vickers hardness used in Figure 63 was measured at room temperature. Since data of Figure 62 were obtained at room temperature, there was no corrosion or change in mechanical properties due to temperature. The wear rate (or erosion rate) appears to decrease sharply with increasing Vickers hardness of the metals. This trend is anticipated and has been reported by Finnie et al. ${ }^{166}$ and Hutchings ${ }^{157}$. However, the same trend is not observed in Figure 63 for the wear test at $500 \mathrm{C}$, where the wear rates are more than an order-of-magnitude higher and the data scatter somewhat. The hardness of aluminum, copper, and brass normally decreases rapidly with increasing temperature while the decrease in the hardness of steels with temperature is generally not so significant. Thus, it is expected at high temperature that the wear rates of aluminum, copper, and brass would be much larger than those of steels. However, an exception was observed where wear rate of steel is larger than that of brass 


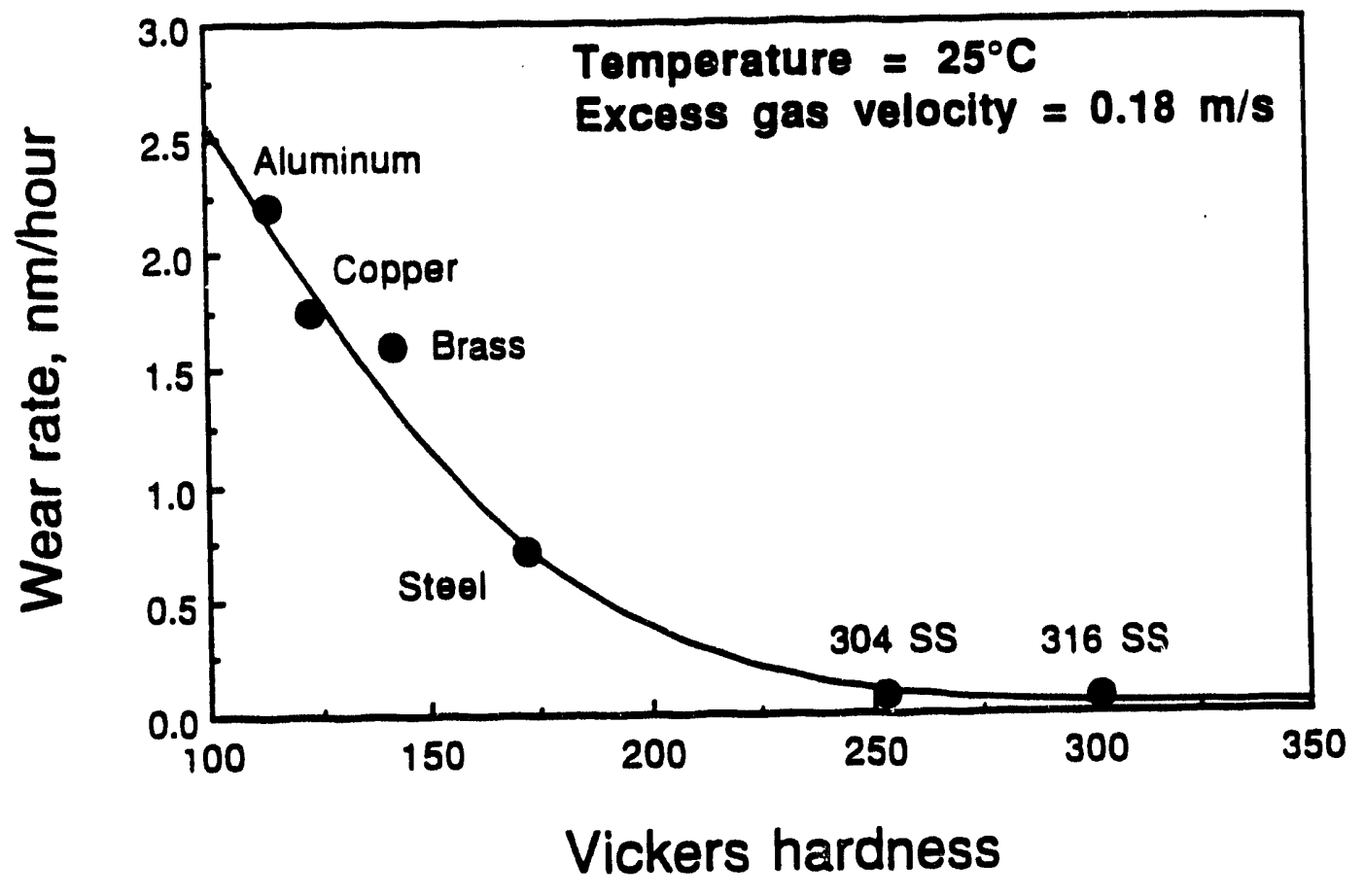

Figure 62. Correlation of erosion rate of six metals with hardness at a test temperature of $25^{\circ} \mathrm{C}$. 


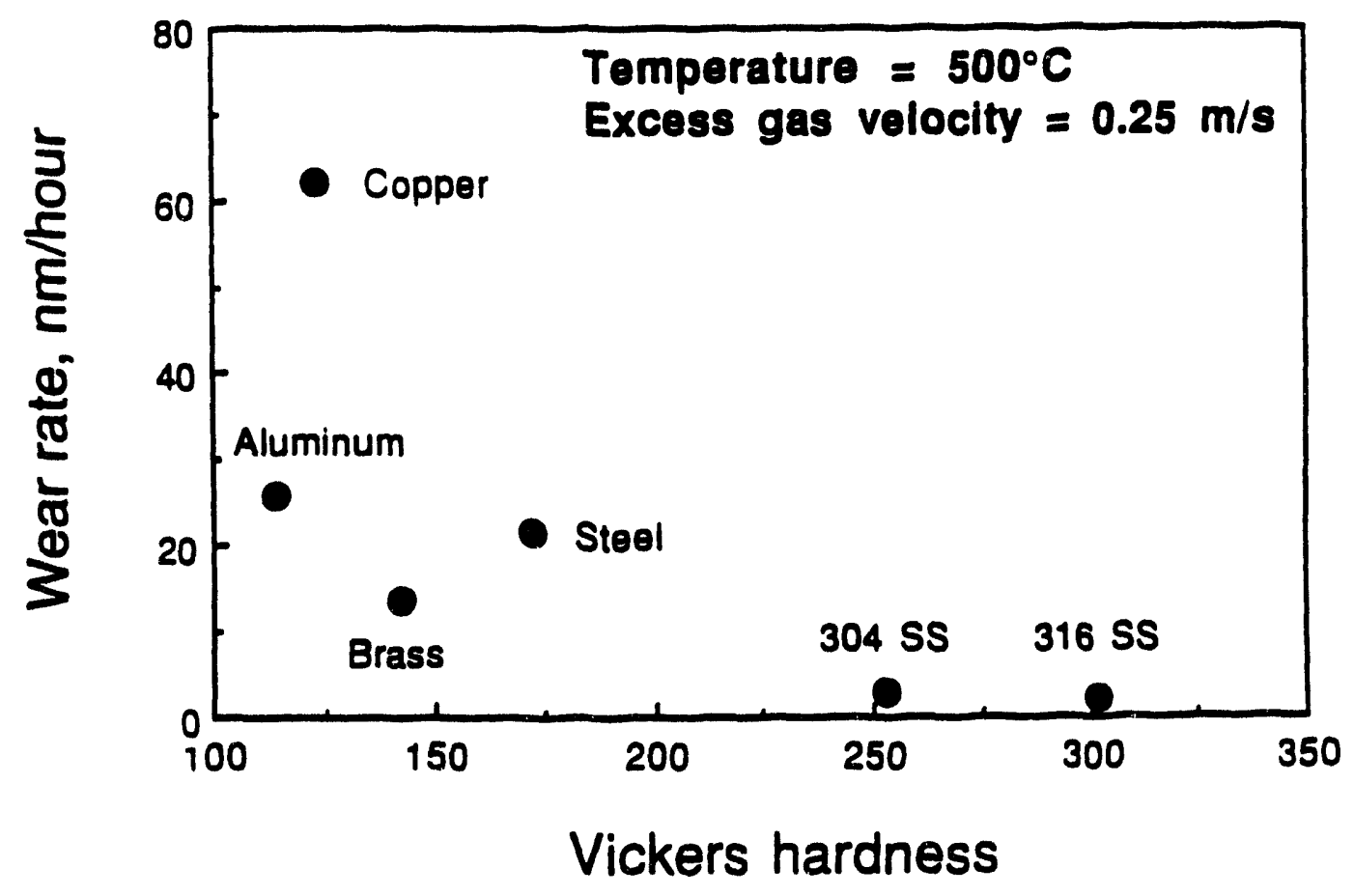

Figure 63. Variation of wear rate of six metals with hardness at a test temperature of $500^{\circ} \mathrm{C}$. 
as shown in Figure 63. This indicates that some other process occurring at high temperature does not depend on vickers hardiness.

Hardness of numerous steels measured in an argon atmosphere at temperatures ranging from ambient to $450 \mathrm{C}$ was found by witherel1 ${ }^{167}$ to decrease only slightly with temperature. Hence, the extreme increase in the wear rate of $316 \mathrm{sS}$ at high temperatures is not likely due to the slight decrease in the hardness.

It was observed that steel and copper rods formed fragile and loosely adherent scales on their surface after high-temperature wear tests. Coincidentally, these two metals exhibited relatively high wear rates. Type 304 ss and 316 ss rods also formed thin, adherent oxide scales, revealed by a change in the surface color. To further identify the major mechanism responsible for the rapid increase in the wear rate of stainless steels at high temperature, a wear test with vertical 316 ss rods at $500 \mathrm{C}$ was made using inert nitrogen as the fluidizing gas (excess gas velocity $=0.115 \mathrm{~m} / \mathrm{s}$ ) to avoid corrosion. The initial wear rate obtained was $0.31 \mathrm{~nm} / \mathrm{hour}$, which is much less than the wear rate of $1.27 \mathrm{~nm} /$ hour obtained from a test under identical conditions, but using air as the fluidizing gas. Therefore, it is concluded that the rapid increase in the wear rate of $316 \mathrm{SS}$ at relatively high temperature is related to corrosion. The wear rate of $0.31 \mathrm{~nm} / \mathrm{hour}$ obtained from the test in nitrogen at $500 \mathrm{C}$ is larger than that $(0.02 \mathrm{~nm} / \mathrm{hour})$ estimated on the basis of wear tests in air and at 25C. Thus, it appears that. a decrease in the hardness of 316 ss at high temperature can enhance the wear rate; however, this effect is not as significant 
as the effect of corrosion. Since 316 ss and 304 sS have approximately the same hardness and resistance to corrosion, their wear rates were approximately the same at 25 and $500 \mathrm{C}$.

In view of the above results, it is strongly suggested that high-temperature wear tests with 316 ss rods might involve a combination of erosion and corrosion. It should be noted that, unless the oxide scale is being eroded off as it forms, oxidation is accompanied by weight gain. Thus, three 316 ss rods of approximately 44.5 gram were heated to $500 \mathrm{C}$ in a laboratory electric oven in still air and held at that temperature for two weeks to assess the degree of oxidation. A weight gain of approximately $5 \mathrm{mg}$ was obtained, showing that oxidation did occur at the high-temperature conditions. For further confirmation of oxidative corrosion, the compositions of Ss 316 rods after a wear test at $500 \mathrm{C}$ for two weeks were measured by energy dispersive $\mathrm{X}-$ ray (EDX) spectrometry. As shown in Figure 64 , the relative amount of Iron, chromium, and nickel on the surface is lower than that in the center due to oxidation on the surface. Although not included in Figure 64, the EDX also showed that the outer layer of scale contained a much higher concentration of oxygen and silica compared to the compositions in the center. The increase in silica concentration on the surface is probably due to silica sand becoming embedded in both the metal surface and the oxide scale. The high concentration of oxygen observed on the surface provides concrete evidence that the 316 ss surface was oxidized to form an oxide scale. Thus, the wear process investigated in this study 

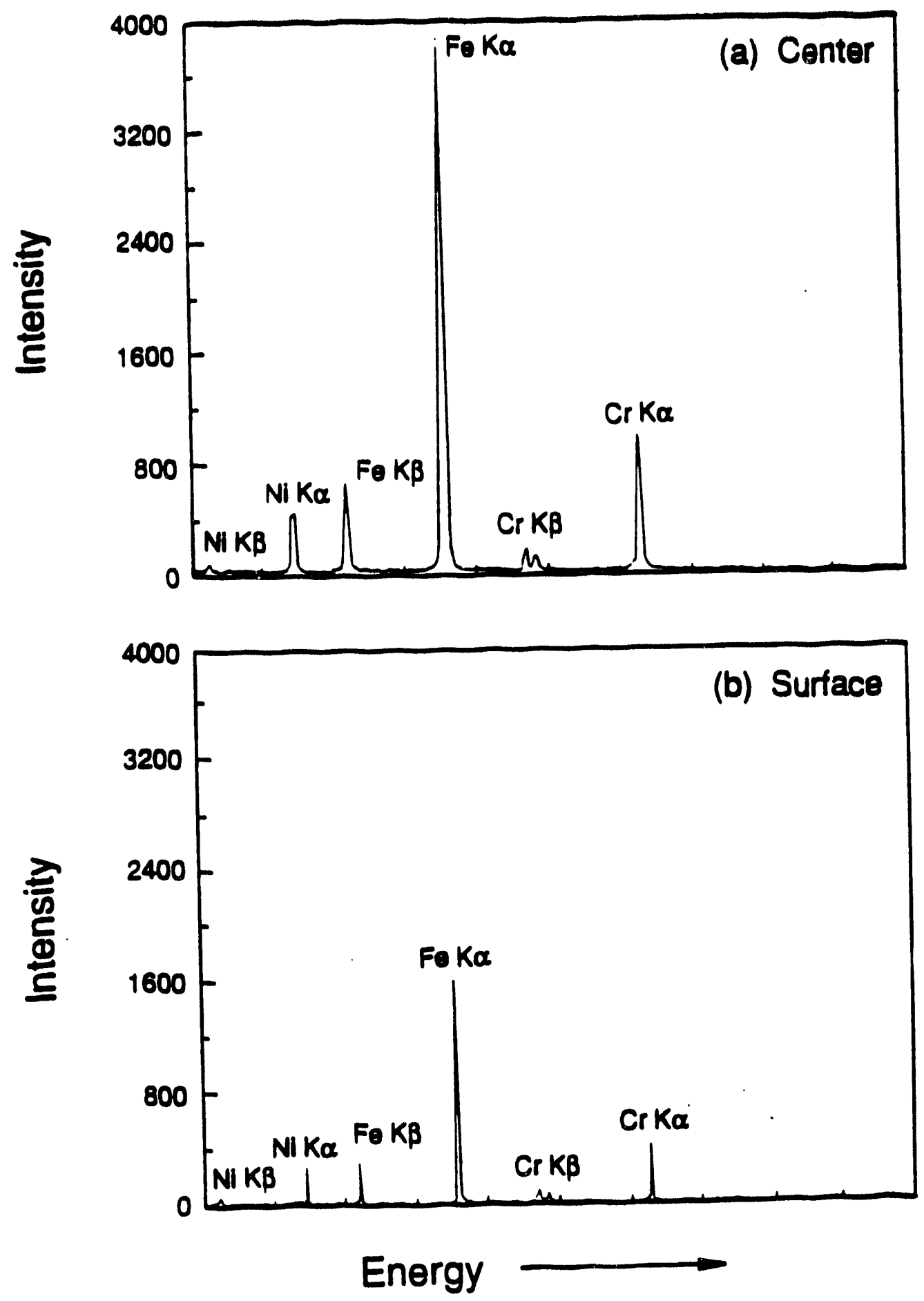

Figure 64. Analysis of the relative compositions in the center and at the surface of a 316 ss rod, after a hightemperature wear test, by energy dispersive $\mathrm{X}$-ray spectrometry. 
consists of erosion and corrosion mechanisms that are combined.

Weight loss due mainly to corrosion (i.e., corrosiondominated) was determined by carrying out a wear test at $500 \mathrm{C}$ and near zero excess gas velocity (data point 1 of Figure 59). As shown, the weight change caused by corrosion is small. Weight loss due mainly to erosion (i.e., erosion-dominated) was determined by conducting a wear test with a high fluidizing velocity at room temperature (data point 2 of Figure 59). The weight loss as a result of pure erosion was found to be relatively small. By comparing the total weight loss of the specimens at elevated temperature and high gas velocity (data point 3 of Figure 59) with the sum of the weight losses obtained from corrosion and erosion dominated tests (data points 1 and 2 of Figure 59), it is found that the former weight loss is much larger than the latter one. As discussed before, this much larger weight loss can not be explained by an increase in erosion rate at high temperature. Consequently, It is proposed that erosion and corrosion took place simultaneously, interacting in a way leading to ac ielerated degradation of the 316 ss rods, i.e., a synergistic effect, as discussed by pitt et al. ${ }^{168}$.

Wear due to a synergistic effect can be described by the following steps: formation of surface scale by corrosion, loss of the scale by erosion, and formation of new surface scale. In a gaseous oxidizing atmosphere at high temperature, 316 ss rods initially oxidized rapidly to develop a protective oxide layer (i.e., scale), after which the rate of oxidation decreased with 
increasing thickness of the scale due to increasing diffusion resistance of oxygen through the scale. Therefore, if the wear process had not involved erosion, the protective film could have reduced corrosion rate and, thus, overall wear rate. However, in the real situation, the scale thickness increased with time up to a certain level where the stresses and strains generated in the scale reduced the adhesive forces of the scale to the metal rods. Then, the loosely adherent oxide scale could be easily eroded as long as the sliding forces of fluidizing particles were larger than the adhesive forces. After removal of the loosely adherent scale, another oxide scale was formed and subsequently removed. This sequential process of corrosion and erosion increased the overall wear rate of the 316 ss rods. Thus, the resultant metal loss due to the synergistic effect of corrosion and erosion was much larger than if corrosion and erosion occurred separately.

As discussed earlier, the convex shape of the curve shown in Figure 59 for wear at $500 \mathrm{C}$ is not similar to that reported for a temperature of $25 \mathrm{C}$ by $\mathrm{Zhu}$ et al. ${ }^{125}$, who obtained a concave curve. The synergistic effect proposed here successfully explains the trend observed in Figure 59. It is plausible that in the corrosion-dominated region, an oxide layer was formed continuously, but the sliding force of silica sand was not large enough to cause wear of the oxide layer due to a relatively low fluidizing velocity. Wear only occurred when the oxide layer reached a certain thickness where the adhesive force between the surface oxide and the specimen was lower than the particle sliding force. 


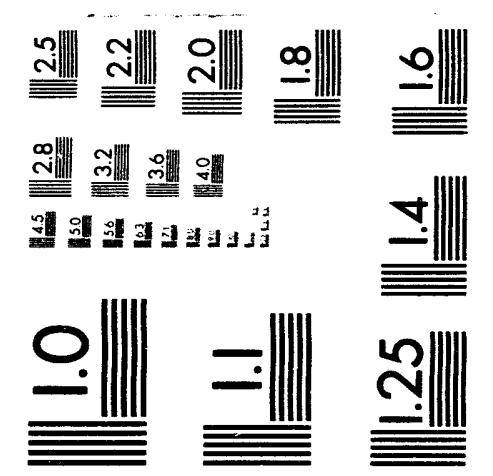



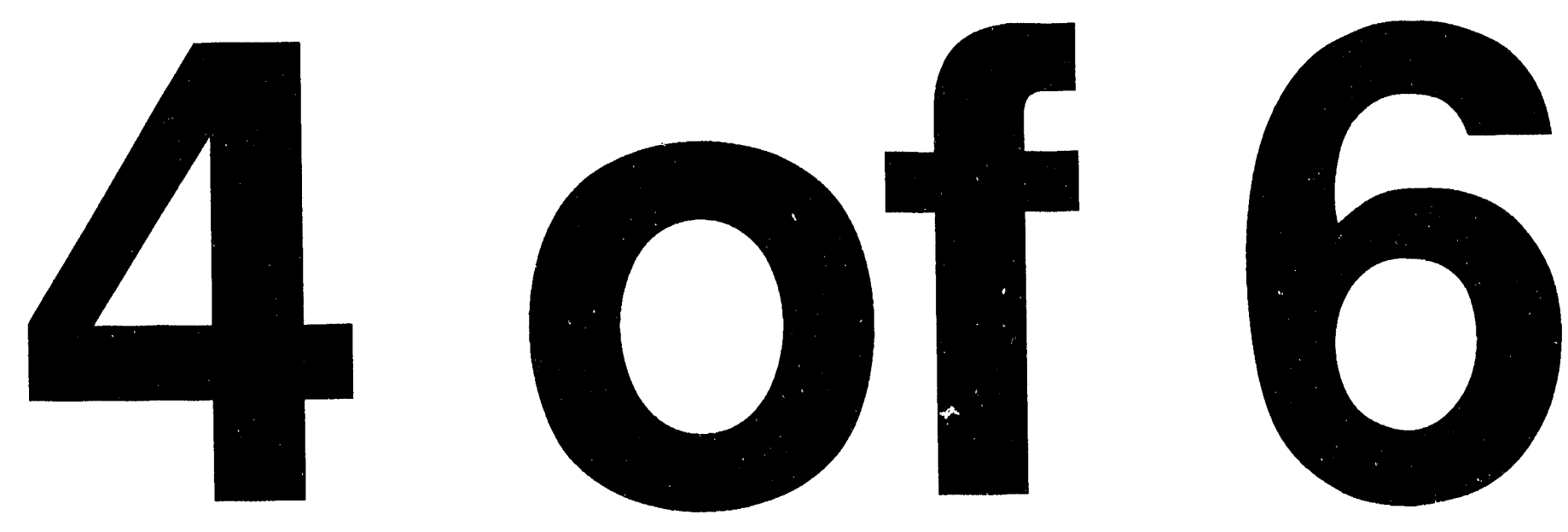
Thus, it is expected that in this region the weight loss would be strongly dependent on the fluidizing velocity because increasing gas velocity results in higher particle sliding forces that can more easily cause wear of the oxide layer. When the fluidizing velocity is relatively large, the sliding forces become sufficiently high to remove most of the oxide scale. Under such a condition, the oxide scale as a result of corrosion might not be formed fast enough to compensate for the wear due to erosion. Therefore, increasing gas velocity has less effect on total weight loss compared to that in the low gas velocity region.

Based on the above discussion, the thickness of the oxide scale is crucial in the wear process. Dispersive microanalysis was used to examine the distribution of chromium in the cross-sections of polished ss 316 rods after two-week wear tests at 500C. Figure 65 shows the microanalysis results of two $316 \mathrm{ss}$ rods under identical test conditions except excess gas velocity. The crosssection analysis reveals a considerably lower chromium content in the outer surface than in the base metal. The thickness of the oxide layer is herein defined as the layer with the lower chromium content. Thus, the thicknesses of the oxide layers were determined to be 20 and $16 \mathrm{~mm}$, as shown in Figure 65, for specimens after tests at $500 \mathrm{C}$ with excess gas velocity of 0.05 and $0.34 \mathrm{~m} / \mathrm{s}$, respectively. With the same test temperature and duration, the thickness of the oxide scale decreased with increasing gas velocity. It is believed that a higher gas velocity causes greater abrasion on the metal rods, which in turn reduces the scale 
(a) Excess gas velocity $=0.05 \mathrm{~m} / \mathrm{s}$

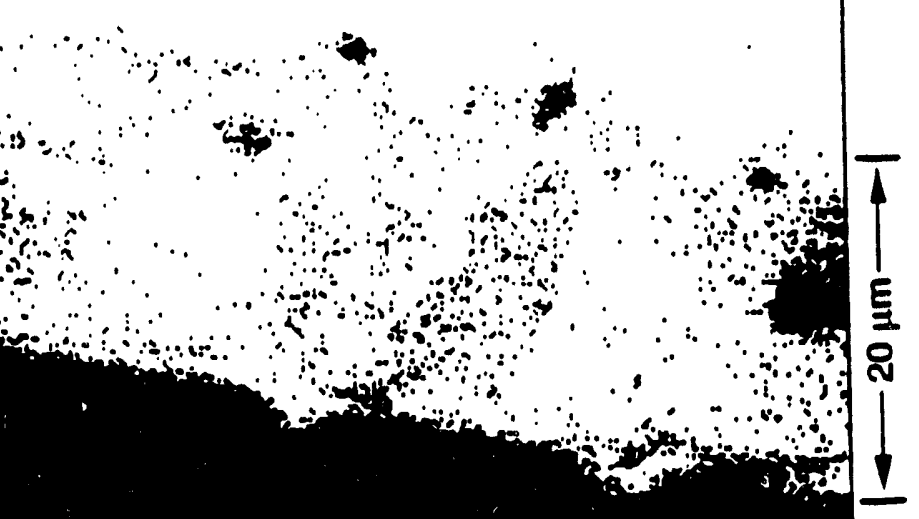

(b) Excess gas velocity $=0.34 \mathrm{~m} / \mathrm{s}$

Figure 65.

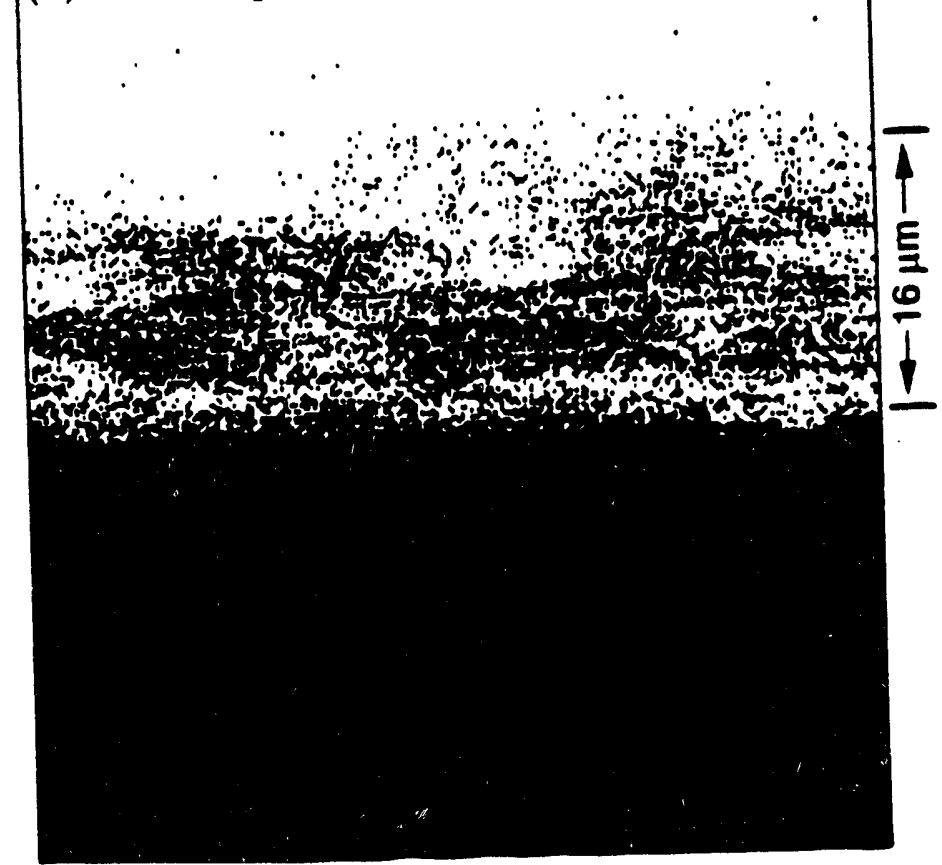

Determination of the thickness of oxide scale by dispersive microanalysis. 
thickness due to removal of the more strongly adherent oxide scale. This result is in line with the proposed synergistic effect.

The combined erosion-corrosion behavior of steels has been investigated by others over a range of temperature and in an oxidizing atmosphere. Some investigators, e.g. Levy et al. ${ }^{169}$ and Levy and $\operatorname{Man}^{170}$, found that corrosion was the dominant mechanism, while other researchers, e.g. Parkinson et al. ${ }^{171}$, concluded that erosion was the dominant process. It is apparent that the dominant mechanism is mainly determined by the test conditions and the specimen properties. Since the wear of 316 ss rods investigated herein is dominated by the synergistic effect of erosion and corrosion, the ideal material for heat-pipe construction should have both mechanical properties yielding low erosion and a chemical composition that provides high corrosion resistance such as $304 \mathrm{~L}$ stainless steel.

\section{Rod orientation}

Another important aspect of this research was to investigate the difference in wear behavior of vertical and horizontal rods in fluidized beds. To study the effect of rod orientation, three horizontal 316 ss rods as wear specimens were tested at 500C and a range of excess gas velocities. Average wear rate of the three rods was used to assess the dependence of the wear rate upon excess gas velocity. As can be seen in Figure 66, the wear rate increases with increasing excess gas velocity. The wear rate of each horizontal rod was found to increase with the vertical distance between the specimen and the gas distributor plate. 


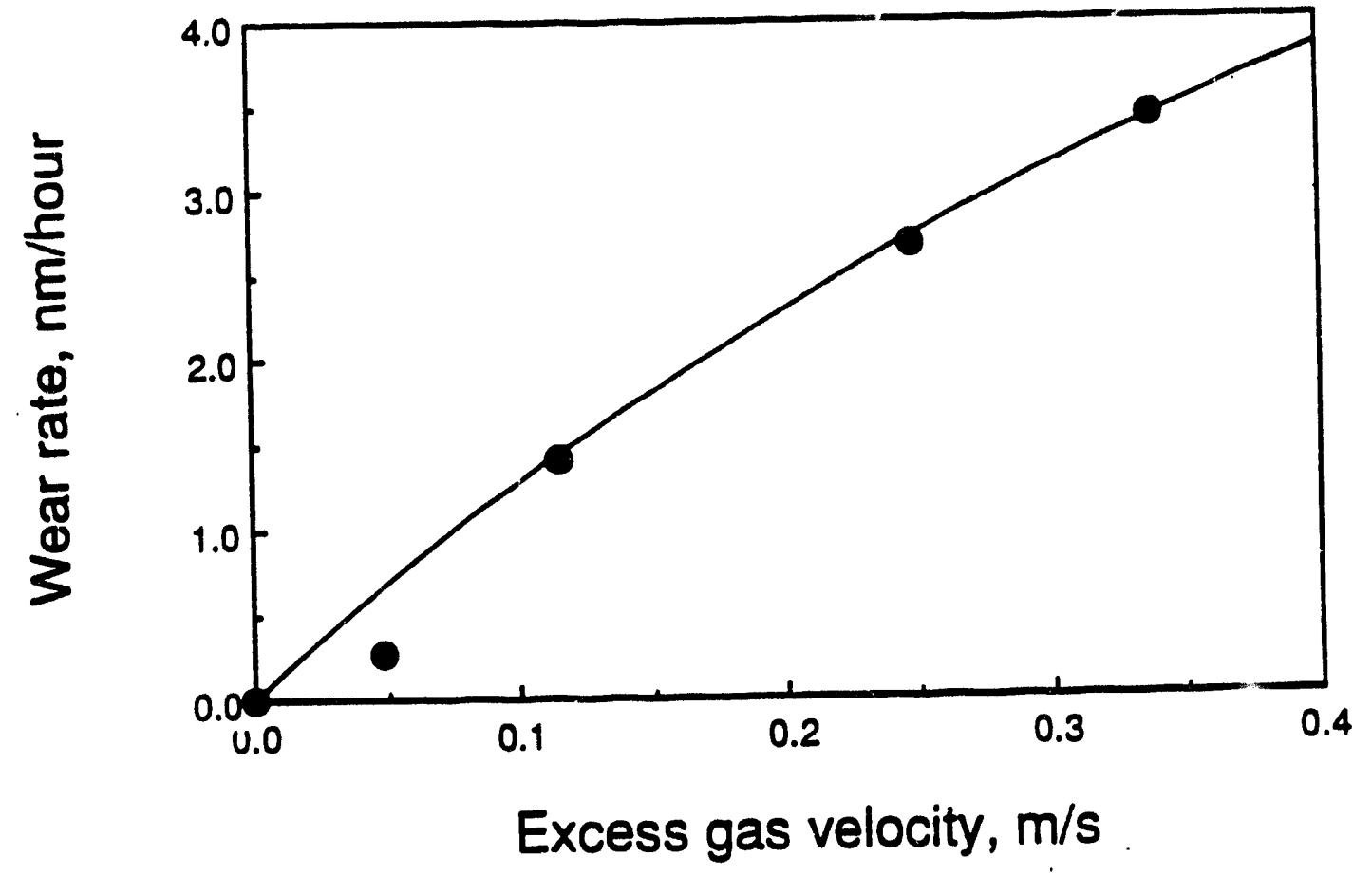

Figure 66. Effect of excess gas velocity on the wear rate of
horizontal $316 \mathrm{ss}$ rods at a test temperature of $500^{\circ} \mathrm{C}$. 
Because the average specimen height of the three horizontal rods was exactly the same as that of the six vertical rods, a reasonable comparison between the two sets wear data (i.e., Figure 59 and Figure 66) can be made. It is seen that the wear rate of the horizontal rods was consistently larger than that of the vertical rods under identical test conditions. The difference in the wear rates was most significant at the highest fluidizing velocity, but there the horizontal rods experienced only $30 \%$ more wear.

Zhu et al. ${ }^{125}$ conducted wear tests in a fluidized bed with a horizontal tube of square cross-section to determine the influence of the erosion mechanism on the tube wear. The erosion at the tube bottom was mainly caused by normal particle impacts while the wear at the two sides was mainly caused by angled abrasion of solid particles. They found that erosion associated with normal impacts was much more severe than that caused by particle abrasion occurring at lower angles. Accordingly, the wear at the bottom of the vertical 316 ss rods in the study reported here is believed to be more severe than on the peripheral surface of the rods. With the vertical orientation, the wear rate could be reduced because only a small fraction of the surface is subjected to normal impacts. The more linear curve observed in Figure 66 as compared to the curve in Figure 59 suggests that the wear of horizontal rods is more sensitive to excess gas velocity, due probably to a larger rod surface area exposed to normal impacts. This study implies that erosion of heat transfer tubes in fluidized beds can be reduced by using vertical tubes instead of horizontal tubes. 
As mentioned above, the wear rate of each horizontal $316 \mathrm{SS}$ rod was found to increase with the vertical distance between the rod and the gas distributor. For the case of test runs using horizontal rods, three rods mounted in the different sections of the fluidized bed were tested simultaneously. After the test run, the wear rate of each horizontal rod was measured to assess the extent of its wear. The effect of specimen height on wear rate for a range of excess gas velocities is illustrated in Figure 67 . Since the wear rates of the $316 \mathrm{sS}$ rods at the lowest location are relatively small, it is believed that all the metal specimens were located above the height of the jets so that the effect of highvelocity jets on the metal wear was not significant. Within a small distance of the jet height, the jet is transformed into bubbles. Gansley and $\mathrm{O}^{\prime} \mathrm{Brien}^{161}$, in a theoretical study on erosion of surfaces caused by particle motion induced by bubbles rising in fluidized beds, indicated that erosion rate strongly depended on bubble size, i.e., erosion increased with bubble size. Therefore, the specimen mounted in the lower section of the fluidized bed had a lower wear rate because bubbles did not have a chance to grow to full size before reaching the specimen.

It was concluded that metal loss of heat-transfer tubes in fluidized-bed combustors may be caused by erosion and/or corrosion, depending on operating conditions. Based on this study, the wear of 316 ss rods in the bubbling fluidized bed was mainly caused by the synergistic effect of erosion and corrosion rather than by either erosion or corrosion alone. Thus, the ideal material for 


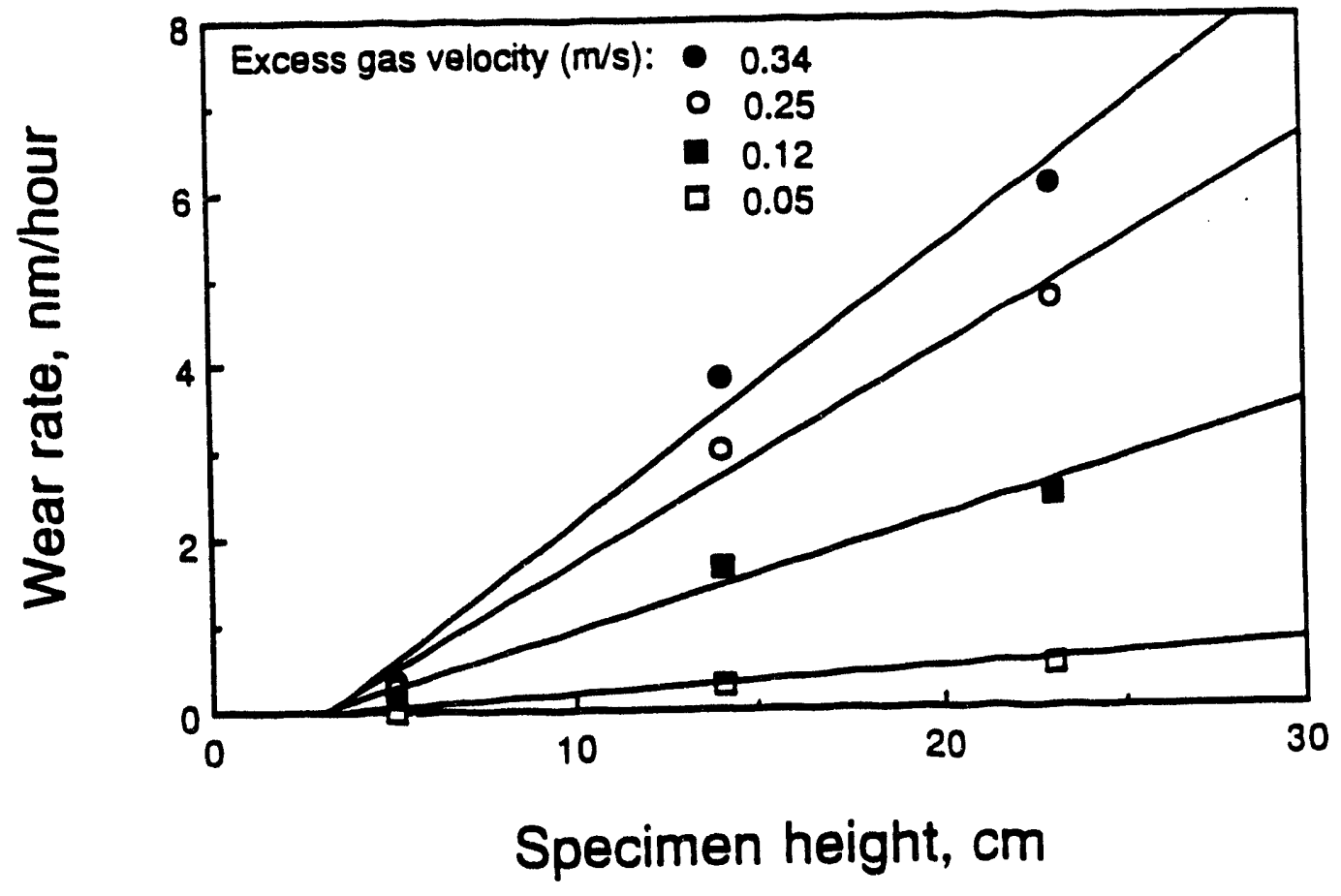

Figure 67. Increase in the wear rate of horizontal 316 ss rods with increasing distance between the rods and the gas distributor plate. 
the heat-pipe construction should have both mechanical properties yielding low erosion and chemical compositions providing high corrosion resistance.

In addition to the influence of operating parameters, rod orientation also has a large effect on wear rate. This study suggests that the metal wastage of tubes in fluidized beds can be reduced by using a vertical instead of horizontal orientation. In the event that horizontal tubes are necessary, the tubes might be mounted in the lower region of the fluidized bed, but above the jet penetration zone to minimize the influence of bubble size on erosion rate.

\section{Minimum slugging Velocity}

Typical pressure-drop data for a bubbling bed and for a slugging bed are shown in Figure 68. In both beds, the fluctuations are characterized by both high and irregular frequencies, reflecting the stochastic nature of the bubbling phenomenon in a fluidized bed. The pressure-drop fluctuations in the slugging bed are larger in magnitude and are more uniform in frequency when compared to those in a bubbling bed. Figure 69 shows some statistical quantities of the pressure-drop fluctuations over a spectrum of fluidizing-gas velocity, from a low velocity (bubbling regime) to a high velocity (slugging regime). Shown are the mean, the standard deviation, the minimum and the maximum of the pressure drop, excluding the extreme $5 \%$ from each of the latter two quantities. For a bubbling bed, the magnitude of the average pressure drop is in all cases well described by the well-known 


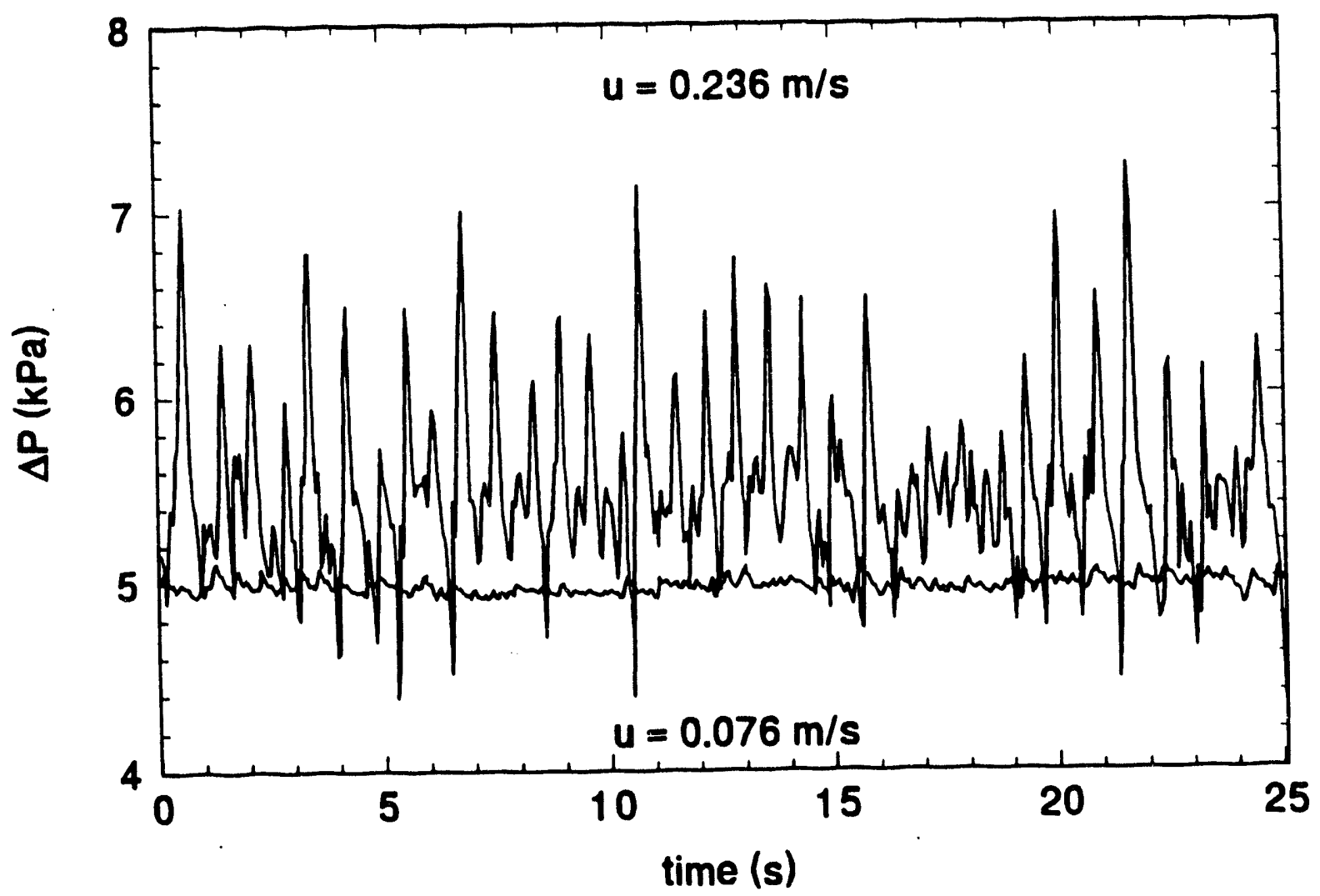

Figure 68. Pressure-time records; $L_{m}=0.396 \mathrm{~m} ; u=0.236 \mathrm{~m} / \mathrm{s}$ 273 


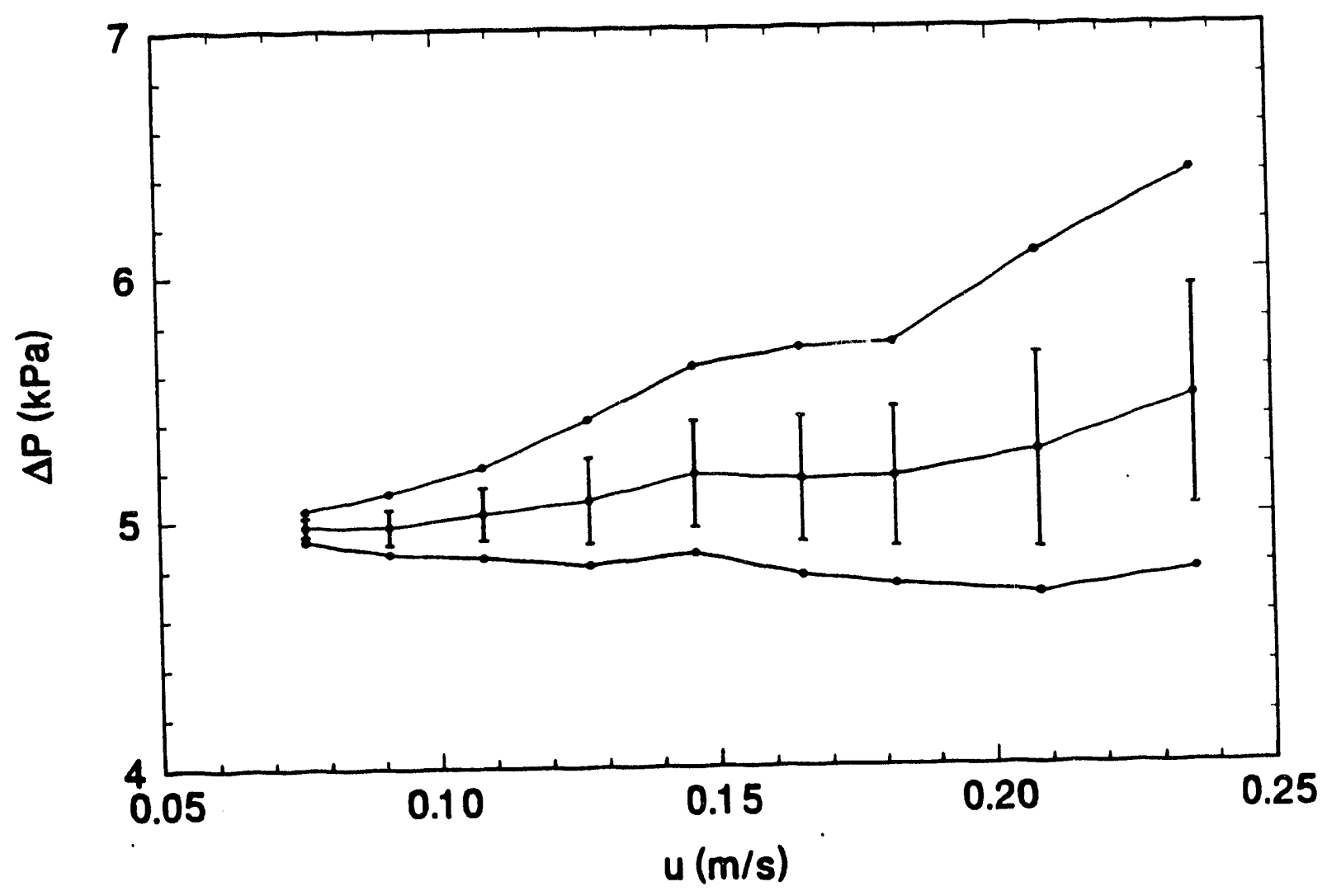

Figure 69. Statistical properties of pressure fluctuations as a function of fluidizing-gas velocity; $I_{m}=0.396 \mathrm{~m}$; the minimum, maximum, mean, and standard deviation are shown. 
relationship:

$$
D P=g\left(1-e_{m f}\right) r_{s} L_{m f}
$$

which says simply that all the sand is being supported by the fluidizing gas so that DP is independent of $u$. As seen in Figure ?(sic)69, the average pressure drop in a slugging bed increases somewhat with $u$, confirming a trend noted by others ${ }^{172}$, who attribute the increased pressure drop to particle acceleration.

Figure 70 shows the PSDFs, for nine different gas velocities, of the pressure-drop fluctuations for a bed with a settled bed height of $0.396 \mathrm{~m}$. Included at the extremes are the PSDFs for the two gas velocities of Figure 68. In these plots, power is used loosely to refer to the relative energy in the pressure-fluctuation signal that can be associated with a particular frequency. The units of this power are arbitrary, since they are as much a function of the computation procedure as they are influenced by the physical phenomena. It is the relative power that is of importance here. When a PSDF exhibits a single peak which overwhelmingly dominates the spectrum, then it can be said that the original signal is very nearly periodic. on the other hand, if the PSDF is seemingly chaotic and exhibits no clear peak, then the original signal is either dominated by noise or is not periodic. Comparing the spectra in Figure 70 , it is evident that the magnitude of the power increases with the gas velocity. Qualitatively, this is indicative of increased kinetic energy in the bed due to intensified bubble agitation. The dominant frequency, $f_{d}$, and the side frequency, $f_{s}$, are hereby defined as the 

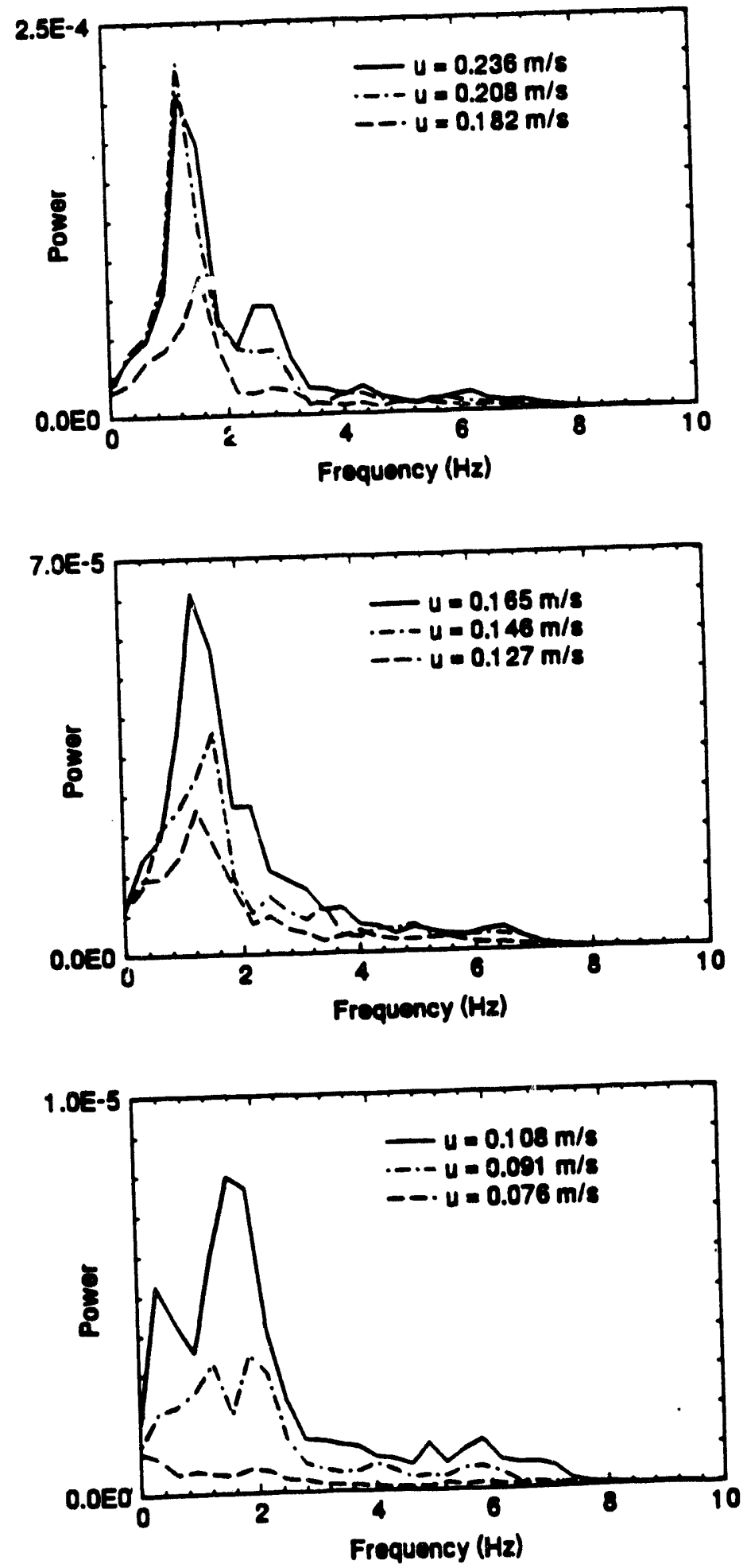

Figure 70. Power spectral density function of pressure
fluctuations at several velocities; $I_{m}=0.396 \mathrm{~m}$. 276 
two frequencies corresponding to the largest and second largest peak in each PSDF, respectively. Some of the spectra exhibit only one peak, while some exhibit several peaks. Generally, there are fewer major peaks in the spectrum of a slugging bed, indicating that the rate of bubble/ slug eruptions is very nearly periodic. All the spectra from a bubbling bed show a peak at $0 \mathrm{~Hz}$. This is because the pressure drop in a bubbling bed is relatively constant, i.e., it is not periodic.

The two principal frequencies, $f_{d}$ and $f_{s}$, for the spectra of Figure 70 are shown in Figure 71 as a function of gas velocity. Kage et al. ${ }^{148}$ studied the pressure-fluctuation frequencies taken from the plenum chamber, and determined that it is possible to identify as many as three distinct physically meaningful frequencies in a bubbling fluidized bed: a natural frequency of the bed, a bubble-eruption frequency, and a bubble-generation frequency. They give an equation for the natural frequency, $f_{n}$ as

$$
f_{n}=(1 / 2 p)\left(P_{p} A_{B} / V_{p} L_{m f} r_{B}\right)^{0.5}
$$

For the conditions of Figure 71, Eq. (4) predicts $f_{n}=3 \mathrm{~Hz}$. For a shallower bed with $L_{m f}=0.173 \mathrm{~m}$, Eq. (4) predicts $f_{n}=5 \mathrm{~Hz}$, which is in fair agreement with $f_{s}$ shown in Figure 72 . Thus, it is concluded that, in this system, the side frequency of the PSDF is the same as the natural frequency of the bed, i.e., $f_{s}=f_{n}$. Therefore, the side frequency need be considered no longer in our analysis; it is a phenomenon caused by the bed rather than the fluidization, and it can be assumed that $f_{d}$ is the bubble-eruption frequency. 


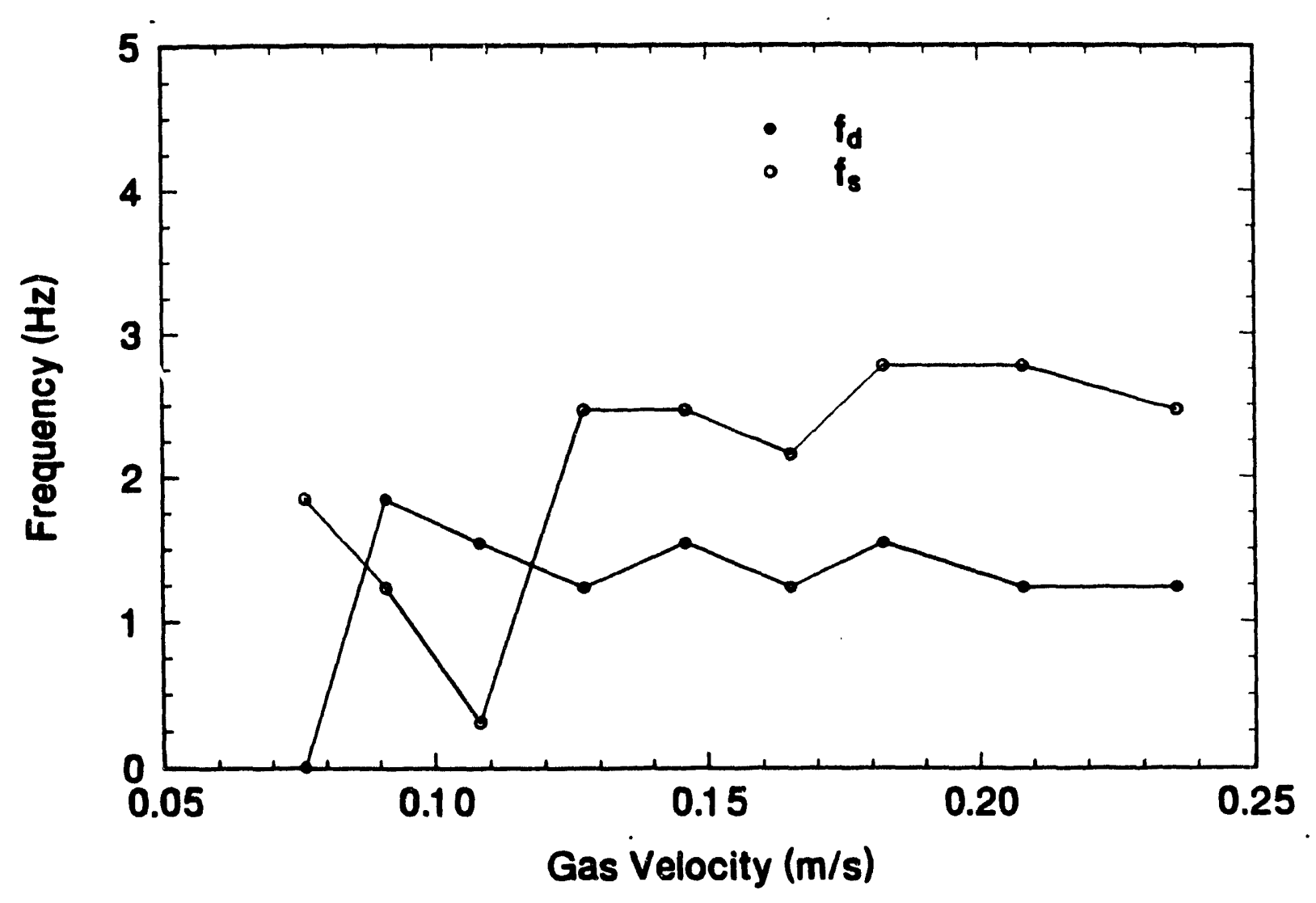

Figure 71. Dominant frequencies in the PSDF as a function of gas velocity $L_{m}=0.396 \mathrm{~m}$. 


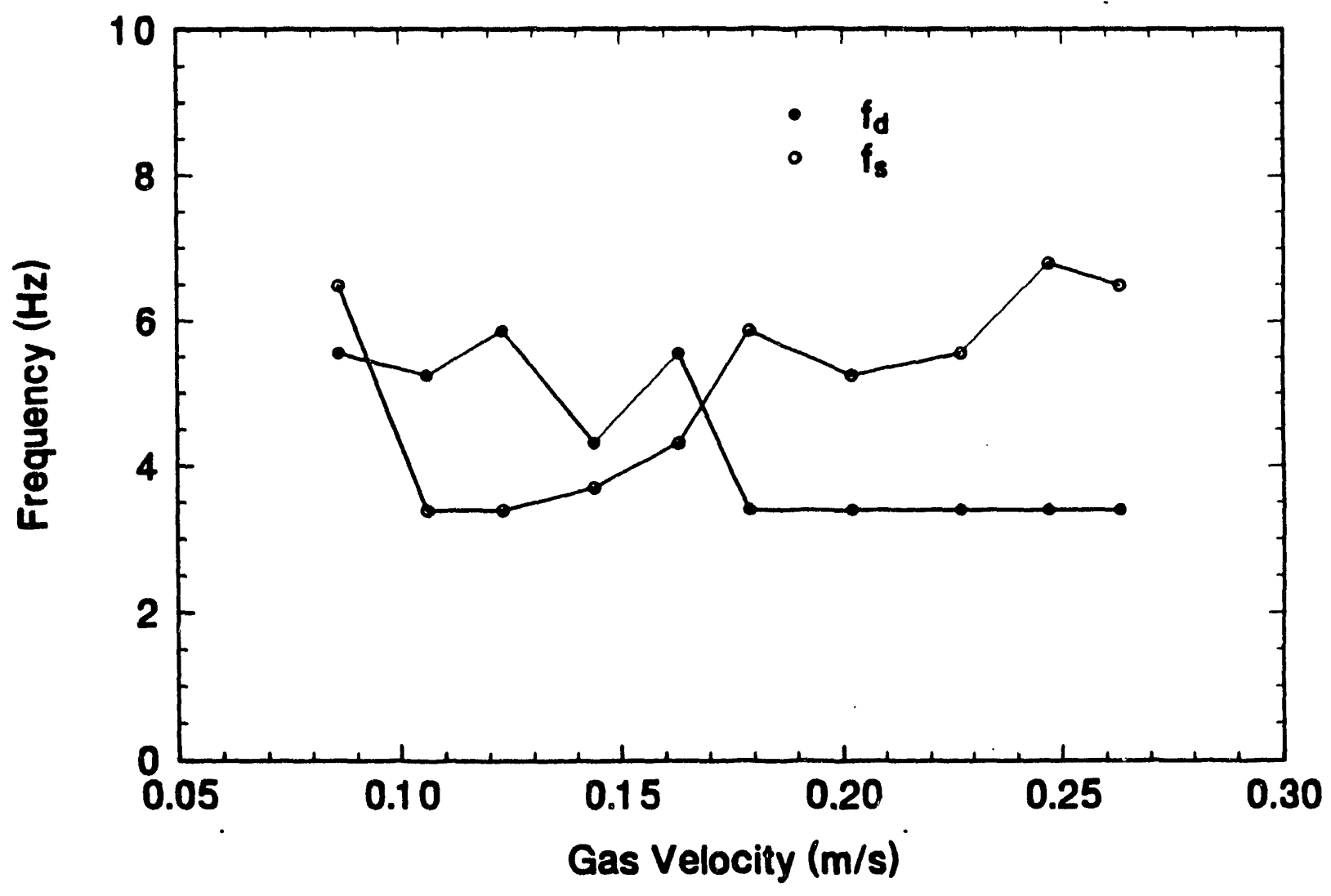

Figure 72. Dominant frequencies in the PSDF as a function of gas velocity: $I_{m}=0.173 \mathrm{~m}$. 
Figure 73 shows the dominant frequency as a function of gas velocity while varying the amount of sand in the bed. Each of these curves exhibits a similar trend. As the gas velocity increases from above $u_{m f}(0.056 \mathrm{~m} / \mathrm{s})$, the dominant frequency increases to a maximum, decreases, and finally reaches a constant level at higher gas velocities. These tailing frequencies are lower in deeper beds.

The effect of $u$ on slugging frequency has been the subject of several previous reports ${ }^{141,150,157,172-174)}$. Some claim that as long as the bed is operated in the slugging regime, the slugging frequency is not effected by the rate of gas flow, while others claim that $f_{d}$ is either slightly reduced or slightly increased by increasing $u$. It seems safe to conclude that, although not exactly constant, $f_{d}$ is approximately constant in the slugging regime with respect to changing gas velocity. Thus, $u_{m s}$, the minimum slugging gas velocity, corresponds to the point in each curve of Figure 73 from which $f_{d}$ is constant. The values determined from Figure 73 for $u_{m s}$ are shown in Figure 74 as a function of settled bed depth, along with the visually observed minimum slugging range. Also shown is the following semi-empirical correlation predicting $u_{m s}{ }^{141}$ :

$$
u_{m s}=u_{m f}+0.07\left(g D_{B}\right)^{0.5}+0.16\left(1.3 D_{B}^{0.175}-L_{m f}\right)^{2} \text {, if } L_{m f}<1.3 D_{B}^{0.175}
$$

$$
u_{m s}=u_{m f}+0.07\left(g D_{B}\right)^{0.5} \text {, if } L_{m f}>\text { or }=1.3 D_{B}^{0.175}
$$

where the second equation coincides with Eq. (1) for sufficiently deep beds. The first equation is a dimensional equation, in which 

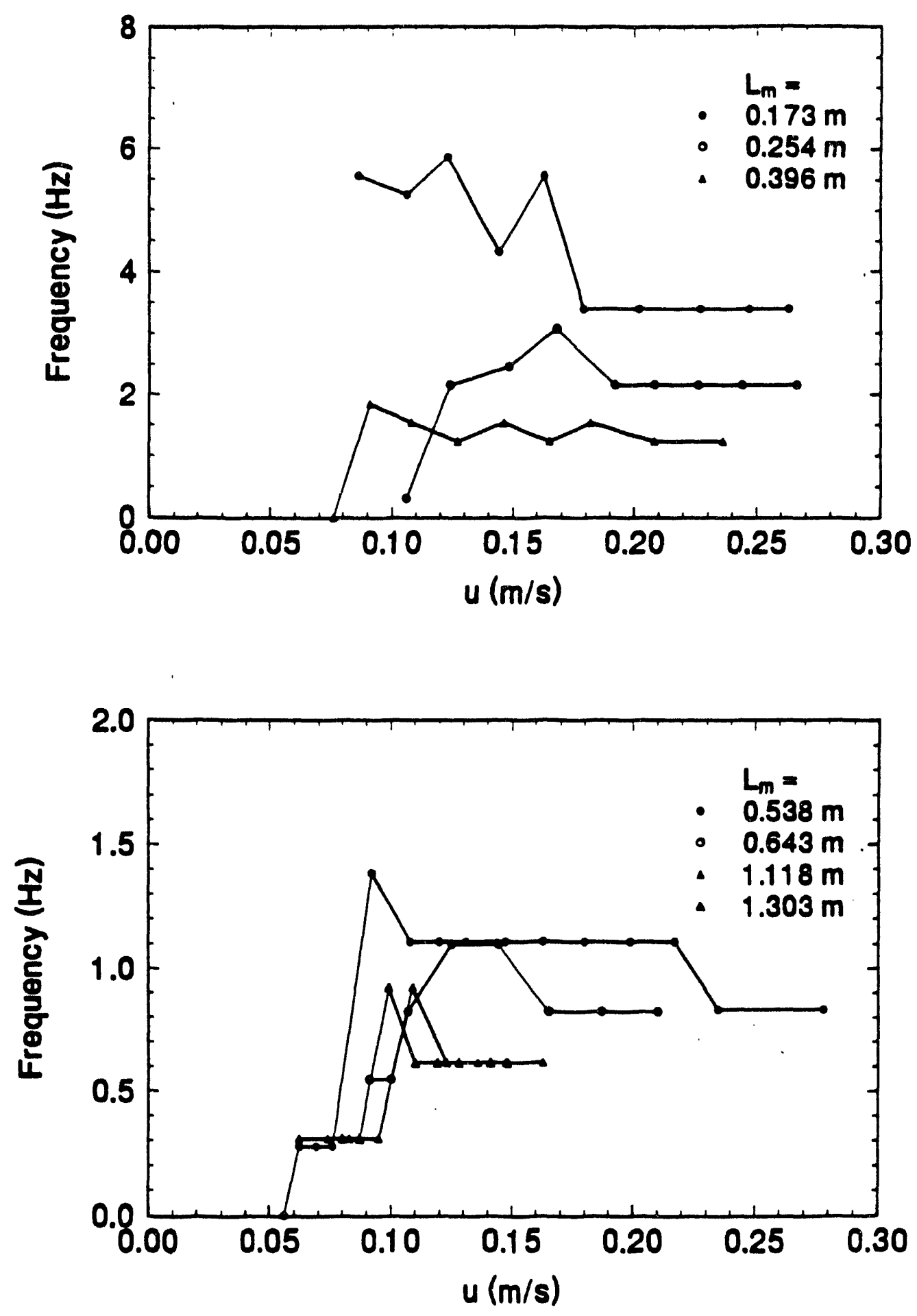

Figure 73. Dominant frequency, $f_{d \prime}$ as a function of gas velocity and settled bed height. 


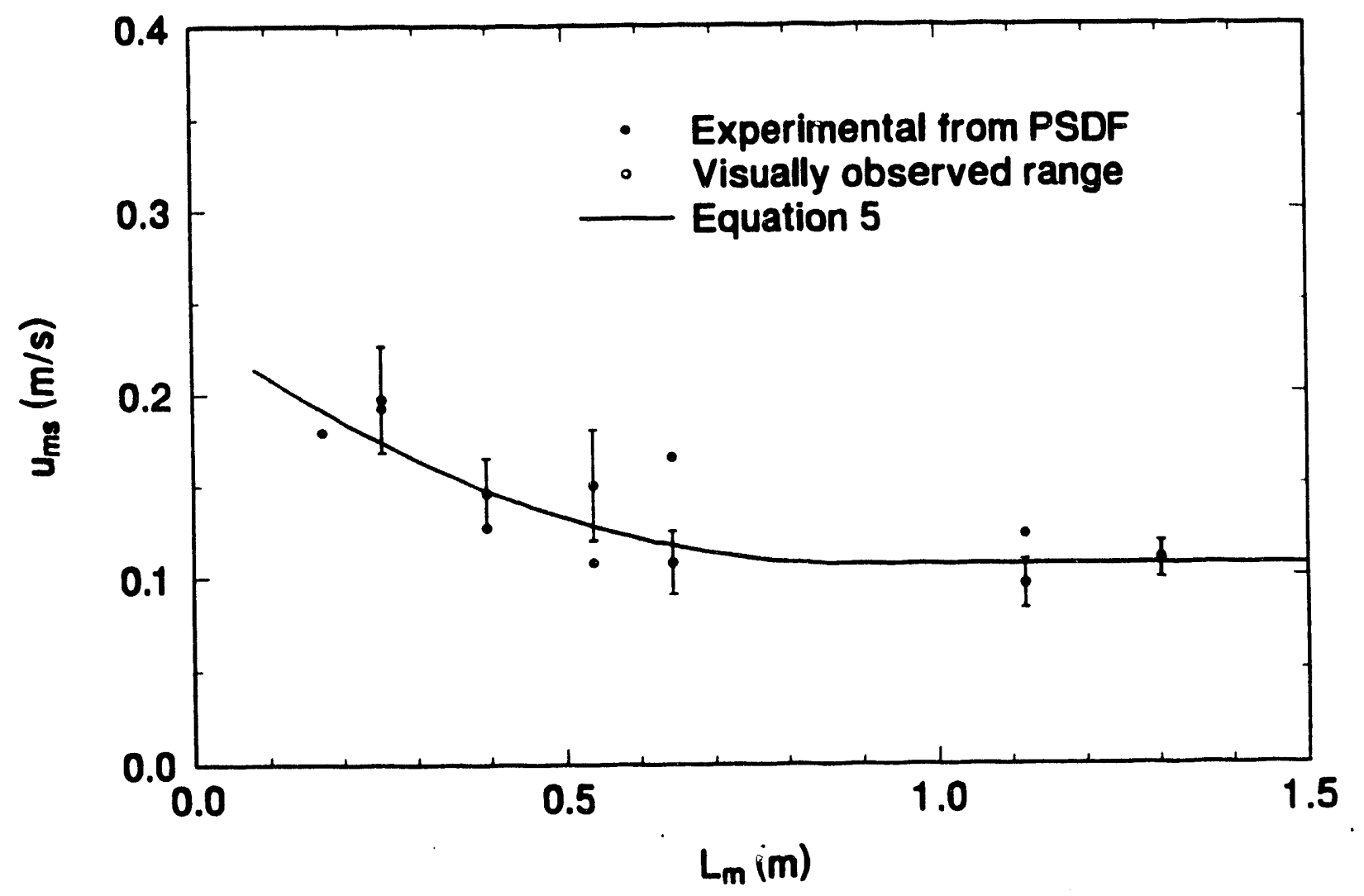

Figure 74. Minimum slugging velocity as a function of settled bed height. 
$L_{m f}$ and $D_{B}$ are given in meters. The fact that our experimental values of $u_{m s}$ agree reasonably well with equation and that the experimental values of $u_{m s}$ fall within the range established by visual observation is taken as confirmation of the method presented here for determining $u_{m s}$.

Figure 75 shows the dominant frequencies, $f_{d}$, determined from Figure 73 for the slugging condition as a function 0 settled bed height. Also shown are the dominant slugging frequency curves predicted by other workers. The trends of the predicted frequency curves $^{138,174}$ agree with the trend of our experimentally determined dominant slugging frequencies. This is taken as further verification of the technique for ascertaining the onset of the slugging condition developed in this paper, although our measured frequencies are higher.

The PSDF method described above for determining the minimum slugging velocity was next applied to the case where three vertical rods were present. The pressure-fluctuation data were processed in a manner similar to that above for the open beds. The dominant frequencies for six settled bed heights are shown in Figure 76. As in the case of an open bed, the dominant frequency is smaller in deep beds than in shallow beds. In the deepest bed, $f_{d}$ reached a constant value at $u=0.123 \mathrm{~m} / \mathrm{s}$, which lies in the visually observed range for the onset of slugging of $0.085-0.123 \mathrm{~m} / \mathrm{s}$. Apparently, for the other five cases studied, the bed was in the bubbling regime over the full range of gas velocity studied. However, it should be noted that visual observation indicated that the beds 


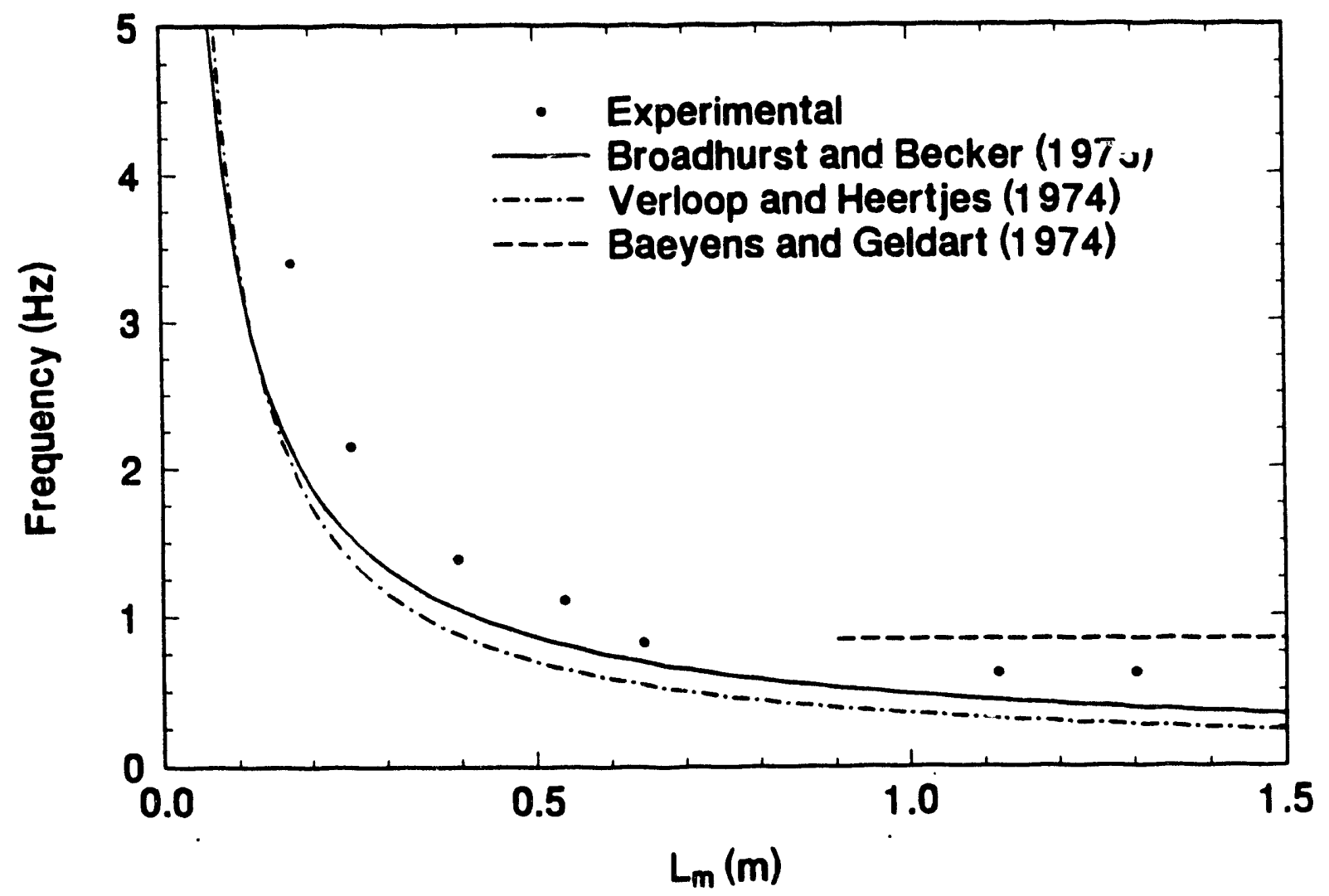

Figure 75. Dominant frequency of a slugging bed as a function
of settled bed height. 

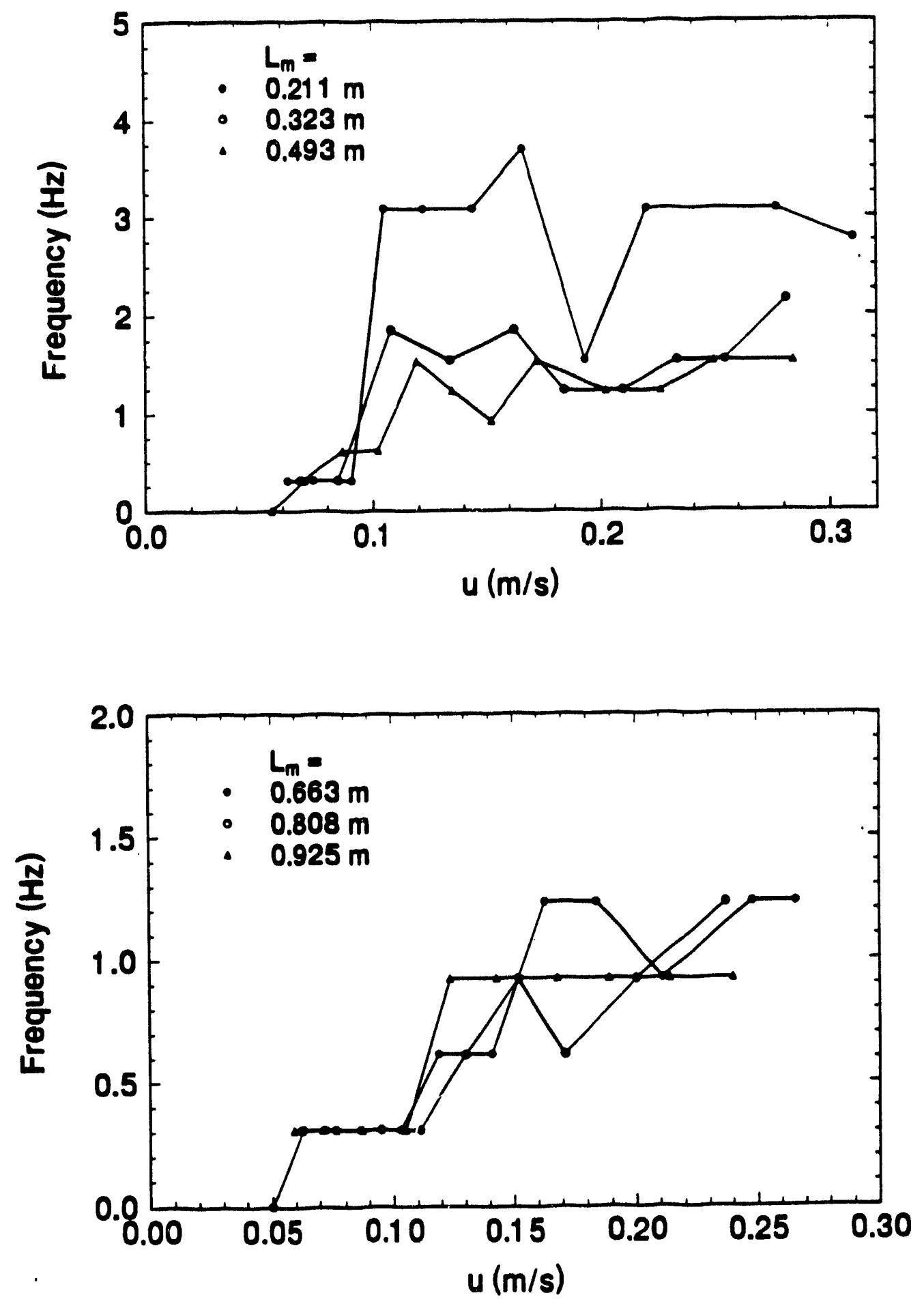
Figure 76. Dominant frequency, $f_{d \prime}$ as a function of gas with three vertical rods. 
with $I_{m f}=0.808 \mathrm{~m}$ and $0.663 \mathrm{~m}$ exhibited slugging or developing slugging at the highest gas velocities. Due to equipment limitations, it was not possible to study the effects of gas velocity greater than about $0.32 \mathrm{~m} / \mathrm{s}$. Therefore, in the cases when $f_{d}$ never reached a constant value, it is assumed that $u_{m s}$ is greater than the highest gas velocity studied for that case. This is indicated in Figure 77 by the arrows pointing up. The curve predicted by Eq. (5) is shown, and it is obvious that $u_{m s}$ is significantly increased in the presence of the rods.

Grace and Harrison ${ }^{175}$ showed that vertical rods in a fluidized bed will tend to limit bubble coalescence, provided that: 1) The rods are not spaced closer than 30 times the average particle diameter, and 2) The tube diameter is not greater than about $20 \%$ of the expested bubble diameter. Vertical tubes have been prescribed as heat exchangers for the purpose of increasing gas-solid contacting, a phenomenon usually associated with s...aller gas bubbles ${ }^{146}$. In light of the work presented here, these previous conclusions can be extended to mean that slugging will be suppressed when vertical tubes are present within a tluidized bed.

In conclusion, a new method for determining the onset of slugging in fluidized beds was developed. Pressure-drop data, measured from the plenum chamber, below the distributor, to the gas exit line, were used to characterize the regime of fluidization. The dominant frequency, $f_{d^{\prime}}$ in the power spectral density function (PSDF) of the pressure fluctuations was constant in the slugging regime. Therefore, the criterion for slugging proposed here is 


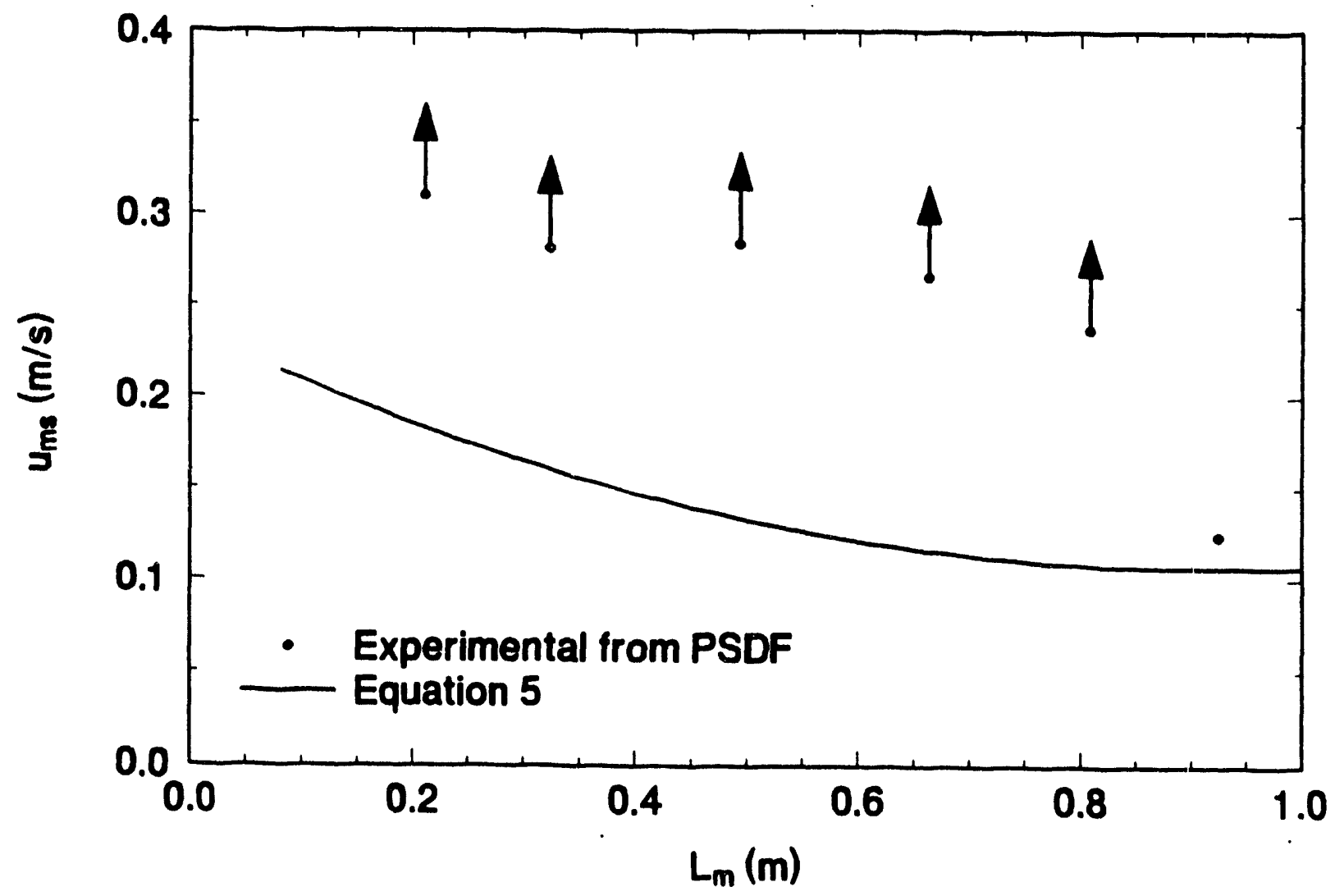

Figure 77. Minimum slugging velocity as a function of settled bed height for a bed fitted with three vertical rods. An arrow pointing up indicates that $u_{m s}$ is greater than the value at the base of the arrow. 
that $f_{d}$ is constant over a range of fluidizing gas velocity. Using this method, it was shown that, at least for a $10-\mathrm{cm}$ diameter fluidized bed of sand, $u_{m s}$ is increased, i.e., slugging is suppressed, when the bed contains vertical rods.

FUTURE ACTIVITIES

The following activities are scheduled during the 1992-1993 fiscal year:

1. Development of an integrated mathematical model that includes the thermally coupled pyrolysis bed and the previously completed model for the first combustion bed, for use in optimizing the reactor configuration and operating conditions for the energyefficient extraction of bitumen

2. Development of an advanced control scheme based on internal model control to determine appropriate tuning parameters.

3. Operation of the revamped and upgraded laboratory unit to validate the model and the control scheme. 
NOTATION

$$
\begin{aligned}
& A_{B}=\text { Area of bed, }\left(\mathrm{m}^{2}\right) \\
& D_{B}=\text { Diameter of bed, (m) }
\end{aligned}
$$

Mean $d_{p}=$ Average particle diameter, $(m)$

$\mathrm{d}_{\mathrm{j}}=$ Particle diameter, (m)

$\mathrm{f}_{\mathrm{d}}=$ Dominant frequency in a PSDF, $(\mathrm{Hz})$

$f_{n}=$ Natural frequency of a bed, (Hz)

$f_{\mathrm{s}}=$ Second dominant frequency in a PSDF, (Hz)

$g=$ Acceleration of gravity, $\left(\mathrm{m} / \mathrm{s}^{2}\right)$

$\mathrm{L}_{\mathrm{m}}=$ Settled bed height, (m)

$\mathrm{L}_{\mathrm{mf}}=$ Bed height at minimum fluidization, (m)

$\mathrm{N}_{\mathrm{r}}=$ Number of data points in a record, (-)

$\mathrm{P}_{\mathrm{p}}=$ Average pressure in plenum, ( $\left.\mathrm{Pa}\right)$

$\mathrm{R}=$ Wear rate, $(\mathrm{mm} / \mathrm{hr})$

$\mathrm{U}, \mathrm{u}=$ Superficial gas velocity, $(\mathrm{m} / \mathrm{s})$

$\mathrm{U}_{\mathrm{mf}}, \mathrm{u}_{\mathrm{mf}}=$ Minimum fluidization velocity, $(\mathrm{m} / \mathrm{s})$

$u_{m s}=$ Superficial gas velocity at which a bubbling

bed becomes a slugging bed, (m/s)

$\mathrm{V}_{\mathrm{p}}=$ Volume of plenum chamber, $\left(\mathrm{m}^{3}\right)$

$\mathrm{w}_{\mathrm{j}}=$ weight fraction of a particle size, (-)

\section{Greek:}

$$
\begin{aligned}
& \mathrm{DP}=\text { Pressure drop across a fluidized bed, (Pa) } \\
& \mathrm{e}_{\mathrm{mf}}=\text { Void fraction at minimum fluidization, (-) } \\
& \mathrm{f}_{\mathrm{s}}=\text { Particle shape factor, }(-) \\
& \mathrm{p}=3.1416 \ldots(-) \\
& r_{\mathrm{B}}=\text { Average density of bed, }\left(\mathrm{kg} / \mathrm{m}^{3}\right) \\
& r_{\mathrm{s}}=\text { Particle density, }\left(\mathrm{kg} / \mathrm{m}^{3}\right)
\end{aligned}
$$


DEVELOPMENT OF A FLUIDIZED BED REACTOR SYSTEM

FOR REDUCED PRESSURE PYROLYSIS STUDIES

Professor

Graduate student
F.V. Hanson

John V. Fletcher

\section{INTRODUCTION}

Fluidized bed reactors have been successfully adapted to a wide range of chemical and physical processes requiring contact and interaction between solids and a fluid. Many combinations of solids and fluids are possible, based on the properties and function of the materials. One important application is the gassolids fluidization reactor, where the solid, the gas, or both may undergo a process change. Reactors of this type have been the subject of a considerable body of literature on the application of fluidization principles to the design of practical systems. One potential application of the gas-solids fluidized bed reactor is for the thermal processing of mined oil sands such as those found in the state of Utah.

The thermal processing of Canadian oil sands using a fluidized bed reactor has been studied by several investigators. ${ }^{176-178}$ The fluidized bed pyrolysis of Utah oil sands has been extensively studied by many investigators at the University of Utan. ${ }^{179-187}$ Emphasis in the fluidized bed studies at the University of Utah has been on the influence of process variables on the product. distribution, yields, and liquid product quality for the pyrolysis of oil sands. In these studies, both laboratory and small-pilot scale fluidized bed reactors have been used including reactor diameters from $3.5 \mathrm{~cm}$ to $10.2 \mathrm{~cm}$. The process variables of 
interest have included reactor temperature, solids retention time, fluidizing gas velocity, and average feed sand particle size. ${ }^{188} \mathrm{~A}$ schematic flow diagram typical of the fluidized bed systems is presented in Figure 78 .

Analysis of the performance characteristics of the small diameter $(3.5 \mathrm{~cm})$ and the larger diameter $(10.2 \mathrm{~cm})$ reactors suggested that both were operated as slugging beds rather than bubbling beds. ${ }^{189}$ This finding led to a reexamination of fluidized bed reactor performance and design parameters applicable to oil sands processing as described in this report.

In the process variables studies, ${ }^{179-187}$ the influence of average solids retention times, pyrolysis temperatures, and fluidizing gas velocities on product yields and quality were evaluated. Yields of $\mathrm{C}_{5}{ }^{+}$liquids decreased with increasing pyrolysis temperature and sand retention time, but were insensitive to fluidizing gas velocity. ${ }^{189}$ The results of the process development efforts at the University of Utah offer some interesting contrasts in terms of the influence of process variables on product yields when oil sands are pyrolyzed in a fluidized bed reactor. In the heat pipe coupled system, developed by the former Chemical Engineering department, liquid yields were found to increase as temperature increased up to $500^{\circ} \mathrm{C},{ }^{184}$ a trend that reportedly reverses above $525^{\circ} \mathrm{C}$ in a conventional fluidized bed. ${ }^{190}$ The effect of retention time on liquid yields is not at all clear. Smart ${ }^{184}$ reported a decrease in liquids at shorter residence times; however, Venkatesan, ${ }^{181}$ Dorius, ${ }^{185}$ Sung, ${ }^{186}$ and Shun $^{187}$ reported just the opposite. Likewise 


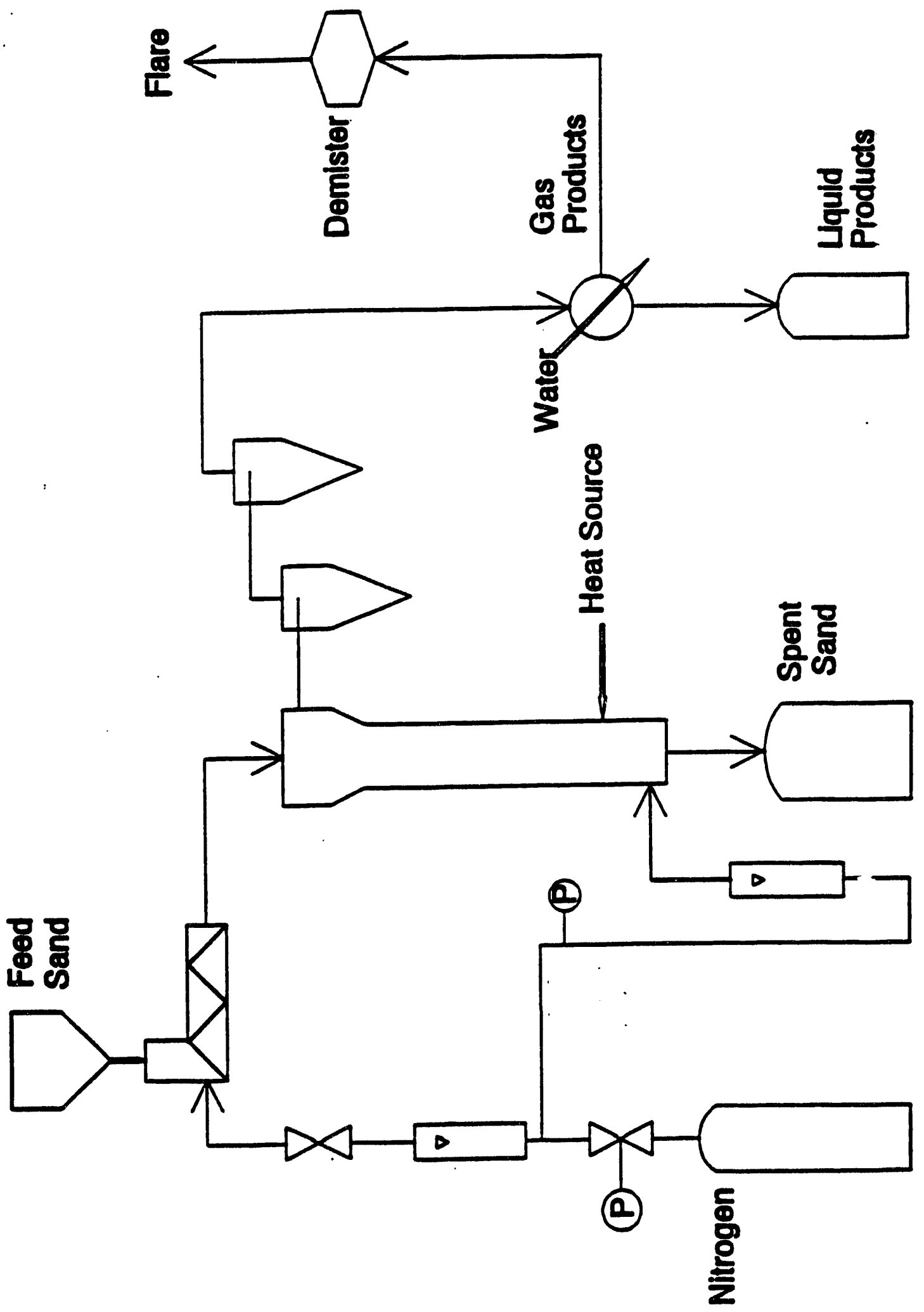

Figure 78. Typical Fluidized Bed Oil Sands Pyrolysis System 292 
Smart ${ }^{184}$ found a decrease in coke with increasing temperature, but Venkatesan, ${ }^{181}$ Dorius, ${ }^{185}$ Sung $^{186}$ and Shun $^{187}$ reported no appreciable change. The fluidizing gas velocity was one process variable that all researchers seem to agree had no influence on product distribution and yields, or on the liquid product quality. The results of fluidized bed pyrolysis process variable studies at the University of Utah can be summarized as follows:

1. Liquid yields will be a maximum near $800 \mathrm{~K}$.

2. Coke yields will not vary appreciably with temperature but are sensitive to oil sand source.

3. Liquid yields are inversely proportional to retention time below 29-30 minutes and proportional to retention times greater than 29-30 minutes.

4. $C_{1}-C_{4}$ gas yields increase as pyrolysis temperature increases.

5. The fluidizing gas velocity does not appear to effect product yields, quality, or distribution.

6. $723 \mathrm{~K}$ is the lower temperature limit for oil sand pyrolysis in a fluidized bed, according to Wang. ${ }^{183}$

The trends above suggest that in order to maximize liquid yields and keep $c_{1}-c_{4}$ gases at a minimum, the pyrolysis temperatures should be kept low. However, lower pyrolysis temperatures should lower the bitumen volatility ${ }^{191}$ and increase the extractables on the coke. ${ }^{183}$ Also, temperature is known to have significant effects on rates and selectivities of paraffin pyrolysis, 192 with high temperatures increasing cracking rates and 
favoring light products.

One fluidized bed process variable that has not been studied at the University of Utah is reactor pressure. The studies summarized above were all conducted at nominally atmospheric pressures. The effect of an applied pressure less than atmospheric on hydrocarbons is to increase their volatility. ${ }^{193}$ A lower reactor pressure is thus a potential solution to the processing problems described by Wang ${ }^{183}$ as resulting from incomplete distillation of bitumen at lower temperature.

Pressure, as a variable in fluidization engineering, usually implies atmospheric or greater pressure. ${ }^{194-197}$ subatmospheric pressure applications of fluidized bed technology are few ${ }^{198,199}$ and experimental techniques are not well documented. ${ }^{195}$

Although a limited number of investigations on fluidization at less than atmospheric pressure have been conducted, ${ }^{198-203}$ they all indicated that gas-solids fluidization in that pressure range was feasible. In fluidization engineering, the term pressure means above atmospheric pressure. Studies at pressures below atmospheric use "reduced," 199,203 "sub-atmospheric,"198 or "low, "200 synonymously. The word "reduced" has a modest connotation and therefore the term reduced pressure was adopted for this work. Reduced pressure is defined as a pressure range from less than ambient atmospheric to $75 \mathrm{kPa}(563 \mathrm{~mm} \mathrm{Hg}, 0.74 \mathrm{~atm})$ absolute.

\section{Research Objectives}

This investigation was carried out in an effort to correct several engineering problems common to both the $3.5 \mathrm{~cm}$ ID and the 
$10.2 \mathrm{~cm}$ ID fluidized bed reactors and to study the pyrolysis of oil sands at reduced pressure. The engineering problems were most recently described by sung ${ }^{186}$ and includec mechanical difficulties with the feeder, cyclones, and spent sand withdrawal systems. Analysis of the performance of the two reactors led to the conclusion that the best way to correct their slugging problems was to design a new $15.2 \mathrm{~cm}$ ID reactor.

The specific research objectives of this phase of the project were:

1. Design, install, and startup a $15.2 \mathrm{~cm}$ ID fluidized bed pyrolysis reactor.

2. Develop a method, including minimum dilution ratios, for feeding oil sands uniformly and on demand to a fluidized bed reactor operating at $500^{\circ} \mathrm{C}$.

3. Develop a method for continuous and controlled withdrawal of spent sand from a fluidized bed reactor operating at $500^{\circ} \mathrm{C}$.

4. Design and test a simple, efficient product recovery system.

5. Determine the physical nature of the oil sand as it enters the reactor.

6. Evaluate the relative merits of thermal recovery of bitumen at less than ambient pressures as compared to previous ambient pressure studies. (to be completed in 1993)

7. Reexamine the effect of excess fluidizing gas flow, 
$\mathrm{U} / \mathrm{U}_{\mathrm{mf}}$, on liquid product yields. (to be completed in 1993)

8. Reexamine the eftzct of residence time on liquid product yields. (to be completed in 1993)

9. Propose and experimentally verify correlations between $\mathrm{U}_{\mathrm{mf}}$, temperature, and pressure for the spent sand in a well-mixed fluidized bed.

10. Demonstrate that hot flue gases from the reactor heat source can be used as the process fluidizing media.

11. Contribute experimentally to the development of a suitable mathematical process model of the fluidized bed pyrolysis reactor.

\section{EXPERIMENTAL}

The fluidized bed reactor and support systems used in this investigation constitute a small-pilot scale continuous flow pyrolysis process development unit, and consists of an oil sand feeder, a fluidized bed reactor, pyrolysis products withdrawal and recovery systems, and various process monitoring and support systems. A process flow diagram is presented in Figure 79.

\section{oil Sands Feeder and controls}

The oil sands feeder used in this investigation was a standard commercial dry materials feeder supplied by Acrison. Discussion with factory and local representatives led to the following set of initial specifications:

- Acrison Model BDF-1.5/E/2 feeder 


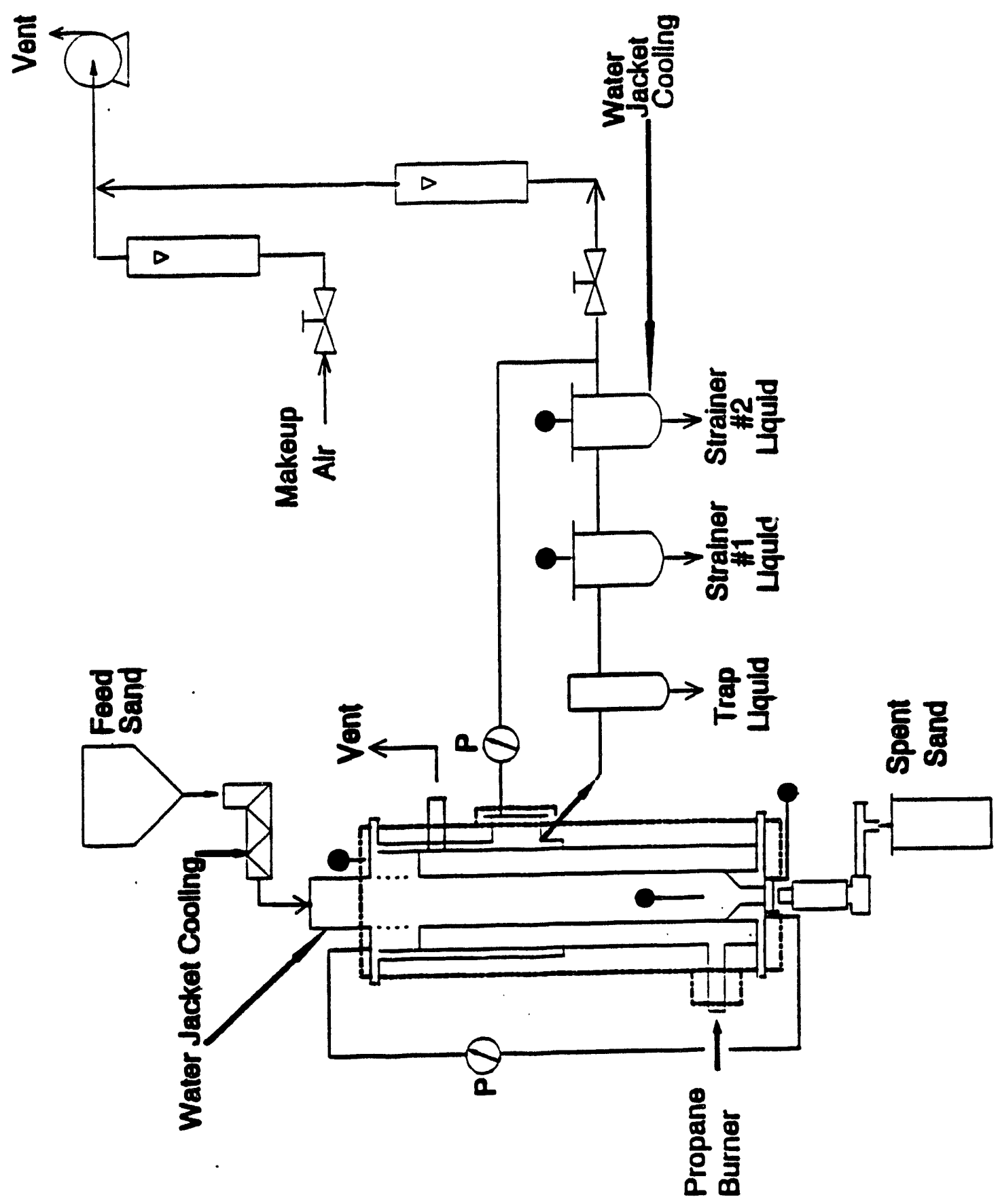

Figure 79. Reduced Pressure Process Flow Diagram 
- Stainless steel solid shaft feed auger and cylinder

- Stainless steel 4 inch ID cylinder downspout with an auger end bearing and a downspout cover with $2-3 / 8$ inch NPT fittings

- $\quad 0.5$ psig pressure rating

- 6 cubic foot hopper

- Hopper cover with 2-1/4 inch NPT fittings and a 6 inch circular fill opening with coupler

- Model 050-2A SCR-DC remote mounted speed controller, 30:1 speed range

- Quick clamp construction for feed auger assembly

Subsequent to the calibration studies the feeder was modified by changing the feed auger and cylinder downspout for use on the 6 inch ID fluidized bed reactor. The new auger specification was:

- Stainless steel $\mathrm{d} / 2$ feed auger, $24 \mathrm{j}$.nch length

- Stainless steel 6 inch ID cylinder downspout with an auger end bearing and a downspout cover with 2-3/8 inch NPT fittings

- Stainless steel auger cylinder with water jacket and 1/2 inch NPT fittings for counter current water flow

- $\quad 0.5$ psig pressure rating

\section{Reactor Design and Construction}

\section{Reactor Body}

Analysis of fluidization data from the small-pilot scale reactor (Sung, 1988) indicated that it was operating in the slugging mode, even though 
generally accepted slugging criteria, ${ }^{195}$ suggests that the reactor should not have slugged.

$$
H_{B} \geq 60 D^{0.175}(\mathrm{~cm})
$$

The right hand side of equation (1) equals $90 \mathrm{~cm}$ for the $10.2 \mathrm{~cm}$ ID bed and Sung (1988) reported a lower bed height, $H_{B}$, of $61 \mathrm{~cm}$, for the runs with a bed mass, $M_{B}$, of $6 \mathrm{~kg}$. Because wall effects are well known in small diameter reactors ${ }^{195}$ and slugging is virtually unknown when $H / D \leq 2,{ }^{204}$ it was decided to rebuild the reactor with a larger diameter. For the same $M_{B}=6 \mathrm{~kg}$, the settled bed in a $15.2 \mathrm{~cm}$ ID reactor yields an $H / D$ of 1.8 . Therefore, the decision was made to redesign the fluidized bed pyrolysis system around a bed diameter of $15.2 \mathrm{~cm}$ or 6.0 inches.

Key reactor specifications:

- Reactor body $=6.0$ inch ID $\times 0.25$ inch wall $\times 70$ inch seamless tube $(15.2 \mathrm{~cm} \times 0.64 \mathrm{~cm} \times 188 \mathrm{~cm})$

- Disengager walls $=12.0$ inch ID $\times 0.375$ inch wall $\times 7.0$ inch seamless pipe $(30.5 \mathrm{~cm} \times 0.95 \mathrm{~cm} \times 17.8 \mathrm{~cm})$

- Disengager floor $=3 / 8$ inch flat steel $(0.95 \mathrm{~cm})$

- Height from bottom to top flange $=78$ inches $(198 \mathrm{~cm})$

- Cross sectional bed area $=28.4$ square inches $\left(182 \mathrm{~cm}^{2}\right)$

Because this was a prototype reactor design, heavy wall carbon steel instead of stainless steel was used to reduce costs and make future modifications easier. The transition from the $15.2 \mathrm{~cm}$ ID reactor to the $30.5 \mathrm{~cm}$ ID disengager was made with a $90^{\circ}$ horizontal floor rather than a $60^{\circ}$ tapered bell also reduced costs. 
Heating and Fuel

The $10.2 \mathrm{~cm}$ ID reactor described by Sung $^{186}$ had been heated successfully by burning natural gas and channeling the hot combustion gases through an outer shell that enclosed the reactor body. A similar concept was adapted for this reactor wherein propane (LPG) was chosen as the fuel, which would facilitate monitoring consumption based on cylinder mass losses. The LPG was purchased in $30 \mathrm{lb}$ refillable cylinders.

Mole percents of the LPG components were determined using dual $80 / 100$ mesh chromosorb 102 columns (3.18 $\mathrm{mm}$ OD and $6.1 \mathrm{~m}$ long) in a 5830A hewlett Packard gas chromatograph with dual conductivity detectors. The LPG analysis and the physical properties of the light hydrocarbons are presented in Table 24, which was adapted from Table 9-13 in Perry's Chemical Engineering Handbook. 205 Calculated energy values for the LPG are presented in Table 25 along with values reported in the literature.

The heating jacket for the reactor was designed to envelop the full length of the $15.2 \mathrm{~cm}$ ID reactor tube. The outer wall was built from a section of the same $30.5 \mathrm{~cm}$ material used for the disengager. Wall thickness was 0.95 inches.

The gas burner was placed on the lower side of the heating section so that burner gases entered the heating jacket at the bed level and then rose to the exhaust port at disengager height. A strip of 16 gauge stainless steel was tack welded in a spiral around the reactor tube so that the heating gases were forced to make four revolutions around the heat envelope in the lower half of 
TABLE 24

Physical Properties of Light Hydrocarbons

\begin{tabular}{|c|c|c|c|c|c|c|c|}
\hline & $\begin{array}{c}\text { Wasatch } \\
\text { LPG }\end{array}$ & & & & Gross & $\begin{array}{l}\text { Heat ing } \\
(\mathrm{HHV})\end{array}$ & Value \\
\hline Species & Vol \& & $f t^{3} / 1 b$ & $\mathrm{ft}^{3} / \mathrm{ga}$ & $\begin{array}{r}1 b / g a \\
1\end{array}$ & $\begin{array}{r}B T U / \frac{f}{t^{3}} \\
\end{array}$ & $\begin{array}{r}\mathrm{BTU} / \mathrm{l} \\
\mathrm{b}\end{array}$ & $\begin{array}{r}\mathrm{BTU} / \mathrm{ga} \\
\mathrm{l}\end{array}$ \\
\hline $\mathrm{CH}_{4}$ & 0.22 & $23.60^{\circ}$ & 59.0 & 2.50 & 1012 & 23885 & $59708^{b}$ \\
\hline $\mathrm{C}_{2} \mathrm{H}_{6}$ & 5.44 & 12.50 & $39.31^{c}$ & $3.14_{5}$ & 1786 & 22323 & 70210 \\
\hline $\mathrm{C}_{3} \mathrm{H}_{8}$ & 93.86 & 8.55 & 36.28 & 4.24 & 2522 & 21560 & 91500 \\
\hline$i-C_{4} H_{10}$ & 0.14 & 6.55 & 32.80 & 5.01 & 3163 & 20732 & 103750 \\
\hline$n-C_{4} H_{10}$ & 0.34 & 6.49 & 31.46 & 4.85 & 3261 & 21180 & 102600 \\
\hline
\end{tabular}

a from BTU/ $\mathrm{ft}^{3}$ and $\mathrm{BTU} / \mathrm{Ib}$

Source: Perry's Handbook(30)

b from BTU/ $\mathrm{ft}^{3}$ and $\mathrm{lb} / \mathrm{gal}$

c from BTU/ft $\mathrm{ft}^{3}$ and BTU/gal

TABLE 25

LPG Energy Content Data

\begin{tabular}{lrrr}
\hline Data Source & Wasatch LPG $^{\mathrm{a}}$ & $\begin{array}{c}\text { Bland and } \\
\text { Davidson }\end{array}$ & $\begin{array}{c}\text { Combustion } \\
\text { Handbook }^{\mathrm{C}}\end{array}$ \\
\hline $\mathrm{BTU} / \mathrm{ft}^{3}$ & 2,482 & 2,522 & 2,558 \\
$\mathrm{BTU} / \mathrm{lb}$ & 21,590 & 21,560 & 21,573 \\
$\mathrm{BTU} / \mathrm{gal}$ & 90,444 & 91,500 & $\mathrm{~N} / \mathrm{A}$ \\
\hline
\end{tabular}

- Calculated from Table 7

b Bland \& Davidson (31)

c North American Combustion Handbook(32)

the reactor, roughly equivalent to the bed plus splash zone. 


\section{Propane Burner}

The propane burner was site built using a $1 / 2$ inch black iron pipe tee for the premix chamber. A schematic of the burner is presented in Figure 80 . The gas nozzle was built from a brass Swagelock cap, and drilled for a $0.0795 \mathrm{~cm}$ diameter orifice. The orifice horizontal position in the tee was adjustable and a midpoint placement was used. This burner design gave a combination premix and diffusion flame burner capable of at least a $5 / 1$ turndown ratio. A permanent propane pilot flame was used as shown in Figure 80 .

\section{Fuel Control}

Propane fuel delivery to the burner was controlled using a combination of a cylinder regulator and a pneumatically operated gas control valve. Primary cylinder regulation was manually adjustable using a Matheson Model 1 regulator (1L-510) specified for propane service. Process control of the propane used the bed temperature type- $\mathrm{K}$ thermocouple signal as an input to a Beckman 7200 digital controller. The 4 to 20 milliampere output of the controller was linked to a Fisher type 546 electro-pneumatic transducer which produced a 3 to 15 psig air signal. The air signal actuated an I-trim Badger Control Valve (Model No. 1001GCN363VOPILN36) which used air to open and a spring to close. A Matheson 6103 flash arrestor was installed between the Badger Control Valve and the fuel/air premix chamber. In operation, the Beckman controller was set to operate the Badger Control Valve in the 15 to $55 \%$ range. This controller had provisions for 


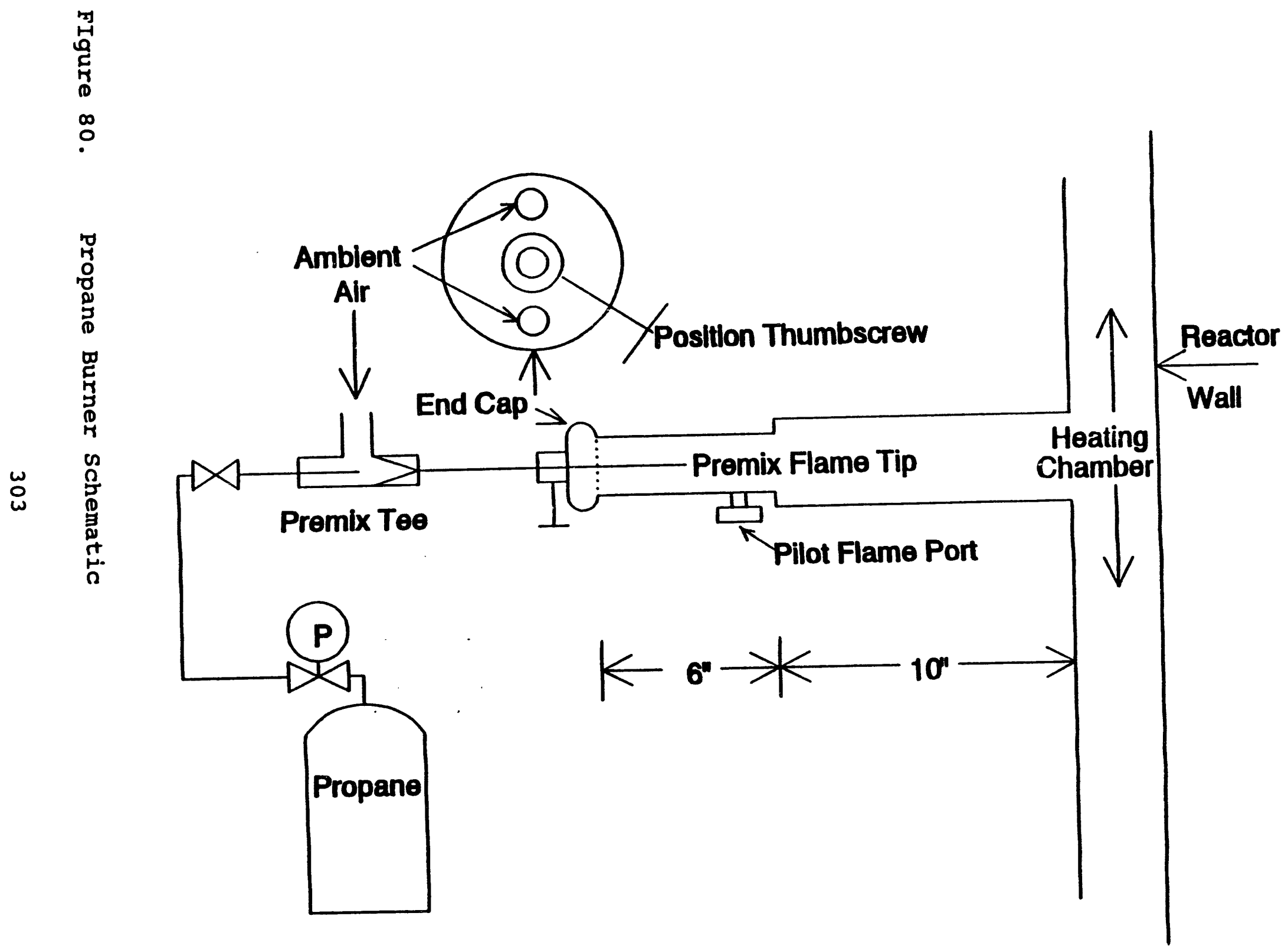


proportional (P), integral (I), and differential (D) control. The PID functions were set at $6.6,0.20$, and 0.20 , respectively.

Gas Distributor

The gas distributor (Figure 81) was an inverted carbon steel cone ${ }^{195}$ machined to fit inside the reactor against a machined retaining ring. The lower end of the cone terminated in a 1.5 inch standpipe. Thirty-three holes, $3 \mathrm{~mm}$ in diameter, were drilled radially in the cone giving an open area of $1.28 \%$ based on the reactor bed area. Each hole was drilled at an angle of 15 degrees from the horizontal in order to reduce weeping of solids into the windbox. Solids weeping was further reduced by covering the outside of the cone with a 42 mesh stainless steel screen. A type$\mathrm{K}$ thermocouple and a pressure tap were located below the distributor in the windbox.

\section{Sand Removal system}

As noted by sung, ${ }^{186}$ spent sand removal was a persistent problem in the Eluidized bed oil sand pyrolysis reactors. Because the problems associated with spent sand removal were mechanical in nature, a nonmechanical L-Valve design, described by knowlton, 208 was adopted after modification. The Modified L-Valve for this system had two individually adjustable aeration points fed by nitrogen gas. The spent sand removal section is diagrammed in Figure 82. Nitrogen aeration, which caused spent sand to flow out of the reactor, was controlled by a Foxboro differential pressure (DP) controller. The DP scale was used as "scale units" only, but had an upper limit of approximately 50 inches of water. 


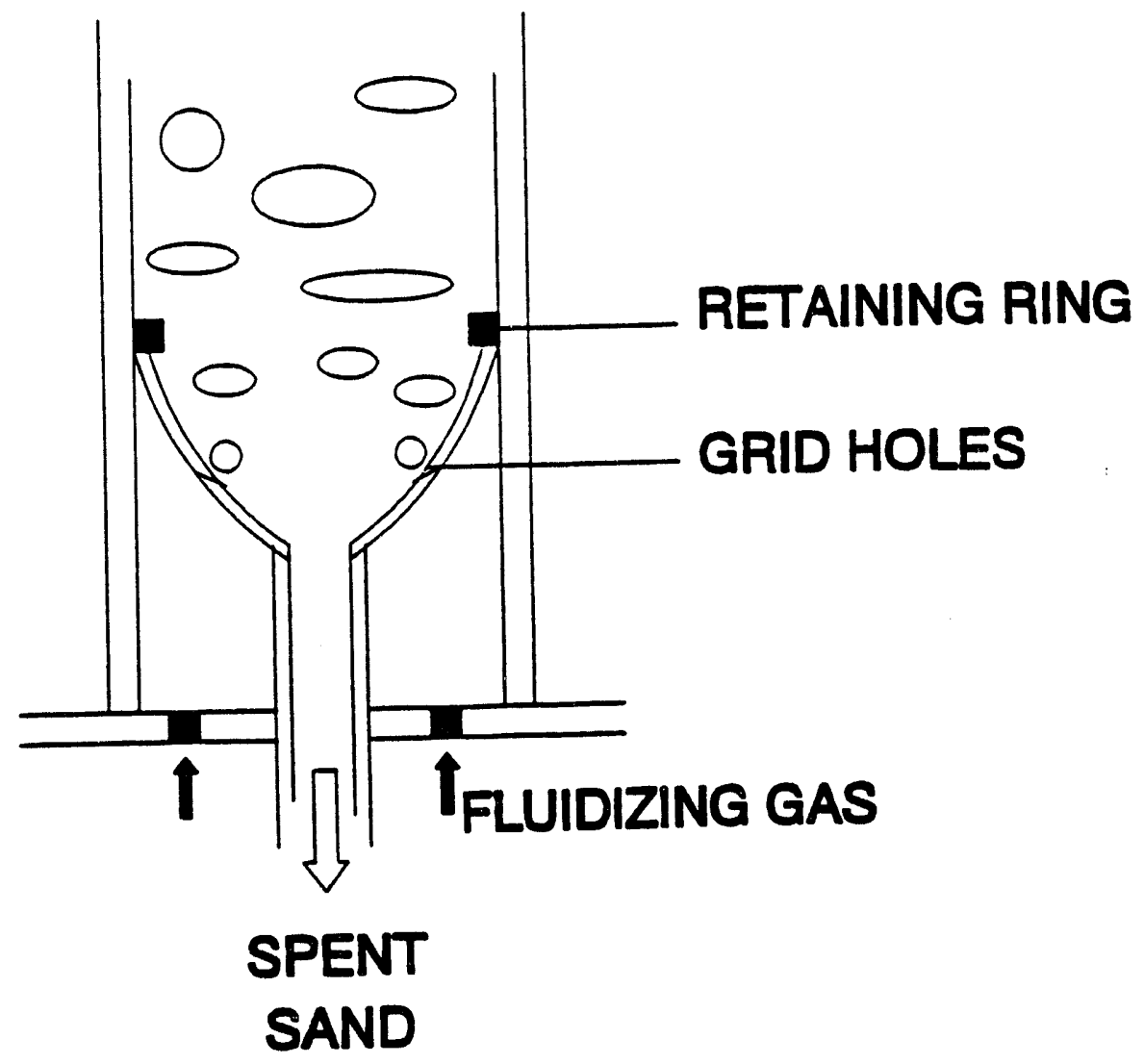

Figure 81. Fluidized Bed Gas Distributor 305 


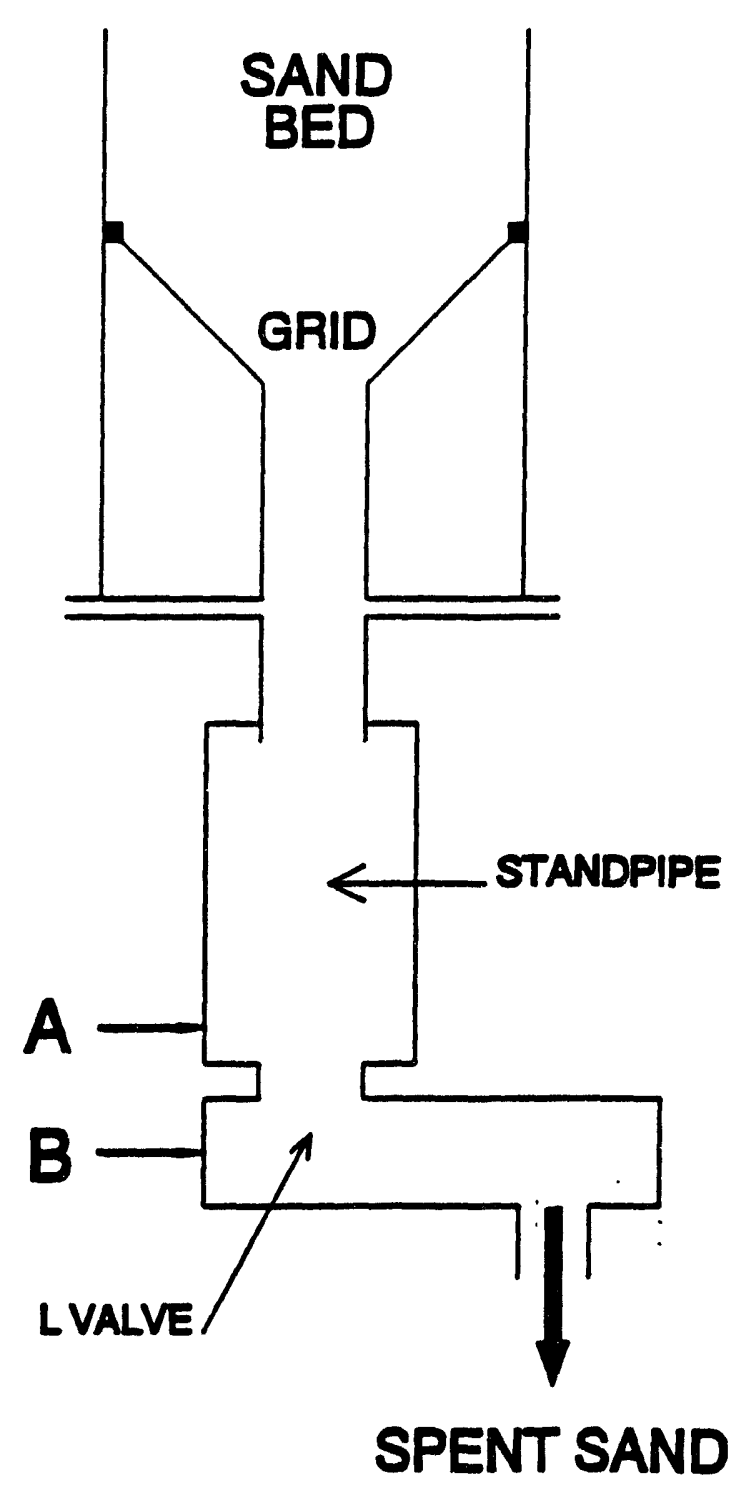

Figure 82. Diagram of Spent Sand Removal System with standpipe and Modified L-Valve 
Bed pressure drop, $\Delta \mathrm{P}_{B}$, was monitored with a Dwyer Magnehelic 2050 differential pressure gauge plumbed in parallel with the DP controller. Pressure taps in the windbox and above the dissengager were used to measure bed pressure drop. When $\Delta \mathrm{P}_{\mathrm{B}}$ exceeded the set point value, the DP controller would reduce the 20 psig air pressure to the Foxboro, normally open, air actuated control valve. This allowed 12 psig nitrogen from a cylinder to flow through rotameters $A$ and $B$, fitted with Matheson needle valves and Matheson 603 tube cubes, into aeration points A and B (Figure 82).

Aeration caused sand to flow from the reactor through the distributor cone (Figure 81) and standpipe (Figure 82) into the spent sand receiver. When loss of sand from the reactor caused $\Delta \mathrm{P}_{B}$ to decrease below the set point, the DP controller would increase air pressure at the nitrogen valve, aeration of the solids standpipe/L valve would cease, and spent sand withdrawal would stop.

The spent sand receiver was a commercial 30 gallon drum. The drum lid was fitted with two $1 / 4$ inch NPT couplers, one for a type$K$ thermocouple and the other for a gas vent. The center of the lid had a 1.5 inch fitting which allowed flexible connection to the outlet of the Modified L-Valve. The standard lid rubber gasket was replaced with a high temperature fiberglass gasket.

\section{Liquid Product Recovery System}

Sung $^{186}$ and others ${ }^{181,183,185,187,209}$ have noted a "mist" in the product gas/liquid stream and have described various attempts to eliminate it. Also, cyclones in the product stream have not 
removed sand as expected. ${ }^{186}$ In order to reduce the solids loading in the product stream, traps were designed into the reactor (Figure 83) and the liquid product recovery system (Figure 79).

Pyrolysis and fluidizing gases exit the reactor through the bottom of a trap and cleanout port located near the axial midpoint of the reactor. Exit temperatures were monitored with a type-k thermocouple. The 1.5 inch exit pipe transitioned into a 1 inch pipe 8 inches down stream from the cleanout port where the insulation ended.

The liquid product recovery system consisted of three components through which all of the product gases passed. The liquid product recovery system was designed around two stainless steel Rosedale Model 4 commercial basket strainers (Model 4-6-1P-2$200-\mathrm{N}-\mathrm{S}-\mathrm{V}-\mathrm{N}-\mathrm{B})$. These strainers were placed in series using a prestrainer trap made from 1 inch pipe fittings. The trap and both strainers had bottom drains for removal of liquids. The first strainer had a 100 mesh stainless steel basket when spent sand only was fluidized and a 200 mesh basket when oil sand pyrolysis was carried out. The second strainer was fitted with a 25 micron polyester filter bag (Rosedale PE-25-P35). The strainer housings were externally wrapped with $1 / 4$ inch copper cooling coils. strainer \#2 also had an internal $1 / 4$ inch copper cooling coil. Inlet and outlet gas piping was 1 inch on both strainers.

Type-K thermocouples were used to monitor the internal temperature for both strainers. A pressure tap at the reactor outlet and a second tap at the exit of strainer \#2 were connected 


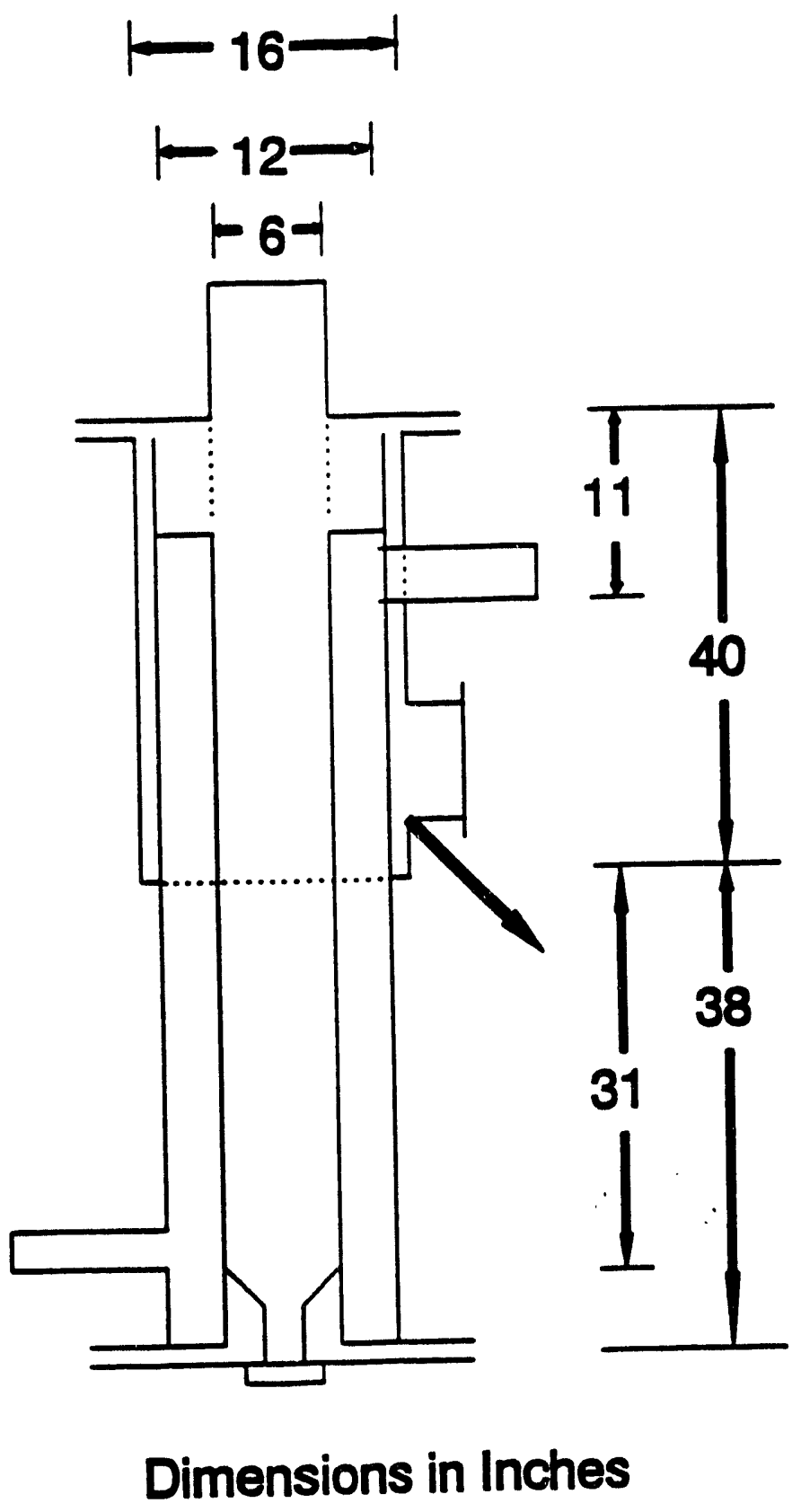

Figure 83.

Reactor Schematic 
to a 0-100 inches of water differential pressure gauge (Dwyer Magnehelic 2100 ) to monitor plugging of the filters.

\section{Process Support Systems}

The complete oil sands pyrolysis system had two support systems working in conjunction with the main reactor, feeder, and sand removal and liquid product recovery systems. These were the gas pumping system and the cooling system.

Gas Pumping system

System design calculations indicated that the fluidized bed pyrolysis reactor would require gas flows over 100 SCFH. Gas compressors or vacuum pumps are the usual choice for such an application but $100+$ SCFH is too great for laboratory devices and two little for commercial devices such as a Roots blower. Therefore, a gas pumping system was built using a belt driven sliding vane pump which had $3 / 4$ inch inlet and outlet ports and a 5 inch drive sheeve.

The drive motor was a 1 horsepower Universal AC/DC type with a 10 ampere speed control (W.W. Grainger Cat. No. 2 M191 and 4x797). An AC ammeter was wired in series to indicate gas pump load. A 20 ampere DPDT switch was used for system on/off control and a 10 ampere slow blow fuse was used for protection. system ground was a third wire to the electrical distribution panel ground buss.

The inlet and outlet lines to the gas pump were fitted with manually drained knockout pots. The entire system was frame mounted and guarded with wire mesh. A 6 inch fan was used to cool the drive motor and a type- $K$ thermocouple was used to monitor the 
drive motor jacket temperature.

\section{Cooling system}

Both water and air were used to cool equipment and materials. Laboratory cooling water was used to maintain a constant temperature in the feed sand auger cylinder. A parallel stream of the same water was used in the liquid product recovery cooling coils. Water temperature was monitored at the exit port of the feed auger cylinder using a type-K thermocouple. The reactor had a water jacket on the feed inlet tube between the top flange and the feeder downspout (Figure 83). This jacket used a portion of the water exiting the feed auger cylinder for cooling. No cooling water was in direct contact with oil sands or pyrolysis products.

Air was used to cool the gas pump drive motor. A fan was also used to sweep the portable propane cylinders and provide cooling air to the 30 gallon spent sand receiver.

\section{Process Monitoring}

The status of the various process systems and components was monitored based on pressures, temperatures and fluid flows.

Pressure Monitoring

Atmospheric pressure was calculated from barometric pressure as read from a mercury barometer. Corrections for latitude, gravity, and temperature were made according to the outline in Lange's Handbook of Chemistry. ${ }^{210}$ The force due to gravity, $g^{*}$, at the University of Utah was taken as $979.75 \mathrm{~cm} / \mathrm{s}^{2}$ based on corrections for latitude and elevation.205,211

Differential pressure was read using Dwyer Magnehelic 
differential pressure gauges, factory calibrated and certified at \pm 18 accuracy. Following the recommendation of Hong et al., ${ }^{212}$ the upper pressure tap for $\Delta \mathrm{P}_{B}$ measurements was placed above the disengager.

\section{Temperature and Data Logging}

A total of 16 type-K thermocouples was used to monitor process and equipment temperatures. Each thermocouple, tested at the same ambient temperature on its respective panel readout position, agreed $\pm 1^{\circ} \mathrm{C}$ with the others. The temperature of the ambient temperature thermocouple (\#13) agreed with the mercury thermometer on the laboratory barometer to within $\pm 0.5^{\circ} \mathrm{C}$ difference. The thermocouple numbers and their system locations are shown in Table 26. Thermocouples $1-6$ were on one rotary switch and panel meter and 7-16 were on a second rotary switch and panel meter.

TABLE 26

Thermocouple Numbers and Locations

\begin{tabular}{llll}
\hline 1 & Feed Sand & 9 & Heater Exhaust \#1* \\
2 & Gas Pump Motor & 10 & Windbox* \\
3 & Bed Profile* & 11 & Water at Feed Auger \\
4 & Disengager Top* & 12 & Coked Sand Receiver \\
5 & Heater Exhaust \#2* & 13 Ambient \\
6 & Clean Out Top* & 14 & 25 Micron Bag Strainer \\
7 & Product Exit Port* & 15 & $100 / 200$ Mesh Strainer \\
8 & Reactor Dead Zone* & 16 & Disengager Bottom \\
\hline
\end{tabular}

* Computer monitored

In addition to manual temperature readings, eight of the thermocouples were wired in parallel to a data logger (DCC 
Corporation Hotmux) which used the serial port of an IBM PC for computer monitoring and temperature recording. Each thermocouple was read every 30 seconds, with software controlled timing, and all data were stored to a file on the computer hard disk. The software (also from DCC Corporation) allows data recall and plotting from the stored file. The eight computer monitored thermocouples are also identified in Table 26.

Fluid Flow Monitoring and Rotameter Calibration

Rotameters were used to monitor fluid flows. Cooling water was controlled and monitored using a Dwyer VFC-EC (2-20 GPM water) rotameter. Dwyer RMC-102 (10-100 SCFH) and RMC-103 (20-200 SCFH) flowmeters with stainless steel valves were used to monitor and control gas flows into the gas pump. The Dwyer water rotameter factory scale was used as received.

The Dwyer gas flowmeters and the two Matheson 603 tube cubes were calibrated using a Singer Model DTM-115 Dry Test Meter. Scale readings on the Dwyer meters were found to vary less than $2 \%$ over the range of pressures used in this study and were therefore accepted as accurate. Calibration curves for the Matheson 603 tube cubes used in rotameters $A$ and $B$ to monitor nitrogen flow to the spent sand removal system are shown in Figure 84 .

\section{Feeder Calibration}

Using spent sand produced in the $10.2 \mathrm{~cm}$ ID fluidized bed reactor (Sung, 1988), mass delivered versus time data were collected for the E/2 feed auger at 15\%, 30\%, 45\%, 60\%, and 75\% of total speed. This calibration data is presented in Figure 85, 


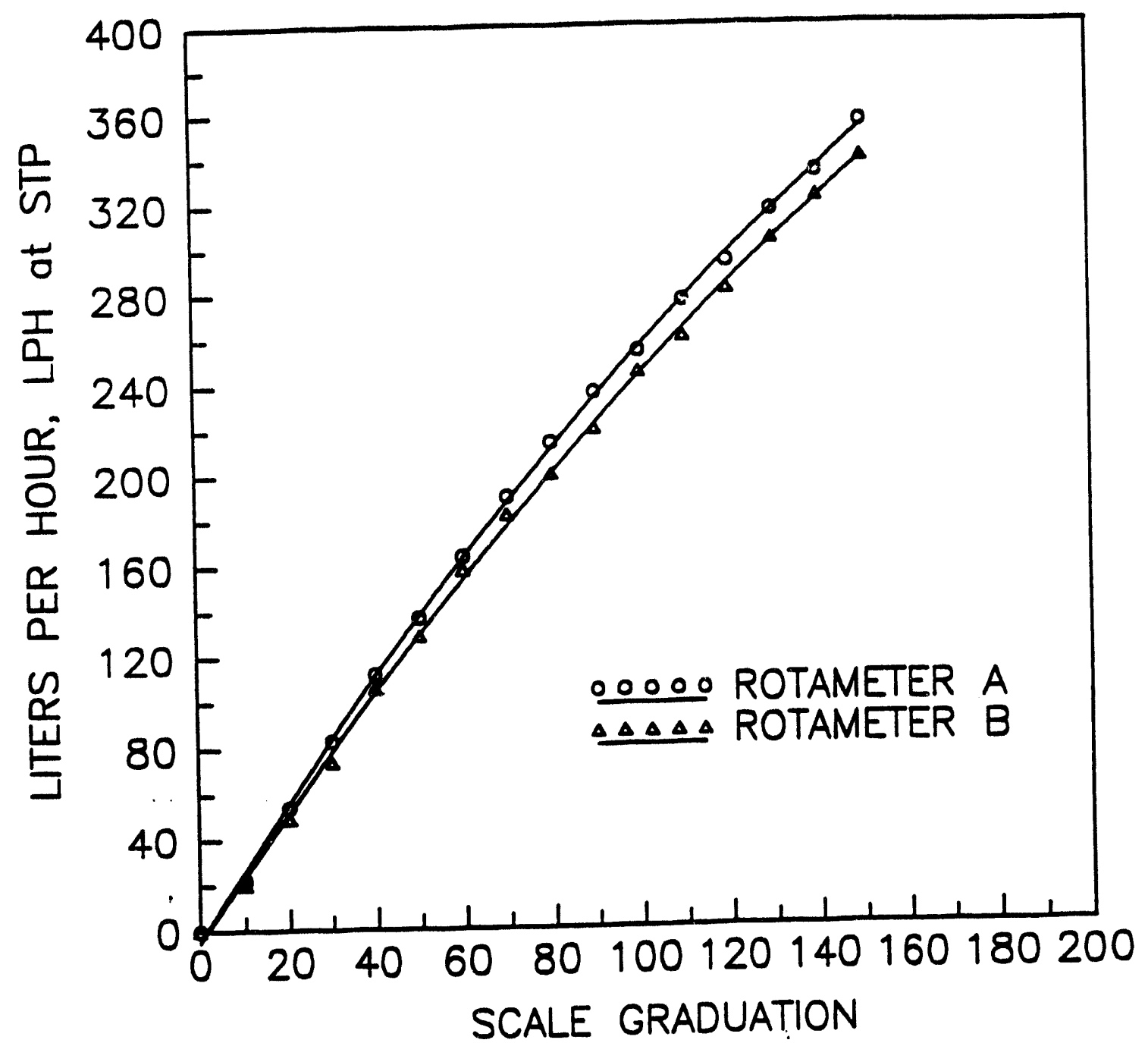

Figure 84. Rotameter Calibration Curves 


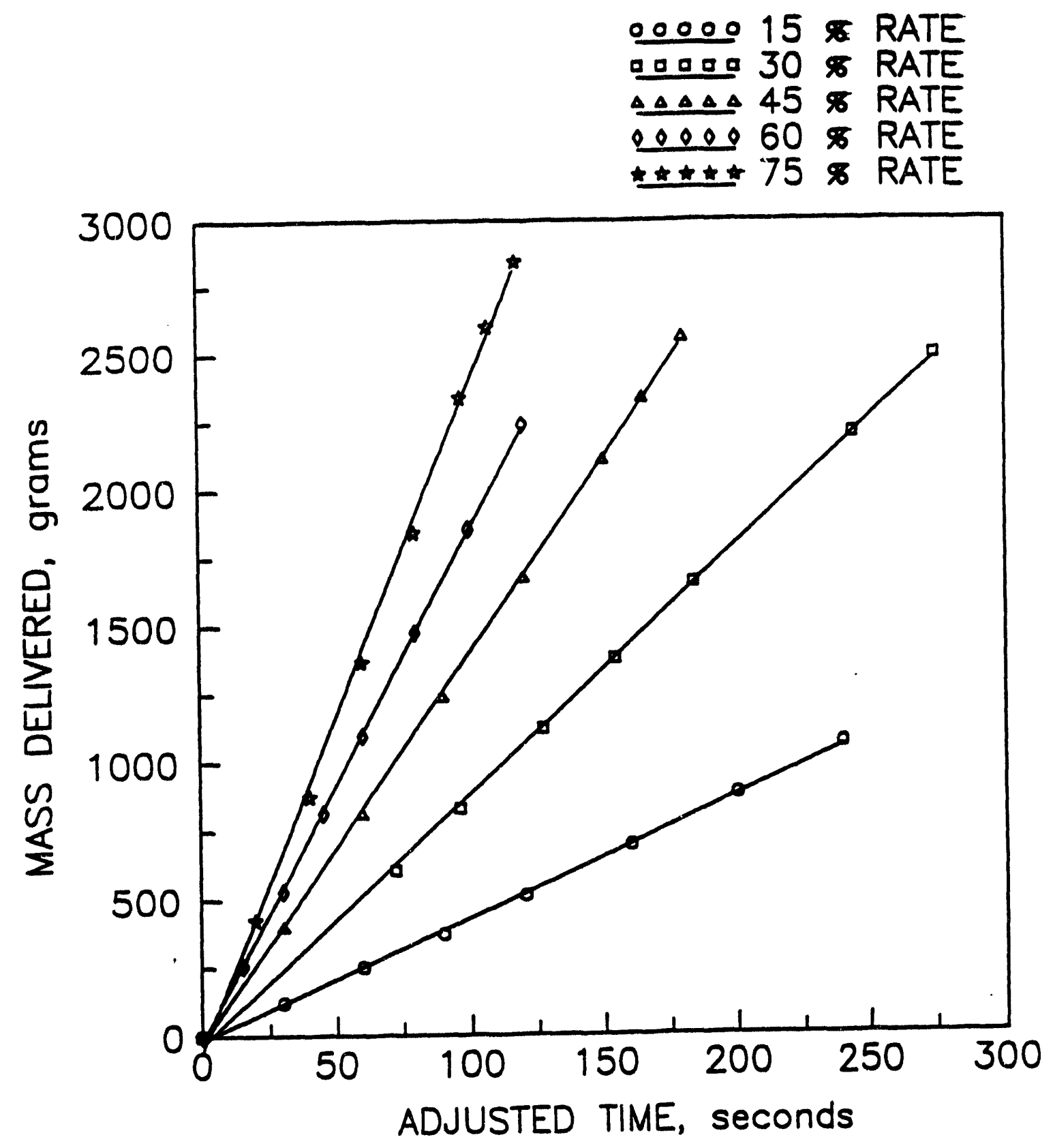

Figure 85. E/2 Auger Spent Sand Calibration Curves 
where time has been adjusted for a 3.3 second delay between switching the feeder on and observed auger motion. At $100 \%$ of speed the E/2 auger fed $1.86 \mathrm{~kg}$ of spent sand per minute. Similar tests with 1:1 and 1:3 mixtures of spent sand to oil sand exhibited no observable performance changes.

Mass versus time data was also taken for $100 \%$ whiterocks (WN) oil sand (Cha, 1991) at 60\%, 75\%, and $90 \%$ feed rates and is shown in Figure 86. Mass delivered versus time data for the $H / 2$ feed auger using Whiterocks (WN) oil sand is shown in Figure 87.

Mass delivered in eight minutes at $5 \%$ of full speed with the H/2 auger is shown as a function of $q$ moisture in Figure 88 . Percent moisture was calculated from the mass loss of a $10 \mathrm{~g}$ sample of oil sand, placed in a weighing boat at a depth $<0.5 \mathrm{~cm}$, which had been left at ambient laboratory conditions for at least 72 hours. The final state of the sample was defined as air dry and $0 \%$ moisture.

\section{Spent Sand Withdrawal system operation}

Nitrogen at 12 psig was injected at points $A$ and B (Figure 82) when spent sand was to be removed from the reactor bed. Jet $A$ was set at approximately $240 \mathrm{LPH}(8.5 \mathrm{SCFH})$ and jet $\mathrm{B}$ was set at $1 / 3$ of jet $A$. Both jet flows were adjusted with a rotameter needle valve. The DP controller that actuated nitrogen flow to jets $A$ and $B$ could be operated manually or automatically by placement of the set point indicator. 


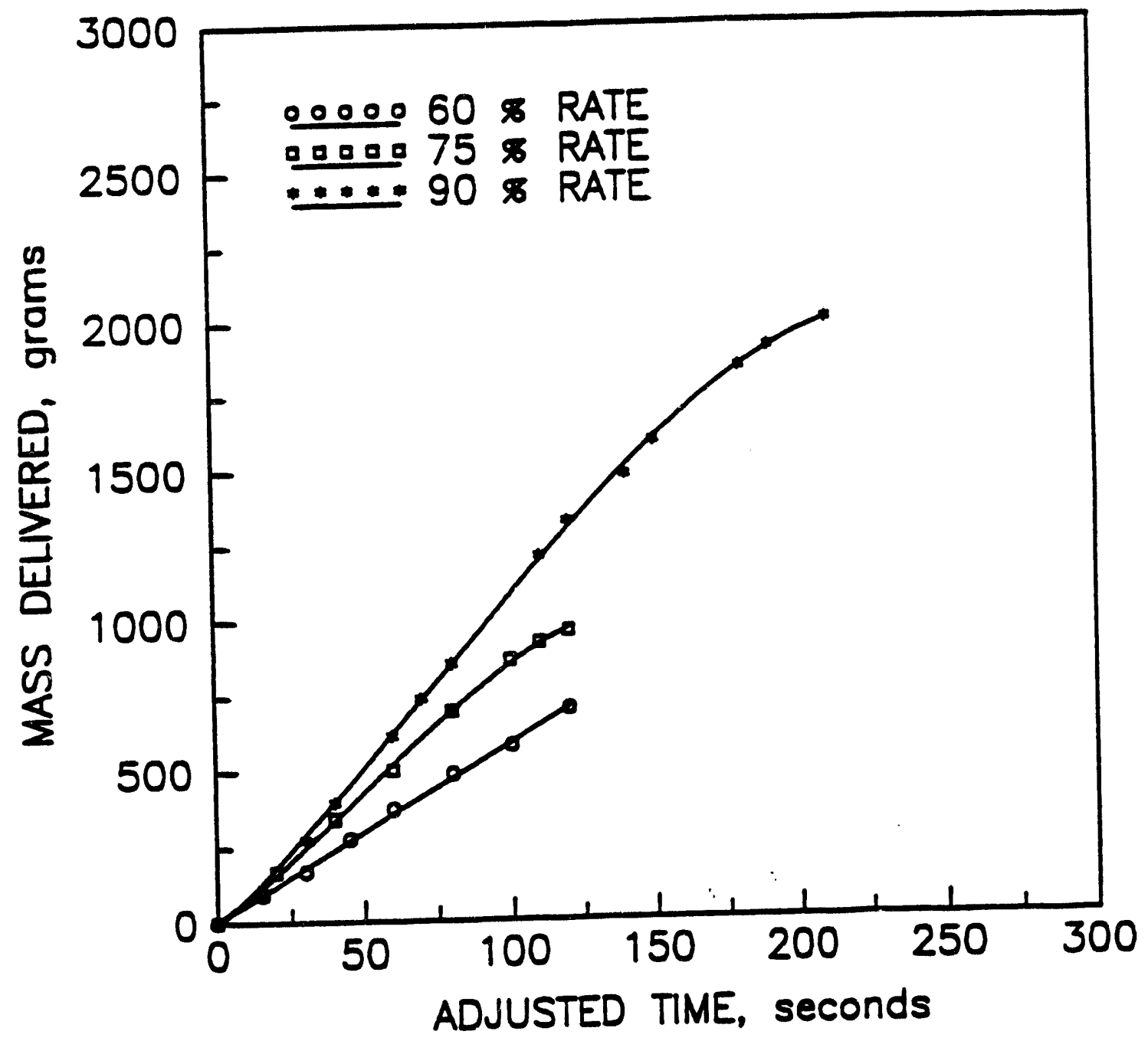

Figure 86. E/2 Auger Oil Sand Calibration Curves 


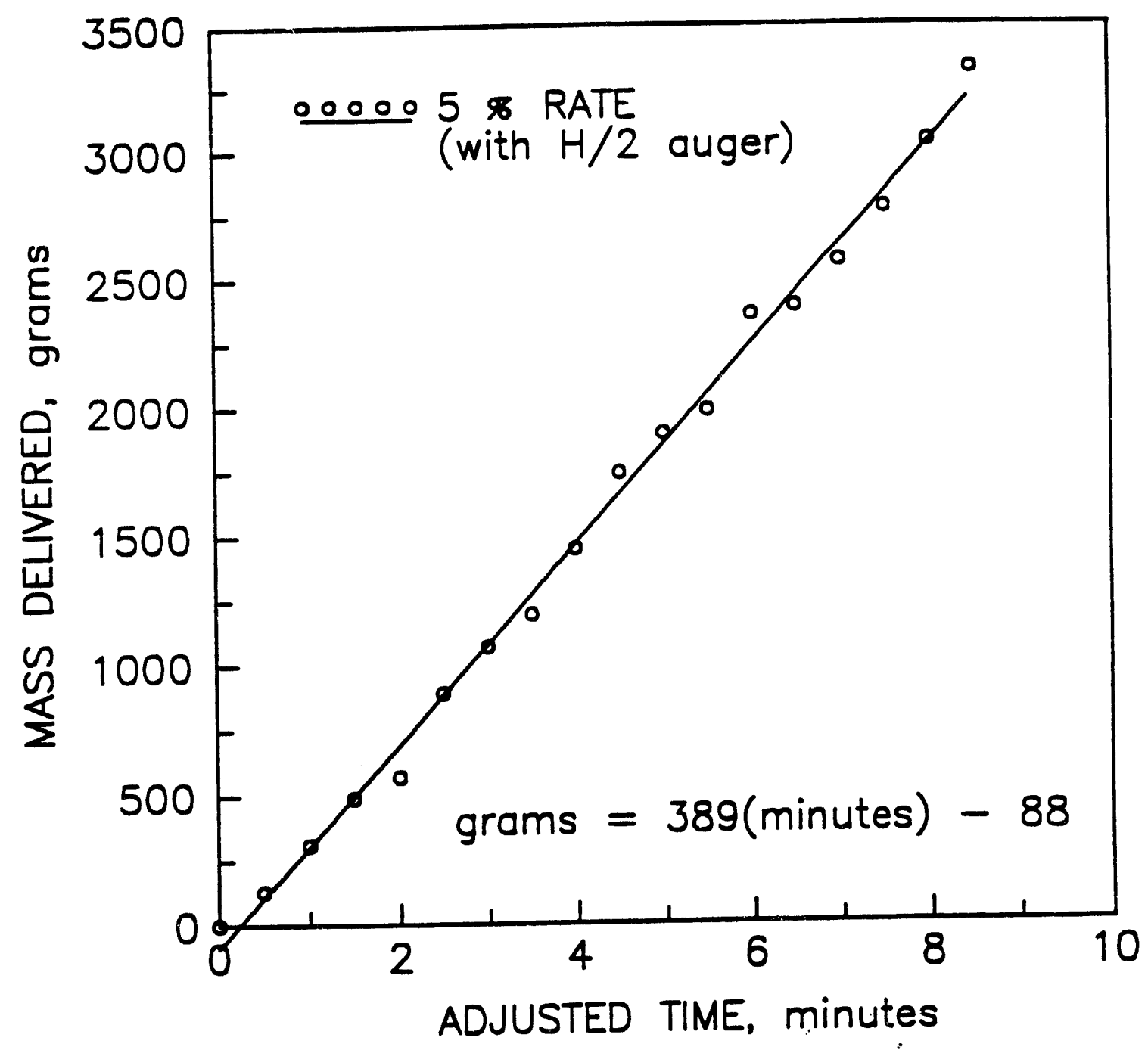

Figure 87. H/2 Auger Oil Sand Calibration Curves 318 


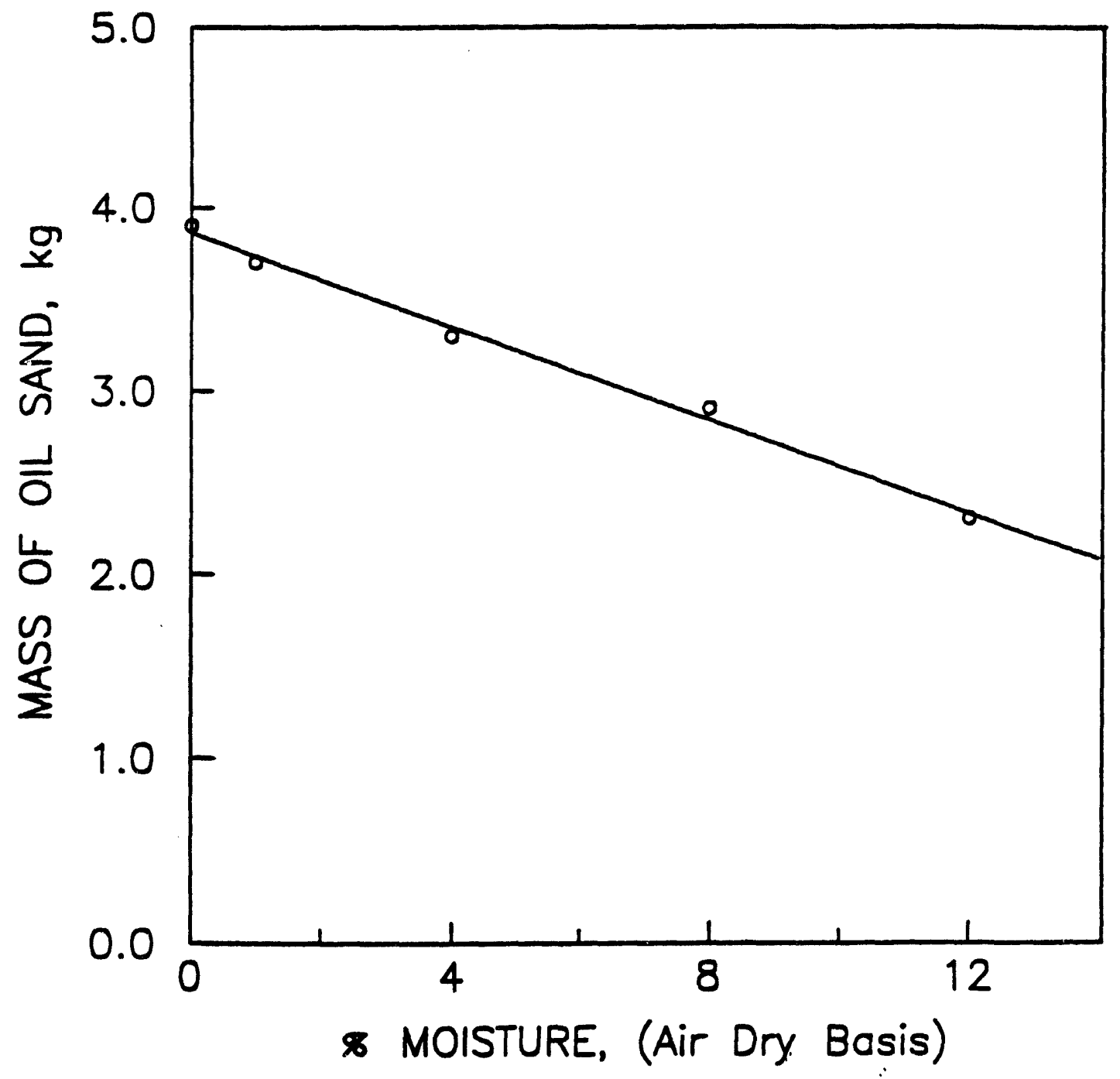

Figure 88. Oil Sand Mass Delivered versus Moisture Content for 8 Minutes at 5\% Speed 
Reactor Calibration and startup

Ambient Procedures and Air Fluidization.

In order to verify that the reactor was performing as expected and without any appreciable leaks, a series of air fluidization runs were made with spent sand produced in the previous study with the $10.2 \mathrm{~cm}$ ID fluidized bed reactor. ${ }^{186}$ Samples of the sand were sieved and the average particle diameter, $\bar{a}_{p}$, was calculated in the conventional manner ${ }^{213}$ :

$$
\bar{d}_{p}=\frac{1}{\sum\left(x_{i} / d_{p i}\right)}
$$

Sieve data for three spent sand samples are shown in Table 27. Knowledge of $\bar{d}_{p}$ allowed calculation of a predictive $U_{m f}$ as detailed in Fletcher et al. 214

Data in the air fluidization studies were taken for both increasing and decreasing gas flow rates. A plot of the maximum pressure drop across the bed, $\Delta \mathrm{P}_{\mathrm{B}}$, obtained at $\mathrm{U}=2.5 \mathrm{U}_{\mathrm{mf}}$, versus mass of bed material, $M_{B}$, is shown in Figure 89. A similar plot for settled bed height $H_{B}$, is shown in Figure 90. $H_{B}$ was measured after fluidization data were taken using the inside ring of holes in the distributor as the zero reference height. Figures 89 and 90 were later used to calculate $M_{B}$ and $H_{B}$ from $\Delta P_{B}$ operating data.

When the ambient air fluidization studies were complete, the reactor windbox was modified by closing the two $3 / 8$ inch NPT air inlet ports on the bottom plate and cutting three $3 / 8$ inch wide slots in the $1 / 8$ inch thick windbox gasket. This allowed gases from the reactor heating zone (Figure 83) to enter the windbox. 
TABLE 27

Sieve Analysis of Spent Sand Feed Before $U_{m f}$ studies (8/6/91 Data)

\begin{tabular}{|c|c|c|c|c|c|c|c|c|}
\hline $\begin{array}{c}\text { standard } \\
\text { U.S. } \\
\text { Sieve }\end{array}$ & $\begin{array}{c}\text { Sieve } \\
\text { Size } \\
(\mu \mathrm{m})\end{array}$ & $\begin{array}{c}\text { Average } \\
\mathrm{Dj}_{\mathrm{d}} \text { ameter } \\
\mathrm{p}_{\mathrm{p}}(\mu \mathrm{m})\end{array}$ & $\begin{array}{l}\text { Trial } \\
\# 1 \text { (g) }\end{array}$ & $\begin{array}{l}(100 \\
\left.x_{i}\right)_{1}\end{array}$ & $\underset{\# 2}{\operatorname{Trial}}$ & $\begin{array}{l}(100 \\
\left.x_{i}\right)_{2}\end{array}$ & $\underset{\# 3 \quad \text { (g) }}{\operatorname{Tr}}$ & $\left.x_{i}^{100}\right)_{3}$ \\
\hline 6 & 3350 & 4838 & 9.98 & 3.34 & 11.27 & 3.77 & 7.03 & 2.35 \\
\hline 18 & 1000 & 2168 & 5.68 & 1.90 & 5.42 & 1.81 & 5.50 & 1.84 \\
\hline 25 & 710 & 855 & 2.23 & 0.75 & 2.16 & 0.72 & 2.54 & 0.85 \\
\hline 45 & 355 & 532 & 8.92 & 2.99 & 8.14 & 2.72 & 9.87 & 3.30 \\
\hline 50 & 300 & 328 & 7.68 & 2.57 & 6.92 & 2.32 & 8.37 & 2.80 \\
\hline 70 & 212 & 256 & 180.47 & 60.40 & 175.15 & 58.60 & 174.54 & 58.35 \\
\hline 100 & 150 & 181 & 37.26 & 12.47 & 34.69 & 11.61 & 38.24 & 12.78 \\
\hline 140 & 106 & 128 & 26.29 & 8.80 & 31.96 & 10.69 & 29.73 & 9.94 \\
\hline 200 & 75 & 90 & 10.03 & 3.36 & 12.41 & 4.15 & 12.94 & 4.33 \\
\hline pan & 0 & 38 & 10.27 & 3.44 & 10.78 & 3.61 & 10.35 & 3.46 \\
\hline & & Total & 298.81 & 100.02 & 298.91 & 100.00 & 299.11 & 100.00 \\
\hline & & Loss & 1.19 & - & 1.10 & - & 0.89 & - \\
\hline & & & $\bar{d}$ & $193 \mu \mathrm{m}$ & & $188 \mu \mathrm{m}$ & & $187 \mu \mathrm{m}$ \\
\hline
\end{tabular}




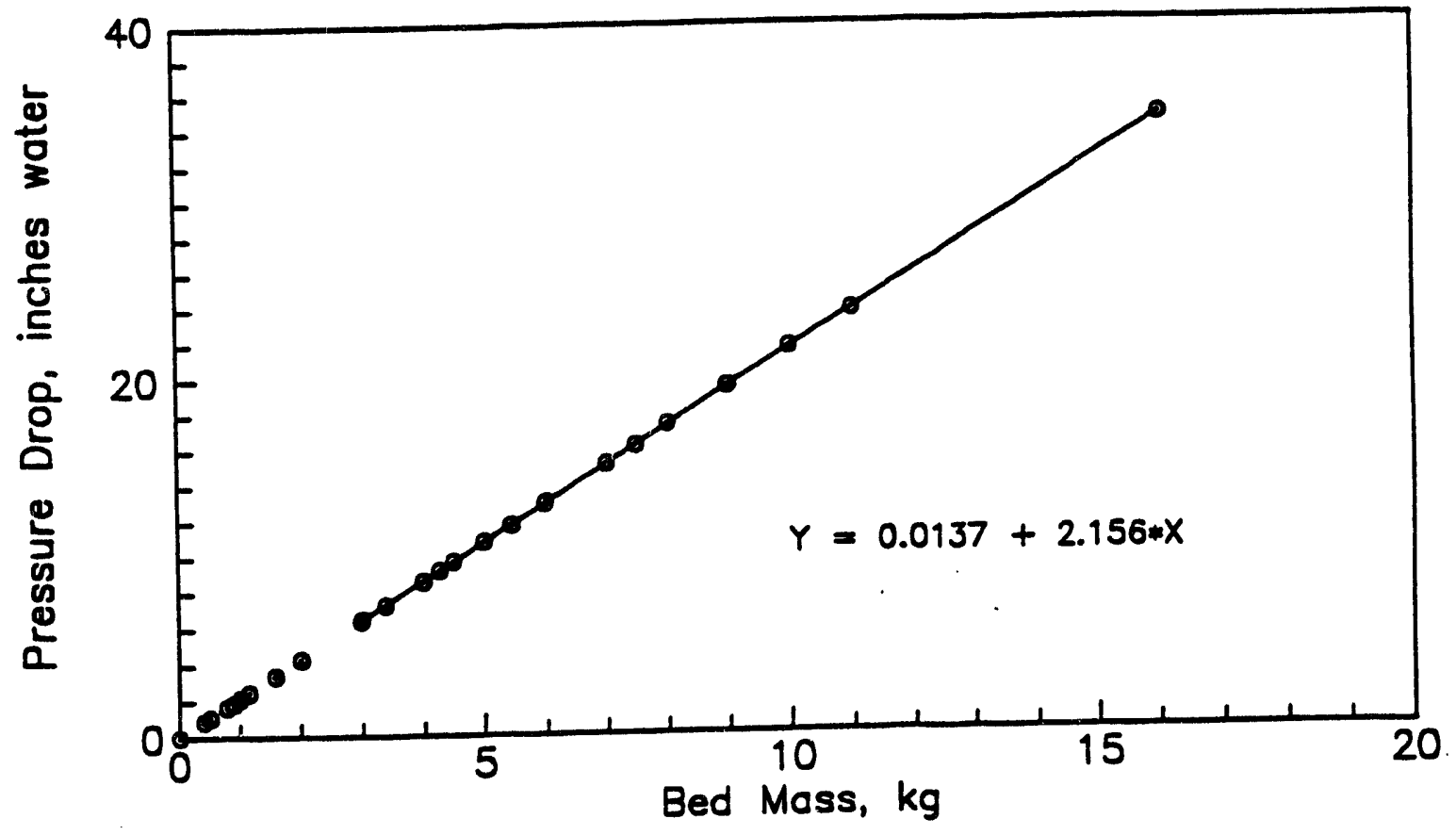

Figure 89. Bed Pressure Drop versus Mass of Bed Sand 


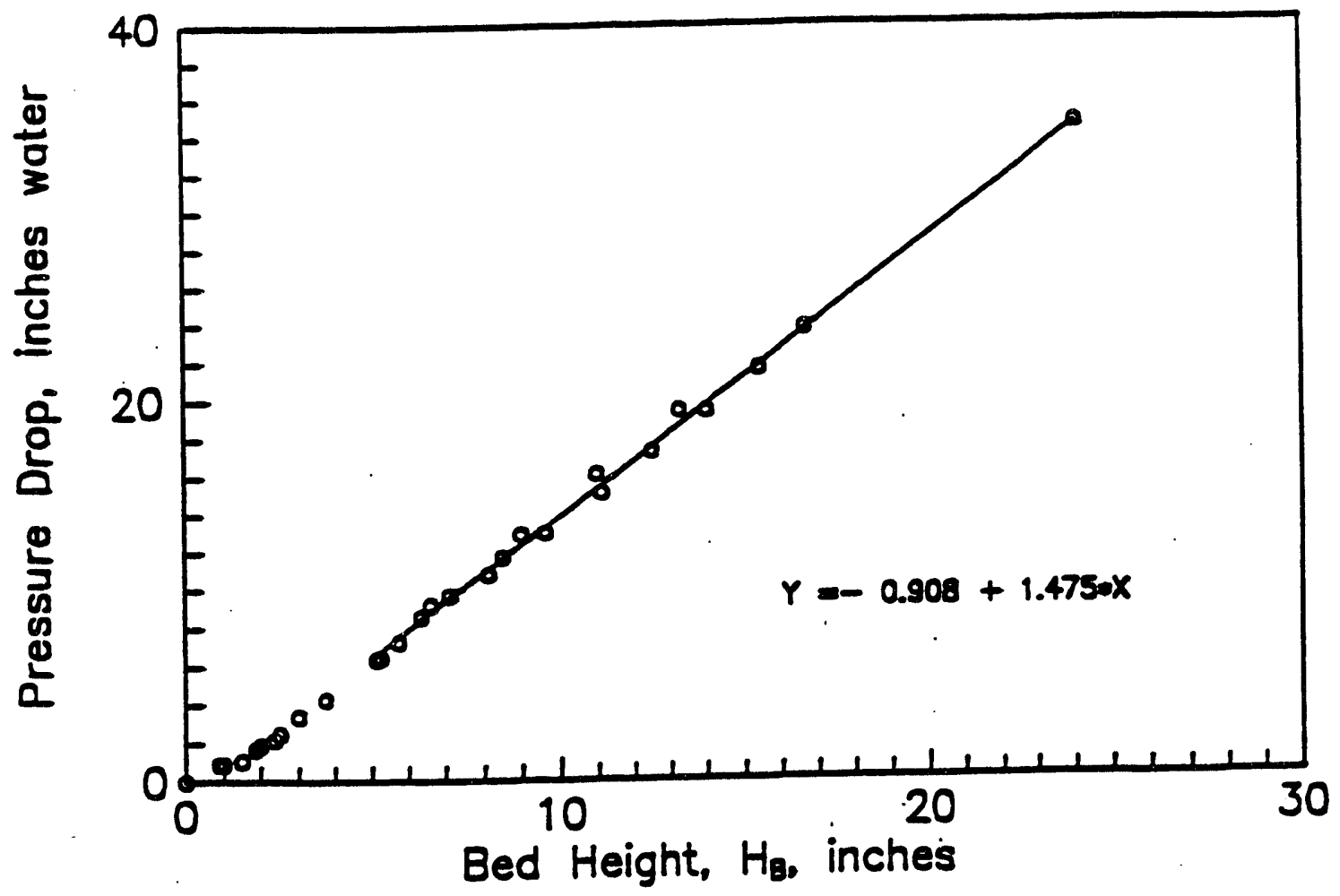

Figure 90. Bed Pressure Drop versus settled Bed Height 
For air fluidization studies at temperatures above ambient, the burner was allowed to heat the static bed until the bed temperature was above the target temperature. The burner was then shut off and the bed was allowed to cool while the heating zone was purged of exhaust gases using a draft inducer fan in the chimney (Tjernlund Model DJ3-HD) . Fluidizing air was then drawn from the exhaust-purged heating zone into the windbox and the reactor. Fluidizing and defluidizing data were taken as the reactor cooled. This procedure gave a temperature change in the sand bed, $\Delta T_{B}$, and a temperature difference between the bed and the windbox, $T_{B}-T_{W b x}$, of $10^{\circ} \mathrm{C}$ or less for one complete fluidization cycle. A fluidization cycle included incrementally changing $Q_{R \times r}$ from 0 to $200 \mathrm{CFH}$ and back to $0 \mathrm{CFH}$ and recording $\Delta \mathrm{P}_{B}$ for each $Q_{R \times r}$ setting.

\section{Shutdown}

The reactor and support systems were designed for fast shutdown in an emergency. A switch on the feeder control would stop oil sand feed. The control panel master switch would shutdown the gas pump. Propane could be shutoff with the switch on the Beckman controller for the Badger Control Valve, at the propane tank, or at the propane burner with a manual valve.

\section{RESULTS AND DISCUSSION}

A $15.2 \mathrm{~cm}$ ( $6.0 \mathrm{inch})$ ID fluidized bed reactor was designed, built, installed, and operated at reduced pressures as preparation to pyrolyze oil sands from the Whiterocks deposit of Utah. significant engineering accomplishments include trouble free solids 
feeding and solids withdrawal, efficient product recovery, and reactor operation at reduced pressure using combustion gases for fluidization.

\section{Variables Effecting Feeder Calibration}

As described above, the Acrison $B D F-1.5 / E / 2$ feeder showed a marked decrease in feed rate when the feed stock was shifted from spent sand to oil sand. At a $90 \%$ setting, the feeder would deliver 1674 grams per minute of spent sand but only 660 grams per minute of oil sand. Also, the feed rate using oil sands was not linear with time and, as shown in Figure 86, higher speeds accentuated the disparity.

In a feeder test with the $\mathrm{E} / 2$ auger, oil sand at $24^{\circ} \mathrm{C}$ in the hopper was fed at the $90 \%$ rate. In the course of 60 minutes of operation the temperature of the oil sand delivered increased $5^{\circ} \mathrm{C}$ and the hopper oil sand increased $3^{\circ} \mathrm{C}$. This temperature increase occurred even though ambient temperatures were $22^{\circ} \mathrm{C}$ throughout the test. The temperature increase with time on stream is believed to be due to mechanical shear in both the hopper and the feed auger cylinder. The temperature increase in turn causes the oil sands to become sticky, hence the feed rate decreases.

Augers are interchangeable on the Acrison feeder, so a larger $\mathrm{H} / 2$ auger was purchased and installed. In order to control the temperature of the feed sand and reduce the sticky nature of the sand, the $\mathrm{H} / 2$ auger cylinder was fitted with a water jacket. The initial calibration runs with the $\mathrm{H} / 2$ auger at $5 \%$ of full speed produced inconsistent results. The data in Table 28, for 10 
independent trials, illustrate the type of data obtained.

Noting that the temperature of the oil sand delivered was constant for the tests reported in Table 28, oil sand moisture content was considered as an influencing variable. The effect of moisture on feed rate was evaluated from air dry ( 0 wtz) to 12 wt? moisture. The term "air dry" was adopted from its usage in the wood fuels industry and was given an operational definition based on 72 hours of exposure in the laboratory.

TABLE 28

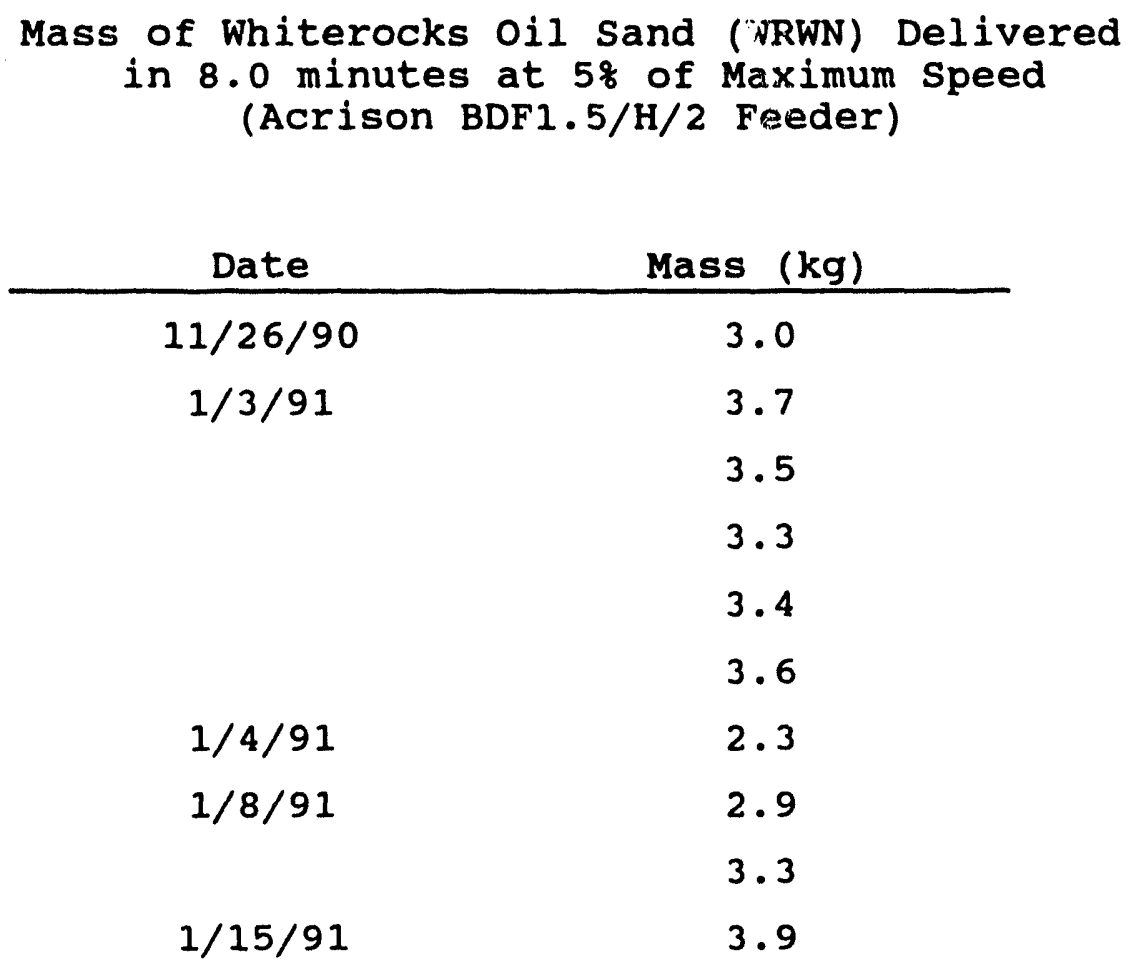

A plot of mass of oil sand delivered in 8 minutes versus moisture content was found to be linear at $5 \%$ of maximum speed with 
the $\mathrm{H} / 2$ auger. This is illustrated in Figure 88 above, where the range of moistures studied includes the data in Table 28 .

Finally, the physical state of the oil sand was evaluated as a feeder variable. Whiterocks WN (WRWN) and WS (WRWS) oil sands as described by $\mathrm{Cha}^{209}$ were run in mass versus time feeder tests as previously described. The WRWS, a 7.3 wt? bitumen oil sand, was additionally screened through a 1/4 inch mesh which removed about 25 wty of the material, both rock and consolidated oil sand. This screened finer material fed at a rate of $5.0 \mathrm{~kg}$ in 20 minutes, only half the $10.1 \mathrm{~kg}$ in 20 minutes rate of the higher bitumen $(7.6$ wt\%) WRWN sand used in all of the earlier feeder tests. The WRWS sand was also returned to the feed hopper and rerun at the same settings after 48 hours. The second 20 minute test produced 4.6 $\mathrm{kg}$. These tests suggest that screening of the oil sands to produce smaller and more uniform particles will result in lower feed rates from the Acrison feeder. Conversely, higher bitumen sands may feed more successfully if they are not screened to a $1 / 4$ inch or smaller size.

The discharge of oil sand from the auger cylinder was observed to pulse in direct relation to the auger speed. This is typical of solid flight augers and the pulsing is unavoidable at low speeds. The oil sand itself would fall from the feeder as both fine particles and large, loose packed lumps. A $5 / 8$ × $13 / 4$ inch diamond screen was placed vertically $3 / 8$ inches from the end of the auger flights and served to break up the lumps and smooth out the feed pulses. With the screen in place, oil sands fell from the 
feeder as an almost uniform pattern of particles.

The results of the preliminary feeder studies may be summarized as follows:

- The Acrison BDF $1.5 / \mathrm{H} / 2$ will feed oil sands at a linear rate provided:

a) delivered oil sand temperature is below $20^{\circ} \mathrm{C}$ and kept constant with a water jacketed feed auger, and b) oil sands are air dry and previously unused in a screw feeder

- The feed rate is inversely proportional to oil sand moisture on an air dry basis

- The absolute feed rate is sensitive to oil sand source and size

- The feed exits the auger cylinder with a pulsing flow

\section{Control of Solids Flow with a Modified L-Valve}

Tests with a bench scale mockup of a solids withdrawal system, based on the $J$ valve described by Knowlton, ${ }^{203}$ confirmed that solids flow from the standpipe could be started and stopped with this device, but the flow rate could not be controlled at any acceptably low and reproducible value. An additional problem with the $J$ valve only became apparent when narrow-size-range test sand was replaced with a sample of spent sand having a broader size distribution. When larger pieces were present in the discharging sand, e.g., 3 $\mathrm{mm}$, they would not always clear the bottom of the $\mathrm{J}$ and eventually a plug would develop. The J valve would not operate reliably with typical wide-size-distribution spent sand and was therefore 
abandoned.

The $J$ valve was rebuilt to simulate an L-Valve but with two aeration points. The Modified L-Valve and its relation to the fluidized bed reactor is 1llustrated in Figure 82 . In theory, an L-Valve works because solids in a standpipe flow when fluidized and choke when they are not. A detailed analysis of the L-Valve operating principles and mechanisms was presented recently by ouldDris and Molodsof. ${ }^{215}$ Test results with the wide-size-distribution spent sand showed that at least a $3 / 4$ inch I.D. hole was required at the standpipe top in order to avoid bridging of the spent sand above. The standpipe itself was larger in diameter so that the expansion caused by fluidization would tend to force solids down rather than up.

The segregation of solids as they flowed down the standpipe and through the nonmechanical valve did not cause even occasional plugging in the standpipe/L valve after the top restriction in the standpipe was drilled to 1.0 inch ID. Control of mass flow at low rates using one injection point was a problem, however, and the use of two injection points for nitrogen aeration was required to solve the flow control problem. Point A (Figure 82) was used to reduce the density of the packed bed in the standpipe so that flow would begin, and point $B$ (Figure 82 ) was used to maintain or increase flow across the horizontal leg of the valve. The A-B combination allowed operation of the Modified L-Valve at mass flow rates as low as $1 \mathrm{~kg}$ per minute with the 1.0 inch ID restriction at the standpipe top. Efforts to "calibrate" the Modified L-Valve based 
on nitrogen flow rates were not successful.

Adjustment of gas flow at either point A or point B (Figure 82) would alter the mass flow of solids from the reactor, but point A was much more sensitive and flexible. In order to give quick response when aeration was initiated, the horizontal length of the Modified L-Valve was built so that without aeration, the solids would flow to within 0.5 inch of the exit to the spent sand drum (Figure 82).

\section{Air Fluidization with Push and Pull Gas Flows}

A reactor in the "Pull" configuration must have, by design, a pressure above the distributor that is less than the windbox pressure for gas to flow through the distributor (neglecting $\Delta \mathrm{P}_{\text {Dist }}$ ). This establishes the sub-atmospheric requirement above a distributor which is at atmospheric pressure on the windbox side. A reactor pressure analysis and the results of fluidization studies were included in the 1991 Annual Report. The fluidized bed configuration in which gas was pulled through the bed had several potentially advantageous features:

1. Tuning of the distributor pressure drop to higher values should improve bed mixing and distributor performance

2. Lower pressures above the bed should allow faster vaporization or a lower operating temperature for heat sensitive processes

3. Entrainment and elutriation should be lowered due to lower gas density above the bed

4. Deeper beds appear to be operable without slugging 330 
compared to ambient pressure beds where the gas is pushed 5. Distributor jet momentum and associated disturbances should be reduced using a pull configuration

\section{Relationship Between $U_{m f}$ and Temperature for spent sand}

A method for predicting $U_{m f}$ at elevated temperatures was proposed by Fletcher et al. ${ }^{214}$ using, in part, the fluidization data from earlier studies on oil sands. ${ }^{180,181,186}$ Investigations indicated that many published sets of data for $U_{m f}$ and $T$ could be correlated by

$$
U_{m f} T^{0.27}=k_{f}
$$

The procedure for predicting $U_{m f}$ at elevated temperatures includes:

- Determine a value for $U_{m f}$ at a selected temperature either by experiment or by use of equations ${ }^{214}$

- Calculate the fluidization constant, $k_{f}$, using equation (3)

- Predict $U_{m f}$ at another temperature by solving equation (3) at that temperature using the $k_{f}$ determined above. It was preferred that $k_{f}$ be determined as an experimental value. Data were taken in this study to test this predictive method and are presented in Table 29. Following the procedures outlined 
by Fletcher et al. , 214 the predicted $U_{m f}$ and $k_{f}$ may be calculated for

TABLE 29

Experimental $U_{m f}$ and $k_{f}$ at Various Temperatures

Material = Whiterocks spent sand

$\bar{a}_{\rho} \quad=169 \mu \mathrm{m}$

Gas $\quad=$ Air

\begin{tabular}{cccc} 
Date & $\mathrm{T}(\mathrm{K})$ & $\begin{array}{c}\mathrm{U}_{\mathrm{mf}} \\
(\mathrm{cm} / \mathrm{s})\end{array}$ & $\mathbf{k}_{\mathrm{f}}$ \\
\hline $9 / 13 / 91$ & 295 & 2.7 & 13 \\
$10 / 17 / 91$ & 295 & 2.9 & 14 \\
$10 / 18 / 91$ & 295 & 2.7 & 13 \\
& 295 & 2.9 & 14 \\
$12 / 17 / 91$ & 527 & 2.5 & 14 \\
& 534 & 2.2 & 12 \\
& 547 & 2.5 & 14 \\
$12 / 19 / 91$ & 455 & 2.6 & 12 \\
\hline
\end{tabular}

an air fluidized bed at $295 \mathrm{~K}$ and compared to the experimental values:

Calculated $\mathrm{Ar}=360$
Calculated $\mathrm{Re}_{\mathrm{mf}}=0.25$
Calculated $\mathrm{U}_{\mathrm{mf}}=2.7 \mathrm{~cm} / \mathrm{s}$
Calculated $\mathrm{k}_{\mathrm{f}}=13$

The average experimental $U_{m f}$ at $295 \mathrm{~K}$ is $2.8 \mathrm{~cm} / \mathrm{s}$ and agreement with the calculated $U_{m f}$ is within $4 \%$. The experimental $k_{f}$ for all temperatures (Table $X$ ) is 13 , the same as that predicted from calculations above. Using $\mathrm{k}_{\mathrm{f}}=13, \mathrm{U}_{\mathrm{mf}}$ at $455 \mathrm{~K}$ would be predicted at $2.5 \mathrm{~cm} / \mathrm{s}$ using equation (3). The experimental $U_{\mathrm{mf}}$ was 
$2.6 \mathrm{~cm} / \mathrm{s}$ at $455 \mathrm{~K}$.

SUMMARY AND CONCLUSIONS

A fluidized bed pyrolysis reactor system was designed, constructed, and tested at reactor pressures less than atmospheric using crushed oil sands and spent sands from the Whiterocks deposit of Utah. A $15.2 \mathrm{~cm}$ ID fluidized bed reactor was fed spent sand on a continuous basis while maintaining a bed height of approximately $30 \mathrm{~cm}$ using a modified nonmechanical L-Valve for spent sand withdrawal.

The reactor used propane for heating and the hot propane combustion product gases could be used for fluidization. Fluidizing gas was pulled through the reactor from the windbox using suction from a variable speed gas pump. Sand was fed to the reactor from a dry materials feeder which had a jacketed and cooled auger. Off gases were condensed and filtered using commercial basket strainers modified with water cooling coils. Included in the engineering phase of this work was the development of systems to feed oil sands, withdraw spent sands, and efficiently recover liquid products. The data taken from a small-pilot plant reactor, suggests that multisized spent sand particles can be successfully fluidized at moderately reduced pressures. It has been found that reduced pressure fluidization can be accomplished by pulling the gas from above the sand bed, and that, by restricting the gas flow into the reactor, the equivalent of distributor pressure tuning can be accomplished.

The characteristics of bed pressure drop, $\Delta \mathrm{P}_{B}$, versus 
superficial gas velocity, $U$, were determined during fluidization and defluidization of spent sand using laboratory air.

Reduced pressure fluidization and defluidization curves for multisized particles have a shape similar to atmospheric curves when the distributor is at atmospheric pressure. Defluidization curves for a below atmospheric pressure distributor were shaped more like atmospheric fluidization curves, sometimes showing a sharp change in pressure near the "interpreted" $U_{m f}$. As in atmospheric fluidized beds, a plot of $\Delta P$ vs $U$ for decreasing gas flow was easier to interpret at reduced pressure and is thus recommended for reduced pressure studies. An "interpreted" $U_{m f}$, using either the right hand side of the defluidization $\Delta \mathrm{P}$ hump or the point where $\Delta P$ was $95 \%$ of its theoretical $M_{B} / A$ value, was shown to give good agreement with the predictive correlation of Fletcher et $a 1.214$

The relationship $U_{m f} T^{0.27}=k_{f}$, as proposed by Fletcher et al. , 214 was experimentally verified from $295 \mathrm{~K}$ to $559 \mathrm{~K}$ for spent sand fluidized by air. The predictive methodology for $U_{\mathrm{mf}}$, based on $R e_{m f}=A r / 1400214$ was also verified experimentally at ambient conditions where reactor gas pressure is accounted for in the Archimedes number and the $U_{m f}$ calculations from $\operatorname{Re}_{m f}$.

With reference to the specific research objectives for this investigation, which were outlined above, the following conclusions were made:

1. A $15.2 \mathrm{~cm}$ ID fluidized bed with an H/D of 2 will operate in the bubbling, rather than slugging regime, using spent 
sand in the bed. Fluidization using a pull rather than push system for gas movement is feasible, and beds with H/D up to at least 4 can be smoothly fluidized in this manner .

2. Oil sand can be fed to a hot fluidized bed reactor using an Acrison dry materials feeder, provided the auger cylinder is cooled to at least $15^{\circ} \mathrm{C}$ and the auger is sufficiently large in diameter to allow speeds of only a few rpm.

3. A Modified L-Valve, into which two aeration points have been designed, can be used to withdraw hot spent sand from a fluidized bed reactor.

4. Cornmercial basket strainers, modified to also serve as condensers, can efficiently recover liquids with no observable mist formation.

5. Oil sand leaving the Acrison feed auger falls as a pulsing media ranging from single sand grains to agglomerates up to $1 / 4$ inch in diameter.

6. The relationship $U_{m f} T^{0.27}=k_{f}$ as proposed by Fletcher et al. ${ }^{214}$ is valid over the range 295 to $559 \mathrm{~K}$ using air as the fluidizing gas.

7. Hot combustion gases from a propane (LPG) burner regulated to avoid excess oxygen can be used to fluidize the spent sand bed as part of the fluidized bed pyrolysis processing of Whiterocks oil sands. 
FUTURE ACTIVITIES

The next phase of this project includes the operation of the semi-pilot scale pyrolysis reactor in order to get pyrolysis data for several temperatures including those below $500^{\circ} \mathrm{C}$. We will attempt to determine if optimum process conditions are at longer residence times and lower temperatures than previously reported. ${ }^{179-}$ 187,209 Liquid yields and coke formation will be determined when combustion product gases are used for fluidization instead of the more traditional nitrogen. Any potential advantage of reduced pressure operation will be identified. Specifically we will attempt to:

1. determine if reduced pressure pyrolysis of bitumen gives higher liquid yields and makes less gas and coke (carbonaceous material), when compared to previous ambient pressure studies.

2. find the temperature at which maximum liquid products are produced.

3. reexamine if $U / U_{m f}$ has an influence on product yields for the ratios where the bed stays well mixed.

4. examine the liquid yields and product distributions for a range of residence times.

5. verify the observation of previous workers using $\mathrm{TGA}^{216}$ that bitumen pyrolysis rates peak at temperatures below $500^{\circ} \mathrm{C}$.

6. find experimental conditions where coke formation is suppressed, and increased liquid yields are favored over 
increased gas yields.

7. determine the yields and properties of pyrolysis products using whiterocks oil sands. 
A

Ar

B

$C_{1} \mathrm{C}_{2}$

D

$d_{p}, \bar{d}_{p}$

$d_{p i}$

F

$g^{*}$

h

$\mathrm{H}_{\mathrm{B}}$

$\mathrm{H}_{\text {RXr }}$

$\mathrm{H}_{\mathrm{s}}$

ID

$k_{d}$

$k_{f}$

$M_{B}$

$M_{\text {prop }}$

min

mw

$P_{\text {Atm }}$

$\mathrm{P}_{\text {Bar }}$

$P_{\text {Top }}$

$P_{\text {Wbx }}$

$\Delta \mathrm{P}_{\text {Bed }}$

$\Delta \mathrm{P}_{\text {Dist }}$

OD

$Q_{\text {Rxr }}$

$\mathrm{Re}_{\mathrm{mf}}$

rpm

$\mathrm{T}$

Area of empty reactor bed, $\mathrm{m}^{2}$

Archimedes number from equation (7), --

Constant in equation (1), --

Constants in equation (13), --

Diameter of the empty reactor bed, $\mathrm{m}$

Average size of particles, m

Size of particles in ith fraction, $m$

Feed rate of oil sand, $\mathrm{g} / \mathrm{min}$

Local acceleration due to gravity, $\mathrm{m} / \mathrm{s}^{2}$

Abbreviation for hour, $h$

Settled bed height, $m$

Reactor height, m

Maximum slug height, $m$

Internal diameter, $m$

Mass transfer coefficient, $\mathrm{m} / \mathrm{s}$

Fluidization constant from equation (17), --

Mass of bed, $\mathrm{kg}$

Mass of propane, $1 \mathrm{~b}$

Abbreviation for minute, min

Molecular weight, $\mathrm{g} / \mathrm{mol}$

Atmospheric pressure, Kpa

Barometric pressure, Kpa

Pressure measured in the freeboard, Kpa

Pressure measured in the windbox, Kpa

Pressure drop across the bed, Kpa

Pressure drop across the distributor, Kpa

Outside Diameter

Flow rate of gas in the reactor, $L / \mathrm{min}$

Reynolds number at minimum fluidization from

equation (2), (13), or (14), --

Revolutions per minute, $\min ^{-1}$

Temperature, $\mathrm{K}$ 


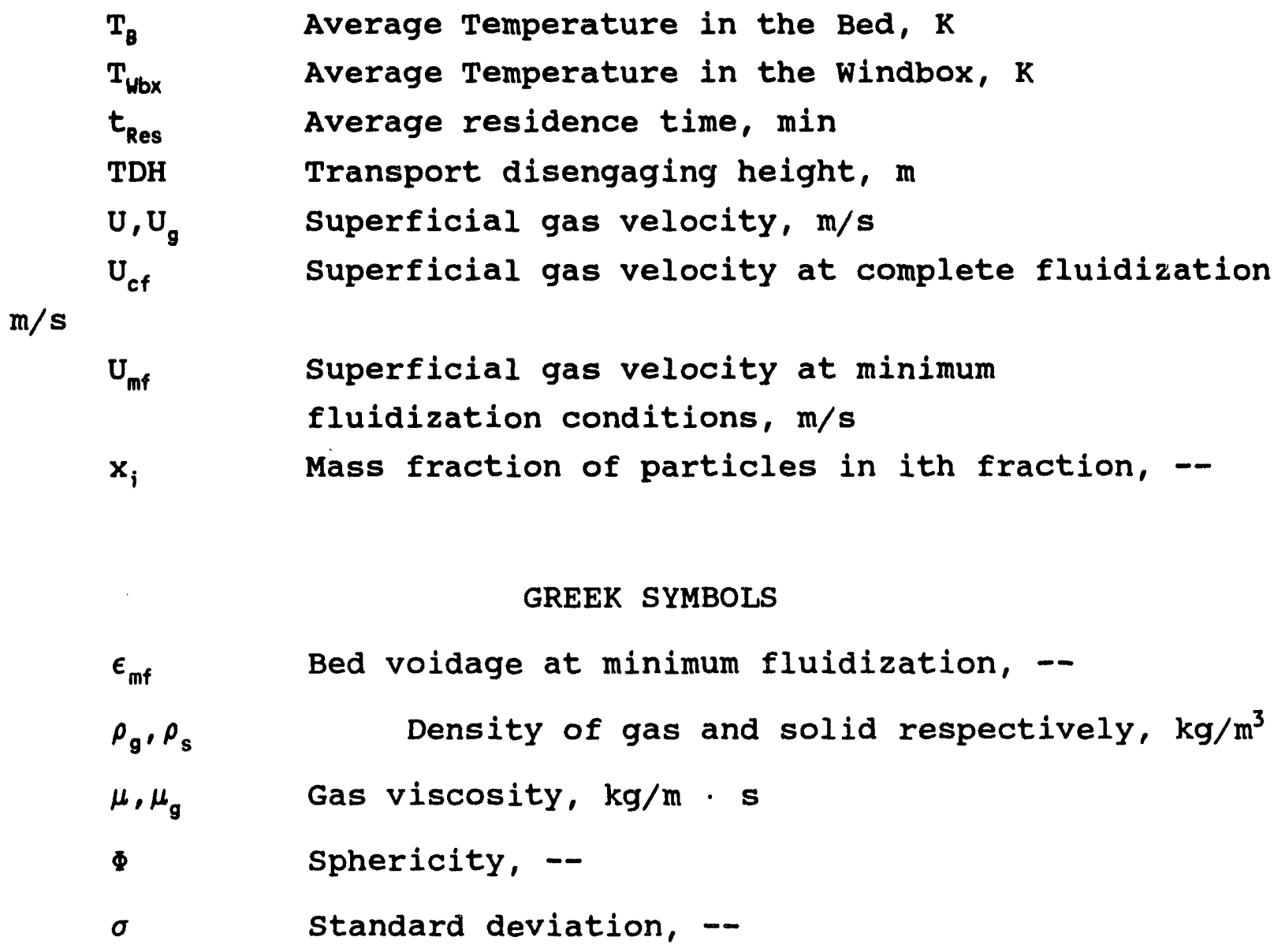


PYROLYSIS OF OIL SANDS IN A ROTARY KILN REACTOR
Principal Investigator
Graduate student
F.V. Hanson
H. Zheng

\section{INTRODUCTION}

The efficiency of the liquid recovery system was a persistent problem in previous studies with the rotary kiln. The glass recovery system was fragile and prone to leaks rendering material balance closure difficult. Thus a more efficient, metal recovery system was designed and fabricated (Figure 91). The design calculations were predicated on feeding PR Spring oil sand ore ( 9 wt: bitumen saturation) to the rotary kiln and on the assumption that the bitumen-derived liquid (i.e., the condensables) would represent $80 \%$ of the produced hydrocarbons. Volumetric flow rates were computed using the <PROCESS> simulation software package. These flow rates were used to compute the stream velocities in the recovery system transfer lines. The <PROCESS> software was also used to perform the heat transfer calculations.

SUMMARY AND CONCLUSIONS

Preliminary tests indicate that the recovery system is approximately $98 \%$ efficient in recovering the condensable, bitumen derived hydrocarbon liquids.

FUTURE ACTIVITIES

Modify the rotary kiln dry materials feeder to handle $100 \%$ oil sand feed. 


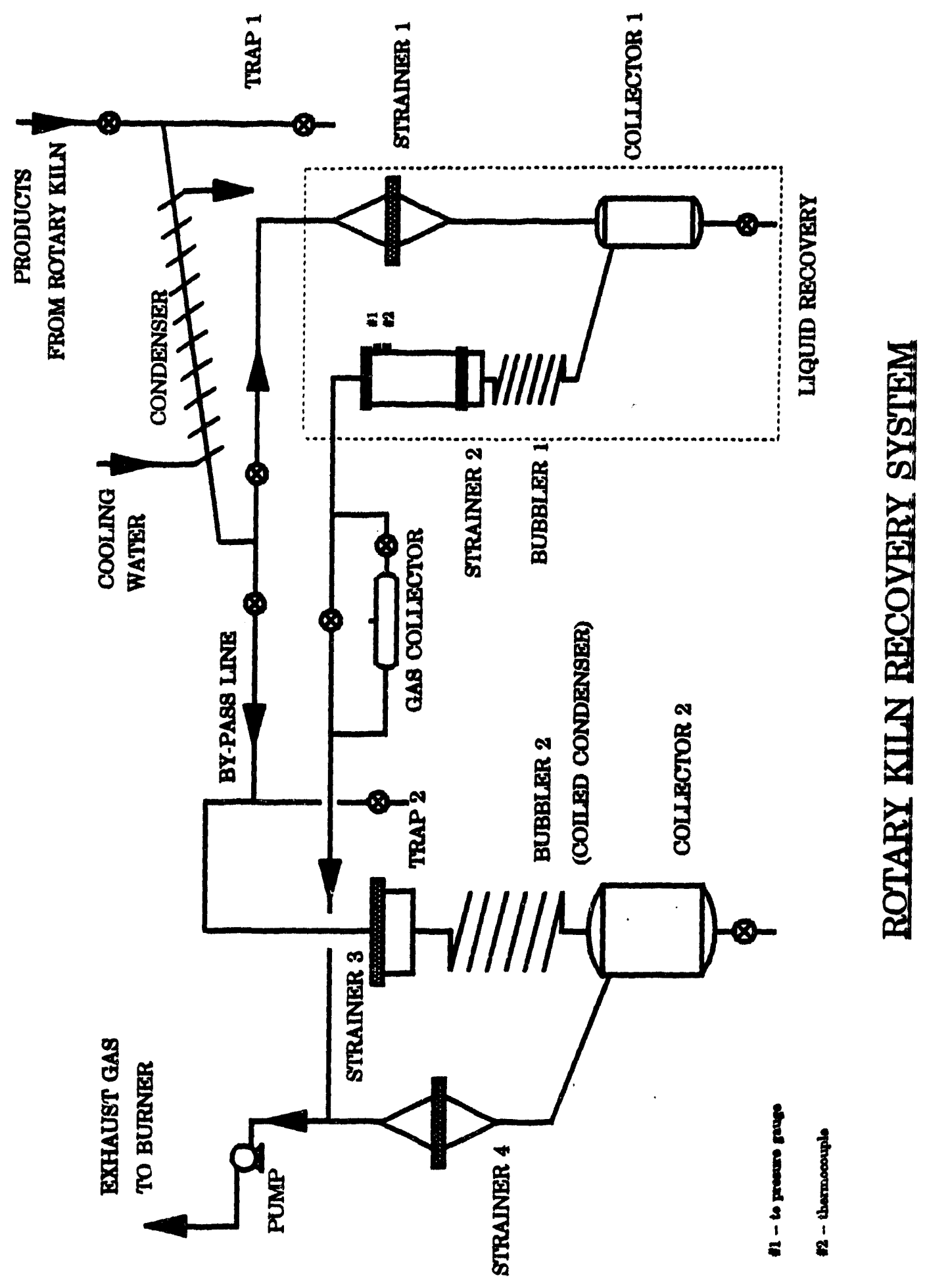

Figure 91. Rotary kiln product recovery system 


\section{HYDROTREATING THE BITUMEN FROM THE \\ WHITEROCKS OIL SAND DEPOSIT}
Principal Investigator
F.V. Hanson
Graduate student
D.C. Longstaff

\section{INTRODUCTION}

The exploitation of Utah's Uinta Basin oil sand resource will occur by a combination of in-situ thermal recovery and miningsurface recovery techniques. It has been estimated that 15-25\% of the Uinta Basin oil sand resource is amenable to mining production ${ }^{217}$. The mining-surface recovery processes include aqueous separation ${ }^{218,219}$, pyrolysis $220-222$ and solvent extraction $223-225$. The separation and extraction processes produce the bitumen which can be used as an asphalt base stock and/or a refinery feedstock 226,227 . The amount of water available in the Uinta Basin may not be sufficient to sustain production-scale aqueous separation operations ${ }^{228}$, thus fluidized bed and rotary kiln pyrolysis have been extensively studied 220-222,229-232. The pyrolysis processes produce a bitumen-derived liquid which can be used as a refinery feedstock 233,234 .

The inigh nitrogen content of the Uinta Basin bitumens and bitumen-derived 1 iquids $(0.8-1.2 \%)^{235}$ indicated that hydrotreating would be required as a primary upgrading process. The bitumen from the Whiterocks oil sand deposit was used as the feed in these studies.

The objective of this investigation was to determine the influence of process variables on bitumen denitrogenation, desulfurization and residuum conversion. The variables studied 
included temperature, pressure and weight hourly space velocity (WHSV) •

EXPERIMENTAL METHODS AND MEANS

Feedstock Preparation

Bitumen recovered by toluene extraction of the Whiterocks oil sand was used as the feedstock in this study. The toluene/bitumen solutions were concentrated by rotary evaporation and batch distillation to produce a bitumen which contained $<0.1$ wto toluene. selected physical and chemical properties of the bitumen are presented in Table $30^{236}$.

\section{Hydrotreater Process Unit}

Process studies were conducted in a fixed-bed reactor which operated in the upflow mode to minimize thermal gradients in the catalyst bed and to ensure complete wetting of the catalyst. The design, construction and operation of the hydrotreater system have been discussed in detail by Longstaff $f^{236}$. A schematic of the hydrotreater system is presented in Figure 92 . The denitrogenation and desulfurization data were correlated using the kinetic average temperature, $T_{k}$, which was defined as follows ${ }^{237}$ :

$$
T_{k}=\frac{\left(-\frac{E_{a}}{R}\right)}{\ln \left[\frac{1}{L} \int_{0}^{L} \exp \left[-\frac{E_{a}}{R T(x)}\right] d x\right]}
$$

where $E_{\theta}$ is the apparent activation energy and $T(x)$ is an appropriate function which describes the variation of the reactor temperature as a function of axial distance, $x$, in the bed. 
Table 30 Analysis of the Whiterocks Bitumen

\begin{tabular}{|c|c|}
\hline $\begin{array}{l}\text { Gravity }(\text { API) } \\
\text { Density }(288.7 \mathrm{k})\left(9 \mathrm{~cm}^{-1}\right) \\
\text { Pour Point, } \mathrm{K} \\
\text { Asphaltenes, wt. }\end{array}$ & $\begin{array}{l}11.4 \\
0.989 \\
330 \\
5.0\end{array}$ \\
\hline $\begin{array}{l}\text { Simulated Distillation } \\
\text { Volatility (wtr) } \\
\text { IBP, K } \\
477-617 \mathrm{~K} \text { (wtq) } \\
617-811 \mathrm{~K} \text { (wtq) } \\
>811 \mathrm{~K} \text { (wtq) }\end{array}$ & $\begin{array}{l}43.3 \\
489 \\
6.3 \\
37.0 \\
56.7\end{array}$ \\
\hline $\begin{array}{l}\text { Elemental Analysis } \\
\mathrm{C} \text { (wt } q) \\
H \text { (wt } z) \\
\mathrm{N}(w t z) \\
S \text { (wt } z)\end{array}$ & $\begin{array}{l}85.9 \\
11.1 \\
1.07 \\
0.37\end{array}$ \\
\hline H/C Atomic Ratio & 1.54 \\
\hline $\begin{array}{l}\text { Metals content } \\
\text { Ni (ppm) } \\
\text { V (ppm) } \\
\text { As (ppm) }\end{array}$ & $\begin{array}{r}78 \\
4 \\
3\end{array}$ \\
\hline
\end{tabular}

"Pentane Insolubles

The base case operating conditions for the bitumen hydrotreating study were as follows: temperature, $642 \mathrm{~K}\left(696^{\circ} \mathrm{F}\right)$; weight hourly space velocity, $0.75 \mathrm{~h}^{-1}$; total pressure, $13.7 \mathrm{MPa}$ and hydrogen-to-oil feed ratio, $890 \mathrm{~m}^{3} \mathrm{~m}^{-3}$ (5000 SCF/bbl). The process variable study was conducted by changing a single variable at a time in a random manner to avoid systematic errors. The experiments were sequenced so that an equilibrated experiment at the base case conditions (Table 31) was conducted between each process variable experiment. All mass balances were greater than $97.5 \%$.

The extent of nitrogen removal was the key reactivity 


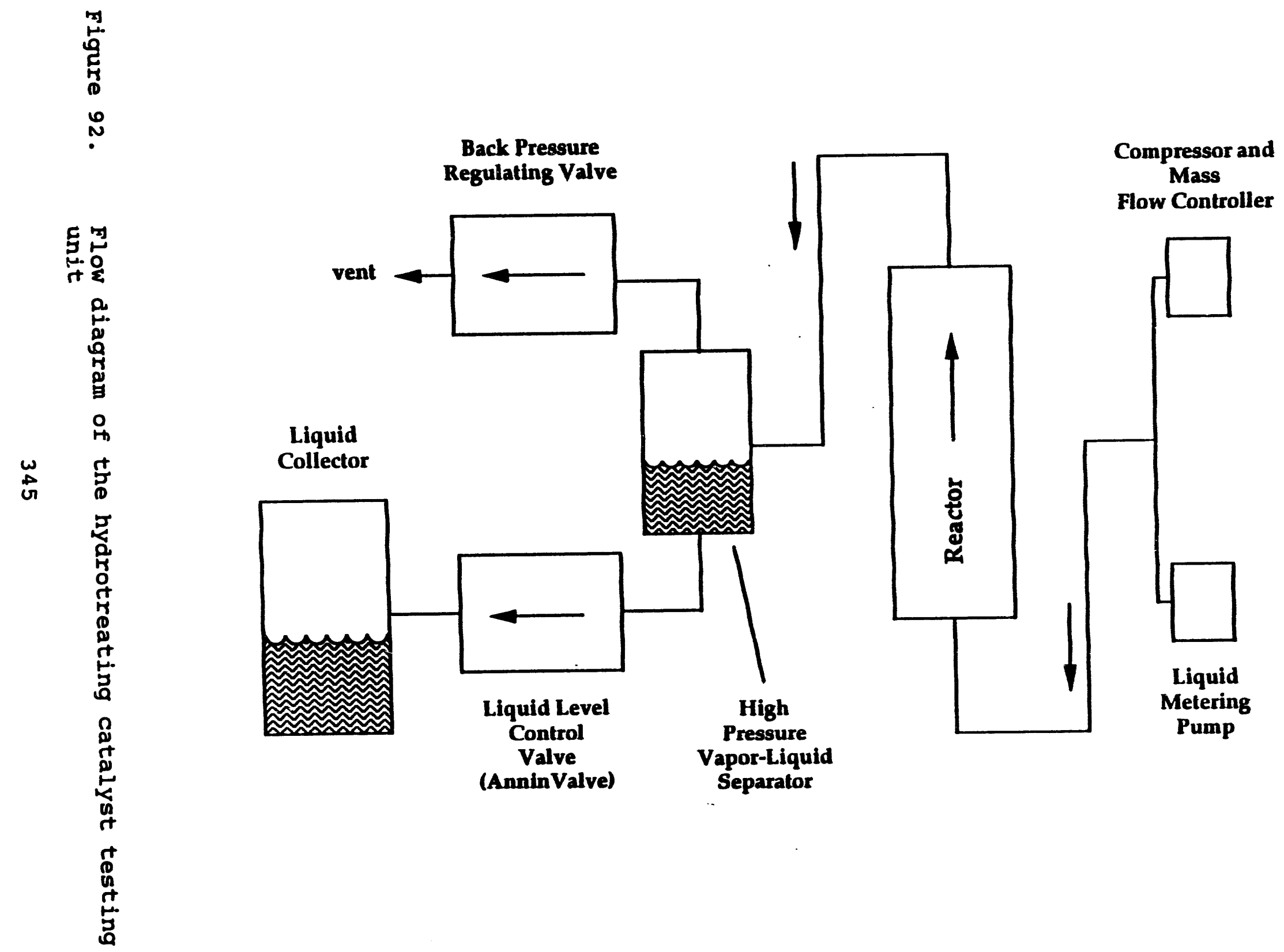


Table 31 Catalyst Properties, Base-Case Conditions and Process Variable Ranges

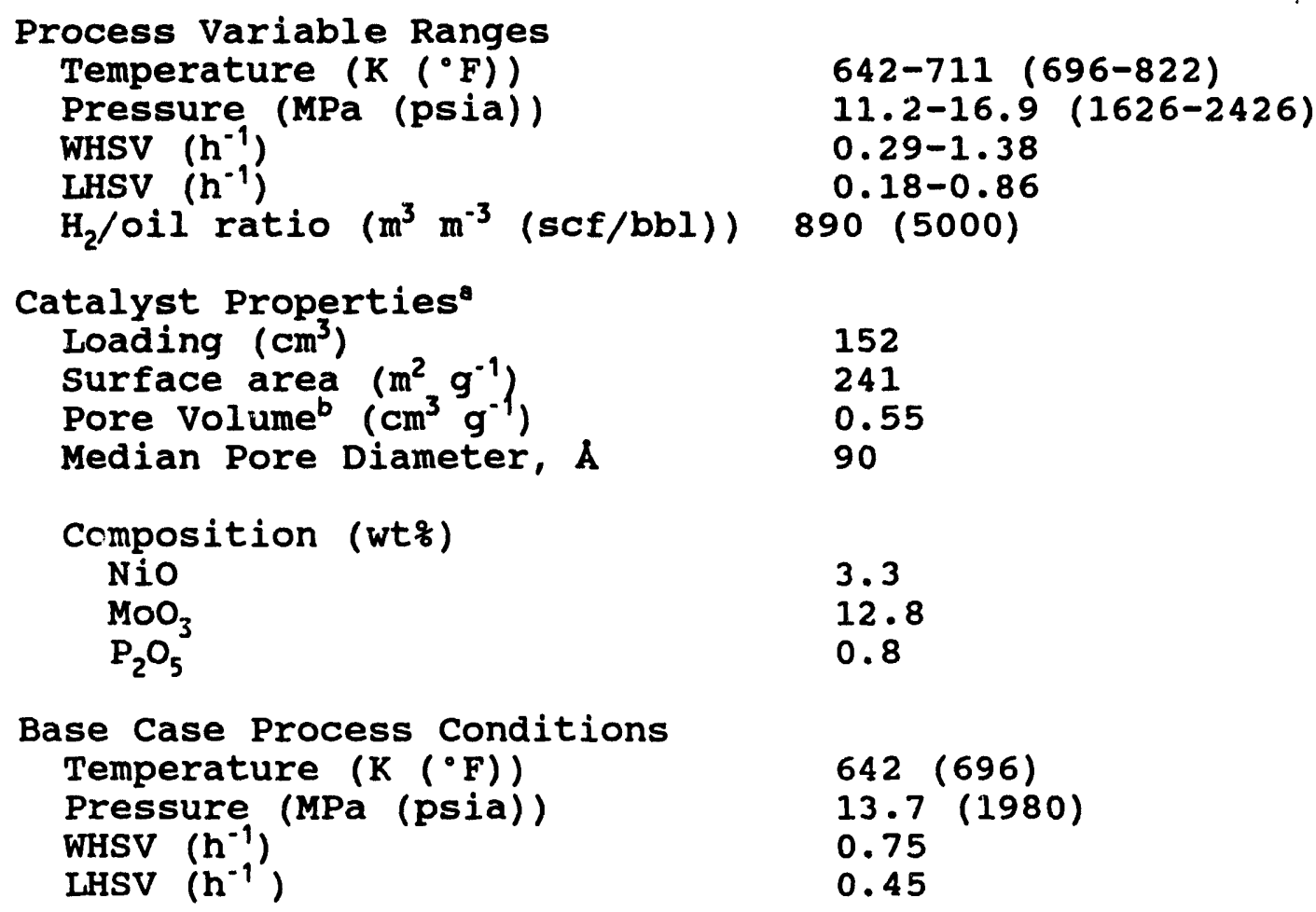

"UNOCAL 1/16" quadralobe

$\mathrm{b}_{\mathrm{Hg}}$ porosimetry

parameter followed during the course of the study; however, the key operating parameter followed on the catalyst testing unit during the run was the specific gravity of the total liquid product. The nitrogen content of the total liquid products produced during the hydrotreating of the whiterocks bitumen ${ }^{236}$ and the bitumen-derived liquid 236 varied as a function of API gravity (Figure 93). The nitrogen-gravity data reported by sullivan and stangeland 238 for shale oil hydrotreating are also included in Figure 93. The similarity between the trends indicated that the nitrogen-gravity correlation for the hydrodenitrogenation (HDN) of the bitumen could 


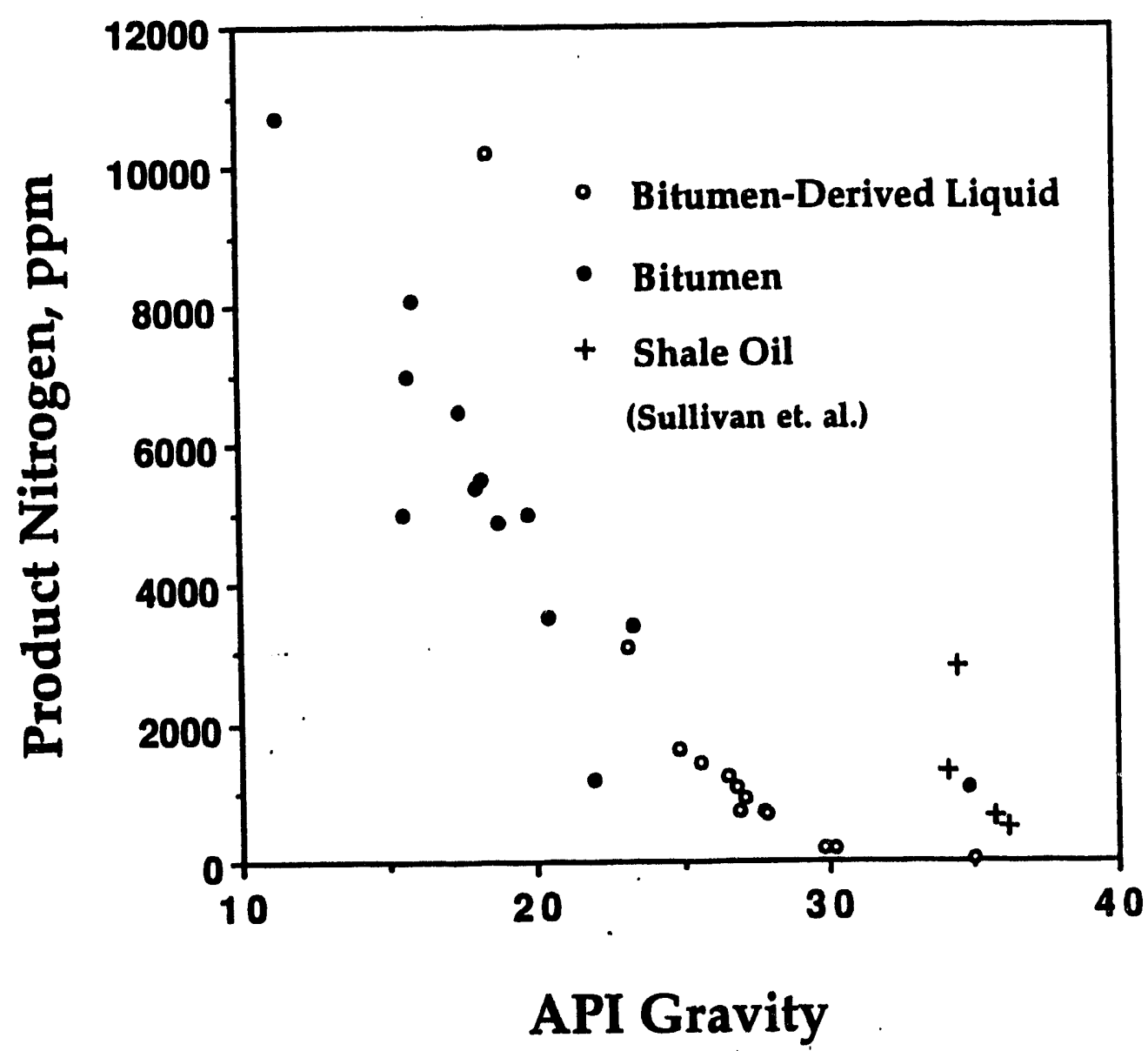

Figure 93. Nitrogen concentration versus API gravity 
be used with confidence as an on-line guide to estimate the real time influence of changes in operating variables during the course of the study.

\section{Catalyst and Catalyst Activation}

A UNOCAL Ni/MO/ $\mathrm{Al}_{2} \mathrm{O}_{3}$ hydrodenitrogenation catalyst was used in this study. The catalyst contained 3.3 wt: $\mathrm{NiO} ; 12.8$ wto $\mathrm{MoO}_{3}$, and 0.8 wt: $\mathrm{P}_{2} \mathrm{O}_{5}$; had a surface area of $241 \mathrm{~m}^{2} \mathrm{~g}^{-1}$; a pore volume of 0.55 $\mathrm{cm}^{3} \mathrm{~g}^{-1}$ and an average pore diameter of $90 \mathrm{~A}$. The alumina support had a unimodal pore structure. Selected properties of the catalyst are reported in Table 32 . The catalyst was dried and sulfided insitu at a LHSV of $1.0 \mathrm{~h}^{-1}$ and a hydrogen-to-kerosene ratio of 5000 SCF $h^{-1}$. The sulfiding solution was dimethyl disulfide in kerosene ( $\sim 2$ wto sulfur). During sulfiding the reactor temperature was ramped from room temperature to $505 \mathrm{~K}$ at $28^{\circ} \mathrm{C} \mathrm{h}^{-1}$ and held at 505 $\mathrm{K}$ for two hours or until sulfur breakthrough was observed. The temperature was then raised to $664 \mathrm{~K}$ at $28^{\circ} \mathrm{C} \mathrm{h}^{-1}$, and held at 664 $\mathrm{K}$ for an additional 2 hours. The catalyst and catalyst activation procedure have been described in detail by Longstaff and coworkers 233,236 .

RESULTS AND DISCUSSION

Process Variable study

The primary process variables investigated were temperature, total pressure and weight hourly space velocity (Table 32). Three sets of experimental data were obtained at the following conditions: (1) the reaction temperature was varied at constant 
Table 32 Run Conditions Employed to Hydrotreat the Whiterocks Bitumen

\begin{tabular}{|c|c|c|c|c|}
\hline $\begin{array}{l}\text { Run } \\
\text { Number }\end{array}$ & $\begin{array}{l}\text { Time on } \\
\text { stream } \\
\text { (h) }\end{array}$ & $\begin{array}{l}\text { Reaction } \\
\text { Temperature } \\
\text { (K) }\end{array}$ & $\begin{array}{l}\text { WHSV } \\
\left(h^{-1}\right)\end{array}$ & $\begin{array}{l}\text { Reactor } \\
\text { Pressure } \\
\text { (MPa) }\end{array}$ \\
\hline $\begin{array}{l}5 \\
6 \\
7 \\
8 \\
9 \\
10 \\
11 \\
12 \\
13 \\
14 \\
15 \\
16 \\
17 \\
18 \\
19 \\
20 \\
21 \\
22 \\
23 \\
24 \\
25 \\
26 \\
27 \\
28 \\
29 \\
30\end{array}$ & $\begin{array}{r}98 \\
122 \\
141 \\
165 \\
193 \\
239 \\
261 \\
284 \\
312 \\
335 \\
363 \\
407 \\
415 \\
437 \\
461 \\
485 \\
513 \\
539 \\
559 \\
582 \\
605 \\
629 \\
664 \\
692 \\
713 \\
735\end{array}$ & $\begin{array}{l}642 \\
685 \\
642 \\
664 \\
642 \\
664 \\
642 \\
664 \\
642 \\
663 \\
642 \\
665 \\
642 \\
643 \\
664 \\
642 \\
675 \\
642 \\
662 \\
643 \\
665 \\
642 \\
665 \\
643 \\
712 \\
642\end{array}$ & $\begin{array}{l}0.67 \\
0.75 \\
0.75 \\
0.76 \\
0.76 \\
0.29 \\
0.75 \\
0.76 \\
0.73 \\
0.76 \\
0.74 \\
0.43 \\
0.76 \\
0.79 \\
0.73 \\
0.77 \\
0.74 \\
0.75 \\
1.38 \\
0.76 \\
0.76 \\
0.74 \\
0.43 \\
0.77 \\
0.76 \\
0.71\end{array}$ & $\begin{array}{l}13.7 \\
13.7 \\
13.6 \\
13.6 \\
14.0 \\
13.5 \\
13.6 \\
16.7 \\
13.6 \\
11.2 \\
13.7 \\
13.7 \\
13.5 \\
13.5 \\
15.3 \\
13.7 \\
13.8 \\
13.8 \\
13.7 \\
13.7 \\
13.7 \\
13.7 \\
13.6 \\
13.7 \\
13.8 \\
13.6\end{array}$ \\
\hline
\end{tabular}

pressure (13.7 $\mathrm{MPa}(1980 \mathrm{psia}))$ and WHSV $\left(0.75 \mathrm{~h}^{-1}\right) ;(2)$ the WHSV was varied at constant temperature $\left(664 \mathrm{~K}\left(735^{\circ} \mathrm{F}\right)\right)$ and pressure (13.7 MPa); and (3) the total pressure was varied at constant temperature $(664 \mathrm{~K})$ and WHSV $\left(0.75 \mathrm{~h}^{-1}\right)$. The hydrogen-to-bitumen ratio was $890 \mathrm{~m}^{3} \mathrm{~m}^{-3}(5000 \mathrm{scf} / \mathrm{bbl})$. After the steady state was attained and a material balance was completed, a second experiment was conducted at the base-case conditions listed in Table 31 . 
The decrease in the API gravity of the total liquid product produced at the base-case operating conditions was nearly linear from 0-800 hours (Figure 94). It should be noted that the spread of the points above and below the least squares fit is accentuated by the expansion of the $y$-axis to a range of $0.4{ }^{\circ} \mathrm{API}$. The difficulty associated with exact reproduction of the temperature and space velocity in the base-case experiments also contributed to the scatter of the data. The deactivation or aging rate was estimated to be $0.20^{\circ} \mathrm{C} \mathrm{day}^{-1}$ over approximately 700 hours on-stream. The deactivation rate was similar to the deactivation rate obtained with the bitumen-derived liquid produced during the fluidized bed pyrolysis of the Whiterocks oil sand ${ }^{236}$. Even though the residuum content of the bitumen was three times that of the bitumen-derived liquid the deactivation rates were similar. This is attributed to the presence of 2-3 ppm arsenic in both the bitumen-derived liquid and the bitumen.

Prior to the final run at the base-case conditions, the reactor was operated at $712 \mathrm{~K}$ (Run 29) to determine the extent of molecular weight reduction which could be achieved at high temperatures. Although substantial molecular weight reduction occurred there was a significant increase in the specific gravity relative to the total liquid products produced during the previous runs at the base-case conditions. This increase was due to the rapid catalyst deactivation at $712 \mathrm{~K}$. It was concluded that semicontinuous catalyst replacement would be necessary for high temperature hydrotreating of bitumen. 


\section{Product API vs. Time On Stream}

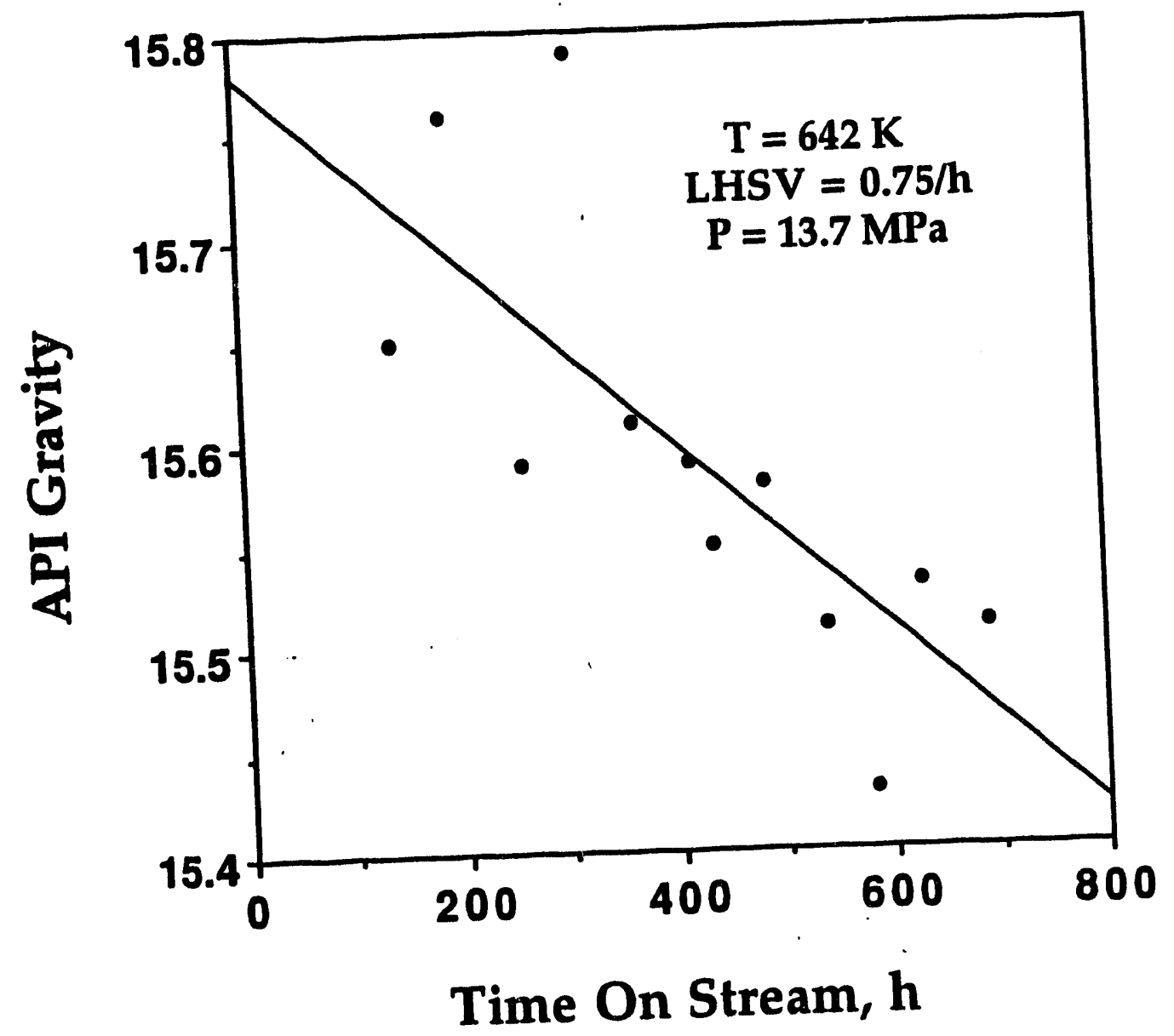

Figure 94. API gravity versus time on-stream for base case
runs 351 


\section{Preliminary Process Kinetics}

The rates of sulfur, nitrogen and residuum conversion may be fit by power rate law kinetics ${ }^{239-242}$ :

$$
r_{i}=k_{i} c_{i}^{a} P_{H_{2}}^{\beta}
$$

When a significant fraction of the heteroatoms or the residuum are'present in unreactive fractions such as asphaltenes, the kinetics of their conversion can be represented by two parallel first order reactions ${ }^{236}$. The fraction unconverted for any component $j$, which consists of a reactive or facile fraction and a less reactive or refractory fraction is given by Equation $3^{236,243}$ :

$$
f_{j}=\left(1-x_{r}\right) \exp \left[-k_{f} \tau\right]+x_{r} \exp \left[-k_{r} \tau\right]
$$

where $f_{j}$ is the unconverted fraction of component $j, x_{r}$ is the fraction of component $j$ which is refractory, $T$ is the reciprocal WHSV, and $k_{f}$ and $k_{r}$ are the first order rate constants for the facile and refractory fractions of component $j$.

The nitrogen conversion data appecured to fit pseudo-first order kinetics (Figure 95) with a rate constant of $0.6 \mathrm{~h}^{-1}$. A plot of $-\ln (1-x)$ for sulfur conversion versus reciprocal WHSV (Figure 96) gave a straight line which had a y-intercept greater than zero. This indicates that sulfur conversion data can be described by two parallel reactions according to Equation 3 . The rate constants, $k_{f}$ and $k_{r}$, for facile and refractory sulfur conversion were $4.8 \mathrm{~h}^{-1}$ and $0.5 \mathrm{~h}^{-1}$, respectively. Thus $35 \%$ of the bitumen sulfur is 


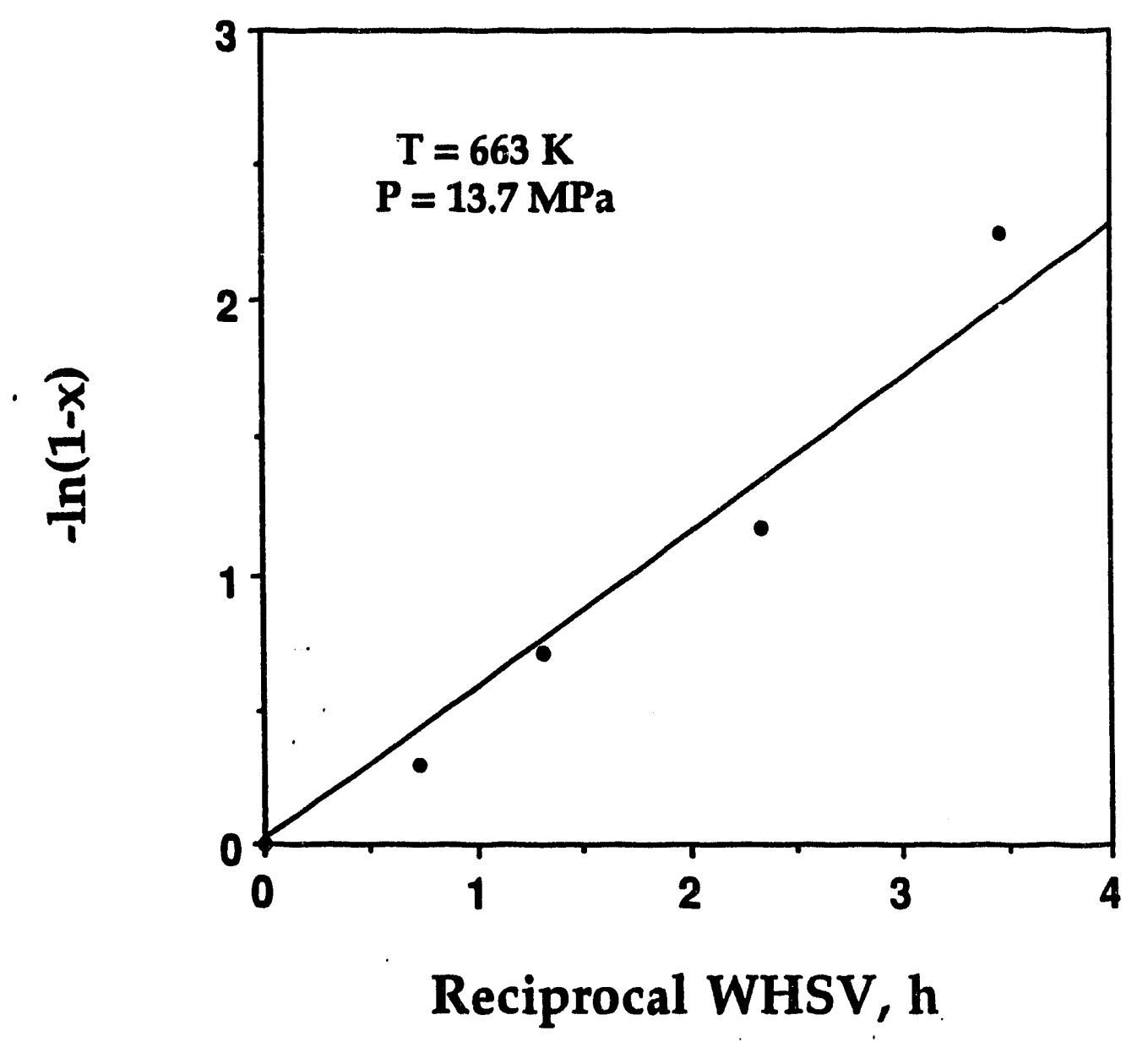

Figure 95. Plot of - In $(1-x)$ versus reciprocal WHSV for nitrogen conversion 
$-\ln (1-x)$ vs $1 /$ WHSV for

Sulfur Conversion

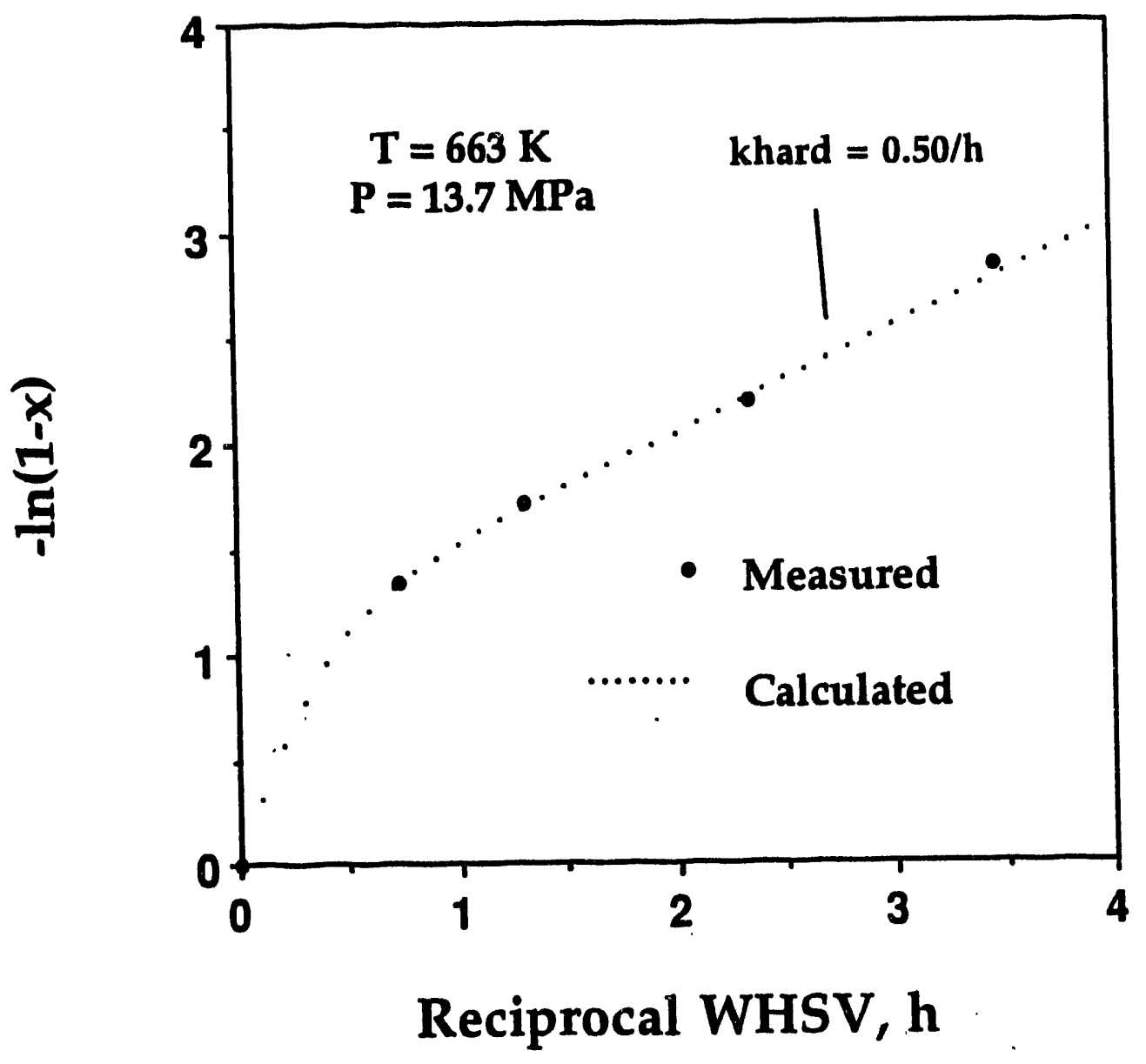

Figure 96. Plot of -In $(1-x)$ versus reciprocal WHSV for sulfur conversion 
refractory, which represents 0.12 wt\% of the total bitumen feed. This agrees with data reported by Riley ${ }^{240}$ and Ohtsuka ${ }^{244}$. The conversion of residuum can also be analyzed in terms of facile and refractory fractions (Figure 97). The data at the highest reciprocal WHSV suggests that residuum conversion goes through a maximum. This is not the case, but rather is an artifact resulting from insufficient line-out time between Run 9 and Run 10. The first order rate constants for facile and refractory residuum conversion were determined to be $3.8 \mathrm{~h}^{-1}$ and $0.25 \mathrm{~h}^{-1}$, respectively. Furthermore, the data indicated that $62 \%$ of the residuum was refractory, which represents $35 \%$ of the total bitumen. The dotted lines in Figures 96 and 97 are the least-squares fit using the values of $k_{f}, k_{r}$ and $x_{f}$ for sulfur and residuum conversion. Mosby et. al. ${ }^{245}$ have reported that residuum consisted of facile and refractory fractions.

The apparent link between sulfur and residuum conversion kinetics infers that the refractory sulfur fraction consisted of organic sulfur present in high molecular weight moieties which crack slowly. Thus, residuum conversion was presumed to be the rate determining step for refractory sulfur conversion. It has been suggested that refractory sulfur is the sulfur present in asphaltenes; ${ }^{240,244}$ however, this is an unsatisfactory explanation for Whiterocks bitumen because less than $7 \%$ of the bitumen sulfur is asphaltenic. ${ }^{245}$ Refractory sulfur in asphaltene fractions and in the Whiterocks bitumen is unreactive because it consists of sulfur which is sterically hindered due to the high molecular weight of 


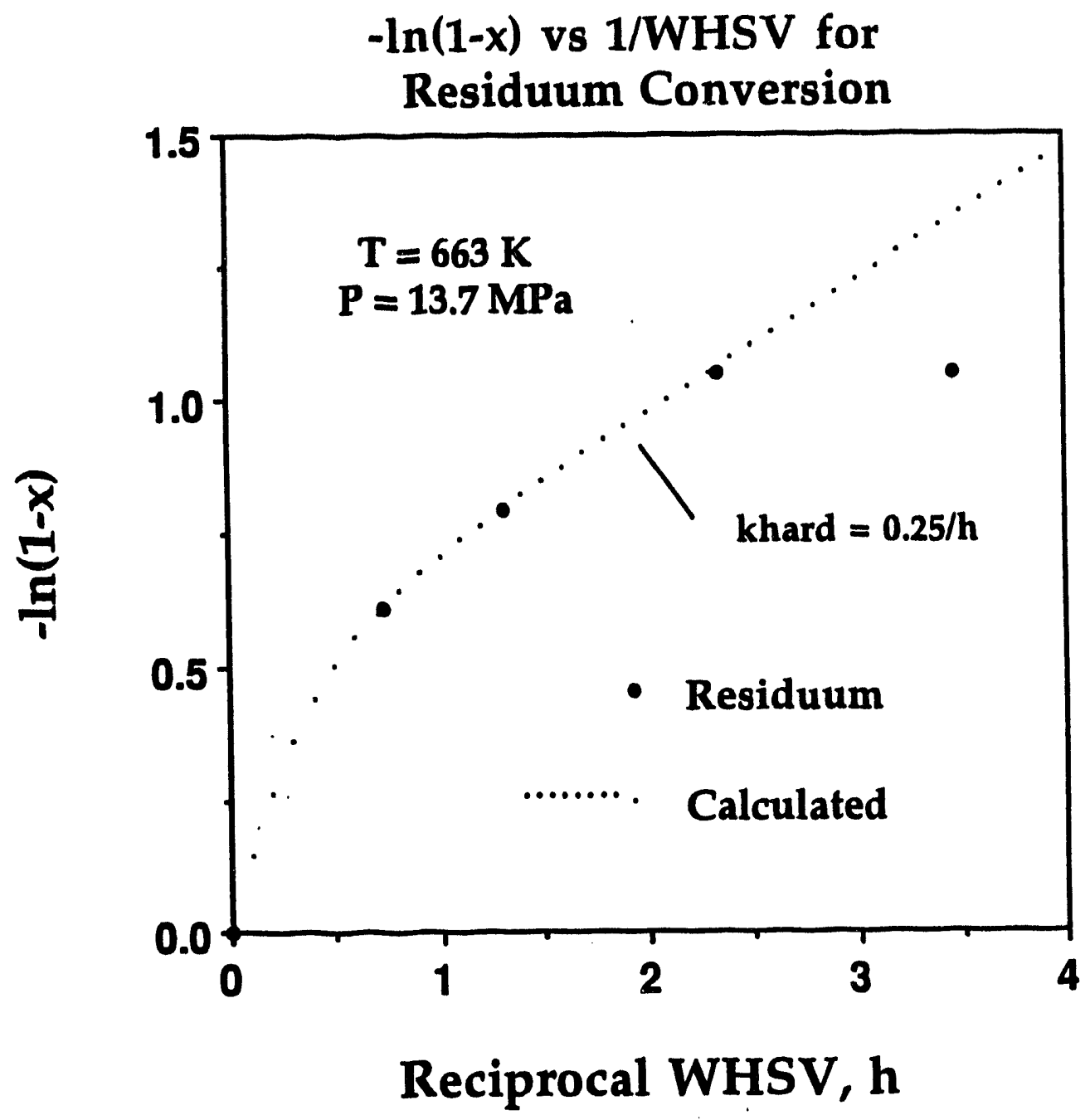

Figure 97. Plot of -In $(1-x)$ versus reciprocal wHSV for 
the species in which it is bound rather than because it is present as inherently unreactive functionalities. This postulate is based on the notion that asphaltenes and residuum are a continuum of functionalities which are also present in lower molecular weight, reactive species ${ }^{247,248}$. This is in agreement with work by Trytten and co-workers 249 who reported over an order of magnitude difference between the intrinsic rate constants for nitrogen and sulfur conversion as the average molecular weight of the feed increased from 200 to $450 \mathrm{~g} \mathrm{~mol}^{-1}$.

The apparent activation energy for refractory sulfur conversion, $146 \mathrm{~kJ} \mathrm{~mol}^{-1}$, is similar in magnitude to the apparent activation energy for refractory residuum conversion, $134 \mathrm{~kJ} \mathrm{~mol}^{-1}$, which supports the contention that refractory residuum conversion is the rate limiting step for refractory sulfur conversion (Figures 98 and 99).

The Arrhenius plot for the whole residuum conversion indicated that there were two regions of residuum conversion: a lower temperature region where facile residuum conversion occurred and a higher temperature region where the facile residuum was presumably totally converted (Figure 99). The low apparent activation energy for residuum conversion in the low temperature region suggested that facile residuum conversion was the result of diffusionally hindered catalytic hydrocracking. Refractory residuum conversion may be related to thermal cracking of the refractory portion of residuum. Activation energies of $230 \mathrm{~kJ} \mathrm{~mol}^{-1}$ for mild hydrocracking of residuum in ebullieted beds have been 


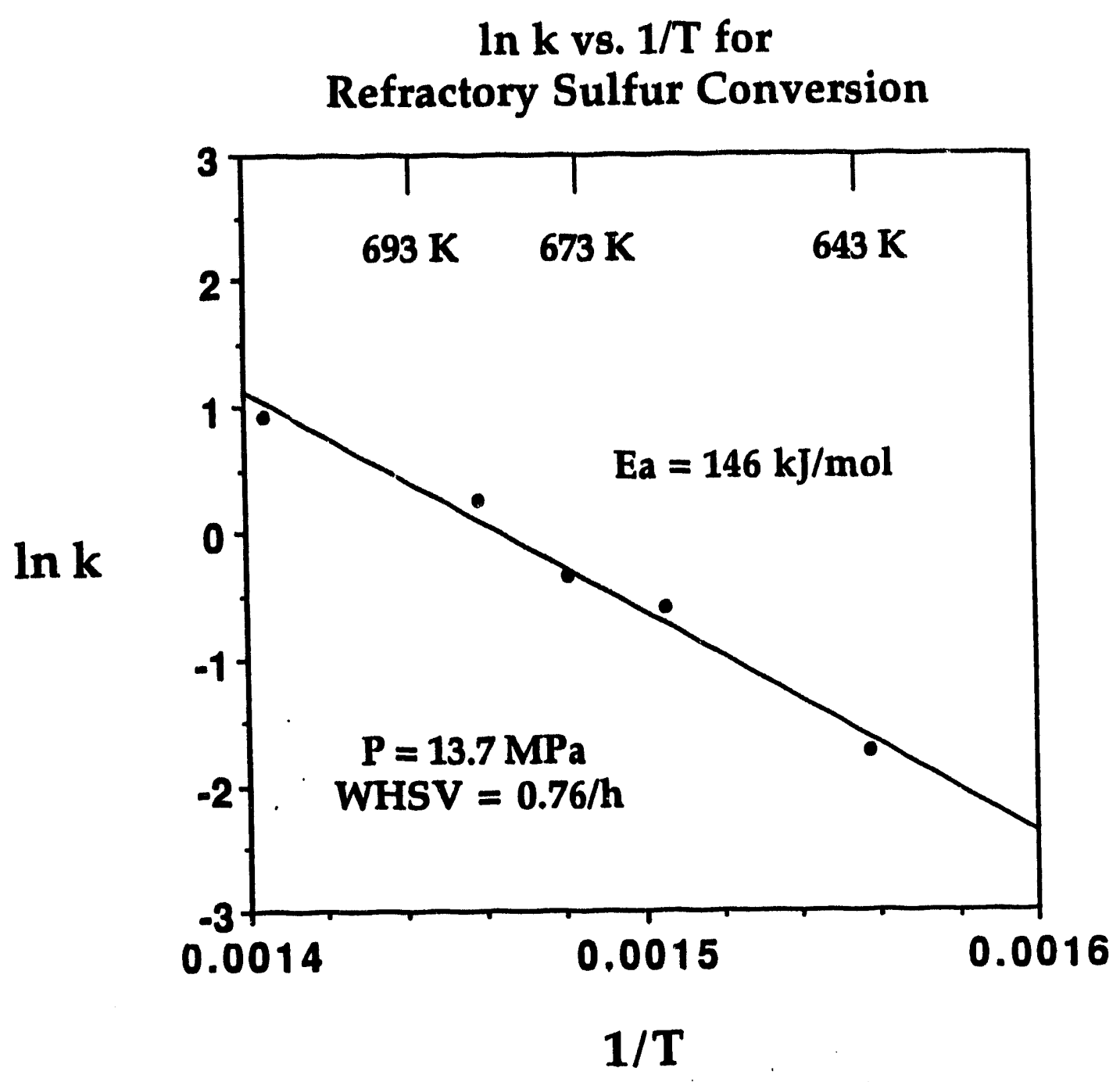

Figure 98. Arrhenius plot for desulfurization 358 


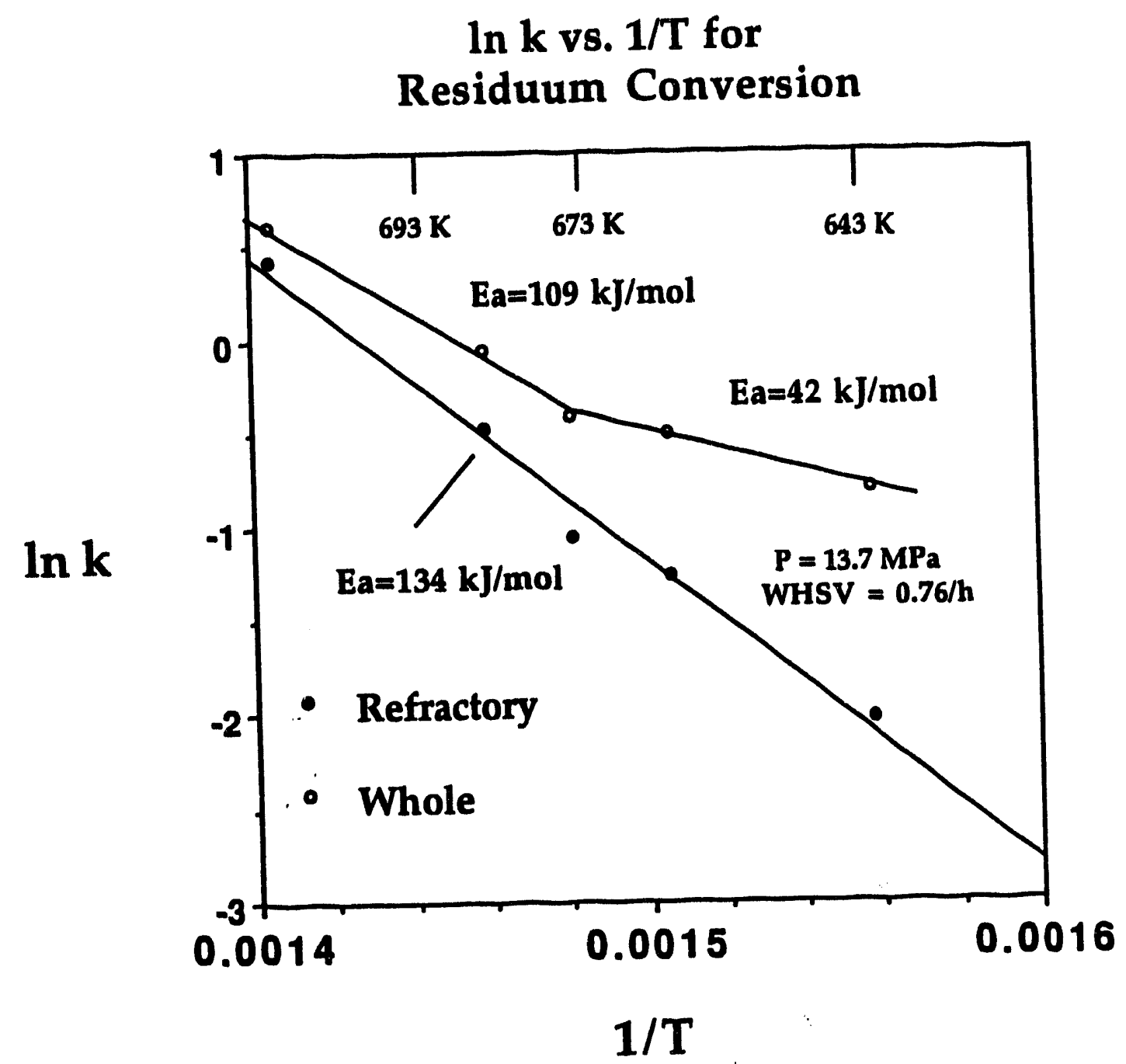
Figure 99. Arrhenius plot for conversion of refractory and
whole residuum 


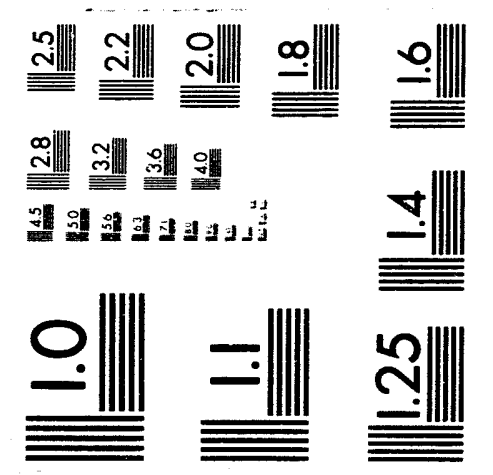



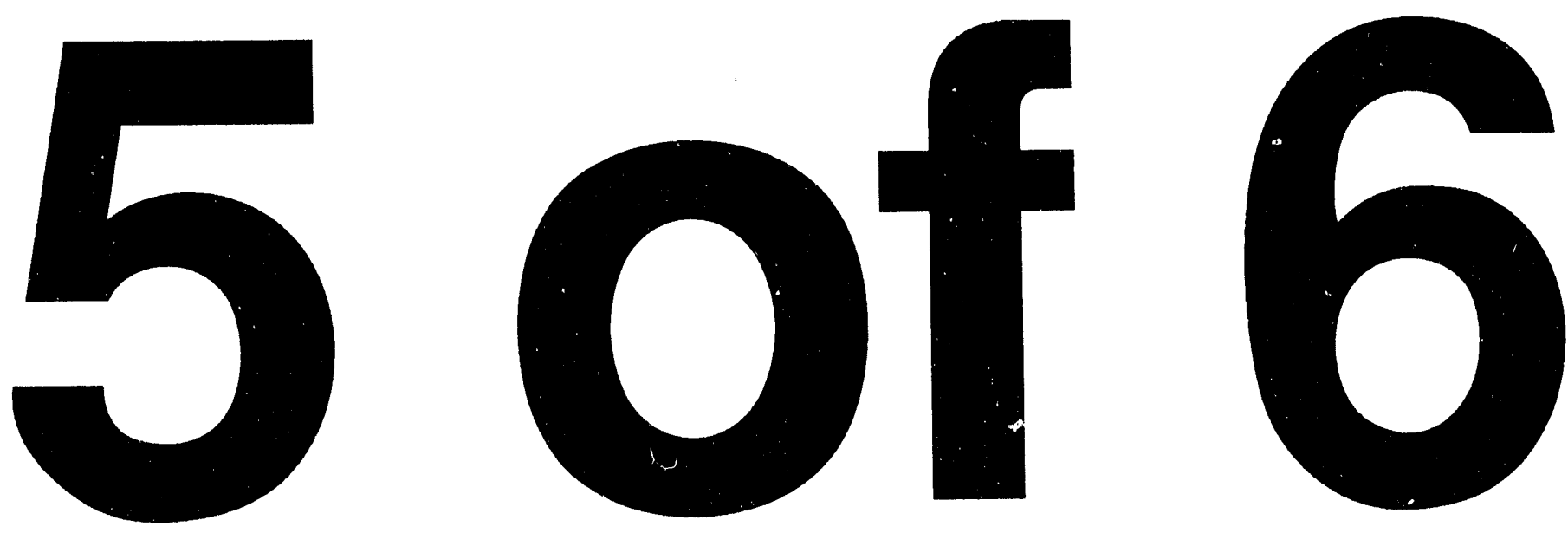
reported 250,251 . The difference may be related to differences in reactor scale and configuration.

The Arrhenius plot for nitrogen conversion (Figure 100) gave an activation energy of $93 \mathrm{~kJ} \mathrm{~mol}^{-1}$ for denitrogenation, which compared favorably with activation energies, $121 \mathrm{~kJ} \mathrm{~mol}^{-1}$, reported for coker gas oil denitrogenation $(723-773 \mathrm{~K})^{249}$. The difference may be related to the difference in the reactor operating modes: the coker gas oil was hydrotreated in a trickle-bed, downflow reactor whereas the bitumen was hydrotreated in an upflow reactor The reaction order with respect to hydrogen partial pressure, $\beta$, for nitrogen, refractory sulfur and refractory residuum conversion were determined to be $0.7,0$ and 0 , respectively. The higher value of $\beta$ for denitrogenation is indicative of the greater importance that hydrogen plays in denitrogenation ${ }^{252}$. The fact that the order with respect to hydrogen was the same for refractory sulfur and residuum conversion supported the contention that refractory sulfur conversion is linked to residuum conversion and not to hydrogenation of aromatic rings.

\section{Effect of WHSV}

The effect of WHSV on the product distribution and yields and on denitrogenation and desulfurization is presented in Table 33. The space velocity experiments were conducted at a pressure of 13.7 MPa, a temperature of $664 \mathrm{~K}$ and a $\mathrm{H}_{2} / 0 i 1$ ratio of $890 \mathrm{~m}^{3} \mathrm{~m}^{-3}$. The product volumetric yield was independent of the WHSV in the range 0.3 to $1.4 \mathrm{~h}^{-1}$ at $663 \mathrm{~K}$; however, the $\mathrm{C}_{5}^{+}$liquid yield decreased from 99 wt $\%$ to 95 wt $\%$ as the retention time increased from 0.7 to $3.5 \mathrm{~h}$. 
ln $\mathrm{k}$ vs. 1/T for Nitrogen Conversion

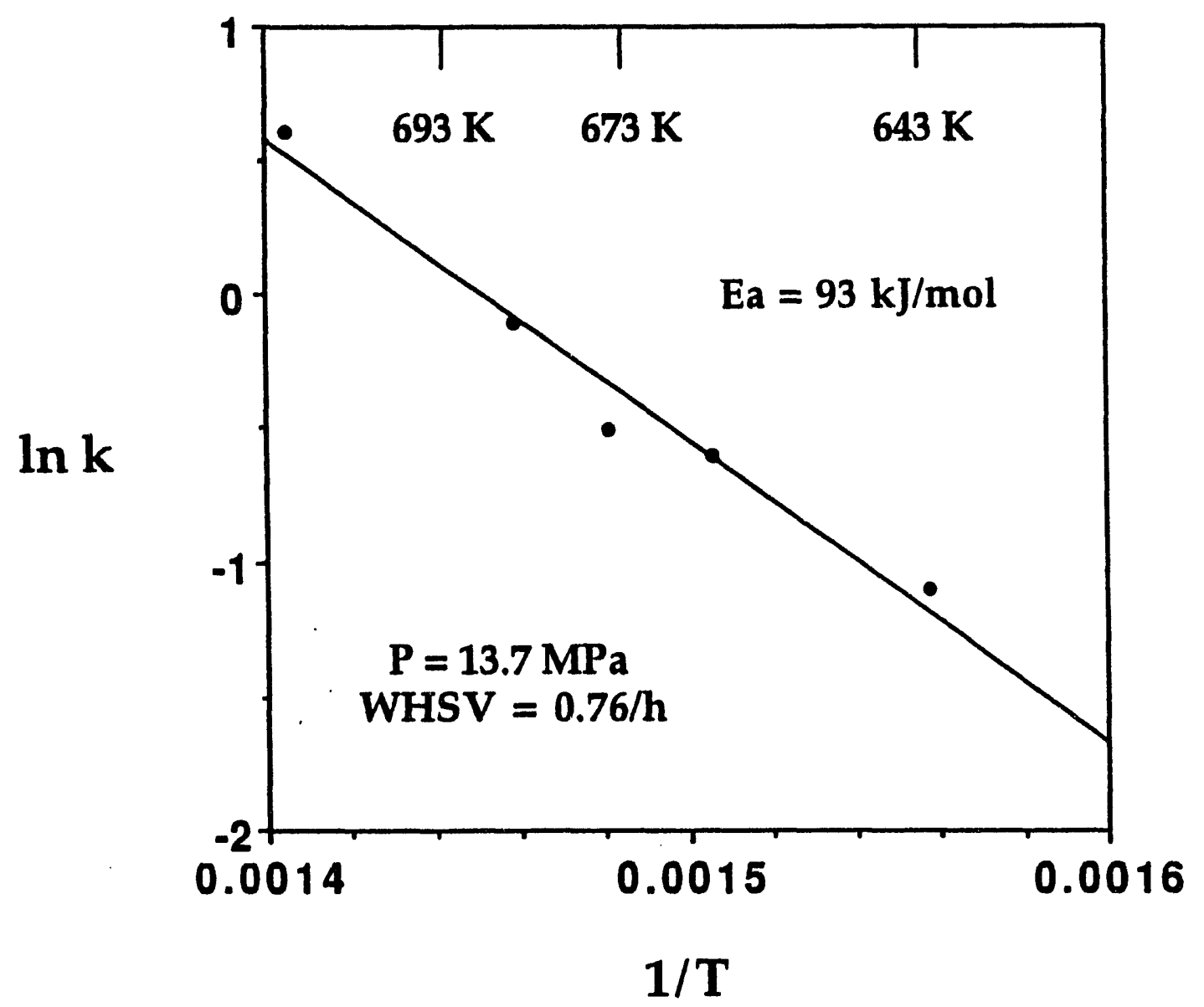

Figure 100. Arrhenius plot for denitrogenation 
Table 33 Effect of WHSV on the Product Properties of the Hydrotreated Bitumen from the Whiterocks oil Sand Formation

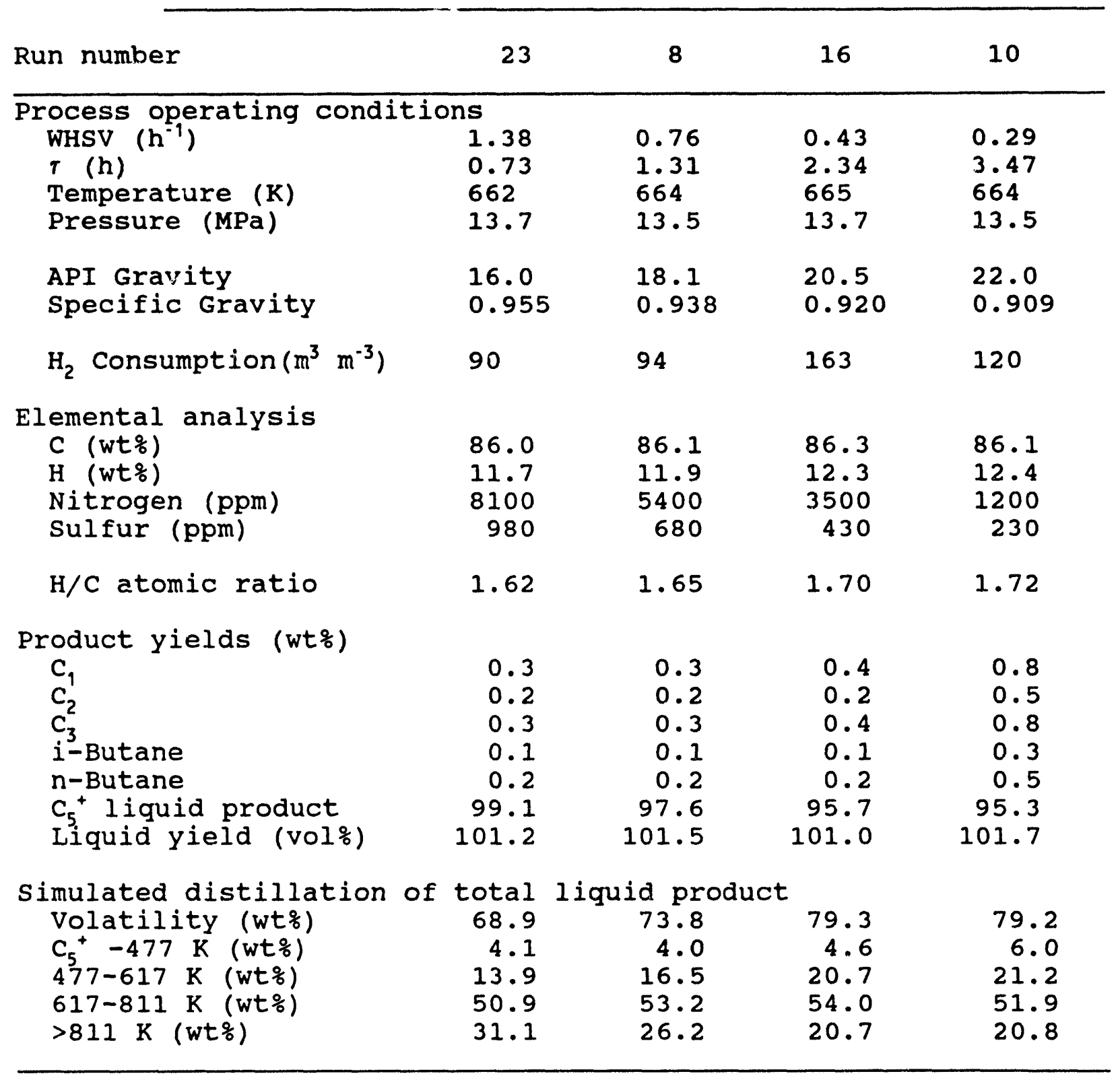


The product distribution was dependent upon the space velocity at WHSV's greater than $0.5 \mathrm{~h}^{-1}$ and appeared to be independent of space velocity at longer retention times, that is, at WHSV's below $0.5 \mathrm{~h}^{\text {- }}$ 1. The distillate yield increased with increasing retention time and appeared to be constant at WHSV's below $0.5 \mathrm{~h}^{-1}$. The residuum yield decreased with increasing retention time and appeared to be constant at WHSV's below $0.5 \mathrm{~h}^{-1}$. The gas oil yield did not exhibit a distinct trend for WHSV's in the range of 0.3 to $1.4 \mathrm{~h}^{-1}$. The extent of denitrogenation and desulfurization increased with decreasing space velocity: the fractional nitrogen conversion increased from 0.24 at $1.4 \mathrm{~h}^{-1}$ to 0.89 at $0.3 \mathrm{~h}^{-1}$ and the fractional sulfur conversion increased from 0.74 at $1.4 \mathrm{~h}^{-1}$ to 0.94 at $0.3 \mathrm{~h}^{-1}$. Effect of Reaction Temperature

The effect of reaction temperature on product distributions and yields and on denitrogenation and desulfurization is presented in Table 34. The experiments in which the temperature was varied were conducted at a WHSV of $0.76 \mathrm{~h}^{-1}$ and a pressure of $13.7 \mathrm{MPa}$. The reaction temperature exerted a significant influenco on the product distribution and yields. The volatility increased from 68.4 wt\% at $642 \mathrm{~K}$ to $83.4 \mathrm{wt} \%$ at $685 \mathrm{~K}$. Concomitant with the increase in residuum conversion, the naphtha and distillate yields increased; however, the gas oil yield was approximately constant in the temperature range 642-685 $\mathrm{K}$. At $712 \mathrm{~K}$ there was decrease in the total liquid product due to excessive coking in the void spaces of the bed and a significant increase in the residuum and gas oil conversion due to thermal cracking. The nitrogen content of the 
Table 34 Effect of Temperature on the Product Properties of the Hydrotreated Bitumen from the Whiterocks oil sand Formation

\begin{tabular}{|c|c|c|c|c|c|}
\hline un Number & 9 & 8 & 21 & 6 & 29 \\
\hline $\begin{array}{l}\text { Process operating conditions } \\
\text { Temperature (K) } \\
\left.\text { WHSV ( } \mathrm{h}^{-1}\right) \\
T(\mathrm{~h}) \\
\text { Pressure (MPa) }\end{array}$ & $\begin{array}{l}642 \\
0.76 \\
1.32 \\
14.0\end{array}$ & $\begin{array}{l}664 \\
0.76 \\
1.31 \\
13.5\end{array}$ & $\begin{array}{l}675 \\
0.74 \\
1.35 \\
13.8\end{array}$ & $\begin{array}{l}685 \\
0.75 \\
1.32 \\
13.7\end{array}$ & $\begin{array}{l}712 \\
0.76 \\
1.32 \\
13.8\end{array}$ \\
\hline $\begin{array}{l}\text { API Gravity } \\
\text { Specific Gravity }\end{array}$ & $\begin{array}{l}15.8 \\
0.956\end{array}$ & $\begin{array}{l}18.1 \\
0.939\end{array}$ & $\begin{array}{l}19.9 \\
0.925\end{array}$ & $\begin{array}{l}23.4 \\
0.898\end{array}$ & $\begin{array}{l}34.8 \\
0.811\end{array}$ \\
\hline $\mathrm{H}_{2}$ Consumption $\left(\mathrm{m}^{3} \mathrm{~m}^{-3}\right)$ & 91 & 94 & 122 & 124 & 127 \\
\hline $\begin{array}{l}\text { Elemental analysis } \\
\text { C (wto) } \\
\text { H (wt }) \\
\text { Nitrogen (ppm) } \\
\text { Sulfur (ppm) }\end{array}$ & $\begin{array}{l}85.9 \\
11.7 \\
7000 \\
1100\end{array}$ & $\begin{array}{r}86.1 \\
11.9 \\
5400 \\
680\end{array}$ & $\begin{array}{r}86.2 \\
12.1 \\
5000 \\
530\end{array}$ & $\begin{array}{r}86.1 \\
11.9 \\
3400 \\
250\end{array}$ & $\begin{array}{r}86.1 \\
12.7 \\
1100 \\
50\end{array}$ \\
\hline $\mathrm{H} / \mathrm{C}$ atomic ratio & 1.62 & 1.65 & 1.63 & 1.65 & 1.76 \\
\hline $\begin{array}{l}\text { Product yields (wt }) \\
\mathrm{C}_{1} \\
\mathrm{c}_{2} \\
\mathrm{C}_{3} \\
i^{-} \text {-Butane } \\
\text { n-Butane } \\
\mathrm{C}_{5}^{+} \text {liquid product } \\
\text { Liquid yield (vol\%) }\end{array}$ & $\begin{array}{l}0.1 \\
0.1 \\
0.1 \\
0.04 \\
0.1 \\
99.0 \\
101.7\end{array}$ & $\begin{array}{r}0.3 \\
0.2 \\
0.3 \\
0.1 \\
0.2 \\
97.7 \\
101.5\end{array}$ & $\begin{array}{r}0.6 \\
0.4 \\
0.5 \\
0.2 \\
0.4 \\
97.4 \\
102.0\end{array}$ & $\begin{array}{r}0.9 \\
0.6 \\
0.9 \\
0.9 \\
0.6 \\
97.5 \\
103.5\end{array}$ & $\begin{array}{r}2.1 \\
1.6 \\
2.8 \\
1.2 \\
2.2 \\
89.3 \\
98.7\end{array}$ \\
\hline $\begin{array}{l}\text { Simulated distillation of tot } \\
\text { Volatility (wt\%) } \\
\mathrm{C}_{5}^{+}-477 \mathrm{~K} \text { (wt\%) } \\
477-617 \mathrm{~K} \text { (wt\%) } \\
617-811 \mathrm{~K} \text { (wt\%) } \\
>811 \mathrm{~K} \text { (wt\%) }\end{array}$ & $\begin{array}{l}\text { al } 1 \text { iqu } \\
68.4 \\
1.0 \\
12.6 \\
54.8 \\
31.6\end{array}$ & $\begin{array}{l}\text { id proc } \\
73.8 \\
4.0 \\
16.5 \\
53.2 \\
26.2\end{array}$ & $\begin{array}{r}\text { luct } \\
76.2 \\
5.6 \\
19.8 \\
50.8 \\
23.8\end{array}$ & $\begin{array}{r}83.4 \\
6.2 \\
25.0 \\
52.2 \\
16.6\end{array}$ & $\begin{array}{r}94.5 \\
26.1 \\
40.6 \\
27.7 \\
5.5\end{array}$ \\
\hline
\end{tabular}


total liquid product decreased from $7000 \mathrm{ppm}$ at $642 \mathrm{~K}$ to $3400 \mathrm{ppm}$ at $685 \mathrm{~K}$ which corresponded to fractional conversions of 0.35 and 0.68 , respectively. The sulfur content of the total liquid products decreased with increasing temperature. The sulfur conversion ranged from 0.7 at $642 \mathrm{~K}$ to 0.93 at $685 \mathrm{~K}$ and approached 0.99 at $712 \mathrm{~K}$ despite the excessive coking at that temperature.

\section{Effect of Pressure}

The effect of reaction pressure on product distribution and yields and on denitrogenation and desulfurization is presented in Table 35. The reaction temperature and WHSV were held constant at $663 \mathrm{~K}$ and $0.76 \mathrm{~h}^{-1}$, respectively, while the pressure varied from 11.2 to $16.7 \mathrm{MPa}$. The reactor pressure did not exert a significant influence on the product distribution and yields (Table 35). The naphtha, distillate, gas oil and resıduum yields were virtually identical in the pressure range from 11.2 to $16.7 \mathrm{MPa}$. The API gravity and the $\mathrm{H} / \mathrm{C}$ atomic ratio of the total liquid product were insensitive to the increase in reactor pressure at a fixed temperature and WHSV. The sulfur content of the total liquid products did not vary significantly as the pressure increased which was consistent with the speculation that residuum and refrastory sulfur conversion are related. The fractional sulfur conversion exceeded 0.81 over the range of pressures studied at $663 \mathrm{~K}$. The nitrogen content of the total liquid products decreased from 6500 ppm at $11.2 \mathrm{MPa}$ to $4900 \mathrm{ppm}$ at $16.7 \mathrm{MPa}$. The fractional nitrogen conversions at $663 \mathrm{~K}$ were 0.39 at $11.2 \mathrm{MPa}$ and 0.54 at $16.7 \mathrm{MPa}$. 
Table 35 Effect of Pressure on the Product Properties of the Hydrotreated Bitumen from the Whiterocks oil sand Formation

\begin{tabular}{|c|c|c|c|c|}
\hline Run number & 14 & 8 & 19 & 12 \\
\hline $\begin{array}{l}\text { Process operating conditions } \\
\text { Pressure (MPa) } \\
\text { Temperature (K) } \\
\text { WHSV }\left(\mathrm{h}^{-1}\right) \\
T(\mathrm{~h})\end{array}$ & $\begin{array}{l}11.2 \\
663 \\
0.76 \\
1.31\end{array}$ & $\begin{array}{l}13.5 \\
664 \\
0.76 \\
1.31\end{array}$ & $\begin{array}{l}15.3 \\
664 \\
0.73 \\
1.38\end{array}$ & $\begin{array}{l}16.7 \\
664 \\
0.76 \\
1.32\end{array}$ \\
\hline $\begin{array}{l}\text { API Gravity } \\
\text { Specific Gravity }\end{array}$ & $\begin{array}{l}17.5 \\
0.943\end{array}$ & $\begin{array}{l}18.1 \\
0.938\end{array}$ & $\begin{array}{l}18.3 \\
0.937\end{array}$ & $\begin{array}{l}18.8 \\
0.933\end{array}$ \\
\hline $\mathrm{H}_{2}$ Consumption $\left(\mathrm{m}^{3} \mathrm{~m}^{-3}\right)$ & 65 & 94 & 110 & 126 \\
\hline $\begin{array}{l}\text { Elemental analysis } \\
\text { C (wt\%) } \\
\text { H (wt\%) } \\
\text { Nitrogen (ppm) } \\
\text { Sulfur (ppm) }\end{array}$ & $\begin{array}{r}86.1 \\
11.9 \\
6500 \\
620\end{array}$ & $\begin{array}{r}86.1 \\
11.9 \\
5400 \\
680\end{array}$ & $\begin{array}{r}86.1 \\
12.0 \\
5500 \\
610\end{array}$ & $\begin{array}{r}86.2 \\
12.1 \\
4900 \\
580\end{array}$ \\
\hline $\mathrm{H} / \mathrm{C}$ atomic ratio & 1.64 & 1.65 & 1.67 & 1.67 \\
\hline $\begin{array}{l}\text { Product yields (wt\%) } \\
C_{1} \\
C_{2} \\
C_{3} \\
i_{-B} \text {-Butane } \\
\text { n-Butane } \\
C_{5}^{+} \text {liquid product } \\
\text { Liquid yield (vol\%) }\end{array}$ & $\begin{array}{c}0.1 \\
0.04 \\
0.1 \\
0.02 \\
0.04 \\
96.0 \\
100 .\end{array}$ & $\begin{array}{r}0.3 \\
0.2 \\
0.3 \\
0.1 \\
0.2 \\
97.6 \\
101.5\end{array}$ & $\begin{aligned} 0.1 \\
0.05 \\
0.1 \\
0.03 \\
0.05 \\
97.1 \\
101.6\end{aligned}$ & $\begin{array}{r}0.3 \\
0.2 \\
0.3 \\
0.1 \\
0.2 \\
98.6 \\
103.2\end{array}$ \\
\hline $\begin{array}{l}\text { Simulated distillation of tot } \\
\text { Volatility (wt\%) } \\
\mathrm{C}_{5}^{+}-477 \mathrm{~K} \mathrm{(wt \% )} \\
477-617 \mathrm{~K} \text { (wt\%) } \\
617-811 \mathrm{~K} \text { (wt\%) } \\
>811 \mathrm{~K} \text { (wt\%) }\end{array}$ & $\begin{array}{l}\text { tal liquid } \\
72.9 \\
3.6 \\
16.3 \\
53.1 \\
27.1\end{array}$ & $\begin{array}{l}\text { product } \\
73.8 \\
4.0 \\
16.5 \\
53.2 \\
26.2\end{array}$ & $\begin{array}{r}73.5 \\
3.6 \\
16.5 \\
53.3 \\
26.5\end{array}$ & $\begin{array}{r}73.9 \\
3.7 \\
16.4 \\
53.8 \\
26.1\end{array}$ \\
\hline
\end{tabular}




\section{Molecular Weight Reduction}

Although denitrogenation was the main objective of Whiterocks bitumen hydrotreating, significant levels of boiling range reduction were observed (Tables $33-35$ ). Boiling range reduction was modelled according to the reaction network suggested by Mosby et. al. ${ }^{245}$ (Figure 101) which was used to predict boiling range yields in industrial hydrocrackers. The model accounts for conversion of facile and refractory residuum as well as virgin and cracked gas oil to lighter fractions. Fourteen rate constants are required and it has been reported by Beaton et. al. ${ }^{251}$ that all fourteen are necessary for satisfactory prediction of distillate yields. The model can be simplified so as to require only eleven rate constants by treating product and virgin gas oils as a single lump.

Equations relating the yield of gas $\left(C_{1}-C_{4}\right)$, naphtha $\left(C_{5}-477\right.$ $\mathrm{K})$, distillate $(477-617 \mathrm{~K})$, gas oil $(617-811 \mathrm{~K})$ and residuum (>811 K) were derived ${ }^{236}$ and rate constants and activation energies were determined using software employing the multidimensional simplex method $^{253}$ (Table 36). The kinetic data in Table 36 were used to calculate the yields of gas, naphtha, distillate, gas oil and residuum with respect to reciprocal WHSV and temperature (Figures 102 and 103). Agreement between experimental and calculated results was good; however, the rate constants and activation energies should not be used to draw meaningful conclusions about facile residuum conversion because low bitumen conversion data were not obtained in this study. 


\section{Residuum Conversion Model}

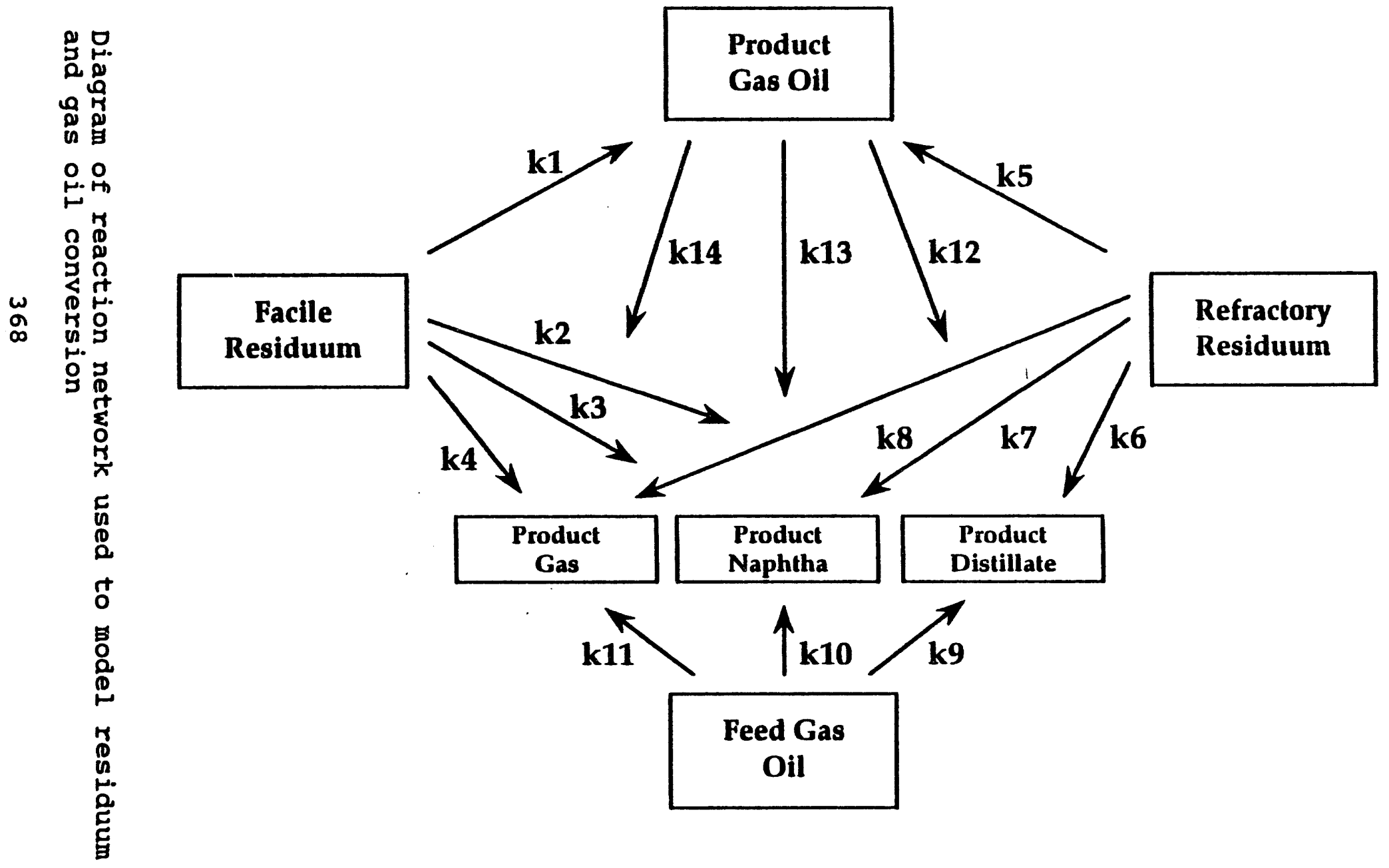


Table 36 Values of Rate Constants, Activation Energies and Preexponential Factors Derived for the Mosby Model

i $\quad k_{i}\left(h^{-1}\right) \quad E_{0, i}\left(k J\right.$ mol $\left.^{-1}\right) \quad A_{0, i}\left(h^{-1}\right)$

\begin{tabular}{llrl}
1 & 2.51 & 3 & $1.2 \times 10^{0}$ \\
2 & 1.09 & 36 & $8.0 \times 10^{2}$ \\
3 & 0.50 & 39 & $5.7 \times 10^{2}$ \\
4 & 0.01 & 33 & $4.3 \times 10^{0}$ \\
5 & 0.22 & 155 & $3.3 \times 10^{11}$ \\
6 & 0.00 & 69 & $3.3 \times 10^{1}$ \\
7 & 0.00 & 80 & $8.3 \times 10^{2}$ \\
8 & 0.005 & 296 & $9.3 \times 10^{20}$ \\
9 & 0.10 & 187 & $4.8 \times 10^{13}$ \\
10 & 0.003 & 7 & $1.1 \times 10^{-2}$ \\
11 & 0.025 & 189 & $1.9 \times 10^{13}$ \\
12 & 0.00 & 128 & $4.1 \times 10^{6}$ \\
13 & 0.05 & 227 & $2.1 \times 10^{0}$ \\
14 & 0.002 & 107 & $4.7 \times 10^{5}$ \\
\hline
\end{tabular}

SUMMARY AND CONCLUSIONS

The bitumen from the whiterocks oil sand deposit in the Uinta Basin of eastern Utah was hydrotreated in a fixed-bed reactor to determine the extent of upgrading as a function of process operating variables. The process variables investigated included pressure (11.2-16.7 MPa); temperature $(641-712 \mathrm{~K})$ and liquid hourly space velocity $\left(0.19-0.77 \mathrm{~h}^{-1}\right)$. The hydrogen/oil ratio, $890 \mathrm{~m}^{3} \mathrm{~m}^{-3}$, was fixed in all experiments. A sulfided Ni-Mo on alumina hydrodenitrogenation catalyst was used in these studies.

The deactivation of the catalyst, $0.2^{\circ} \mathrm{C} /$ day, was monitored by the decline in the API gravity of the total liquid product with time on-stream at a standard set of conditions. The effect of temperature, weight hourly space velocity, and pressure on denitrogenation, desulfurization and residuum conversion were 


\section{Product Yields vs. 1/WHSV for Whiterocks Bitumen}

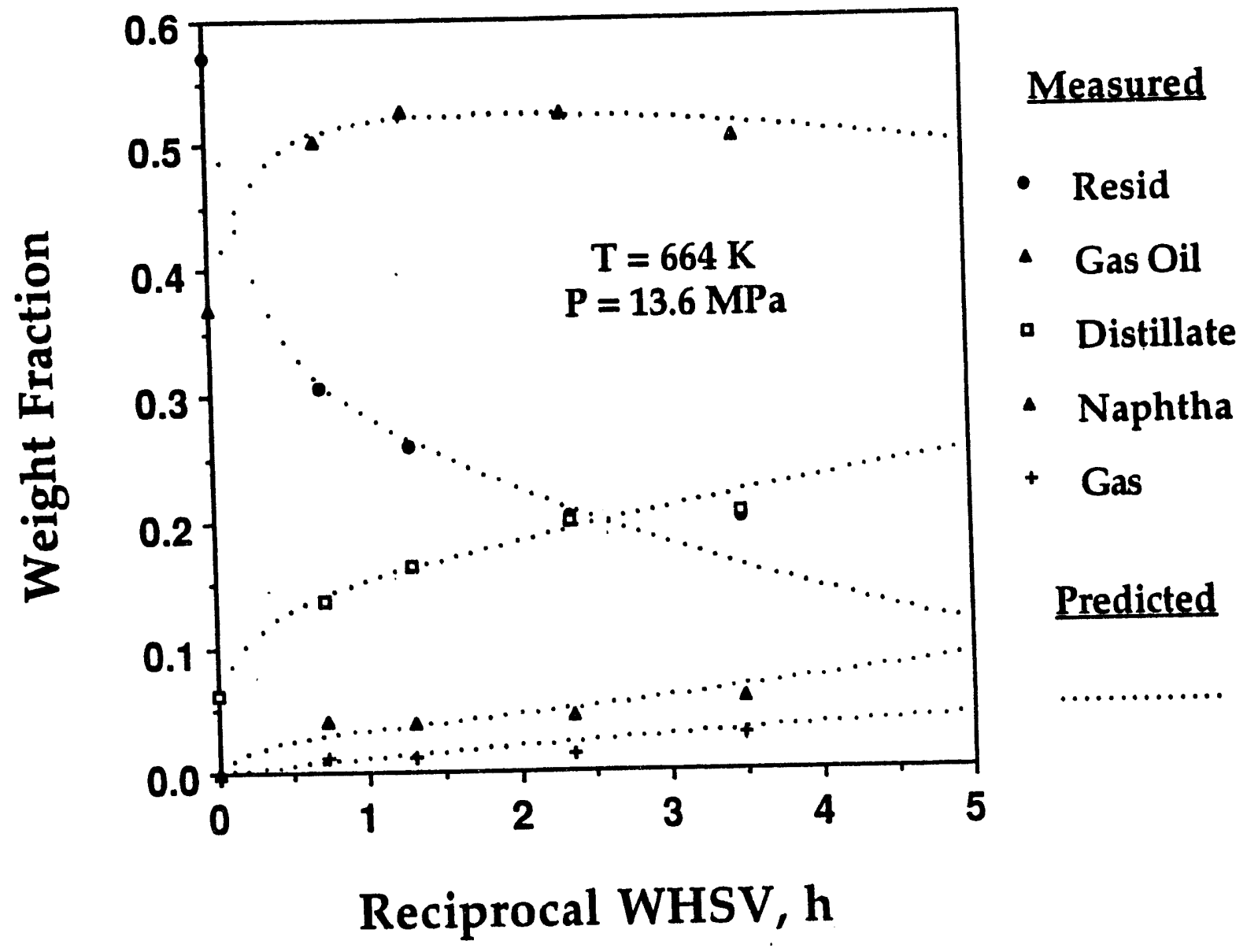

Figure 102. The effect of reciprocal WHSV on the calculated and measured yields of residuum and distillate fractions 
Product Yields vs. Temperature for Whiterocks Bitumen

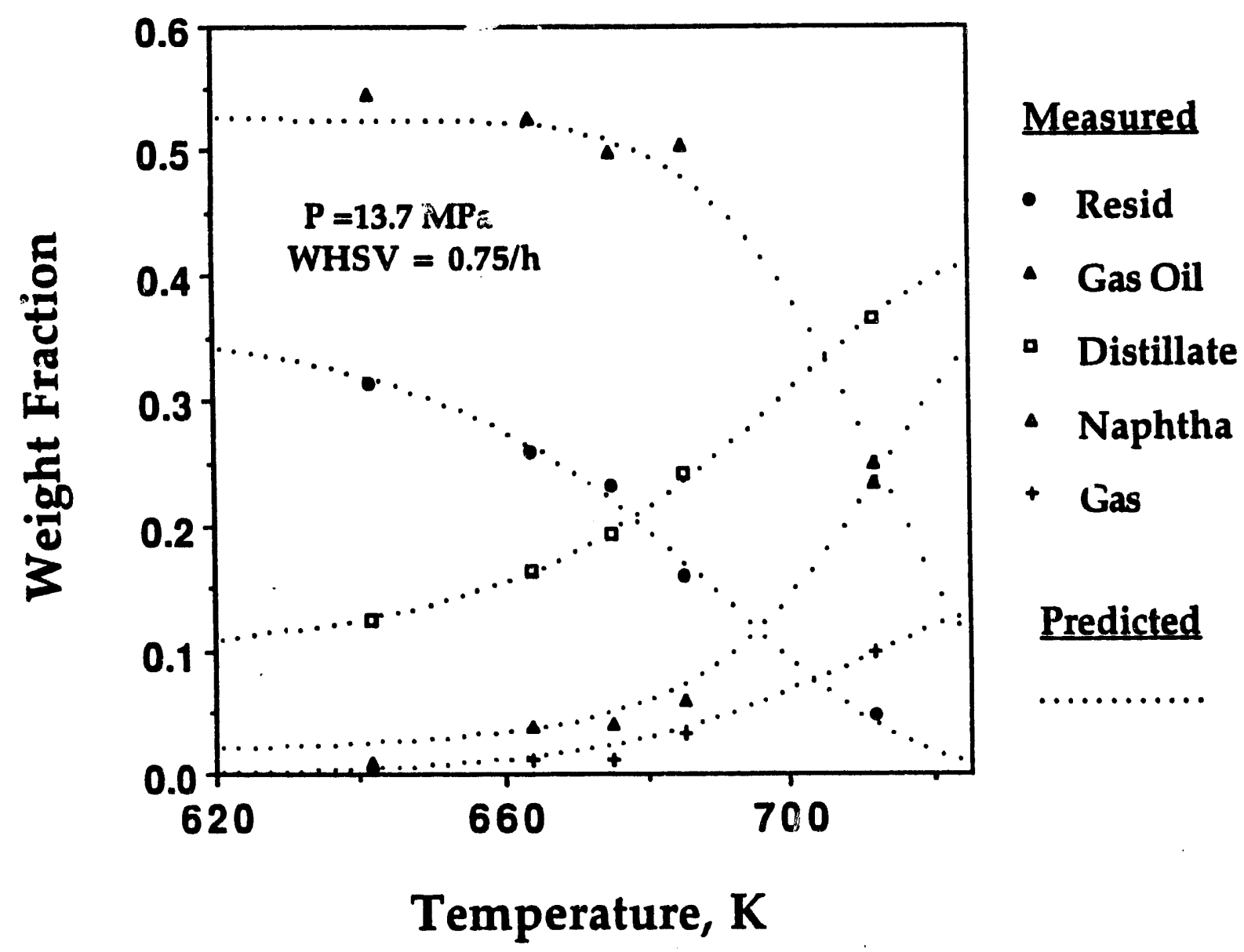

Figure 103. The effect of temperature on the calculated and measured yields of distillate fractions 
studied and apparent kinetic parameters determined. The effect of process variables on residuum conversion and Conradson carbon residue reduction was also investigated.

Substantial molecular weight reduction occurred during hydrotreating which was the result of thermal and catalytic cracking. Catalyst activity remained stable for over 700 hours during normal hydrotreating conditions. The deactivation rate was $0.2^{\circ} \mathrm{C}$ day $^{-1}$. The activity was substantially reduced after processing bitumen for short times temperatures above $700 \mathrm{~K}$.

Denitrogenation was pseudo-first order, while desulfurization and residuum conversion were adequately represented by two parallel first order reactions. Sulfur conversion was linked to residuum conversion because sulfur contained in residuum moieties is unreactive until those moieties are cracked. The apparent activation energies for denitrogenation, refractory sulfur conversion, and refractory residuum conversion were $93 \mathrm{~kJ} \mathrm{~mol}^{-1}, 146$ $\mathrm{kJ} \mathrm{mol}^{-1}$ and $134 \mathrm{~kJ} \mathrm{~mol}^{-1}$, respectively.

\section{Future Activities}

The whiterocks bitumen will be hydrotreated over a commercial hydrodemetallation catalyst. The influence of temperature, pressure and WHSV on denitrogenation, desulfurization, and resid conversion will be determined. 


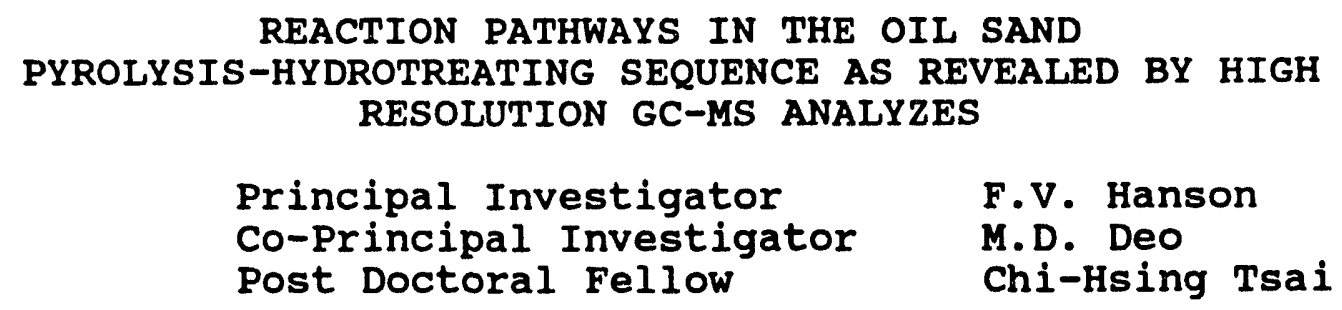

\section{INTRODUCTION}

The utilization of Utah's Uinta Basin oil sands resource will most likely involved a combination of in-situ and mining-surface recovery techniques. It has been reported that 15-30\% of Utah's oil sands are amenable to mining-surface recovery processes. ${ }^{254}$ The mining-surface recovery processes include aqueous separation 255,256 , solvent extraction $257-259$ and pyrolysis.260-272 The production of refinery feedstocks from mined oil sands can be accomplished by a number of processing sequences: aqueous separation or solvent extraction followed by coking and hydrotreating of the coker liquids or hydrotreating of the full range bitumen and rotary kiln or fluidized bed pyrolysis followed by hydrotreating of the bitumen-derived liquid.

The objective of this investigation was to explore the molecular transformations that occurred in the processing sequence. pyrolysis of the mined oil sand ore in a fluidized bed ${ }^{263}$ or rotary kiln ${ }^{271}$ followed by hydrotreating of the bitumen-derived liquid ${ }^{273}$. Several reaction pathways will be discussed to explain bitumen conversion to a refinery feedstock by this sequence. 
EXPERIMENTAL METHODS AND MEANS

\section{Fluidized Bed Pyrolysis System}

The bitumen-derived liquid used in the hydrotreating studies was produced from the Whiterocks oil sand ore in a large diameter, fluidized bed pyrolysis reactor. The reactor temperature ranged from 773 to $813 \mathrm{~K}$, and the average feed sand retention time was 17.2 minutes during the course of the production run. The production of the bitumen-derived hydrocarbon liquid from the Whiterocks oil sand has been described in detailed by sung ${ }^{268}$.

\section{Hydrotreater Process Unit}

Process studies were conducted in a fixed-bed reactor which was operated in the upflow mode to minimize thermal gradients in the catalyst bed and to ensure complete wetting of the catalyst. A schematic of the hydrotreater system is presented in Figure 104. The reactor was designed for operation at a maximum pressure of $5000 \mathrm{psi}$ at $500^{\circ} \mathrm{C}$. The catalyst was diluted with quartz sand (50\% by volume) in the inlet region of the bed $(-20 \%)$ to trim the exotherm which resulted from olefin hydrogenation reactions.

The base case operating conditions for the hydrotreating study were: reaction temperature, $346^{\circ} \mathrm{C}$; liquid hourly space velocity (LHSV), $0.5 \mathrm{~h}^{-1}$; total reactor-pressure, $1980 \mathrm{psia}$ and hydrogen-tohydrocarbon feed ratio, $5000 \mathrm{SCF} / \mathrm{b}$. The API gravity of the total liquid product was constant at $23.2^{\circ}$ A.PI after the reactor was onstream for 94 hours at the base case conditions. At this point, it was assumed that the catalyst had equilibrated and that $95 \%$ of the coke deposition had occurred. A series of experiments were 


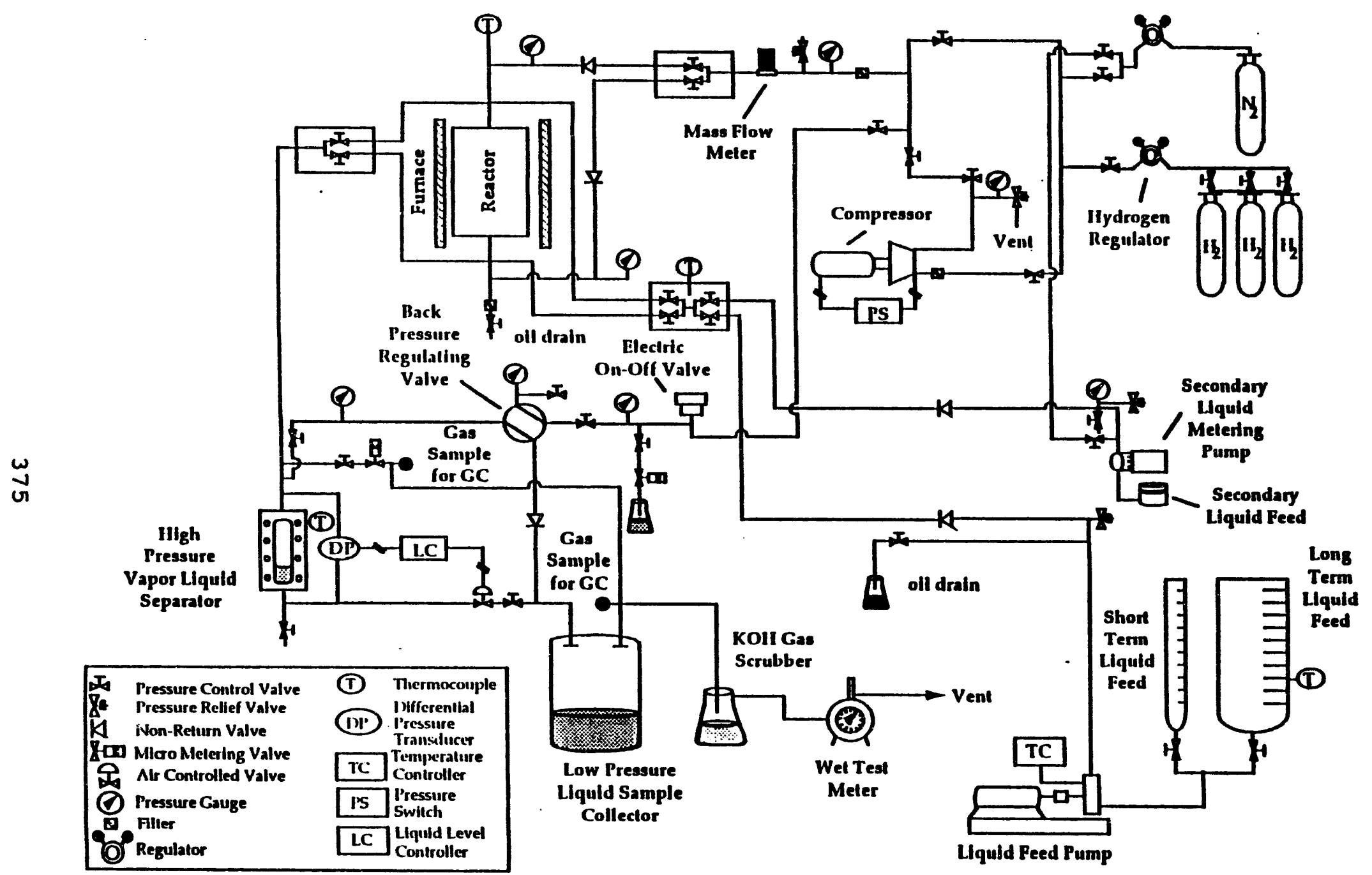

Figure 104. Hydrotreater reactor schematic 
conducted in which the system was operated in a cyclic mode (base case condition/desired reaction condition/base case condition) for approximately 1000 hours. The total liquid product from each experiment was collected for analyses. The analytical test procedures conformed to those outlined in the ASTM manuals.

Mass balances were taken for 3 hours at the end of a 16-hour lineout period after the system had attained a stationary state at the reaction conditions. The mass balances were conducted by monitoring the liquid fed to the reactor system for discrete time periods. At the conclusion of each mass balance the collected gas and liquid samples were weighed and the gas sample was weathered into a vapor collector and analyzed by gas chromatography. All the mass balances were greater than 97.5 wt:

The extent of nitrogen removal was the key reactivity parameter followed during the course of the study; however, the key operating parameter followed on the catalyst testing unit during the run was the API gravity of the total liquid product.

\section{Catalyst}

A UNOCAL quadralobe $\mathrm{Ni} / \mathrm{MO} / \mathrm{Al}_{2} \mathrm{O}_{3}$ hydrodenitrogenation (HDN) catalyst was used in this study. The catalyst contained 3.3 wt\% $\mathrm{NiO}, 12.8 \mathrm{wt} \% \mathrm{MOO}_{3}$, and 0.8 wt? $\mathrm{P}_{2} \mathrm{O}_{5}$; had a surface area of $241 \mathrm{~m}^{2} / \mathrm{g}$; and a pore volume ( $\mathrm{Hg}$ porosimetry) of $0.55 \mathrm{~cm}^{3} / \mathrm{g}$. The $\mathrm{A} /{ }_{2} \mathrm{O}_{3}$ support had a unimodal pore structure. The sulfiding conditions were specified by the catalyst manufacturer. A solution of dimethyl disulfide in kerosene ( $\sim 2$ wto sulfur) was used to sulfide the catalyst at a LHSV of $1.0 \mathrm{~h}^{-1}$. The hydrogen-to-sulfiding solution 
ratio was $5000 \mathrm{SCF} / \mathrm{B}$. The reactor temperature was adjusted to the initial run temperature after sulfur breakthrough at which point the sulfiding solution was discontinued.

A description of the experimental apparatus and operating procedures; a description of the catalyst and the catalyst activation procedures; and a summary of the process variable study have been reported by Longstaff, et al.274. The design, construction and operation of the hydrotreater catalyst testing unit have been discussed in detail by Longstaff ${ }^{273}$.

\section{Analysis of Liquid Products}

Simulated Distillation. The boiling point distributions of the hydrotreated products were determined by simulated distillation. The samples were dissolved in dichloromethane and the analyses were performed on a programmed Hewlett-Packard Model $5730 \mathrm{~A}$ gas chromatograph: the oven temperature was programmed from $-30^{\circ} \mathrm{C}$ to $350^{\circ} \mathrm{C}$ at $11^{\circ} \mathrm{C} /$ minute and was held at $350^{\circ} \mathrm{C}$ for 16 minutes; the injector temperature was initially set at $250^{\circ} \mathrm{C}$ and raised to $350^{\circ} \mathrm{C}$ after 12 minutes and the FID detector temperature was $400^{\circ} \mathrm{C}$. The boiling point temperatures were calibrated with a standard mixture of normal paraffins $\left(C_{5}-C_{44}\right)$.

Fourier Transform Infrared Spectroscopic Analysis. The FTIR spectra were obtained with a Perkin Elmer 1600 spectrometer which was operated in the transmission mode. Transmission spectra of the neat liquids from the bitumen-derived liquid and the hydrotreated products were determined in a liquid cell with a path length less than $0.015 \mathrm{~mm}$. Primary spectra of the bitumen-derived liquid and 
the hydrotreated total liquid products were obtained with a nominal resolution of $4 \mathrm{~cm}^{-1}$ in the range of $4000-450 \mathrm{~cm}^{-1}$.

Gas Chromatography-Mass Spectrometry Analysis. The bitumenderived liquid feed, the hydrotreated total liquid products and the volatile-fraction of the bitumen $\left(<538^{\circ} \mathrm{C}\right)$ were analyzed with a gas chromatograph (Hewlett-Packard Model 5890 Series II) using a fused silica capillary column coated with 5\% phenyl methyl silicone bonded stationary phase $(30 \mathrm{~m} \times 0.25 \mathrm{~mm} I>D ., D B-5, J \& W$ scientific). The temperature program was ramped from $50^{\circ} \mathrm{C}$ to $300^{\circ} \mathrm{C}$ at $3^{\circ} \mathrm{C} / \mathrm{min}$, with a hold at $300^{\circ} \mathrm{C}$ for 20 minutes for the bitumenderived liquid and the volatile fraction of the bitumen. The final oven temperature was $320^{\circ} \mathrm{C}$ for hydrotreated total liquid products. Gas chromatograph-mass spectrometry analyses were performed on a Finnigan MAT high resolution gas chromatography/mass spectrometer (Finnigan MAT ICIS II operating system) fitted with a DB-5 gas chromatographic column ( $30 \mathrm{~m} \times 0.25 \mathrm{~mm}$ I.D.).

\section{RESULTS AND DISCUSSION}

The bitumen-derived liquid was significantly upgraded relative to the native bitumen (Table 37 ): $18.5^{\circ} \mathrm{API}$ versus $11.9,36 \mathrm{API}$; a viscosity of 85.4 centipoise at $15.6^{\circ} \mathrm{C}$, versus 7,900 centipoise at $60^{\circ} \mathrm{C} ;$ a volatility $\left(<538^{\circ} \mathrm{C}\right)$ of 82.2 wt versus 44.1 wt\%; a Conradson carbon residue of 4.7 wto versus 8.8 wto; etc., respectively. The atomic hydrogen-to-carbon (H/C) ratio of the bitumen-derived liquid was lower than that of the native bitumen. This reduction was related to dealkylation and dehydrogenation reactions during pyrolysis which resulted in the production of a 
Table 37. - Properties of Bitumen and Bitumen-Derived Liquids from the Whiterocks Oil sand Deposit

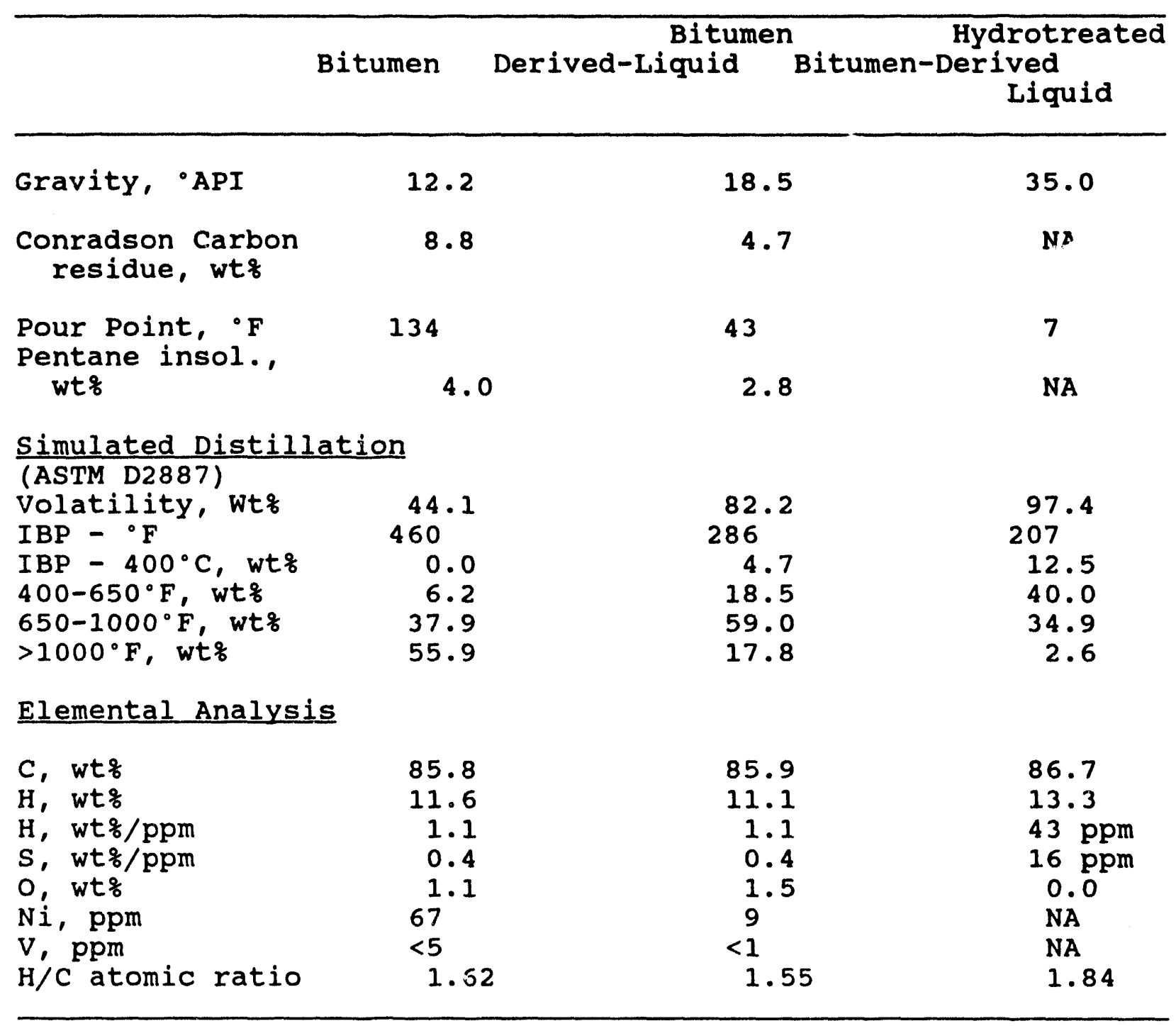

$\mathrm{NA}=$ Not available. 
more aromatic hydrocarbon liquid and consequently a lower H/C ratio. Furthermore, since the asphaltene (pentane insolubles) and resin fractions in the bitumen was assumed to be the primary precursor of the carbonaceous residue deposited on the spent sand $^{275}$, the coking tendency of the bitumen-derived liquid during hydrotreating was expected to be less than that of the native bitumen.

\section{GC-MS Analyses}

Identification of individual compounds in the volatile fraction (IBP-538 $\mathrm{C}$ ) of the Whiterocks bitumen, the bitumen-derived liquid and the hydrotreated total liquids was based on the comparison to known spectra from the literature or were tentatively assigned based on interpretation of the mass spectrum ${ }^{276-324}$. The individual compounds identified in these samples are summarized in Tables 38-39. The identification of individual isomers was not attempted due to the complexity of compound types and the coelution of several compounds at the same retention time in GC-MS analysis. The biological markers found in these samples were described in general terms such as hopane 17-21-secophane, sterane, perhydrophenanthrene, etc. (Tables 38-40) due to the lack of standard compounds for comparison. In addition, most of the single ring cycloalkanes were assigned as cyclohexanes due to the similarity of the fragmentation ion peaks from cyclohexanes and cyclopentanes. For the same reason, most of the bicyclic alkanes were assigned as decalins even though lesser amounts of hexahydroindanes were present. In addition to saturates, aromatics 
Table 38. - Compounds detected in the volatile fraction (IBP-538 ${ }^{\circ} \mathrm{C}$ ) of the Whiterocks Bitumen

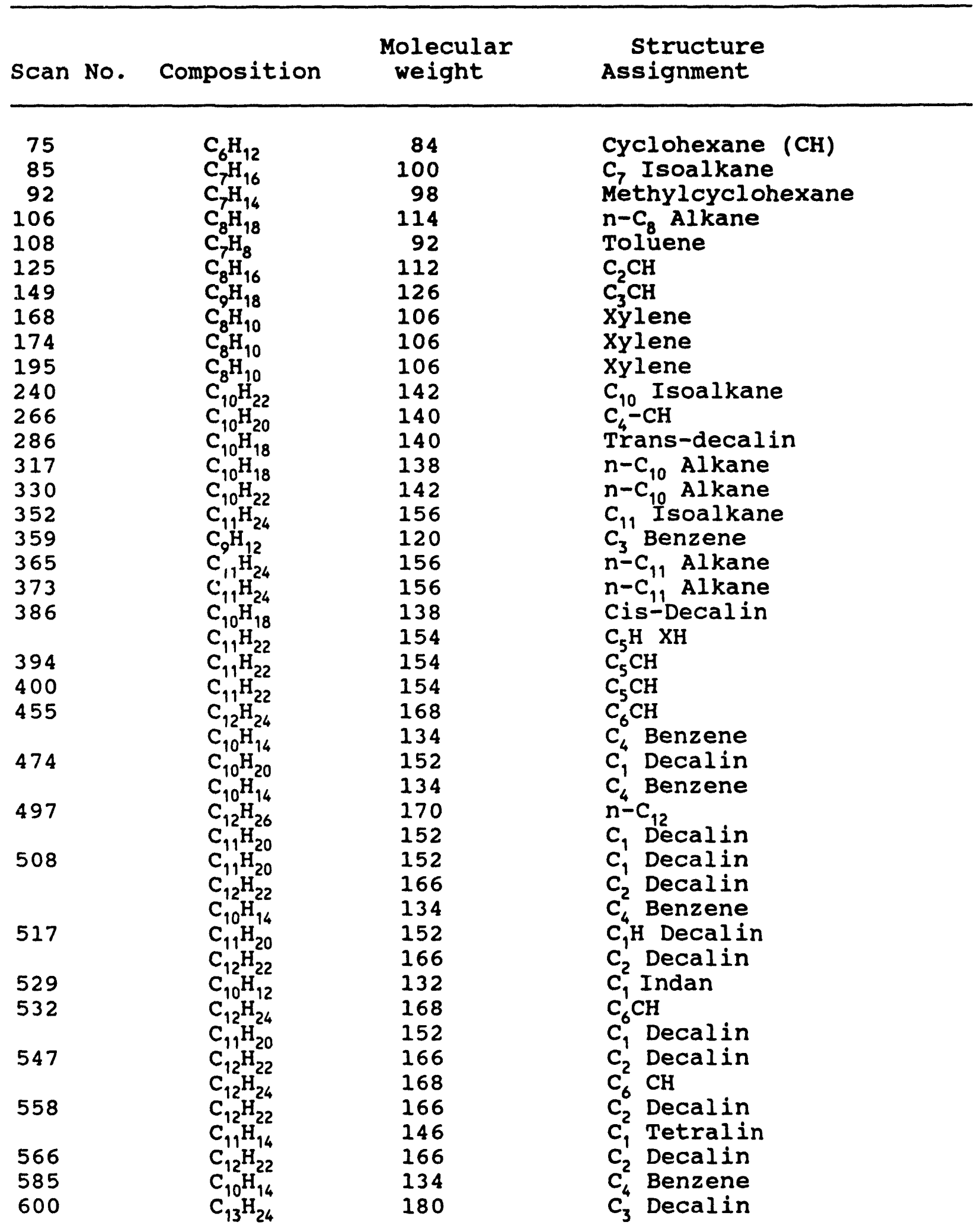




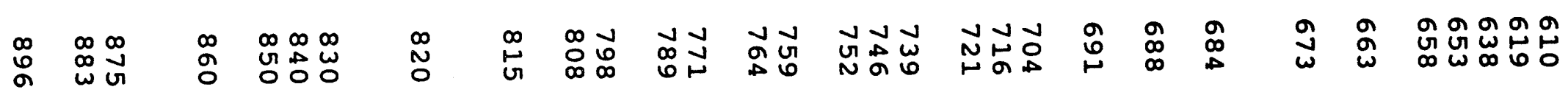

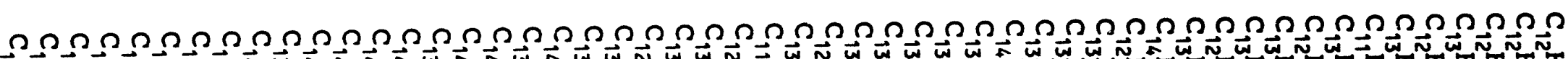

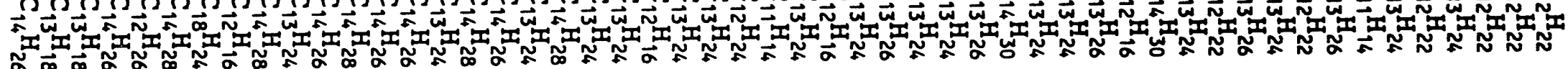

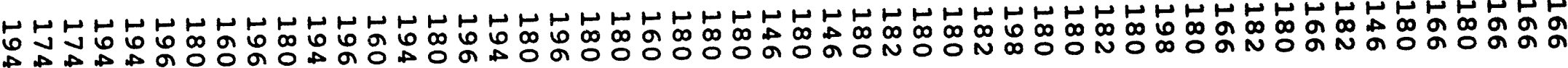

$\underset{\substack{\omega \\ N}}{\omega}$

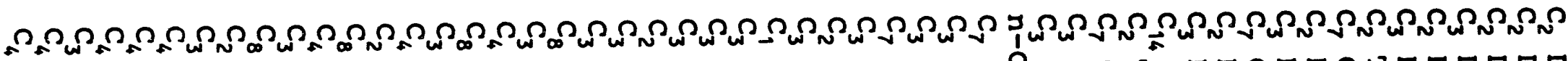

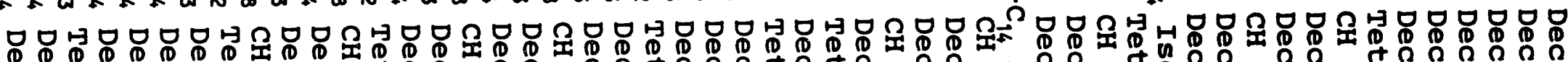

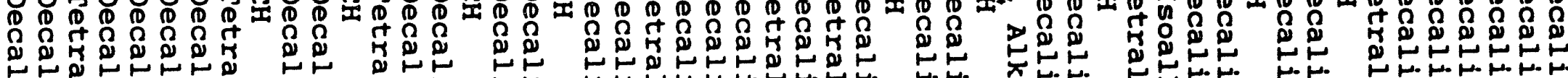

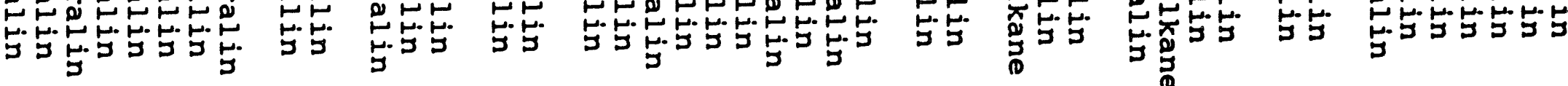




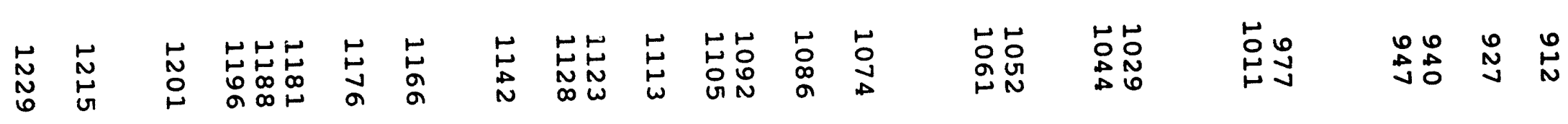

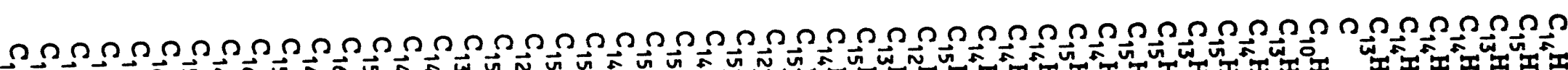

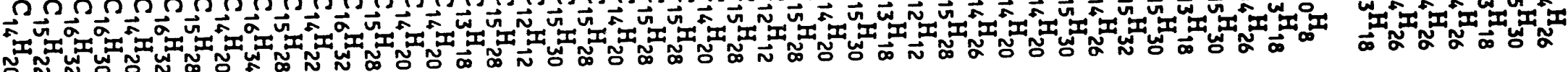

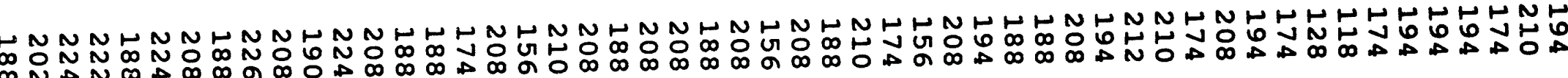

$\underset{\omega}{\omega}$

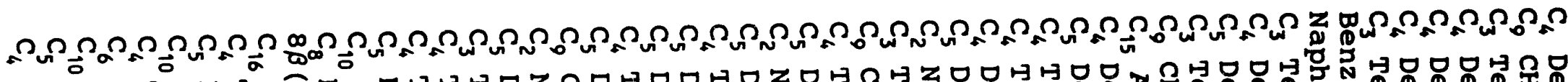

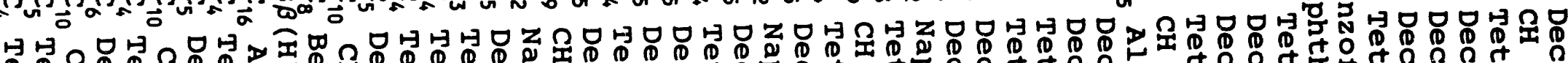

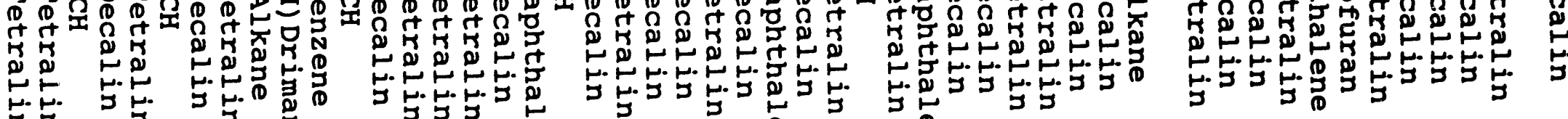

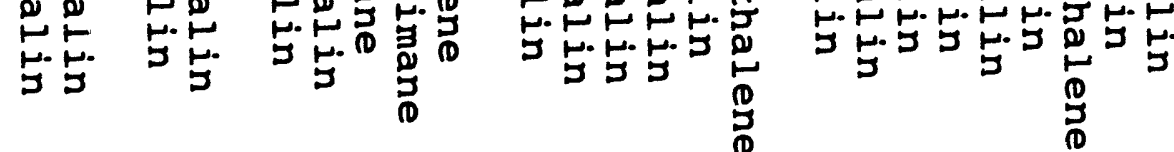




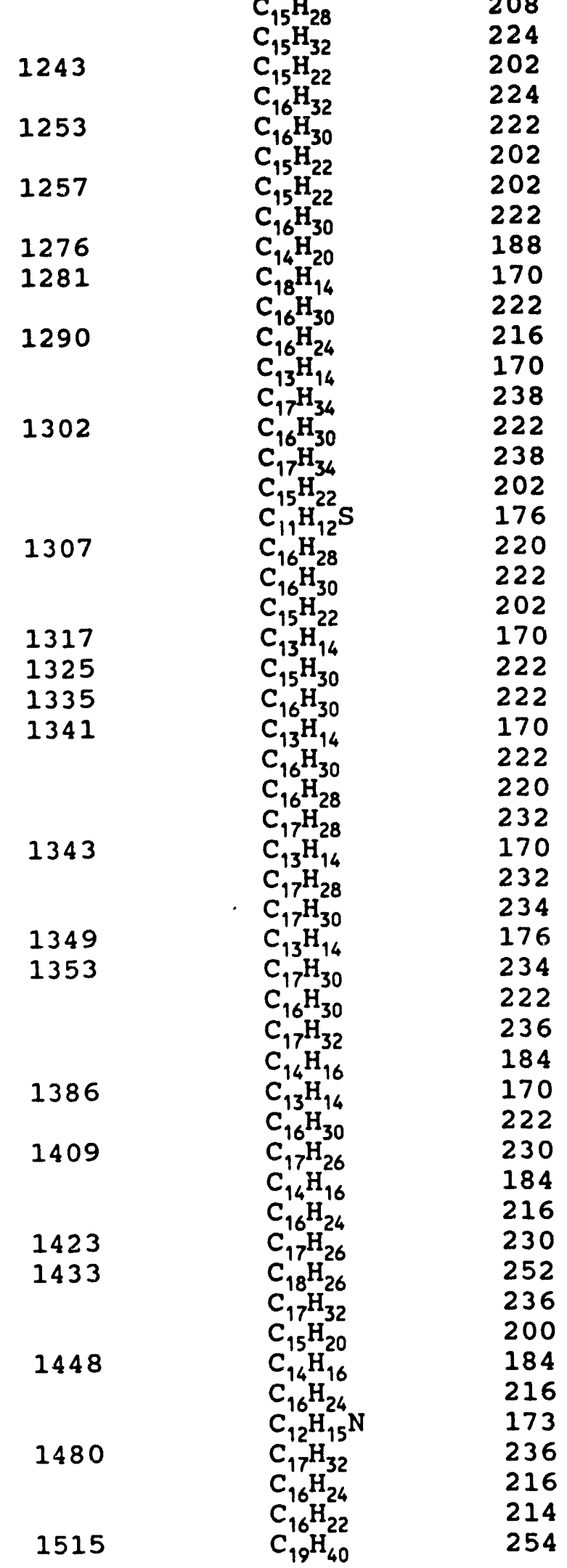

$C_{5}$ Decalin

$\mathrm{C}_{10} \mathrm{CH}$

$\mathrm{C}_{5}$ Tetralin

$\mathrm{C}_{10} \mathrm{CH}$

$\mathrm{C}_{6}$ Decalin

$C_{5}$ Tetralin

$c_{5}$ Tetralin

$C_{6}$ Decalin

$\mathrm{C}_{4}$ Tetralin

$C_{3}$ Naphthalene

$C_{6}$ Decalin

$c_{2}$ Phenylcylcohexylethane

$c_{3}$ Naphthalene

$\mathrm{C}_{11} \mathrm{CH}$

$\mathrm{C}_{6}$ Decalin

$\mathrm{C}_{11} \mathrm{CH}$

$\mathrm{C}_{5}$ Tetralin

$c_{3}$ Benzothiophene

$C_{2}$ Perhydrophenanthrene

$C_{6}$ Decalin

$C_{5}$ Tetralin

$C_{3}$ Naphthalene

$C_{6}$ Decalin

$C_{6}$ Decalin

$C_{3}$ Naphthalene

$C_{6}$ Decalin

$C_{2}$ Perhydrophenanthrene

$c_{11}$ Benzene

$C_{3}$ Naphthalene

$c_{11}$ Benzene

$C_{2}$ Perhydrophenanthrene

$\mathrm{C}_{3}$ Naphthalene

$C_{3}$ Perhydrophenanthrene

$\mathrm{C}_{6}$ Decalin

$C_{7}$ Decalin

$C_{4}$ Naphthalene

$C_{3}$ Naphthalene

$C_{6}$ Decalin

$c_{3}$ Phenyl (cyclohexyl) ethane

$C_{4}$ Naphthalene

$\mathrm{C}_{6}$ Tetralin

$c_{3}$ Phenyl (cyclohexyl) ethane

$\mathrm{C}_{12} \mathrm{CH}$

$\mathrm{C}_{7}$ Decalin

$C_{1}$ octahydrophenanthrene

$C_{4}$ Naphthalene

$\mathrm{C}_{6}$ Tetralin

$\mathrm{C}_{4}$ Indole

$c_{7}$ Decalin

$c_{6}$ Tetralin

$C_{2}$ Octahydrophenanthrene

$2,6,10,14$-Tetramethyl- 


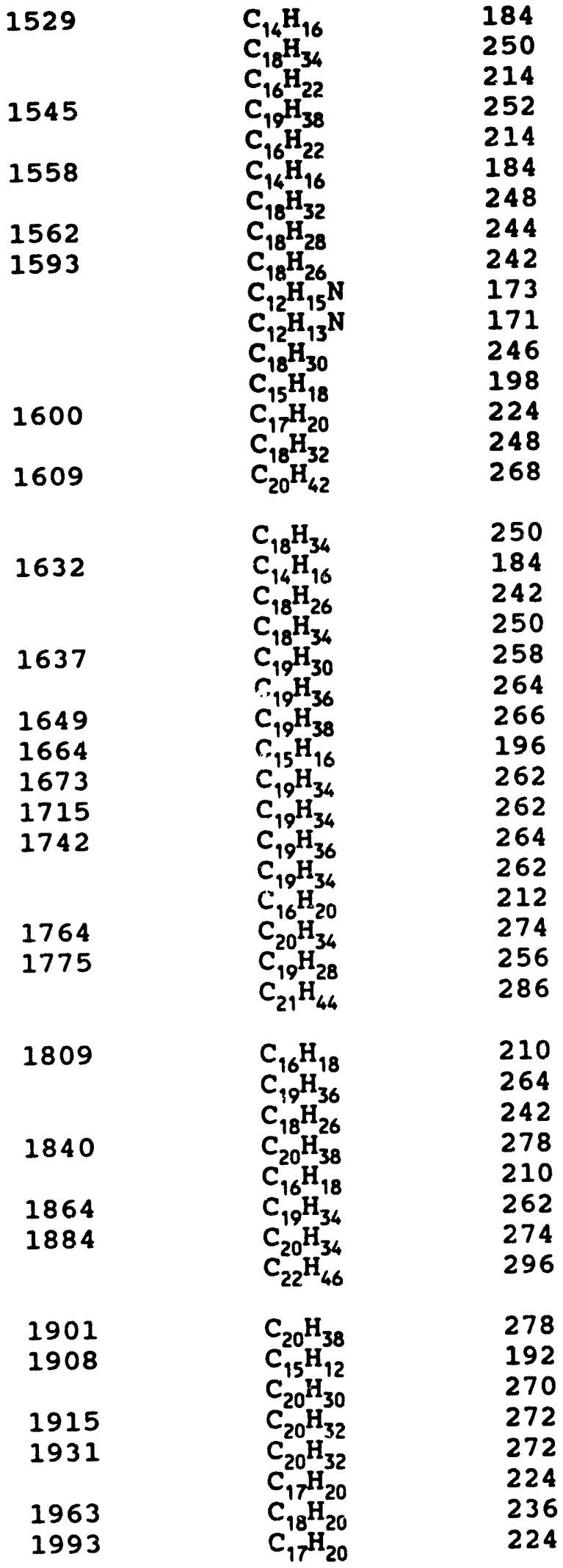

pentadecane (pristane)

$C_{4}$ Naphthalene

C. Decalin

$C_{2}$ Octahydrophenanthrene

$\mathrm{C}_{12} \mathrm{CH}$

$C_{2}^{12}$ Octahydrophenanthrene

$C_{4}$ Naphthalene

$C_{4}$ Perhydrophenanthrene

$c_{4}$ Phenyl (cyclohexyl) ethane

$c_{4}$ octahydrophenanthrene

$C_{4}$ Indole

$C_{3}$ Quinoline

$C_{12}$ Benzene

$C_{5}$ Naphthalene

$c_{3}$ Tetraphydrophenathrene

$C_{4}$ Perhydrophenanthrene

$2,6,10,14$-tetramethyl

hexadecane (phytane)

$C_{8}$ Decalin

$C_{4}$ Naphthalene

$C_{4}$ octahydrophenathrene

$C_{8}$ Decalin

$C_{5}$ Phenyl (cyclohexyl) ethane

$c_{0}$ Decalin

$\mathrm{C}_{13} \mathrm{CH}$

$\mathrm{C}_{13}$ Tetrahydrophenanthrene

$C_{5}$ Perhydrophenanthrene

$C_{5}$ Perhydrophenanthrene

$C_{9}$ Decalin

$C_{5}$ Perhydrophenanthrene

$C_{6}$ Naphthalene

$C_{14}$ Benzene

$\mathrm{C}_{2}$ Indan (cyclohexyl) ethane $2,4,6,10$-Tetramethylheptadecame

C, Tetrhydrophenathrene

$C_{9}$ Decalin

$\mathrm{C}_{4}$ Octahydrophenanthrene

$C_{10}$ Decalin

$C_{2}$ Tetrahydrophenanthrene

$C_{5}$ Perhydrophenanthrene

$C_{14}$ Benzene

$2,4,6,10$-Tetramethyloctadecane

$\mathrm{C}_{10}$ Decalin

$C_{1}$ Phenanthrene

$c_{3}$ Indan(cyclohexl) ethane

$c_{6}$ Phenyl (cyclohexyl) ethane

$c_{6}$ Phenyl (cyclohexyl) ethane

$c_{3}$ Tetrahydrophenanthrene

Dilaromatic sterane

$C_{3}$ Tetrahydrophenanthrene 


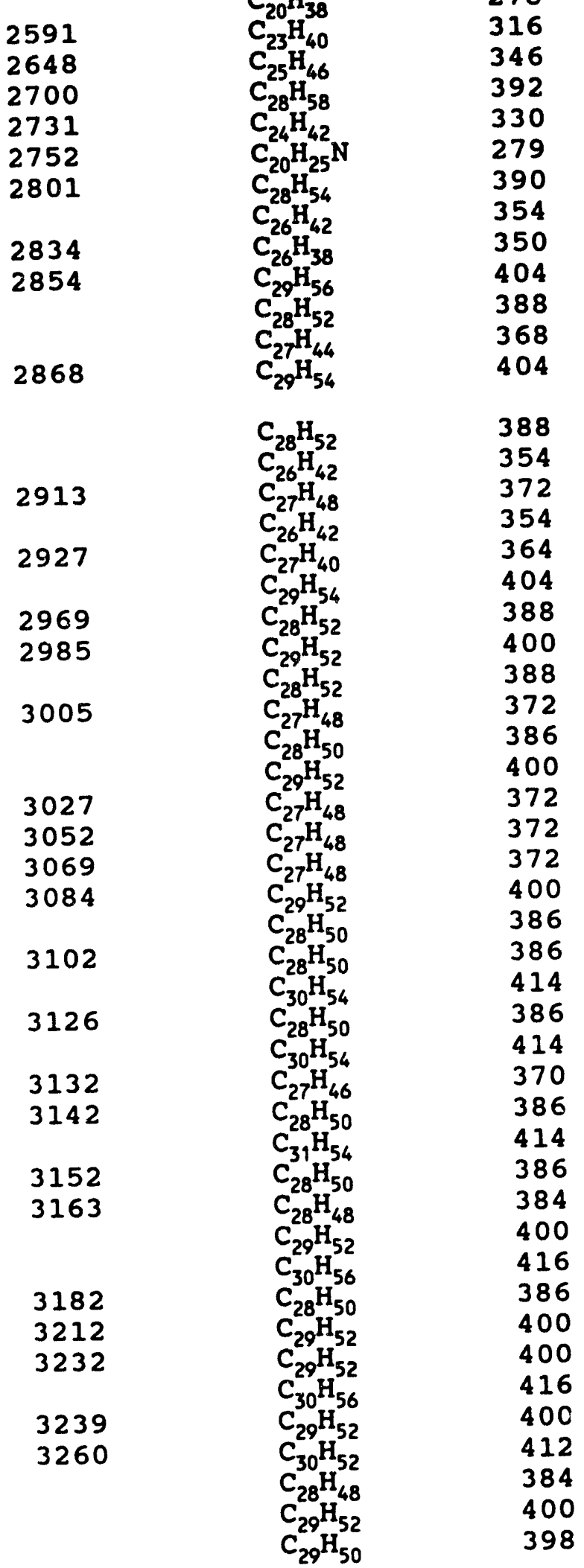

$C_{16}$ Decalin

Diaromatic sterane

$C_{5}$ Perhydrocrysene

$c_{11}$ Perhydrophenanthrene

$c_{28}$ Isoalkanes

17,21 -secohopane $\left(C_{24}\right)$

$\mathrm{C}_{8}$ Carbazole

$c_{18}$ Decalin

$C_{12}$ Octahydrophenanthrene

$c_{12}$ Tetrahydrophenanthrene

$C_{19}$ Decalin

$C_{14}$ Perhydrophenanthrene

$c_{13}$ octahydrophenanthrene

$\mathrm{C}_{19}$ Decalin

$c_{14}$ Perhydrophenanthrene

$C_{12}$ Octahydrophenanthrene

17,21 -secohopane $\left(C_{27}\right)$

$C_{12}$ Octahydrophenanthrene

$C_{13}$ Tetrahydrophenanthrene

$\mathrm{C}_{19}$ Decalin

$\mathrm{C}_{14}$ Perhydrophenanthrene

$c_{29}$ sterane

$\mathrm{C}_{14}$ Perhydrophenanthrene

$c_{27}$ sterane

$\mathrm{C}_{28}$ Sterane

$\mathrm{C}_{29}$ Sterane

$C_{27}$ Sterane

17,21 -secohopane $\left(C_{27}\right)$

$C_{27}$ sterane

$c_{29}$ sterane

$\mathrm{C}_{28}$ Sterane

$\mathrm{C}_{28}$ Sterane

$\mathrm{C}_{30}$ 4-methylsterane

$c_{28}$ sterane

$C_{30}^{28}$ 4-methylsterane

Trisnorphopane

$\mathrm{C}_{28}$ Sterane

$\mathrm{C}_{30}^{28}$ 4-methylsterane

$c_{30}$ 4-methylsterane

Bisnorhopane

$C_{29}$ Sterane

$C_{16}$ Perhydrophenanthrene

$\mathrm{C}_{28}$ Sterane

$\mathrm{C}_{29}$ sterane

$C_{29}$ Sterane

$C_{16}^{29}$ Perhydrophenanthrene

$C_{16}$ Perhydrophenanthrene

3-Methyl-30-norphopane

Bisnorhopane

$\mathrm{C}_{29}$ 4-methylstrane

Norhopane 
Something missing here

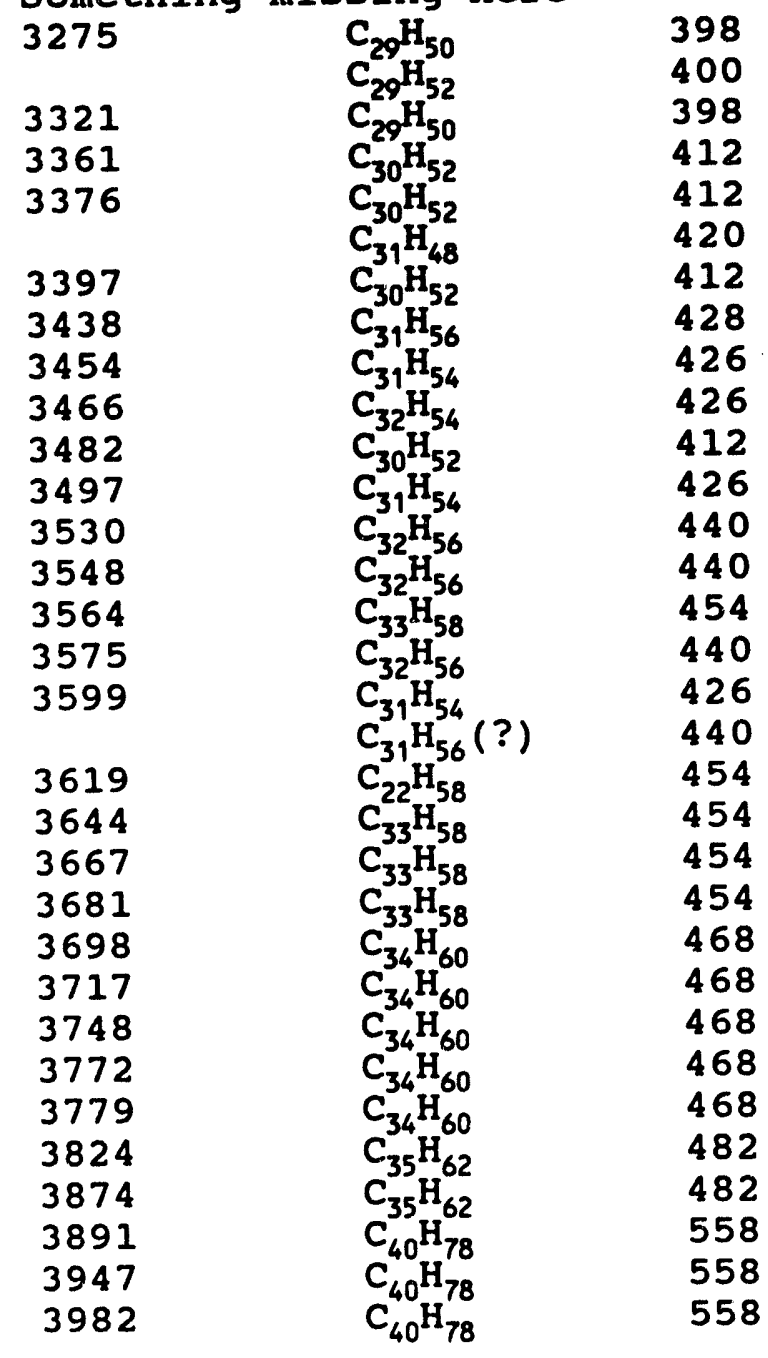

Norhopane

$\mathrm{C}_{29}$ Sterane

Norhopane

Methyl-norhopane

Hopane

$$
\text { ? }
$$

Hopane

C $_{31}$ 24-Methyl-lanostane

Homohopane

Homohopane

Gammacerane

$C_{31}$ 4-methylhopane

Bishomohopane

Bishomohopane

Trishomohopane

Bishomohopane

Homohopane

Bishomohopane

Trishomohopane

Trishomohopane

Trishomohopane

Trishomohopane

Tetrakishomohopane

Tetrakishomohopane

Tetrakishomohopane

Tetrakishomohopane

Tetrakishomohopane

Pentakishomohopane

Pentakishomohopane

Perhydrocarotene

Perhydrocarotene

Perhydrocarotene 
Table 39. - Compounds Detected in the Bitumen-Derived Liquid Produced from the Whiterocks oil sand in a Large Diameter Fluidized-Bed Pyrolysis Reactor

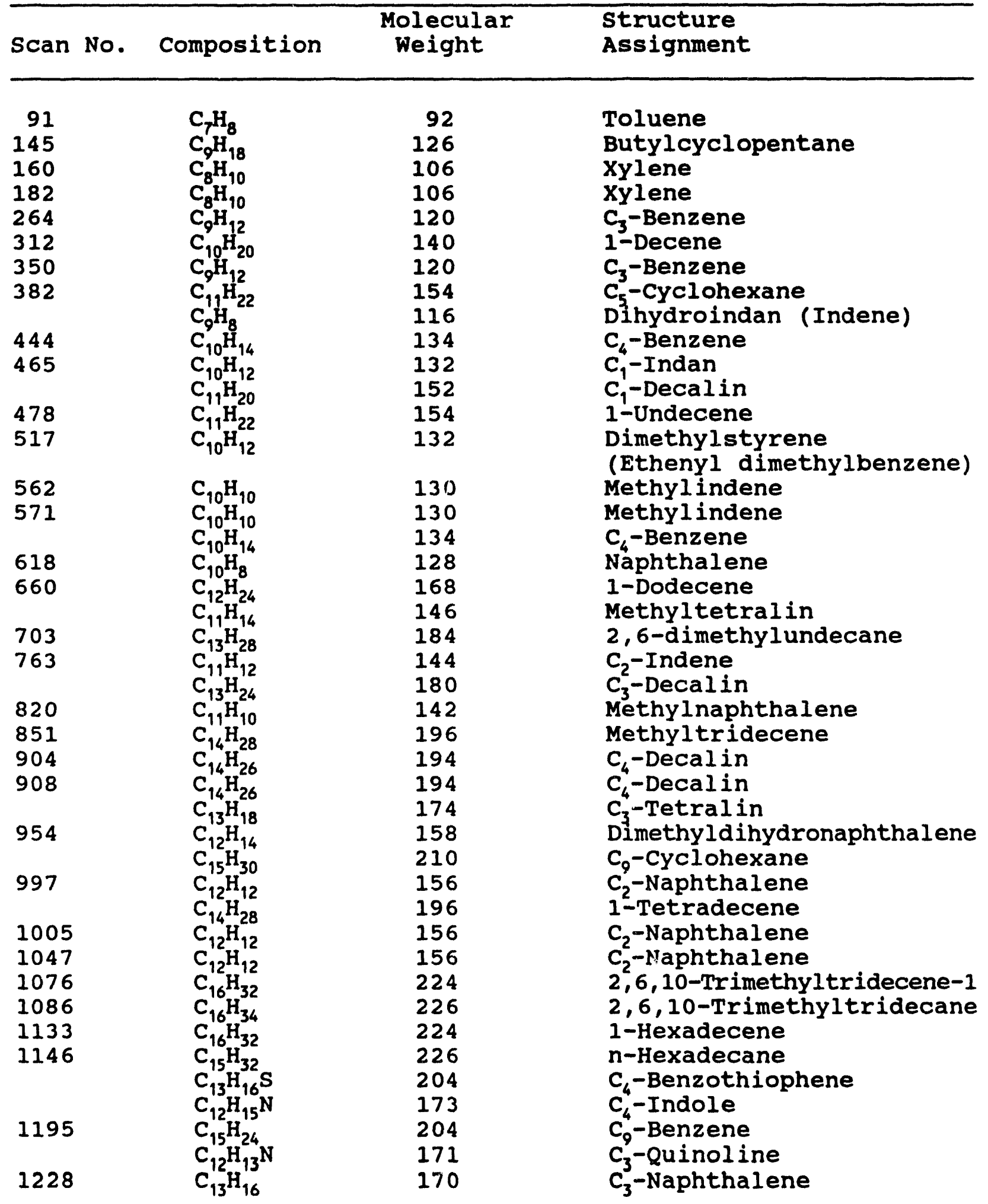




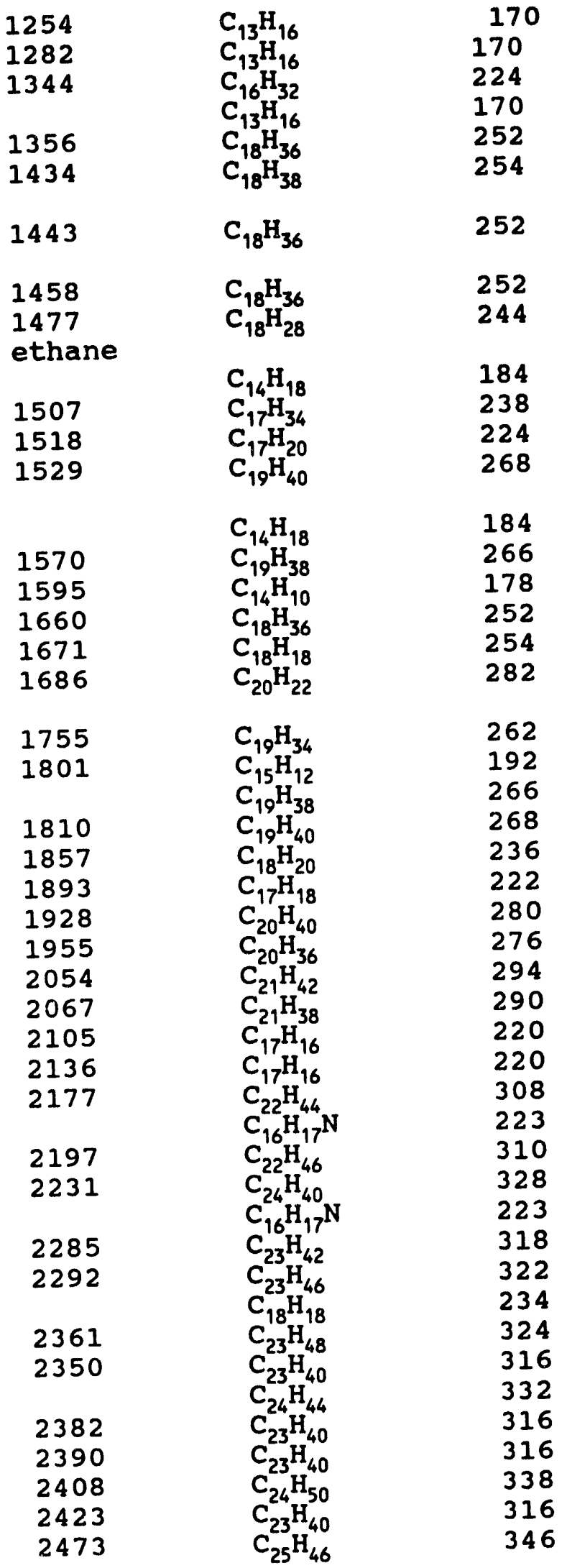

$\mathrm{C}_{3}$-Naphthalene

$C_{3}$-Naphthalene

$\mathrm{C}_{10}$-Cyclohexane

$C_{3}$-Naphthalene

$C_{18}$ Isoprenoid alkene

$2,6,10-$ Trimethylpentadecane (norpristane)

$C_{18}$ Isoprenoid alkene

(norpristene)

$C_{18}$ Isoprenoid alkene

$c_{3}$ Phenyl (cyclohexyl)

$\mathrm{C}_{4}$-Naphthalene

1-Heptadecene

$\mathrm{C}_{3}$-Tetrahydrophenanthrene

$2,6,10,14-$ Tetramethy 1 pentadecane

$C_{4}$-Naphthalene

Prist-1-ene

Phenanthrene

1-octadecene

n-octadecane

$2,6,10,14$-Tetramethylhexadecane (phytane)

$\mathrm{C}_{5}$-Perhydrophenanthrene

$C_{1}$-Phenanthrene

1-Nonadecene

1-Nonadecane

$c_{1}$-Indan (pheny 1 ) ethane

$C_{3}$-Dihydrophenanthrene

1-Eicosene

$C_{6}$-Perhydrophenanthrene

1-Unosene

$C_{7}$-Perhydrophenanthrene

$\mathrm{C}_{3}$-Phenanthrene

$\mathrm{C}_{3}$-Phenanthrene

1-Decosene

$\mathrm{C}_{4}$-Carbazole

n-Dococane

$C_{10}$-Phenyl (cyclohexyl) ethane

$\mathrm{C}_{4}$-Carbazole

$\mathrm{C}_{9}$-Perhydrophenanthrene

1-Tricosene

$\mathrm{C}_{4}$-Phenanthrene

n-Tricosane

$\mathrm{C}_{5}$-Perhydrochrysene

$\mathrm{C}_{10}$-Perhydrophanenthrene

$\mathrm{C}_{5}$-Perhydrochrysene

$\mathrm{C}_{23}$-sterane

n-Tetracosane

$\mathrm{C}_{5}$-Perhydrochrysene

$\mathrm{C}_{11}$-Perhydrophenanthrene 
2517

2539

2550

2570

2638

2730

2747

2866

2921

2972

2999

3056

3095

3128

3137

3169

3218

3228

3245

3291

3305

3368

3414

3494

3522

3543

3578

3588

3627

3658

3694

3797

3826
279

366

350

380

350

372

370

386

400

400

398

398

414

398

414

412

412

426

426

412

426

440

440

454

454

454

468

468

468

482

482

482

556

556

558
$\mathrm{C}_{4}$-Benzoquinoline

$\mathrm{C}_{5}$-Carbazole

n-Pentacosane

$C_{12}$-Phenyl (cyclohexyl) ethane

$\mathrm{C}_{6}$-Perhydrochrysene

(17,21-Secohopiane)

$\mathrm{C}_{8}$-Carbazole

n-Hexacosane

$\mathrm{C}_{12}$-Tetrahydrophananthrene n-Heptacosane

$C_{12}$-Tetrahydrophenanthrene

$\mathrm{C}_{27}$-sterane

Trisnorhopane

$\mathrm{C}_{28}$-sterane

$\mathrm{C}_{29}$-Sterane

$\mathrm{C}_{29}$-sterane

Norhpane

Norhpane

$\mathrm{C}_{30}$-sterane

Norhpane

$\mathrm{C}_{30}$-sterane

Hopane

Hopane

Homohopane

Homohopane

Gammacerane

Homohopane

Bishomohopane

Bishomohopane

Trishomohopane

Trishomohopane

Trishomohopane

Tetrakishomohopane

Tetrakishomohopane

Tetrakishomohopane

Pentakishomohopane

Pentakishomohopane

Pentakishomohopane

olefinic carotane

olefinic carotane

Perhydro- $\beta$-carotane 
Table 40 - Compounds Detected in the Hydrotreated Total Liquid (B-13)

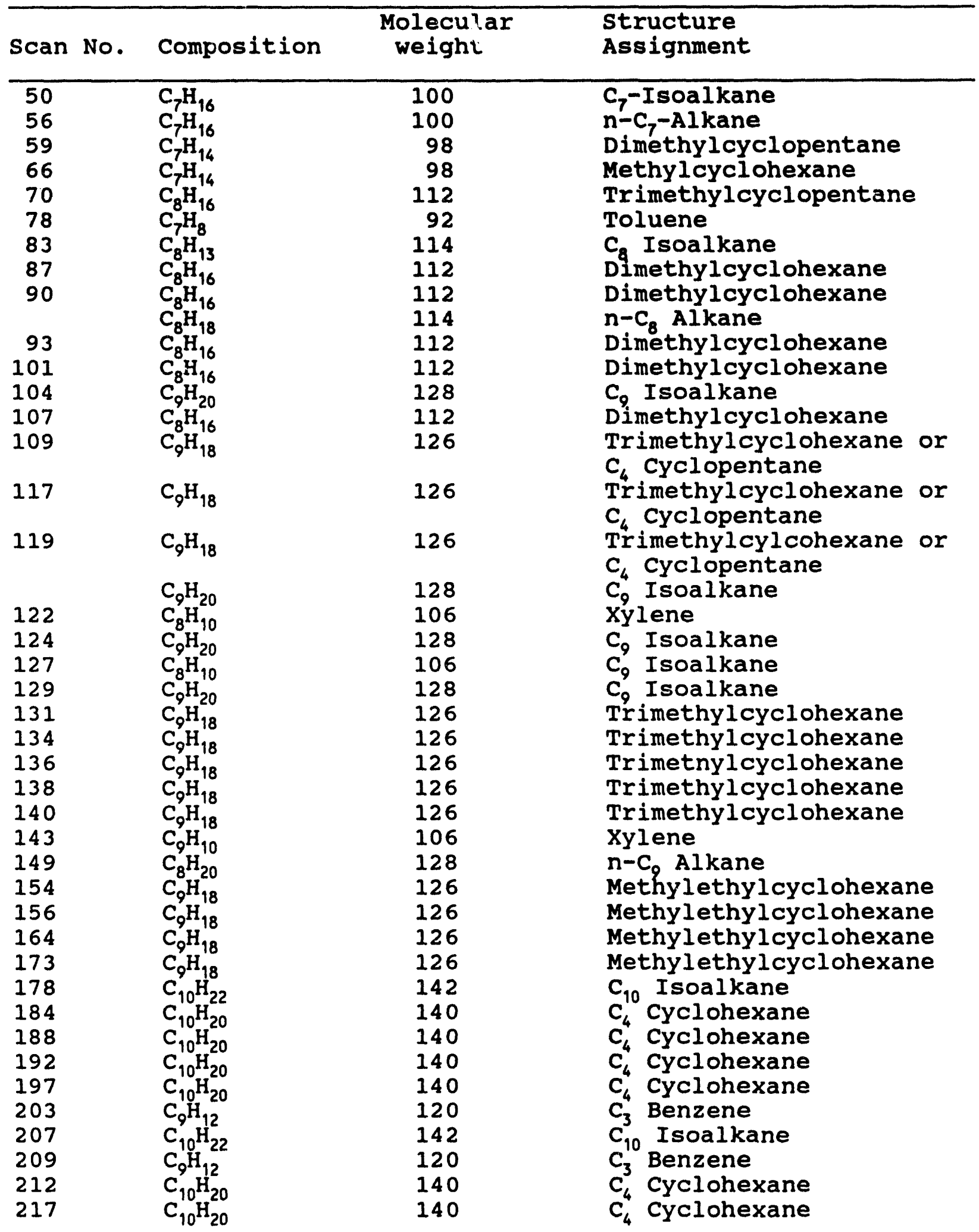




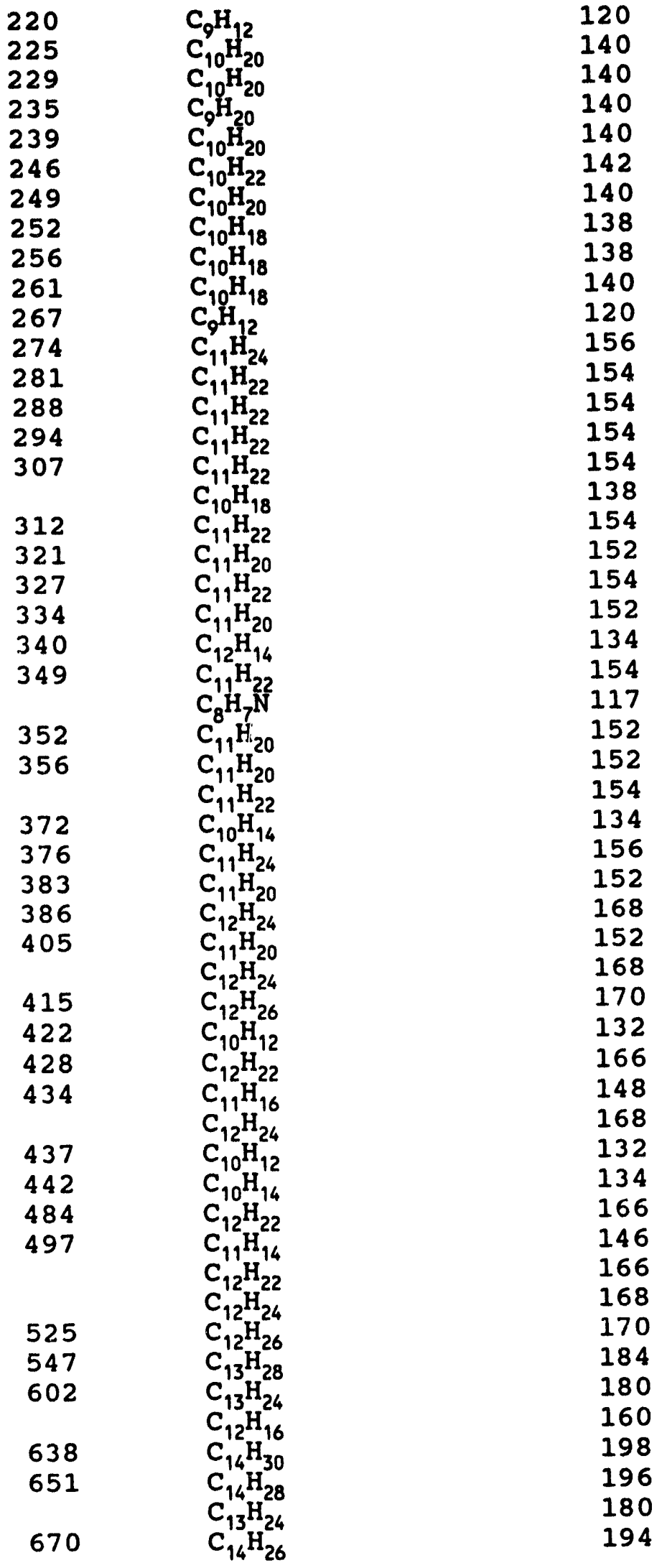

$\mathrm{C}_{3}$ Benzene

$C_{4}$ Cyclohexane

$c_{4}$ cyclohexane

$C_{4}$ cyclohexane

$c_{4}$ Cyclohexane

$n-C_{10}$ Alkane

$C_{4}$ Cyclohexane

Methylhexahydroindan

trans-Decal in

$C_{4}$ Cyclohexane

$C_{3}$ Benzene

$C_{11}$ Isoalkane

$C_{5}$ Cyclohexane

$C_{5}$ Cyclohexane

$C_{5}$ Cyclohexane

$C_{5}$ Cyclohexane

cis-Decalin

$C_{5}$ Cyclohexane

$c_{2}$ Hexahydroindan

$C_{5}$ Cyclohexane

$c_{2}$ Hexahydroindan

$\mathrm{C}_{4}$ Benzene

$C_{5}$ Cyclohexane

Indole

Methyldecalin

Methyldecalin

$C_{5}$ Cyclohexane

$\mathrm{C}_{4}$ Benzene

n-C 11 Alkane

Methyldecalin

$C_{6}$ Cyclohexane

Methyldecalin

$C_{6}$ Cyclohexane

$C_{12}$ Isoalkane

Methyl indan

Dimethyldecalin

$C_{5}$ Benzene

$C_{5}$ Cyclohexane

Tetralin

$C_{4}$ Benzene

Dimethyldecal in

Dimethylindan

Dimethyldecal in

$\mathrm{C}_{5}$ Cyclohexane

$n-C_{12}$ Alkane

$\mathrm{C}_{13}$ Isoalkane

Trimethyldecalin

Dimethyltetralin

$\mathrm{C}_{14}$ Isoalkane

$\mathrm{C}_{8}$ Cyclohexane

Trimethyldecal in

Tetramethyldecal in 
$\mathrm{C}_{14} \mathrm{H}_{28}$

$\mathrm{C}_{12} \mathrm{H}_{16}$

$\mathrm{C}_{14} \mathrm{H}_{30}$

$\mathrm{C}_{13} \mathrm{H}_{16}$

$\mathrm{C}_{14} \mathrm{H}_{26}$

$\mathrm{C}_{8} \mathrm{H}_{6} \mathrm{O}$

706

723

795

831

853

879

922

930

943

977

1001

1068

1117

1186

1206

1253

1264

1286

1363
212

212

194

174

174

226

224

208

188

240

208

188

240

216

188

208

200

222

240

202

200

226

200

254

252

236

234

214

240

250

234

214

268

266

250

214

228

268

264

228
$C_{8}$ Cyclohexane

Dimethyltetral in

n-C ${ }_{14}$ Isoalkane

Dimethyltetral in

Tetramethyldecal in

Benzofuran

$C_{15}$ Isoalkane

Dimethyldecal in

Tetramethyldecal in

$C_{15}$ Isoalkane

$c_{15}$ Isoalkane

Tetramethyldecal in

Trimethyltetral in

Trimethyltetral in

$\mathrm{C}_{16}$ Isoalkane

$C_{10}$ Cyclohexane

$C_{5}$ Decalin

$C_{4}$ Tetralin

$C_{17}$ Isoalkane

$C_{5}$ Decalin

$c_{1}$ Tetralin

$C_{17}$ Isoalkane

$c_{2}$ Phenyl (cyclohexyl)

$\mathrm{C}_{4}$ Tetralin

$C_{5}$ Decalin

c, Octahydrophenanthrene

$c_{6}$ Decalin

$C_{17}$ Isoalkane

$C_{5}$ Tetralin

$c_{1}$ octahydrophenanthrene $n-\mathrm{C}_{16}$ Alkane

$c_{1}$ octahydrophenanthrene

$C_{18}$ Isoalkane

$C_{12}$ Cyclohexane

C. Decalin

$C_{3}$ Perhydrophenanthrene

$\mathrm{C}_{2}$ octahydrophenanthrene $n-\mathrm{C}_{17}$ Alkane

$\mathrm{C}_{8}$ Decalin

$C_{3}$ Perhydrophenanthrene

$\mathrm{C}_{2}$ octahydrophenanthrene

$2,6,10,14$-Tetramethylpentadecane (pristane)

$C_{13}$ Cyclohexane

$\mathrm{C}_{8} \mathrm{H}_{8}$ Decal in

$\mathrm{C}_{2}$ octahydrophenanthrene

$\mathrm{C}_{3}$ octahydrophenanthrene

$C_{19}$ Isoalkane

c, Decalin

$C_{3}$ octahydrophenanthrene 


\begin{tabular}{|c|c|c|}
\hline 1394 & $\begin{array}{l}\mathrm{C}_{18} \mathrm{H}_{38} \\
\mathrm{C}_{19} \mathrm{H}_{36} \\
\mathrm{C}_{20} \mathrm{H}_{38} \\
\mathrm{C}_{17} \mathrm{H}_{24} \\
\mathrm{C}_{20} \mathrm{H}_{42}\end{array}$ & $\begin{array}{l}254 \\
264 \\
278 \\
228 \\
282\end{array}$ \\
\hline 1462 & $\begin{array}{l}\mathrm{C}_{20} \mathrm{H}_{38} \\
\mathrm{C}_{20} \mathrm{H}_{42} \\
\mathrm{C}_{17} \mathrm{H}_{24} \\
\mathrm{C}_{18} \mathrm{H}_{26} \\
\mathrm{C}_{18} \mathrm{H}_{28} \\
\mathrm{C}_{19} \mathrm{H}_{34} \\
\mathrm{C}_{20} \mathrm{H}_{38} \\
\mathrm{C}_{17} \mathrm{H}_{24} \\
\mathrm{C}_{18} \mathrm{H}_{26}\end{array}$ & $\begin{array}{l}278 \\
282 \\
228 \\
242 \\
244 \\
262 \\
278 \\
228 \\
242\end{array}$ \\
\hline 1496 & $\begin{array}{l}\mathrm{C}_{21} \mathrm{H}_{44} \\
\mathrm{C}_{19} \mathrm{H}_{34} \\
\mathrm{C}_{21} \mathrm{H}_{42} \\
\mathrm{C}_{18} \mathrm{H}_{26} \\
\mathrm{C}_{20} \mathrm{H}_{38}\end{array}$ & $\begin{array}{l}296 \\
262 \\
294 \\
242 \\
278\end{array}$ \\
\hline 1505 & & $\begin{array}{l}296 \\
292\end{array}$ \\
\hline 1536 & $\begin{array}{l}\mathrm{C}_{21} \mathrm{H}_{42} \\
\mathrm{C}_{20} \mathrm{H}_{38} \\
\mathrm{C}_{19} \mathrm{H}_{34} \\
\mathrm{C}_{18} \mathrm{H}_{26}\end{array}$ & $\begin{array}{l}294 \\
278 \\
262 \\
242\end{array}$ \\
\hline 1570 & $\begin{array}{l}\mathrm{C}_{20} \mathrm{H}_{38} \\
\mathrm{C}_{21} \mathrm{H}_{40} \\
\mathrm{C}_{18}^{2} \mathrm{H}_{26} \\
\mathrm{C}_{19} \mathrm{H}_{28}\end{array}$ & $\begin{array}{l}278 \\
292 \\
242 \\
256\end{array}$ \\
\hline 1622 & & $\begin{array}{l}310 \\
292 \\
276\end{array}$ \\
\hline 1633 & & $\begin{array}{l}276 \\
310\end{array}$ \\
\hline 1642 & & $\begin{array}{l}308 \\
276 \\
292 \\
286\end{array}$ \\
\hline 1683 & $\begin{array}{l}\mathrm{H}_{42} \\
\mathrm{H}_{34} \\
\mathrm{H}_{38}\end{array}$ & $\begin{array}{l}306 \\
284 \\
290\end{array}$ \\
\hline 1732 & $\begin{array}{l}\mathrm{C}_{23} \mathrm{H}_{48} \\
\mathrm{C}_{21} \mathrm{H}_{38}\end{array}$ & $\begin{array}{l}324 \\
290\end{array}$ \\
\hline 1779 & $\begin{array}{l}\mathrm{C}_{24} \mathrm{H}_{48} \\
\mathrm{C}_{23} \mathrm{H}_{44} \\
\mathrm{C}_{22} \mathrm{H}_{40} \\
\mathrm{C}_{21} \mathrm{H}_{34} \\
\mathrm{C}_{20} \mathrm{H}_{28}\end{array}$ & $\begin{array}{l}336 \\
320 \\
304 \\
284 \\
268\end{array}$ \\
\hline
\end{tabular}

n- $\mathrm{C}_{18}$ Alkane

C. Decalin

$C_{10}$ Decalin

$C_{3}^{10}$ Octahydrophenanthrene

$2,6,10,14$-Tetramethylhexadecane (phytane)

$c_{10}$ Decalin

$C_{20}$ Isoalkane

$\mathrm{C}_{3}$ Octahydrophenanthrene

$\mathrm{C}_{4}$ Octahydrophenanthrene

$C_{8}$ Decalin

$C_{5}$ Perhydrophenanthrene

$c_{10}$ Decalin

$\mathrm{C}_{3}$ Octahydrophenanthrene

$c_{4}$ octahydrophenanthrene

$\mathrm{C}_{21}$ Isoalkane

$C_{5}$ Perhydrophenanthrene

$c_{15}$ Cyclohexane

$\mathrm{C}_{4}$ octahydrophenanthrene

$C_{10}$ Decalin

$C_{21}$ Isoalkane

$C_{11}$ Decalin

$C_{15}$ Cyclohexane

$C_{10}$ Decalin

$\mathrm{C}_{5}$ Perhydrophenanthrene

$\mathrm{C}_{4}$ Octahydrophenanthrene

$C_{16}$ Decalin

$C_{11}$ Decalin

$c_{4}$ Octahydrophenanthrene

$C_{5}$ Octahydrophenanthrene

$C_{22}$ Isoalkane

$C_{11}^{22}$ Decal in

$C_{6}^{11}$ Perhydrophenanthrene

$c_{6}$ Perhydrophenanthrene

$n-\mathrm{C}_{22}$ Alkane

$\mathrm{C}_{16}$-Cyclohexane

$C_{5}$ Perhydrophenanthrene

$c_{11}$ Decalin

$C_{7}$-Phenyl (cyclohexyl) ethane

$\mathrm{C}_{12}$ Decalin

$\mathrm{C}_{4}$ Indan(cyclohexyl) ethane

$C_{7}$ Perhydrophenanthrene

$C_{23}$ Alkane

$\mathrm{C}_{7}^{23}$ Perhydrophenanthrene

$c_{18}$ Cyclohexane

$C_{13}$ Decalin

$C_{8}$ Perhydrophenanthrene

$C_{7}$ octahydrophenanthrene

Monoaromatic sterane 


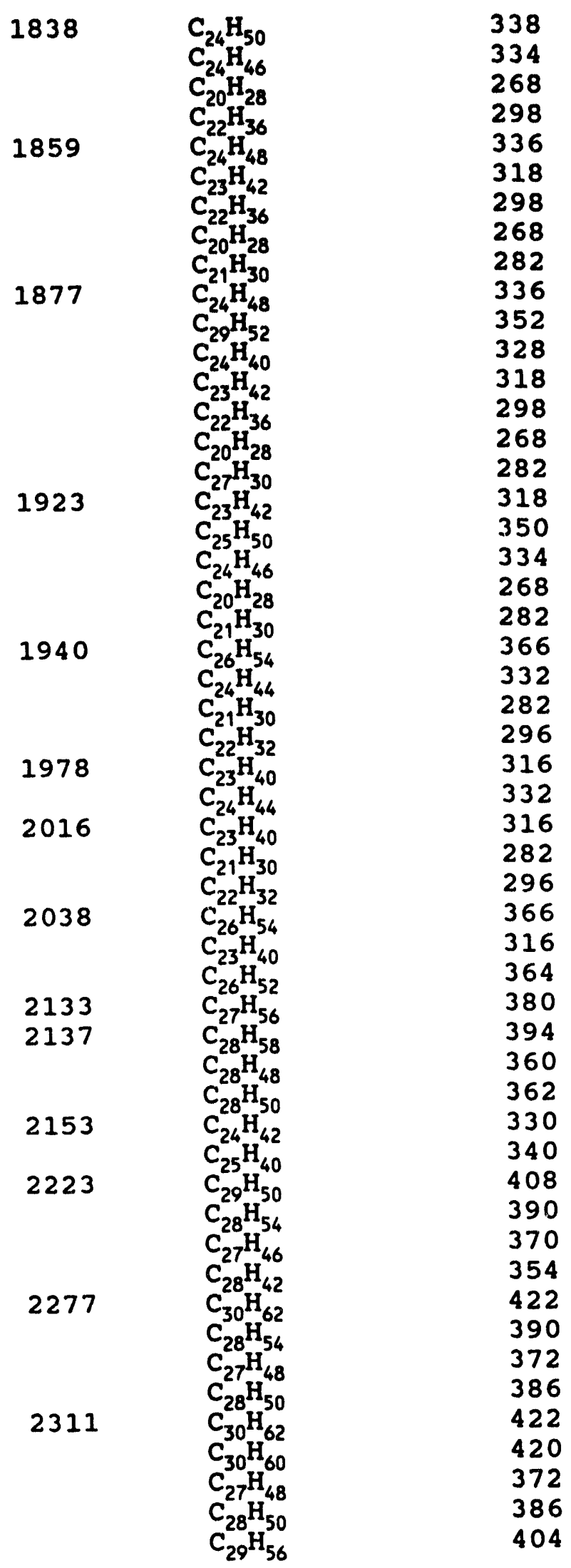

C Alkane

$\mathrm{C}_{14}$ Decalin

Monoaromatic sterane

$C_{8}$ Octahydrophenanthrene

$C_{18}$ Cyclohexane

$C_{9}$ Perhydrophenanthrene

$\mathrm{C}_{8}$ Octahydrophenanthrene

Monoaromatic sterane

Monoaromatic sterane

$C_{18}$ Cyclohexane

$C_{25}$ Alkane

$c_{14}$ Tetralin

$\mathrm{C}_{9}$ Perhydrophenanthrene

$\mathrm{C}_{8}$ Octahydrophenathrene

Monoaromatic sterane

Monoaromatic sterane

$C_{0}$ Perhydrophenanthrene

$C_{19}$ Cyclohexane

$C_{14}$ Decalin

Monoaromatic sterane

Monoaromatic sterane

$\mathrm{C}_{26}$ Isoalkane

$\mathrm{C}_{10}$ Perhydrophenanthrene

Monoaromatic sterane

Monoaromatic sterane

$C_{5}$ Perhydrochrysene

$C_{10}$ Perhydrophenanthrene

$c_{23}$ Sterane

Monoaromatic sterane

Monoaromatic sterane

$C_{26}$ Alkane

$\mathrm{C}_{23}$ Sterane

$C_{20}$ Cyclohexane

C. Alkane

$C_{28}$ Alkane

$C_{12}$ Perhydrophenanthrene

$c_{16}$ Decalin

17,21 secohopane

$C_{11}$ Octahydrophenanthrene

C. Alkane

$C_{18}^{29}$ Decalin

Trisnorhopane

$C_{12}$ Octahydrophenanthrene

$c_{30}$ Isoalkane

$C_{18}$ Decalin

$C_{27}$ Sterane

$\mathrm{C}_{28}$ sterane

$C_{30}^{26}$ Alkane

$c_{24}$ Cyclohexane

$c_{27}$ sterane

$C_{28}$ Sterane

$C_{19}$ Decalin 


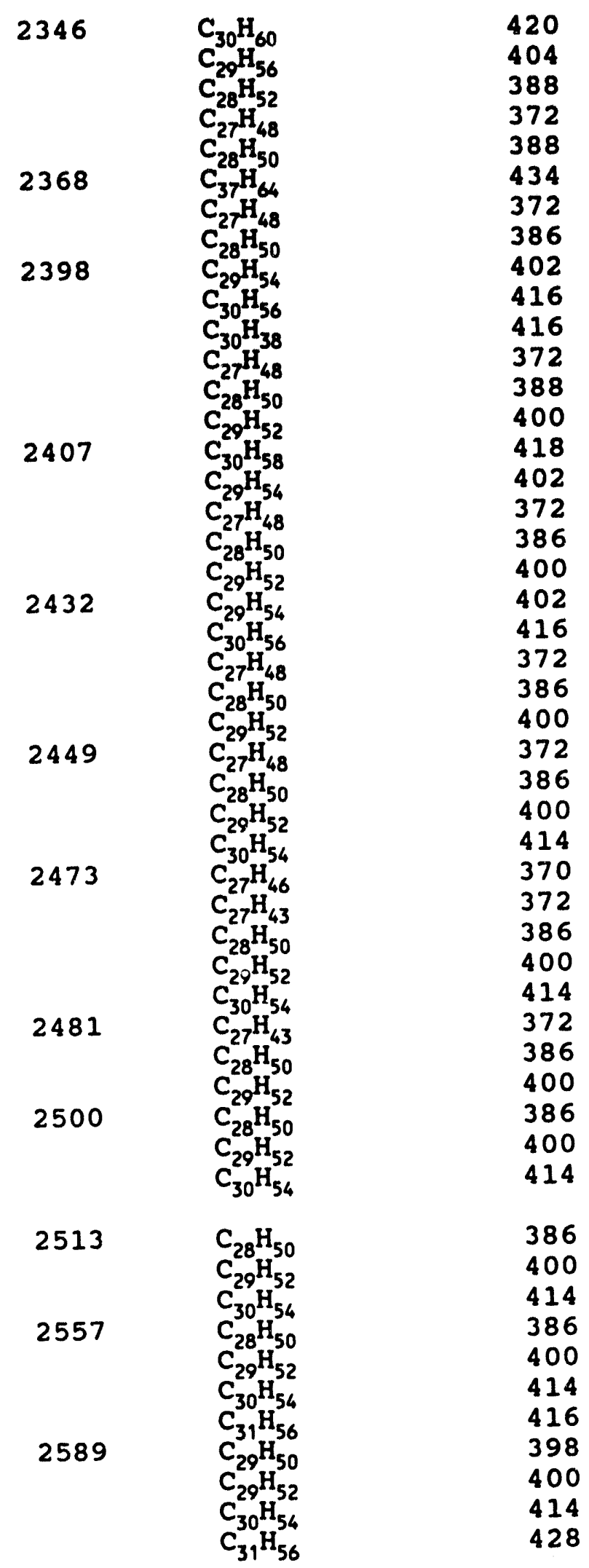

$c_{23}$ Cyclohexane

$C_{19}$ Decalin

$C_{14}$ Perhydrophenanthrene.

$C_{27}$ Sterane

$C_{28}$ sterane

$C_{31}$ Alkane

$C_{27}$ Sterane

$C_{28}^{27}$ sterane

$C_{15}$ Perhydrophenanthrene

$c_{16}$ Perhydrophenanthrene

$C_{27}$ Sterane

$c_{27}$ Sterane

$c_{28}$ sterane

$C_{29}$ sterane

$c_{20}$ Decalin

$C_{15}$ Perhydrophenanthrene

$C_{27}$ Sterane

$C_{28}$ sterane

$c_{29}$ sterane

$C_{15}$ Perhydrophenanthrene

$C_{16}$ Perhydrophenanthrene

$\mathrm{C}_{27}$ Sterane

$\mathrm{C}_{28}$ Sterane

$\mathrm{C}_{29}$ Sterane

$C_{27}$ Sterane

$C_{28}$ Sterane

$\mathrm{C}_{29}$ Sterane

$C_{12}$ Perhydrochrysene

Trisnorhopane

$\mathrm{C}_{27}$ Sterane

$\mathrm{C}_{28}$ Sterane

$C_{29}$ Sterane

$C_{12}$ Perhydrochrysene

$C_{27}$ Sterane

$C_{28}$ sterane

$C_{29}$ saterane

$\mathrm{C}_{29}$ Sterane

$C_{29}$ Sterane

$C_{12}^{29}$ Perhydrochrysene

$C_{28}$ sterane

$\mathrm{C}_{29}$ Sterane

$C_{12}$ perhydrochrysene

$C_{28}$ sterane

$C_{29}$ Sterane

$C_{12}$ Perhydrochrysene

$C_{16}$ Perhydrophenanthrene

Norhopane

$\mathrm{C}_{29}$ Sterane

$C_{12}$ Perhydrochrysene

$C_{13}$ Perhydrochrysene 


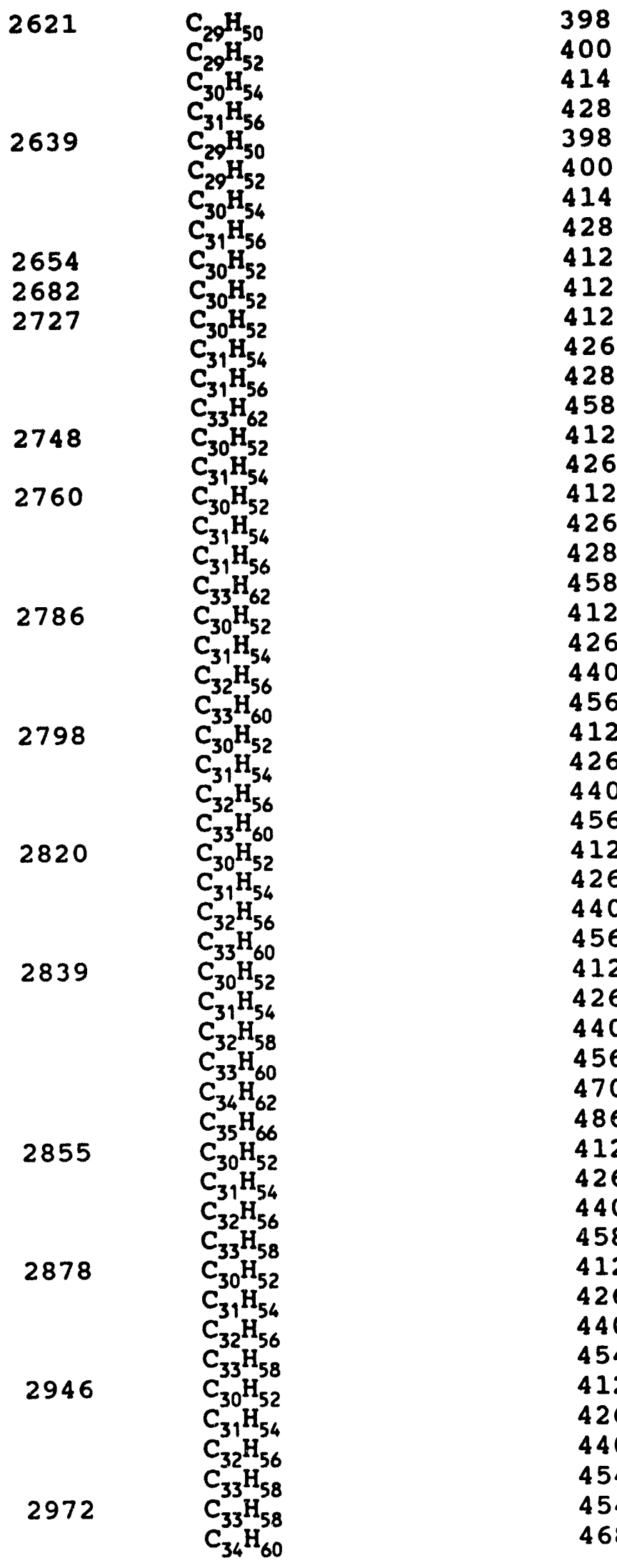

Norhopane

$\mathrm{C}_{29}$ sterane

$C_{12}$ Perhydrochrysene

$c_{13}$ Perhydrochrysene

Norhopane

$C_{29}$ sterane

$C_{12}^{29}$ Perhydrochrysene

$C_{13}$ Perhydrochrysene

Hopane

Hopane

Hopane

Homohopane

$C_{13}$ Perhydrochrysene

$C_{19}$ Perhydrochrysene

Hopane

Homohopane

Hopane

Homohopane

$C_{13}$ Perhydrochrysene

$C_{19}$ perhydrophenanthrene

Hopane

Homohopane

Bishomohopane

$C_{15}$ Perhydrochrysene

Hopane

Homohopane

Bishomohopane

$C_{15}$ Perhydrochrysene

Hopane

Homohopane

Bishomohopane

$C_{15}$ Perhydrochrysene

Hopane

Homohopane

Bishomohopane

$C_{16}$ Perhydrochrysene

$C_{16}$ Perhydrochrysene

$C_{21}$ Perhydrophenanthrene

Hopane

Homohopane

Bishomohopane

Trishomohopane

Hopane

Homohopane

Bishomohopane

Trishomohopane

Hopane

Homohopane

Bishomohopane

Trishomohopane

Trishomohopane

Tetrakishomohopane 


$$
\mathrm{C}_{35} \mathrm{H}_{64}
$$

3020

3104

3182
$\mathrm{C}_{33} \mathrm{H}_{58}$

$\mathrm{C}_{34} \mathrm{H}_{60}$

$\mathrm{C}_{35} \mathrm{H}_{62}$

$\mathrm{C}_{34} \mathrm{H}_{60}$

$\mathrm{C}_{35} \mathrm{H}_{62}$
484

454

468

468

482

468

482
$C_{17}$ Perhydrochrysene

Trishomohopane

Tetrakishomohopane

Tetrakishomohopane

Pentakishomohopane

Tetrakishomohopane

Pentakishomohopane

and heteroatomic species, the bitumen-derived liquid contained olefinic compounds, therefore, only the predominent species in a co-eluted peak is reported in Table 39.

\section{Alkanes and Alkenes}

High concentrations of alkanes were detected in the hydrotreated bitumen-derived liquid, in particular normal alkanes ranging from $c_{7}$ to $c_{32}$ were identified. Higher molecular weight alkanes (up to $\mathrm{C}_{40}$ ) were also present in low concentrations in the hydrotreated product produced under the most severe hydrotreating conditions $\left(T=680 \mathrm{~K}\right.$, wHSV $\left.=0.3 \mathrm{~h}^{-1}, P_{t}=13.5 \mathrm{MPa}\right)$. At milder hydrotreating conditions, the unconverted steranes and hopanes in the liquid product coeluted with the high molecular weight alkanes. Thus, they were difficult to detect due to the low molecular ion peaks for high molecular weight alkanes. Alkanes in the range of $C_{8}-C_{23}$ were the most abundant. The abundance of $c_{13}-C_{17}$ normal alkanes in the hydrotreated products produced from the bitumenderived liquid indicated a greater input of algal or bacterial materials.

Branched alkanes constitute about $40 \%$ of the total alkanes in the hydrotreated bitumen-derived liquid and comprise homologous 
series of 2- and 3-methyl-alkanes and isoprenoid alkanes. The isoprenoid alkanes were the most abundant compounds in the branched alkane fraction. The principal regular isoprenoid alkanes present in the hydrotreated products were 2,6,10-trimethyldodecane (farnesane), 2,6,10-trimethyltridecane, 2,6,10-trimethylpentadecane (nor pristane), 2,6,10,14-tetramethylpentadecane (pristane), and $2,6,10-14$-tetramethy 1hexadecane (phytane).

Some of the alkanes identified in the hydrotreated bitumenderived liquid were the hydrogenation products of the alkenes present in the bitumen-derived liquid. Terminal and internal olefins with structures similar to the normal and branched alkanes were observed in the bitumen-derived liquid feedstock. Additional evidence for the presence of $\alpha$-olefins in the bitumen-derived liquid was obtained by FTIR analyses. The absorbance bands at 988.4 and $908.8 \mathrm{~cm}^{-1}$, were attributed to the $\mathrm{CH}$ and $\mathrm{CH}_{2}$ out-of-plane deformation $\left(\mathrm{CRH}=\mathrm{CH}_{2}\right)$ and the band at $885.6 \mathrm{~cm}^{-1}$ was attributed to $\mathrm{CH}$ out-of-plane deformation in $\mathrm{CR}_{1} \mathrm{R}_{2}=\mathrm{CH}_{2}{ }^{3}$. Internal olefins were present in lower concentrations.

Alkanes and alkenes identified in the bitumen-derived liquid were presumed to have been derived from the cleavage of side chains on naphthenic, naphtheno-aromatic, and aromatic species present in the bitumen because only small concentrations of alkanes were detected in the whiterocks bitumen.

\section{Cycloalkanes}

Monocyclic Compounds. The single-ringed naphthenic compounds present in the volatile fraction of bitumen, the bitumen-derived 
liquid and the hydrotreated products were substituted cyclohexanes and cyctopentanes. $1,1,3$-trimethyl-2-alkylcyclohexanes $\left(c_{10}-c_{25}\right)$ were the predominant compounds in the cyclohexane homologous series in these samples which could have been formed from carotenoids. single-ring naphthenic compounds were also present in relatively lower concentrations. The hydrotreated total liquid product produced at severe conditions $\left(680 \mathrm{~K}, 13.5 \mathrm{MPa}\right.$, WHSV $=0.3 \mathrm{~h}^{\text {- }}$ ${ }^{1)}$, contained approximately 12.5 wto naphtha. Substituted cyclohexane and cyclopentane $\left(c_{7}-c_{10}\right)$ were the predominant compounds in this fraction. These compounds were probably derived from higher molecular weight naphthenes present in the bitumen and the bitumen-derived liquid.

Bicyclic compounds. The bicyclic alkanes identified in these samples were unsubstituted and substituted decalins and hexahydrocarbons $\left(c_{10}-c_{24}, c_{26}, c_{28}-c_{30}\right)$. Hexahydroindane homologs were present in relatively low concentrations. The bicyclic alkanes concetration increased significantly in the hydrotreated total liquid products. This suggested that these bicyclic alkanes were derived from tricyclic alkanes, steranes and hopanes via thermal and/or catalytic cracking. The base peaks for these bicyclic alkanes were 81,95 , and 123 whereas the alkyl substituted hexahydroindanes have base peaks at 110 and $124^{327}$. In addition, the fragmentation ion peaks of these bicyclic alkanes were similar to those of polymethylated decalins and drimanes 328,329. The concentration of decalin derivatives increased at higher reaction temperatures, and lower liquid hourly space velocityies, while the 
concentration of hexahydroindanes was practically unchanged. This suggested that most of these bicyclic alkanes are decalin derivatives. Therefore, the mechanisms proposed for the formation of hexahydroindanes 279,327 , the opening B-ring in steroids and C-ring in hopanoids, were not applicable to the thermal degradation in the pyrolysis reactor or to catalytic degradation in the hydrotreater. Tricyclic Compounds. Several alkyl substituted perhydrophenanthrenes $\left(c_{16}-c_{26}, c_{28}-c_{30}\right)$ were identified in these samples. Methyl side chains were the predominant alkyl group attached to rings. Higher homologs $\left(>C_{20}\right)$ have fragmentation ion patterns similar to those of tricyclic terpanes which were presumed to contain a regular isoprenoid side chain at c-14. The lower abundance of the $\mathrm{C}_{27}$ homolog in these samples was expected due to branching at $c-27$. The formation of the $C_{27}$ homolog was attributed to the cleavage of two carbon-carbon bonds and is, therefore, unfavored $284,288,307,309$. Although it has been suggested that these types of tricyclic terpanes were derived from biodegradation of hexaprenol or cheilanthatriol 284,288 the formation of tricyclic terpanes from steranes by opening the D-ring or from hopanes by opening the $D$ - and E-rings should not be ruled out. The $C_{27}-C_{30}$ homologs were identified in the hydrotreated total liquids which suggested that ring opening of steranes and hopanes before cleavage of the long alkyl side chains was a feasible reaction pathway for the degradation of steranes and hopanes in the presence of hydrotreating catalysts. 
Tetracyclic compounds. Tetracyclic terpanes, such as steranes $\left(c_{21}, c_{23}, c_{27}-c_{29}\right)$, the 4-methylsteranes $\left(c_{29}, c_{30}\right)$, 24-methyllanostane $\left(c_{31}\right)$, and 17,21 -secohopanes $\left(c_{23}, c_{24}, c_{27}, c_{30}-c_{35}\right.$, were identified in these samples. Steranes were the most abundant components of this type. The 4-methylsteranes and 24-methyllanostane were present in relatively low concentrations. Higher homologs of 17,21 -secohopanes $\left(C_{30}-c_{35}\right)$ were present only in the hydrotreated total liquid product. This suggested that these compounds are intermediates in the thermal and catalytic hydrocracking of hopanes via opening the E-ring steranes were present in significant amounts in the bitumen from the Whiterocks, Asphalt Ridge and sunnyside oil sand deposits 280-282 and in the bitumen from Green River oil shale 279 . The presence of 4methylsterane and the lack of steranes in the bitumen from the P.R. Spring deposit reported by Reed ${ }^{282}$ is puzzling. Analysis of the bitumens from the P.R. Spring and Hill creeks deposits (Uinta Basin, Utah) will be performed in the future in an attempt to confirm the observation of Reed ${ }^{282}$.

The fragmentation patterns of the steranes $\left(C_{27}-C_{29}\right)$ GC-MS spectra were in reasonable agreement with those reported by Anders and Robinson ${ }^{279}$. The ion peak 149 exhibited stronger intensity than the ion peak 151 in all of the steranes suggesting that $5 \alpha$-steranes were the predominant isomers.

Pentacyclic compounds and Tetraterpanes - The triterpenoid, alkanes, such as hopanes $\left(C_{27}-C_{35}\right)$, methylhopanes $\left(C_{30}, C_{31}\right)$, gammacerane, were identified in these samples. Gammacerane was 
detected in small quantity. Considerable amounts of extended hopanes $\left(c_{31}-c_{35}\right)$ were present in the whiterocks bitumen. The $c_{33}$ and $C_{34}$ homologs were the predominant species. Approximately 15 wt 8 steranes and hopanes were detected in the Whiterocks bitumen. Utah coal resins contained significant amounts of tetracyclic and pentacyclic terpenoids 333 . These resins have been proposed for use as specialty chemicals feedstocks. Thus rather than convert these steranes and hopanes to transportation fuels, perhaps it would be better to use them as feedstocks for the production of resins for printing inks and adhesives. Compared to steranes, hopanes are more easily converted to lighter compounds in thermal and catalytic processes. During pyrolysis most of the steranes were not converted and were present in the bitumen-derived liquid, whereas significant amounts of the hopanes were thermally cracked to lower molecular weight compounds. At severe hydroprocessing conditions $(T>673 \mathrm{~K})$, the concentrations of both steranes and hopanes were reduced significantly.

Carotenoid Alkanes. Several carotenoid-derived alkanes were identified in the volatile fraction of the bitumen and bitumenderived liquid. Their structures were presumed to be similar to $\beta-$ carotane.

Unsaturated compounds. The volatile fraction of the bitumen contained substituted benzenes, tetralins, indans, naphthalenes, phenyl (cyclohexyl) ethanes, octahydrophenanthrenes, tetrahydrophenanthrenes, indan (cyclohexyl) ethanes, phenanthrenes and diaromatic steranes. In addition to these aromatic compounds, 
the bitumen-derived liquid contained indene homologs, dimethylstyrene (ethanol dimethylbenzene), dihydrophenanthrene and a $C_{40}$ alkene with a structure similar to that of $\beta$-carotane except for a carbon-carbon double bond in one of the cyclohexyl rings. The concentration of substituted benzenes, unsubstituted and substituted naphthalenes and phenanthrenes in the bitumen-derived liquid was higher than in the volatile fraction of the bitumen. This suggested that dealkylation and saturated ring opening followed by dealkylation readily occurred in the pyrolysis reactor. on the other hand, partial hydrogenation was the major reaction in the hydrotreater, since monoaromatics were the predominant aromatic species in the hydrotreated liquid products.

Heteratom species. Several oxygen-, nitrogen- and sulfurcontaining species were identified in these samples. These species included benzofuran, indole, quinoline, carbazole and benzoquinoline homologs, and benzothiophene homologs.

\section{Pyrolysis-Hydrotreating Reaction Pathways}

Thermal cracking, dealkylation, dehydrogenation, polymerization and condensation, and decarboxylation occur readily at pyrolysis reactor conditions. 331,334 The hydrocarbon liquid obtained from oil sand pyrolysis was derived via the above reactions coupled with hydrogen transfer. It should be noted that the product distributions and compositions of the bitumen-derived liquids produced during oil sand pyrolysis were reported to be a function of operating conditions: reaction temperature and solids residence time 271 . At reaction temperatures above $823 \mathrm{~K}$ dehydrogenation, 
polymerization and condensation, and secondary cracking reactions play an important role as indicated by the increased yields of coke, light gas, naphtha and distillate fractions and aromatic species in the liquid product. Similar trends were reported for the pyrolysis reactor as the solids retention time increased ${ }^{271}$. It is interesting to note that when the bitumen pyrolysis temperature was near the operating temperature for delayed coking the coke yield from bitumen pyrolysis was similar to that obtained from a delayed coker using petroleum feedstocks.

Approximately 20 wt: of the bitumen-derived liquids were normal and branched (mostly isoprenoid) alkanes and $\alpha$-alkenes. The bitumen contained virtually no alkanes and/or alkenes. Therefore, it was presumed that these compounds produced during pyrolysis were present in the high boiling fraction of the bitumen as alkyl groups attached to aromatic rings and/or from alkyl bridges between two aromatic clusters, two naphthenic clusters, and/or one aromatic cluster and one naphthenic cluster. Carotane is a typical compound which has a long alkyl bridge. Under thermal treatment (773-813 K), 1,1,3-trimethyl-2-alkylcyclohexanes are formed via free radical reactions involving various tertiary $\mathrm{CH}$ and $\mathrm{CH}_{2}$ groups.<smiles>[R]C1C(C)CCCC1(C)C</smiles>

$$
\left(\mathrm{R}-\mathrm{C}_{n} \mathrm{H}_{2 n+1}, \mathrm{n}=1-22\right)
$$


The detalled structures of compounds which contain long alkyl chains have not been completely determined due to the limitation of spectroscopic and analytical techniques. Based on information in the literature $e^{335-338}$ and the data gathered in our studies ${ }^{331,334}$, there were indications that two types of compounds could be present in the bitumen: long alkyl chains attached to two to five ring terpenoids through $\mathrm{C}-\mathrm{C}$ bonds (alkyl groups linked to naphthenic, naptheno-aromatic and aromatic moieties); ester linkages which formed during reactions between steroid and hopanoid acids and alkanoid alcohols and/or between fatty acids and condensed alcohols and phenols.

The bitumen contained numerous biologically derived hopane and sterane classes of compounds. Fused naphthenic rings and short branched alkyl substituents were also identified. At pyrolysis conditions, free radical reactions involving the branched sidechains and the cyclopentane ring produced low molecular weight naphthenic compounds with cyclohexyl rings and alkanes and alkenes. The reaction schemes proposed in this work correspond to those sugested by other investigators ${ }^{327,338}$. The concentration of alkyl hexahydroindans which are presumed to be produced from steranes and hopanes by cleavage of cyclohexyl rings, the B-ring in steranes and the c-ring in hopanes, did not increase in the bitumen-derived liquid. This suggested that the proposed geochemical degradation mechanism, the rupture of $\mathrm{C}-\mathrm{C}$ bonds at the $\mathrm{B}-\mathrm{ring}$ of steranes and at the c-ring of hopanes, did not obtain during pyrolysis.

The presence of alkylindenes, dihydronaphthalenes, 
dihydrophenanthrenes, and the increase in alkyl napthalenes and phenanthrenes indicated that stepwise dehydrogenation of hydroromatics occured readily during pyrolysis.

Carbonaceous residues or chars are a primary product of thermal processes. The carbonaceous residue yield depended upon the reaction temperature and the solids residence time in oil sand pyrolysis ${ }^{271}$. At high temperatures and long residence times, high yields of coke were obtained. It is believed that polymerization and condensation reactions involving olefins and polynuclear aromatics are favorable at these conditions. In addition, the clays in the solid substrate may have been activated at pyrolysis conditions and may have catalyzed polymerization and condensation reactions and dehydrogenation of naphthenes and hydroaromatics during pyrolysis 339 .

Carbon dioxide and hydrogen were detected in the produced gases during pyrolysis of the Whiterocks oil sand. It was presumed the $\mathrm{CO}_{2}$ was produced by thermal decomposition of carboxylic acid functional groups present in the bitumen or of carbonate minerals present in the reservoir rock. The decarboxylation reaction was inferred by the absence of the $1700 \mathrm{~cm}^{-1}$ band in the bitumen-derived liquid and its presence in the bitumen. The decomposition of R$\mathrm{COOH}$ bonds readily occurs at $623 \mathrm{~K}^{339}$. The $\mathrm{CO}_{2}$ could have been produced from the decomposition of siderite and calcite, in temperatures above $723 \mathrm{~K}^{339}$. Furthermore, dolomite reacts to form periclase and $\mathrm{CO}_{2}$ in the temperature range $773-823 \mathrm{~K}^{340}$. The formation of hydrogen was believed to have been related to the 
production of naphthas and middle distillates from higher molecular weight fractions and to the formation of the carbonaceous residue on the sand grains 341 .

Hydrogenation of olefinic bonds was a major reaction in hydrotreating the bitumen-derived liquid as indicated by the absence of olefins in the hydrotreated products and the heat released in the inlet region of the catalyst bed where indenes and alkenes were converted to indans and alkanes (Tables 39 and 40 ).

The amount of hydroaromatic species; indans, tetralins, octahydrophenanthrenes and monoaromatic steranes, increased in the hydrotreated liquid product relative to the bitumen-derived liquid feedstock in all cases. These hydroaromatics result from partial hydrogenation of polynuclear aromatics.

The concentration of hopanes and steranes decreased at lower liquid hourly space velocities and higher reaction temperatures. The presence of bicyclic and tricyclic terpanes in the hydrotreated products was due to the cracking of steranes and hopanes under hydroprocessing conditions.

The high concentration of methane in the product gas from the hydrotreater is probably derived from the hydrodealkylation of terpanes present in in the feedstock.

The amounts of alkylbenzenes increased in the hydrotreated products. Some of these alkylbenzenes could have been produced by cracking of condensed aromatics in the bitumen-derived liquid.

Heteroatom conversion/removal occurred in the hydrotreater, however, the lack of reactivity of pyrole-type nitrogen was 
observed from GC-MS and FTIR analysis.

\section{SUMMARY AND CONCLUSIONS}

The volatile fraction $\left(<1000^{\circ} \mathrm{F}\right)$ of the Whiterocks bitumen; the bitumen-derived liquid produced from the pyrolysis of Whiterocks oil sand in a fluidized bed; and the total liquid products obtained from subsequent catalytic hydrotreating have been analyzed by high resolution gas chromatography-mass spectrometry. Major compound types found in the $1000^{\circ} \mathrm{F}$ minus fraction of the bitumen were substituted and unsubstituted cyclohexanes, benzenes, decalins, tetralins, naphthalenes, perhydrophenanthrene (tricyclic terpanes), octahydrophenanthrenes, tetrahydrophenanthrenes, phenanthrenes, phenyl(cyclohexyl) alkanes, indan (cyclohexyl) alkanes, perhydrochrysenes $\left(17,21\right.$-secohopanes), steranes $\left(C_{27}-C_{29}\right)$, hopanes $\left(C_{27}-C_{35}\right)$ and traces of paraffins. Several additional compound types were also identified in the bitumen-derived liquid: normal alkanes $\left(C_{7}-C_{30}\right)$ and $\alpha$-alkenes, branched alkanes $\left(C_{7}-C_{28}\right)$ and alkenes, cyclopentanes, styrenes, indenes, dihydronaphthalenes, dihydropenanthrenes, and the olefin related to perhydro- $\beta$-carotane. The hydrotreated bitumen-derived liquid consisted primarily of saturated compounds, such as alkanes (normal and branched) and cycloalkanes (1-5 rings). It also contained low concentrations of aromatic compounds which were predominantly monoaromatics. Several thermal reaction pathways have been proposed based on the structural analyses of these three samples. These reactions include cleavage of long side chains or bridges, dehydrogenation, polymerization and condensation, and decarboxylation. 
Hydrogenation, hydrogenolysis and heteroatom removal were the principal reactions which occurred in the hydrotreater.

This work demonstrates that most of compound types in the volatile fraction of the bitumen, bitumen-derived liquid and hydrotreated products of the bitumen-derived liquid can be determined by GC-MS analyses. Two types of compounds present in the nonvolatile fraction of the whiterocks bitumen have been proposed: long alkyl chain attached to two- to five-ring terpenoids through $\mathrm{C}-\mathrm{C}$ bonds (alkyl groups linked to naphthenic, naphtheno-aromatic and aromatic moieties) and ester linkages formed during reactions between steroid and hopanoid acids and alkanoid alcohols and/or between fatty acids and condensed alcohols and phenols.

Several reaction pathways in the bitumen pyrolysishydrotreating sequence can be rationalized through the structural identification of various samples. In the thermal process, these reactions include cleavage of long side chains (or bridges), dehydrogenation, cracking, polymerization and condensation and decarboxylation. On the other hand, hydrogenation, hydrogenolysis, hydrodealkylation and heteroatom removal were the principal reactions which occurred in the hydrotreater. The processing sequence oil sand pyrolysis-hydrotreating over an HDN catalystic appeared to be a technically reasonable concept for the upgrading of the bitumen from mined oil sands to a hydrogen refining feedstock. 


\section{FUTURE ACTIVITIES}

The processing sequence extraction-hydrotreating will be examined as an alternative to pyrolysis-hydrotreating. 
SUPERCRITICAL EXTRACTION OF WHITEROCKS BITUMEN

ASPHALTENE REJECTION

Principal Investigator

Co-Principal Investigator

Graduate Student
F.V. Hanson

M.D. Deo

M. Subramanian

\section{INTRODUCTION}

Asphaltenes are precipitates that separate from petroleum, petroleum residua or bituminous materials upon treatment with low-boiling hydrocarbon solvents ${ }^{342}$. The solvents for effecting this separation are $n$-pentane and $n$-heptane, although other light hydrocarbon solvents have also been used ${ }^{343}$. The amount and composition of asphaltene fractions are important from both production and processing considerations. In petroleum refining, asphaltene fractions can precipitate in heat exchangers and/or can deposit on catalysts causing excessive coke formation. A number of physical properties of the crude oils such as density and viscosity are also determined by the asphaltenes. In petroleum production operations, asphaltenes can precipitate and cause extensive formation damage. Asphaltene precipitation in oil reservoirs has proved to be a difficult problem to define and study 344,345 . In recent years, several papers on modeling the onset of asphaltene precipitation from reservoir fluids caused by temperature-pressure variations or by the introduction of dense gas solvents have been published 345,348 .

speight ${ }^{342}$ provided a detailed discussion on the influence of solvent type on asphaltene precipitation for a western canadian bitumen. Yields of precipitate using various solvents indicated that when the solvent carbon number increased, the yields (wt? 
bitumen) decreased. This was particularly true for the n-alkane homologous series and was also applicable to a lesser degree for naphthenic and aromatic compounds.

Yields of asphaltenes using solvent mixtures also varied depending on the ratio of the solvents used ${ }^{343}$. These data suggest that the amount of asphaltene precipitate will be influenced by the lighter cosolubilizing components in the petroleum or bitumen. The work reported in this paper on continuous supercritical fluid extraction (SFE) of an oil sands bitumen with propane provides direct evidence of the influence the lighter components exert on asphaltene precipitation.

Kawanaka et al..$^{349}$ hypothesize that essentially two factors are responsible for maintaining the mutual solubility of compounds in petroleum crudes. (1) Ratio of polar to nonpolar molecules. (2) Ratio of high to low molecular weight molecules.

The SFE alters both the ratios in the extracted oils and the residual fractions relative to the original mixture. The effect of this alteration on the asphaltene content of the residual fractions is presented in this paper.

\section{EXPERIMENTAL}

The SFE system was custom-built for the University of Utah by Autoclave Engineers, Inc. A schematic of the apparatus is presented in Figure 105. Central to the system was a temperature controlled extractor with a capacity of $300 \mathrm{~cm} \$ \wedge 3 \$$ and rated to a pressure of $37 \mathrm{MPa}$ at $615 \mathrm{~K}$. The extractor was equipped with a magnetic-drive packer-less stirring device. Propane was charged into the extractor 


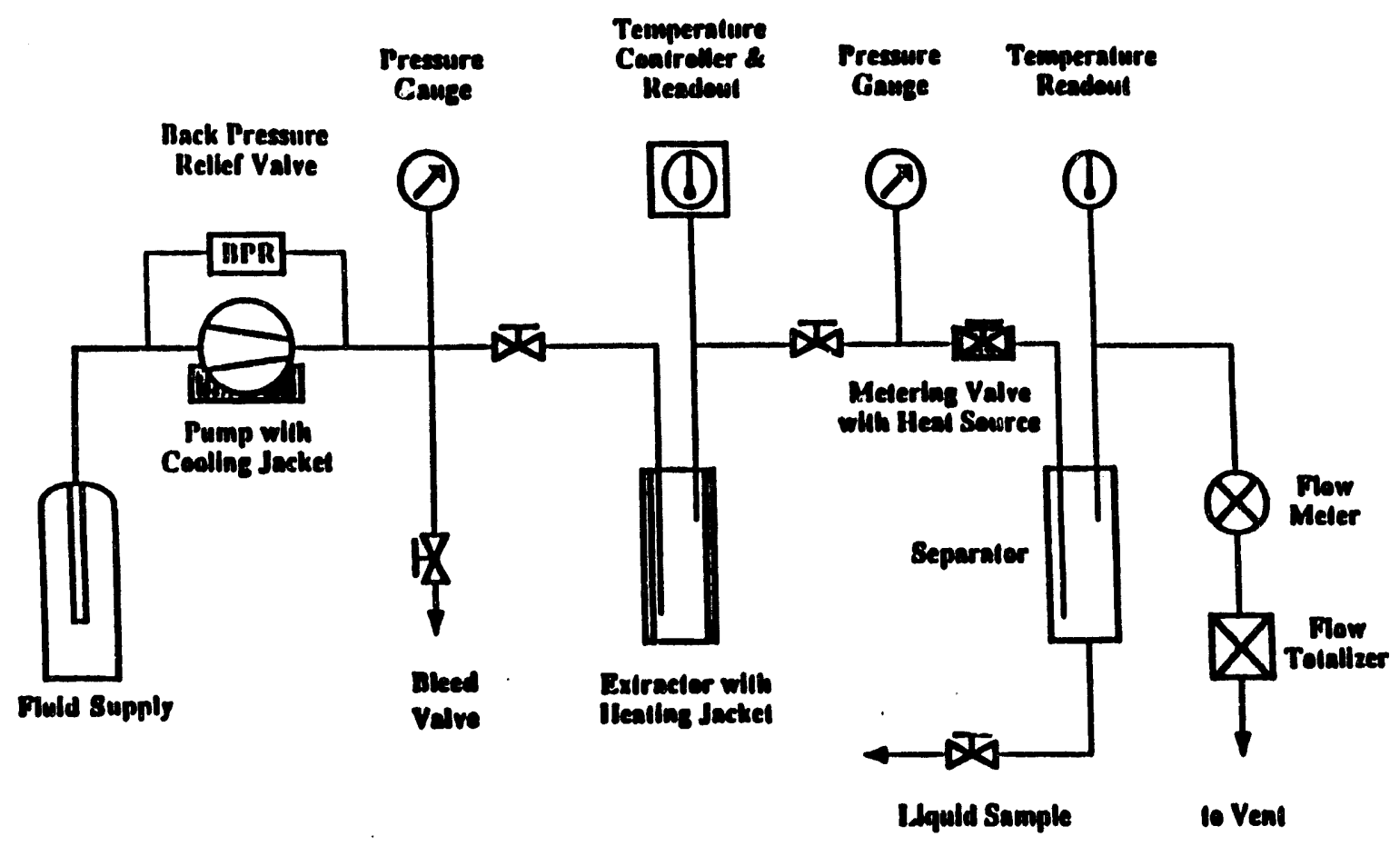

Figure 105. $\begin{aligned} & \text { Schematic of the supercritical fluid extraction } \\ & \text { system }\end{aligned}$ 
and the system was brought to the desired pressure using a high-pressure liquid pump. Pressure control was achieved by incorporating a back pressure regulator in parallel with the pump. The pump-head was cooled by a circulating cooling bath to ensure that the propane was maintained in a liquid state at the pump-head. In all the experiments, a known amount of bitumen, $50 \mathrm{~g}$, was charged into the extractor and the continuous extraction process was started. Selected properties of the bitumen are presented in Table 41. This bitumen is an ultra heavy naphthenic crude oil and the terms bitumen and oil have been used interchangeably in this paper for the original material. Asphaltene content of this feed material as determined by the pentane-insolubles test was 5.9 wt . once the initial equilibrium state was attained, propane was continuously pumped into the extractor. Commercial grade propane containing about $96 \%$ propane and $4 \%$ of other C1 - C4 hydrocarbon gases was used in this work. A heated metering valve was used to transfer the extracted phase from the extractor to the separator. The separator was held at ambient pressure. The solvent separated from the extract phase in the separator was vented through a flow totalizer which measured the cumulative volume of solvent withdrawn from the separator. The oil in the separator was collected and weighed. After about 25 liters of solvent (at room temperature) had passed through the totalizer, the amount of oil accumulated was collected and weighed. When the amounts of oil extracted became small relative to the amount extracted in the first 25 liters $1<5 \%$ of the amount extracted in the first extraction window), the 
Table 41

Selected Properties of the Whiterocks Bitumen

$\begin{array}{lc}\text { Specific Gravity (288 K) } & 0.98 \\ \text { Conradson Carbon Residue } & \text { (Wt }) 9.5 \\ \text { Four Point, K } & 327 \\ \text { Viscosity (323 K), Pa-s } & 27 \\ \text { Asphaltenes, Wt\% } & 5.9 \\ \text { (Pentane Insolubles) } & \\ \text { simulated Distillation } & \\ \text { Volatility, Wt\% } & 32.5 \\ \text { IBP, K' } & 520 \\ \text { IBP-477 K, Wt\% } & 0.0 \\ 478-616 \mathrm{~K}, \text { Wt\% } & 5.6 \\ \text { 617-811 K, Wt\% } & 26.9 \\ \text { >811 K, Wt\% } & 67.5\end{array}$


extraction was stopped. The extractor was depressurized and the residue was weighed and analyzed for maltenes and asphaltenes. In each extraction sequence, seven to eight extract samples were collected. Each sample corresponded to an extraction window of 25 liters of propane vented through the totalizer or about 20 minutes of extraction time.

Asphaltene contents of the residual fractions produced during the propane extraction of the native bitumen were measured by the analytical method developed by AOSTRA ${ }^{350}$. Two grams of the residual fraction were dissolved in an equal volume of toluene. Forty volumes of $n$-pentane were added for each volume of toluene. The AOSTRA method recommends benzene as the diluent; however, toluene was used in place of benzene for safety reasons. The precipitate was filtered from the solution, dried and weighed.

\section{RESULTS AND DISCUSSION}

Experiments were performed at three different pressures $(5.5$ $\mathrm{MPa}, 10.3 \mathrm{MPa}$ and $17.2 \mathrm{MPa}$ ) at a constant temperature of $380 \mathrm{~K}$ and at three different temperatures $(339 \mathrm{~K}, 380 \mathrm{~K}$ and $422 \mathrm{~K})$ at a constant pressure of $10.3 \mathrm{MPa}$. The critical temperature of propane is $369.8 \mathrm{~K}$ and its critical pressure is $4.25 \mathrm{MPa}$. The effect of pressure on the extraction yields at $380 \mathrm{~K}$ is presented in Figure 106 and the effect of temperature on the extraction yields at 10.3 MPa is presented in Figure 107. Attempts have been made to link the extraction performance of dense gases to density 351,352 . The reduced densities of pure propane at the experimental conditions, as calculated by the Peng-Robinson equation of state ${ }^{353}$, are presented 


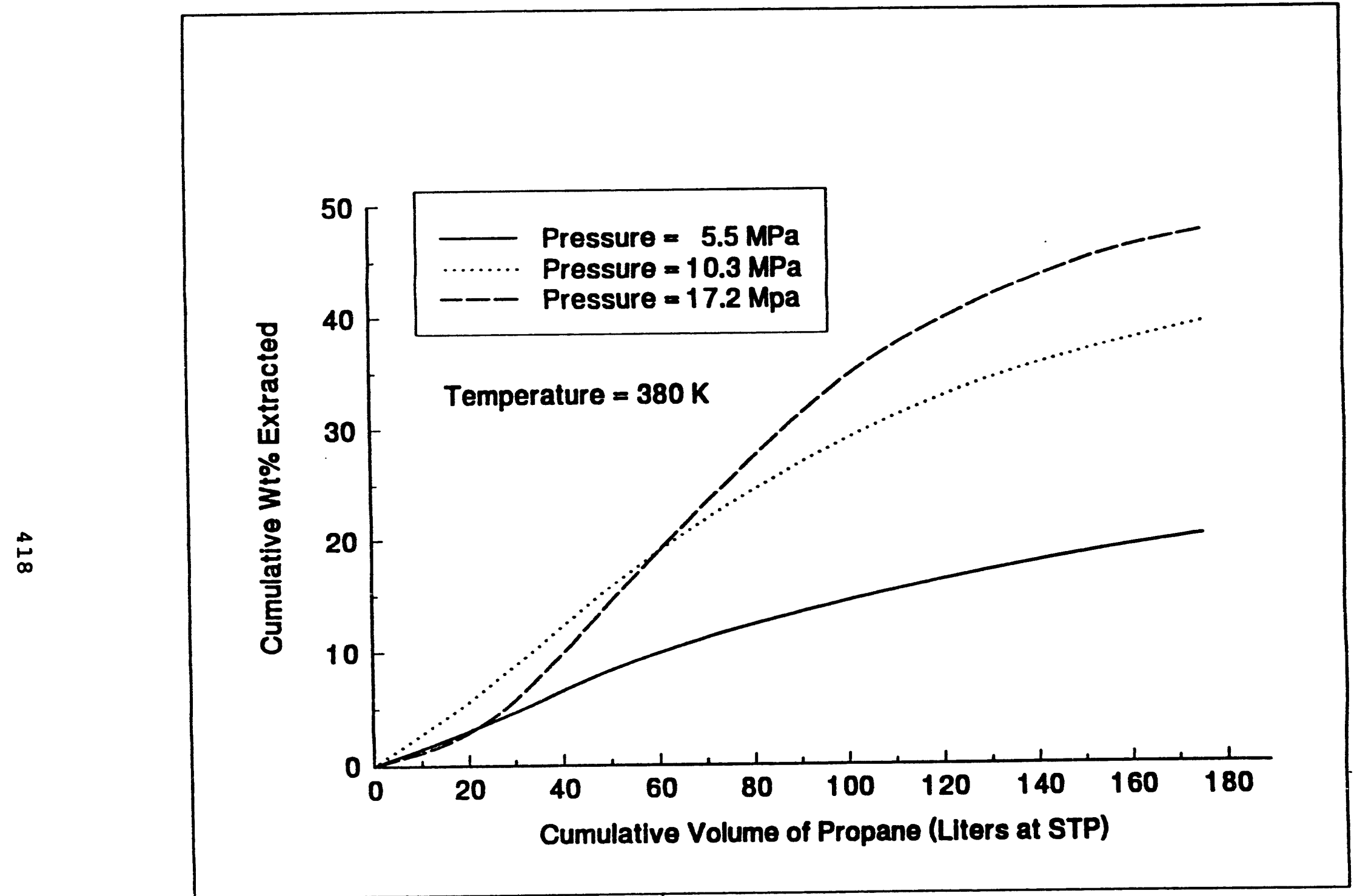

Figure 106. Extraction yields for the bitumen with propane at different pressures and a constant temperature of $380 \mathrm{~K}$. 


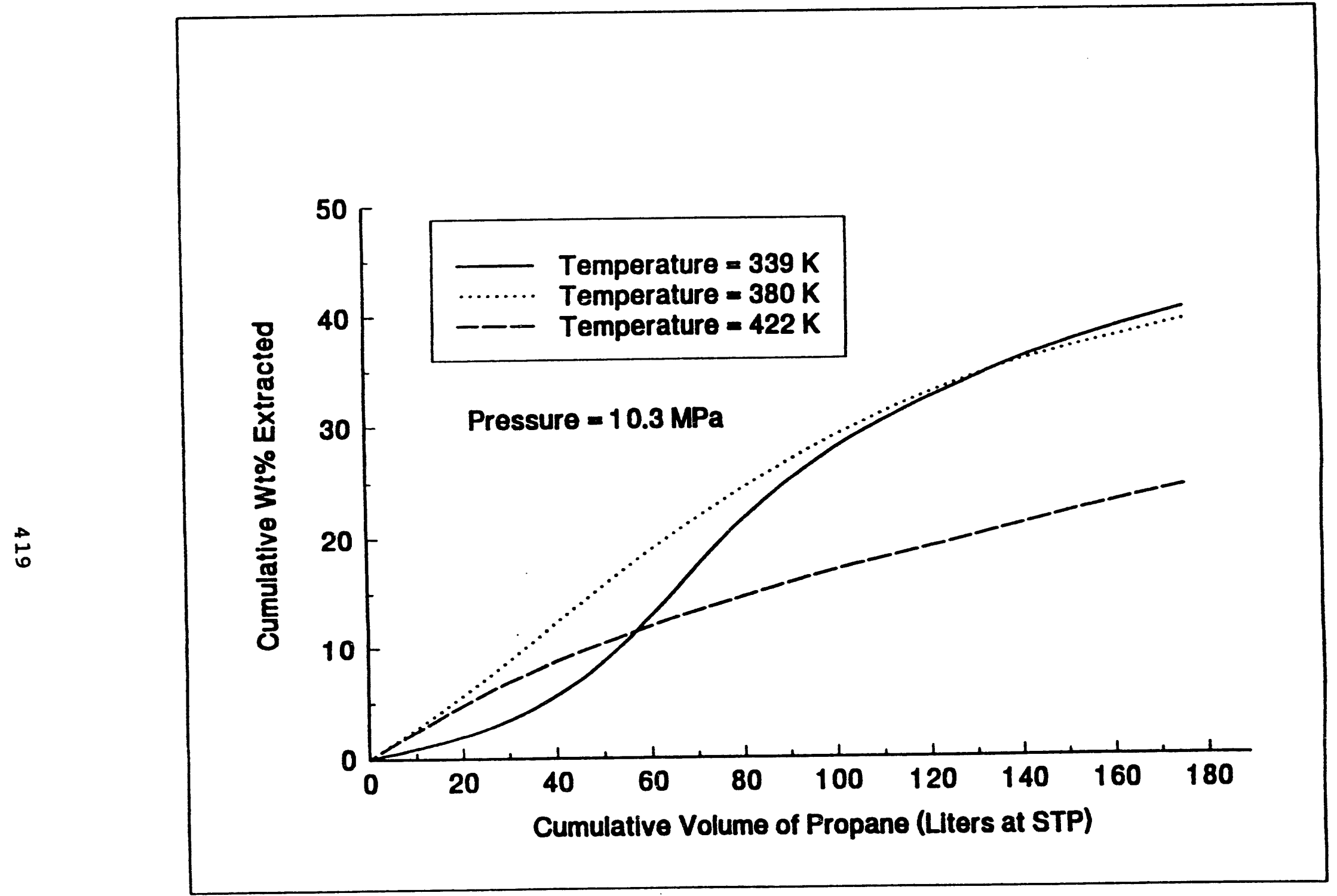

Figure 107. Extraction yields for the bitumen with propane at different temperatures and a constant pressure of $10.3 \mathrm{MPa}$. 
in Table 42. It is recognized that pure solvent density in the Table 42

Reduced Density of Propane at Experimental Conditions

\begin{tabular}{lccccc}
$\begin{array}{l}\text { Temperature } \\
T_{R}\end{array}$ & $\begin{array}{l}311 \mathrm{~K} \\
0.84\end{array}$ & $\begin{array}{c}339 \mathrm{~K} \\
0.92\end{array}$ & $\begin{array}{c}380 \mathrm{~K} \\
1.03\end{array}$ & $\begin{array}{c}408 \mathrm{~K} \\
1.10\end{array}$ & $\begin{array}{r}422 \mathrm{~K} \\
1.14\end{array}$ \\
\hline $\begin{array}{l}\text { Pressure } \\
5.5 \mathrm{MPa}\end{array}$ & 2.81 & & & & - \\
$10.3 \mathrm{MPa}$ & 2.92 & 2.64 & 2.11 & 1.69 & 1.48 \\
$17.2 \mathrm{MPa}$ & 3.04 & - & 2.44 & - & - \\
\hline
\end{tabular}

Notes :

Reduced density was calculated based on a density of $0.18 \mathrm{~g} / \mathrm{cm}^{3}$ at the critical point of propane $\left(P_{c}=4.25 \mathrm{MPa} ; \mathrm{T}_{c}=370 \mathrm{~K}\right)$.

All the densities were calculated using the Peng-Robinson equation of state.

vicinity of its critical temperature strongly affects extraction ${ }^{354}$. This is evidenced in Figure 106 where the extraction yields increased with increased pressure (increased pure solvent density) at constant temperature. However, the data presented in Figure 107 demonstrates that pure solvent density is not the only governing parameter. Direct evidence for this observation is presented in Figure 108, where the extractions at two different pure solvent reduced densities are compared. Enhanced extraction behavior is observed at a lower solvent reduced density. This behavior is possibly related to the phase behavior of the propane-bitumen system just above the critical temperature of propane. It should 


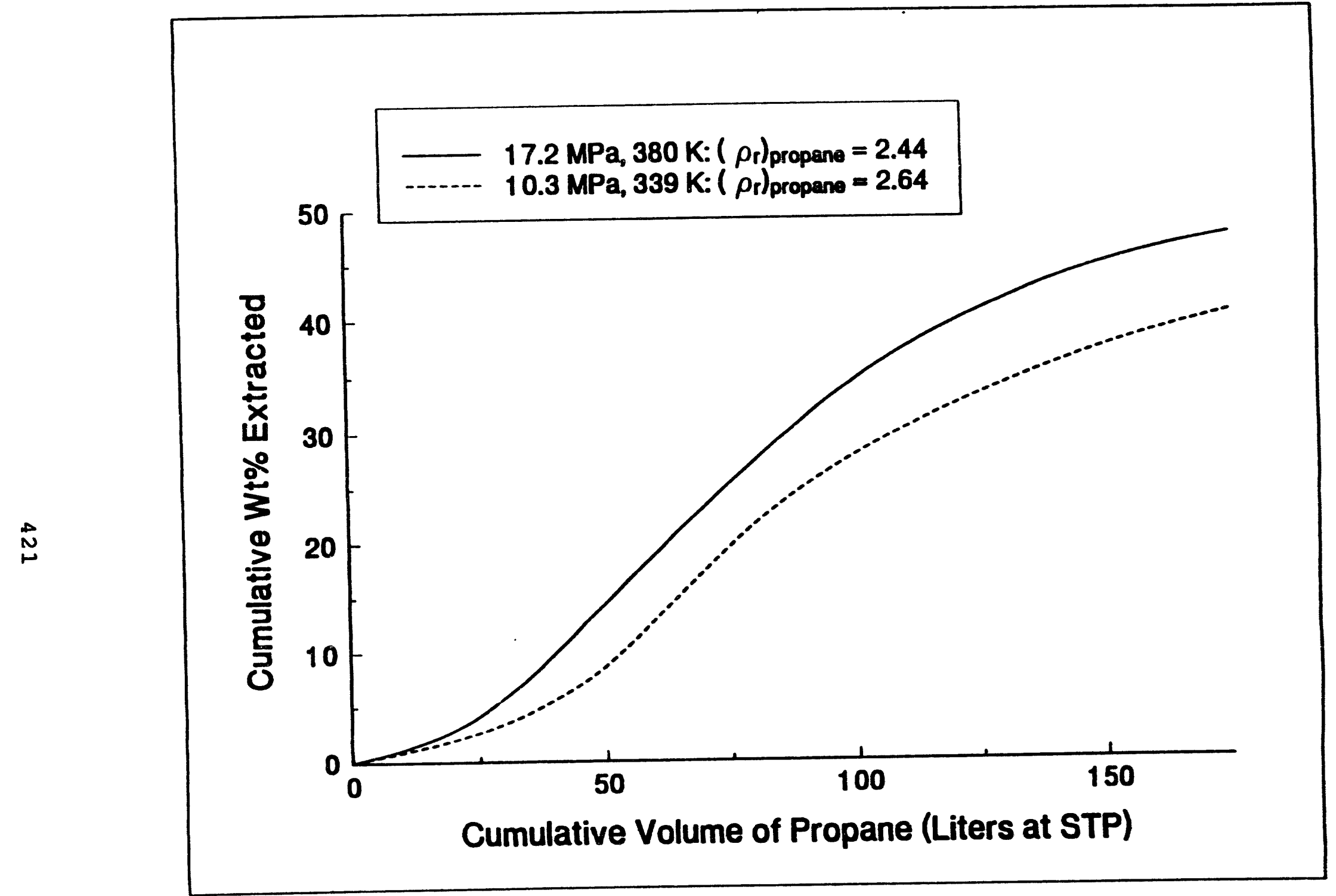

Figure 108. Comparison of the bitumen-propane extraction yields at two different pure propane reduced densities. 
also be observed that the highest extraction yield was obtained at $380 \mathrm{~K}$ and $17.2 \mathrm{MPa}$.

Compositional variation in the extracted material as a function of time can be determined by examining the carbon number distributions of the first, middle and the last extracts for the experiments at $10.3 \mathrm{MPa}$ and $380 \mathrm{~K}$ (Figure 109). The middle and the last extracts contained compounds heavier than the first fraction. Compositional variation in the extract phases as a function of pressure can be ascertained by examining the middle extracts at $5.5,10.3$ and $17.2 \mathrm{MPa}$. The carbon number distributions (Figure 110) indicated that heavier compounds are extracted at higher pressure. Thus, as the extraction efficiency increased (at higher pressures and thus higher reduced densities), heavier compounds were found in the extracts. Compositional changes in the middle extracts as a function of temperature are presented in Figure 111. It is is seen that the heaviest compounds were extracted at $380 \mathrm{~K}$, where the extraction efficiency was also the highest. Thus the composition information on the extracted fractions was consistent with the extraction yield data.

Residual fractions from all the extraction experiments were dark black solids. The asphaltene contents of the residual fractions are listed in Tables 43 and 44 along with the elemental analyses of the residual fractions. It should be noted that the asphaltene content of the feed material was 5.9\%. The asphaltene contents of all the residual fractions were significantly higher than the original heavy oil. The asphaltene content of the residual 


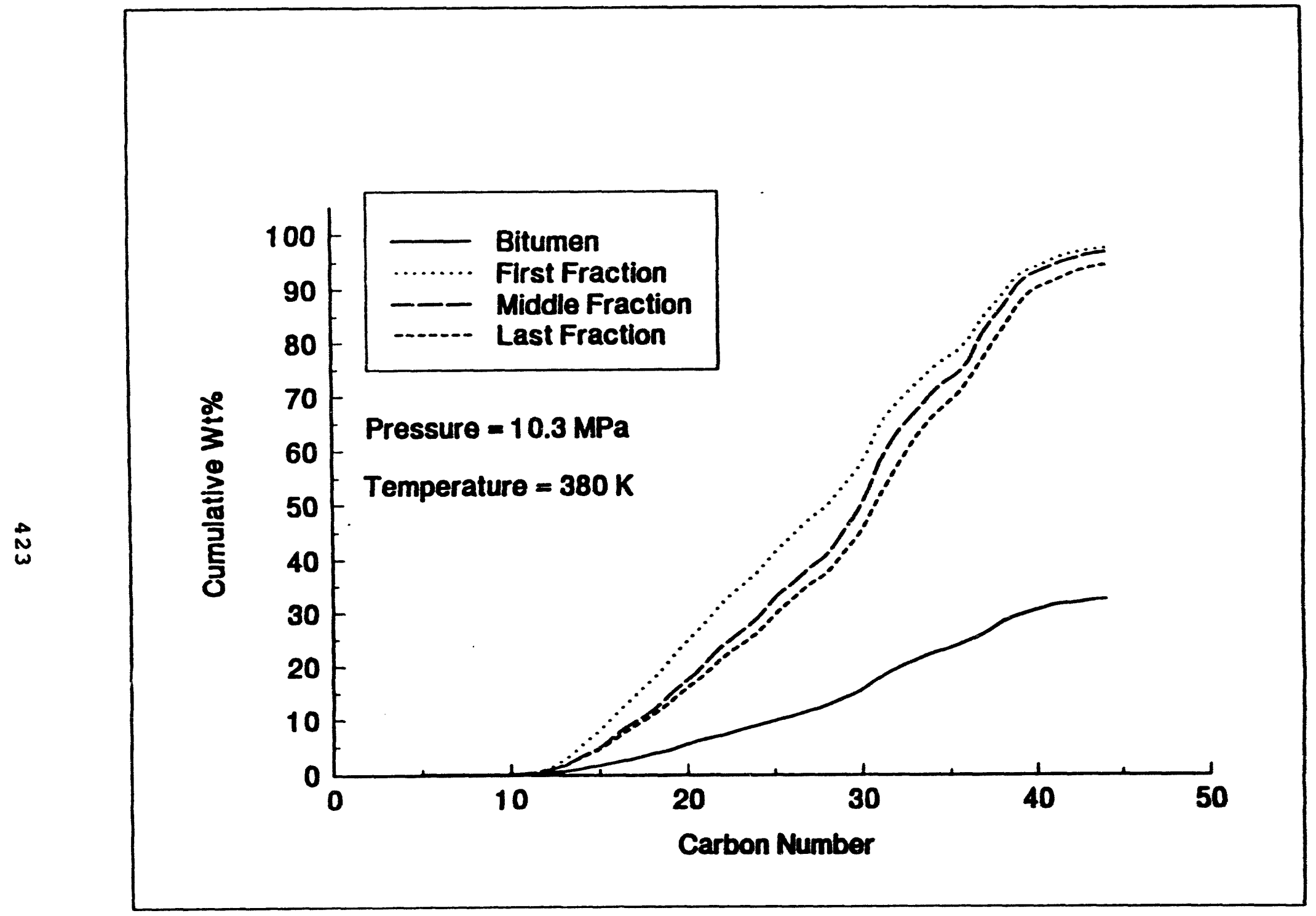

Figure 109. Changing compositions as a function of time for bitumen-propane extracts at $380 \mathrm{~K}$ and $10.3 \mathrm{MPa}$. 


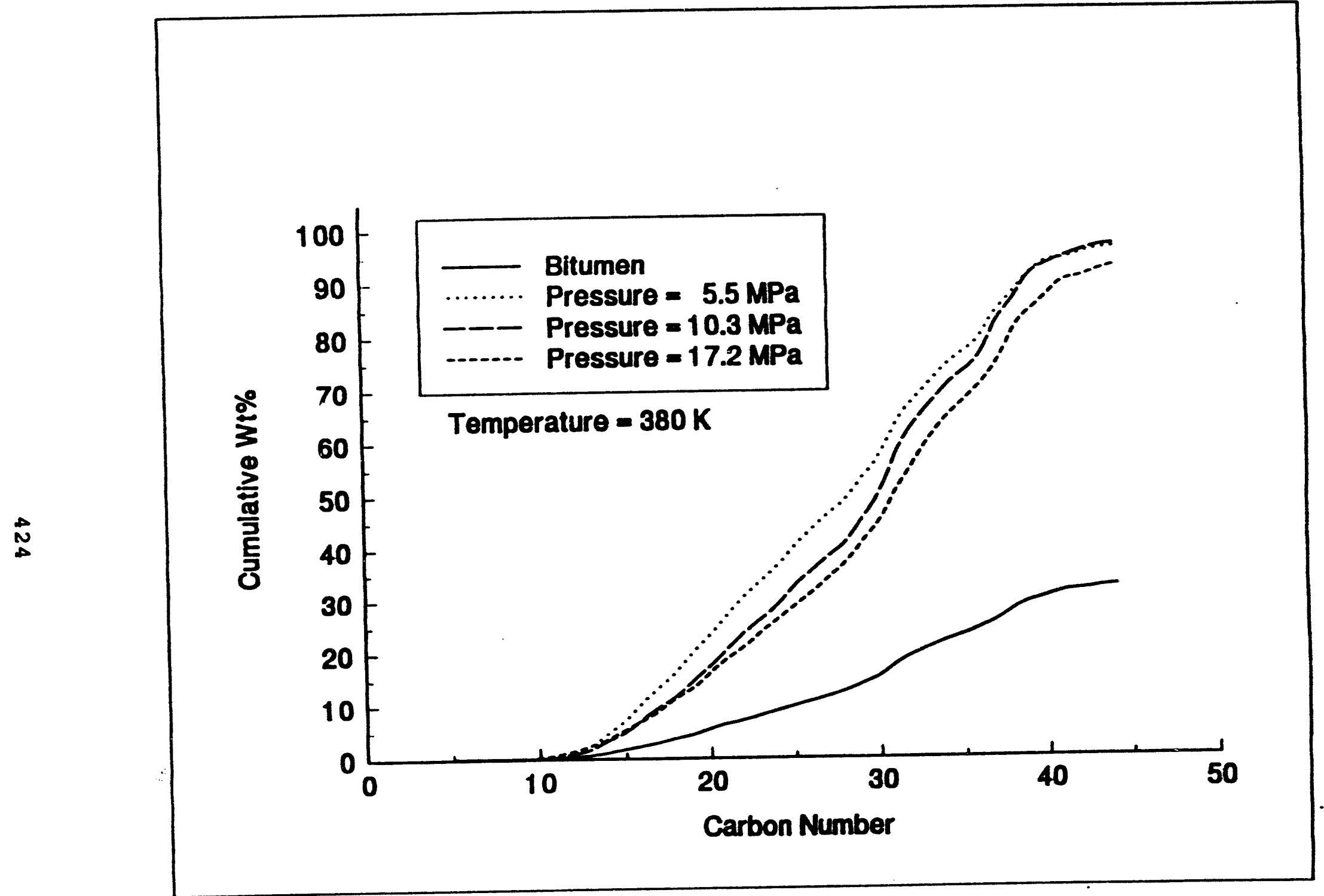

Figure 110. Compositional changes as a function of pressure for bitumen-propane extractions at $380 \mathrm{~K}$. 


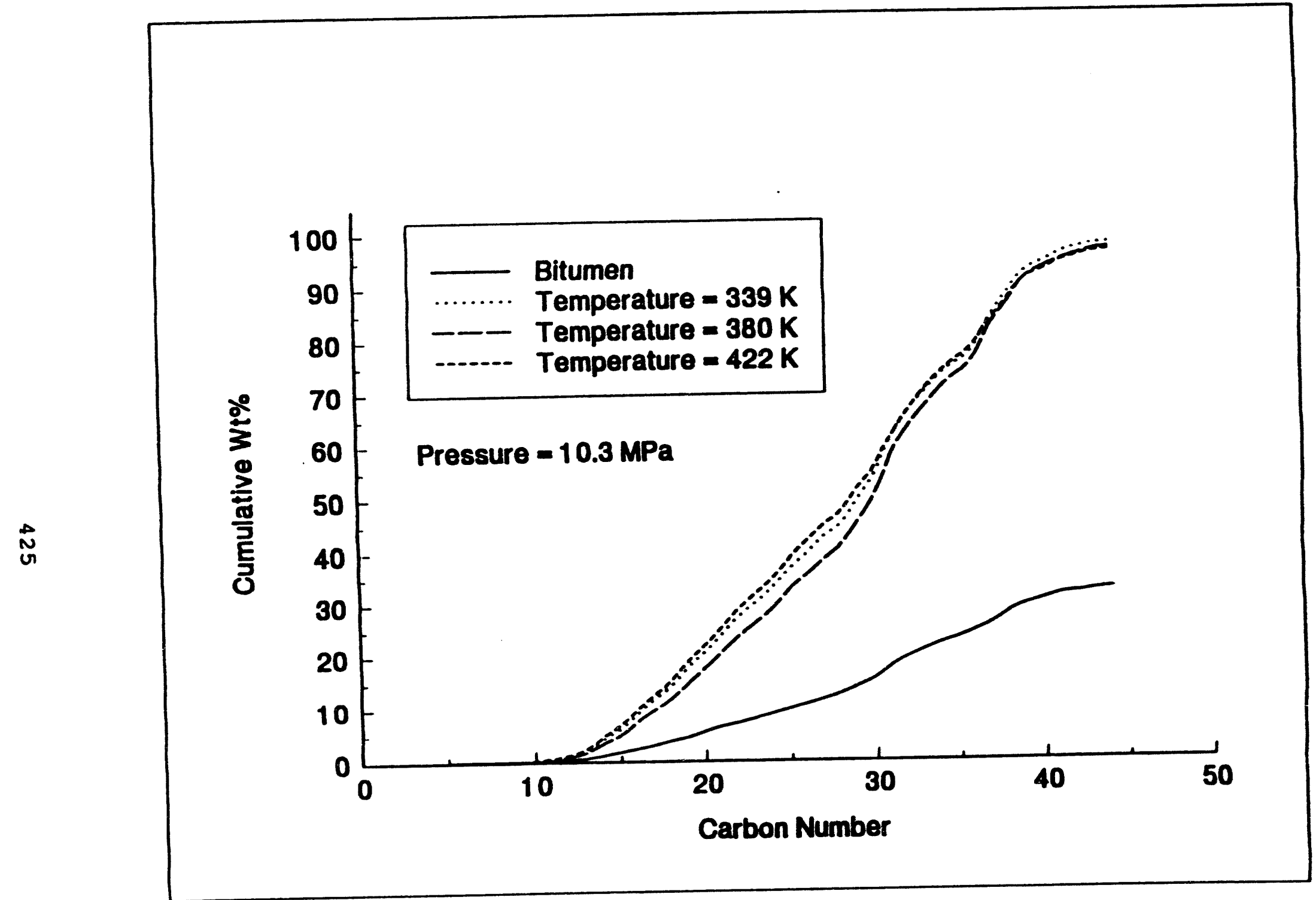

Figure 111. Compositional changes as a function of temperature for the bitumen-propane extractions at $10.3 \mathrm{MPa}$. 
Table 43

Selected Properties of the Residual Fractions After Propane Extractions of Bitumen: Pressure $=10.3 \mathrm{MPA}$

Extraction

Temperature (K)
339
Bitumen

380

Product Yield (r)

Extract Phase

40

39

24

Residual Phase

59

58

73

Asphaltene/Maltene

Asphaltenes, wt?

12.5

15.0

9.8

5.9

Maltenes, wt?

87.5

85.0

90.2

94.1

Asphaltenes

wt? original oil

7.4

8.7

7.2

5.9

Elemental Analysis

C, wt?

86.7

86.7

86.7

87.0

H. Wt?

10.8

10.8

11.1

11.3

N wt?

2.0

2.0

1.8

1.4

S, wt?

0.5

0.5

0.5

0.4

H/C Atomic Ratio

1.49

1.53

1.56 
Selected Properties of the Residual Oils After Propane Extractions of Bitumen: Temperature $=380 \mathrm{~K}$

\begin{tabular}{|c|c|c|c|c|}
\hline $\begin{array}{l}\text { Extraction } \\
\text { Pressure (MPa) }\end{array}$ & 5.5 & 10.3 & 17.2 & Bitumen \\
\hline \multicolumn{5}{|l|}{ Product Yield $(\%)$} \\
\hline Extract Phase & 20 & 39 & 48 & \\
\hline Residual Phase & 79 & 58 & 50 & \\
\hline \multicolumn{5}{|l|}{ Asphaltene/Maltene } \\
\hline Asphaltenes, Wt\% & 14.0 & 15.0 & 20.2 & 5.9 \\
\hline Maltenes, wt\% & 86.0 & 85.0 & 79.8 & 94.1 \\
\hline $\begin{array}{l}\text { Asphaltenes } \\
\text { wt\% original oil }\end{array}$ & 11.0 & 8.7 & 10.1 & 5.9 \\
\hline \multicolumn{5}{|l|}{ Elemental Analysis } \\
\hline C, wt\% & 86.8 & 86.7 & 86.8 & 87.0 \\
\hline H. Wt? & 11.0 & 10.8 & 10.6 & 11.3 \\
\hline$N$, wt? & 1.8 & 2.0 & 2.1 & 1.4 \\
\hline$s$, wt\% & 0.5 & 0.5 & 0.5 & 0.4 \\
\hline H/C Atomic Ratio & 1.52 & 1.49 & 1.46 & 1.56 \\
\hline
\end{tabular}


fractions increased with pressure. This was consistent with the observation that increased extraction of heavier compounds occurred as the extraction pressure was increased. The highest asphaltene content was found in the residual fraction from the extraction at $380 \mathrm{~K}$ and $17.2 \mathrm{MPa}$ where the extraction yield was also the highest. The asphaltene contents of the extracts were not measured in this study. The percentage of asphaltenes as a fraction of the original oil feed are also listed in Tables 43 and 44 . These values were also considerably higher than the asphaltene content of the original oil. Obviously, compounds that did not precipitate from the original oil as pentane insolubles were precipitating from the residual fractions.

Selected high-temperature simulated distillation analyses were performed on some residual fractions. A short $15 \mathrm{~m}$ capillary column was used for these experiments. The end boiling point for these analyses was $993 \mathrm{~K}(1328 \mathrm{~F})$ corresponding roughly to a carbon number of 100. A comparison of the boiling point distributions of two of the residual fractions with the high-temperature boiling point distribution of the bitumen is presented in Figure 112. The figure graphically demonstrates the depletion of compounds over a wide carbon number range from the original bitumen. It is this depletion that leads to the significant increase in the asphaltene content of the residual fractions. It is also observed that the residual fraction at $10.3 \mathrm{MPa}$ and $380 \mathrm{~K}$ is heavier than the residual fraction at $10.3 \mathrm{MPa}, 339 \mathrm{~K}$. This is consistent with the observations that heavier compounds were extracted at $380 \mathrm{~K}$ and 


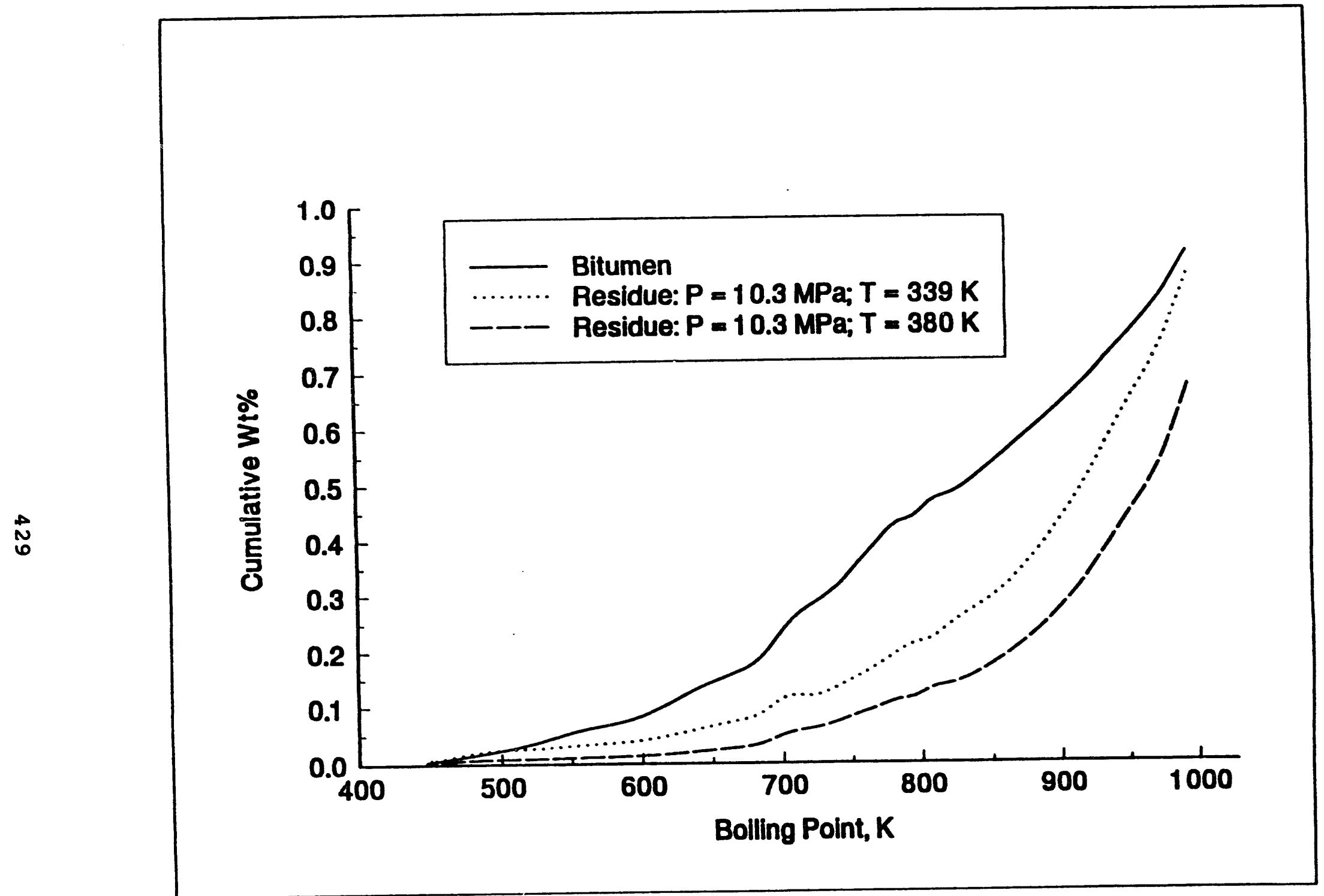

Figure 112. Comparison of the high-temperature boiling point distributions of two of the residual fractions with the distribution for the bitumen. 
that the asphaltene content of the residual fraction at $380 \mathrm{~K}$ was higher.

These experiments established the fact that asphaltenes, as defined in this study (pentane-insolubles), are not a definite compound class but are a collection of compounds specific to a given mixture. Lighter compounds in these mixtures helped keep the asphaltene fraction in solution when a pentane solubility test was performed on the mixture. During the extraction process, these lighter compounds were stripped from the original mixture, thus decreasing the tendency of the heavier molecules to be in solution. As a result of this, the pentane-insolubles fraction increased in the residual fractions. It is apparent from this reasoning that the asphaltene content of the residual fractions would be higher for the residuals produced at conditions that led to more efficient extraction of the lighter components. The data demonstrated this with the exception of the extraction at $5.5 \mathrm{MPa}$ and $380 \mathrm{~K}$. In the experiment at $5.5 \mathrm{MPa}$ and $380 \mathrm{~K}$, despite an extraction of only about $20 \%$ of the relatively lighter compounds (Figures 106 and 109), an asphaltene fraction of $14 \%$ was observed in the residual oil. Extractions in the vicinity of the critical temperature of propane ( $\mathrm{Tr}$ at $380 \mathrm{~K}$ is 1.03 ) and the quality of the compounds extracted may explain this data point. However, detailed compositional information on the extracts (possibly by gas chromatography - mass spectrometry), their asphaltene contents, etc. would be required to evaluate this.

The elemental analysis of the residual fractions reported in 
Tables 43 and 44 indicated that the H/C ratio of the residual fractions decreased relative to the $\mathrm{H} / \mathrm{C}$ ratio of the original bitumen. This suggested that saturated compounds are preferentially extracted by propane and that the heavier portion of the bitumen is relatively more unsaturated than the bitumen as a whole. It was also seen from the data that the nitrogen and sulfur contents of residual fractions were higher than the original bitumen. This indicated that the heteroatomic species are concentrated in the unextractable heavier portion of the bitumen.

The effect of solubilizing co-solvents ${ }^{343}$ led us to presume that as lighter components are extracted, more of the heavier components ought to precipitate. The data reported in this paper are thus a direct confirmation of the hypothesis of Kawanaka et al. ${ }^{349}$. There is absolutely no doubt that lighter components are being extracted in SFE. The $\mathrm{H} / \mathrm{C}$ ratio comparisons suggest that the residual fractions are more polar than the original oil. Thus the the polar to nonpolar compounds ratio is higher in the residual fractions than in the original oil. There is some evidence to believe that extraction of lighter components alone will not cause an increase in the asphaltene content of the residual fractions ${ }^{355}$. Bukka 355 found no significant change in the asphaltene content of several bitumens when he distilled and separated the lighter $10 \%$ and $20 \%$ of the original material. This suggests that alteration of the polar-to-nonpolar compounds ratio in the residual fractions maybe more important than the depletion of lighter components. More studies on the chemical nature of the residual fractions and the 
extracted oils are necessary before a conclusive statement is made regarding the cause for the increased asphaltene content of the residual fractions.

The data presented in this paper do point out that it would be misleading to perform material balances on the asphaltene portions of the fractionated bitumens and/or oils (as reported by Burke et al. ${ }^{344}$ ) since the type and amounts of asphaltenes in different fractions would depend on the solubility character of the specific fractions. Since residual fractions recovered in the extractions were dark black solids, it may be wrong to presume that only the pentane-insolubles asphaltene fraction of the original oil is susceptible to precipitation in any given recovery or refining process.

\section{SUMMARY AND CONCLUSIONS}

Asphaltene precipitation and subsequent formation damage during oil production remains a serious problem in oil production. Asphaltenes are also of concern in petroleum processing. In this work, asphaltene precipitation in dense gas processes has been examined using continuous supercritical fluid extraction experiments. Experiments were performed on a bitumen (ultra heavy oil) using propane as the solvent at several temperatures and pressures and the asphaltene contents of the original material and residual fractions were determined.

The experimental data indicated that as the cosolubilizing lighter components of the oil are extracted, more of the heavier compounds precipitate in the pentane-insolubles test, thus showing 
an increase in the asphaltene content of the residual fractions. The polar to nonpolar compounds ratio also increased for the residual fractions relative to the original bitumen. This indicates that asphaltenes, defined as pentane-insolubles, are not a definite compound class but are specific to a given mixture. The study also indicated that it may be inappropriate to perform asphaltene balances on different fractions of crude oils and bitumens since the solubility and precipitation characteristics of the mixtures change with composition. The asphaltene content of the original oil may not be an appropriate index in order to define the precipitation characteristics since this is not the only fraction susceptible to precipitate in a dense gas flooding process.

1. When an oil sand bitumen was subjected to supercritical extraction with propane, the residual fractions left in the extractor exhibited significantly higher values of asphaltene fractions than the orginal oil (bitumen). The loss of cosolubilizing lighter components from the original oil during the extraction process caused more of the heavier components to precipitate thus increasing the apparent asphaltene content. This established that pentane-insoluble asphaltenes were not a definite compound class and that their nature and quantity in a given mixture was determined by the overall composition of the mixture. 2. As the extraction pressure increased at a constant temperature of $380 \mathrm{~K}$, the asphaltene content of the residual fraction also increased. This was consistent with the observation that the extraction yields increased with pressure and that heavier 
compounds were extracted at higher pressures. 3. The $\mathrm{H} / \mathrm{C}$ ratio in the residual fractions was lower than the original oil establishing that saturated compounds were preferentially extracted leaving the residual fractions richer in unsaturated compounds (and thus more polar) than the original oil. The nitrogen and sulfur contents of the residual fractions were also higher which indicated that heteroatomic compounds concentrated in the heavier (unextracted) portion of the original oil.

4. This study indicated that care should be exercised when performing material balances on asphaltenes from fractionated oils and/or bitumens and that it may be inappropriate to presume that only the pentane-insoluble asphaltene fractions of the original materials are susceptible to precipitate in a given recovery (enhanced oil recovery) or refining process.

\section{Future Activities}

Asphaltene rejection via supercritical fluid extraction with propane will be investigated using the PR Spring bitumen. The data generated will permit the comparison of supercritical fluid extraction applied to a low asphaltene content bitumen, Whiterocks, and to a high asphaltene content bitumen, PR spring. 


\title{
BITUMEN RECOVERY DURING TAILINGS DEWATERING
}

\author{
Principal Investigator D.A. Dahlstrom
}

\section{INTRODUCTION}

In the aqueous processing of tar sands, one of the major critical processing areas is separation and recovery of bitumen from the sand and fine solids. Bitumen in Utah tar sands has a specific gravity very close to 1.0 making a separation on the basis of specific gravity difference with water more difficult than Canadian tar sands. Also, much of the solids in Utah tar sands do not have a layer of water between the bitumen and the sand particle surfaces. This, together with the viscosity of the bitumen (also higher than Canadian bitumen), makes it difficult to free the bitumen from the solids. In many cases, a "penetrating agent" will have to be employed to reduce viscosity and also ease the separation. This may also increase the specific gravity difference between water and bitumen which will aid bitumen recovery. However, the kerosene that has been used is more valuable than the bitumen so its recovery will be important. It would appear from the work done to date by others that the kerosene tends to dissolve in the bitumen (or vice versa). If so, recovery of kerosene will depend on bitumen recovery and it further emphasizes the importance of this factor.

Water reuse and recovery is another extremely important 
economic factor. Utah is a desert area and also usually possesses a high permeability due to the amount of sand and pebbles. Water is scarce as the average annual precipitation is only 11 inches. As tar sands must be mined at a high tonnage rate for economic reasons, it is therefore felt that tallings ponds cannot be employed. Because of the low humidity and number of warm to hot days per year, loss of water by evaporation per unit area of surface can be high. Secondly, due to the permeability of the strata, plastic membranes at the base of the tailings ponds would be a requirement to prevent percolation of water into the ground water or even an aquifer. There are several other federal and state design requirements for tailings ponds that make them very expensive in both capital and operating costs. Thus it is very desirable to eliminate the tailings pond if at all possible.

From previous work, it is apparent that if the tailings pond is to be eliminated, the application of a "superthickener" or also called a "high-density thickener" should be applied if at all possible. This is a very recent development wherein very high underflow concentrations in terms of weight percent solids have been achieved. In the processing of bauxite, a very fine solids termed "red mud" are obtained which may have an average particle size of a microns. The tar sands solids contain iron, silicates, and other solids and normally has a deep red color. This new thickener was first applied in Australia near Perth which formerly produced only around 35 weight? solids in conventional "settlers" ("industrial-duty"-type thickeners but much lower torque than the 
heavy density thickener). With the high-density thickener, solids concentrations increased to 52 weightr, which is a 50.38 elimination of liquor. Furthermore, the thickened solids exhibit a "slump" when poured and do not seek a common level. It is highly viscous but can and is pumped by high-pressure pumps (100-150 atmospheres) $4 \mathrm{~km}$ to a final disposal area. The slurry dries to $75+8$ solids by weight and is $2 / 3$ of its original volume from the thickener underflow. This performance permitted the company to shut down the large number of filters that were used to reduce the moisture and resulted in a very sloppy material which had to be transported in trucks, allowed to dry; and eventually the solids had to be moved at a significant cost. with the high-density thickener, the final solids in the underflow, were left in the final disposal area and did not have to be moved. This system resulted in a good economic solution.

Classifiers would be used initially to make the primary separation of finer solids from coarser solids. In addition, the classifiers must obtain a $90+\%$ recovery of bitumen in the streams that go to final processing of the bitumen for product. Three different classifiers are being considered. The underflow from these classifiers would contain too many extreme fines after the initial separation so these fines would have to be largely removed in order to obtain a very low moisture content of the coarse solids. Thus the slurry would be sent to a second classifier after dissolution with process water where it is again classified resulting in a large rejection of fines to the overflow. In 
addition, the coarse solids are transported out of the bottom of this classifier pool and above the liquid surface by a spiral screw. With the further removal of fines permitting better drainage, the solids would exit from the discharge probably at around $18 \mathrm{wt}$ moisture or less. This material could be transported either by conveyor or combined with fines from the superthickener and pumped to the disposal area (probably to the abandon mines workings).

It is apparent that the coarse and fine particles are separated from each other in order to maximize water recovery. They cannot be dewatered to the high concentrations anticipated due to the highly different sedimentation rate (the coarse settled much faster than the fines even though the latter had been flocculated). Accordingly, the presentations will be made under the following categories within each major subject area:

1. Primary classifier

a. Three product classifier

b. Two product separator (conventional hydrocyclone)

c. Conventional three product classifier-thickener used at present in Canada on Athabaska Tar Sands.

2. Secondary Classifier

Spiral classifier where the products are first an 
overflow from a weir on the sedimentation pool (fine solids) and the spiral screw lifts the coarse solids above the pool to further dewater the solids with major elimination of fines. The overflow reports to the high density thickener.

3. This is the high-density or superthickener and will be used to greatly concentrate the fine solids, probably primarily less than 200 microns.

EXPERIMENTAL

The three product hydrocyclone has been completely water tested as to velocities, flow patterns and pressure drops as a function of throughput. The unit is constructed of transparent plastic, is 11-1/2" inches in diameter with a large included angle in the bottom conical section. The cylinder section is 11-1/2" I.D. all the way in the vertical cylinder and is around 8 feet high. There is a central overflow which points downward and covers the bottom of the tangential inlet feed nozzle. This stream is called a middlings stream. There is an overflow well above the middlings pipe and it points upward. Thus, the unit acts as an overflow when the flow rate is high enough or if the middlings stream is throttled to let the level rise to the overflow.

To our surprise, the unit does not act with a free vortex (tangential velocity increase as the radial distance decreases). Thus, the maximum centrifugal force exists at the radius of the 439 
overflow (in this case the middings pipe radius if a free vortex existed). Instead a forced vortex occurs (tangential velocity decreases as the radial distance decreases). Accordingly, the centrifugal force does not increase and in fact, probably decreases as the radius decreases.

This will exhibit an appreciably lower centrifugal force and should probably classify at around 150-250 microns. This could be important to tar sands processing as this could be a desirable coarse size for the fine tailings. It would make it possible to get a higher underflow solids concentration in the fine tailings thickener.

This would also mean the unit will not make as sharp classification as compared to the conventional two product hydrocyclone. It is believed however that this will not be a problem. The main thing is to get a $90+\%$ recovery of solids coarser than probably 200-250 microns and larger in the underflow. The other important factor is to recover better than $90+\%$ of the bitumen in the overflow plus the middling stream.

The conventional two product hydrocyclone has not been tested. There is very great deal of literature available which allows the prediction of particle size recovery in the underflow as a function of major variables. It obviously is possible to obtain a $90+8$ recovery in the underflow of particles coarser than 75-125 microns with reasonable size cyclones (at least 3 inches diameter and larger). However, the big factor is, - can $90+8$ recovery of bitumen in the overflow be achieved? We cannot determine this 
until we can operate our equipment in the pilot plant we hope to construct in salt Lake city south of the petroleum refinery complex. However, we could obtain digested Utah tar sands for performance testing prior to building the total pilot plant. We plan on using a 4 inch diameter cyclone for this purpose and we can determine both bitumen recovery in the overflow and the coarse solids size range recovered in the underflow.

The three product classifier thickener also does not need to be tested. There is enough data existing from the full scale work and practice now being employed in the Athabaska region in Canada. However, when the feed is over $8 \%$ bitumen, the flotation plant is not required as they get $90+\frac{8}{8}$ recovery of bitumen in their "overflow." With bitumen content below $8 \%$, they must send the middlings stream through flotation for obtaining $90+$ recovery of bitumen. They also have a cut-off in their mining at $6 \%$ bitumen ore. We believe we can design this eet, if necessary, without testing it.

The secondary classifier (proposed spiral classifier) does not need to be tested at this time. There is enough literature on this unit to allow reasonable performance prediction.

We have finally been able to test a material we found at the bottom of an old tailings pond used in the previous pilot plant which we are sure was from very fine solids that were obviously associated with bitumen.

There was a very thin layer of brown and tan solids that contained very fine particle sizes, it felt like a powder when 
rubbed between the fingers, and it is believed these were the last solids to settle or be filtered out by the lower coarser solids layer. Undoubtedly, bitumen had also adsorbed to some extent on these solids. The solids tested at $50 \%$ minus 12 microns and there were about $1 \%$ solids that were finer than 1 micron. When the solids were placed in water, the color turned to a dark brown, indicating the presence of aged bitumen.

The material was taken to the EIMCO Process Equipment Company Laboratories in salt Lake city where it could be tested for application to the high-density thickener. They have a test apparatus that can be employed to see if a very high solids concentration (about $50 \%$ more water removal by sedimentation as compared to a conventional thickener).

The test work was highly successful. A very thick slurry was achieved that exhibited a "slump," was the consistency of bread dough and would not exhibit a common level. It is pumpable but with high pressure pumps that would have to be employed (as are used with the installation of the high-density red mud thickener).

\section{RESULTS AND DISCUSSION}

As indicated earlier, the three product cyclone employing a forced vortex should obtain better than $90+\%$ of particle coarser than 150 to 250 microns in the underflow. Because of the forced vortex, the classification results will not be as sharp as with the conventional two product cyclone.

We believe the coarser size split to the underflow, and therefore the presence of solids below the 150-250 microns in the 
middlings stream in higher percentages than with the conventional cyclone can be beneficial to obtaining higher solids concentrations in the final underflow from the high-density thickener. This could mean further improvement in total water recovery and reuse.

However, emphasis will still remain as to whether we can achieve $90+\%$ recovery of bitumen in the overflow and middlings streams. We cannot test this important facet until we can run pilot plant tests on an actual tar sands feed after digestion.

We have not finished the calculations for determining the conventional two product hydrocyclone application from a solids classifications standpoint. We can calculate this from the literature. However, it is essential that $90+8$ recovery of the bitumen must be possible for its application in the cyclone overflow. This we cannot test until we can do it in a pilot plant setup with a digested tar sands feed as indicated earlier.

The three product classifier-thickener can be employed if the other classifiers can not produce the necessary $90+$ recovery in the proper streams. The classifier-thickeners are in operation now in Canada on tar sands. At the same time, if we can make the hydrocyclones work efficiently, it will reduce significantly the capital costs.

The secondary classifier (spiral classifier) taking the underflow from the primary classifier should work effectively. Its purpose is to reduce the fines below about 150 microns from the first stage classifier underflow. These fine solids can be more effectively concentrated in the high-density thickener and 
therefore reduce the coarse solids concentration. We can predict these results once we have completed the three product cyclone tests and the calculations on the first stage classifiers that could be applied. We do believe we can get at least $18 \%$ moisture and probably less in the dewatered coarse tailings product that could be transferred for disposal by a belt conveyor.

As indicated earlier, we were able to dewater the very fine solids found at the old pilot plant tailings pond to almost 43 wt solids. The material was very viscous, exhibited a slump and had the consistency of bread dough. This might seem low in weight percent solids when aluminum red mud was dewatered to 52 wt percent solids. However, the red mud solids have a specific gravity of 3.1 while the solids we tested had only a 2.08 specific gravity. When the two different solids were converted to volume percent solids, the value was exactly the same. Therefore, it obviously was at a maximum solids concentration.

This can be interpreted to mean we can apply the high-density thickener to dewater these fine solids from tar sands and at the same time, eliminate the tailings pond. The solids would be pumped to the abandoned mine workings where they would dry to $2 / 3$ or less of its volume after dewatering. Most of the bitumen would have been removed so it should be a logical disposal place. This would also be the disposal area for the coarser solids. There should be no free water generated at the disposal area so water recovery is maximized. Elimination of the tailings pond would mean an extremely significant reduction in capital and operating costs. 
There are many factors that evidently influence the high solids concentration in the thickener underflow. These can be stated as follows:

1. Particle size distribution of the fine solids, -particularly the colloidal range.

2. Chemical nature of the solids, particularly the surface chemistry.

3. Flocculant type and dosage.

4. Flocculant concentration in the polymer solution employed for flocculation.

5. Mixing method of flocculant and feed solids.

6. Wt. $\%$ suspended solids in the feed slurry at the time of flocculation.

7. Detention time of the flocculated solids in the thickener.

8. Height of the sludge blanket in the thickener.

9. Design of the rake mechanism.

10. Velocity of the rake mechanism.

There may be some other factors but these appear to be the most prominent. There is sufficient knowledge to at least determine how to obtain the high solids concentration well above that from a conventional type thickener. Also, we will be able to use the testing equipment at EIMCO process Equipment Company to determine necessary conditions for the ten items listed above to obtain maximum dewatering. However, this means that we will have 
to install en gh equipment in the pilot plant to produce digested tar sands at the processing temperature.

\section{SUMMARY AND CONCLUSIONS}

The three product cyclone exhibited a forced vortex and therefore a lower centrifugal force. It should recover $90+8$ of solids coarser than a particle size between 150 to 250 microns. The unit was tested with polyelthylene pellets of 0.97 specific gravity and less than 18 was found in the underflow. As the pellets were around $1 / 4$ inch in size, these results cannot be considered as representing bitumen recovery. Furthermore, most of Utah bitumen has been indicated to lie between 0.99 and 1.0 specific gravity which will add to its separation difficulty. We hope to reduce its specific gravity by exposing it to very small bubbles of air.

The unit must be tested on digested tar sands in the pilot plant for final determination of applicability. It is felt that $90+\%$ of bitumen must be recovered in the combined overflow and middling streams. We are still encouraged that this can be achieved.

The two product hydrocyclones must be tested on digested utah tar sands to see if it will recover $90+\%$ of bitumen in the overflow. If it cannot, we would be unable to use it. This testing has to await the development of the pilot plant. We can size the pilot plant equipment from the literature.

The three product classifier-thickener can be designed for the pilot plant through Canadian operating data available to us as it 
obtains $90+\frac{7}{6}$ recovery of bitumen in the overflow stream. It would seem logical that it can be achieved on Utah tar sands, although the higher specific gravity of Utah bitumen should also increase the difficulty. It is also known that in Canada, bitumen grade of 6-8\% is much more difficult to achieve recovery in the overflow and flotation must also be employed on the middling stream.

The secondary classifier (spiral classifier) should be able to remove at least $80 \%$ of the remaining fine solids from the primary classifier underfilow which should permit reduced coarse solids moisture content to $18 \mathrm{wt}$ or less. This should be transportable by a belt conveyor.

Further work needs to be done on the high-density thickener. However, this must wait until digested Utah tar sands can be produced in the pilot plant for testing. Because of our tests on a sample described earlier, we feel very encouraged that the high-density thickener for fine solids can be employed to final dewater this difficult fraction.

FUTURE ACTIVITIES

The following should be accomplished in the future:

1. Testing of the three product hydrocyclone should be completed with respect to solids particle size separation to the underflow. This is presently being run. In addition, we will run some tests with lubricating oil and water to see if we can obtain any conclusions as to the recovery of bitumen in the 
cyclone overflow and middling stream. We will also fabricate a test set up for use in the pilot plant for digested tar sands. This is necessary in order to determine actual bitumen recovery in the overflow and bitumen screen. Bitumen recovery of $90+\%$ if achieved should be excellent.

2. We intend to test the conventional two product hydrocyclone (free vortex type) for bitumen recovery with proper recovery of coarse solids in the underflow. If over $90+8$ recovery of bitumen can be achieved, this would be a very good unit to employ in the flowsheet. This must be done on digested Utah tar sands in the pilot plant.

3. We will make the necessary calculations on the data available to us to predict the design of the three product classifier-thickner for the pilot plant. If items 1 and 2 do not work, we can employ this unit and feel it will be successful because of proven operation in Canada.

4. We will make the necessary calculations to predict performance and size of the secondary classifier (spiral classifier) for the pilot plant. This should give us a coarse tailings performance that will permit conveyer transport to the final disposable area.

5. From running the digestion system for testing of primary classifier performance, we can produce digested tar sands for further testing of the high-density thickener of fine solids tailings for final disposal. This would permit us to determine requirements for the ten factors listed earlier 
under "Results \& Discussion." This is very essential in order to achieve real performance predictions. 


\section{REFERENCES}

1. Oblad, A.G., J.W. Bunger, F.V. Hanson, J.D. Miller, H.R. Ritzma and J.D. Seader. (1987). Oil Sand Research and Development at the University of Utah. Ann. Rev. Energy, $12,283$.

2. Probstein, R.F. and R.E. Hicks, (1981). Synthetic Fuels, McGraw-Hill, New York, p.327.

3. Bunger, J.W. (1979). Processing Utah oil Sand Bitumen. Ph.D. Dissertation, University of Utah, Salt Lake City, Utah.

4. Bunger, J.W., D.E. Cogswell, A.G. Oblad (1979) . Catalytic Cracking of Asphalt Ridge Bitumen. Adv. Chem. Ser., 179. Chapter 5, pp. 67-84, ACS, Washington, D.C.

5. Biswas, J. and I.E. Maxwell (1990). Recent Process- and Catalyst-Related Developments in Fluid Catalytic Cracking. Applied Catal., 63, 197.

6. Viscosity Graded Asphalt Cement, AAsHTO Materials Part I Specifications, (1978), American Association of State and Highway Transportation officials, Washington, D.C., DesM226-78, pp. 539-542.

7. Tsai, C.H., M.D. Deo, F.V. Hanson, and A.G. Oblad. (1991). Characterization and Potential Utilization of Whiterocks (Utah) oil Sand Bitumen. Fuel Sci. and Tech. Internat., $\underline{9}(10), 1259$.

8. Bukka, K., (1991) private communication

9. Tsai, C.H. (1990). Novel Synthetic Approaches to Advanced Jet Fuels, Ph.D. Dissertation, University of Utah, Salt Lake City, Utah.

10. Ander, D.E. and W.E. Robinson. (1971). Cycloalkanes Constituents of the Bitumen from Green River Shale. Geochim. Cosmochim. Acta, 35, 661.

11. Anderson, P.C., P.M. Gardner and E.V. Whitehead, (1969). The Isolation of steranes from Green River oil shale. Geochim. Cosmochim. Acta, 33, 1304.

12. Aquino Neto, F.R., J.R. Restle, J.Connan, P. Albrecht and G. ourisson. (1982). Novel Tricyclic Terpanes $\left(C_{19}, C_{20}\right)$ in Sediments and petroleums. Tetrahedron Letters, 23 (19), 2027. 
13. Dimmler, A., T.D. Cyr and O.P. Strausz (1984). Identification of Bicyclic origin in the saturate Fraction of Athabasca Oil Sand Bitumen. Org. Geochem., I(3/4), 231.

14. Ekweozor, C.M. and O.P. Strausz. (1982). 18,19-Bisnor$13 \beta \mathrm{H}, 14 \alpha \mathrm{H}-\mathrm{Cheilanthane:} \mathrm{A} \mathrm{Novel} \mathrm{Degraded} \mathrm{Tricyclic}$ Sesquiterpenoid-Type Hydrocarbon from the Athabasca oil Sands. Tetrahedron Letters., 23(27), 2711.

15. Gallegos, E.J. (1973). Identification of Phenylcycloparaffin Alkanes and Other Monoaromatics in Green River Shale by Gas Chromatography-Mass Spectrometry, Anal. Chem., $45(8), 1399$.

16. Gallegos, E.J. (1971). Identification of New Steranes, Terpanes and Branched Paraffins in Green River shale by Combined Capillary Gas Chromatography and Mass Spectrometry. Anal. Chem., 43(10), 1151.

17. Han $J$. and $M$. Calvin (1969). Occurrence of $C_{22}-C_{25}$ Isoprenoid in Bell Creek Crude Oil. Geochim. Cosmochim. Acta, 33, 733 .

18. Henderson, W., V. Wollrab and G. Eglinton, (1968). Identification of Steroids and Triterpanes from a Geological Source by Capillary Gas-Liquid Chromatography Chem. Commun., 710 .

19. Kimble, B.J., J.R. Maxwell, R.p. Philp and Eglinton. (1974a). Tri- and Tetraterpenoid Hydrocarbons in the Messel oil Shale. Geochim. Cosmochim. Acta, 38, 1165.

20. Kimble, B.J., J.R. Maxwell, R.P. Philp and G. Eglinton. (1974b). Identification of steranes and Triterpanes in Geolipid Extructs by High-Resolution Gas Chromatography and Mass spectrometry. Chem. Geology, 14, 173.

21. Philp, R.P. (1985). Fossil Fuels Biomarkers - Applications and Spectra. Methods in Geochemistry and Geophysics. Elservier, Amsterdam.

22. Reed, W.E., (1977). Molecular Compositions of Weathered Petroleum and Comparison with its Possible source. Geochim. Cosmochim. Acta, 41, 237.

23. Richardson, J.S. and D.E. Miller (1983) . BiologicallyDerived Compounds of Significance in the Saturate Fraction of a Crude oil having a Predominant Terrestrial Input. Fuel, 62,524 . 
24. Richardson, J.S. and D.E. Miller (1982). Identification of Dicyclic and Tricyclic Hydrocarbons in the Saturate Fraction of a Crude Oil by Gas Chromatography/Mass Spectrometry. Anal. Chem., 54, 765.

25. Rullkotter, J., D. Lethaeuser and D. Wendish (1982). Novel 21,28-bisnorlupanes in Tertiary Sediments widespread Occurrence of Nuclear Demethylated Triterpanes. Geochim. Cosmochim. Acta, 46, 2501.

26. Trendel, J.M., A. Restle, J. Connan and P. Albrecht. (1982). Identification of a Novel series of Tetracyclic Terpene Hydrocarbons $\left(C_{24}-c_{27}\right)$ in sediments and Petroleums. J. Chem. Soc., Chem. Commun., 304.

27. Bendoraitis, J.G. (1974). Hydrocarbons of Biogenic Origin in Petroleum-Aromatic Triterpanes and Bicyclic Sesquiterpenes in Advanced In Geochemistry, 1973 (ed. B. Tissot and F. Bienner), Technip. Paris, p. 209.

28. Simoneit, B.R.T. (1977). Diterpenoid Compounds and other Lipids in Deep-Sea Sediments and Their Geochemical significance, Geochim. Cosmochim. Acta, 41, 463.

29. Tissot, B.P., and D.H. Welte, (1984), Petroleum Formation and Occurrence, 2nd Ed., Springer-Verlog, Berlin, p. 41.

30. Ensminger, A., A. Van Dorsselaer, Ch. Spycherelle, P. Albrecht and G. Ourisson (1974). Pentacyclic Triterpanes of the Hopanes Type as Ubiquitous Geochemical Markers: Origin and Significance, in Advanced in Geochemistry, 1973 (eds. B. Tissot and F. Bienner), Techip, Paris, p. 258 .

31. Leontaritis, K.J., Mansoori, G.A., and Jiang, T.S. Asphaltene Deposition in Oil Recovery: A Survey of Field Experiences and Research Approaches. J. Pet. Sci. Eng., Vol. 1, pp. 229-239, 1988 .

32. Leontaritis, K.J. Asphaltene Deposition: A Comprehensive Description of Problem Manifestations and Modelling Approaches. Paper No. SPE 18892, presented at the SPE Prod. operations symposium, Oklahoma City, Oklahoma, March 13-14, 1989.

33. Kokal, S.I., Najman, J., Sayegh, S.G., and George, A.E. Measurement and Correlation of Asphaltene Precipitation from Heavy Oils by Gas injection. J. Can. Pet. Tech., Vol. 31(4), pp. 24-30, 1992 .

34. Hasket, C.E., and Tartera, M. A Practical Solution to the Problem of Asphaltene Deposits-Hassi-Messaoud Field, Algeria. J. Pet. Tech., Vol. 17, pp. 387-391, 1965. 
35. Nellensteyn, F.J. "The Colloidal Structure of Bitumens". The Science of Petroleum, Oxford University Press, New York City, 4, p. 2760, 1938.

36. Pfeiffer, J.P., and Saal, R.N.J. "Asphaltic Bitumen As a Colloidal System". J. Phys. Chem., Vol. 44, p. 139, 1940.

37. Long, R.B. The Concept of Asphaltenes. Chapter 2, in Chemistry of Asphaltenes. Eds. Bunger and $\mathrm{L} i$, Advances in Chemistry Series, No. 195, ACs Publication, Washington, D.C., pp. 17-27, 1981 .

38. Mitchell, D.L., and speight, J.G. The Solubility of Asphaltenes in Hydrocarbon Solvents. Fuel, Vol. 52, pp. $149-152,1973.20$.

39. Corbett, L.W., and Petrossi, U. Differences in Distillation and Solvent Separated Asphait Residua. Ind. Eng. Chem. prod. Res. Dev., Vol. 17(4), pp. 342-346, 1978 .

40. Hirshberg, A., De Jong, L.N.J., Schipper, B.A., and Meijer, J.G. Influence of Temperature and Pressure on Asphaltene Flocculation. SPE J., Vol. 34(3), pp.283-293, 1984.

41. Mansoori, G.A., Jiang, T.S., and Kawanaka, S. Asphaltene Deposition and its Role in Petroleum Production and Processing. Arabian J. Sci. Eng., Vol. 13(1), pp. 17-34, 1987 .

42. Lichaa, P.M. Asphaltene Deposition Problems in Venezuelan Crudes - Usage of Asphaltenes in Emulsion Stability. CIM Conference on the Oil Sands of Canada and Venezuela, pp. $609-624,1977$.

43. Bulmer, J.T., and Starr, J., Eds: "Syncrude Analytical Methods For oil Sand and Bitumen Processing." Syncrude Canada Limited, Edmonton, Alberta, Canada, 1979.

44. Bukka, K., Hanson, F.V., Miller, J.D., and Oblad, A.G. Fracticnation and Characterization of Whiterocks Tar Sands Bitı" "n. Energy \& Fuels, Vol. 6, pp. 160-165, 1992.

45. Koots, J.A., and Speight, J.G. Relation of Petroleum Resins to Asphaltenes. Fuel, Vol. 54, pp. 179-184, 1975.

46. Small, D.M. "Handbook of Lipid Research 4. The Physical Chemistry of Lipids: From Alkanes to Phospholipids." Chapter 7, pp. 183-232, Plenum Press, New York and London, 1986.

47. Bukka, K. Unpublished results. 
48. Okuno, I., Latham, D.R., and Haines, W.E. Separation of Sulfoxides from Petroleum Fractions by Cation Exchange Resin Chromatography. Anal. Chem., vol. 39, pp. 1830-1833, 1967.

49. Petersen, J.C., Dorrence, S.M., Nazir, M., Plancher, H., and Barbour, F.A. Oxidation of Sulfur compounds in Petroleum Residues: Reactivity-structural Relationships. Prepr.- Am. Chem. Soc., Div. Pet. Chem., Vol. 26, pp. 898-906, 1981.

50. Green, J.B., Yu, S.K.-T., Pearson, C.D., and Reynolds, J.W. Analysis of Sulfur Compound Types in Asphalt. Energy \& Fuels, Vol. 7, pp. 119-126, 1993.

51. Moschopedis, S.E., and Speight, J.G. oxygen Functions in Asphaltenes. Fuel, Vol. 55, pp. 334-336, 1976.

52. Frakman, Z., Ignasiak, T.M., Lown, E.M., and Strausz, O.P. oxygen Compounds in Athabasca Asphaltene. Energy \& Fuels, Vol. 4, pp. 263-270, 1990.

53. Bukka, K., Miller, J.D., Hanson, F.V., and Oblad, A.G. The Influence of Carboxylic Acid content on Bitumen Viscosity'. Fuel, in press, 1993.

54. Dickinson, E.M. Structural Comparison of Petroleum Fractions Using Proton and ${ }^{13} \mathrm{C} \mathrm{n.m.r.} \mathrm{Spectroscopy.} \mathrm{Fuel,}$ Vol. 59, pp. 290-295, 1980.

55. Netzel, D.A., and Miknis, F.P. N.m.r. Study of US Eastern and Western Shale Oils Produced by Pyrolysis and Hydropyrolysis. Fuel, Vol. 61, pp. 1101-1109, 1982.

56. Suzuki, T., Itoh, M., Takegami, Y., and Watanabe, Y. Chemical structure of Tar-sand Bitumens by ${ }^{13} \mathrm{C}$ and ${ }^{1} \mathrm{H}$ n.m.r. Spectroscopic Methods.; Fuel, Vol. 61, pp. 402-410, 1982 .

57. Thiel, J., Gray, M.R. NMR Spectroscopic Characteristics of Alberta Bitumens. AOSTRA J. Res., Vol. 4, pp. 63-73, 1988.

58. Brekke, T., Barth, T., Kvalheim, O.M., and Sletten, E. "Multivariate Analysis of Carbon-13 Nuclear Magnetic Resonance Spectra. Identification and Quantification of Average structures in Petroleum Distillates." Anal. Chem., 62 , pp. 49-56, 1990 .

59. Axelson, D.E. "Solid State Nuclear Magnetic Resonance of Fossil Fuels." Multiscience Publications in cooperation with CANMET and Canadian Government Publishing Centre, ottawa, Canada, p. 219, 1985. 


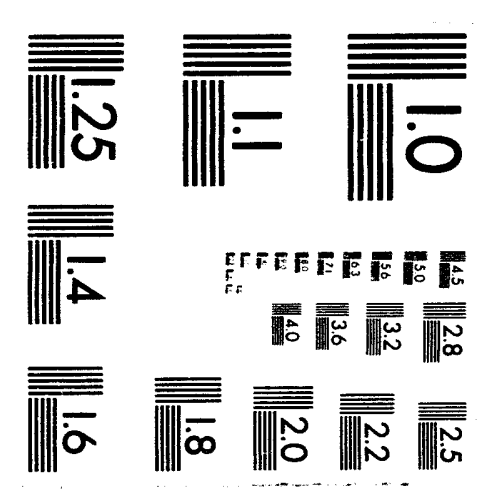



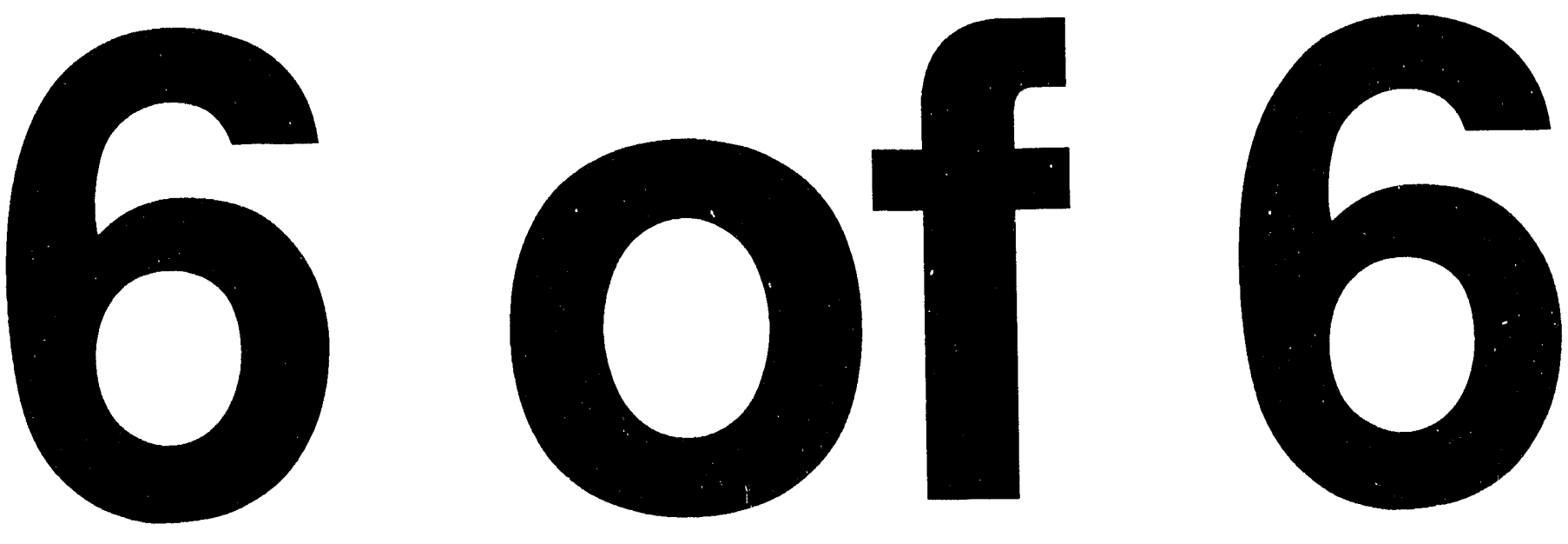
60. Hupka, J., Miller, J. D., and Cortes, A., Importance of Bitumen Viscosity in the Hot Water Processing of Domestic Tar Sands, Mining Eng., 35(12), 1635-1641 (1983).

61. Hupka, J., and Miller, J. D., Tar Sand Pretreatment with Diluent, Preprint No 92-122 of the 121st SME AIME Annual Meeting in Phoenix, AZ, Feb. 24-27, 1992; Minerals and Metallurgical Processing, 1993, in print.

62. U.S Production of Liquid Transportation Fuels: Costs, Issues, and Research and Development Directions, National Academy Press, Washington, D.C., 1989; pp. 4-23.

63. Oblad, A. G., Bunger, J. W., Hanson, F. V., Miller, J. D., and Seader, J. D., Recovery and Upgrading of oil from Utah Tar Sands, 1984-85 First Annual Report submitted to U.S. Department of Energy, Office of Fossil Energy, Morgantown Energy Technology Center, Laramie Project office, Contract \# DE-FG20-84LC11057, University of Utah, Salt Lake City, pp. 44-45.

64. Shaw, R. C., and Kratochvil, B., Near-Infrared Diffuse Reflectance Analysis of Athabasca Oil Sand, Anal. Chem., 62, 167-174 (1990).

65. Dougan, P. D. , Near-Infrared Reflectance Analysis: Its Potential Application in Oil Sands Processing, AOSTRA J. Res., 5, 203-209 (1989).

66. Bukka, K., Miller, J. D., Hanson, F. V., and Oblad, A. G., Mineral Matter Distribution during the Hot Water Processing of Utah Tar Sand, AOSTRA J. Res., 7, 101-109 (1991).

67. Bukka K., Miller, J. D., Hanson, F. V., and oblad, A. G., Fractionation and Characterization of Whiterocks Tar Sand Bitumen, Energy and Fuels, 6, 160 (1992).

68. Tsai, C. H., Deo, M. D., Hanson, F. V., and oblad, A. G., Fuel. Sci. Technolo., 9(10), 1259 (1991).

69. Bukka, K., Miller, J. D., and Oblad, A. G., Fractionation and Characterization of Utah Tar Sand Bitumens: Influence of Chemical Composition on Bitumen Viscosity, Energy and Fuels, 5, 333-340 (1991).

70. Hupka, J., Budzich, M., and Miller, J. D., Preliminary Examination of oil Bonding at Sand surfaces and its Influence on Hot Water Separation, Proceedings of the 1991 Eastern Oil Shale Symposium, Nov. 13-15, 1991; Lexington, Kentucky, p. 202-207. 
71. Hupka, J., Drelich,J., Miller, J.D., White, R.R., Hanson, F.V., and Oblad, A.G., Impact of Eater Recycle on WaterBased Processing of Whiterocks Tar Sand, Proceedings of the 1990 Eastern Oil Shale Symposium - Oil Shale - Tar Sands • Heavy Oil, Nov. 6-8, 1990, Lexington, Kentucky, p.39-44; Fuel, 70, 1313-1316 (1991).

72. Sanford, E.C., Processibility of Athabasca oil Sand: Interrelationship Between Oil Sand Fine Solids, Process Aids, Mechanical Energy and Oil Sand Age After Mining, Can. J. Chem. Eng., 61, 554-560 (1983).

73. Schweitzer, P.A., editor, Handbook of Separation Techniques for Chemical Engineers, McGraw-Hill Book Company, New York, $1979,1-345$.

74. Lelinski, D., Hupka, J., Ye, Y., and Miller, J.D., The Potential for Air-Sparged Hydrocyclone Flotation in Tar Sands Processing, Abstract Proceedings of the 1991 Eastern oil Shale Symposium - Oil Shale - Tar Sands • Heavy Oil, Nov. 13-15, 1991, Lexington, KY, p. 33 .

75. Hupka, J., and Miller, J. D., Electrophoretic Characterization and Processing of Asphalt Ridge and Sunnyside Tar Sands, Intern. J. Mineral Proc., 31, 217-231 (1991).

76. Vittoratos, E., Scott, G. R., and Beattle, C. I., Cold Lake Cyclic steam stimulation: A Multiwell process, SPE Reservoir Eng. 5, 19-24 (1990).

77. Johnson, L. A., Fahy, L. J., Romanowski, L. J., Thomas, K. P., and Hutchinson, H. L., A Steamflood in a Utah Tar Sand, J. Petrol. Tech. 34, 1119-1128 (1982).

78. Clark, K. A., Hot Water Separation of Alberta Bituminous Sand, Can. Inst. Mining Metallurgy Trans. 47, 257-274 (1944).

79. Hupka, J., Miller, J. D., and Cortes, A., Importance of Bitumen Viscosity in the Hot Water Processing of Domestic Tar Sands, Mining Eng. 35, 1635-1641 (1983).

80. de Malherbe, R., Doswell, S. J., Mamalis, A. G., and de Malherbe, M. C., Synthetic Crude from Oil Sands, Fortschritt-Berichteder VDI Zeitschniften, VDI-Verlag, Berlin (1983).

81. Hupka, J., Drelich, J., Miller, J. D., White, R. R., Hanson, F. V., and Oblad, A. G., Impact of Water Recycle on WaterBased Processing of Whiterocks Tar Sand, Fuel 70, 13131316 (1992). 
82. Bukka, K., Miller, J. D., Hanson, F. V., and Oblad, A. G., Mineral Matter Distribution During the Hot Water Prccessing of Utah Tar Sand, AOSTRA J. Res. 1, 101-109 (1991).

83. Bukka, K., Hanson, F. V., Miller, J. D., and Oblad, A. G., Fractination and Characterization of Whiterocks Tar Sands Bitumen, Energy Fuels $6,160-165$ (1992).

84. Drelich, J., Hupka, J., Miller, J. D., and Hanson, F. V., Fine Sand and water separation from Bitumen Concentrate, presented at the 1991 Eastern oil Shale Symposium, Lexington, 1991.

85. Schramm, L. L., and Smith, R. G., The Influence of Natural Surfactant on Interfacial Charges in the Hot Water Process for Recovering Bitumen from the Athabasca oil Sands, Colloids Surf. 14, 67-79 (1985).

86. Schramm, L. L., Smith, R. G., and stone, J. A., The Influence of Natural surfactant Concentration on the Hot Water Process for Recovering Bitumen from the Athabasca oil Sands, AOSTRA J. Res. 1, 5-13 (1984).

87. Takamura, K., Physico-Chemical Characterization of Athabasca Oil Sand and Its Significance to Bitumen Recovery, AOSTRA J. Res. 2 , 1-10 (1985).

88. Hupka, J., and Miller, J. D., Moderate-Temperature WaterBased Bitumen Recovery from Tar Sand, Fuel 70, 1308-1312 (1991).

89. Miller, J. D., and Misra, M., Hot Water Process Development for Utah Tar Sands, Fuel Proces. Technol. 6 , 27-59 (1982).

90. Sonntag, H., Colloids (in Polish), PWN, Warszawa 1982.

91. Leja, J., and Bowman, C. W., Application of Thermodynamics to the Athabasca Tar Sands, Can. J. Chem. Eng. 46, 479-481 (1968).

92. Kotlyar, L. S., Sparks, B. D., and Kodama, H., Isolation of Inorganic Matter-Humic Complexes from Athabasca Oil Sands, AOSTRA J. Res. 2, 103-111 (1985).

93. Hupka, J., and Miller, J. D., Moderate-Temperature WaterBased Processing of Tar Sands, Fuel 70, 1308-1312 (1991).

94. Hupka, J., Miller, J. D., and Cortes, A., Importance of Bitumen Viscosity in the Hot water Processing of Domestic Tar Sand, Mining Eng. $\underline{35}(12), 1635-1641$ (1983). 
95. Hupka, J., Oblad, A. G., and Miller, J. D., Diluent-Assisted Hot-Water Processing of Tar Sands, AOSTRA J. Res. 3 , 95-102 (1987).

96. Hall, E.'S., and Tollefson, E. L., Fines-Bitumen-Water Dispersion in Tailings from Oil-Sand Extraction Plants that use the Hot Water Process, Can. J. Chem. Eng. 60(12), 812-821 (1982).

97. Hall, E. S., and Tollefson, E. L., Recovery of Residual Bitumen from the Aqueous Tailings from Hot Water Extraction of Oil Sands by Air Sparging, Energy Processing 72, 39-46 (1980).

98. Bednarski, S., and Listewnik, J., Hydrocyclones for Simultaneous Removal of oil and Solid Particles from Ships' Oily Waters, 3 rd International Conference on Hydrocyclones, sept. 30-Oct. 2, oxford, England, 181-192 (1987).

99. Miller, J. D., and Ye, Y., Froth characteristics in AirSparged Hydrocyclone Flotation, Mineral Processing and Technology Review 5, 307-327 (1989).

100. Miller, J. D., and Hupka, J., Water De-Oiling in an AirSparged Hydrocyclone, Filtr. \& Sep. 20(4), 279-282 (1983).

101. Beeby, J. P., and Nicol, S. K., Concentration of Oil-inWater Emulsion Using the Air-Sparged Hydrocyclone, Filtr. \& Sep. 30(2), 141-146 (1993).

102. Miller, J. D., and Kinneberg, D. J., Fast flotation in an air-sparged hydrocyclone, Proc. of MINTEK 50, South Africa, vol. 1, March, 373-383 (1984).

103. Miller, J. D., Upadrashta, K. R., Kinneberg, D. J., and Gopalakrishnan, S., Fluid-Flow Phenomena in che Air-Sparged Hydrocyclone, Proceedings of the XV International Mineral Processing Congress, Cannes, France, vol. II, 87-99 (1985).

104. Lelinski, D., M.Sc. thesis, University of Utah, Department of Metallurgical Engineering, ASH Flotation of Dispersed Oil Droplets - A Model System for Bitumen Flotation from Tar Sands (1993).

105. Hupka, J., Leliński, D., and Miller, J. D., Air Bubble Filming During Bitumen Flotation From Digested Tar Sand Slurry, Proceedings of the Extended Abstracts of the 22-nd Annual Meeting of the Fine Particle Society, July 31-Aug. 1, San Jose, California, 83-84 (1991). 
106. Hupka, J., Kościukiewicz, J., and Drelich, J., Extraction of oil from Emulsion in the Presence of Surfactants, Chemia Analityczna $36,847-853,(1991)$, (in Polish).

107. Leja, J., and Bowman, C. W., Application of Thermodynamics to the Athabasca Tar Sands, Can. J. Chem. Eng. 46, 479-481 (1968).

108. Adamson, A., Physical Chemistry of Surfaces, John Wiley \& Sons, Inc., 109-119 (1990).

109. Schramm, L. L., and Smith, R. G., Two Classes of Anionic Surfactants and their Significance in Hot Water Processing of Oil Sands, Can. J. Chem. Eng. 65, 799-811 (1987).

110. Hupka, J., D.Sc. thesis, Technical University of Gdansk, Faculty of Chemistry, the Fundamentals for the

Implementation of Coalescence in Bed in Deoiling Wastewaters, (1988), (in Polish).

111. Gutkowski, B., Hupka, J., and Szyk, L., The Influence of Zeta Potential on oil Flctation from water, Chimia i Technologia Topliw i Masel $5,42-45$ (1989), (in Russian).

112. Yurko, W. J., and Wiggins, E. J., Alberta Oil Sands Technology - status of Development an Future Trends, Proceedings of the 1991 Eastern oil Shale Symposium • oil Shale - Tar Sands - Heavy Oil, Nov. 1.3-15, 1991; Lexington, KY, pp. 98-105.

113. Expansion of Underground Test Facility in Progress, Tar Paper, 13(4), 3 (1990).

114. Hupka, J., and Miller, J. D., Tar Sand Pretreatment with Diluent, Preprint No 92-122 of the 12lst SME AIME Annual Meeting in Phoenix, AZ, Feb. 24-27, 1992; Minerals and Metallurgical Processing, 1993, in print.

115. Evers, J. L., Update on Hydraulic Mining in the US, Mining Eng., 36(10), 1418-1422 (1984).

116. Savanick, G. A., Borehole (Slurry) Mining of Coal, Uraniferous Sandstone, Oil Sands, and Phosphate ore, Bureu of Mines Report of Investigations, RI 9101, 1987, $40 \mathrm{pp}$.

117. Herkenhoff, E. C., When Are We Going to Mine oil?, Eng. Min. $\mathrm{J} ., \underline{173}(6), 132-138$ (1972).

118. Knoke, G. S., and Archibald, W. R., Borehole Mining: An Environmentally Compatible Method for Mining oil Sands, BuMines OFR 50-81, 1980, 114 pp.; NTIS P's 81-214231. 
119. Hupka, J., Oblad, A.G., and Miller, J.D., Diluent-Assisted Hot water Processing of Tar Sands, AOSTRA J. Res. , 3, 95-102 (1987).

120. Hupka, J., and Miller, J.D., Moderate Temperature WaterBased Bitumen Recovery from Tar Sand, Fuel, 70, 1308-1312 (1991).

121. Drelich, J., Hanson, F.H., Hupka, J., and Miller, J.D., Water Recycle in Moderate-Temperature Bitumen Recovery from Whiterocks Tar Sand, AOSTRA J. Res., 1993, in print.

122. Law, D.H.S., Masliyah, J.H., and Nandakumar K., Ablation of Frozen oil Sands Under the Influence of Turbulent

Axisymmetric Jets, AOS'TRA J. Res., 고, 177-182 (1987).

123. Anderson, J. S., Carls, E. L., Mainhardt, P. J., Swift, W. M., Wheeldon. J. M., Brooks, S., Minchener, A. J. and Stringer, J., Wastage of In-Bed Heat Transfer Surfaces in the Pressurized Fluidized Bed Combustor at Grimethorpe, $J$. Eng. for Gas Turbines and Power 109, 298-304 (1987).

124. Dennis, R., Wear of 6061 Aluminum Test specimens during An In-Bed Exposure to An AFB Cold Model Environment, Wear 131, 241-250 (1989).

125. Zhu, J., Grace, J.R. and $\mathrm{T}$ im, C. J., Tube Wear in Gas Fluidized Beds-I. Experimental Findings, Chem. Eng. Sci. 45, 1003-1015 (1990).

126. MacAdam, S. and Stringer, J., Development of A Unique Laboratory Scale Fluidized Bed Wear Testing Unit, Wear 135, 403-422 (1990).

127. Zhu, J., Lim, C. J., Grace, J. R. and Lund, J. A., Tube Wear in Gas Fluidized Beds-II. Low Velocity Impact Erosion and Semi-Empirical Model for Bubbling and Slugging Fluidized Beds, Chem. Eng. Sci. 46, 1151-1156 (1991).

128. Wright, I. G., Nagarajan, V. and stringer, J., Observations on the Role of oxide Scales in High-Temperature Erosion-Corrosion of Alloys, Oxidation of Metals 25, 175$199(1986)$.

129. Levy, A. V., Wang, B. Q. and Geng, G. Q., Erosion-Corrosion of Carbon steel by Particles in Circulating Fluidized Bed Combustor, Mater. Sci. Eng. A121, 603-609 (1989).

130. Stott, F. H., Green, S. W. and Wood, G. C., The Influence of Temperature on the Erosion oxidation of steels in a Fluidized-Bed Environment, Mater. Sci. Eng. Al21, 611-617 (1989). 
131. Fontana, M. G., Corrosion Engineering, 3rd ed, McGrawHill, Inc., New York, NY (1986).

132. Smeltzer, G. E., Gulden, M. E. and Compton, W. A., Mechanisms of Metal Removal by Impacting Dust Particles, $J$. Basic Eng. Trans. ASME 92, 639-654 (1970).

133. Young, J. P. and Ruff, A. W., Particle Erosion Measurements on Metals, J. Eng. Mater. Tech. Trans. ASME 99, 121-125 (1977).

134. Oblad, A. G., Bunger, J. M., Hanson, F. V., Miller, J. D., Ritzma, H. R. and Seader, J. D., Tar Sand Research and Development at The University of Utah, Ann. Rev. Energy 12, 283-356 (1987).

135. Coronella, C. J. and Seader, J. D., Combustion of Coked Sand in a Two-Stage Fluidized Bed System, Fuel, 71 , 143150 (1992).

136. Clift, R., Gas Fluidization Technology, ed. D. Geldart, Wiley, New York (1986).

137. Wen, C. Y., Recent Advances in the Engineering Analysis of Chemically Reacting systems, ed. L. K. Doraiswamy, Wiley Eastern, New Delhi, (1984).

138. Broadhurst, T.E. and Becker, H. A., A.I.Ch.E. J. 21, 238 (1975).

139. Stewart, P. S. B, and Davidson, J. F., Powder Technol. 1, 61 (1967).

140. Darton, R. C., LaNauze, R. D., Davidson, J. F., and Harrison, D., Trans. Instn. Chem. Engrs. 55, 274 (1977).

141. Baeyens, J. and Geldart, D., Chem. Engng Sci. 29, 255 (1974).

142. Yates, J. G., Ruiz-Martinez, R. S. and Cheesman, D. J., Chem. Engng Sci. 45, 1105 (1990).

143. Grace, J. R. in 'Chemical Reactor Design' (Ed. H. delasa), Martinus Nijhof, den Haag, Netherlands (1986).

144. Sitnai, O. and Whitehead, A. B. in 'Fluidization (2nd edition)', ch. 14, (Ed. J. F. Davidson, R. Clift, and D. Harrison), Academic Press, London (1985).

145. Kunii, D. and Levenspiel, O., Ind. Engng Chem. Fundam. I, 446 (1968). 
146. Volk, W., Johnson, C. A., and Stotler, H. H., Chem. Engng Progr. 58, 44 (1962).

147. Saxena, S. C. and Rao, N. S., Energy 15, 489 (1990).

148. Kage, Iwasaki, H., N., Yamaguchi, H., and Matsuno, Y., J. Chem. Engng Japan 24, 76 (1991).

149. Dutta, A. and Dullea, L. V., A.I.Ch.E. Symp. Ser. No. 276, p. 26., AIChE, New York, (1990).

150. Broadhurst, T.E. and Becker, H. A., in Fluidization 'echnology, ed. by D.L. Keairns, Hemisphere Pub., Washington (1976).

151. Casal, J., A. Lucas, and Arnaldos, J., Chem. Engng J. $\underline{30}$, 155 (1985).

152. Rockey, J. M., Mei, J. S., Nakaishi, C. V., and Robey, E. H. in 1989 International Conference on Fluidized Bed Combustion: FBC - Technology for Today', Vol. 1, ed. by A. M. Manaker, p. 249. ASME, New York (1989).

153. Press, W. H., Flannery, B. P., Teukolsky, S. A., Vetterling, W. T., Numerical Recipes, Cambridge Press, Cambridge (1986).

154. Bendat, J. S. and Piersol, A. G., Random Data Analysis and Measurement Procedures, John wiley, New York (1986).

155. Noordergraaf, L. W., Van Dijk, A., and Van Den Bleed, C. M.. Powder Technol. $\underline{52}, 59$ (1987).

156. Tucker, R. C., Wear Failures, Metals Handbook, 9th ed., vol. 11, ASM, Cleveland, 145-162 (1978).

157. Hutchings, I. M., Wear by Particulates, Chem. Eng. Sci. 42, 869-878 (1987).

158. Shamlou, P. A., Liu, Z. and Yates, J. G., Hydrodynamic Influences on Particle Breakage in Fluidized Beds, Chem. Eng. Sci. 45, 809-817, (1990).

159. Yates, J. G., On the Erosion of Metal Tubes in Fluidized Beds, Chem. Eng. Sci. 느, 379-380 (1987).

160. Geldart, D., Single Particles, Fixed and Quiescent Beds, Gas Fluidization Technology, ed. D. Geldart, John Wiley \& Sons, New York, NY, 11-32 (1986).

161. Gansley, R. R. and O'Brien, T. J., A Model for BubbleInduced Erosion in Fluidized-Bed Combustors and Comparison with Experiment, Wear 137, 107-127 (1990). 
162. Finnie, I., Erosion of Surfaces by Solid Particles, Wear 3, 87-103 (1960).

163. Finnie, I. and McFadden, D. H., on the Velocity Dependence of the Erosion of Ductile Metals by Solid Particles at Low Angles of Incidence, Wear 48, 181-190 (1978).

164. Levy, A. V., Yan, J. and Patterson, J., Elevated

Temperature Erosion of Steels, Wear 108, 43-60 (1986).

165. Kruschov, M. M., Principles of Abrasive Wear, Wear 28, 6988 (1974).

166. Finnie, I., Wolak, J. and Kabil, Y., Erosion of Metals by Solid Particles, J. Mater. 2, 682-700 (1967).

167. Witherell, C. E., Metallurgical Characterization of Wasted Surfaces of In-Bed Carbon steel Evaporator Tubes,

Proceedings of the International Conference on Fluidized Bed Combustion, FBC - Technology for Today, ed. by A. M. Manaker, vol. II, ASME, NY, 937-944 (1989).

168. Pitt, C. H., Chang, Y. M., Wadsworth, M. E. and Kotlyar, D., Laboratory Abrasion and Electrochemical Test Methods as a Means of Determining Mechanism and Rates of Corrosion and Wear in Ball Mills, Int. J. Miner. Process 22, 361-380 (1988).

169. Levy, A., Slamovich, E. and Jee, N., Elevated Temperature Combined Erosion-Corrosion of Steels, Wear 110, 117-149 (1986).

170. Levy, A. and Man, Y. F., Elevated Temperature ErosionCorrosion of 9Cr-1Mo Steel, Wear 111, 135-159 (1986).

171. Parkinson, M. J., Napier, B. A. Jury, A. W. and Kempton, T. $J .$, Cold Model studies of PFBC Tube Erosion, Proceedings of 8 th International Conference on Fluidized Bed Combustions 2, 730-738 (1985).

172. Baker, C. G. J. and Geldart, D., Powder Technol. 19, 177 (1978).

173. Sadasivan, Barreteau, N. D., and Laguerie, C., Powder Technol. 26, 67 (1986).

174. Verloop, J. and Heertjes, P. M., Chem. Engng Sci., 29, 1035 $(1974)$.

175. Grace, J. R. and Harrison, D. in The Engineering of Gas Solid Reactions, p. 63., Institution of Chemical Engineers, London (1968). 
176. Gishler, P.E., "The Fluidization Technique Applied to Direct Distillation of Oil from Bituminous Sand," Can. J. of Research, 27, Sec. F. 104-111 (1949).

177. Peterson, W.S., and Gishler, P.E., "Oil from Alberta Bituminous Sands," Petrol. Eng., 236, C-66 (1951).

178. Donnel.ly, J.K., Moore, R.G., Bennion, D.W., and Trenkwalder, A.E., "A Fluidized Bed Retort of Oil Sands," The Can. J. Chem. Eng., 59, 68-75 (1981).

179. Weeks, J.K., Jr., Fluidized-Bed Processing of Utah Tar Sands. M.S. Thesis, University of Utah, Salt Lake City, Utah (1977).

180. Jayakar, K.M., Thermal Recovery of oil from Tar Sands. $\mathrm{Ph} . \mathrm{D}$. Dissertation, University of Utah. Salt Lake City, Utah (1979).

181. Venkatesan, V.N., Fluid Bed Thermal Recovery of Synthetic crude from Bituminous Sands of Utah, Ph.D. Dissertation, University of Utah. Salt Lake City, Utah (1980).

182. Bezama, R.J., An Energy-Efficient Method for Thermal Processing of Utah Tar Sands. Ph.D. Dissertation, University of Utah, Salt Lake City, Utah (1983).

183. Wang, J., The Production of Hydrocarbon Liquids from a Bitumen-Impregnated Sandstone in a Fluidized Bed Pyrolysis Reactor. M.S. Thesis, University of Utah, Salt Lake City, Utah (1983).

184. Smart, L.M., Thermal Processing of Utah Tar Sands. M.S. Thesis, University of Utah, Salt Lake City, Utah (1984).

185. Dorius, J.C., The Pyroloysis of Bitumen-Impregnated Sandstone from the PR Spring (Utah) Deposit in a Fluidized Bed. Ph.D. Dissertation, University of Utah, Salt Lake City, Utah (1985).

186. Sung, S.H., The Fluidized Bed Pyrolysis of BitumenImpregnated Sandstone in a Large Diameter Reactor. M.S. Thesis, University of Utah, Salt Lake City, Utah (1988).

187. Shun, D., The Pyrolysis of Bitumen-Impregnated Sandstone from the circle cliffs (Utah) Deposit in a Fluidized-Bed Reactor. Ph.D. Dissertation, University of Utah, Salt Lake City, Utah (1990). 
188. Hanson, F.V., and Oblad, A.G., "The Fluidized Bed Pyrolysis of Bitumen-Impregnated Sandstone from the Tar Sand Deposits of Utah," Fourth UNITAR/UNDP Proceedings, 5, Paper No. 155, 421-438 (1988).

189. Deo, M.D., Fletcher, J.V., Shun, D., Hanson, F.V., and Oblad, A.G., "Modelling the Pyrolysis of Tar Sands in Fluidized Bed Reactors," Fuel, 70, 1271-1276 (1991).

190. Oblad, A.G., Bunger, J.W., Hanson, F.V., Miller, J.D., Ritzma, H.R., and Seader, J.D., "Tar Sand Research and Development at the University of Utah," Ann. Rev. Energy 1987, 12, 283-356 (1987).

191. Abdrabboh, M.A. and Karim, G.A., "A Study of Mass Transfer Around Oil Sand Fragments inn High Temperature Atmospheres," J. of Energy Resources Technoli, 111, 97-99 (1989).

192. Rebick, C., "Pyrolysis of Heavy Hydrocarbons," Chapt 4 in Albright, L.F., et al. (eds) (1983). Pyrolysis: Theory and Industrial Practice. New York, NY: Academic Press. 69-87 (1983).

193. Reid, R.C., Prausnitz, J.M., and Poling, B.E., The Properties of Gases and Liquids, 4th ed. New York, NY: McGraw-Hill., Ch.9 (1987).

194. Davidson, J.F., Clift, R., and Harrison, D., (eds.), Fluidization, 2/E. London: Academic Press (1985).

195. Geldart, D. (ed.), Gas Fluidization Technology. Chichester, GB: John Wiley \& Sons (1986).

196. Howard, J.R., Fluidized Bed Technology, Principles and Applications. Bristol: Adam Hilger (1989).

197. Kunii, D., and Levenspiel, O., Fluidization Engineering, 2/E. Boston: Butterworth-Heinemann (1991).

198. Bhat, G.N., and whitehead, A.B., "Heat Transfer in Subatmospheric Fluidized Beds," Aust. J. Appl. Sci., 14, 198-203 (1963).

199. Huschka, H., and Popp, W., "Coating of Feed- and BreedParticles in a Fluidised Bed Under Reduced Pressure," J. Nucl. Mater., 23, 109-110 (1967).

200. Kawamura, S., and Suezawa, Y., "The Flow of Gas in a Fluidized Bed at Low Pressure," Kagaku Kogaku, 25, 524-530 (1961). 
201. Germain, B., and Claudel, B., "Fluidization at Mean Pressures Less Than 30 Torr," Powder Technol,, 13, 115-121 (1976).

202. Zabrodsky, S.S., Atonishin, N.V., and Parnas, A.L., "On Fluidized Bed-to-Surface Heat Transfer," Can. J. Chem. Eng., 54, 52-58 (1976).

203. Kusakabe, K., Kuriyama, T., and Morooka, S., "Fluidization offine Particles at Reduced Pressure," Powder Technol., 58, 125-130 (19نy).

204. Grace, J.R., "Contacting Modes and Behavior Classification of Gas-Solid and Other Two-Phase Suspensions," Can. J. Chem. Eng. 64. 353-363 (1986).

205. Perry, R.H., Green, D.W., and Maloney, J.O. (eds), Perry's Chemical Engineers' Handbook. 6/E. New York, NY: McGrawHill (1984).

206. Bland, W.F., and Davidson, R.L. (eds), Petroleum Processing Handbook. New York, NY: McGraw-Hill (1967).

207. Reed, R.J. (ed), North American Combustion Handbook. Cleveland, OH: North American Mfg. Co. (1978).

208. Knowlton, T.M., Chapter 12 in Geldart, D. (ed.) (1986). Gas Fluidization Technology. Chichester, GB: John wiley \& Sons, Inc. (1986).

209. Cha, Soon-Man., Pyrolysis of Oil sands from the whiterocks Tar Sand Deposit in a Rotary Kiln. Ph.D. Dissertation, University of Utah, Salt Lake City, Utah (1991).

210. Dean, J.A. (ed), Lange's Handbook of Chemistry, 13e. New York, NY: Mcgraw-Hill (1985).

211. Perry, J.H. (ed), Chemical Engineers' Handbook. 3/E. New York, NY: McGraw-Hill (1950).

212. Hong, S.C., Jo, B.R., Doh, S. and Choi, C.S., "Determination of Minimum Fluidization Velocity by the statistical Analysis of Pressure Fluctuations in a Gas-Solid Fluidized Bed," Powder Technol., 60, 215-221 (1990).

213. Geldart, D., "Estimation of Basic Particle Properties for Use in Fluid-Particle Process Calculations," Powder Technol., 60, 1-13 (1990). 
214. Fletcher, J.V., Deo, M.D., and Hanson, F.V., "Re-examination of Minimum Fluidization Velocity Correlations Applied to Group B Sands and Coked Sands," Powder Technol., 69, 147-155 (1992).

215. Ould-Dris, A., and Molodsof, Y., "Basic Mechanisms and Principles of the Operation of a Nonmechanical L-Valve," in Anthony, E.J. (ed.). Proceedings of the 1991 International Conference on Fluidized Bed Combustion. NY: ASME (1991).

216. Lin, L.C., Deo, M.D., Hanson, F.V., and Oblad, A.G., "Kinetics of Tar Sand Pyrolysis Using a Distribution of Activation Energy Model," AIChE J., 36, (10), 1585-1588 (1990).

217. Resnick, B. S., Dike, D. H., English, L. M. and Lewis, A. G., Evaluation of Tar Sand Mining: Vol I. An Assessment of Resources Amenable to Mine Production, 1981, Final Report DOE/ET/30201-1 (DE82010249).

218. Miller, J. D. and Misra, M., Fuel proc. Technol., 1982, 6, 27.

219. Miller, J. D. and Misra, M., Int. J. Miner. Process, 1982, 9,269 .

220. Hanson, F. V. and Oblad, A. G., Proceedings of the Fourth UNITAR/UNDP International Conference on Heavy Crude and Tar Sands, AOSTRA, Edmonton, Alberta, Canada, 1989, Vol. 5, p. 421 .

221. Cha, S., PhD Dissertation, University of Utah, Salt Lake City, 1991.

222. Cha, S., Hanson, F. V., Longstaff, D. C. and Oblad, A. G. , Fuel, 1991, 70, 1357 .

223. Randall, J. S. US Patent No. 4,160,718.

224. Randal1, J. S. US Patent No. 4,160,718.

225. Randal1, J. S. US Patent No. $4,160,718$.

226. Tsai, C. H., Deo, M. D., Hanson, F. V. and Oblad, A. G., Fuel Sci. Technol Int., 1991, 9, 1259.

227. Tsai, C. H., Deo, M. D., Hanson, F. V. and Oblad, A. G., Fuel Sci. Technol. Int., 1992, 10, 1437.

228. Keefer, T. N. and McQuivey, R. S., water Availability for Development of Major Tar Sand Areas in Utah, 1979, Final Report SCR 337-79-010 (LETC-0013-1). 
229. Venkatesan, V., PhD Dissertation, University of Utah, Salt Lake City, UT, 1979.

230. Wang, C., MS Thesis, University of Utah, Salt Lake City, UT, 1983.

231. Dorius, J., PhD Dissertation, University of Utah, Salt Lake City, UT, 1985.

232. Shun, D., PhD Dissertation, University of Utah, Salt Lake City, UT, 1990.

233. Longstaff, D. C., Deo, M. D., Hanson, F. V., and Oblad, A. G., Fuel, 1992, 71, 1407.

234. Tsai, C. H., Longstaff, D. C., Deo, M. D., Hanson, F. V. and Oblad, A. G., Fuel, 1992, 71, 1473.

235. Wood, R. E. and Ritzma, H. R., Utah Geological and Mineralogical survey, Special studies 39, (1972).

236. Longstaff, D. C., PhD Dissertation, University of Utah, Salt Lake City, UT, 1992.

237. Kirchen, R. P. and Sanford, E. C., AOSTRA J. Res., 1989, 5, 287.

238. Sullivan, R. F. and Stangeland, B. E., symp. on Refining of synthetic Crudes, ACS Mtg., Chicago, IL, 1977.

239. Yui, S. M., AOSTRA J.Res., 1989, 5, 211.

240. Riley, K. L., Prepr. Am. Chem. Soc. Div. Pet. Chem,, 1978, 23, 1104 .

241. Ho, T. C. and Aris, R., AIChE J., 1987, 33, 1050.

242. de Bruijn, A., Proc. Sixth Internat. Conf. Catal., 1976, 2, 951 .

243. Kemp, R. R. D. and Wojciechowski, B. W., Ind. Eng. Chem., Fundam., 1974, 13, 332 .

244. Ohtsuka, T., Catal. Rev. Sci. Eng., 1977, 16, 291.

245. Mosby, J. F., Buttke, R. D., Cox, J. A. and Nickolaides, C., Chem. Eng. Sci., 1986, 41, 2, 989.

246. Bukka, K., Hanson, F. V., Miller, J. D. and Oblad, A. G., Energy \& Fuels, 1992, 6, 160. 
247. Bunger, J. W., Cogswell, D. E. and Zilm, K. W., Prepr. Am. Chem. Soc. Div. Pet. Chem., 1979, 24, 1017.

248. Speight, J. G., Proceedings of the 1991 Eastern Oil Shale Symposium, Lexington, Kentucky, United States, 1991, p. 17.

249. Trytten, L. C., Gray, M. R. and Sanford, E. C., Ind. Eng. Chem. Res., 1990, 29, (5), 725.

250. Free, H. H. and Lovink, H. J., Erdoel Kohle, 1987, 40, 346 .

251. Beaton, W. I. and Bertolacini, R. J., Catal. Rev.-Sci. Eng., 1991, 33, 281.

252. Ho, T. C., Catal. Rev.-Sci. Eng., 1988, 30, 117.

253. Press, W. H. , Flannery, B. P. , Teukolsky, S. A. and Vetterling, $W$. T., Numerical Recipes: The Art of Scientific Computing, Cambridge University Press, Cambridge, 1986, p. 289.

254. Resnick, B.S., Dike, D.H. English, L.M., and Lewis, A.G.' "Evaluation of Tar Sand Mining, Vol. 1. An Assessment of Resources Amenable to Mine Production," DOE/ET/30201-1 (DE82010249).

255. Miller, J.D. and Misra, M., "Hot Water Process Development for Után Tar Sands," Fuel Proc. Technol, 1982, $6,27$.

256. Miller, J.D. and Misra, M., "Concentration of Utah Tar Sands by an Ambient Flotation Process," Internat. J. Miner. Proc., $1982,269$.

257. Rendall, J.S., "Hot Water Bitumen Extraction Process," U.S. Pat., 4,875,998 (Oct. 24, 1989).

258. Rendall, J.S., "Solvent Extraction Process," U.S. Pat. $4,160,718$ (July 10, 1979).

259. Rendall, J.S., "Method and Apparatus for Solvent Extraction," U.S. Pat. 4,424,112 (Jan. 3, 1984).

260. Taciuk, W., Turner, L.R., and Wright, B.C., "Oil shale Processing with the AOSTRA Taciuk Processor," Proc. 4th UN TAR/UNDP Internat. Conf. on Heavy Crude and Tar Sands, 1989, $5(237), 439$.

261. Taciuk, W., "Process for Thermal Cracking a Heavy Hydrocarbons" U.S. Pat. 4,180,455 (1977). 
262. Boyer, L.D., Sooter, M.C., and Save, F.E., "Method for Production of Distillable Hydrocarbonaceous Fuels and Carbonaceous Agglomerates from Heavy Crude oil," U.S. Pat. $4,473,464(1984)$.

263. Zimmermann, K.F., "Rotary Kiln for Drying and Deoiling oil Sands and Oil Shales," Germany Pat. DE 3,042,146 (1980).

264. Cha, C.Y. and Guffey, F.D., "Recycle Oil Pyrolysis and Extraction of Tar Sand,": Proc. of 4 th UNITAR/UNDP Internat. Conf. on Heavy Crude and Tar Sands, 1987, ㅍ(106) 449 .

265. Venkatesan, V.N., "Fluidized-Bed Thermal Recovery of Synthetic Crude from Bituminous Sands of Utah," Ph.D. Dissertation, University of Utah, Salt Lake City, Utah (1979).

266. Wang, J., "The Production of Hydrocarbon Liquids from a Bitumen-Impregnated Sandstone in a Fluidized Bed Pyrolysis Reactor," M.S. Thesis, University of Utah, Salt Lake city, Utah (1983).

267. Dorius, J.C., "The Pyrolysis of Bitumen Impregnated Sandstone from the P.R. Spring (Utah) Deposit in a Fluidized Bed," PhD. Dissertation, University of Utah, salt Lake City, Utah (1985).

268. Sung, S.H., "The Fluidized Bed Pyrolysis of BitumenImpregnated Sandstone in a Large Diameter Reactor," M.S. Thesis, University of Utah, Salt Lake City, Utah (1988).

269. Shun, D., "Fluidized bed Pyrolysis of the BitumenImpregnated Sandstone from the Circle Cliff Deposit," Ph.D. Dissertation, University of Utah, Salt Lake City, Utah (1990).

270. Cha, S., Hanson, F.V., Longstaff, D.C., and Oblad, A.G., "Pyrolysis of Bitumen Impregnated sandstones: A comparison of Fluidized Bed and Rotary Kiln Reactors," Proc. 1990 Eastern Oil Shale Conf., 136-1245(1991); FUEL, 1991, 70, 1357 .

271. Cha, S., "Pyrolysis of oil sands from the Whiterocks Tar Sands Deposit in a Rotary Kiln," Ph.D. Dissertation, University of Utah, Salt Lake City, Utah (1991).

272. Hanson, F.V. and Oblad, A.G., "The Fluidized Bed Pyrolysis of Bitumen-Impregnated Sandstone from the Tar Sand Deposits of Utah," Proc. Fourth UNITAR/UNP Internat. Conf. on heavy Crude and Tar Sands, 1989, 5(155), 421 . 
273. Longstaff, D.C., "Hydrotreating the Bitumen and BitumenDerived Liquid from the Whiterocks oil sand Deposit," Ph.D. Dissertation, University of Utah, Salt Lake City, Utah (1992)

274. Longstaff, D.C., Deo, M.D., Hanson, F.V., and Oblad, A.G., "Hydrotreating the Bitumen-Derived Hydrocarbon Liquid Produced in a Fluidized-Bed Pyrolysis Reactor," Proc. 1991 Eastern oil Shale Symp., FUEL, 1992 (in press).

275. Banerjee, D.K., Laidler, K.J., Nandi, B.N. and Patmore, D.T., "Kinetic Studies of Coke Formation in Hydrocarbon Fractions of Heavy Crudes," FUEL, 1986 65, 480 .

276. Philp, R.P., Fossil Fuel Biomarkers - Applications and Spectra, 1985, Elsevier, Amsterdam, The Netherlands.

277. Henderson, W., Wollrab, V., and Eglinton, G., "Identification of steroids and Triterpenes from a Geological Source by Capillary Gas-liquid Chromatography," Chem. Commun., 1968, 710

278. Anderson, P.C., Gardner, P.M. and Whitehead, E.V., "The Isolation of Steranes from Green River Shale," Geochim. Cosmochim. Acta, 1969, 33, 1304 .

279. Anders, D.E. and Robinson, W.E., "Cycloalkanes constituents of the Bitumen from Green River Shale, "Geochm. Cosmochim. Acta, 1971, 35, 661.

280. Gallegos, E.J., "Identification of New Steranes, Terpanes and Brandied Paraffins in Green River Shale by Combined Capillary Gas Chromatography and Mass Spectrometry," Anal. Chem., 1971, 43(10), 1151 .

281. Gallegos, E.J., "Identification of Phenylcycloparaffin Alkanes and other Monoaromatics in Green River shale by Gas Chromatography-Mass Spectrometry," Anal. Chem., 1973, 45(8), 1399.

282. Reed, W.E., "Molecular Compositions of Weathered Petroleum and Comparison with its Possible sources," Geochim. Cosmochim. Acta, 1977, 41, 237.

283. Trendel, J.M., Restle, A., Connan, J. and Albrecht, P., "Identification of Novel Series of Tetracyclic Terpene Hydrocarbons $\left(\mathrm{C}_{24}-\mathrm{C}_{27}\right)$ in sediments and Petroleum, "J. Chem. Soc., Chem., Commun., 1982, 304. 


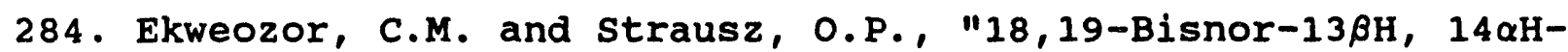
Cheilanthane: A Novel Degraded Tricyclic Sesquieterpenoidtype Hydrocarbon from the Athabasca oil sands," Tetrahedron Letters, 1982, 23(27), 2711.

285. Whitehead, E.V., "The Structure of Petroleum Pentacyclanes," in Advances in Geochemistry (eds, B. Tissot and F. Bienner), Editions, Technips, Paris, 1974, 225.

286. Bendoraitis, J.G., "Hydrocarbons of Biogenic origin in Petroleum-Aromatic Triterpanes and Bicyclic Sesquiterpenes," in Advances in Geochemistry (eds, B. Tissot and F. Bienner), Editions, Technips. Paris, 1974, 209.

287. Kimble, B.J., Maxwell, J.R., Philp, R.P. and Eglinton, G.," Identification of Steranes and Triterpanes in Geolipid Extracts by High Resolution Gas Chromatography and Mass Spectrometry," Chem. Geology, 1974, 14, 173.

288. Aquino Neto, F.R., Restle, J., Connan, J., Albrecht, P. and Ourissoh, G., "Novel Tricyclic Terpanes $\left(C_{19}-C_{20}\right)$ in Sediments and Petroleums," Tetrahedron Letters, 1982, $\underline{23}(19), 2027$.

289. Boduszynski, M.M., "Composition of Heavy Petroleums 2. Molecular Characterization," Energy and Fuels, 1988, 2 (5), 597 .

290. Barakat, A.O. and Yen, T.F., "Distribution of Pentacyclic Triterpenoids in Green River oil Shale Kerogen," Org. Geochim., 1990, 15(3), 299.

291. Van Dorseelaer, A., Ensiminger, A., Spyckerelle, C., Dastilling, M., Sieskand, O., Arpino, D., Albrecht, P. and Ourisson, E.," "Degraded and Extended Hopane Derivatives $\left(\mathrm{C}_{27}\right.$ to $C_{35}$ ) as Ubiquitous Geochemical Markers," Tetrahedron Letters, $1974,15,(14), 1349$.

292. Rullkotter, J., and Philp, P., "Extended Hopanes up to $\mathrm{C}_{40}$ in Thornton Bitumen," Nature, 1981, 292, 616.

293. Huang, P. and Curry, D.J., "Isoprenoids in a Costa Rican Seep Oil," Geochim. Cosmochim. Acta, 1974, 28, 601.

294. Killops, S.D., "Novel Aromatic Hydrocarbons of Probable Bacterial origin in a Jurassic Lacustrine Sequence," Org. Geochem., 1991, 17(1), 25.

295. Hussler, G., Connan, J. and Albrecht, P., "Novel Families of Tetra- and Hexacyclic Aromatic Hopanoids Predominant in Carbonate Rocks and Crude Oils," Org. Geochim., 1984, 6, 39. 
296. Summons, R.E., and Powell, T.G., "Identification of Aryl Isoprenoids in Source Rocks and Crude Oils: Biological Markers for the Green Sulphur Bacteria," Geochim. Cosmochim. Acta, 1987, 57557 .

297. Jiang, Z., Fowler, M.G., Lewis, C.A., and Philp, R.P. " Polycyclic Alkanes in a Biodegraded oil from the Kelamayi Oilfield. Northwestern China, "Org. Geochem., $1990,15(1), 35$.

298. Petrov, Al.A., Vorobyava, N.S. and Zemskova, Z.K.," Isoprenoid Alkanes with Irregular "Head-to-Head" Linkages," org. Geochem., 1990, 16(416), 1001.

299. Goodwin, N.S., Mann, A.L. and Patience, R.L., "Structure and Significance of $\mathrm{C}_{30}$ 4-Methyl sterane in Lacustrine Shales and Oils," Org. Geochim., 1988, 12(5), 495.

300. Azerdeo, D.A., Aquino Neto, F.R., and Simoneit, B.R.T., "Mass Spectrometric Characteristics of a Novel Series of Ring-C Monoaromatic Tricyclic Terpanes Found in Tasmanian Tasmanite," Org. Mass Spectrometry, 1990, 25, 475.

301. Greiner, A. Ch., Spyckerelle, C., and Albrecht, P., "Aromatic Hydrocarbons from Geological Sources- I. New Naturally occurring Phenanthrene and Chrysene Derivatives," Tetrahedron letters, 1975, 32, 257 .

302. Jiang, Z., Philp, R.P. and Lewis, C.a., "Identification of Novel Bicyclic Alkanes from Steroid Precursors in Crude oils from Kelamayi Oilfield of Chian," Geochim. Cosmochim. Acta, $1988, \underline{52}, 491$.

303. Chen, J.H., Philp, R.P. Fu, J.M, and Sheng, G.Y., "The Occurrence and Identification of $C_{30}-C_{32}$ Lanostanes. A novel Eries of Tetracyclic Triterpenoid Hydrocarbons," Geochem. Cusmoschim. Acta, 1989, 53, 2775.

304. Modowan, J.M., Lee, C.Y., Watt, D.S., Jeganathan A., SLongiu, N. and Gallegos, E.J., "Analysis and Occurrence of $\mathrm{C}_{26}$-steranes in Petroleum and source Rocks," Geochim. cosmochim. Acta, 1991, 55, 1065.

305. Petrov, A.A., Pehk, T.Y., Vorobieva, N.S., and Zemstova, Z., "Identification of Some Novel Tetracyclic Diterpene Hydrocarbons in Petroleum," Org. Geochem., 1988, 12(2), 151.

306. Azevedo, D.A., Aquino Neto, F.R., Zimoneit, B.R.T., and Pinto, A.C., "Novel Series of Tricyclic Aromatic Terpanes Characterized in Tasmanian Tasmanite," Org. Geochem., 1992, $18(1), 9$. 
307. Heissler, D., Ocampo, R., Albrecht, D., Riehl, J. and Ourisson, G., "Identification of Long Chain Tricyclic Terpene Hydrocarbons $\left(\mathrm{C}_{21}-\mathrm{C}_{30}\right)$ in Geological Samples," $\mathrm{J}$. Chem. Soc., Chem. Commun., 1984, 496.

308. Chicarelli, M.I., Aquino Neto, F.R. and Albrecht, P., "Occurrence of Four Stereoisomeric Tricyclic Terpene Series in Immature Brazilian Shales," Geochm. Cosmochim. Acta, $1988, \underline{52}, 1955$.

309. Moldowan, J.M. and seifert, W.K., "Identification of an Extended Series of Tricyclic Terpane in Petroleum", Geochim. Cosmochim. Acta, 1983, 47, 1531.

310. Seifert, W.K., Moldowan, J.M., Smith, G.W. and Whitehead, E.V., "First Proof of structure of a $\mathrm{C}_{28}$-pentaterpanes in Petroleum," Nature, 1978, 271, 436.

311. Volman, J.K., Alexander, R., and Kagai, R.J., "GC-MS Characterization of $C_{27}$ and $C_{28}$ Triterpanes in sediments and Petroleum," Geochim. Cosmochim. Acta, 1983, 47, 1033.

312. Summons, R.E., and Jahnke, L.L., "Identification of the Methylhopanes in Sediments and Petroleum," Geochim. Cosmochim. Acta, 1990, 54, 247.

313. Moldowan, J.M. Fago, F.J., Carlson, R.M.K. , Young, D.C., Duyne, G.V., Clardy, J., Schoell, M., Pillinger, C.T. and Watt, D.S., "Rearranged Hopanes in sediments and Petroleum",Geochim. Cosmochim. Acta, 1991, 55, 3333.

314. Dunlap, N.K., Sabol, M.R., Bauer, P.E., Watt, D.S., Reibenspies, J.H., Anderson, O.P., Seifert, W.K. and Moldowan, J.M., "Synthesis of Biological Markers in Fossil Fuels. 3. Degraded and Rearranged $\mathrm{C}_{27}$ Hopanes," J. Org. Chem., 1985, 50, 1826.

315. Bauer, P.E., Dunlap, N.K., Arseniyadia, S., Watt, D.S., Seifert, W.K. and Moldowan, J.J., "Synthesis of Biological Markers in Fossil Fuels $1.17 \alpha$ and $17 \beta$ Isomers of $30-$ Norhopane and 30-Normoretane," J. Org. Chem., 1983, 48, 4493 .

316. Moldowan, J.M. and Seifert, W.K., "Structire Proof and Significance of Stereoisomic 28,30-Bisnonopanes in Petroleum and Petroleum Source Rocks," Geochim. Cosmochim. Acta, 2984, 48 1651.

317. Hussler, G., Chappe, B., Wehrung, P. and Albrecht, P., "C $\mathrm{C}_{27}$ ${ }^{\wedge} \mathrm{C}_{29}$ Ring a Monoaromatic Steroids in Cretaceous Black Shales," Nature, 1981, 294, 556. 
318. Ensminger, A., Joly, G. and Albrecht, P., "Rearranged Steranes in Sediments and Crude Oils," Tetrahedron Letters, $1978,1575$.

319. Ourisson, G., Albrecht, P. and Rohmer, M., "The Hopanoids. Palaeochemistry and Biochemistry of a Group of Natural Products," Pure \& Appl. Chem., 1979, 51, 709.

320. Zundel, M. and Rohmer, M., "Prokaryotic Triterpenoids, 1. $3 \beta$-Methylhopanoids from Acetobacteris species and Methylococcus Capsulatus," Eur. J. Biochem., 1985, 150, 23.

321. Bisseret, P., Zundel, M. and Rohmer, M., "Prokaryotic Triterpenoids, 2. 2 $\beta$-Methylhopanoids from Methylobacterium Organophilum and Nostoc Muscorum, a New Series of

Prokaryotic Triterpenoids," Eur. J. Biochem., 1985, 150, 29.

322. McEvoy, J. and Giger, W., "Origin of Hydrocarbons in Triassic Serpiano Oil Shales: Hopanoids," Org. Geochem., $19986,10,943$.

323. Wolff, G.A., Lamb, N.A. and Maxwell, J.R., "The Origin and Fate of 4-Methyl steroids - II. Dehydration of stanols and occurrence of $C_{30}$ 4-Methyl steranes," Org. Geochem., 1986, 10, 965 .

324. Noble, R.A., Alexander, R., Kagi, R.I. and Knox, J., "Identification of Some Diterpenoid Hydrocarbons in Petroleum," org. Geochem., 1986, 10, 825.

325. Jiang, Z.S. and Fowler, M.G., "Carotenoid-Derived Alkanes in Oils from Northwestern China," Org. Geochem., 1986, 10, 831.

326. Bellamy, L.J., The Infrared Spectra of Complex Molecules, 1975, Third Ed., Chapman and Hall, London.

327. Jiang, Z., Philp, R.P. and Lewis, C.A., "Identification of Novel Bicyclic Alkanes from Steroid Precursors in Crude Oils from Kealmayi Oilfield at China," Geochim. Cosmochim. Acta, $1988, \underline{52}, 491$.

328. Alexander, R., Kagi, R. and Noble, R., 'Identification of the bicyclic Sesquiterpenes Drimane and Eudesmane in Petroleum," J. Chem. Soc., Chem. Commun., 1983, 226.

329. Tsai, Chi H., "Novel Synthetic Approaches to Advanced Jet Fuels," Ph.D. Dissertation, University of Utah, Salt Lake City, Utah (1990).

330. Bukka, K. and Rose, P., unpublished results. 
331. Tsai, Chi-H., Deo, M.D., Hanson, F.V. and Oblad, A.G., "Characterization and Potential Utilization of Whiterocks (Utah) Tar Sand Bitumen," Fuel Sci. Technol. Internat., 1991.

332. Tsai, Chi H., Deo, M.D., Hanson, F.V. and Oblad, A.G., "Characterization and Potential Utilization of Asphalt Ridge (Utah) Tar Sand Bitumen. I. Gas Chromatograph-Mass Spectrometry and Pyrolysis-Mass Spectrometry, Fuel Sci. Technol. Internat, (in press).

333. Tsai, Chi-H. and Oblad, A.G., unpublished results.

334. Tsai, C.H., Deo, M.D., Hanson, F.V. and Oblad, A.G., "Characterization and Potential Utilization of Whiterocks (Utah) Tar Sand Bitumen. II. Pyrolysis Mass spectrometry and Nuclear Magnetic Resonance Analyses," Fuel Sci. Technol. Internat., 1992, 10(9), 1437.

335. Strauss, O.P., "Structural Features of Athabasca Bitumen Related to Upgrading Performance," Am. Chem. Soc., Div. Pet. Chem., 1989, 34 (2), 395.

336. Rudnick, L.R. and Galya, L.G., "Structural and Chemical Changes during coking of Two Petroleum Residua: Hydrogen and Carbon Distribution of Liquid Products," Energy \& Fuels, $1991, \underline{5}, 733$.

337. Speight, J.G., "The Chemistry and Technology of Petroleum," 2nd Ed., 1991, Marcel Dekker, New York, Chapter 11.

338. Kissin, Y.V., "A Cyclic Components in Dewaxed Heavy Distillates," FUEL, 1990, 69, 1283.

339. Espitalie, J., Makadi, K.S. and Trichet, J., "Role of the Mineral Matrix during Kerogen Pyrolysis," Org. Geochem., $1984, \underline{6}, 365$.

340. Graf, D.L. and Goldsmith, J.R.," " Geochim. Cosmochim. Acta, 1955, I, 109.

341. Ritchie, R.G.S., Roche, R.S. and Steedman, W., "NonIsothermal Programmed Pyrolysis studies of oil sand Bitumens and Bitumen Fractions. I. Athabasca Asphaltene," FUEL, $1985,64,391$.

342. Speight, J. G., 1991. The Chemistry and Technology of petroleum. Second Edition, Marcel Dekker, New York, NY.

343. Mitchell, D. L. and speight, J.G., 1973. The solubility of Asphaltenes in Hydrocarbon Solvents. FUEL, 52, 151. 
344. Burke, N. E., Hobbs, R. E. and Kashou, S. F., 1990. Measurement and Modeling of Asphaltene Precipitation. J. Pet. Tech., 42, 1440 .

345. Chaback, J. J., 1991. Discussion of Measurement and Modeling of Asphaltene Precipitation. J. Pet. Tech., 43, 1519.

346. Hirschberg, A., de Jong L.N.J., Schipper, B.A., Meijers, J.G., 1984. Influence of Temperature and Pressure on Asphaltene Flocculation. Soc. Pet. J., 24(3), 283.

347. Leontaritis, K.J. and Mansoori, G.A., 1987. Asphaltene Flocculation During Oil Production and Processing: A Thermodynamic Colloidal Model. Paper SPE 16258 presented at the SPE Symposium on Oilfield Chemistry held in San Antonio, Texas, February 4-6, 1987.

348. Kawanaka S., Park, S.J. and Mansoori, G.A., 1991. Organic Deposition from Reservoir Fluids: A Thermodynamic Predictive Technique. SPE Res. Eng., 6(2), 185-192.

349. Kawanaka, S. Leontaritis, K.J., Park, S.J. and Mansoori, G. A., 1989. Thermodynamic and Colloidal Models of Asphaltene Flocculation. Oil-field Chemistry and Enhanced Recovery and Production Stimulation. ACS Symp. Series 396, Ch. 24, 444-458.

350. AOSTRA, 1979. Syncrude Analytical Methods for Oil Sand and Bitumen Processing. Edmonton, Alberta, Canada.

351. Orr, F. M., Jr. and Silva, M. K., 1983. Equilibrium Phase Compositions of $\mathrm{CO} 2$ /Hydrocarbon Mixtures-Part 1: Measurement by a Continuous Multiple-contact Experiment. Soc. Pet. Eng. J., 23, 272 .

352. Orr, F. M., Jr. and Silva, M. K. and Lien, C., 1983. Equilibrium Phase Compositions of Co\$_\$/Crude oil Mixtures- Part 2: Comparison of Continūous Multiple Contact and Slim-Tube Displacement Tests. Soc. Pet. Eng. J., 23, 281 .

353. Peng, D. Y. and Robinson D. B., 1976. A New Two-Constant Equation of State. Ind. Eng. Chem. Fund., 15, 59.

354. McHugh, M.A. and Krukonis, V.J., 1986. Supercritical Fluid Extraction - Principles and Practice. Butterworths, Boston, MA.

355. Bukka, K., 1992. Personal Communications. 


\section{APPENDIX A}

\section{WHITEROCKS OIL SAND DEPOSIT BIBLIOGRAPHY}

Barb, C.F., 1942, Rubber from the Uinta Basin of Utah: Mines Magazine, 32, \#10, 521-524

Ball Associates, Ltd. 1964, Surface and Shallow 0il-Impregnated Rocks and Shallow oil Fields in the United States, U.S. Bureau of Mines, Monograph 12 .

Ball, D., Marchant, L.C., and Goldburg, A., 1982, The IocC Monograph Series: Tar Sands, Interstate oil Compact Commission, oklahoma City, Oklahoma

Barb, C.F., and J.D. Ball, 1944, Hydrocarbons of the Uinta Basin: Quart 39 , \#1

Bukka, K., Miller, J.D., Hanson, F.V., and Oblad, A.G., 1991, Mineral Matter Distribution During the Hot Water Processing of Utah Tar Sand, AOSTRA J. Res, 7, 101-109

Bukka, K., Hanson, F.V., Miller, J.D., and Oblad, A.G., 1992, Fractionationa and Characterization of Whiterocks Tar sand Bitumen, Energy and Fuels $6,160-165$.

Campbell, J.A., and H.R. Ritzma, 1976, Structural Geology and Petroleum Potential of the South Flank of the Uinta Mountain Uplift [abstract]: American Assoc. of Petrol. Geol., Bull 60, $1392-1393$

Cashion. W.B., Jr., 1964, other Bituminous Substances: Utah Geol. Min. Sur. Bull. 73, Mineral and Water Resources of Utah

Cha, S., Pyrolysis of the Whiterocks Tar Sand in a rotary Kiln Reactor, Ph.D. Dissertation, University of Utah, Salt Lake City, Utah

Cha, S., Longstaff, D.C., Hanson, F.V., and Oblad A.G., 1990, Pyrolysis of Bitumen Impregnated Sandstones: A Comparison of Fluidized - Bed and Rotary Kiln Reactors, Proc. 1990 Eastern Oil Shale Symposium, 136-145

Cha, S., Longstaff, D.C., Hanson, F.V., and Oblad, A.G., 1991, Pyrolysis of Bitumen Impregnated Sandstones: A Comparison of Fluidized-Bed and Rotary-Kiln Reactors, Fuel, 70, 1357-1361.

Covington, R.E., 1963, Bituminous Sandstone and Limestone Deposits of Utah: Utah Geol. and Min. Sur., Bull. 54, 225-247 
Covington, R.E., 1964, Bituminous Sands with Viscous Crude Oils: Brigham Young University, First Intermountain Symposium of Fossil Hydrocarbons, 364-374

Covington, R.E., 1964, Bituminous Sandstone in the Uinta Basin: Intermtn. Assoc. of Petrol. Geol., 13th Annual Field Conference, $227-242$

Covington, R.E., 1964, Thermal Recovery May Bring Industry's quiet Revolution: Oil \& Gas Journal, 62, \#47, 112-118

Covington, R.E., 1965, Some Possible Applications of Thermal Recovery in Utah: Petrol. Tech. 17, \#11, 1277-1284

Deo, M.D., and Hanson, F.V., 1993, Asphaltene Precipitation: A Need for a Broader View, SPE 25193

Deo, M.D., Hwang, J., and Hanson, F.V., 1993. The Effect of Cosolubilizing Lighter Components on the Asphaltene Content of Heavy Oils, Fuel Proc. Technol, In Press

Deo, M.D., Hwang, J., and Hanson, F.V., 1991, Supercritical Fluid Extraction of a Crude Oil, Bitumen-Derived Liquid and Bitumen by Carbon Dioxide and Propane, Fuel, 71, 1519-1526.

Dorius, J.C., 1985, The Pyrolysis of Bitumen Impregnated sandstone from the PR Spring (Utah) Deposit in a Fluidized Bed: Ph.D. dissertation, University of Utah, Salt Lake City, Utah

Drelich, J., 1993, The Role of Wetting Phenomena in the Hot water Process for Bitumen Recovery from Tar Sand, Ph.D. Dissertation, University of Utah, Salt Lake City, Utah.

Drelich, J., Hanson, F.V., Hupka, J, and Miller, J.D., 1993, water Recycle in Moderate-Temperature Bitumen Recovery from Whiterocks Tar Sands, AOSTRA J. Res, in print.

Drelich, J., and Miller, J.D., 1993, Surface/Interfacial Tension of the Whiterocks Bitumen and its Relationship to Tar Sand Processing, Proc. 1992 Eastern Oil Shale Symposium, 265-275.

Fletcher, J.V., Deo, M.D., and Hanson, F.V., 1993, Fluidized Bed Pyrolysis of Bitumen-Impregnated sandstone at Sub-Atmospheric Conditions, Proc. 1992 Eastern Oil Shale Symposium, 247-256.

Hanson, F.V., Dorius, J.C., Utley, J.K., and Van Nguyen, T., 1992, The Application of Compound-Type Analyses to the Correlation of Product Distributions and Yields from the Fluidized-Bed Pyrolysis of Oil Sands, Fuel 71, 1365-1372. 
Hunt, J.M., F. Stewart, and P.A. Dickey, 1954, Origin of Hydrocarbons of Uinta Basin, Utah: Amer. Assoc. Petrol. Geol. Bull. 38, \#8, 1671-1698

Hupka, J., Drelich, J., Miller, J.D., White, R.R., Hanson, F.V., and Oblad, A.G., 1990, Impact of Water Recycle on Water-Based Processing of Whiterocks Tar Sand. Proc. 1990 Eastern Oil Shale, 39-44

Hupka, J., Drelich J., Miller, J.D., White, R.R., Hanson, F.V., and Oblad, A.G., 1991, Impact of Water Recycle on Water-Based Processing of Whiterocks Tar Sand, Fuel, 70, 1313-1316

Hwang, J., 1993, Application of Supercritical Fluid Extraction to the Recovery and Upgrading of oil Sands, Ph.D. Dissertation, University of Utah, Salt Lake City, Utah.

Keefer, T.N., and McQuivey, R.S., 1979, Water Availability for Development of Major Tar Sands Areas in Utah, U.S. Department of Energy, LETC-0013-1.

Kinney, D.M., 1955, Geology of Uinta River and Brush CreekDiamond Mountain Areas, Duchesne and Uinta Counties, Utah: U.S. Geolog. Sur., Bull. 1007

Kuuskru, V.V., and Hammershaimb, V.A., eds., 1984, Major Tar Sand and Heavy Oil Deposits of the United States, Interstate oil Compact Commission, oklahoma city, Oklahoma.

Kwak, S., Longstaff, D.C., Deo, M.D., and Hanson, F.V., 1993, Hydrotreating Process Kinetics for Bitumen and Bitumen-Derived Liquids, Proc. 1992, Eastern Oil Shale Symposium, 208-215.

Longstaff, D.C., 1992, Hydrotreating the Whiterocks Oil Sand Bitumen and Bitumen-Derived Liquid, Ph.D. Dissertation, University of Itah, Sait Lake City, Utah.

Longstaff, D.C., Deo, M.D., Hanson, F.V., Oblad, A.G., and Tsai, C.H., 1992, Hydrtreating the Bitumen-Derived Hydrocarbon Licuid Produced in a Fluidized Bed Pyrolysis Reactor, Fuel 71, 14071419.

Longstaff, D.C., Deo, M.D., and Hanson, F.V., 1993, Hydrotreating the Bitumen from the Whiterocks oil Sand Deposit, Proc. 1992 Eastern Oil Shale Symposium, 199-207.

Oblad, A.G., Bunger, J.W., Hanson, F.V., Miller, J.D., Ritzma, H.R., and Seader, J.D. 1987. Tar Sand Research and Development at the University of Utah. Ann Rev. Energy. 12:283-356.

Peterson, P.R., 1985, the Whiterocks Tar Sand Deposit: Utah Geolog. Ast:oc., 12, 243-252 
Pruitt, R.G., Jr., 1961, The Mineral Resources of Uintah County: Utah Geological and Mineralogical Survey, Bulletin 71

Resnick, B.S., D.H. Dike, L.M. English, III, and Alan G. Lewis, 1981, Evaluation of tar sand mining, Volume 1 - An assessment of resources amenable to mine production: U.S. Department of Energy, DOE/ET/30201-1.

Ritzma, H.R., 1968, Preliminary Location Map Oil - Impregnated Rock Deposits of Utah, Utah Geological and Mineralogical Survey, Map No. 25, $1 \mathrm{pg}$.

Ritzma, H.R. 1973. Oil-Impregnated Rock Deposits of Utah, Utah Geological and Mineralogical Survey, Map No. 33, 2pp.

Ritzma, H.R. 1979. Oil-Impregnated Rock Deposits of Utah, Utah Geological and Mineralogical Survey, Map 47, 2pp.

Sung, S.H., 1988, The Fluidized Bed Pyrolysis of BitumenImpregnated Sandstone in a Large Diameter Reactor, M.S. Thesis, University of Utah, Salt Lake City, Utah.

Tsai, C.H., Deo, M.D., Hanson, F.V., and Oblad, A.G., 1991 Characterization and Potential Utilization of Whiterocks (Utah) Tar Sand Bitumen, Fuel Sci. Tech. Int., 9, 1259-1286.

Tsai, C.H., Deo, M.D., Hanson, F.V., and Oblad, A.G., 1992, Characterization and Potential Utilization of Whiterocks Tar Sand Bitumen II. Pyrolysis Man Spectrometry and Nuclear Magnetic Resonance Analyses, Fuel Sci. Tech. Int., 10, 1437-1459.

Tsai, C.H., Longstaff, D.C., Deo, M.D., Hanson, F.V., and Oblad, A.G., 1992. Characterization and Utilization of Hydrotreated Products from the Whiterocks (Utah) Tar sand Bitumen-Derived Liquid, Fuel, 71, 1473-1482.

Wang, J., 1983, The Production of Hydrocarbon Liquids from a Bitumen-Impregnated Sandstone in a Fluidized Bed Pyrolysis Reactor: M.S. Thesis, University of Utah, Salt Lake City, Utah

Wang, J., Hanson, F.V., Obald, A.G., 1983, The Fluidized Bed Pyrolysis of the Bitumen-Impregnated Sandstone from the Whiterocks (Utah) Deposit, Preprint AICHE Symp. Adv. Tar sand Technol., Denver, Colo., Aug. 


\section{APPENDIX B}

\section{ASPHALT RIDGE OIL SAND DEPOSIT BIBLIOGRAPHY}

Abraham, H. 1969. Asphalts and Allied Substances: D. Van Nostrand Co., Inc., Princeton, New Jersey, 6th Edition, 5 Volumes.

Alford, H.E., and Derby, R.E. 1981. Utah Tar Sands to be Developed: Hydrocarbon Process, Vol. 60, n.6, p.127-130.

Anonymous, 1974. Fairbrim \& Arizona Fuels to Begin Oil Sands Recovery Tests on Sohio Property in Utah: Synthetic Fuels, September.

Anonymous, 1981. Sohio Slates Tar Sands Pilot Plant in Utah: The Oil and Gas Journal, Vol. 79, n. 3, p. 42-43.

Ball, D., Marchant, L.C., and Goldburg, A., 1982, The IOCC Monograph Series: Tar Sands, Interstate oil Compact Commission, oklahoma City, Oklahoma

Ball, M.W. 1951. Oil-Impregnated Strippable Deposits in Utah, May 22, 1950: U.S. Bureau of Mines, The Synthetic Liquid Fuel

Potential of Utah, Appendix D, p. 1-18.

Ball Associates, Ltd. 1964. Surface and Shallow Oil-Impregnated Rocks and Shallow oil Fields in the United States: U.S. Bureau of Mines, Monograph 12.

Barb, C.F. 1942. Rubber from the Uinta Basin of Utah: The Mines Magazine, Vol. 32, n. 10, p. 521-524.

Barb, C.F. 1944. Review of Geology and Field Work: Colorado School of Mines, Quarterly of the Colorado School of Mines, iol. $39, n$. 1, Hydrocarbons of the Uinta Basin of Utah and Colorado.

Barb, C.F., and Ball, J.D. 1944. Hydrocarbons of the Uinta Basin: Quarterly of Colorado School of Mines, Vol. 39, n. 1 .

Barbour, R.V., Dorrence, S.M., Vollmer, H., and Harris, J.D., 1976, Pyroloysis of Utah Tar Sands--Products and Kinetics, ACS, Preprints, Div. of Fuel Chem. 21, 6, 278-289.

Bunger, J.W. 1974. Characterization of a Utah Tar Sand Bitumen: American Chemical Society, Division of Chemistry, Reprint 19(2), p. 231-241, Also In Shale Oi, Tar Sands and Related Fuel Sources:

T. F. Yen [Editor], Advances in Chemistry Series n. 151, c. 10, p. $121-136,1976$. 
Bunger, J.W.: Cogswell, D.E.: and Oblad, A.G. 1978. Thermal Processing of a Utah Tar Sand Bitumen: Canadian Institute of Mining and Metallurgy, CIM Special Vol. 17- Proceedings of the Canada-Venequela Oil Sands Symposium-77, p. 178-182.

Bunger, J.W.; Cogswell, D.E.; and Oblad, A.G. 1979. Catalytic Cracking of Asphalt Ridge Bitumen: American Chemical Society, Refining of Sythetic Crude Oils, Advances in Chemistry Series.

Campbell, J.A., and Ritzma, H.R. 1976. Structural Geology and Petroleum Potential of the South flank of the Uinta Mountain Uplift [Abstract]: American Assoc. of Petroleum Geologists, Bulletin Vol. 60, p. 1902-1393.

Campbell, J.A., and Ritzma, H.R. 1979. Geology and Petroleum Resources of the Major Oil-Impregnated Sandstone Deposits of Utah: Utah Geological and Mineralogical Survey, special studies 50, Also In U.N. Institute for Training oand Research, First International Conference on the Future of Heavy $0 i l$ and Tar Sands.

Cashion, W.B., Jr. 1964. Other Bituminous Substances: Utah Geological and Mineralogical Survey, Bulletin 73, Mineral and Water Resources of Utah.

Covington, R.E. 1957. The Bituminous Sandstones of the Asphalt Ridge Area, Northeastern Utah: Intermountain Assoc. of Petrol. Geologists, 8th Annual Field Conference, p. 172-175.

Covington, R.E. 1963. Bituminous Sandstone and Limestone Deposits of Utah: Utah Geological and Mineralogical Survey, Bulletin 54, p. 225-247.

Covington, R.E. 1964. Bituminous Sands With Viscous crude Oils: Brigham Young University, First Intermountain Symposium on Fossil Hydrocarbons, p. 364-374.

Covington, R.E. 1964. Bituminous Sandstone in the Uinta Basin: Intermountain Assoc. of Petrol. Geologists, 13th Annual Field Conference, p. 227-242.

Covington, R.E. 1964. Thermal Recovery May Bring Industry's Quiet Revolution: The oil and Gas Journal, Vol. 62, n. 47, p. 112-118.

Covington, R.E. 1965. Some Possible Applications of Thermal Recovery in Utah: Journal of Petroleum Technology, Vol. 17, n.11, p. 1277-1284.

Covington, R.E., and McDonald, R.L. 1965. Stratigraphic and Structural Controls of Bituminous Sandstone Deposits in Utah [Abstract]: American Assoc. of Petroleum Geologists, Bulletin Vol. 49, n. 9, p. 1577. 
Covington, R.E., and Young, K.J. 1985. Brief History and Recent Developments in Tar Sand Deposits of Uinta Basin: Utah Geological Association, Geology and Energy Resources, Uinta Basin of Utah.

Dyni, J.R., and Goodwin, J.C. 1972. American Assoc. of Petroleum Geologists Field Trip Roadlog-Vernal, Utah to Rio Blanco, Colorado: Rocky Mountain Assoc. of Geologists, Mountain Geologist Vol. 9, n. 2-3, p. 115-134.

Eldridge, G.H. 1901. Asphalt and Bituminous Rock Deposits: U.S. Geological Survey, Annual Report 22, p. 361-364.

Erickson, R.L., Myers, A.T., and Horr, C.A. 1954. Association of Uranium and Other Metals with Crude Oil, Asphalt, and Petroliferous Rock: American Assoc. of petroleum Geologists, Bulletin Vol. 38 , n. 10, p. 2200-2218.

Hills, R.C. 1985. Description of an Asphalt-Like Mineral from Asphalt Wash, Utah: Colorado Scientific Society, Proceedings Vol. 2 , part 1, p. 27-28.

Hunt, J.M., Stewart, F., and Dickey, P.A. 1954. Origin of Hydrocarbonsof Uinta Basin, Utah: American Assoc. of Petroleum Geologists, Bulletin Vol. 38, n. 8, p. 1671-1698.

Hupka, J., and Miller, J.D. 1991. Temperature Water-Based Bitumen Recovery from Tar Sand, Fuel 70, 1308-1312.

Hupka, J., and Miller, J.D. 1991. Electrophoretic Characterization and Processing of Asphalt Ridge and Sunnyside Tar Sands, Intern, J. Mineral Proc. 31, 217-231. Kayser, R.B. 1966. Bituminous Sandstone Deposits Asphalt Ridge: Utah Geological and Mineralogical Survey, Special studies 19.

Keefer, T.N., and McQuivey, R.S., 1979, water Availability for Development of Major Tar Sands Areas in Utah, U.S. Department of Energy, LETC-0013-1.

Kinney, D.M. 1955. Geology of Uinta River and Brush Creek-Diamond Mountain Areas, Duchesne and Uinta Counties, Utah: U.S. Geological Survey, Bulletin 1007.

Kuuskra, V.V., and Hammershaimb, V.A., eds., 1984, Major Tar Sand and Heavy Oil Deposits of the United states, Interstate oil Compact Commission, Oklahoma city, Oklahoma.

Lowe, R.M. 1976. The Asphalt Ridge Tar Sand Deposits: American Institute of Chemical Engineers Symposium Series, Vol. $72, n$. 155 , p. 55-60. 
Mauger, R.L., Kayser, R.B., and Gwynn, J.W. 1973. A Sulfur Isotopic Study of Uinta Basin Hydrocarbons: Utah Geological and Mineralogical Survey, Special studies 41.

Oblad, A.G., Seader, J.D., Miller, J.D., and Bunger, J.W. 1976. Recovery of Bitumen from Oil-Impregnated Sandstone Deposists of Utah: American Institute of Chemical Engineers, Oil Shale and Tar Sand Symposium, Vol. 72, n. 155, p. 69.

Oblad, A.G., Seader, J.D., Miller, J.D., Bunger, J.W., and Cogswell, D.E. 1977. Recovery of Oil from Utah's Tar sands: National Tech. Information Service, Report PB-294-680.

Oblad, A.G., Bunger, J.W., Hanson, F.V., Miller, J.D., Ritzma, H.R., and Seader, J.D. 1987. Tar Sand Research and Development at the University of Utah. Ann. Rev. Energy. 12:283-356.

Pruitt, R.G., Jr. 1961. The Mineral Resources of Uinta County: Utah Geological and Mineralogical Survey, Bulletin 71.

Resnick, B.S., D.H. Dike, L.M. English, III, and Alan G. Lewis, 1981, Evaluation of tar sand mining, Volume 1 - An assessment of resources amenable to mine production: U.S. Department of Energy, DOE/ET/30201-1.

Ritzma, H.R., 1968, Preliminary Location Map Oil - Impregnated Rock Deposits of Utah, Utah Geological and Mineralogical Survey, Map No. 25, 1 pg.

Ritzma, H.R. 1973. Oil-Impregnated Rock Deposits of Utah, Utah Geological and Mineralogical Survey, Map No. 33, 2pp.

Ritzma, H.R. 1974. Asphalt Ridge, Structure, stratigraphy, and Oil-Impregnated Sands: Utah Geological Assoc., Publication 4, p. 60 .

Ritzma, H.R. $1974-b$.

Ritzma, H.R. 1974-C.

Ritzma, H.R. 1979. Oil-Impregnated Rock Deposits of Utah: Utah Geological and Miseralogical Survey, Map 47, 2pp.

Shea, G.B., and Higgins, R.V. 1952. Separation and Utilization Studies of Bitumens from Bituminous Sandstones of the Vernal and Sunnyside, Utah Deposits: U.S. Bureau of Mines Report of Investigation 4871 .

Smith, R.J. 1980. Asphalt Ridge Tar Sands: Flotation Behavior and Process Design: University of Utah, Dept. of Metallurgy and Metallurgical Engineering, M.S. Thesis. 
Smith, R.J., and Miller, J.D. 1981. Flotation Behavior of Digested Asphalt Ridge Tar Sands: Mining Engineering, Vol. 33, p. 1719-1724: Discussion of Article, Vol. 34, p. 1598.

Speiker, E.M. 1931. Bitu:linous Sandstone near Vernal, Utah: U.S. Geological Survey, Bulletin 822-C, p. 77-100.

Stone, G.H. 1891. Note on the Asphaltum of Utah and Colorado: American Journal of Science, Vol. 142, p. 148-159.

Tsai, C.H., Deo, M.D., Hanson, F.V., and Oblad, A.G., 1993. Characterization and Potential Utilization of the Asphalt Ridge Tar Sand Bitumen I. Gas Chromatography - Mass Spectrometry and Pyrolysis - Mass spectrometry Analysis Fuel Sci. Technol. Int'l $11,475-506$.

U.S. Bureau of Land Management. 1986. Proposed Leased Conversion for Sohio within the Asphalt Ridge Special Tar Sand Area: U.S. Dept. of Interior.

Untermann, G.E., and Untermann, B.R. 1964. Geology of Uinta County: Utah Geological and Mineralogical Survey, Bulletin 72 .

Walton, P.T. 1944. Geology of the Cretaceous of the Uinta Basin, Utah: Geological Society of America, Bulletin Vol. 55, p. 91-130.

Wenger, W.J., Hubbard, R.L., and Whisman, M.L. 1952. Separation and Utilization studies of Bitumens from Bituminous sandstones of the Vernal and Sunnyside, Utah Deposits: U.S. Bureau of Mines, Report of Investigation 4871, part II, Analytical Data on Asphalt Properties and Cracked Products of the Separated Bitumens.

Wolfgramm, R.P. 1978. Asphalt Ridge Tar Sands Characterization: University of Utah, Dept. of Fuels Engineering, BS Honors Degree.

Wood, R.E., and Ritzma, H.R. 1972. Analyses of oil Extracted from Oil-Impregnated Sandstone Deposits in Utah: Utah Geological and Mineralogical survey, Special studies 39. 


\section{APPENDIX C}

\section{PR SPRING OIL SAND DEPOSIT BIBLIOGRAPHY}

Abraham, H., 1960, Asphalts and allied substances: D. Van
Nostrand Co., Inc., Princeton, New Jersey, 6th edition, 5 volumes

Ball, D., Marchant, L.C., and Goldburg, A., 1982, The IOCC Monograph Series: Tar Sands, Interstate oil Compact Commission, Oklahoma City, Oklahoma

Ball, M.W., 1951, Oil-impregnated strippable deposits in Utah, May 22, 1950: U.S. Bureau of Mines, The synthetic liquid fuel potential of Utah, appendix D, p. 1-18

Barbout, R.V., Domence, S.M., Vollmer, H., and Harris, J.D., 1976, Pyroloysis of Utah Tar Sands--Products and Kinetics, ACS, Preprints, Div. of Fuel Chem. 21, 6, 278-289.

Bunger, J.W., D.E. Cogswell, and A.G. Oblad, 1978, Thermal processing of a Utah tar sand bitumen: Canadian Institute of Mining and Metallurgy, CIM Special volume 17- Proceedings of the Canada-Venezuela oil Sands symposium-77, p. 178-182

Byrd, W.D., II, 1967, Geology of the bituminous sandstone deposits, southeastern Uinta Basin, Uintah and Grand counties, Utah: University of Utah M.S. thesis.

Byrd, W.D., II, 1970, P.R. Spring oil-impregnated sandstone deposit, Uintah and Grand Counties, Utah: Utah Geological and Mineralogical Survey, special studies 31

Campbell, J.A., and Ritzma, H.R., 1979, Geology and petroleum resources of the major oil-impregnated sandstone deposits of Utah: Utah Geological and Mineralogical Survey, Special studies 50, also in U.N. Institute for Training and Research, First International conference on the Future of Heavy Oil and Tar sands

Cashion, W.B., Jr., 1964, Other bituminous substances: Utah Geological and Mineralogical Survey, Bulletin 73, Mineral and water resources of Utah

Cashion, W.B., Jr., 1967, Geology and fuel resources of the Green River Formation, southeastern Uinta Basin, Utah and colorado: U.S. Geological Survey, Professional Paper 548

Clem, K.C, 1984, Economic Potential of the P.R. spring oilimpregnated deposit, Uinta Basin, Utah: Utah Geological and Mineralogical Survey, Special studies 65 
Covington, R.E., 1963, Bituminous sandstone and limestone deposits of Utah: Utah Geological and Mineralogical survey, Bulletin 54, p. 225-247

Covington, R.E., 1964, Bituminous sands with viscous crude oils: Brigham Young University, First Intermountain symposium on Fossil Hydrocarbons, p. 364-374

Covington, R.E., 1965, Some possible applications of thermal recovery in Utah: Journal of Petroleum Technology, v. 17, n. 11, p. $1277-1284$

Covington, R.E., and R.L. MCDonald, 1965, stratigraphic and structural controls of bituminous sandstone deposits in Utah [abstract]: American Assoc. of Petroleum Geologists, Bulletin v. 49 , n. 9, p. 1577

Cupps, C.Q., L.A. Johnson, and L.C. Marchant, 1976-a, Properties of Utah tar sands, South seep Ridge area, P.R. Spring deposit: U.S. Dept. of Energy, Report of Investigation DOE-LC-RI-75/6

Dahm, J.N., 1980, Tar sand reserves - P.R. Spring Deposit, Uintah and Grand Counties, Utah: Utah Geological and Mineralogical Survey, Open file report 27 , also in University of Utah, state College of Mines and Mineral Industries, Utah Engineering Experiment Station, Phase I: Final Report, 1981

Dana, G.F., and D.J. Sinks, 1984, Characteristics of the P.R. Spring tar sand deposil, Uinta Basin, Utah, U.S.A.: U.N. Institute for Training and Research, 2nd International Conference, The Future of Heavy Crude and Tar Sands, p. 220-236

Dorius, J.C., 1985, The pyrolysis of bitumen-impregnated sandstone from the P.R. Spring (Utah) deposit in a fluidized bed; Ph.D. Dissertation, University of Utah, Salt Lake City, Utah.

Eldridge, G.H., 1901, Asphalt and bituminous rock deposits: U.S. Geological Survey, Annual Report 22, p. 361-364

Fouch, T.D., W.B. Cashion, R.T. Ryder, and J.A. Campbell, 1976, Field guide to lacustrine and related nonmarine depositational environments in Tertiary Rocks, Uinta Basin, Utah: Professional Contributions of the Colorado school of Mines, No. 8, p. 358-385

Glassett, J.M., and J.A. Glassett, 1976, The production of oil from intermountain west tar sands deposits: U.S. Bureau of Mines, Contract No. S024429 
Gwynn, J.W., 1971, Instrumental analysis of tar and their correlations in oil-impregnated sandstone beds, Uintah and Grand Counties, Utah: Utah Geological and Mineraloglcal Survey, special Studies 37, also in University of Utah, Department of Geological and Geophysical Sciences, Ph.D. Dissertation

Hanson, F.V., Dorius, J.C., Utley, J.K., and Van Nguyen, T., 1992, The Application of Compound-Type Analyses to the

Correlation of Product Distributions and Yields from the Fluidized-Bed Pyrolysis of Oil Sands, Fuel 71, 1365-1372.

Hunt, J.M., F. Stewart, and P.A. Dickey, 1954, Origin of hydrocarbons of Uinta Basin, Utah: American Assoc. of Petroleum Geologists, Bulletin v. 38, n. 8, p. 1671-1698

Johnson, L.A., L.C. Marchant, and C.Q. Cupps, 1975, Properties of Utah tar sands - Asphalt Wash area, P.R. Spring deposit: U.S. Bureau of Mines Report of Investigation 8030

Johnson, L.A., L.C. Marchant, and C.Q. Cupps, 1975-b, Properties of Utah tar sands - North Seep Ridge area, P.R. Spring deposit: U.S. Dept. of Energy, Report of Investigation ERDA LERC/RI-75/6

Johnson, L.A., L.C. Marchant, and C.Q. Cups, 1975-C, Properties of Utah tar sands - South Seep Ridge area, P.R. Spring deposit: U.S. Bureau of Mines, Report of Investigation 8003

Keefer, T.N., and McQuivey, R.S., 1979, Water Availability for Development of Major Tar Sands Areas in Utah, U.S. Department of Energy, LETC-0013-1.

Kuuskra, V.V., and Hammershaimb, V.A., eds., 1984, Major Tar Sand and Heavy Oil Deposits of the United States, Interstate oil Compact Commission, Oklahoma City, Oklahoma.

Laramie Energy Technology Center, 1983, Unpublished Iithologic descriptions of oil shale core holes in the P.R. Spring area, Uintah County, Utah: U.S. Department of Energy.

Marchant, L.C., L.A. Johnson, and C.Q. Cupps, 1974, Properties of Utah tar sands - threemile Canyon, P.R. Spring deposit: U.S. Bureau of Mines, Report of Investigation 7923

Oblad, A.G., Bunger, J.W., Hanson, F.V., Miller, J.D., Ritzma, H.R., and Seader, J.D. 1987. Tar Sand Research and Development at the University of Utah. Ann. Rev. Energy. 12:283-356.

Peterson, P.R., 1975, Lithologic logs and correlation of coreholes, P.R. Spring and Hill creek oil-impregnated sandstone deposits, Uintah County, Utah: Utah Geological and Mineralogical Survey, Report of Investigation 100 
Peterson, P.R., and H.R. Ritzma, 1974, Informational core drilling in Utah's oil-impregnated sandstone deposits, southeast Uinta Basin, Uintah county, Utah: Utah Geological and Mineralogical Survey, Report of Investigation 88 .

Picard, M.D., 1971, Petrographic criteria for recognition of lacustrine and fluvial sandstone, P.R. spring oil-impregnated sandstone area, southeast Uinta Basin, Utah: Utah Geological and Mineralogical Survey, Special studies 36

Picard, M.D., and L.R. High, Jr., 1970, Sedimentology of oilimpregnated lacustrine and fluvial sandstone, P.R. spring area, southeast Uinta Basin, Utah: Utah Geological and Mineralogical survey, special studies 33 .

Pitman, J.K., Fouch, T.D., and Glodhaber, M.B., 1982, Depositational setting and diagenetic evolution of some Tertiary unconventional reservoir Rocks, Uinta Basin, Utah: American Assoc. of Petroleum Geologist, Bulletin, volume 66, number 10 .

Pruitt, R.G., Jr., 1961, The mineral resources of Uintah county: Utah Geological and Mineralogical Survey, Bulletin 71

Reed, W.E., 1977, Molecular compositions of weathered petroleum and comparison with its possible source: Geochima et Cosmochimica Acta, v. 41, n. 2, p. 237-247

Resnick, B.S., D.H. Dike, L.M. English, III, and Alan G. Lewis, 1981, Evaluation of tar sand mining, Volume 1 - An assessment of resources amenable to mine production: U.S. Department of Energy, DOE/ET/30201-1.

Ritzma, H.R., 1968, Preliminary Location Map Oil - Impregnated Rock Deposits of Utah, Utah Geological and Mineralogical Survey, Map No. 25, 1 pg.

Ritzma, H.R. 1973. Oil-Impregnated Rock Deposits of Utah, Utah Geological and Mineralogical survey, Map No. 33, $2 \mathrm{pp}$.

Ritzma, H.R., 1979, Oil Impregnated Rock Deposits of Utah, Utah Geological and Mineralogical Survey, Map 47, 2pp.

Ritzma, H.R., and Campbell, J.A., 1981, Geology and petroleum resources of the major oil-impregnated sandstone deposits of Utah: United Nations Institute for Training and Research, First International Conference on the future of heavy crude oils and tar sands

Sinks, D.J., 1985, Geologic influence on the in-situ process of tar sand at the North West Asphalt Ridge deposit, Utah: U.S. Dept. of Energy, Report No. AD-89-F-0-026-0 
Sinks, D.J., and G.F. Dana, 1984, Bituminous sandstone resource evaluation of P.R. Spring deposit, Uintah and Grand Counties, Utah [abstract]: American Assoc. of Petroleum Geologists, Bulletin v. 68 , n. 4 , p. 528

U.S. Bureau of Land Management, 1985, P.R. Spring combined hydrocarbon lease conversion, final environmental impact statement: U.S. Dept. of Interior

Whittier, W.H., and R.C. Becker, 1945, Geologic map and sections of the bituminous sandstone deposits in the P.R. spring area, Grand and Uintah Counties, Utah: U.S. Geological survey, open file report

Wiley, D.R., 1967, Petrology of bituminous sandstones in the Green River Formation, southeastern Uinta Basin, Utah: University of Utah, Master's Thesis. 


\section{APPENDIX D}

\section{UNIVERSITY OF UTAH OIL SANDS BIBLIOGRAPHY}

\section{Theses and Dissertations}

Sepulveda, J.E. 1977. Hot Water Separation of Bitumen from Utah Tar Sands. M.S. Thesis. University of Utah, Salt Lake City, Utah.

Weeks, J.K. Jr. 1977. Fluidized-Bed Processing of Utah Tar Sands. M.S. Thesis. University of Utah, Salt Lake City, Utah.

Bunger, J.W. 1979. Processing Utah Tar Sand Bitumen. Ph.D. Dissertation. University of Utah, Salt Lake City, Utah.

Jayakar, K.M. 1979. The Thermal Recovery of 0 il from Tar Sand Ph.D. Dissertation. University of Utah, Salt Lake City, Utah.

Venkatesan, V.N. 1979. Fluidized-Bed Thermal Recovery of Synthetic Crude from Bituminous Sands of Utah. Ph.D. Dissertation. University of Utah, Salt Lake City, Utah.

Hanks, K.C. 1979. Chemistry of 0il Production from Tar Sand. M.S. Thesis. University of Utah, Salt Lake City, Utah.

Smith, R. 1980. Asphalt Ridge Tar Sands-Flotation Behavior and Process Design. M.S. Thesis. University of Utah, Salt Lake City, Utah.

Misra, M. 1981. Physical Separation of Bitumen from Utah Tar Sands. Ph.D. Dissertation. University of Utah, Salt Lake City, Utah.

Brechte1, C.E. 1981. Hydrotreating Utah Tar Sand Products. M.S. Thesis. University of Utah, Salt Lake City, Utah.

Umoh, R.A. 1981. Steam Cracking of Utah Tar Sand Bitumen in a Kellogg Millisecond Furnace. M.S. Thesis. University of Utah, Salt Lake City, Utah.

Aguilar, R. 1982. Physical Separation of Bitumen from Utah Tar Sands. M.S. Thesis. University of Utah, Salt Lake City, Utah.

Bezama, R.J. 1983. An Energy Efficient Method for Thermal Processing of Utah Tar Sands. Ph.D. Dissertation. University of Utah, Salt Lake City, Utah.

Hsu, J.C.L. 1983. Digital Control of Thermal Processing System for Tar Sands. M.S. Thesis. University of Utah, Salt Lake City, Utah.

Wang, J. 1983. The Production of Hydrocarbon Liquids from a Bitumen-Impregnated Sandstone in a Fluidized Bed Pyrolysis Reactor. M.S. Thesis. University of Utah, Salt Lake City, Utah. 
Wang, C.J. 1984. The Solubility of Carbon Dioxide in Tar Sand Bitumens. M.S. Thesis. University of Utah, Salt Lake City, Utah.

Smart, L.M. 1984. Thermal Processing of Tar Sands. M.S. Thesis. University of Utah, Salt Lake City, Utah.

Dorius, J.C. 1985. The Pyrolysis of Bitumen Impregnated Sandstone from the P.R. Spring (Utah) Deposit in a Fluidized Bed. Ph.D. Dissertation. University of Utah, Salt Lake City, Utah

Tsai, C.H. 1987. Reaction Kinetics and Mechanisms of Hydropyrolysis Processing of Tar Sand Bitumen and Related Materials. M.S. Thesis. University of Utah, Salt Lake City, Utah.

Lin, L.C. 1988. The Kinetics of the Pyrolysis of Tar Sand and of the Combustion of Coked Sands. Ph.D. Dissertation. University of Utah, Salt Lake City, Utah.

Sung, S.H. 1988. The Fluidized Bed Pyrolysis of Bitumen-Impregnated Sandstone in a Large Diameter Reactor. M.S. Thesis. University of Utah, Salt Lake City, Utah.

Coronella, C.J. 1989. Modelling a Coupled Fluidized-Bed Reactor for Extraction of Bitumen from Tar Sands. M.S. Thesis. University of Utah, Salt Lake City, Utah.

Ryu, H. 1989. Kinetic Modelling Applied to Hydrocarbon Process Design and Engineering: I Hydropyrolysis of Heavy 0ils, II: Acetylene from Calcium Carbide, Ph.D. Dissertation. University of Utah, Salt Lake City, Utah.

Shun, D. 1990. Fluidized Bed Pyrolysis of the Bitumen-Impregnated Sandstone from the Circle Cliffs Deposit. Ph.D. Dissertation. University of Utah, Salt Lake City, Utah.

Cogswel1, D. 1990. Effect of $\mathrm{H}_{2} \mathrm{~S}$ on the Hydropyrolysis of Tetralin. M.S. Thesis. University of Utah, Salt Lake City, Utah.

Cha, S.M., 1991. Pyrolysis of Oil Sands from the Whiterocks Tar Sand Deposit in a Rotary Kiln, Ph.D. Dissertation, University of Utah, Salt Lake City, Utah.

Deshpande, D.A., 1992. Application of Three Phase Ebullieted Bed Reactors to Petroleum Upgrading, Ph.D. Dissertation, University of Utah, Salt Lake City, Utah.

Fletcher, J.V., 1992. The Pyrolysis of 0il Sands in a Fluidized Bed at Reduced Pressure, Ph.D. Dissertation, University of Utah, Salt Lake City, Utah.

Longstaff, D.C., 1992. Hydrotreating the Whiterocks Oil Sand Bitumen and Bitumen-Derived Liquid, Ph.D. Dissertation, University of Utah, Salt Lake City, Utah. 
Hwang, J., 1993. Application of Dynamic Supercritical Fluid Extraction to the Recovery and Upgrading of Complex Hydrocarbon Mixtures, Ph.D. Dissertation, University of Utah, Salt Lake City, Utah.

Drelich, J. 1993. The Role of Wetting Phenomena in the Hot Water Process for Bitumen Recovery from Tar Sand, Ph.D. Dissertation, University of Utah, Salt Lake City, Utah.

\section{Final Reports}

Oblad, A.G.; Bunger, J.W.; Miller, J.D.; Seader, J.D. 1977. Recovery of 0il from Utah's Tar Sands. Final Report. Grant ASR74-21867, Nat1. Sci. Found. RANN Program

Oblad, A.G.; Bunger, J.W.; Hanson, F.V.; Miller, J.D.; Seader, J.D. 1979. Recovery of 0 il from Utah's Tar Sands. Final Report, 1977-79. US Dept. Energy (DOE) Contract \#ET77-S-03-1762. 140 pp.

Bunger, J.W., Wells, H.M. 1980. Economic Evaluation of Tar Sand Resources Located in the State of Utah. Phase I. Final Report. Utah Eng. Exp. Stn., Sept. 2. $211 \mathrm{pp}$.

Wells, H.M.; Bunger, J.W.; Jensen, G.F. 1984. Economic Evaluation of 0 il Shale and Tar Sands Located in the State of Utah. Final Report. Utah Eng. Exp. Stn. 5 volumes, May

Oblad, A.G.; Bunger, J.W.; Hanson, F.V.; Miller, J.D.; Seader, J.D. 1984. Recovery of 0 il from Utah's Tar Sands. Final Report. DOE Contract \# DE-AS20-80LC10332, May

Oblad, A.G.; Bunger, J.W.; Hanson, F.V.; Miller, J.D.; Seader, J.D. 1984. Recovery and Hydropyrolysis of 0 il from Utah's Tar Sands. Final Report. DOE Contrart \#DE-AS20-82LC10942, Dec.

Oblad, A.G.; Bunger, J.W.; Hanson, F.V.; Miller, J.D.; Seader, J.D. 1985. Recovery and Upgrading of $0 i 1$ from Utah Tar Sands. First Annual Report. DOE Contract \#DE-FC20-84LC11057, Sept.

Oblad, A.G.; Bunger, J.W.; Hanson, F.V.; Miller, J.D.; Seader, J.D. 1986. Recovery and Upgrading of 0 il from Utah Tar Sands. Second Annual Report. DOE Contract DE-FC20-84LC11057, Sept.

Oblad, A.G.; Bunger, J.W.; Hanson, F.V.; Miller, J.D.; Seader, J.D. 1987. Recovery and Upgrading of 0 il from Utah Tar Sands. Final Technical Report. DOE Contract * DE-FC20-84LC11057, Jan.

Oblad, A.G., Hanson, F.V. 1988. Production of Bitumen-Derived Hydrocarbon Liquids from Utah's Tar Sands. Final Technical Report. DOE Contract \# DE-FC21-87MC11090, Sept. 
Oblad, A.G.; Bunger, J.W.; Hanson, F.V.; Miller, J.D.; Seader, J.D. 1989. The Extraction of Bitumen from Western Tar Sands, Final Technical Report. DOE Contract \#DE-FC21-38MC25046.

Oblad, A.G.; Bunger, J.W.; Deo, M.D.; Hanson, F.V.; Miller, J.D.; and Seader, J.D. 1990. The Extraction of Bitumen from Western Tar Sands, Final Technical Report. DOE Contract \# DE-FC21-89MC26268.

Oblad, A.G.; Bunger, J.W.; Deo, M.D.; Hanson, F.V.; Miller, J.D.; and Seader, J.D. 1991. The Extraction of Bitumen from Western Tar Sands, Final Technical Report. DOE Contract \#DE-FC21-89MC26268.

\section{Patents}

Miller, J.D., Sepulveda, J.E. Oct. 17, 1978. Separation of Bitumen from Dry Tar Sands. U.S. Patent 4,120,776.

Seader, J.D., Jayakar, K.M. July 10, 1979. Process and Apparatus to Produce Synthetic Crude 0il from Tar Sands. U.S. Patent 4,160,720.

Oblad, A.G., Shabtai, J.S. Nov. 3, 1981. Hydropyrolysis of Tar Sand Bitumens and Heavy Petroleum 0ils. U.S. Patent 4,298,487.

Hanson, F.V.; Miller, J.D.; Oblad, A.G. June 29, 1982. Process for Obtaining Products from Tar Sands. U.S. Patent 4,337,143.

Hanson, F.V.; Miller, J.D.; Oblad, A.G. Oct. 11, 1983. Process for Recovering Products from Tar Sand. U.S. Patent 4,409,090.

Miller, J.D., Hupka, J. Sept. 11, 1984. Bitumen Recovery from Tar Sands. U.S. Patent $4,470,899$.

Miller, J.D., Misra, M. Dec. 4, 1984. Process for Separating High Viscosity Bitumen from Tar Sands. U.S. Patent 4,486,294.

\section{Publications}

1976

Bunger, J.W.; Mori, S.; Oblad, A.G. 1976. Processing of Tar Sand Bitumens. Part I. Thermal Cracking of Utah and Athabasca Tar Sand Bitumens. Preprints, Div. Fuel Chem., ACS, 21(6):147.

Oblad, A.G.; Seader, J.D.; Miller, J.D.; Bunger, J.W. 1976. Recovery of Bitumen from 0il-Impregnated Sandstone Deposits of Utah. Oil Shale and Tar Sands. AIChE Symp. Ser. 72, No. 155, p.69. 
Sepulveda, J.E.; Miller, J.D.; Oblad, A.G. 1976. Hot Water Extraction of Bitumen from Utah Tar Sands. I. Symp. on $0 i 1$ Shale, Tar Sands and Related Materials-Production and Utilization of Synfuels, Preprints, Div. Fuel Chem., ACS 21(6):110.

1977

Bunger, J.W. 1977. Development of Utah Tar Sands-A Status Report, Mines and Mineral Rep. No. 5, 1-10, Oct.

Bunger, J.W. 1977. Techniques of Analysis of Tar Sand Bitumens. Preprints, Div. Pet. Chem., ACS 22(2):716-26.

1978

Sepulveda, J.E., Miller, J.D. 1978. Separation of Bitumen from Utah Tar Sands by a Hot Water Digestion-Flotation Technique. Min. Eng. 30(9):1311 (a) so published in Trans SME/AIME, Sept. 1978).

Sepulveda, J.E.; Miller, J.D.; Oblad, A.G. 1978. Hot Water Extraction of Bitumen from Utah Tar Sands III. Min. Eng. 30:1311.

Bunger, J.W.; Cogswell, D.E.; Oblad, A.G. 1978. Influence of Chemical Factors on Primary Processing of Utah Tar Sand Bitumen. Preprints, Div. Fuel Chem., ACS 23(4):98-109.

Bunger, J.W.; Cogswell, D.E.; Oblad, A.G. 1977. Thermal Processing of a Utah Tar Sand Bitumen. Proc. Canada-Venezuela 0il Sand Symp. -77. Edmonton, Alberta, Canada; The 0il Sands of Canada-Venezuela-1977, ed. D.A. Redford, A.G. Winestock. 1978. CIM Special 17:178-82.1979

Bunger, J.W.; Cogswell, D.E.; Oblad, A.G. 1979. Catalytic Cracking of Asphalt Ridge Bitumen. Refining of Synthetic Crude Oils, ACS Adv. Chem., Ser. 179,67 .

Venkatesan, V.N.; Hanson, F.V.; Oblad, A.G. 1979. The Thermal Recovery of Synthetic Crude from the Bituminous Sands of the Sunnyside (Utah) Deposit, Proc. First Int. Conf. on the Future of Heavy Crude and Tar Sands. Edmonton, Alberta, Canada, June 4-12.

1980

Hanson, F.V.; Miller, J.D.; Oblad, A.G. 1980. A Combined Hot Water-Thermal Pyrolysis Strategy for the Production of Bitumen-Derived Liquids. 15th

Intersoc. Energy Conversion Conf. Seattle, Wash. Aug. 
Bunger, J.W., Cogswe11, D.E. 1981. Characteristics of Tar Sand Bitumen Asphaltenes as Studied by Conversion of Bitumen by Hydropyrolysis. Chemistry of Asphaltenes, ACS Adv. Chem. Ser., ed. J.W. Bunger, N.C. Li. No. 195, Pp. 219-36. ACS, Washington, D.C.

Miller, J.D., Misra, M. 1981. Hot Water Process Development for Utah Tar Sands. Presented at the 90th Nat7. AIChE Meet. Houston, Tex. Apr. 5-8.

Smith, R.J., Miller, J.D. 1981. Flotation Behavior of Digested Asphalt Ridge tar sands, Mining Eng. 33(12):1724.

Misra, M., Miller, J.D. 1981. Surface Chemistry Features in the Hot Water Processing of Utah Tar Sands. Presented at the Symp on Separation Sci. and Technol., Gatlinburg, Tenn. May 5-8; Separation Sci. Technol. $16(10): 1523-44$.

Bunger, J.W.; Cogswe11, D.E.; Oblad, A.G. 1981. Hydropyrolys is-Potential for Primary Upgrading. Oil Shale, Tar Sands and Related Material, ed. $H$. Stauffer. ACS Symp. Ser., No. 163: pp. 369-80.

Jayakar, K.M., Seader, J.D., Oblad, A.G., and Hanks, K.C., 1981. "Thermal Recovery of 0 il from Tar Sands by an Energy-Efficient Process" in Oil Shale, Tar Sands, and Related Materials, ACS Symposium Series 163, ACS, Washington, D.C.

1982

Venkatesan, V.N., Hanson, F.V., and Oblad, A.G. 1982. A Fluidized Bed-Thermal Process for the Recovery of a Bitumen-Derived Liquid from the Bitumen-Impregnated Sandstone Deposits of Utah. AIChE, Symp. Ser. 216, 78:42-55.

Hupka, J., Miller, J.D., and Cortes, A. 1982. Modified Hot Water Processing of Domestic Tar Sands. SME/AIME Ann. Meet., Dallas, Tex., Feb. 14-18, 1982. Preprint No. $82-85$.

Miller, J.D., Misra, M. 1982. Hot Water Process Development for Utah Tar Sands. Fuel Proc. Tech. 6:27-59.

Miller, J.D., Misra, M. 1982. Concentration of Utah Tar Sands by an Ambient Flotation Process, Int. J. Miner. Proc. 9:269-87.

1983

Wang, J.; Hanson, F.V.; Oblad, A.G. 1983. The Fluidized Bed Pyrolysis of the Bitumen-Impregnated Sandstone from the Whiterocks (Utah) Deposit, Preprint AIChE Symp. Adv. Tar Sand Technol. Denver, Colo., Aug. 
Hupka, J.; Miller, J.D.; Oblad, A.G. 1984. Hot Water Processing of U.S. Tar Sands-Water Recycle and Tailing Disposal, Stud Environ. Sci.,23, 253-267

Hupka, J.; Miller, J.D.; Cortes, A. 1983. The Importance of Bitumen Viscosity in the Hot Water Processing of Domestic Tar Sands. Mining Eng. 35(12): 1635-41, Dec.

1984

Hatfield, K.E., Oblad, A.G. 1984. Pilot Plant Program for Upgrading of Heavy Oils by Hydropyrolysis. Proc. of the Second Int. Conf. Heavy Crude and Tar Sand. Caracas, Venezuela, Feb. 7-17, UNITAR 1175-79.

Bunger, J.W. 1984. Upgrading Utah Tar Sand Bitumen to Syncrude. Proc. WRI-DOE Tar Sand Symp. Vail, Colo., June 26-29.

Dorius, J.C.; Hanson, F.V.; Oblad, A.G. 1984. The Pyrolysis of the Bitumen-Impregnated Sandstone from the P.R. Spring (Utah) Deposit in a Fluidized-Bed, Proc. WRI-DOE Tar Sand Symp., Vail, Colo., June 26-29.

Smart, L., Seader, J.D. 1984. Thermal Recovery of Bitumen. Proc. WRI-DOE Tar Sand Symp., Vail, Colo., June 26-29.

1985

Bunger, J.W., Oblad, A.G. 1985. Upgrading of Bitumen by Hydropyrolysis-a Process for Low Coke and High Syncrude Yields. Proc. Third Int. Conf. on Heavy Crude and Tar Sands, UNITAR/UNDP Inf. Centr. New York City, Los Angeles, Calif. pp. 1717-26, July 22-31.

Bunger, J.W. 1985. Reactions of Hydrogen During Hydropyrolysis Processing of Heavy Crudes. Preprints, Div. Pet. Chem., Am. Chem. Soc. 30 (4):658-63.

Bunger, J.W. 1985. Inhibition of Coke Formation in Hydropyrolysis of Residual 0ils. Preprints, Div. Pet. Chem., Am. Chem. Soc. 30 (3):549-54.

Seader, J.D., Smart, L.M., 1985. Recovery of Bitumen from Tar Sands by a Thermally Coupled Fluidized-Bed Process. Proc. Third International Conference on Heavy Crude and Tar Sands. Long Beach, CA. July 22-31, 1985, 1067-1079.

1986

Bunger, J.W., Tsai, C.H., Russe11, C.P. 1986. Competing Reactions During Hydropyrolys is Upgrading of Tar Sand Bitumen and Residual Materials. Proc. WRI/DOE Tar Sand Symp., ed. J.D. Westhoff, L.C. Marchant. Jackson, Wyo., July 7-10. 
Seader, J.D., Bezama, R.J., Charavarty, T. 1986. Design and Economic Evaluation of an Energy-Integrated Thermal Process for Recovery of 0 il from Tar Sands. Proc. WRI/DOE Tar Sand Symp., ed. J.D. Westhoff, L.C. Marchant. Jackson, Wyo., July 7-10.

Lin, L.C., Hanson, F.V., Oblad, A.G. 1986. A Preliminary Mathematical Model of the Pyrolysis of Bitumen-Impregnated Sandstone in a Fluidized Bed. Proc. WRI/DOE Tar Sand Symp., ed. J.D. Westhoff, L.C. Marchant. Jackson, Wyo., July 7-10.

1987

Hupka, J., Oblad, A.G., and Miller, J.D., 1987. Diluent-Assisted Hot Water Processing of Tar Sands, AOSTRA J. Res. 3,95-102.

Lin, L.C., Hanson, F.V., Oblad, A.G., and Westhoff, J.D. 1987. The Pyrolysis of Bitumen-Impregnated Sandstone in Short-Contact Time Reactors. I. Cyclone Reactor. Fuel Proc. Tech. 16, 173-190.

Oblad, A.G., Bunger, J.W., Hanson, F.V., Miller, J.D., Ritzma, H.R., and Seader, J.D. 1987. Tar Sand Research and Development at the University of Utah. Ann. Rev. Energy. 12:283-356.

\section{8}

Hanson, F.V., Oblad A.G. 1988. The Fluidized Bed Pyrolysis of Bitumen-Impregnated Sandstone from the Tar Sand Deposits of Utah. Proceedings UNITAR/UNDP International Conference on Heavy Crude and Tar Sands, Vol. 5. Extraction, Upgrading, Transportation, Paper No. 155, 421-438, Edmonton, Alberta, Canada.

1989

Hsu, J.C.L., and Seader, J.D. 1989. Digital Control of a Coupled Fluidized-Bed Thermal Processing System for Tar Sands. Fuel Proc. Tech., 21, 1-17.

Lin, L.C., Hanson, F.V., and Oblad, A.G. 1989. Mathematical Model of the Pyrolys is of Bitumen-Impregnated Sandstone Particles. I. Diffusion Dominant Transport Regime. Fuel Proc. Tech. 22, 41-63.

Yang, Y.J., Bukka, K., Miller, J.D. 1989. Selection and Evaluation of Diluents in the Modified Hot Water Process, Energy Processing, Canada, $82(1)$, $14-21$. 
Lin, L.C., Deo, M.D., Hanson, F.V., and Oblad, A.G. 1990. Kinetics of Tar Sands Pyrolysis Using a Distribution of Activation Energy Model. AIChE J. 36, 1585-1588.

\section{1}

Deo, M.D., Fletcher, J.V., Shun, D.W., Hanson, F.V., and Oblad, A.G., 1991 Modeling of the Pyrolysis of Tar Sand in Fluidized Bed Reactors. Proc. 1990 Eastern 0il Shale Symposium, 105-119.

Cha, S., Longstaff, D.C., Hanson, F.V., and Oblad, A.G. 1991. Pyrolysis of Bitumen Impregnated Sandstones: A Comparison of Fiuidized - Bed and Rotary Kiln Reactors, Proc. 1990 Eastern Oil Shale Symposium, 136-145.

Hupka, J., Drelich, J., Miller, J.D., White, R.R., Hanson, F.V., and Oblad, A.G. 1991. Impact of Water Recycle on Water-Based Processing of Whiterocks Tar Sand. Proc. 1990 Eastern 0il Shale, 39-44.

Seader, J.D. and Coronella, C.J. 1991. An Advanced Energy-Efficient Coupled Fluidized-Bed System for Recovering Bitumen From Tar Sand. Proc. 1990 Eastern oil Shale Symposium, 120-129.

Hupka, J. and Miller, J.D. 1991. Moderate-Temperature Water-Based Bitumen Recovery from Tar Sand. Proc. 1990 Eastern 0il Shale Symposium, 130-135.

Bukka, K., Miller, J.D., and Oblad, A.G. 1991, Fractionation and Characterization of Utah Tar Sand Bitumens: Influence of Chemical Composition on Bitumen Viscosity. Energy \& Fuels 5 , 333-340.

Deo, M.D., Wang, C.J., and Hanson, F.V. 1991. Solubility of Carbon Dioxide in Tar Sand Bitumen: Experimental Determination and Modeling, Ind. Eng. Chem. Res. 30 (3), 532-536.

Misra, M., and Miller, J.D. 1991, Comparison of Water-Based Physical Separation Processes for U.S. Tar Sands. Fuel Proc. Tech. 27, 3-20.

Lin, L.C., Deo, M.D., Hanson, F.V., and Oblad, A.G. 1991. Nonisothermal Analysis of the Kinetics of the Combustion of Coked Sand, Ind. Eng. Chem. Res.. 30, 1795-1801.

Tsai, C.H., Deo, M.D., Hanson, F.V., and Oblad, A.G. Characterization and Potential Utilization of Whiterocks (Utah) Tar Sand Bitumen, Fuel Sci. Tech. Int., 9 , 1259-1286.

Deo, M.D., Fletcher, J.V., Shun, D., Hanson, F.V., and Oblad, A.G. Modeling the Pyrolysis of Tar Sands in Fluidized Bed Reactors, Fuel. 70, 1271-1276.

Hupka, J., Drelich, J., Miller, J.D., White, R.R., Hanson, F.V., and Oblad, A.G., 1991, Impact of Water Recycle on Water-Based Processing of Whiterocks Tar Sand, Fuel, 70, 1313-1316. 
Cha, S., Hanson, F.V., Longstaff, D.C., and Oblad, A.G., 1991, Pyrolysis of Bitumen Impregnated Sandstones: A Comparison of Fluidized-Bed and Rotary-Kiln Reactors, Fue1, 70, 1357-1361.

Bukka, K., Miller, J.D., Hanson, F.V., and Oblad, A.G., (1991), Mineral Matter Distribution During the Hot Water Processing of Utah Tar Sand, AOSTRA J. Res. I, $101-109$.

Hupka, J., and Miller, J.D., 1991, Temperature Water-Based Bitumen Recovery from Tar Sand, Fuel 70, 1308-1312.

Hupka, J., and Miller, J.D., 1991, Electrophoretic Characterization and Processing of Asphait Ridge and Sunnyside Tar Sands, Intern, J. Mineral Proc. 31, $217-231$.

1992

Longstaff, D.C., Deo, M.D., Hanson, F.V., Oblad, A.G., and Tsai, C.H., 1992, Hydrotreating the Bitumen-Derived Hydrocarbon Liquid Produced in a Fluidized Bed Pyrolysis Reactor, Fue1 71, 1407-1419.

Tsai, C.H., Deo, M.D., Hanson, F.V., and iblad, A.G., 1992, Characterization and Potential Utilization of Whiterocks (Utah) Tar Sand Bitumen II. Pyrolysis Mass Spectrometry and Nuclear Magnetic Resonanace Analyses, Fuel Sci. Technol. Int. 10, 1437-1459.

Tsai, C.H., Longstaff, D.C., Deo, M.D., Hanson, F.V., and Oblad, A.G., 1992, Characterization and Utilization of Hydrotreated Products from the Whiterocks (Utah) Tar Sand Bitumen-Derived Liquid, Fuel, 71, 1473-1482.

Bukka K., Hanson, F.V., Miller, J.D., and Oblad, A.G., 1992, Fractionation and Characterization of Whiterocks Tar Sands Bitumen, Energy \& Fuels $\underline{6}, 160$.

Hanson, F.V., Dorius, J.C., Utley, J.K., and Van Nguyen, T., 1992, The Application of Compound-Type Analyses to the Correlation of Product Distributions and Yields from the Fluidized-Bed Pyrolysis of $0 i l$ Sands. Proc. 1991 Eastern 0il Shale Symp., 34-46.

Tsai, C.H., Deo, M.D., Hanson, F.V., and Oblad, A.G., 1992, Characterization and Utilization of Hydrotreated Products Produced from Whiterocks (Utah) Tar Sand Bitumen-Derived Liquid, Proc. 1991 Eastern 0il Shale Symp., 79-90.

Hanson, F.V., Cha, S.M., and Oblad, A.G., 1992, Pyrolysis of 0il Sand from the Whiterocks Tar Sand Deposit in a Rotary Kiln, Proc. 1991, Eastern 0il Shale Symp., 116-128.

Hupka, J., Budzich, M., and Miller, J.D., 1992, Preliminary Examination of $0 i 1$ Bonding at Sand Surfaces and its Influence on Hot Water Separation, Proc. 1991, Eastern 0il Shale Symp., 202-207.

Hwang, J., Deo, M.D., Hanson, F.V., and Oblad, A.G., 1992, Supercritical Fluid Extraction of a Crude 0 il, Bitumen-Derived Liquid and Bitumen by Carbon Dioxide and Propane, Proc. 1991, Eastern 0il Shale Symp., 209-221. 
Fletcher, J.V., Deo, M.D., and Hanson, F.V., 1992, Reexamination of Minimum Fluidization Velocity Correlations Applied to Group B Sands and Coked Sands, Powder Technol. 69 (2), 147-155.

Coronella, C.J., Seader, J.D., 1992, Combustion of Coked Sand in a Two-Stage Fluidized-Bed System, Fuel, 21, 143-150.

Drelich, J., Bryll, G., Kapczynski, J., Hupka, J., Miller, J.D., and Hanson, F.V., 1992, The Effect of Electric Field Pulsation Frequency on Breaking Water-in-0i1-Emulsions, Fuel Processing Technology, 31, 105-113.

Drelich, J., and Miller, J.D., 1992, The Effect of Surface Heterogeneity on Pseudo-Line Tension and the Fiotation Limit of Fine Particles, Colloids and Surfaces, $69,35-43$.

Drelich, J., and Miller, J.D., 1992, The Line/Pseudo-Line Tension in ThreePhase Systems, Particulate Science and Technology, 10, 1-20.

Deshpande, D.A., Deo, M.D., Hanson, F.V., and Oblad, A.G. 1992 A Model for the Prediction of Bubble Size at a Single Orifice in Two-Phase Gas-Liquid Systems, Chem. Eng. Sci. 47, 1669-1676.

Deo, M.D., Hwang, J., and Hanson, F.V. 1992 Supercritical Fluid Extraction of a Crude 0i1, Bitumen-Derived Liquid and Bitumen by Carbon Dioxide and Propane, Fuel $71,1519-1526$.

Hanson, F.V., Cha, S.M., Deo, N.D., and Oblad, A.G. 1992 Pyrolys is of 0il Sand from the Whiterocks Deposit in a Rotary Kiln, Fuel 11, 1455-1463.

Hanson, F.V., Dorius, J.C., Utley, J.K., and Van Nguyen, T. 1992 The Application of Compound-Type Analyses to the Correlation of Product Distributions and Yields from the Fluidized-Bed Pyrolysis of $0 i 1$ Sands, Fuel 71, 1365-1372. 


$$
-m^{2}
$$$$
\text { . }
$$
$-$ 

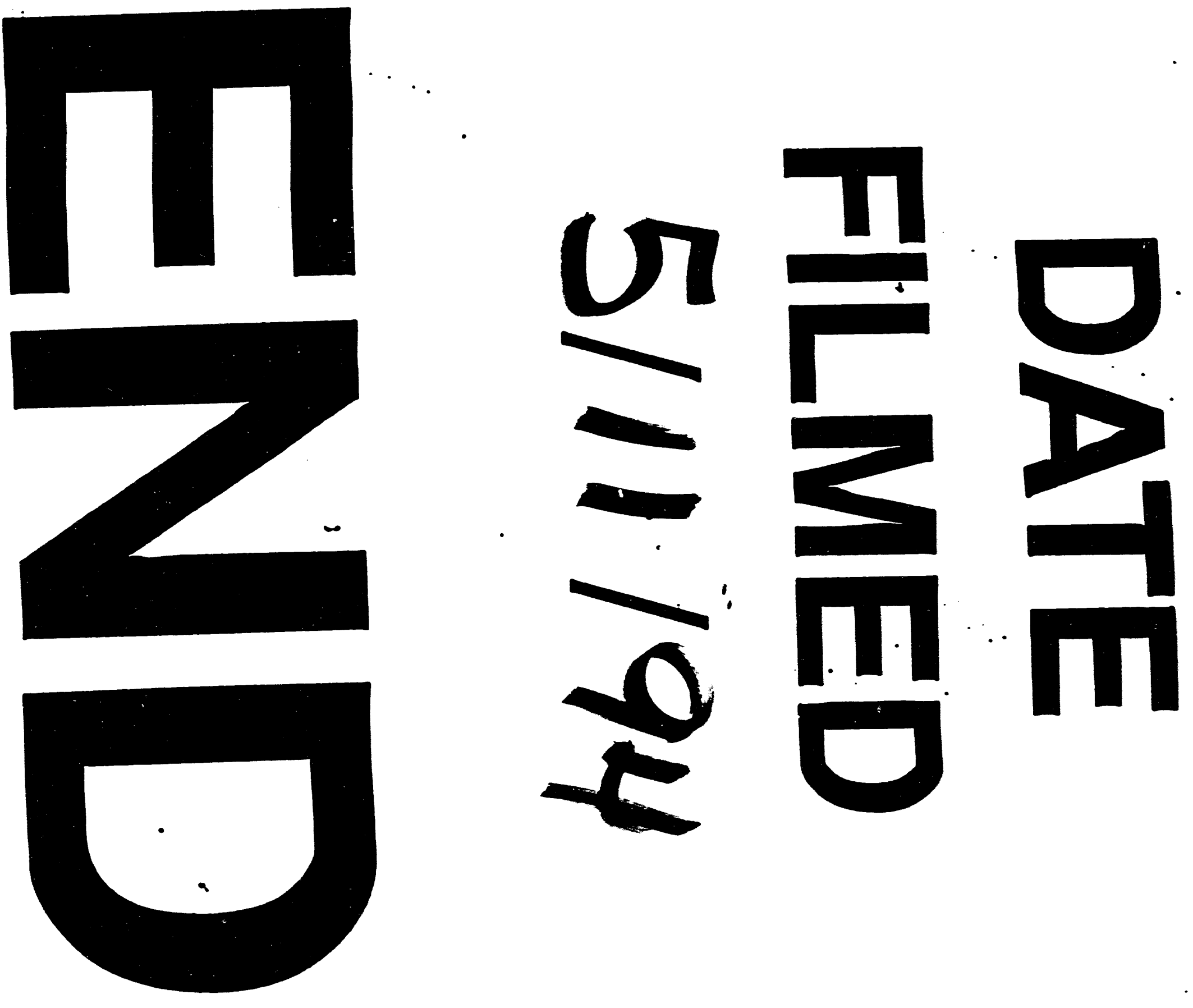
